\title{
Civilisations from East to West
}

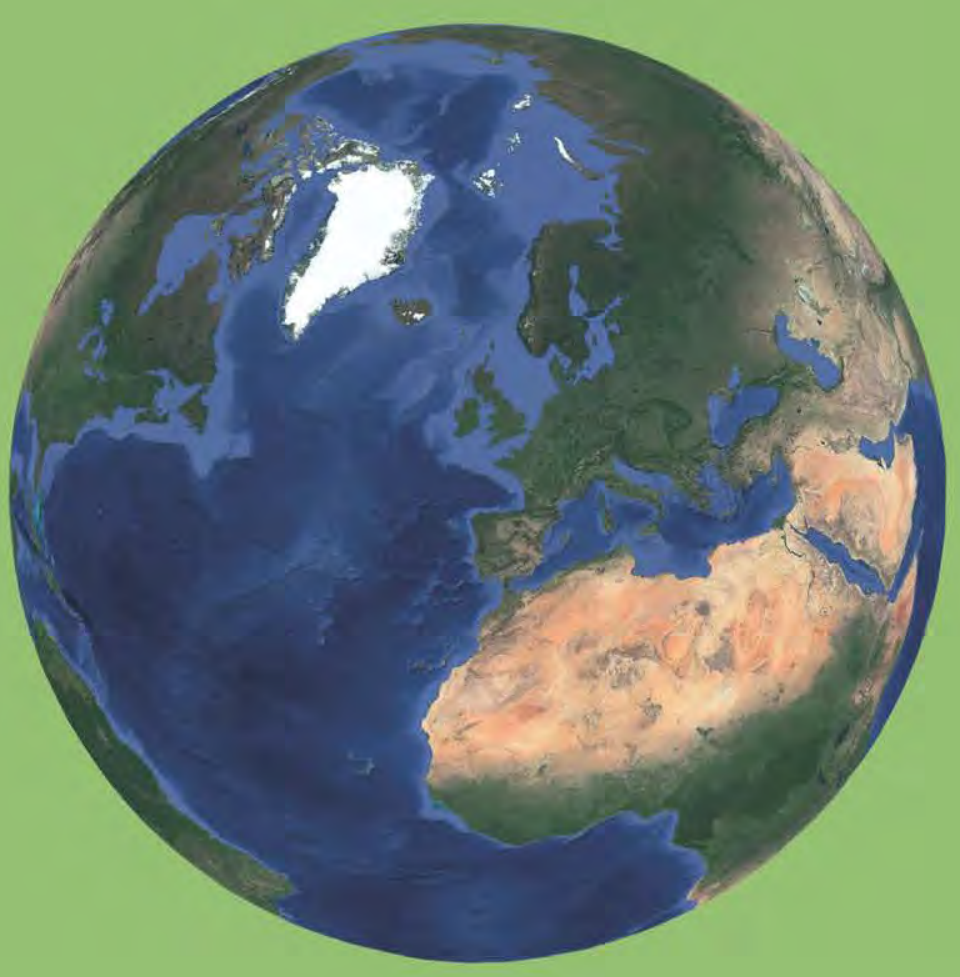


Civilisations from East to West 
Kinga Dévényi (ed.)

Civilisations from East to West

Corvinus University of Budapest Department of International Relations Budapest, 2020 
Editor:

Authors:

Maps:

Revision:

ISBN (printed book): 978-963-503-847-3

ISBN (online): 978-963-503-848-0

Cover photograph: Google Earth, 2018

Photographs were made by Judit Bagi, László Csicsmann, Kinga Dévényi, Mária Ildikó Farkas, Máté L. I ványi, Muhammad Hafiz, Andrea Pór, Zsuzsanna Renner, Miklós Sárközy, Zoltán Szombathy, Erika Tóth. Sources of freely available figures are given individually. Special thanks to the Oriental Collection of the Library of the Hungarian Academy of Sciences for allowing use of manuscript pages.

\section{Published by: Corvinus University of Budapest}
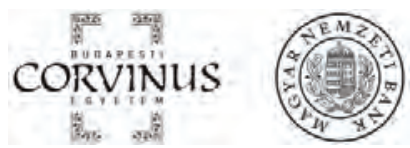

Publication and underlying research sponsored by the National Bank of Hungary. 


\section{Table of Contents}

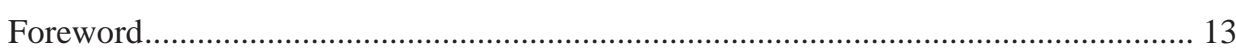

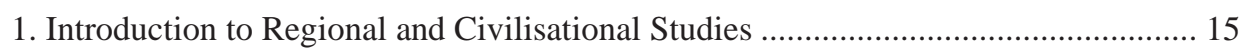

1.1. The New World Order and the Clash of Paradigms - LÁszLó CsICSMAnN ....... 17

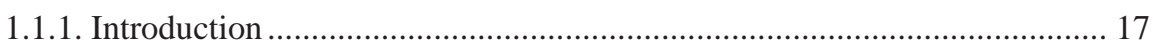

1.1.2. The characteristics of the New World Order and globalisation.................. 18

1.1.3. The competing paradigms of the New World Order ................................. 24

1.1.4. Definition(s) and interpretation(s) of civilisation and culture ................... 28

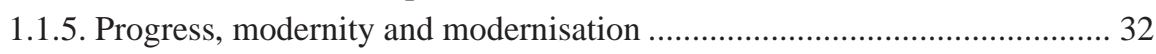

1.1.6. Huntington and the Clash of Civilisations thesis..................................... 37

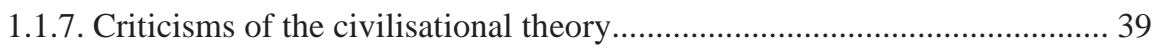

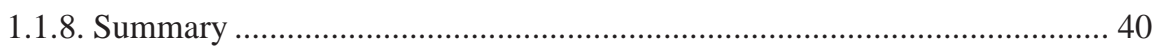

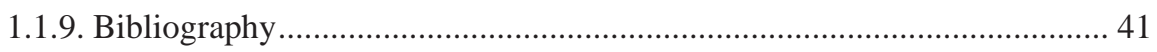

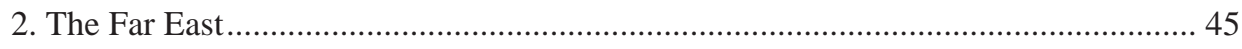

2.1. The Chinese Civilisation - TAMÁs MATURA ................................................... 47

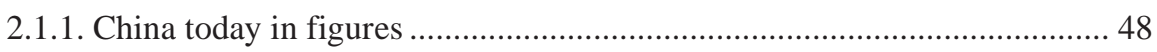

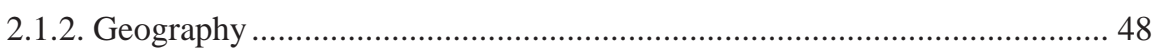

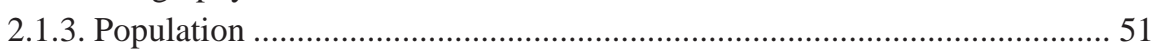

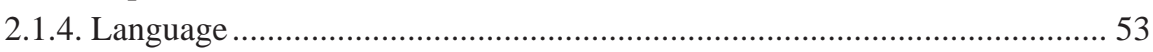

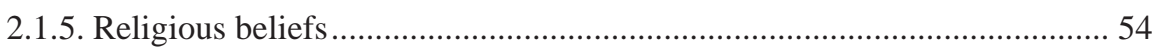

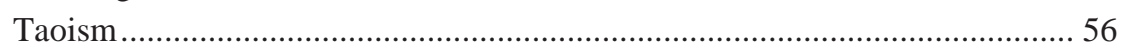

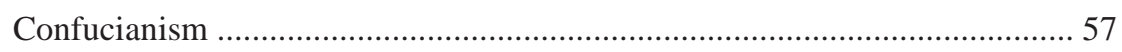

The forerunner of Legalism ........................................................................... 58

2.1.6. The history of China and its effect on international relations ................... 59

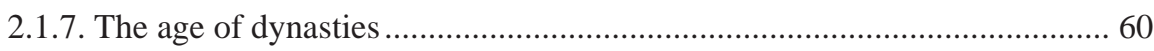

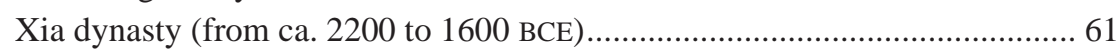

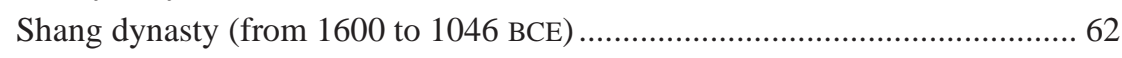

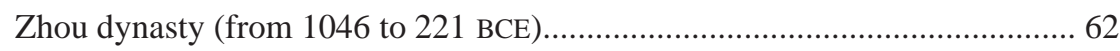

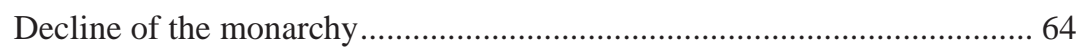

Warring States period (from fifth century BCE to 221 BCE)........................ 65

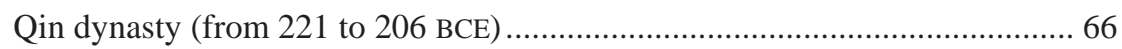

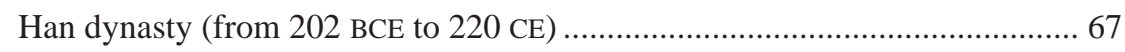

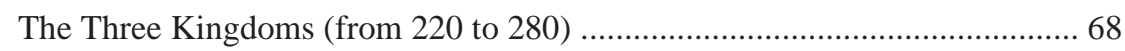

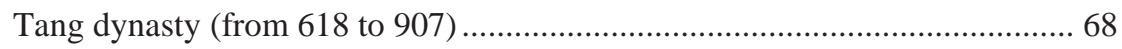

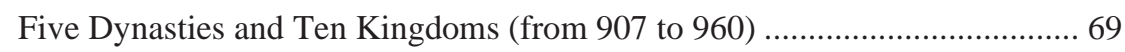

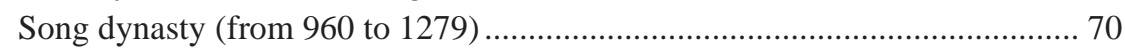

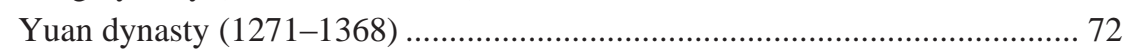

The Ming dynasty and Admiral Zheng He (1371-1433) ............................... 72

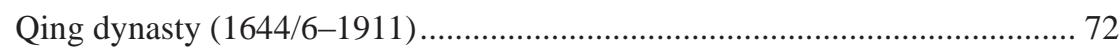




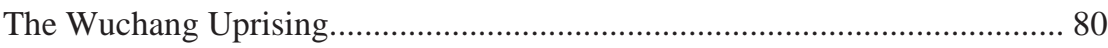

2.1.8. Traditional Chinese strategic culture and its sources .............................. 80

Philosophical foundations - Confucianism and Legalism............................ 81

Sun Tzu and The Art of War ..................................................................... 81

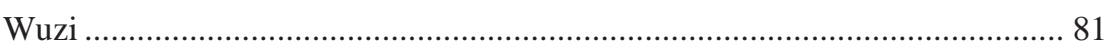

The concept of tianxia and the tributary system ......................................... 82

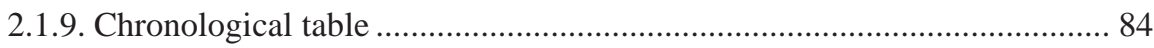

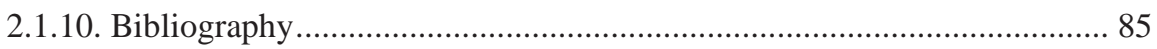

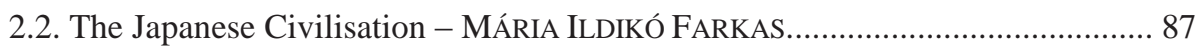

2.2.1. Japan as an independent civilisation? .................................................... 87

2.2.2. Sources and foundations of the Japanese civilisation ............................... 89

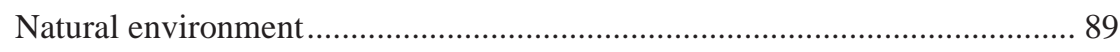

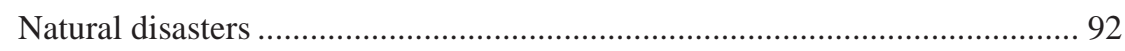

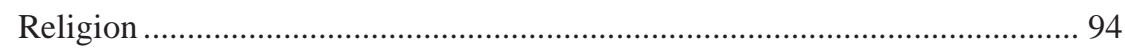

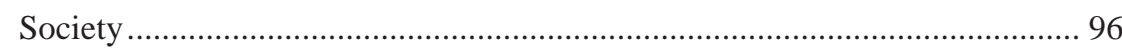

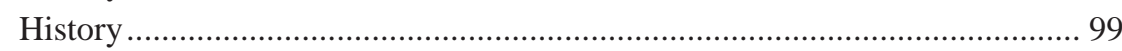

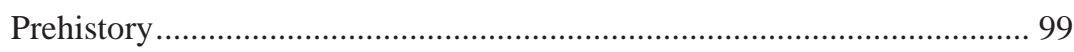

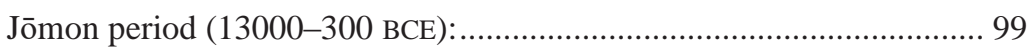

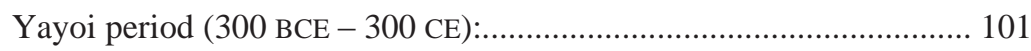

Ancient history ….......................................................................... 101

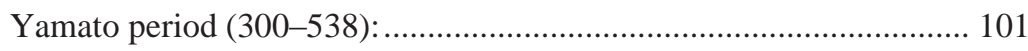

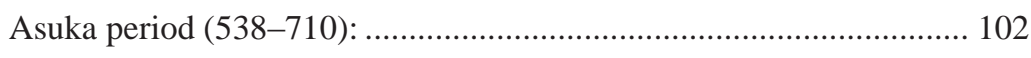

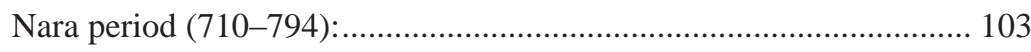

Heian period (794-1185): ................................................................. 104

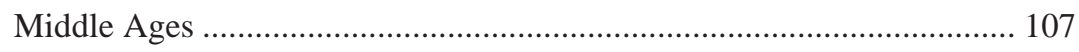

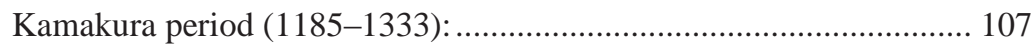

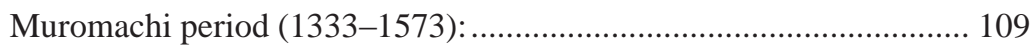

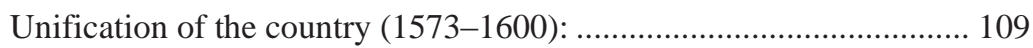

Early Modern Period .......................................................................... 110

Edo period (1603-1867): ................................................................... 110

Modern period ................................................................................... 113

Meiji period (1868-1912):................................................................. 113

Taishō period (1912-1926):................................................................ 117

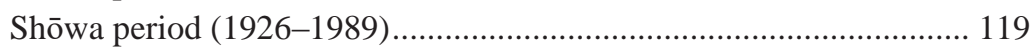

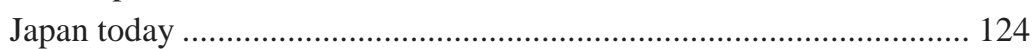

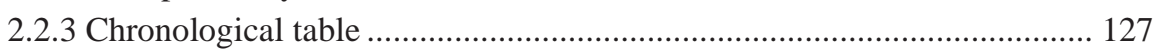

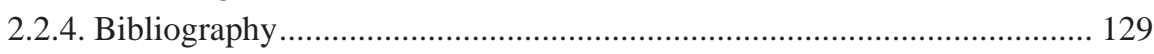

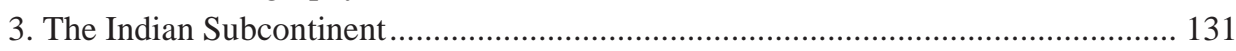

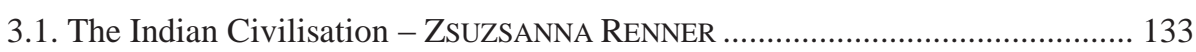

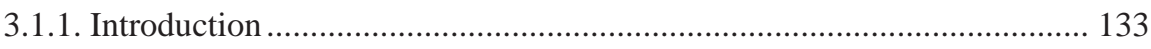


Table of Contents

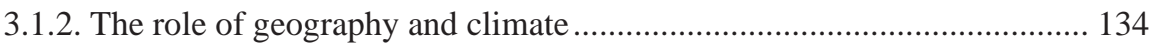

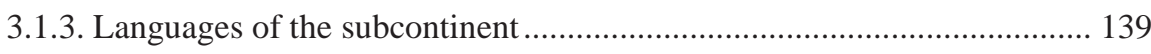

3.1.4. Chronology of the History of Indian Civilisation..................................... 141

Concept of time, chronology, sources ..................................................... 141

Periodisation ................................................................................................ 142

The main features of the historical periods................................................ 143

3.1.5. The main chapters in the history of Indian civilisation ........................... 148

Material culture of the Indus Valley Civilisation ....................................... 148

The Vedic Aryan lifestyle, religion and literature ...................................... 151

Formation of the characteristic social structure of Indian civilisation........... 153

Late Vedic Age: Conquest of the Ganges Valley ........................................ 154

The Age of Second Urbanisation: Jainism and Buddhism .......................... 156

Early Classical Age: the Maurya Empire .................................................. 161

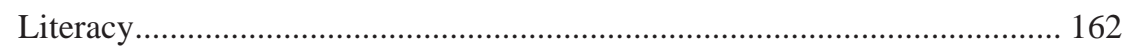

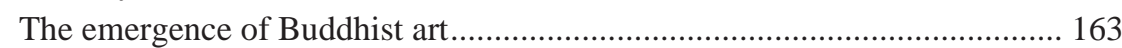

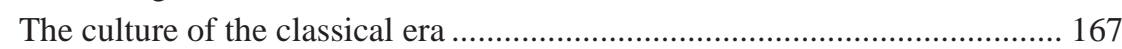

Hinduism ............................................................................................... 171

Early Middle Ages: The age of Hindu dynasties ....................................... 175

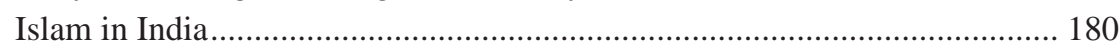

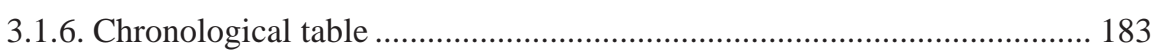

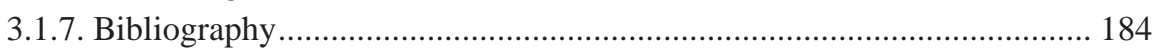

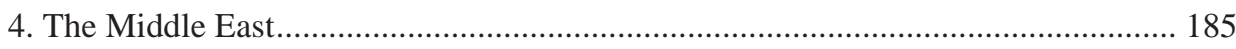

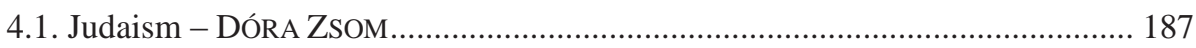

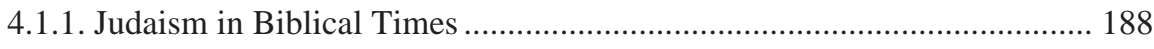

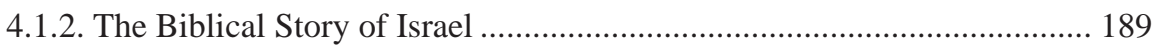

4.1.3. Religious rituals and cult in the Biblical Period..................................... 194

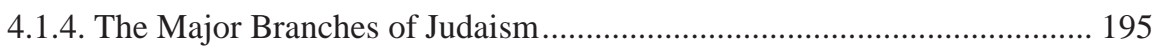

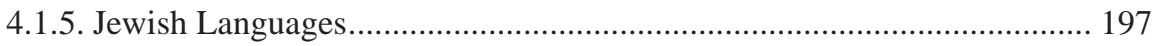

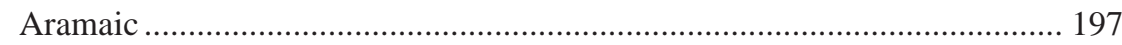

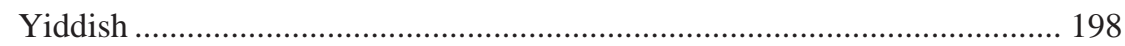

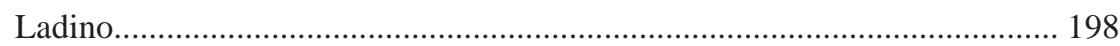

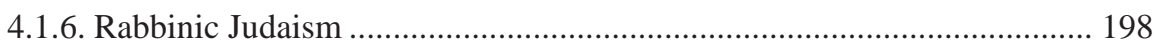

4.1.7. The Most Important Jewish Religious Texts ........................................... 199

4.1.8. Stages of Jewish Life, Certain Religious Rules...................................... 202

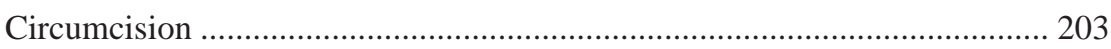

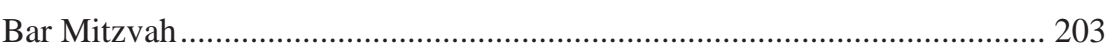

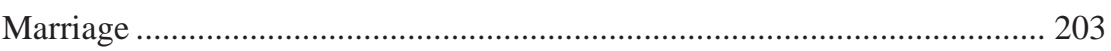

Prayer Shawl, Phylacteries, Mezuzah, Covering the Head............................. 204

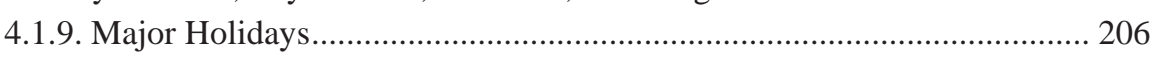

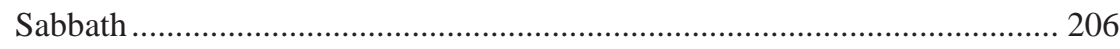


The Days of Awe: Rosh ha-Shanah and Yom Kippur................................ 209

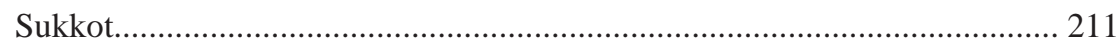

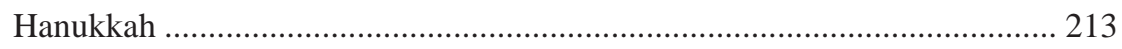

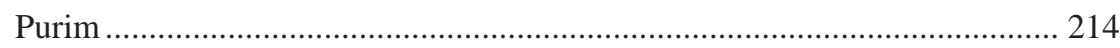

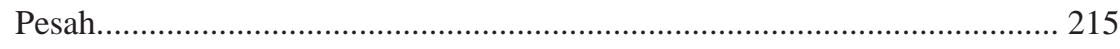

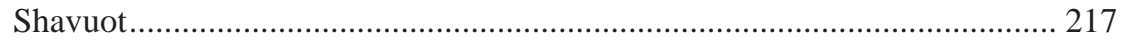

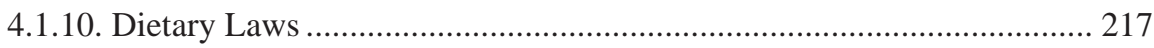

4.1.11. Schools of Thoughts in Judaism........................................................ 218

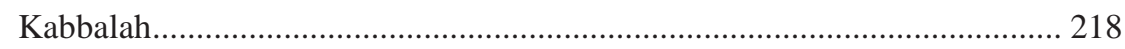

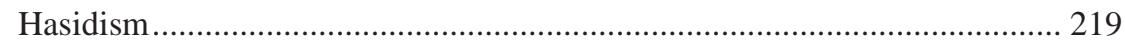

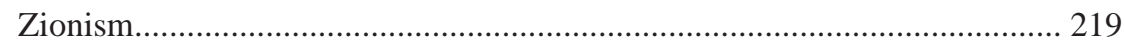

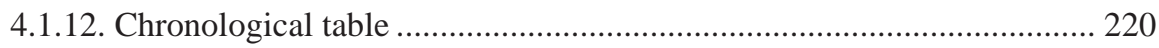

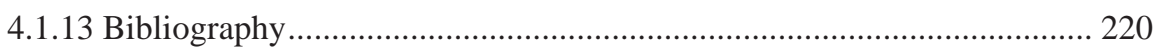

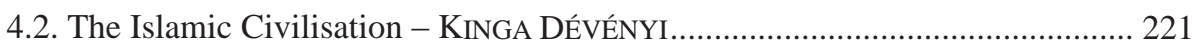

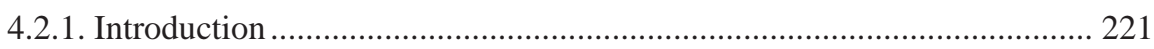

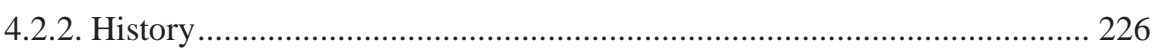

Muhammad and Islam ............................................................................. 226

The origin of the religion of Islam ......................................................... 226

Accounts of the Night Journey and Heavenly Ascension of the Prophet

Muhammad....................................................................................... 228

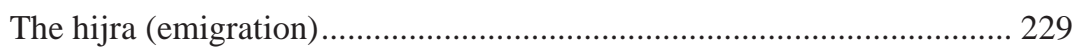

Islam in Medina ................................................................................ 230

The question of succession ................................................................... 232

The Caliphate in Medina: the reign of the four rightly guided caliphs .......... 232

The caliphate of Abu Bakr (632-634) ................................................... 232

The caliphate of Umar (634-644) ......................................................... 233

The caliphate of Uthman $(644-656)$....................................................... 233

The caliphate of Ali (656-661) and the first civil war (fitna)................. 234

The Umayyad Caliphate of Damascus (661-750) ...................................... 234

The second civil war (fitna) (683-692) ................................................. 235

Religious movements in the first half of the eighth century .................... 237

The Abbasid Caliphate of Baghdad (750-1258) ......................................... 238

The age of Harun al-Rashid (786-809), the golden age of the Caliphate of

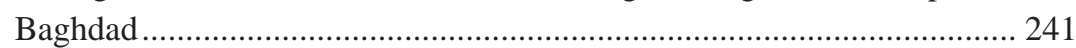

Caliph al-Ma'mun (813-833) ............................................................ 242

The beginning of the fragmentation of the empire .................................. 242

The disintegration of the Abbasid Caliphate ........................................... 243

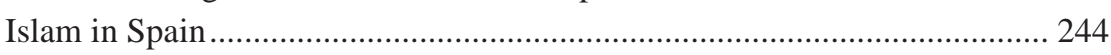

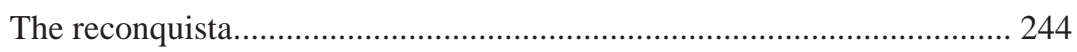

The Middle East after the collapse of the Caliphate of Baghdad.................. 246 
Table of Contents

The Mamluk Sultanate..................................................................... 246

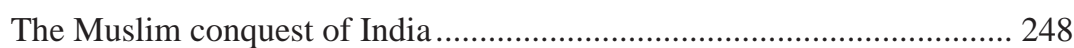

The Indian Mughal Empire................................................................... 248

Iran after the sixteenth century ............................................................ 249

The Ottoman Empire ...................................................................... 250

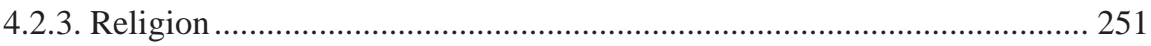

The fundamentals of the religion of Islam................................................ 251

The pillars of Islam......................................................................... 251

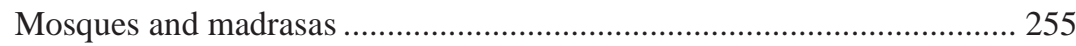

The development of the legal system of Islam .......................................... 257

The establishment of schools of law .................................................... 258

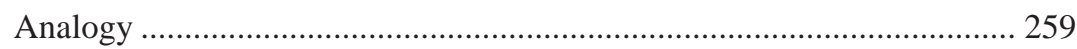

Islamic law and state law in the nineteenth century.............................. 260

The science of Hadith................................................................................ 261

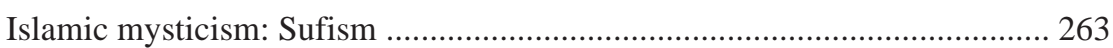

The role of the Quran in mysticism ....................................................... 267

The golden age of Sufi or dervish orders between the thirteenth and

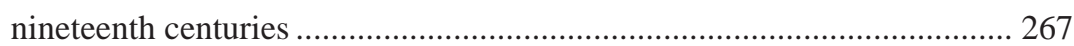

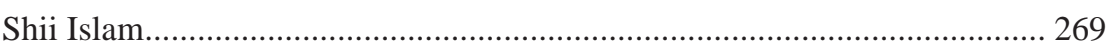

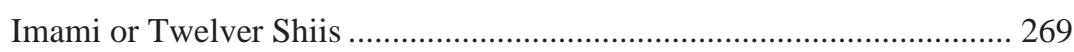

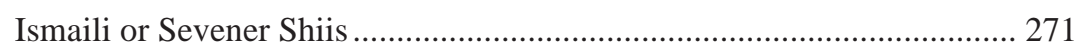

Further Shii branches........................................................................... 272

Branches of Islam in the modern age ........................................................ 272

The Wahhabi branch of Islam................................................................. 272

The nineteenth-century reform age of Islam (nahda) in Egypt ................ 273

Major tendencies of Islam in the twentieth century ................................ 274

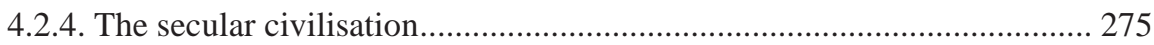

The secular sciences in the East ............................................................. 275

Achievements of Islamic civilisation in Spain ........................................... 276

Literature in the central parts of the Islamic world.................................... 277

Arabic literature in the Middle Ages ..................................................... 277

Persian poetry in the Middle Ages.......................................................... 278

Ottoman-Turkish literature ............................................................... 278

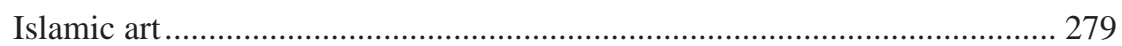

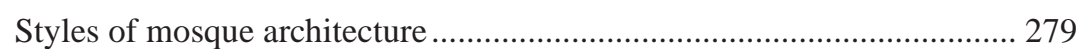

Hypostyle mosques ..................................................................... 279

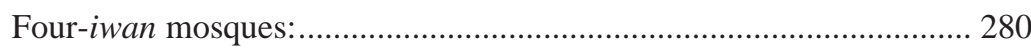

Centrally planned mosques ................................................................ 280

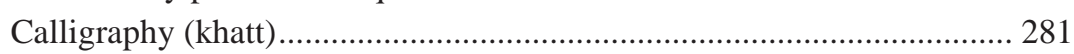

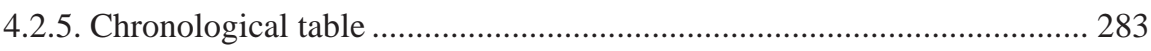




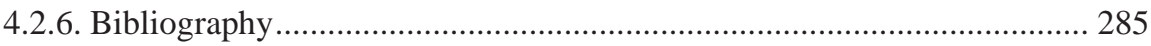

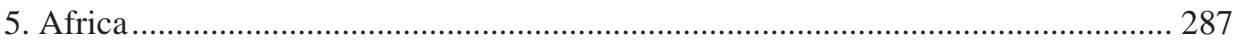

5.1. The Civilisations of Africa - ZoLTÁn SzOMBATHY........................................ 289

5.1.1. Terminological matters and the boundaries of African civilisations ........ 290

5.1.2. Cultural diversity .............................................................................. 291

5.1.3. Images of Africa: distortions, exoticism and ideology ........................... 293

5.1.4. The influence of racism and the African diaspora.................................. 295

5.1.5. Ethnic groups and languages ............................................................ 297

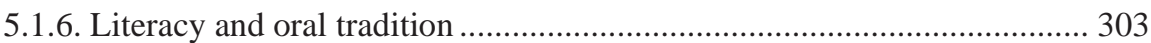

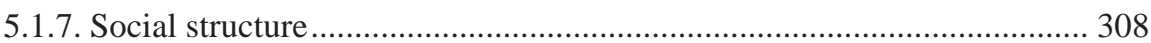

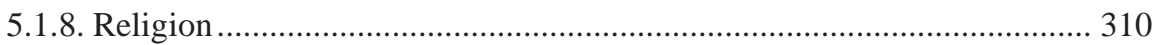

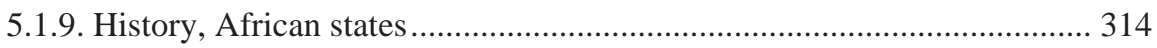

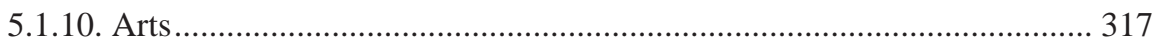

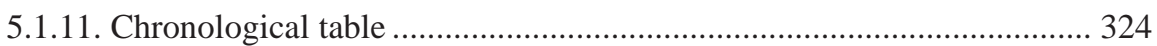

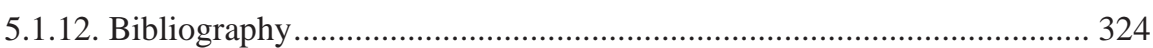

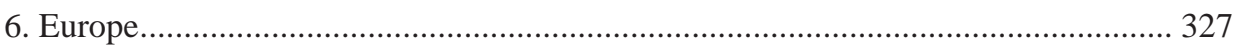

6.1. Orthodox Christian Europe: The Russian Version - ZolTÁn Sz. Bíró............ 329

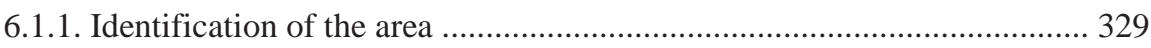

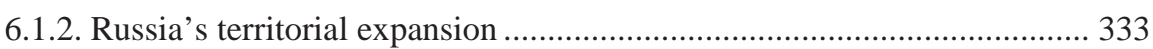

6.1.3. Special features of Russia's historical development ............................... 339

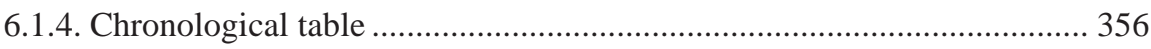

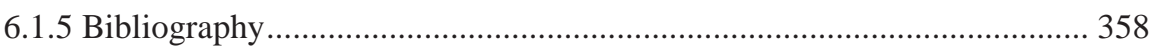

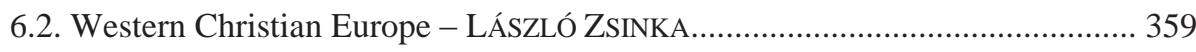

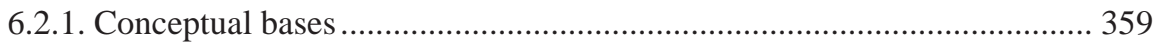

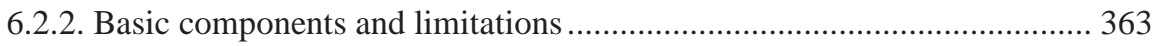

6.2.3. The beginning of the western Christian culture (200-1000) ................... 367

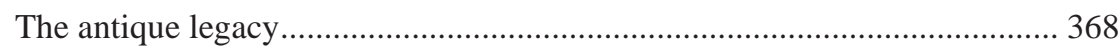

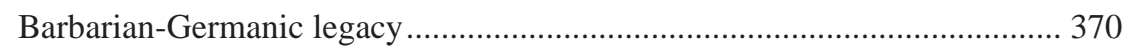

Formation of the Latin Christian cultural community ................................ 372

The historical role of the Carolingian Empire ............................................ 376

Europe under siege ............................................................................... 380

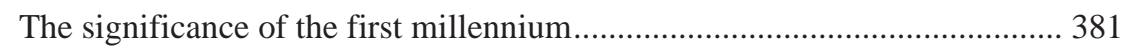

6.2.4. The first "take-off" of Europe in the High Middle Ages (1000-1500) .... 382

The turning point in the eleventh century ................................................... 383

Western European "revolutions" in the High Middle Ages........................... 385

Basic characteristics of the Christian faith ................................................ 386

The social dimension of Christian belief .................................................... 389

Western European societal characteristic .................................................... 390

6.2.5. At the turn of premodern and modern (1500-1800).................................. 393

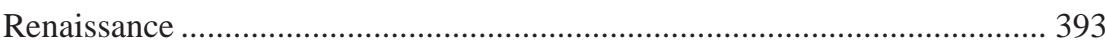


Table of Contents

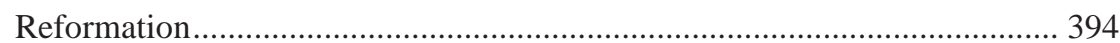

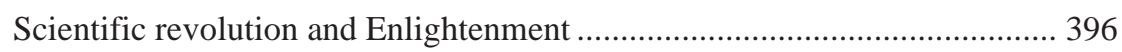

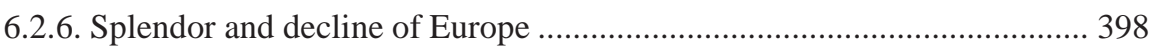

Europe in the "long nineteenth century" .................................................... 398

Europe in the "short twentieth century" .................................................. 400

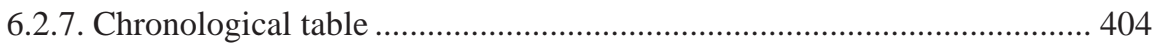

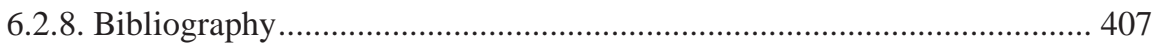

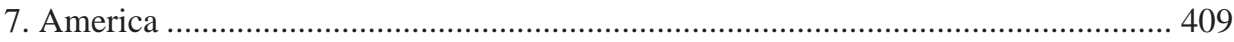

7.1. The North American Civilisation - LÁsZLÓ ZsINKA ..................................... 411

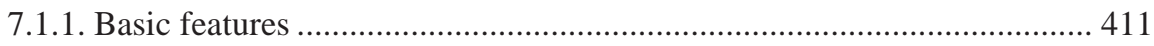

7.1.2. "Establishing" freedom in the United States ......................................... 416

7.1.3. American myth - American values ........................................................ 422

7.1.4. The rise of the United States ................................................................. 426

7.1.5. Progressivism and the New Deal......................................................... 432

7.1.6. American civilisation values in the second half of the twentieth century 436

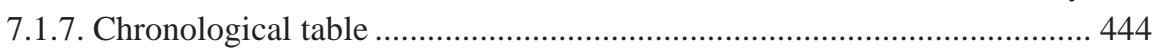

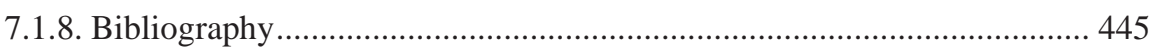

7.2. Latin America: An Interactive System of Civilisations

- BERNADETT LEHOCZKI........................................................................... 447

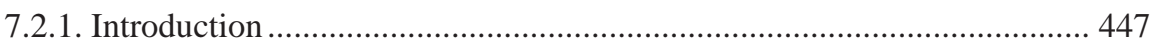

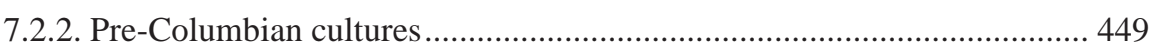

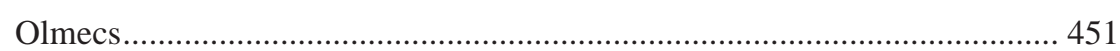

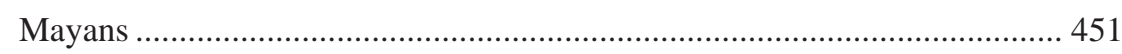

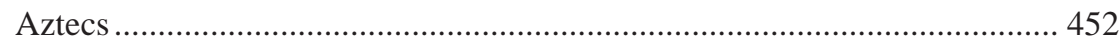

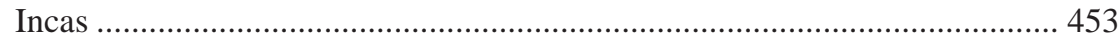

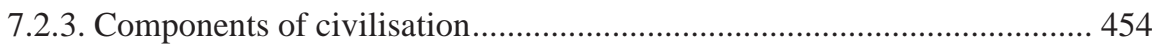

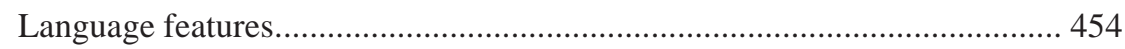

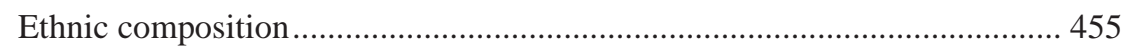

Religion: the most Catholic continent?.................................................... 456

7.2.4. History of Latin American Civilisation ................................................. 457

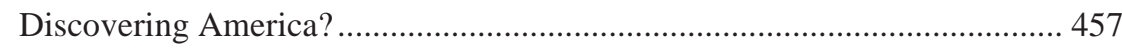

Achieving independence: common goals and aspirations? .......................... 462

7.2.5 Twentieth century dilemmas: A Western or Latin American way? ........... 465

7.2.6. Conclusion....................................................................................... 468

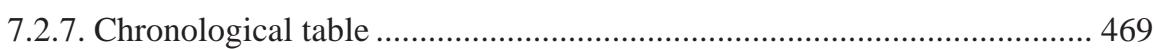

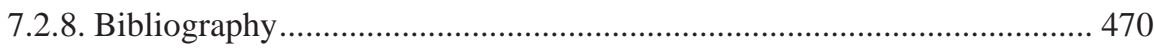

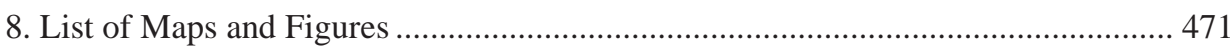

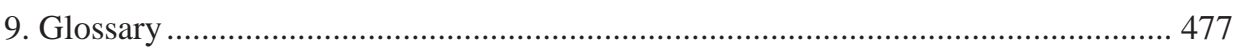




\section{Foreword}

The present volume introduces the world's great civilisations from the beginning of their formation to the first half of the twentieth century. The authors' purpose was to go beyond the events and write a book on the history of cultures and civilisations that also elucidates the background of contemporary events which might sometimes be difficult to grasp. The importance of this endeavour lies in that it comprises in one volume all the significant civilisations still existing in our days.

At the same time, the aim was to present regions, rather than modern-day countries in a complex way. It is true even if today three of these civilisations occupy a country each (China, Japan and India). On the other hand, the three monotheistic religions which evolved in the Middle East (Judaism, Christianity and Islam) influenced the civilisations of two regions, i.e. the Middle East and Europe to such an extent that it necessitated an approach via these religions.

Although each civilisation is presented according to uniform principles, certain differences due to the specific characteristics of the topics and the approaches of the authors occur. Where relevant, each region is introduced by its geographical and climatic features, followed by the emergence and development of social, cultural and religious characteristics described within the given historical context. This, although briefly, may include the description of major literary, artistic trends, and e.g. religious law (in the Islamic world, for example, law permeates every aspect of social and political life). In addition, the geopolitical significance of the specific region or civilisation is also presented in each chapter.

The illustrations, maps and chronological tables, as well as the glossary form an integral part of the chapters and the whole book. A short bibliography accompanies every chapter.

The book authored by subject specialists from the Corvinus University of Budapest and other universities and research centres is primarily aimed at students of international relations; researchers and members of the general public, however, may also find some areas of the topics stimulating.

Budapest, 10 May 2020

The Editor 


\section{I ntroduction to Regional and Civilisational Studies}




\title{
1.1. The New World Order and the Clash of Paradigms
}

\author{
LÁSZLÓ CSICSMANN
}

\subsubsection{Introduction}

The collapse of the bipolar world order built on rivalry between the Soviet Union and the United States in 1989 posed new challenges for the experts of the theory and practice of international relations. Religion, culture and civilisation were recognised to play an even more significant role in current international relations than before. The political, cultural and economic analyses of the processes outside Europe and the Western world, helping to understand the trends of the specific regions based on social science methodology, became greatly appreciated.

The discipline of international relations traditionally comprises four subdisciplines:

- history of international relations/history of diplomacy;

- international law;

- international economics/world economics; and

- international political theory.

In the 1990s regional and civilisational studies were added, with special emphasis on understanding non-European regions. Naturally, Chinese Studies or Middle Eastern Studies (commonly referred to as Area Studies or Regional Studies) had already existed in the pre-1989 era as well and was considered particularly important in the United States in predicting potential Soviet expansion. As mentioned before, in the post-1989 international order defined by experts as the New World Order the role of civilisation, culture and religion became greatly appreciated. Think of the current migration/refugee crisis affecting Europe that particularly highlights cultural differences. Indeed, this type of approach impacts foreign policy decision making as well (see constructivism as a school of thought).

Civilisational studies present the historical and modern-day development of non-Western civilisations, primarily relying on the developmental history of Europe and the Western world. Following a theoretical introduction, this book aims to present the historical milestones and cultural characteristics that distinguish one civilisation from another. The history of Europe and European civilisation is used as a point of reference in every case against which other non-European civilisations measure themselves (see later). All this is considered important 
due to the fact that some of the concepts used by us are often culturally defined. Democracy, as a form of government, is used as reference all over the world, its substance, however, is interpreted differently by the various communities according to their own beliefs, religious faiths and historical recollections. Before examining some key concepts in more detail, certain important characteristics of the New World Order should be highlighted.

\subsubsection{The characteristics of the New W orld O rder and globalisation}

The term New World Order refers to the end of the Cold War period. It is a new era following the Soviet-American rivalry, dominated by the United States. It is no mere coincidence that the 'New World Order' rhetoric is mostly characteristic for US policy. US President George Bush referred to the New World Order, among others, in his State of the Union address delivered in Congress in January 1991 as one to be built on peace, security, democracy and the rule of law. The distinctive feature of the speech made in January 1991 was due to the simultaneous start of the Gulf War launched by US-led coalition forces for the liberation of Kuwait, sanctioned by the UN Security Council. The debate concerning the unipolar or multi-polar nature of the New World Order is not addressed in this study.

In his book James N. Rosenau suggests that the New World Order is characterised by contradictory processes taking place at the same time. The concept of fragmegration introduced by him describes the simultaneity of fragmentation and integration as a key characteristic of the New World Order (ROSENAU, JAMES N. 1997). Others, like sociologist Zygmunt Bauman use the term glocalisation modelled on the word fragmegration to describe some current phenomena (BAUMAN, ZYGMUNT 1998). Thus, globalisation and integration take place in the world concurrently, along with the enhanced role of local factors.

Just think how some accomplishments of Western culture, particularly the ones related to consumer culture (e.g. Hollywood movies, McDonald's, or the English language itself) have spread globally. We can get exactly the same Big Mac burger in Addis Ababa, the capital city of Ethiopia as in New York.

However, local variations of the global trends also evolve, partly as a form of defence. For example, the Indian dialect of English is completely different to the language variations used in Africa or China. Similarly, McDonald's restaurants also sell local products globally: kebab sandwiches in the Arab countries, spicier variants in India, or seafood-filled in Southeast Asia. Another example is the beef ban for India's Hindus, where these popular meals are made from different ingredients. 
As demonstrated above, another key term related to the New World Order is globalisation. The definition of globalisation is beyond the scope of this study, certain characteristics should nevertheless be highlighted. According to Anthony McGrew, 'globalisation refers to the multiplicity of linkages and interconnections that transcend the nation-states in that events, decisions and activities in one part of the world can come to have significant consequences in quite distant parts of the globe' (Anthony McGrew, quoted by: ROSTOVANYI, ZsOLT 1999 pp. 7-8). As regards the beginnings of globalisation, three different views exist.

- Some believe that globalisation is a premodern category that precedes the development of nation states and world economy. As such, globalisation essentially evolved simultaneously with humanity, and has been a scene of ongoing global standardisation since the birth of mankind.

- Others believe, however, that geographical exploration and colonisation leading to a single global economy make it a more modern category. Those who support this view consider the revolution of communication and technology in the second half of the twentieth century an acceleration and intensification of globalisation.

- According to a third approach, globalisation is a postmodern phenomenon emerging in the 1970s due to changes in communication (particularly the fourth industrial revolution). (For more details see MCGREW, ANTHONY 2010 p. 23.)

Generally, the second approach is accepted, considering globalisation more like a modern category. In terms of globalisation three areas can be distinguished:

1. Economic globalisation is the area that is most spectacular and advanced. Globalisation is essentially driven by the free movement of goods, services, people and money. The institutions that evolved due to economic globalisation include, among others, the International Monetary Fund (IMF), the World Bank (IBRD) and the World Trade Organisation (WTO). In terms of economy globalisation has both advantages and disadvantages affecting the individual nation states. The so-called anti-globalisation movements emerged in response to the negative impacts of globalisation.

2. Political globalisation refers to the possibility of world government inherent in the post-WWII development of the United Nations and its specialised agencies. However, the changing power and political structures after the Second World War were not followed by reforms of the United Nations and therefore it is unable to assume national sovereignty at a certain level. As a result, no world government has yet been developed.

3. Cultural globalisation is the dimension considered most important for the purposes of this study. Indeed, globalisation involves not only the move- 
ment of goods between different parts of the world but the movement of cultural elements as well. Due to migratory processes the so-called Davos culture has spread on a global scale. ${ }^{1}$ Davos culture refers to a global elite in possession of the same elements of culture, essentially based on the English language and Western style consumer culture. The Davos culture shares most of the characteristics of Western civilisation. Will the Davos culture promote development towards a single world civilisation or global civilisation? Amongst the catalysts for the development of global civilisation the literature mentions four: global economy, international academic elite, the so-called hamburger culture or McWorld, and Evangelical Protestantism. These four elements are connected by the English language (cf. GOMBÁR, Cs. 2000 p. 28). However, the possibility of a single civilisation is seriously limited, primarily due to local identities strengthened as a form of cultural defence against globalisation and universalism.

The unique characteristics of the New World Order and accelerating globalisation considered important for the purposes of this study are summarised below.

1. Changing role of space and time in international relations. The cliché that the world has become a 'global village' was born out of globalisation. It is now widely accepted that time in the world is calculated and marked according to Western tradition. Non-Western civilisations have different perceptions of time. Just think of the hijra, which in the Islamic civilisation marks the start of the calendar. Also, a year in the Islamic calendar is different from the one used by the West. The worldwide use of the Western calendar is associated with colonisation and the development of global economy. The second millennium, considered in many respects a historical milestone, has no particular significance for the world outside Europe. International economy, finance and decisions rely on timely information available to the decision makers. The significance of territoriality in international relations has decreased gradually, constituting an ongoing process of deterritorialisation at an international level (See KISS J., LÁSZLÓ 2003 p. 82). Currently wars are not waged in order to gain new territories as in past centuries. For one state to gain influence over another there is now no need to occupy territory as national interests can be effectively enforced by economic means. At the same time, the significance of territories particularly associated with community identity has not decreased. Sacred places

\footnotetext{
${ }^{1}$ Davos, Switzerland is the venue for the annually organised World Economic Forum.
} 
often become the centre points of armed conflicts (BADIE, BERTRAND Smouts, MARIE-Claude 1999). For example, in 2018 the United States decided to move its embassy from Tel Aviv to Jerusalem in quasi recognition of the latter as the one and undivided capital of the Jewish state. However, Jerusalem has a special significance for all three monotheistic religions. Another example is the Yasukuni Shrine in Tokyo commemorating the victims of internal and external wars since 1869, including the Second World War. In China, formerly suffering Japanese oppression, regular riots break out whenever Japan's acting prime minister visits the shrine due to unhealed historical wounds.

2. Industry 4.0. The term is used by literature to refer to the extremely rapid changes in technology, and primarily in communication in the early twenty-first century. Communication development, the new media, bring essential changes to international relations. The World Wide Web facilitates access to real-time events, making us quasi involved. We could witness the 9/11 terrorist attacks in the United States, following the events online or on TV. The evolution of Artificial Intelligence may fundamentally transform the identities of cultural communities. Could Artificial Intelligence ever become emotional, express feelings and develop historical narratives suitable to distinguish human communities on a cultural basis? Or is it AI that could lead to the development of global identity? Industry 4.0 and the new technologies will fundamentally influence the culturally defined communities.

3. Widening of the development gap. The development gap between the developed countries of the North and the developing South is a key issue in respect of globalisation. The winner of the globalisation process in economic terms is North, or the Western world, the losers being mostly the countries of Sub-Saharan Africa. The development gap keeps widening as a result of the globalisation process; while the North has accumulated even more profit and developed welfare systems, the poverty indicators of numerous Southern regions have deteriorated. According to UN statistics, one percent of the world's population holds $50.1 \%$ of the global wealth (THE GUARDIAN 2017). In the 2000s the UN and its specialised agencies recognise a North-South internal fragmentation as well, dividing the states into different income categories. The eight Millennium Development Goals of the United Nations adopted in 2000 aim to eliminate the development gap. In terms of development it is clear that certain clusters (e.g. Asia's Little Tigers) are more successful than others (e.g. countries of SubSaharan Africa). The question is whether civilisation and cultural factors have any impact on development. Indeed, it is sometimes suggested that 
Confucian ethics had a major role in the Little Tigers' development. But how does the growing significance of religion and cultural traditions affect the issue of development gap and convergence of the South in particular?

4. Retraditionalisation. A unique feature of the New World Order is that the traditions of certain regions, both religious and cultural, become highly appreciated and manifested both in the community sphere and in politics. Retraditionalisation is characteristic for both the Western and the non-Western world. Generally, an underlying identity crisis gives rise to efforts to solve community challenges by reinterpreting traditions. Identity crisis is often accompanied with modernisation and development crisis. Retraditionalisation in its various forms aims to address the challenges threatening community identity and cohesion, combined with a unique ideology (for more details see RostovÁNYI, Zsolt 2005). For example, the far-right movements in Europe regularly try to use extreme nationalism to address challenges, such as the integration problems of Europe's Muslim minorities. India's Bharatiya Janata Party, a self-identified Hindu nationalist party aims to revise certain values (e.g. secularism) adopted after British colonialism and introduce the principles of Hindu religion and culture as a solution.

5. Intensifying migratory processes. Migration, which facilitates encounters between civilisations and cultures, is a phenomenon particularly significant to our discussion. According to the United Nations 2017 International Migration Report approximately 258 million people live in a country other than their country of birth, an increase of 49\% since 2000. The 2017 report states that $3,4 \%$ of the world's inhabitants are international migrants. Of the 258 million individuals currently 164 million live in developed highincome countries. The primary target of migration is the developed West (Europe and Northern America), with similar trends involving tens of millions in Latin-America, Africa and Asia as well. Currently India has the largest number of persons born in the country who are now living outside its borders. (UNITED NATIONS 2017) Migration is a complex process with a mixture of economic, political and cultural factors. The technical innovations of recent decades have facilitated migration in some respects, but at the same time, migration toward the developed West has become increasingly difficult out of defence against cultural impacts, based on political grounds. Naturally, the explanation of political, economic and legal context is beyond the scope of this study, however, migration resulting from war or other circumstances should certainly be treated differently. Migratory processes may lead to the settlement of larger ethnic or religious groups in certain countries. The number of Muslims living in the territory 
of the European Union is approximately 30-40 million, including many second and third generation immigrants. The current major debates in Europe surround the integration problems of the Muslim community.

6. Increased terrorist activity. Terrorism is not an easily definable term as it has over one hundred definitions. However, the number of attacks carried out as a threat to civilian population has increased significantly over the past two to three decades. The terrorist attacks on 11 September 2001 fundamentally shook the United States and the Western world. According to the Global Terrorism Index the highest number of terrorist attacks in 2017 was attributable to five countries (Iraq, Afghanistan, Nigeria, Syria and Pakistan) (GLOBAL TERRORISM INDEX 2017). Considering the attacks of recent years, the civilisational and cultural aspects of terrorism have generated major debates in Europe. Some analysts speak about Islamic terrorism while rejecting the term in regard to attacks carried out in the name of defending Christianity (e.g. Utøya 2011) (see later). Thus, the political narrative surrounding terrorism is varied. Labelling certain countries, however, has an explicit delegitimation element when using the term terrorism.

7. The increasing role of religion. In the post-bipolar world order religion has become vital. Religion is an important factor in everyday global political decisions and political discussions (BADIE, BERTRAND - SMOUTS, MARIECLAUDE 1999). Think of the presidents of the United States, swearing on the Bible at the inauguration ceremony. For the sake of our discussion it can be highlighted that religion is often used as a point of reference in military conflicts between states of different cultural backgrounds. For example, US President George W. Bush called the 2011 military intervention in Afghanistan a 'long crusade' referring to the historical role of crusades in the Holy Land. Religion as a point of reference appears in the rhetoric of the religious fundamentalist groups in particular. Religious fundamentalism generally addresses situations of crisis. Indeed, some social groups often use religious traditions in response to problems. Religious fundamentalism frequently occurs alongside radicalism. For example, based on the fatwa issued in 1998 by the World Islamic Front for Jihad Against Jews and Crusaders established by Osama bin Laden, all Muslims are obligated by jihad, in this case disrespecting its various meanings, and translating it as holy war.

8. Transformation of nation-state sovereignty. The acceleration of globalisation affects state sovereignty as well. In the classical sense, the only international actors with internal and external sovereignty are the world's states. Some believe that globalisation reduces state sovereignty, but it would perhaps be more accurate to say that nation-state capacity is transformed by 
shifting world order (Kiss J. LÁSZLÓ 2003 pp. 225-248; SCRUTON, ROGER 2004 pp. 39-41). During the process the countries rejecting globalisation lose out significantly. For example, the autarchic development of North Korea cannot be viewed as a successful model either.

9. Simultaneity of modern, premodern and postmodern structures. Although international relations are still dominated by nations (modern category) as key actors, the subnational and supranational players are assuming increasing weight. A paradox inherent in the New World Order is the simultaneous existence of modern, premodern and postmodern structures. For example, the importance of tribalism in Africa is a premodern phenomenon. During the Congo War, also nicknamed Africa's First World War, the surrounding states were drawn in due to cross-border tribal aspects, among others. A postmodern structure, for example, is Greenpeace, a non-governmental organisation promoting sustainable development in international relations with the goal to influence the behaviour of countries worldwide resorting to its own means.

\subsubsection{The competing paradigms of the New W orld Order}

The researchers of international relations in the 1990s sought to find an explanatory theory in order to provide a theoretical framework for the above processes. The arguments of two scientists from the United States had a vital impact on New World Order related ideas.

An optimistic scenario is described in The End of History and the Last Man, a book written by Francis Fukuyama (FUKUYAMA, FRANCIS 1992). Relying on a liberal school of thought in international relations theory, Fukuyama observes global political processes progressing in a positive direction. The collapse of the Soviet Union in 1991 resulted not from a great war but mostly peaceful processes. According to Fukuyama, with the passing of the age of ideologies Western values (including democracy, human rights and free market economy) will conquer the world. At the same time, the spread of democracy will signify the end of history, and the inevitable wars of history will be avoidable because, according to liberal approach, democracies do not fight one another. Indeed, looking at the process defined by the rival theorist Huntington as the third wave of democratisation in the 1990s it can be seen that democracy began to spread not only in Eastern Europe but, primarily, in Asia and Africa as well. Fukuyama's views were influenced by the idea that Western values were inevitably universal values that would sooner or later spread around the world. According to Fukuyama, the end of history is only restricted by intensifying extreme nationalism, manifested in the Yugoslav conflict erupting in the early 1990s, among others. 
As regards the New World Order, a pessimistic scenario is presented by American political scientist Samuel P. Huntington, whose initial views were published in an article in 1993 for Foreign Affairs (HUNTINGTON, SAMUEL P. 1993). According to Huntington, with the passing of the age of ideologies Western values will not conquer, but quite the contrary, the civilisational and cultural differences will increase. His theory was later published in a book The Clash of Civilisations and the Remaking of World Order, making the idea a core thesis (HunTINGTON, SAMUEL P. 1996). In Huntington's view armed conflicts always erupt due to civilisational and cultural differences. As an example, the dissolution of Yugoslavia is mentioned, in so far as the crisis involved a series of armed conflicts amongst three civilisations represented by Yugoslavia's member states: Western Christianity (Slovenia, Croatia), Orthodox Christianity (Serbia) and Islam (Bosnia and Herzegovina). Huntington's theory, to be presented in more detail at a later stage, cannot be regarded as a wholly new idea.

Huntington's book mentions five possible paradigms, the fifth being civilisational theory, which fundamentally goes beyond the shortcomings of the first four (HunTington, SAMUEL P. 1996 pp. 31-35). The first paradigm called One World essentially means the great rival Fukuyama's concept. Without repeating Fukuyama's ideas, it is worth mentioning that, in Huntington's view, the theory fails to stand up in many aspects. First, just because the third wave of democratisation spread in the post-1989 period one cannot conclude that confrontation amongst nations was at an end. Huntington refers to the dissolution of Yugoslavia and the tribal wars of Africa as an example which, in his view, contradict Fukuyama's vision built on the concept of perpetual peace.

The second paradigm, Two Worlds can be viewed as a North versus South or East versus West conflict. The theory, which defines the New World Order as a conflict between the developed North and the developing South, draws on the idea that the acceleration of globalisation marks a new stage in the battle for resources. Those who describe the New World Order as North versus South share the view that all global political conflicts, armed or unarmed, tend to include economic aspects. According to Edward Luttwak, for example, geo-economic wars erupt purely to meet economic needs (LUTTWAK, EDWARD N. 1990 pp. 17-23). The Gulf War erupting in 1990 is an excellent example, with the United States setting out to liberate Kuwait, authorised by the UN Security Council. Based on this theory, the USA represented the developed North, while Iraq led by Saddam Hussein represented the South. The battle itself was explicitly about the control of oil resources. The theory can be well simplified, as many wars do not indicate economic intent to the same extent, or they themselves provide no explanation for the direct cause of military conflict. Oil was undoubtedly an important factor in launching Operation Desert Storm, but it would be simplistic to say that the 
United States went to war only for the sake of oil. Another possible interpretation for the Two World paradigm is the East-West conflict. Essentially, the theory assumes that the non-Western world wants to win over the West's current superiority. The already mentioned Gulf War is a good analogy in many ways. Indeed, Saddam Hussein aimed to compare the Second Gulf War to historical colonialism, the USA wanting to overpower a third-world state. His goal was to convince the general public of the Middle East, and the Third World most of all. However, some 'Eastern' countries, such as Egypt and Syria, supported the United States during the above conflict. According to Huntington, East is in fact everything that is not West: The West and the Rest. A study by Géza Ankerl suggests that although the Western world has been structured uniformly and developed organically, it would be impossible to view the East in the same sense. The Eastern cultures, with completely different traditions and values, cannot be considered homogenous (ANKERL, GÉZA 2000).

The third paradigm is 184 States. It refers to the so-called realism, the classical explanatory theory of international relations according to which the nations' interests clash in the armed conflicts of the New World Order. In fact, the starting point of realism is that despite the changed international relations the key actors are the nations themselves, focusing on their own interests, and engaging in armed conflicts. This is an obvious paradigm, but in Huntington's view it is outdated in so far as it disregards subnational and supranational actors, or premodern and postmodern structures, among others.

The fourth paradigm, Sheer Chaos has grown quite popular. Many thinkers, mostly American, expressed pessimistic views in respect of the New World Order. They describe it as one with no international cooperation, and where international law fails to prevent conflicts amongst the nations. For example, John J. Mearsheimer's 'Back to the Future' theory published in 1990 projected European conflicts more robust than Cold War confrontation (MEARSHEIMER, JOHN J. 1990 pp. 5-56). He considered the role of unified Germany in a negative way in respect of European balance of power. Huntington is opposed to the anarchy concept claiming that international law and international organisations have retained control over the nations, with signs of cooperation witnessed on a daily basis. Rejecting the first four theories Huntington suggests a fifth paradigm, the above presented Clash of Civilisations, which fundamentally goes beyond the first four.

In the early twentieth century two historians, working in different language environments, studied the civilisational processes. In the German-speaking world Oswald Spengler took a pessimistic approach generated by the First World War, and his book The Decline of the West is often used as a point of reference in contemporary debates about European future (SPENGLER, OswALD 2006). Ac- 
cording to Spengler numerous cultures existed and ceased to exist in history (e.g. Ancient Egypt). In his view civilisational development is cyclical, and Western civilisation has reached a decline stage.

Spengler distinguishes eight high cultures: Antique, Arabic, Western, Babylonian, Egyptian, Chinese, Indian and Mexican. His perception is teleological, meaning that as a result of biological laws, decline is inevitable. According to Spengler, every high culture experiences the same stages of development: preculture, early culture, late culture and decline, the final stage identified as civilisation. In his view the history of Western civilisation began around the first millennium. He regards industrial revolution, money and urbanisation as the symbols of decline. Spengler's approach distinguishes between high culture and civilisation. The latter is inevitably part of the decline process. He believes that industrial revolution and urbanisation bring about the simultaneous decline of Western culture, the civilisation stage, which is unstoppable and fatalistically determined.

In his 12-volume book, A Study of History English historian Arnold Toynbee fundamentally criticises his peer, Oswald Spengler's work (TOYNBEE, ARNOLD 1988). Toynbee considers four stages of civilisation: genesis, growth, breakdown and disintegration. Toynbee rejects Spengler's view of fatalistic determination and criticises the theory concerning the isolation of high culture. However, he agrees with Spengler in that Western civilisation has reached a decline stage, although he argues its deterministic nature. Toynbee believes in 'creative minorities' capable of devising solutions to preserve civilisation. Civilisations have always been influenced by external factors encouraging revival. Considering the history of Western civilisation, Toynbee's theory of revival may be well founded.

Bernard Lewis, the recently deceased doyen of Orientalists wrote his thesis on clash of civilisations several years before Huntington. Lewis was a historian specialising in the Middle East and the Islamic world, whose essay entitled The Roots of Muslim Rage published in 1990 in The Atlantic Monthly explored the sentiments of anti-Westernism and anti-Americanism in the Islam world. According to Lewis, US Middle East policy is to blame for the frustration that eventually leads to religious fundamentalism. The latter is explicitly opposed to the values of secularism and modernity (LEWIS, BERNARD 1990 pp. 47-60). Similarly, to Lewis, Tariq Ali interprets the fault line between Islam and Western civilisation as a Clash of Fundamentalisms (ALI, TARIQ 2002).

The clash of civilisations also appears in Benjamin Barber's Jihad vs. McWorld (BARBER, BENJAMIN 1995). Barber's work explores the possible spread of democracy around the world. McWorld is identified as the forces of globalisation, ruled by financial and banking sector norms. Jihad, on the other hand, is against globalisation, aiming to preserve local identities and defend them from 
external influence. Barber's opinion is pessimistic in that neither McWorld nor Jihad can be viewed as a democratic force.

Huntington's reasoning, therefore, is novel in a way that it connects the above views as a coherent whole. Huntington is perhaps the first thinker of the New World Order who applies the Clash of Civilisations thesis to international political relations. Before we explore the theory in more detail, however, some key concepts should be clarified.

\subsubsection{Definition(s) and interpretation(s) of civilisation and culture}

Few terms have such diverse interpretations as civilisation and culture. The terms might have different meanings even within the same language community. The situation is further complicated by the fact that while certain language communities (English speaking countries) often equate civilisation with culture, others clearly distinguish one from the other.

Iván Vitányi's study suggests that the common feature in the interpretations of culture is that culture has a subject, object, action and result (objectivation) (VITÁNYI, IVÁN 2002). The subject of culture is man, or a wider community, who performs the action. Cultures also vary in the sense whether they allow for interpretation as an individual on its own or only as part of a community. The individualistic Western culture fundamentally differs from non-Western cultures generally organised based on communities. Depending on their focus, the interpretations of culture are generally divided into two main categories. The anthropological culture concept focuses on man as an individual or groups of individuals, while the objectivational concept of culture focuses on the result of action (objectivation). The word culture comes from Latin and primarily means 'to cultivate'.

The term civilisation goes back to the age of the French Revolution as opposed to barbaric or primitive society, and in everyday language is still used in contrast to something negative. For example, 'back to civilisation' is often used in the context of returning from a backward environment. This study, as also Huntington's theory, is specifically opposed to the use of 'civilisation' in the above sense. Huntington, who comes from an English-speaking environment, perceives no substantial difference between civilisation and culture.

Culture is 'a repository of social meaning that distinguishes one community from another' (HuntingTON, SAMUEL P. 1996 pp. 40-45). The key ingredients of civilisation include language, religion, tradition, shared history, etc. Huntington considers religion the most important; in his view every civilisation that has ever existed can be best characterised by religion. Civilisation and culture are 
merely distinguishable in space and time, because 'a civilisation is the broadest cultural entity' (HuntingtOn, SAMUEL P. 1996 p. 43).

In certain languages, particularly in German, the concepts of civilisation and culture are sharply opposed, which is attributable to contrasts between aristocracy and citizenry. Culture often refers to intellectual achievement, including arts as well as sciences. Civilisation is associated with material achievement, with emphasis on cultural superiority. In contrast, English speaking communities use civilisation and culture essentially as having the same meaning. ${ }^{2}$

The term civilisation can be used in singular or plural form. The singular form refers to the aforementioned debate whether a single world civilisation or global civilisation could evolve, which would eliminate cultural differences. The subject is all the more interesting because in the context of New World Order characteristics migration is mentioned as a phenomenon in which cultural values change countries. How would the different cultures and civilisations affect each other if they met? Generally, four models of cultural coexistence are mentioned (based on Tariq Modood's study):

- Assimilation is a process where a community's culture becomes integrated into the culture of a host country, the former losing its own characteristics. Individualistic integration means coexistence at individual, rather than at community level. In that case a minority becomes integrated without appearing in the public sphere as a community.

- Multiculturalism, in the normative sense, means the parallel existence of a host culture and a foreign culture, neither of them wanting to eliminate the other. In that case two or more cultures possess equal status in a society.

- Cosmopolitanism is viewed by many as a form of multiculturalism. The essential difference is that multiculturalism involves political and civil rights held by a group or community, while in the case of cosmopolitanism it is not an important characteristic (MODOOD, TARIQ 2011).

If coexistence fails, the opposite model is segregation. It means that a minority is driven to the periphery of society, its rights recognised neither at individual nor at community level. Simplifying the above, assimilation, integration and segregation can be well distinguished as three models describing the relationship between society and foreign culture (See FEISCHMIDT, MARGIT 1997 pp. 729).

These theories generated major debates about which one should be recognised as a desirable model. European discussion is linked with the issue of integrating a Muslim minority of approximately 30-40 million people. Some

\footnotetext{
${ }^{2}$ A more detailed presentation of the European philosophical interpretations of culture is beyond the scope of this study (for more details see WESSELY, ANNA 2003 pp. 7-27).
} 
European politicians, including Angela Merkel and David Cameron, emphasised on numerous occasions that multiculturalism is not a solution, as it leads to parallel societies. The question is, however, whether we can speak of a multiculturalism model genuinely applied in Europe to integrate minorities.

The use of the singular form of civilisation raises multiple dilemmas. As seen before, cultures defend themselves against the universalising impact of globalisation as a result of fragmentation and localisation. Therefore, while the wealthy global elite (see Davos culture) speak the same English language, live similar lives and consume similar products, the cultural differences still survive.

The authors introduced in this study generally use the plural form of civilisation. Spengler, Toynbee and Huntington argue that at any given time several civilisations exist in parallel. Yet it is not possible to distinguish them on the basis of values. For every individual or community, the superior civilisation is the one in which it was born, as perceptions of the world and transcendental matters are determined culturally. In Huntington's view, for example, at present seven or eight civilisations, describable by well distinguishable characteristics, exist simultaneously. These seven or eight civilisations include the following (the list signifies no ranking):

-Western, including two major variants: European and North American,

- Russian-Orthodox, centred around Orthodox Christianity,

- Hindu-Indian,

- Islamic,

- Confucian-Chinese,

- Japanese,

- Latin American, and

- African.

Huntington argues with himself about the last two, wondering the extent to which Latin American or African could be considered individual civilisations. In the case of Latin America, Spanish language and Western Christianity (the 'most Catholic' continent) essentially suggest connection to the West. Nevertheless, Huntington argues that something novel evolved due to external impacts: ancient local cultures encountering Western influence, importation of African slaves. As regards Africa, civilisational determination is left to be decided for his audience. The primary reason is that while civilisation is centred around religion, the African continent is greatly divided on grounds of religion (Islam, Christianity, Animism) and language, therefore the existence of a homogenous civilisation as defined by Huntington is debatable (Huntington, SAmuEL P. 1996 p. 47). Contrary to Fukuyama and other thinkers (e.g. Amartya Sen), Huntington therefore 
holds the view that Western values are not universal, but primarily characteristic of the West. Furthermore, each of the seven or eight civilisations has its own set of values, distinguishing one civilisation from another. Apart from the West, however, Huntington provides no itemised lists of civilisational values.

In Huntington's view Western civilisation can be defined by the simultaneous existence of the following eight characteristics (HUNTINGTON, SAMUEL P. 1996 pp. 69-72):

- classical heritage,

- Western Christianity,

- European languages,

- separation of spiritual and temporal authority,

- rule of law,

- social pluralism,

- civil society,

- government by representation and individualism.

However, Huntington provides no distinguishing characteristics for Latin American civilisation as opposed to the West, for example. Ronald Inglehart and his team drew up a civilisational map of the world based on comparable data of the World Values Survey (WVS) (Figure 1). It depicts closely linked cultural values clearly distinguishing Huntington's seven or eight civilisations based on two dimensions. The $\mathrm{x}$-axis indicates material (survival) values versus self-expression values (e.g. civil and political rights), while the y-axis indicates traditional values versus secular values. Farthest from the origin is Protestant Europe, dominated by self-expression values and secular values. Closest to the origin is African-Islamic civilisation, dominated by traditional and survival values.

Naturally, the cultural map is not identical to Huntington's classification, but they share the idea that every civilisation can be characterised by different values. The Inglehart-Welzel cultural map is the first empirical manifestation of civilisational values. 


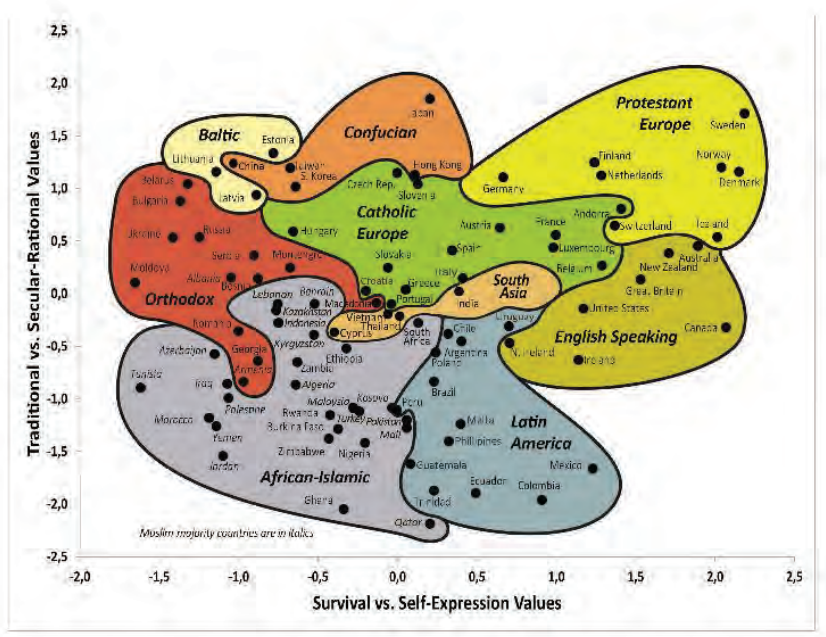

Figure 1: The Inglehart-Welzel cultural map Source: WORLD VALUES SURVEY website ${ }^{3}$

\subsubsection{Progress, modernity and modernisation}

As regards civilisational theory, the major discussion in literature is focused on how a civilisation responds to changes and the challenges faced. Most thinkers engaged in civilisational theory agree that of the currently existing seven or eight civilisations the West occupies the highest level of hierarchy in terms of economy and power. For example, Western dominance is apparent in global economic processes and in military aspects, although decline has already started. Civilisational theorists, including Toynbee, Spengler and Huntington accept the notion of civilisational development. Civilisations survive for centuries or even for millennia (longe durée). They are limited in time and space, generally impossible to be defined accurately. The history of civilisation can be best demonstrated by a product's life cycle. The stages of the life cycle include birth, development, maturity and decline. Toynbee and Spengler suggest that Western civilisation has passed maturity and reached the decline stage. According to Huntington it can be proved empirically as well. The global share of Western territory and population has been diminishing continually. In 1900 Western civilisation made up 30\% of the world's population, dropping to merely $10 \%$ by 2020 . This process can be

\footnotetext{
${ }^{3}$ http://www.worldvaluessurvey.org/WVSContents.jsp?CMSID=Findings - accessed 15
} July 2020 
attributed to decolonisation; in 1990 most of the world's territories, except for Latin America, were under Western control, in a dependent status (HUNTINGTON, SAMUEL P. 1996 pp. 84-91). The question is whether territory, population or GDP data provide sufficient grounds to conclude that Western civilisation is declining. Perhaps decline has rather different characteristics that could be proved empirically to a lesser degree. One need only think of the current European crisis phenomena such as the migrant crisis or sovereign debt crisis which signify identity crisis on a broader scale. However, as Toynbee reminds us, the ability of the Western civilisation to revive is exceptional.

Western civilisation is distinguished by the emergence of enlightenment and faith in mind. The political and social developments of the eighteenth and nineteenth centuries brought along the age of modernity, rejecting former traditions and spreading norms, such as nation state (in the modern sense), secularisation, democracy, free market economy and individualism (human rights). Modernity at present is only characteristic in the history of Western civilisation.

The decline of the West occurs with the simultaneous rise of non-Western civilisations. In particular, Huntington points out East Asia and China whose exceptional economic development and military advancement pose a threat to Western dominance.

The non-Western world aims to catch up with the West as a result of the above mentioned economic and political processes. This can happen in different ways:

- The so called unilinear evolution models suggest that there is only one way to catch up: to follow the path taken by Western civilisation. The modernisation theory dominating twentieth century development studies assumed that transition from rural society to industrialisation and the evolution of the so called modern societies initially took place in the West (for detailed presentation of the modernisation theory see TIPPS, DEAN C. 1973 pp. 199226).

For the non-Western civilisations the modernisation theory offers Westernisation - urbanisation, industrialisation and technological development - as a solution. Supporters of the theory believe that reaching a certain level of economic development (GDP per capita) should induce political changes as a first step toward democratic transformation. A great deal of neoliberal economic prescriptions in the second half of the twentieth century were based on presuppositions of the modernisation theory, however, they failed to address the modernisation crisis emerging in the non-Western world. The latter primarily evolved due to the logic of Westernisation which disregards the local cultural dimensions of development. 
Cultural context, however, is particularly important to understanding that any theory merely promoting Westernisation and Western values is inevitably doomed. One need only think of statehood issues. The modern concept of nation- state is a major accomplishment of the Westphalian system that gradually spread around the world. However, statehood as a political form of community development was alien to most non-Western civilisations. Contrary to the organic development of the Western nationstates, in non-Western civilisations they emerged due to foreign influence, practically in the wake of colonisation. Community identity in Sub-Saharan Africa is primarily linked with tribalism, while the role of the individual in Islamic society is mainly determined by religion. Several political movements today question the existing borders of the non-Western world, including the Islamic State in Iraq and Syria, paradoxically using the idea of statehood to gain territorial sovereignty.

The non-Western civilisations have largely experienced the so-called Western development models (e.g. capitalism, democracy and rule of law) and adopted numerous political and legal institutions (e.g. constitution, parliament). However, Western models are less effective in non-Western cultural and social contexts. Modernisation crisis is generally linked with identity crisis as grounds for increased focus on religious and other cultural traditions. Interpreting modernisation wholly as Westernisation is, therefore, a fundamentally mistaken approach. Adapting to local traditions, for example, was key to the successful introduction of democracy in civilisations such as India and Japan.

- According to the multilinear evolution model modernisation and Westernisation are not the same. There are multiple paths to development, designated by the particular sociocultural context.

Modernisation can only be successful if largely limited to the adoption of Western technological achievement in the initial phase, followed by a path according to the given sociocultural context. Huntington uses the following graph to illustrate correlation between modernisation and Westernisation (Figure 2). 


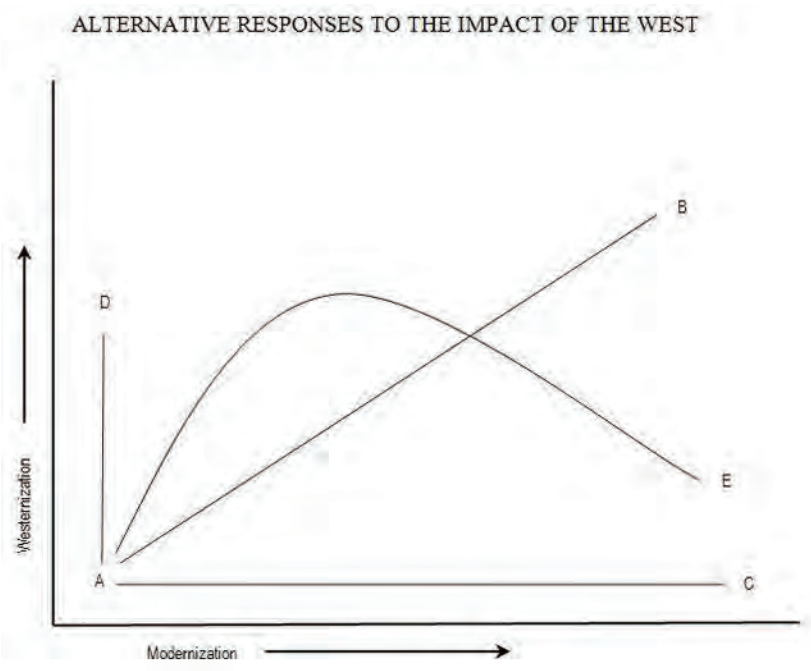

Figure 2: Correlation between modernisation and Westernisation Source: HunTINGTON, SAMUEL P. 1996 p. 111.

According to the graph there are four alternative correlations between modernisation and Westernisation (HUNTINGTON, SAMUEL P. 1996 pp. 72-78).

- Countries progressing along the y-axis equate modernisation with Westernisation (AD). Huntington brings African examples, which might not be particularly accurate considering that retraditionalisation and Africanisation are widely supported in the region. Extreme Westernisation generally overshadows local religious and cultural traditions. The countries opting for extreme Westernisation rely on the presupposition that the only way to solve economic and social difficulties is to adopt Western society and institutions. Using this logic, the other way round, religious and cultural traditions are seen as an obstacle to development. This model is essentially traceable to the unilineal evolution model. The author of this study regards pre-revolutionary Iran an apt example, the Pahlavi dynasty aiming to put ancient Persian-Zoroastrian religious principles in the forefront by degrading Islamic traditions. The religious elite (Ulema) joined by the bazaari carried out a grassroots revolution, bringing unilateral Westernisation to an end. Perhaps Huntington's African example is appropriate in a way that there is an elite detached from the population, focused on its own gains, copying Western civilisation to extreme degrees. As mentioned before, this leads to modernisation crisis, retraditionalisation and religious fundamentalism.

- The second alternative is complete rejection of Westernisation, represented by progression along the $\mathrm{x}$-axis (AC). Interpreting modernisation in this 
manner involves complete rejection of Western values, and on the whole, the globalisation process. An excellent example is North Korea led by Kim Jong-un, where Juche represents superior state ideology building on Korean traditions. The ideology of Juche is built on self-defence and selfreliance, i.e. an autocratic development model, trying to eliminate all external influences. The example of North Korea shows, on the one hand, that this kind of development model leads to breakaway and underdeveloped economic structure, and therefore is regarded unsuccessful. On the other hand, due to interdependence caused by globalisation it is not possible to avoid the so-called Western demonstration effect well visible in the Kim dynasty's luxury consumption.

- The third alternative constitutes progression along the line AB, which Huntington calls Kemalism based on the Turkish example. The author of this study holds the view that Turkey should be mentioned as an example of extreme Westernisation, rather than a modernisation strategy built on a combination of Westernisation and local cultural tradition. The creation of modern Turkey in the 1920s occurred with the simultaneous complete eradication of Ottoman and Islamic traditions. Modern Turkey embarked on a path of historical development relying on a new constitution, French style secularism, Latin-based alphabet and adopted surnames. In the modernisation process Kemal Atatürk disregarded Turkish traditions, in fact, considered them an obstacle to progress. Indeed, assuming that every civilisation has its own set of values (see above), the major discussion in literature is focused on the extent to which these values hinder development, or else how to use them to promote progress. According to Bernard Lewis the values of Islam and modernity are in conflict. In his view the slogans of the French Revolution, such as liberty, equality and fraternity, have historically different meanings in the Islamic civilisation and therefore are unlikely to spread. Lewis's work undoubtedly draws attention to the fact that some known concepts, such as democracy, freedom and human rights might have different meanings in the non-Western world (LEWIS, BERNARD 1990 pp. 82-95). Others claim, however, that these values are not at all conflicting; in fact, some highlight their Islamic roots (cf. MAZRUI, ALI 1997 pp. 118-132). According to Amartya Sen, winner of the Nobel Prize in economics development is possible only with freedom. Democracies and countries respecting human rights are able to develop in the long term. He draws on multiple historical examples including, among others, democratic India (SEN, AMARTYA 2000).

- Huntington regards the fourth development model (curve AE) a norm which combines Westernisation with cultural adaptation. The first stage of 
modernisation focuses on the adoption of Western technological achievements, the second stage focuses on cultural traditions. As an example, the development of Southeast Asia should be highlighted in particular: the Little Tigers took advantage of Western scientific and technological accomplishments, while choosing an independent path of development built on Confucian ethics.

\subsubsection{Huntington and the $\mathrm{C}$ lash of Civilisations thesis}

For a better understanding of Huntington's views on the Clash of Civilisations some of his definitions should be reviewed (HunTINGTON, SAMUEL P. 1996 pp. 135-154):

- Member state: Every civilisation is made up of member states. Hungary is a member state of the West; Argentina belongs to Latin America. Therefore, civilisation is not a politically defined entity but, essentially, it comprises the main actors of international orders: the world's countries.

- Core state: Every civilisation has a dominant political, economic and military regional power responsible for maintaining intra-civilisational order. This role can be shared by multiple states. For example, the United States, France, Germany and Great Britain share responsibility for setting the direction of Western development. In Latin America the dominant role is shared by Mexico, Argentina and Portuguese-speaking Brazil. The major problem of the Islamic world is that no such core state exists. In Huntington's view, essentially shared by Bernard Lewis, Islam's ‘bloody' borders are partly due to its current lack of a core state responsible for maintaining civilisational order. With the outbreak of the Arab Spring a regional competition emerged, defined by some experts as the new Cold War of the Middle East. The competition, primarily taking place between Iran and Saudi Arabia, is manifested in numerous local conflicts (e.g. Syrian civil war).

- The lone counties are not part of any civilisation. One such example is Israel which, within the meaning of this study, belongs to West, yet with traditions setting it apart. Huntington's study mentions Mongolia as a country sharing no commonality with others.

- The kin-country syndrome primarily appears in conflicts where countries belonging to the same civilisation are joined together by external threat. As a typical example, Huntington mentions the Yugoslav wars and the dissolution of Yugoslavia. The external powers evidently supported their own kind during the conflict; thus, Russia took sides with Serbia, Germany and Europe with Catholic Slovenia and Croatia, and Turkey and Saudi 
Arabia with Islamic Bosnia. Likewise, in the Gulf War erupting in 1990, Saddam Hussein tried to call on the Arab/Islamic world opposed against the United States and their allies. One weakness of Huntington's theory is precisely that although in the latter case Arab/Islamic public opinion was quite successfully turned against the US, it failed at the level of Middle Eastern states. On grounds of realpolitik considerations several Middle Eastern countries took sides with the United States (e.g. Egypt and Syria), raising questions about the theory in general.

- The so-called torn countries aim to change from one civilisation to another. Huntington's theory pays little attention to interactions between civilisations. Yet it is important to note those countries which, turning against their past, choose to adopt different civilisational values. Generally, it can be successful if the idea is shared by the wider society, not just a narrow elite, of both cultures. Some concrete examples include Turkey (changing from Islam to Western), Mexico (changing from Latin American to Western) and Russia (changing from Orthodox-Russian to Western). Australia is unique in a way that although it is part of the Western world, it aims to develop its own Australian identity. Europe is probably most concerned with the Turkish developments. As mentioned before, Kemal Atatürk aspired to develop a modern secularist nation-state built mainly on Western values. Turkey's hundredth anniversary will be celebrated in 2023. Currently in Europe, and also in Turkey, there is a gradually developing consensus that Turkey's EU accession could be untimely. It seems as if the definition of Turkey as a Western state agreed over the past ten-twenty years had ceased to exist, which is manifested in the new directions of Turkish foreign policy. Providing more details on inter-civilisational interactions is beyond the scope of this study, however, the civilisation with dominant global role at a given time (in that case the West despite its current decline) becomes a point of reference.

- Cleft countries belong to two or more civilisations at the same time. These countries are bound to break up in the near future due to civilisational fault lines putting pressure on unity. A current example of cleft countries is Ukraine, where part of the population, mostly the eastern regions, is loyal to Russia, while Western Ukraine predominantly embraces European ideals. The Crimean conflict is an ample indication of the characteristics of cleft countries.

Huntington's Clash of Civilisations thesis is based on the assumption that all armed or unarmed confrontations of the New World Order arise out of civilisational conflicts, erupting along civilisational fault lines. Civilisational fault 
lines occur in geographical as well as in a virtual sense. On the one hand, fault lines appear along geographical borders separating one civilisation from another. The dissolution of Yugoslavia emerged at the intersection of three civilisations: Croatia and Slovenia (West), Bosnia and Herzegovina (Islam) and Serbia (Russian Orthodox). On the other hand, fault lines occur not only in a geographical, but in an ideological sense as well. The most distinctive fault lines currently emerge between Western civilisation and Islam, in both a geographical and an ideological sense. The biggest opponent of Western modernity and accelerated globalisation is Islam. A future threat raised by Huntington is an alliance between Confucian-Chinese civilisation and Islam, which would impact the current Western dominance in a negative way. However, he provides no details of a genuine (anti-Western) alliance between these two civilisations. Perhaps close ties between China and Pakistan, or between China and Iran would pose a threat to the West.

According to Huntington the clash of civilisations occurs at two levels (Huntington, SAmuel P. 1996 pp. 246-254):

- Fault line wars erupt mainly along geographically defined fault lines. For, the Kashmir conflict emerged between Kashmiri Muslims supported by Pakistan and India-backed Hindus. Fault line conflicts are rather common; example essentially all armed conflicts occur in this way.

- Core state wars are fought by the dominant powers of two civilisations engaged in armed conflict on a much more serious scale than fault line wars. So far there has been no such incident, but in Huntington's view it is a huge threat imminent in the New World Order. For example, an armed conflict between Russia and the United States would constitute a core state war according to Huntington's definition.

\subsubsection{C riticisms of the civilisational theory}

Although the theory seems to have coherent foundations, a great deal of criticism can be raised.

- The major problem concerning terminology is that the definitions of civilisation and culture appear in a static way, with little attention paid to dual and multiple identities. Huntington himself attaches importance to the historical interconnections and interactions of civilisations, but he fails to note the changes happening to them individually. A major critic of Huntington, Palestinian American literary historian Edward W. Said considers the civilisational paradigm unfounded, suggesting that such contrasts and distinctions between civilisations are man-made and lack any basis. As Said put it, "Huntington is an ideologist, someone who wants to make 'civilisations' and 'identities' into what they are not: shut-down, sealed-off entities that 
have been purged of the myriad currents and under-currents." (SAID, EDWARD W. 2001).

- Huntington analysed the Islam-West conflicts in multiple studies, providing summary findings. Elsewhere he suggests, for example, that fault line wars mostly involve Muslims, the primarily reason being that Muslims are 'difficult to manage'. (HUNTINGTON, SAMUEL P. 2001 pp. 140-144). In his view 'Islam has bloody borders', partly due to its highly militarised state. Although the empirical finding on large-scale Muslim involvement in fault line wars is hardly arguable, Huntington fails to consider historical context (e.g. deciding state borders along Western interests). His findings on Islam, based partly on Bernard Lewis's work, are generally arguable.

- Some unscientific critiques fear that the theory might turn into a self-fulfilling prophecy. The terrorist attacks on 11 September 2001 seemed to justify Huntington's views. Huntington himself said that the series of attacks carried out by extremist groups should not be interpreted as a civilisational conflict, although they could easily escalate into one. (So, are civilisations at war? 2001). The explicit goal of the extremist groups (e.g. $\mathrm{Al}$-Qaeda, Islamic State) is to generate civilisational conflict. Any kind of armed confrontation is fuelled by radicalism.

- It is questionable how novel the theory is; after all, history is about civilisational conflicts. Think of the wars between Islam and the West in the early eighth century. Also, civilisations comprise nation-states, meaning that clashes ultimately arise out of national, rather than civilisational conflicts (see the theory of realism). According to Huntington moreover, civilisation is not a political category, but a culturally defined concept.

- The theory pays little attention to intracivilisational or intercivilisational conflicts defined not necessarily by civilisational, but economic or other aspects. The civilisational paradigm is unlikely to fit all of the world's conflicts.

- Some critics say that the anti-Western alliance between Islam and Confucian-Chinese civilisation is not substantiated by the study. Huntington mentions few concrete examples (e.g. ties between China and Pakistan), but it does not lead to the conclusion that alliance between the Islamic world with its over 50 member states and China would be formed.

\subsubsection{Summary}

Although the so called civilisational paradigm raises numerous criticisms, the theory points out a specific segment of twenty-first century international relations that reflects actual processes. Undoubtedly, in international political rela- 
tions features such as identity, religion, culture and civilisation are growing increasingly important. Think how the current debates on Europe's migration-refugee crisis take on Huntington's approach. Social media and European politics shifting toward intolerance inevitably contrast Muslim migrants and the European majority in a simplistic manner. The civilisational paradigm might help us to understand that the current European crisis phenomena (identity crisis, political crisis, debt crisis) inevitably bring into focus discussions on what European identity actually comprises. At the same time, the multitude of refugees approaching from the Middle East represents an external threat against which we need to protect ourselves.

The ongoing trends concern not only Europe. It is notable, for example, that India's Hindu nationalist party, the BJP won the 2014 general elections. Prime Minister Narendra Modi got caught in the crossfire; as a former Governor of Gujarat state, he played a crucial role in stirring up the Hindu-Muslim conflict. India has the same debates as Europe. Will India turn against Gandhi's 'unity in diversity' concept and openly build an exclusionary Hindu state based on the logic of Hindu nationalism? Seeking paths to modernisation is a distinctive feature of every civilisation; the civilisational paradigm has undoubtedly pointed out its context. However, it would be wrong to make it an absolute theory, or rather, to bring the Clash of Civilisations thesis into the focus of world politics.

Moreover, the civilisational paradigm helps us understand the different values and concepts upheld by each civilisation. In regard to the latter we should note that some concepts associated with Western modernity, such as democracy, human rights or free market economy, have quite different meanings in nonWestern cultures.

\subsubsection{Bibliography}

ALI, TARIQ 2002: The Clash of Fundamentalisms. Crusades, Jihads and Modernity. London and New York: Verso

ANKERL, GÉZA 2000: Nyugat van, Kelet nincs. [The West Exists, but the East does not.] Budapest: Osiris

BAdie, Bertrand - SMOUTS, MARIE-ClAude 1999: Le retournement du Monde: Sociologie de la scène internationale. Paris: Presses de Sciences Po et Dalloz

BADIE, BerTRAND 2000: The Imported State. The Westernization of the Political Order. Stanford: Stanford University Press

BARBER, BenJAmin 1995: Jihad vs. McWorld. New York: Time Books

BAUMAN, ZyGMUNT 1998: Globalization. The Human consequences. New York: Columbia University Press 
FEISCHMIDT, MARGIT 1997: Multikulturalizmus: kultúra, identitás és politika új diskurzusa. [Multiculturalism: the new discourse of culture, identity and politics]. In: FEISCHMIDT, MARGIT (ed.): Multikulturalizmus. [Multiculturalism]. Budapest: Osiris, pp. 7-29.

FUKUYAMA, FRANCIS 1992: The End of History and the Last Man. New York: Free Press.

Global Terrorism Index 2017: - http://globalterrorismindex.org/-15 July 2018.

GOMBÁR, CSABA - HANKISS, ELEMÉR - LENGYEL, LÁSZLÓ - SZILÁGYI, ÁKOS 2000: A kérdéses civilizáció. [Civilisation Questioned]. Budapest: Helikon - Korridor

GOMBÁR, CSABA 2000: Létezik-e globális civilizáció? [Does Global Civilisation Exist?] In: GOMBÁR, CSABA - HANKISS, ELEMÉR - LENGYEL, LÁSZLÓ SZILÁGYI, ÁKOs: A kérdéses civilizáció. [Civilisation Questioned]. Budapest: Helikon - Korridor

HANKISS, ELEMÉR 1999: Proletár reneszánsz. Tanulmányok az európai civilizációról és a magyar társadalomról. [Proletarian Renaissance. Studies on the European civilisation and the Hungarian society]. Budapest: Helikon Publishing

Huntington, Samuel P. 1993: The Clash of Civilizations? Foreign Affairs, Summer 72(3) 22-49.

Huntington, SAmuel P. 1996: The Clash of Civilizations and the Remaking of World Order. New York: Simon \& Schuster

Huntington, SAmuel P. 2001: The Age of Muslim Wars. Newsweek 138, pp. $140-144$.

IngleHART, RonAlD - NORRIS, PIPA 2003: The True Clash of Civilizations. Foreign Policy, March-April (135) 62-70.

KISS J. LÁSZLó 2003: Globalizálódás és külpolitika. [Globalisation and Foreign Policy]. Budapest: Teleki László Foundation

Lewis, Bernard 1990: The Roots of Muslim Rage. Atlantic Monthly, September, 47-60.

LEWIS, BERNARD 2002: What Went Wrong? The Clash between Islam and Modernity in the Middle East. New York: The New York Times

LUTWAK, EDWARD N. 1990: From Geopolitics to Geo-Economics: Logic of Conflict, Grammar of Commerce. The National Interest, Summer (20) 17 23.

MAZRUI, Ali 1997: Islamic and Western Values. Foreign Affairs, SeptemberOctober 76(5) 118-132.

MCGRew, ANTHONy 2010: Globalization and Global Politics. - http://www. good-governance-debates.de/wp-content/uploads/2015/03/Globalizationand-global-politics-by-Anthony-McGrew_2010.pdf - 15 July 2018 
MEARSHEIMER, JoHn J. 1990: Back to the Future: Instability in Europe after the Cold War. International Security, Summer 15(1) 5-56.

MODOOD, TARIQ 2011: Multiculturalism and Integration: Struggling with Confusions. European University Institute, Robert Schuman Centre for Advanced Studies. Accept Pluralism 7th Framework Programme Project. https://www.coe.int/t/dg4/cultureheritage/mars/source/resources/referenc es/others/38\%20-\%20Multiculturalisme\%20and\%20Integration\%20-\% 20Modood \%20 2011.pdf - 15 July 2018

Rosenau, James N. 1997: Along the Domestic-Foreign Frontier: Exploring Governance in a Turbulent World. Cambridge: Cambridge University Press

ROSTOVÁNYI, ZsOLT 1999: Globalizáció avagy civilizációk és kultúrák harca? [Globalisation or clash of civilisations and cultures?] Külpolitika, SpringSummer 5(1-2) 3-45.

RostovÁNyi, ZsOLt 2005: Globalizáció és civilizáció(k). A „glokalizálódó” nemzetközi rendszer civilizációs-kulturális elemzése, különös tekintettel az „iszlám versus Nyugat” szembenállásra. [Globalisation and civilisation(s). The civilisational and cultural analysis of the international system under "glocalisation" with a special attention to the conflict between Islam and the West.] Budapest: MTA Doctoral Dissertation (manuscript)

SAID, EDWARD W. 2001: The Clash of Ignorance. The Nation. https://www.the nation.com/article/archive/clash-ignorance/ - 15 July 2018

SCRUTON, ROGER 2004: England and the Need for Nations. London: Civitas/Institute for the Study of Civil Society. http://www.civitas.org.uk/pdf/EnglandAndThe NeedForNations.pdf

Sen, AmARTYA 2000: Development as Freedom. New York: Anchor

So, are civilisations at war? Interview with Samuel P. Huntington. The Guardian, 21 October 2001. https://www.theguardian.com/world/2001/ oct/21/afghanistan.religion2

SPENGLeR, Oswald 2006: Decline of the West. New York: Vintage

STIGLiTZ, JosePH E. 2002: Globalization and its Discontents. New York: W. W. Norton \& Company

THE GUARDIAN 2017: Richest 1\% own half the world's wealth, study finds. The Guardian, 14 November. https://www.theguardian.com/inequality/2017/ nov/14/worlds-richest-wealth-credit-suisse - 15 July 2018

TIPPS, DEAN C. 1973: Modernization Theory and the Comparative Study of Societies: A Critical Perspective. Comparative Studies in Society and History, Mar. 15(2) 199-226.

TOYNBEE, ARNOLD 1988: Volume I: Abridgement of Volumes I-VI. Oxford: Oxford University Press 
UnITED NATIONS 2017: International Migration Report 2017. New York: United Nations - http://www.un.org/en/development/desa/population/migration/ publications/migrationreport/docs/MigrationReport2017_Highlights.pdf -15 July 2018

VITÁNYI, IVÁN 2002: A civilizáció és a kultúra paradigmái. [The Paradigms of Civilisation and Culture]. Magyar Tudomány (6) 720-729.

Wessely, AnNA (ed.) 2003: A kultúra szociológiája. [The Sociology of Culture]. Budapest: Osiris Láthatatlan Kollégium

World Values Survey - http://www.worldvaluessurvey.org/WVSContents.jsp? CMSID=Findings -15 July 2018 
2. The Far East 


\title{
2.1. The Chinese Civilisation
}

\author{
TAMÁS MATURA
}

China, the 'Middle Kingdom' is one of the oldest surviving civilisations in the world. It has been a cultural centre and a dominant power of the East Asian region for no less than four thousand years. Although historically China has given home to a mixture of ethnic groups, dialects and traditions, the role of the Han culture has been fundamental in the whole region. Consequently, the inhabitants of the Chinese Empire and the subsequent People's Republic of China have looked upon their country and the Sinosphere mainly as a civilisation, not a nation state (Figure 3).

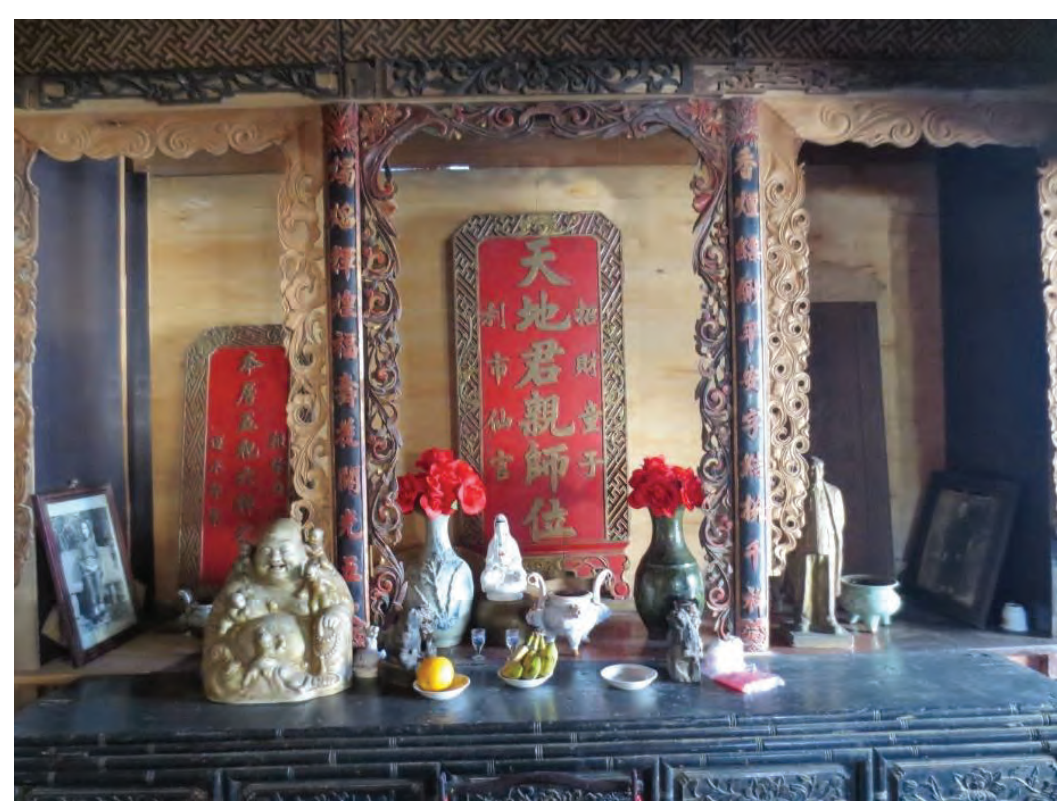

Figure 3: Family altar demonstrating a mixture of religions and politics (Yunnan province)

Source: Photograph by JuDIT BAGI

The regional dominance of the Chinese civilisation is easy to understand considering its geographical and historical characteristics, which led to a mostly isolated development path and the evolution of a unique world with features so different from the West or any other great culture. The enormity of the Chinese civilisation in space as well as in time makes it impossible to provide a full picture 
through this study, therefore, through focusing on the aspects of international studies, some key features will be highlighted. The following chapters provide an overview of various periods from prehistoric China through dynastic cycles to the fall of the Empire considered most important for understanding China's worldview and foreign policy behaviour. ${ }^{4}$

\subsubsection{China today in figures}

Although our aim is to provide a historical and cultural background to each civilisation presented in this book, the characteristics of modern-day China are also worth mentioning. China is known to be the world's most populated country with over 1.4 billion inhabitants, which is 140 times more than the population of Hungary. Although the population of India is likely to overtake in the 2020s, China's vast manpower will continue to represent a significant resource.

\subsubsection{G eography}

With an area of over 9.6 million $\mathrm{km}^{2}$, the Peoples Republic of China (PRC) is the largest country in East Asia and the third or fourth biggest country in the world, which makes it over twice the size of the European Union, and a hundred times bigger than Hungary. The uncertainty in ranking is due to deliberation of disputed territories. Western ranking disregards these territories (e.g. Taiwan, some parts of Kashmir), which makes the PRC somewhat smaller than the United States of America; China's raking, naturally mindful of these territories, makes it slightly bigger than the USA. Regardless of political standing, the area of the continental United States without Alaska measuring 1.5 million $\mathrm{km}^{2}$ is significantly smaller than that of China. China's enormous size and varied topography have determined climatic conditions, which in turn have influenced agricultural potential, with an ultimate impact on Chinese history and culture (Map 1).

\footnotetext{
${ }^{4}$ The author hereby wishes to thank Sándor Kusai, former Ambassador of Hungary to China for his assistance and advice in finalising this chapter. Special thanks to sinologist Judit Bagi for standardising the transcription of Chinese names and providing illustrations.
} 


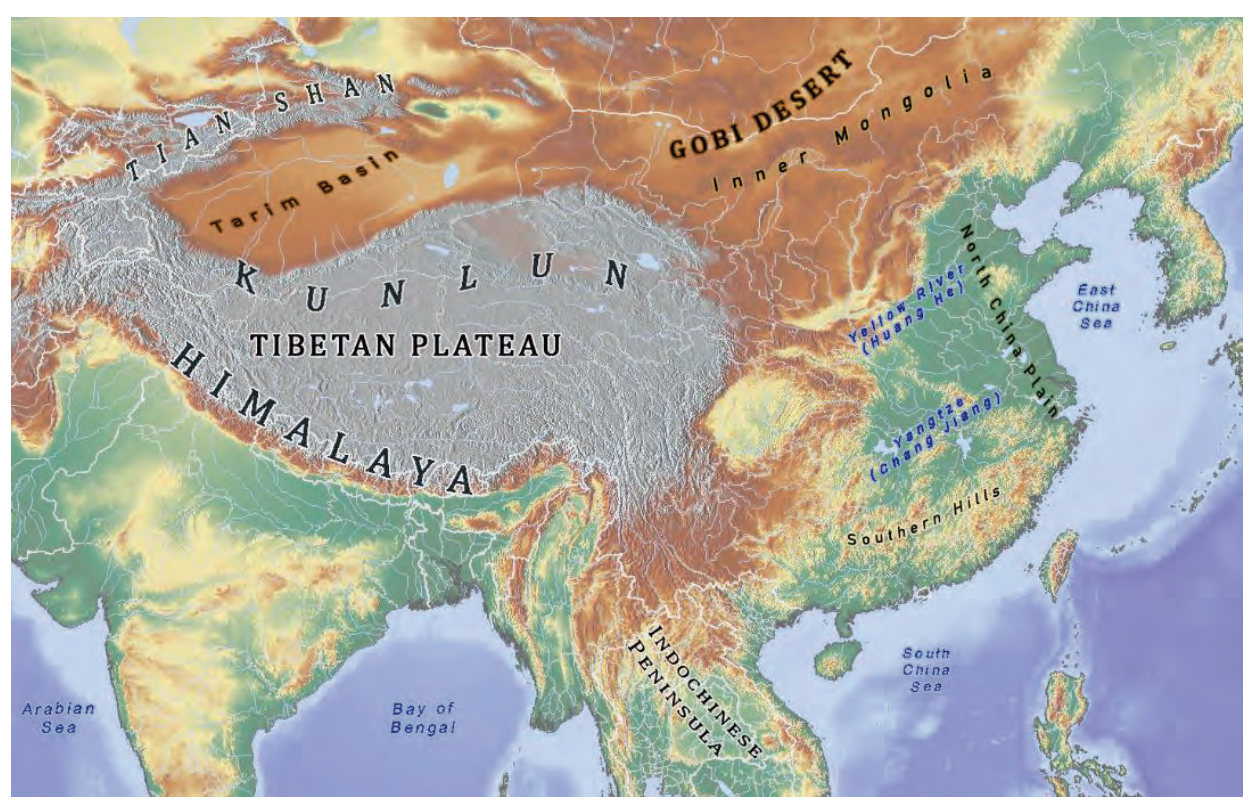

Map 1: The geographical location and natural conditions of China Source: Edited by ÁGNES VARGA

The dominant geographical feature that determines the history, progress and still standing geostrategic considerations of China is the country's naturally isolated position. For a better understanding, let's take an imaginary trip around the borders of China. Due to the fact that most countries of the Indochinese Peninsula had been separated from Northeast Asia by dense rainforest-covered mountains, communications between the historical states occupying modern-day Thailand, Laos, Cambodia and Myanmar respectively the Chinese Empire were restricted, except for the Ancient Tea Horse Road that fostered regular trading. The only, although significant exception was Vietnam, whose coastal location made it easily accessible, leading to lively cultural and political interactions with China. As an additional point of interest, the above described isolation is also identifiable in the languages and, in particular, the writing systems developed across Asia. While the Thai, Cambodian and other Southeast Asian writing systems differed significantly, Vietnam had used Chinese characters until the nineteenth-century French colonisation and changed to the Latin alphabet under pressure from Europe.

Progressing further in a southwesterly direction, the Himalayan mountain range, one of the world's most spectacular natural borders separates China from another ancient surviving civilisation: India. The several thousand kilometres 
long mountain range proved a highly effective barrier; although the Tibetan Plateau fell into Chinese hands on multiple occasions, interactions between China and India remained relatively limited, in fact, the two giants had not even engaged in war against each other until the twentieth century.

Perhaps even more obvious is the vast distance, and the enormous wilderness that separates China and the West. From the core territory of the empire, i.e. modern-day Eastern China the nearest main civilisations that the ancient caravans met comprised Europe towards the west and Persia and the Ottoman Empire towards south-east, each one separated from another by vast barren lands stretching for thousands of kilometres dotted with deserts and nomadic tribes. The Silk Road itself presented several months' or even a year's worth of dangerous journeying, which makes it hardly surprising that cultural interactions between the Roman Empire and the subsequently evolved European and Western Asian states respectively China were rather insignificant.

The northern borders were made up of Mongolia' nomadic tribes and the East Siberian wastelands, while China's eastern coastal position had brought isolation until the start of European invasion in the late eighteenth century, thus limiting civilisational impact to the easily accessible territories, such as Korea, Japan and the Southeast Asian islands.

China's topography is greatly varied; the Tibetan Plateau at an average altitude of 4,000 metres above sea level represents the highest topographical level. Towards the east the altitude decreases gradually; the next level includes the Kunlun Mountains, the Tianshan Mountains and the Yunnan Plateau, followed by the Taklamakan Desert, the Gobi Desert and the Sichuan Basin in Central and Northwest China, and finally the coastal lowlands that represent the core of Chinese civilisation. The vast expanse and the topographical features determine the climatic conditions as well; projecting the map of China over Europe would indicate the northeastern regions of the PRC overlapping the northern range of the Ural Mountains, the western Xinjiang autonomous region overlapping Iceland, and Hainan Island in the south overlapping Sicily. Consequently, the northern regions of former Manchuria experience Siberian winter climate, while the southerly Canton (Guangdong) and Hainan enjoy subtropical conditions. At the same time, the Tibetan Plateau measuring over one million square kilometres in the Himalayan range is often termed the Third Pole of the Earth due to its ice fields containing the largest reserve of fresh water outside the polar regions. However, as precipitation fails to spread to Central Asia, the regions of Qinghai, Xinjiang, Ningxia and Central Mongolia covering in total almost three million square kilometres are dry, bare and often desertlike.

In terms of civilisational development, the three great rivers crossing China have been particularly important. The almost 5,500 km long Yellow River 
(Huanghe) runs in the north, and the 6,380 km long Yangtze (Chang Jiang), the third longest river in the world, runs in Central China. The Pearl River (Zhujiang) is another extensive river system in southern China.

Due to the above presented geographical features the territories suitable for cultivation are relatively small and concentrated in the east, particularly in the plains of Northeast China. At the same time, the western regions are essentially uncultivable, thus resulting in highly varied population density figures across China. The East-West divide is complemented with a barrier that separates the North from the South. Although rice is believed to be the most important staple food in China, it is only characteristic in the south, while the northern regions mostly rely on cereal crops suited to drier climatic conditions (rye, and more recently wheat). According to certain theories these differences have influenced even the mentality of the population. Terraced rice cultivation and irrigation required significant community effort, fostering collective thinking and a more holistic approach in southern China. On the contrary, wheat farming manageable by individual families has led to a more individualistic and analytical approach characteristic in the north. Naturally, the internal migratory processes in recent decades have greatly reduced the differences but, similarly to Europe, the NorthSouth divide in terms of mentality and lifestyle still survives.

\subsubsection{Population}

Historically China has been one of the world's most populated regions. Already two thousand years ago it had an estimated population of seventy million people, roughly the equivalent of the Roman Empire. Over the next centuries the population increased slowly in a wavelike pattern, coming to a period of stagnation during the bloody years of the nineteenth century. When the PRC was founded in 1949 it had approximately 500 million inhabitants, but the stabilisation of food supply led to unprecedented growth. In the mid-1960s the population of China reached 700 million inhabitants, and increased further to over one billion in 1982, and to approximately 1.4 billion in 2010. The number of inhabitants in certain provinces is nowadays comparable to the population of sizeable countries: the provinces of Sichuan, Shandong and Canton each hold more inhabitants than Germany. The population distribution, similar to agriculture, is extremely uneven; 94 percent of the population is concentrated in the east, occupying 45 percent of the total area of China. Consequently, it means that, according to Chinese standards, the larger western part of the country is virtually uninhabited. The Xinjiang Autonomous Region covering over 1.5 million square kilometres holds a population of barely more than 20 million people, while the Tibet Autonomous 
Region covering 1.2 million square kilometres is home to less than three million inhabitants.

Ethnic heterogeneity is another characteristic feature; in addition to the Han Chinese majority there are 55 officially recognised ethnic minority groups in China. Many observers who question the sustainability of the Chinese state argue that holding together a country of 56 ethnic groups is impossible, although they disregard the ratios within the population. Indeed, while the Han Chinese majority constitutes 91.5 percent of the population, the remaining 55 ethnic minorities represent a mere 8.5 percent altogether (Figure 4). The majority of China's society is made up of more than 1.2 billion Han Chinese people; at the same time Zhuang, the largest ethnic minority comprises barely 16 million individuals, while the Tibetan community is officially made up of 6 million people. China's ethnic distribution is also uneven. The vast majority of the Han population is concentrated in the core territory, i.e. the eastern provinces most suited for cultivation with extremely high population density. At the same time, the western regions covering 55 percent of China's total area are virtually uninhabited; the Tibetans, Uyghurs, Mongols and other ethnic groups have very low population numbers compared to the size of their traditionally occupied territories.

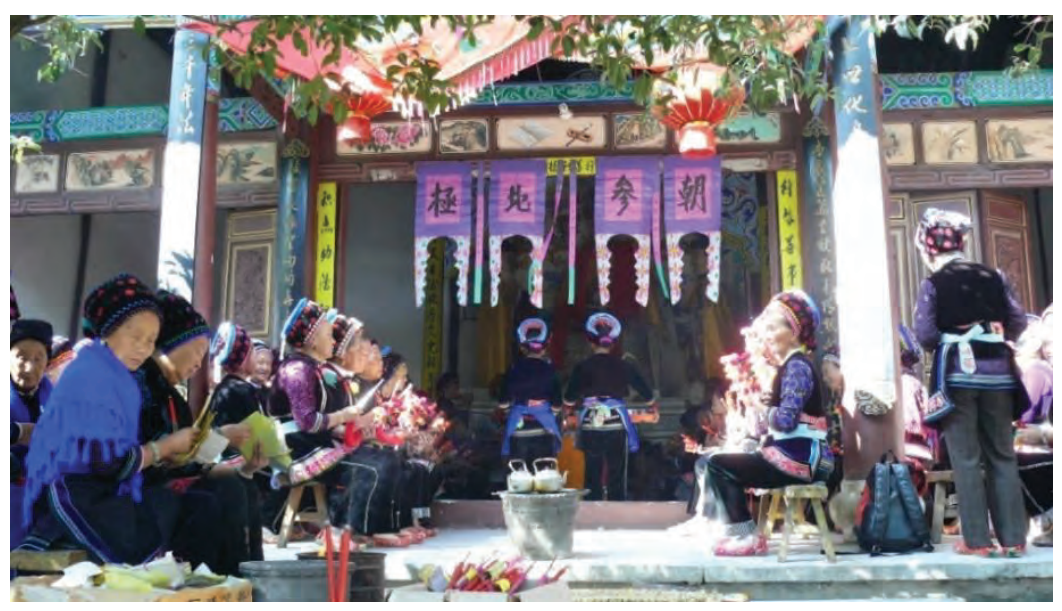

Figure 4: Buddhist women of the Bai ethnic community at a festival honouring the elders, Yunnan province.

Source: Photograph by JUDIT BAGI

The ethnogenesis of the Han Chinese people began 4-5,000 years ago, assimilating numerous ethnic groups throughout history. The process is still ongoing; due to technological development the standard Chinese language called Putonghua is becoming increasingly prominent, gradually reducing the regional 
differences between Chinese dialects, and assimilating more and more minorities into the mainstream society (Figure 5).

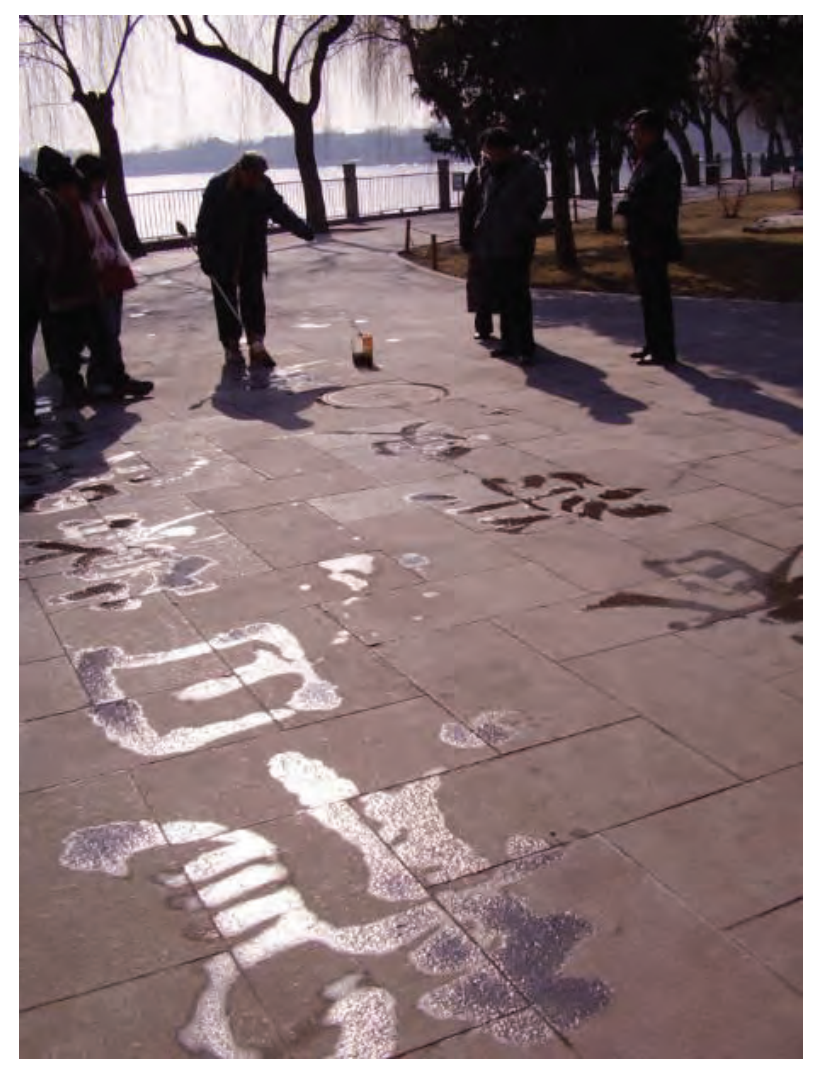

Figure 5: The sacredness of writing. Outdoor calligraphy in Beijing.

Source: Photograph by JUDIT BAGI

All this is connected with the issue of national identity as well, built primarily not on a classical ethnic but on a wider civilisational-political foundation that also includes minorities. It should be noted that the name of the country Chung-hua, Zhonghua (Zhongguo) reflects no ethnic identity either, but a perception of the world: the 'Middle Kingdom'.

\subsubsection{L anguage}

Chinese belongs to the Sino-Tibetan languages; the different varieties of Chinese are used by the 1.2 billion member Han community. In truth it would be more accurate to speak of Chinese languages; according to some linguists the differences in verbal communication across the country are so great that it would 
be more appropriate to identify each version as an individual member of the same language family. The Chinese themselves speak of dialects of the common Chinese language, although the differences between the individual dialects are in fact comparable to those between the Latin (Romance) languages. The most widely used dialect, Mandarin Chinese is spoken by approximately 960 million people, based on a northern dialect which has developed into the standard (Putonghua) language. Other main varieties include Wu (80 million people) spoken in the Shanghai region, along the lower Yangtze River; Min (70 million people) spoken in Southeast China; and Yue (60 million people) used in Canton and the southern region. It is important to note that the speakers of different dialects (languages) do not understand each other easily. The northern Chinese dialects, although similar themselves, greatly differ from the southern dialects, while people in South China often fail to understand one another. The special characteristic of these socalled tonal languages is that there are four major tones to differentiate meaning according to the way the words are pronounced. Fortunately, a standardised system of writing was created during the Qin dynasty to facilitate communication among speakers of different dialects across China, which also explains why the television programmes are subtitled. We should also mention pinyin, the official Romanisation system developed in the 1950s to transcribe Chinese characters into Latin script. One of the linguists developing pinyin, Zhou Youguang died in January 2017, at the age of 111. Nevertheless, different transcriptions of Chinese writing still exist.

\subsubsection{Religious beliefs}

Chinese religious beliefs rely on three elements: Confucianism, Taoism and Buddhism; the first two are the most widespread of Chinese origin. ${ }^{5}$ Although everyday language generally describes them as religions, it would be more appropriate to consider each as a school of philosophy, a way of life and governing, rather than a classical religion in the Western sense. The three main Western religions, Christianity, Judaism and Islam share identical roots and characteristics, such as monotheism, exclusivism and (except for Judaism) proselytism; the Chinese approach, however, is completely different. Firstly, it is not monotheistic; in fact, the Chinese deities are more like Western saints in that they include ancestors who once lived, as well as mythological creatures. Secondly, it is not exclusivist: a Christian cannot embrace Judaism or Islam at the same time (and vice versa); in the Chinese (Eastern) culture, however, there is no distinct dividing line between the individual faiths, and many people follow the teachings and

\footnotetext{
${ }^{5}$ Buddhism is discussed in the chapter dedicated to India.
} 
traditions of several 'religions' in parallel. Perhaps it reflects Chinese pragmatism that is more focused on the possibilities, rather than voluntarily excluding the prospects offered by other religious beliefs.

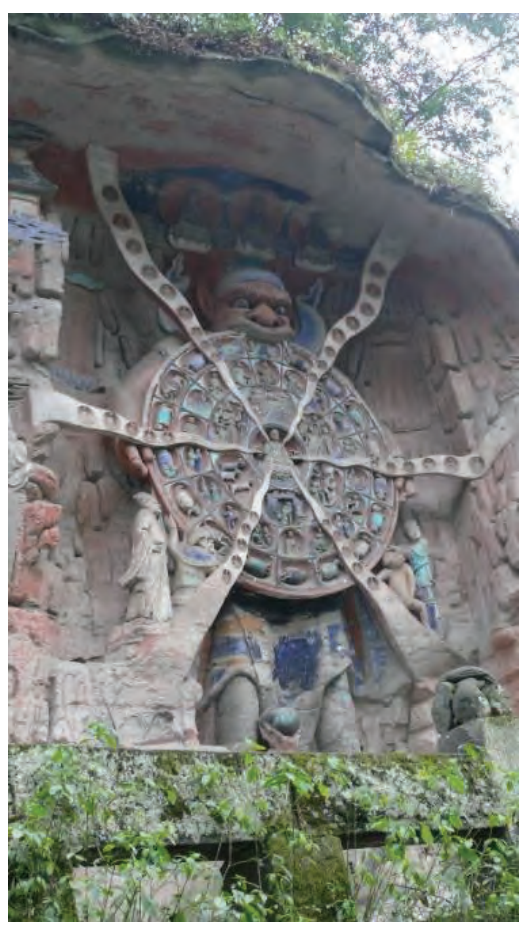

Figure 6: Wheel of Life. Rock carving reflecting Buddhism, Confucianism and Taoism from Dazu (Sichuan province).

Source: Photograph by JUDIT BAGI

Western terminology describes this phenomenon as syncretism: contrary to the monotheistic and exclusivist Western religions and categorical thinking, the Eastern cultures make way for a combination of different beliefs. Therefore, the Eastern cultures are considered intellectually tolerant in so far as they are able to adapt various intellectual disciplines.

This, however, makes the statistics rather complicated, as the number of followers of each faith can only be estimated. The situation is further complicated by the fact that the PRC officially recognises only five religions: Buddhism, Taoism, Islam, Protestantism and Catholicism (not the Roman Catholic Church but the Chinese), while Confucianism has been unofficially re-recognised since the dawn of the twenty-first century (Figure 6). Folk religion should also be mentioned; according to surveys the majority of the population follow some sort of 
folk religion (possibly combined with Taoism), while 10-15\% of the population is Buddhist, 2-4\% Christian and 1-2\% Muslim.

\section{Taoism}

The identity of Lao-Tze (Laozi, sixth century BCE) is uncertain: although regarded as the founder of Taoism, his existence and even his name remain a matter of debate. According to tradition he was an official at the imperial archives who, after leaving the court and travelling for a while, wrote his still influential Tao Te Ching (Dao De Jing), 'The Book of The Way and its Virtue' considered as the main source of Taoism. Lao-Tze's work described his view of the universe in an easily understandable form. Tao (Dao) is a cosmic force behind the workings of the universe that moves spontaneously. According to Lao-Tze, the wise man strives to attain naturalness, a state of emptiness through wu wei, which means 'inaction' or 'effortless action'. The book depicts an idealised patriarchal society spiritually guided by the 'wise man'. The Tao is not a creation: it is everything and nothing, imperceptible to the senses, yet a perpetual inexhaustible force. The Tao exists beyond space and time; the Tao is eternal and absolute and gives birth to all beings. (Should the above seem familiar from modern pop culture, it is no mere coincidence: Star Wars is believed to have relied on Taoism a great deal for describing the 'Force'.)

Taoism teaches that everything in this world is relative, or even illusory, and asks the question why we burden ourselves with problems and social commitments. At the same time, Taoism provided metaphysical foundation for some more practical schools of philosophy, such as Legalism (Fajia). As the name suggests, Legalism is focused on law, i.e. a social order based on rules and laws.

Chinese legal theory is fundamentally determined by Confucianism and Legalism, a key element of which is morality, i.e. the traditional Chinese approach that merges social and legal norms. Law and morality were seen as inseparable, similarly to the unity of judicial and administrative forces; it is hardly surprising that, as a still surviving authoritarian practice, disputes between the citizens and the state generally ended in favour of the latter. Chinese people developed no confidence in law and legal order, and there was not a legal institution in which to trust in case their rights were being eroded. It is noticeable that the Middle Kingdom had no room for the separation of powers, and the legal system was dominated by punishing laws of subordinating nature. In the turbulent years of the fourth century BCE the state lost its ability to maintain social order relying on former administrative practices and required new principles suited to the situation, capable to adapt to the changing conditions. Eventually, this led to the adoption of laws. 
The Legalists came from various schools of philosophy, including Taoism. Legalism spread mostly in the third and fourth centuries BCE, initially opposed to Confucianism which, at that time, contrasted theory with practice. To the followers of Confucianism, the proven principles of customary law and morality represented norm; the Legalists unconditionally believed that law determined behaviour. According to Legalist doctrines the law should change with the passing of time, in fact, no rules should remain unchanged permanently, but should adapt to the particular age. When laws fail to conform, yet remain unchanged, it leads to chaos. This should be avoided all the more because the moral foundation of law is granted through effectiveness, i.e. the ability to ensure appropriate regulation and, consequently, satisfactory outcome.

\section{Confucianism}

Another main school of Chinese philosophy is associated with Confucius (also known as Kong Qui, Kongzi, or Kong Fuzi, 551-479 BCE). Nowadays Confucianism is viewed as a religion, although not in the traditional Western sense. According to Confucius, changing the family and the individual is a precondition for reforming public matters. Moreover, in order to revive social conventions and behavioural rules already emptied of meaning, the rulers themselves must behave in an exemplary manner.

In Confucius's view, a ruler must set an example to inspire people, and that makes even governing much easier. On the contrary, inappropriate behaviour displayed by a ruler eventually leads to disobedience. This fundamental political approach is seen as a still influential universal teaching, which appears to be upheld by the leaders of the PRC as well punishing inappropriate behaviour that reflects negatively on government (e.g. corruption) by the force of law.

In the subsequent Han period criticism of administrative ruling was replaced by the idea of unassailability. The Confucian worldview originally based on humanism turned into an ideological foundation for Chinese bureaucracy with significant influence on the country. Chinese perception suggests close relationship between human being and community, and direct links between human microcosm and universe, respectively mortal macrocosm and deity. It also leads to a vision of society otherwise typical in Eastern Asia, i.e. that the individual's role and interests are subordinate to those of the community (Figure 7). This distinctive feature, very much unlike the Western egocentric society, fundamentally affects Chinese politics in both interior and foreign affairs and provides the philosophical grounds for China's prevailing effective system. In fact, it even supports the argument that Western democracy in this part of the world would be infeasible: it would fail to solve China's problems, and it would not prevent bureau- 
cratic or business abuse and would not protect the interests of ordinary people. Consequently, it would be downright counterproductive and could easily destabilise the country - at least in the opinion of the Chinese leaders.

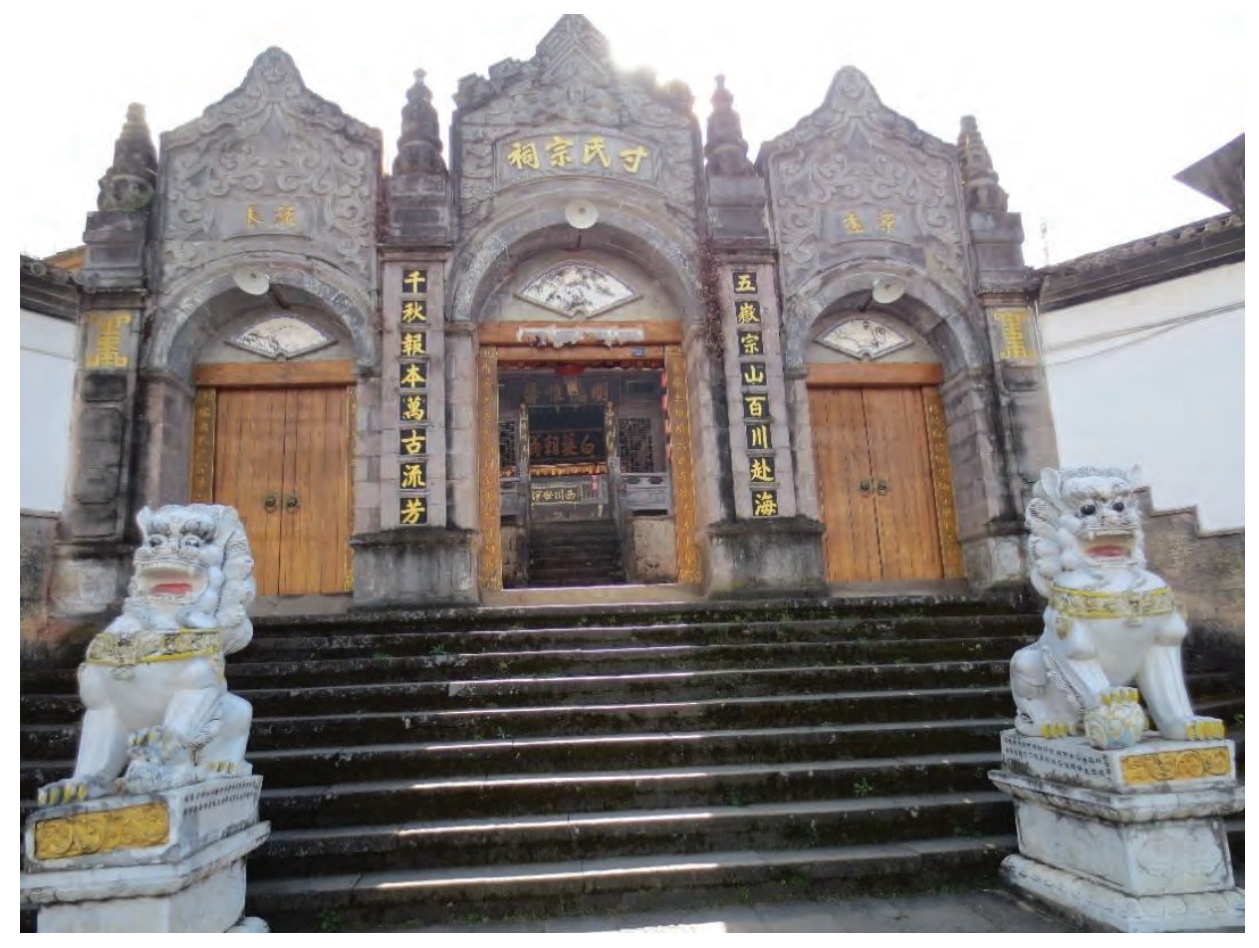

Figure 7: Ancestral Temple, Tengchong, Yunnan province.

Source: Photograph by JUDIT BAGI

\section{The forerunner of Legalism}

In addition to Confucianism and Legalism, there was also a third approach associated with Kuan Chung (also known as Guan Zhong, 720-645 BCE): the theory of balancing the light and the heavy. This approach aimed to administer government through economic activity, clearly ranking matters in an order of importance (urgency) to improve the effectiveness of problem solving. Similar to the Legalists, Kuan Chung's focus in interstate relations was placed on common interest, though unlike the former, he put economic power before law in state administration matters. The law's effectiveness arises not from itself, but from the economic environment in which it emerged. A ruler is only able to govern state matters if economic control is maintained simultaneously. While Confucianism is focused on morality, Kuan Chung's teaching suggests that morality arises 
'merely' out of economic interest. He regards economy to be superior in interstate relations as well, recognising that conflicts are generally won by the party with economic superiority. Therefore, economic power is a key element, and state power can be best measured by the extent of wealth, and the speed with which it can be mobilised in war.

\subsubsection{The history of $\mathrm{C}$ hina and its effect on international relations}

This chapter aims to summarise the major milestones of China's almost five-thousand-year-old history. Modern-day China regards the current world order to be fundamentally different from the 'conventional' world order experienced in the past millennia. During the Empire most of the known world was, on the whole, united by a single ruler, and as the wars mainly erupted for imperial power, they should be viewed as internal rather than actual international conflicts. Prior to the eighteenth and nineteenth centuries China had undoubtedly been the ultimate economic and cultural power in Asia.

Despite the numerous external threats faced throughout its long history, the sheer size and population of the Middle Kingdom led to the eventual assimilation of the invaders into Chinese culture. As a result, the concept of sovereign equal states seemed unnatural to China; outsiders were merely viewed as barbarians, and the deployment of foreign envoys seemed an unnecessary effort. It was true even though China dispatched envoys via the Silk Road from time to time. The system and mechanism of European balance of power had been unknown to China until Western invasion which ended in loss and humiliation. Our aim by outlining the major events and periods of Chinese history is to put into context China's strategic and foreign policy approach. Naturally, providing a full picture is beyond the scope of this study; for this reason, the key episodes of Chinese history and civilisation still influencing foreign policy behaviour will be highlighted.

The territory of modern-day China has been inhabited since prehistoric times; Homo erectus, known as Peking man from fossils discovered in 1965, appeared in Northern China over one million years ago. Some archaeological finds suggest use of fire as early as 1.2 million years ago.

Similar to other ancient civilisations, the first cultures in the territory of China primarily evolved in the valleys of the Yellow River and the Yangtze River, as well as in the coastal regions around 8000 BCE. The earliest evidence of agricultural activity originates from the eighth millennium BCE, i.e. the Neolithic era; later on, a cultural centre emerged in the Yellow River valley, with the establishment of the first permanent settlements. The Chinese civilisation is unique for its long history of literacy. The ancient characters carved into rock in 
Ningxia probably date back to 5000-6000 BCE, but they only vaguely resemble the characters recognised as the earliest authentic Chinese writing. The turtle shells with inscribed characters viewed as genuine evidence of Chinese literacy originate from 2000-1500 BCE, and therefore are at least 3500-4000 years old. Even more surprising is the fact that the shape and meaning of some characters have not or only minimally changed over the past millennia.

The Mythical Period of China associated with the emergence of literacy comprises the rule of the Three Sovereigns (2800-2737 BCE) and the Five (Mythical) Emperors (2737-2698 BCE) revered as demigods in later years, and still recognised among the ancient 'deities' of China (in truth we cannot speak of Chinese gods; see the chapter on religion). The Yellow Emperor, one of the legendary Chinese sovereigns, is still looked upon as the creator and ancestor of the Chinese civilisation and people, though his actual existence has been scientifically debated. He was in all probability a culture hero, taking shape centuries later in historical writings.

\subsubsection{The age of dynasties}

The sequence of dynasties is a primary point of reference in China's history. Chinese people dominantly view history in terms of dynastic cycles and the periodicity of order and chaos. In crudely simplified terms we can say that the European approach to history is lineal with perpetual progress; by contrast, the Chinese (Eastern) perspective is more focused on periodicity and repetitive cycles. What is more, each phase of the cycle is associated with a different social situation, as the birth, rise, glory and fall of a dynasty naturally influences the everyday lives of contemporary people, as well as the future of their children. The rise and fall of China's historical dynasties could be illustrated by a sine wave; for the ordinary people upward movement and positive peaks represented good times, stability and prosperity, while downward movement inevitably brought difficulty and starvation, and eventually war and internal conflict. The founder of each new dynasty, usually a talented low-ranking military leader who rose and solidified his power, put an end to internal conflict, chaos and division and became historically viewed as a great ruler (although contemporaries generally regarded him as a powerful autocratic monarch who ruled by blood and steel to ensure unity in the country).

However, with the passing of decades and centuries his descendants grew less interested in state matters giving rise to court machination, intrigue, increasing corruption and economic difficulties, aggravated from time to time by natural disasters, climate change and the invasion of nomadic tribes. Towards the end, in the final phase, the dynasty lost legitimacy and 'Mandate of Heaven' to rule the 
country due to internal or external challenges. Eventually the fallen monarch became replaced by a new powerful leader who gained 'Mandate of Heaven'. It is important to note that the interim periods generally comprised domestic conflicts, division and disintegration, typically with major losses in population and wealth, which explains why Chinese people attach so much importance to ruling dynasties and stability, and worry about changes in leadership and regime.

\section{Xia dynasty (from ca. 2200 to 1600 BCE)}

The existence of the first mythical dynasty (Xia) has not been entirely proven (Map 2); the written sources from subsequent centuries describe it as an outstanding example of government and public administration. Indeed, it cannot be excluded that the stories describing the Xia dynasty were intended as mere parables. However, some archaeological finds discovered in Henan province can be associated with this period, necessitating further research in the matter. Meanwhile in Europe the Minoan civilisation of Crete flourished between the twentyseventh and fifteenth centuries BCE.

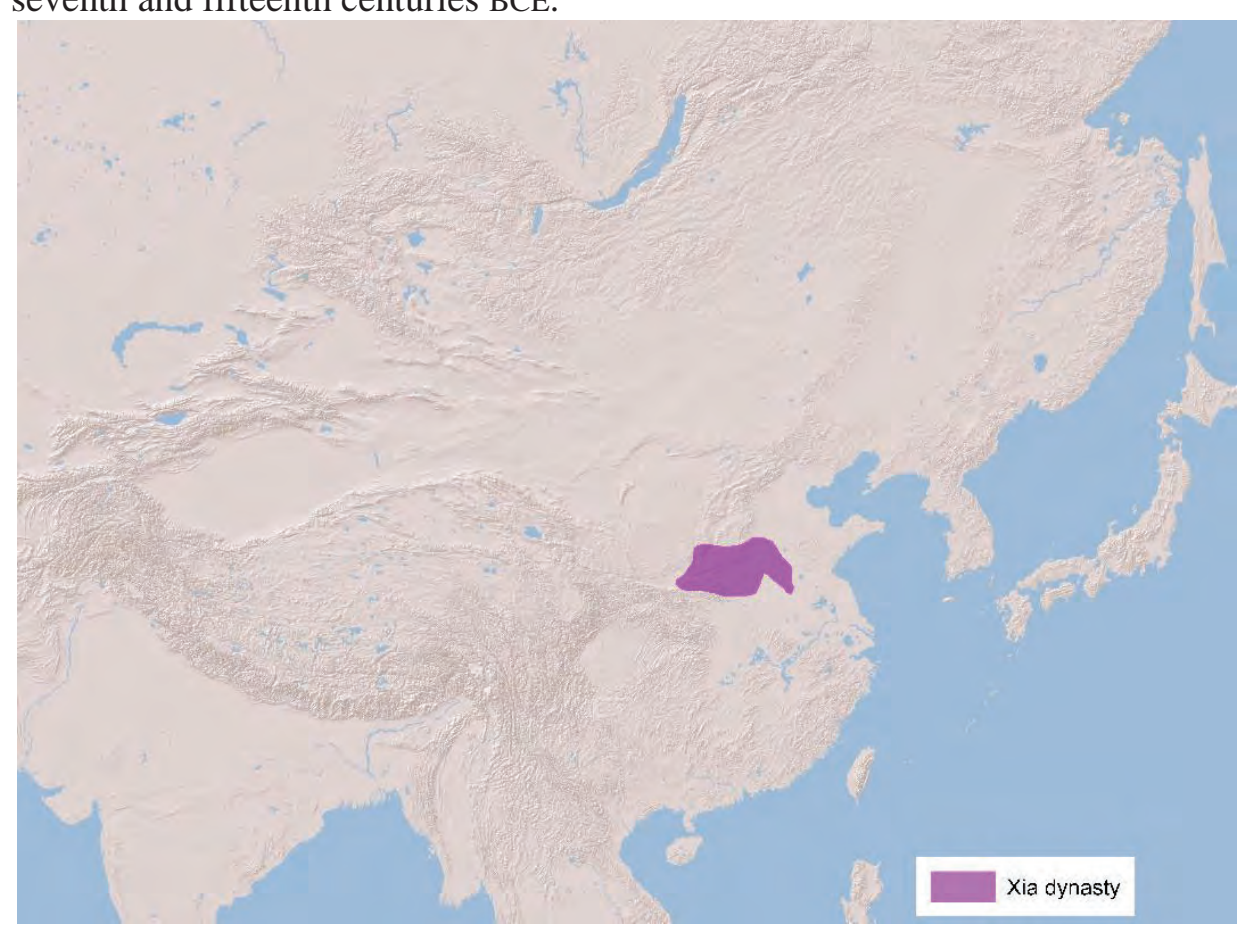

Map 2: Assumed location of the first mythical dynasty Source: Edited by ÁGNES VARGA 
The earliest records of Chinese writing from Bronze Age Shang dynasty include carved oracle bones; later on, a fully evolved system appeared with characters inscribed into bronze, pottery, jade and stone. The last monarch of the Shang dynasty killed himself after his army's defeat at the hands of Zhou. Meanwhile in Europe Mycenae became a cultural centre during the period 1600-1000 BCE.

\section{Zhou dynasty (from 1046 to 221 BCE)}

Zhou was the longest reigning dynasty with a semi-feudal system whose kings introduced the concept 'Mandate of Heaven' to legitimise their power. Chinese history distinguishes two periods within the Zhou era. The dynastic kings of the first period built their capital in the Wei (Weihe) River valley (Western Zhou, from the eleventh century BCE to $771 \mathrm{BCE}$ ). The following period (Eastern Zhou) began by moving the capital to Chengzhou and ended with the defeat of the Zhou in 256 BCE by Jin forces. The period before 221 BCE, i.e. the unification of China is known as the Warring States period (Zhangou) due to permanent wars. The beginning of the Warring States period is estimated at $451 \mathrm{BCE}$, the division of the Jin state, alternatively at 403 BCE, the year when the partition of Jin and the resulting three states (Han, Wei and Zhao) were officially recognised by Zhou. The Chinese 'feudal' system shows unique characteristics based on close ties that led to the political institutions' dependence on ancestor worship and the aggregation of military and religious functions. Thus, the system remained closely tied to the archaic monarchy from which it had evolved. It should be noted, however, that the term 'feudal' in relation to ancient China has lost its original meaning due to regular incorrect use. It seems therefore more appropriate to disregard the term altogether and describe this era through its unique institutions and political and social systems which, in the long history of China, largely resembled European society defined by Western historians as feudal. The Chinese 'feudalism' was based on land tenure hierarchy and ancestor worship. The entire system was focused on the king's landholding and veneration of the Zhou ancestors. The king bore the title Tianzi (Son of Heaven) with power received from Shangdi (Highest God), and therefore was the only one to offer sacrifice to the supreme deity.

\footnotetext{
${ }^{6}$ This chapter heavily relies on Jacques Gernet's fundamental work, A History of Chinese Civilisation (GERNET, J. 2005)
} 
Land expansion was the result of a 'swarming' process. The system of land distribution allowed the noble families to exercise religious and military powers in their respective domains. As such, royal power virtually manifested itself in the extended hierarchy of families and landholdings. The system was held together by ancestor worship. The heads of the noble families from the so-called great lines were lineal descendants of the founding ancestor worshipped through generations. Starting from at least the end of the Shang era, the tradition whereby the firstborn son of the principal wife inherited all duties and religious privileges was upheld by every noble family. This is why the role of principal wife and patrilineal primogeniture was so important.

The states were structured identically to the royal court: the ruler was served by senior officials (daifu) and ministers (qing). The heads of families from the highest nobility held functions that sooner or later became hereditary. The lesser nobles (shi) served under the ministers and senior officials in the hierarchy. Their main duty was to man the war chariots; the infantry was made up of peasants $(t u)$ who also farmed the lands the produce of which was taken by the nobility.

The structure of the army was modelled on the administrative and family hierarchy; the influential members of the royal court, including the noblemen, senior officials and heads of states were required to set up troops of chariots and infantry and go to war as commanded by their superiors.

In the Shang era the cult of kings after their death and the authority of royal descendants deeply influenced the then social and political systems. After that a much more complex and less stable system evolved, essentially limiting the king's power to an arbitratorial role. Although the functions and privileges granted by the king were in principle revocable, the advances of the states and the elite families caused these functions and privileges to become hereditary.

This process further accelerated due to attacks from the Shaanxi province and the diminishing size of the king's landholding from the first half of the eighth century BCE. The closest ally of the Zhou kings during the relocation of the capital, though only temporarily, was the Zheng state; then some more powerful states, such as the Song, Wei, Lu, Cao, Chen, Cai and others also emerged in the plains region. In the eighth century BCE dozens of similar small states existed alongside numerous smaller cities. This intricate system of more or less powerful states was dominated not by the former religious and military autonomy of the king, but by ritual ceremony and ancestral knowledge. The relationships of these states alternated between alliance and rivalry due to wars, vendettas, marital alliances, pacts and the exchange of goods and services. The Zhou era occurred simultaneously with the founding of Rome (753 BCE), the Peloponnesian War (431-404 BCE) and the reign of Alexander the Great (356-323 BCE). 


\section{Decline of the monarchy}

The Spring and Autumn period (Chunqiu) saw intensifying conflicts between the ancient cities and the 'central states' of the Chinese plains (Jin, Qi and $\mathrm{Chu}$ ) on the one hand, and the increasingly powerful outlying states on the other hand. The attacks from Northern China began in the eighth century BCE and intensified toward the middle of the seventh century BCE. The external threats encouraged the rulers of Jin and Qi to form an alliance mainly to protect the borders of China from external attacks. At the same time, these alliances fostered the hegemonic aspirations of the major states. The Hegemony of Qi was declared in 651 BCE. The ruler of Jin became the next hegemon. However, from the early sixth century BCE the nature and purposes of the hegemonies changed following the defeat of the Jin army at the hands of King Zhuang of Chu in 597 BCE. From that point on the more powerful states put pressure on the weaker ones, and this new political situation was sealed with forced loyalty and oaths of allegiance.

With the emergence of major political formations within China the characteristics of the interstate conflicts changed too. The former family feuds fought with weapons became replaced by wars among the allied yet rival states. Nevertheless, these warring states shared more or less similar cultural background and traditions. The southeasterly civilisational expansions led to the formation of two new states: $\mathrm{Wu}$ and Yue. With the coastal Yue and the riverside $\mathrm{Wu}$ gaining power, the western neighbour Chu began to decline in the early sixth century BCE. All this led to growing military focus within the states, naturally transforming social structures and, eventually, pushing them into crisis. The signs of crisis within the elite society began to intensify from 600 BCE. The institutions developed in the sixth century BCE aimed to foster the power and independence of the individual states: tax was imposed on agriculture, as well as the obligation of the nobility to provide weapons and cereal in contribution to war, instead of manpower.

The conflicts among the states escalated from the early fifth century BCE. The heads of three powerful noble families called Mengsun, Shusun and Jisun took power in Lu state, western Shandong province. The Jin state saw conflicts among six elite families in charge of three armies. The fights ended with the defeat and partition of Jin in 453 BCE. This led to the emergence of three independent political formations under the Han, Wei and Zhao families in the territory of the former Jin. The ruling Qi family was finally overthrown by Tian in 386 BCE. The above described conflicts and power struggles escalated into the Warring States period, which inevitably led to the founding of a centralised state, the Empire. 
Warring States period (from fifth century BCE to 221 BCE)

The Warring States period was a particularly significant era in China's history with the formation of seven major states in the dynastic territory of the weakened Zhou, whose ruler had merely a symbolic role at that time (Map 3). The prolonged fight for ultimate power represents the last period in Chinese history that is comparable to European history: wars waged by several similarly powerful states against each other.

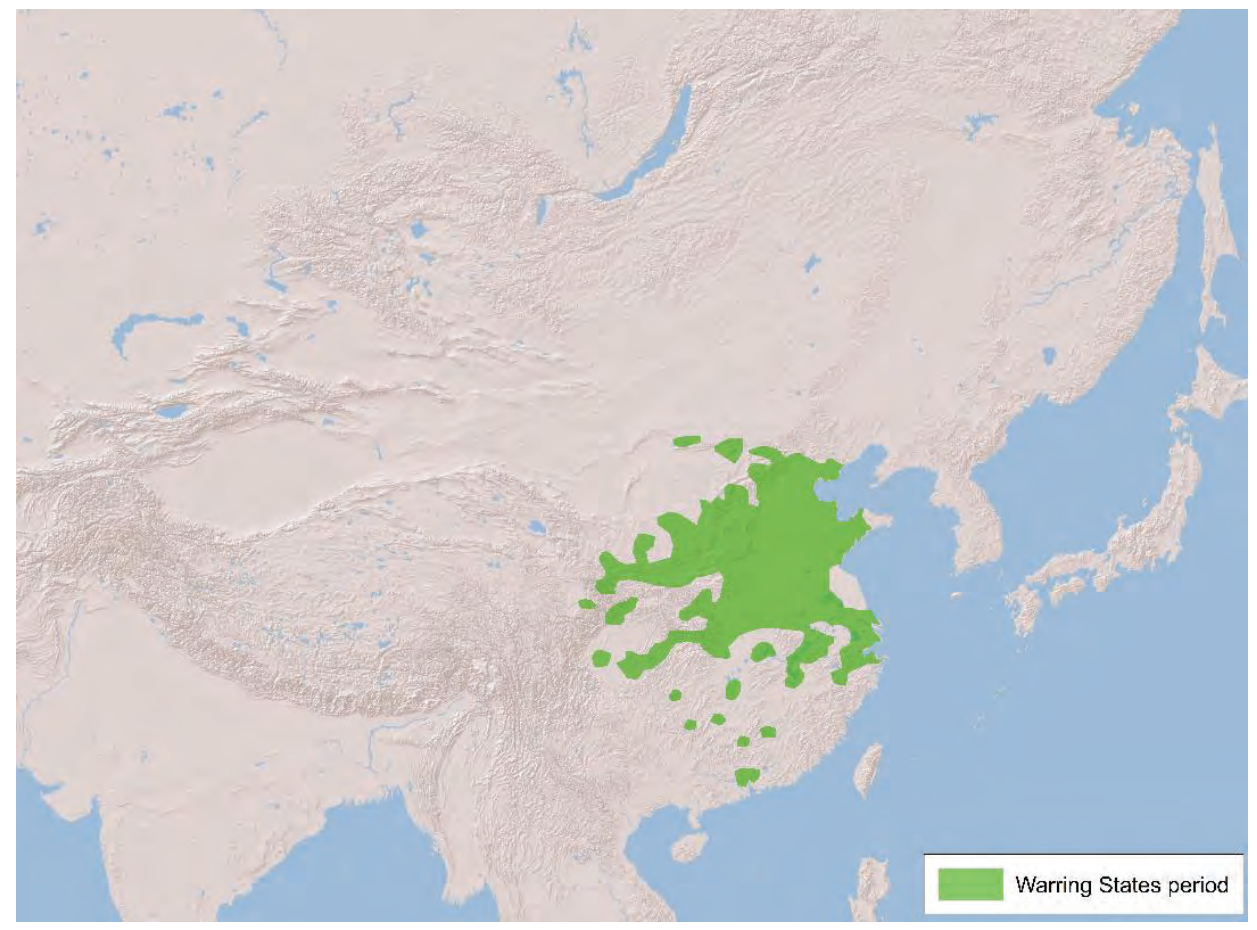

Map 3: Chinese territories from the fifth century BCE to 221 BCE

Source: Edited by ÁGNES VARGA

The wars lasting several centuries finally ended with the strengthening and subsequent territorial expansion of the Qin state. Having been reformed and reorganised, the Qin state achieved its first major military success by defeating the northern nomads in 314 BCE, followed by the invasion of Shu, a state in Chengdu basin, Sichuan province in 311 BCE and the occupation of further territories in $\mathrm{Ba}$, a state in the northern Sichuan Mountains populated by non-Chinese tribes. The invasion of the upper Han River valley led to expansion at the expense of Chu in Hubei province in 278-277 BCE. After that further campaigns were launched against the eastern neighbours: Han, Wei and Zhao. The Qin armies pushed forward to Handan, the Zhao capital situated in the southeast corner of 
Hebei province, but were forced to give up on siege in 257 BCE. Finally, the occupation of Eastern Zhao, Henan province in 249 BCE brought an end to the prestigious Zhao family.

\section{Qin dynasty (from 221 to 206 BCE)}

Despite its short reign, the Qin dynasty (Map 4) fundamentally influenced China's history and culture. King Zheng of Qin (259-210 BCE), who came to power in 247 BCE united China through war and established the first Chinese empire. A decade of fighting destroyed Han (230 BCE), Zhao (228 BCE), Wei (225 BCE), Chu (223 BCE), Yan (222 BCE) and Qi (221 BCE). Having completed the unification of China in 221 BCE, he assumed the title of Huangdi (His Highness), which later on became the traditional name for Chinese emperors. Historically, however, he is recognised by the name Shi Huangdi (First Emperor). The unification extended beyond the regions inhabited by Han Chinese people and reached as far as the South China Sea. More importantly, however, the First Emperor standardised Chinese writing (making written Chinese universally understood despite its various dialects), introduced standardised units of measurement, currency and legal system, oversaw the development of China's imperial road network and the construction of the Great Wall, and became an absolute monarch. Meanwhile, he abolished feudalism and introduced a modern system of public administration. The First Emperor is particularly remembered for his monumental tomb discovered in 1974 containing approximately six thousand life-size terracotta warriors (Figure 8).

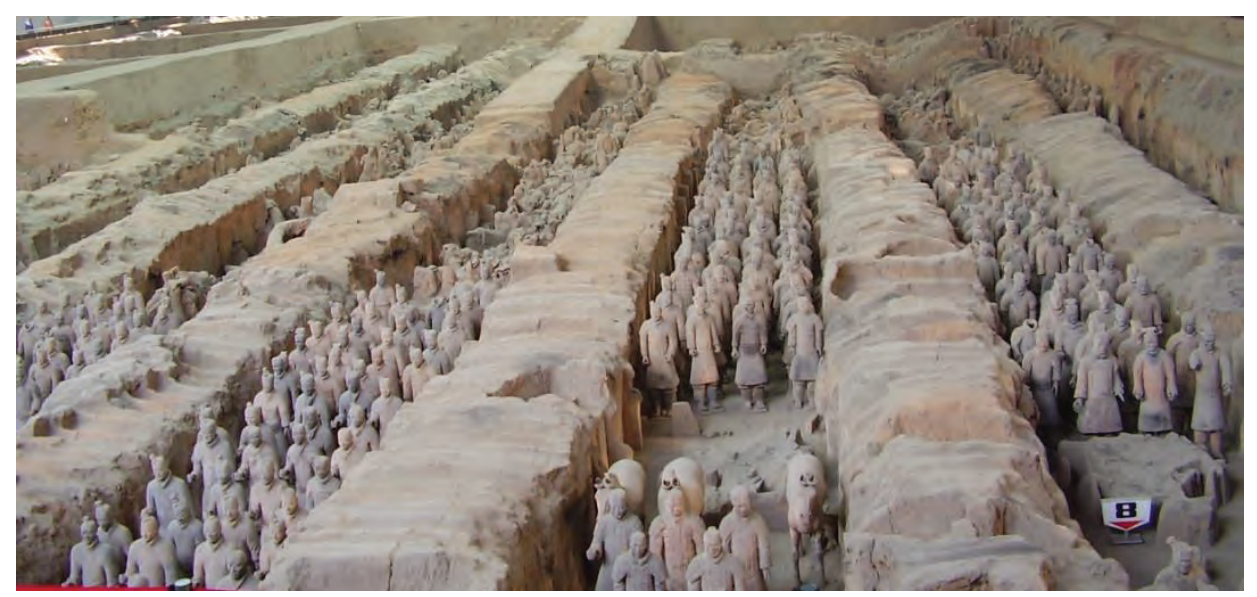

Figure 8: The Terracotta Army near the city of Xi'an. Source: Photograph by JUDIT BAGI 
The reign of the First Emperor occurred simultaneously with the Second Punic War, when the Carthaginian army led by Hannibal crossed the Alps marching overland from Iberia and attacked the Roman Republic in 218 BCE.

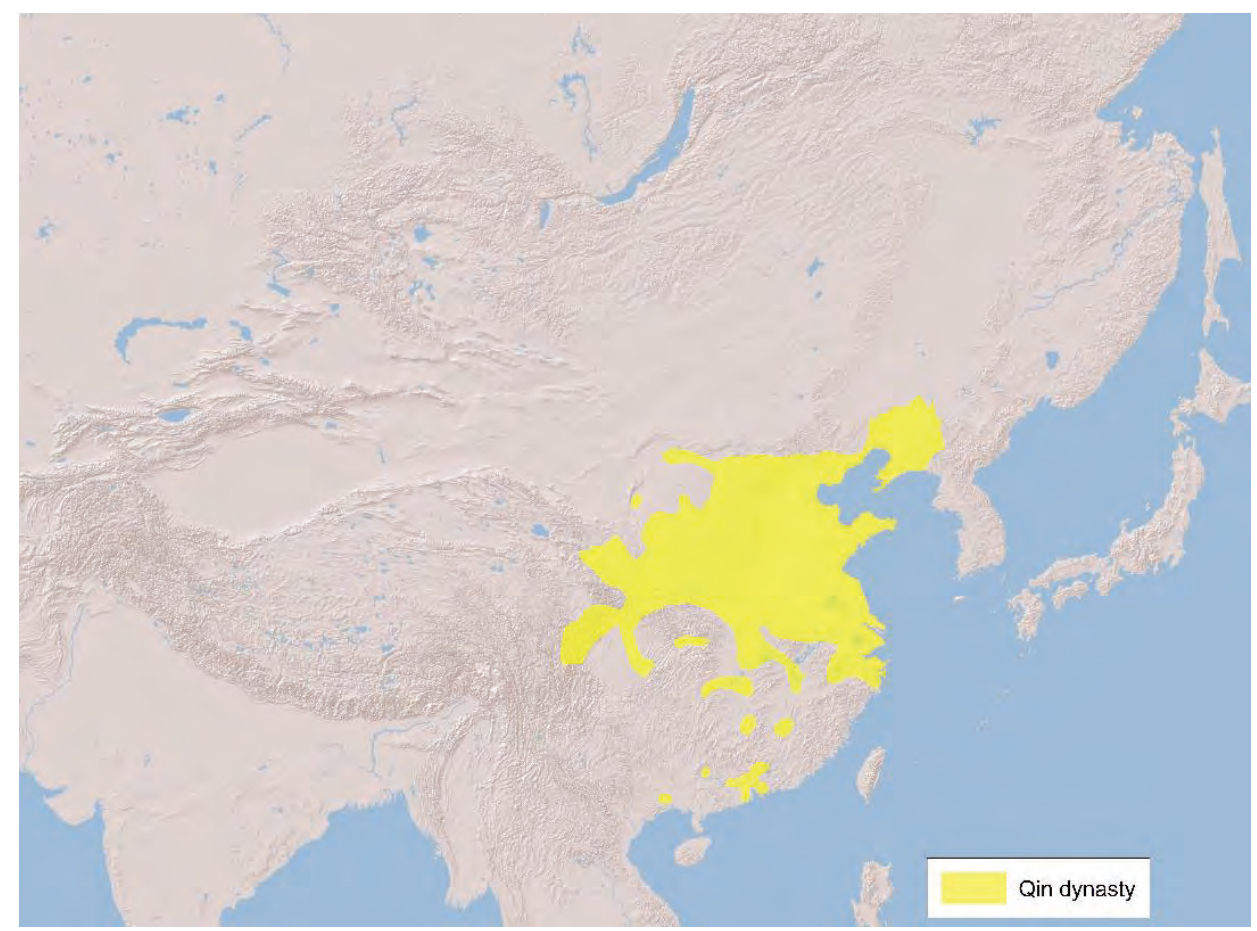

Map 4: China at the end of the third century BCE

Source: Edited by ÁGNES VARGA

Han dynasty (from 202 BCE to $220 \mathrm{CE}$ )

The short but influential period of the Qin dynasty was followed by the Han era, whose rulers ended the power of local warlords, elevated Confucianism to state level, divided the empire into provinces and secured the borders from the attacks of the Xiongnu tribes (Asian Huns; some Chinese believe them to be the ancestors of Hungarian people, hence the Chinese name of Hungary is Xiongyali) (Figure 9). In public administration a civil service examination system was introduced. The importance of the dynasty is signified by the fact that the majority of modern-day Chinese society still regard themselves to be Han. Meanwhile, Europe saw the fall of the Roman Republic and the rise of the mighty Roman Empire. Christianity was born, and Emperor Caracalla reigned toward the end of the Han era. 


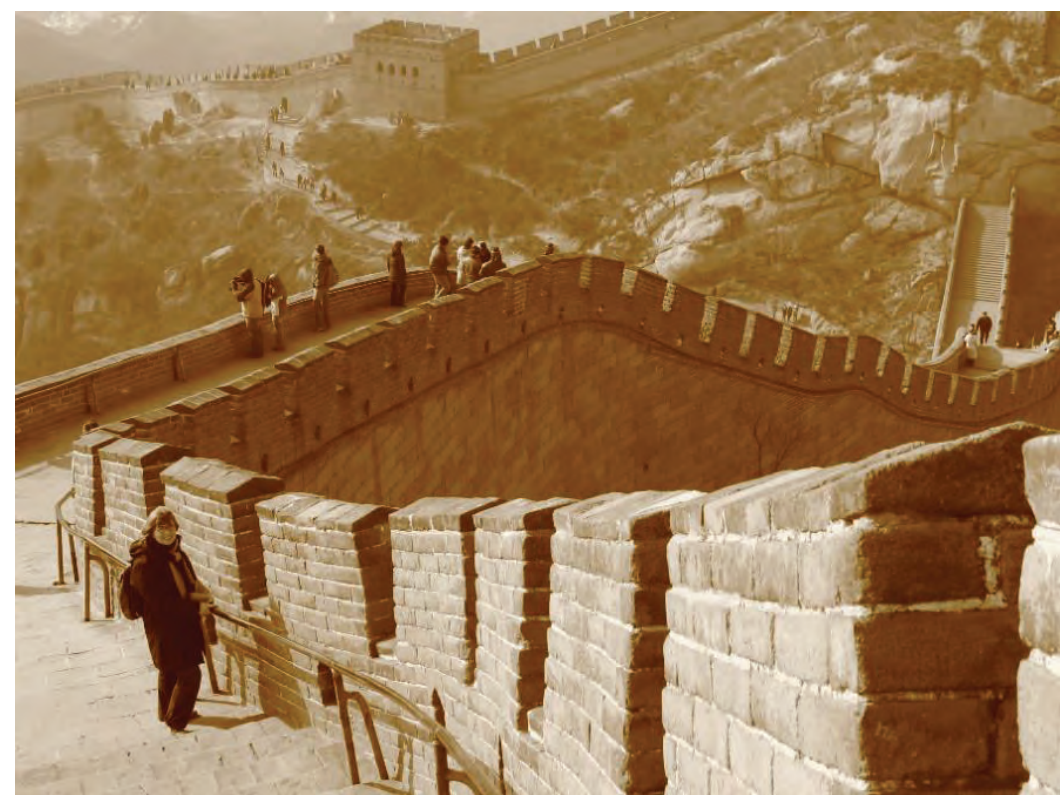

Figure 9: The construction of the Great Wall began during the Han dynasty. Source: Photograph by ERIKA TÓTH

The Three Kingdoms (from 220 to 280)

The collapse of the Han dynasty was followed by the period of the Three Kingdoms. The three states: Wei in the north, Wu in the south and Shu in the west engaged in permanent wars against each other. This relatively short but chaotic era deeply influenced China's historical perspective; the disintegration of the country has ever since been associated with turmoil and devastation. Chinese culture has also been impacted by this period: the Records of the Three Kingdoms was written by Chen Shou in the third century (233-297), the Romance of the Three Kingdoms was written a millennium later by Luo Guanzhong (13301400), and Red Cliff, an epic war film was made in 2008 by director John Woo based on the most famous battle of the period and the fall of the warlord Cao Cao (155-220).

\section{Tang dynasty (from 618 to 907)}

The Tang dynasty extended the borders of the empire to protect the core territories, thus captured parts of the Silk Road towards the west and conquered the Korean Peninsula and Northern Vietnam. However, the Islamic expansion in 
the eighth century led to serial defeats and reduced China's influence in Central Asia.

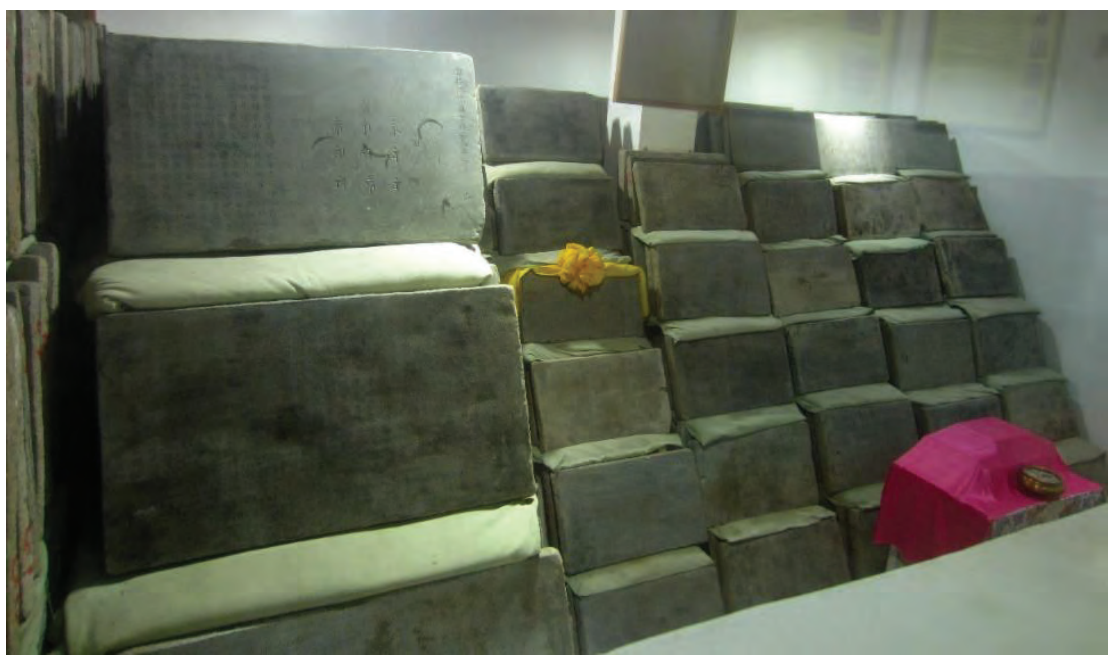

Figure 10: Inscribed stone tablets at Yunju Temple, near Beijing. Source: Photograph by JUDIT BAGI

The numerous technological developments of the Tang era include the discovery of gunpowder, porcelain and an early version of printing (Figure 10). Meanwhile, Europe experienced the turbulent centuries of the Middle Ages: while the plague had destroyed half of its population by the sixth century and the Muslim army set out to conquer Iberia, revival was brought by the reign of Charles the Great (742-814).

\section{Five Dynasties and Ten Kingdoms (from 907 to 960)}

Similar to the period of the Three Kingdoms, China experienced another short but turbulent episode of its history after the fall of the Tang dynasty. Although the north of the country remained under imperial rule, five dynasties succeeded one another in a matter of decades, while Southern China was split into a dozen states (including ten major ones). All this led to anarchy, corruption, starvation and constant military conflicts which fostered desire for unity in the country yet again (Map 5). 


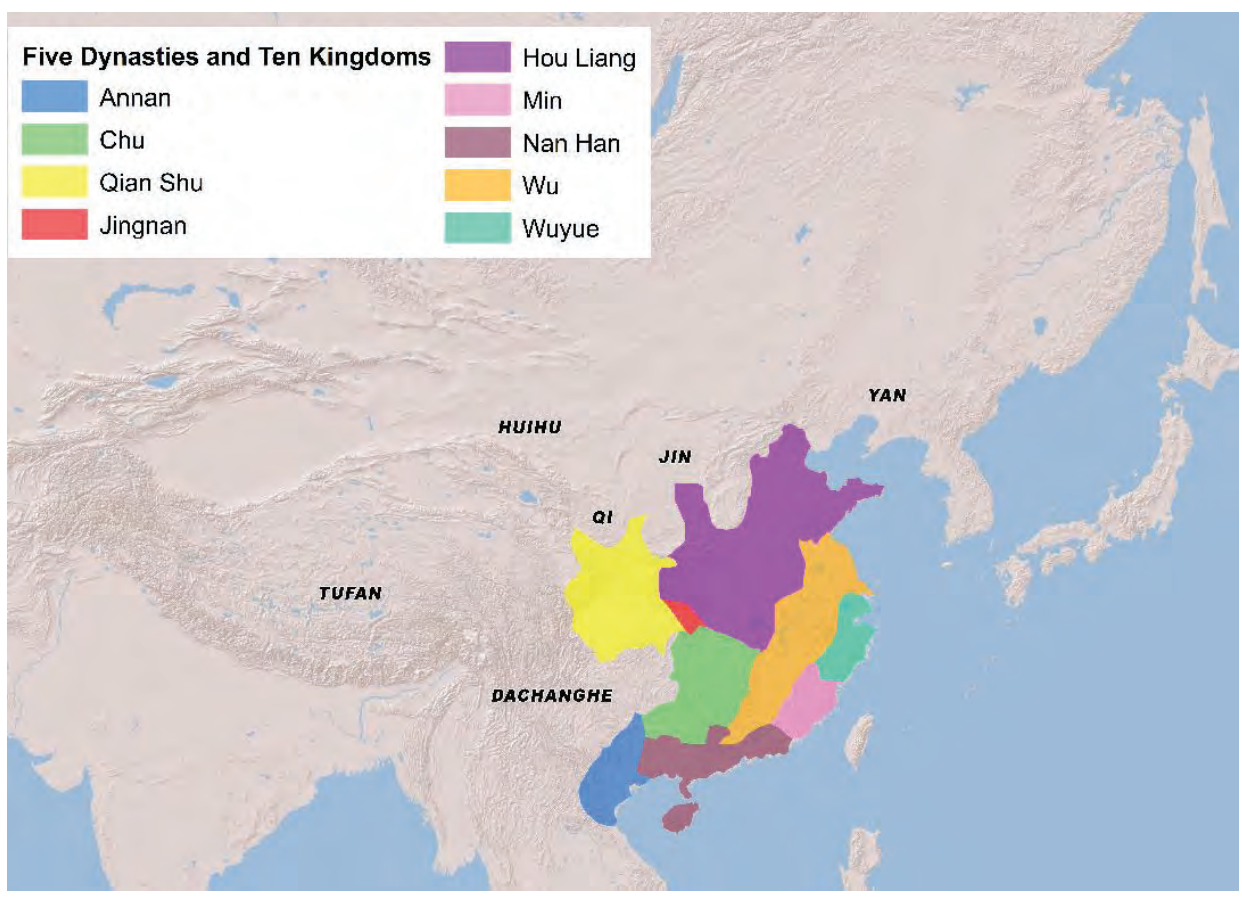

Map 5: Chinese states in the first half of the tenth century Source: Edited by ÁGNES VARGA

Song dynasty (from 960 to 1279)

The chaotic period of the Five Dynasties ended with a coup led by Zhao Kuangyin (927-976), a military commander who became emperor and changed the name of the country to Song aiming to unify the whole of China. He only succeeded in part and only for a limited period; the Jurchens invading from the north ended the unity of Song in 1127 and extended their power over Northern China under the name Jin. Southern Song survived until the Mongol conquest in 1279. The Song dynasty, although less powerful and stable, represents a glorious period of medieval Chinese culture (Figure 11).

The Song era saw the establishment of China's first navy and various inventions such as the compass and the military use of gunpowder. The development of Chinese society, art, literature and printing were also characteristic of this period. 


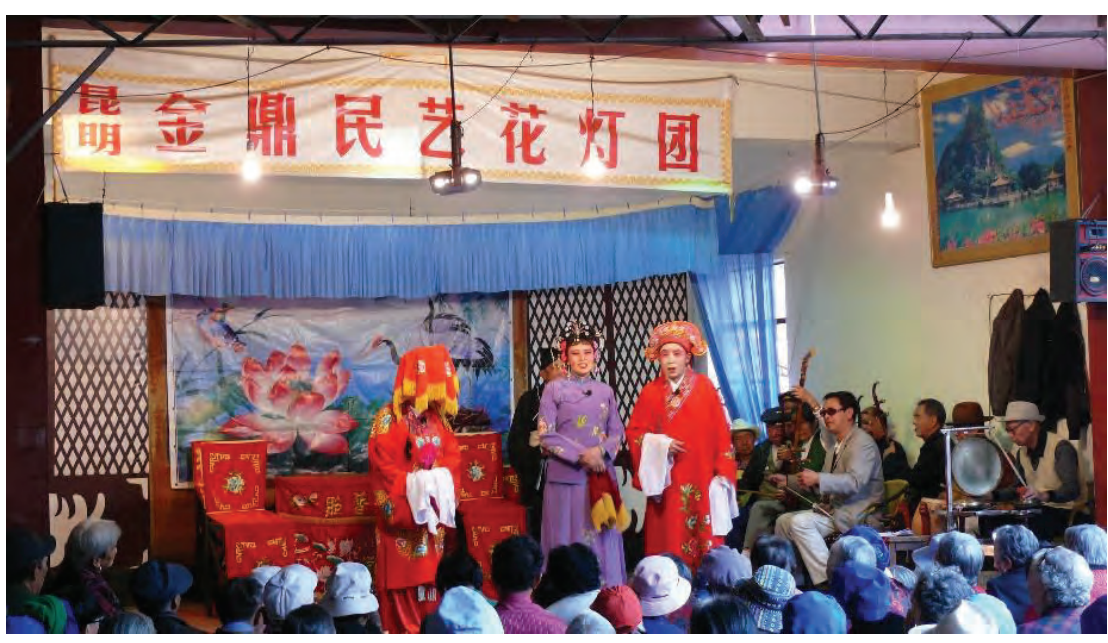

Figure 11: Folk play performed in Kunming, Yunnan province. Source: Photograph by JUDIT BAGI

Yuan dynasty (1271-1368)

The Chinese approach to international relations could be perceived through the history of the Yuan dynasty (Map 6). Although Chinese people are generally proud of this period due to the sheer size of the empire and the invention of paper currency and other technological accomplishments, the Yuan dynasty was in fact the result of Mongol invasion. It took several decades for the Mongol armies led by Kublai Khan to invade the whole country; realising the difference in the size of the population, i.e. between the almost eighty million mostly peaceful settled Chinese people and the few hundred thousand Mongol warriors, the Great Khan introduced numerous reforms to placate the Chinese and established Dadu, the 'great capital', what is now Beijing. Mingling between the conquerors and the Chinese was initially forbidden, but it could not last long; due to the size and cultural superiority of the local population the invaders became finally absorbed and assimilated, and the Yuan emperors gradually turned Chinese in every aspect. This phenomenon repeated itself numerous times throughout history: the foreign enemy China was unable to subdue in battle sooner or later became absorbed and assimilated. This, however, failed to work on the European invaders at the end of the eighteenth century. 


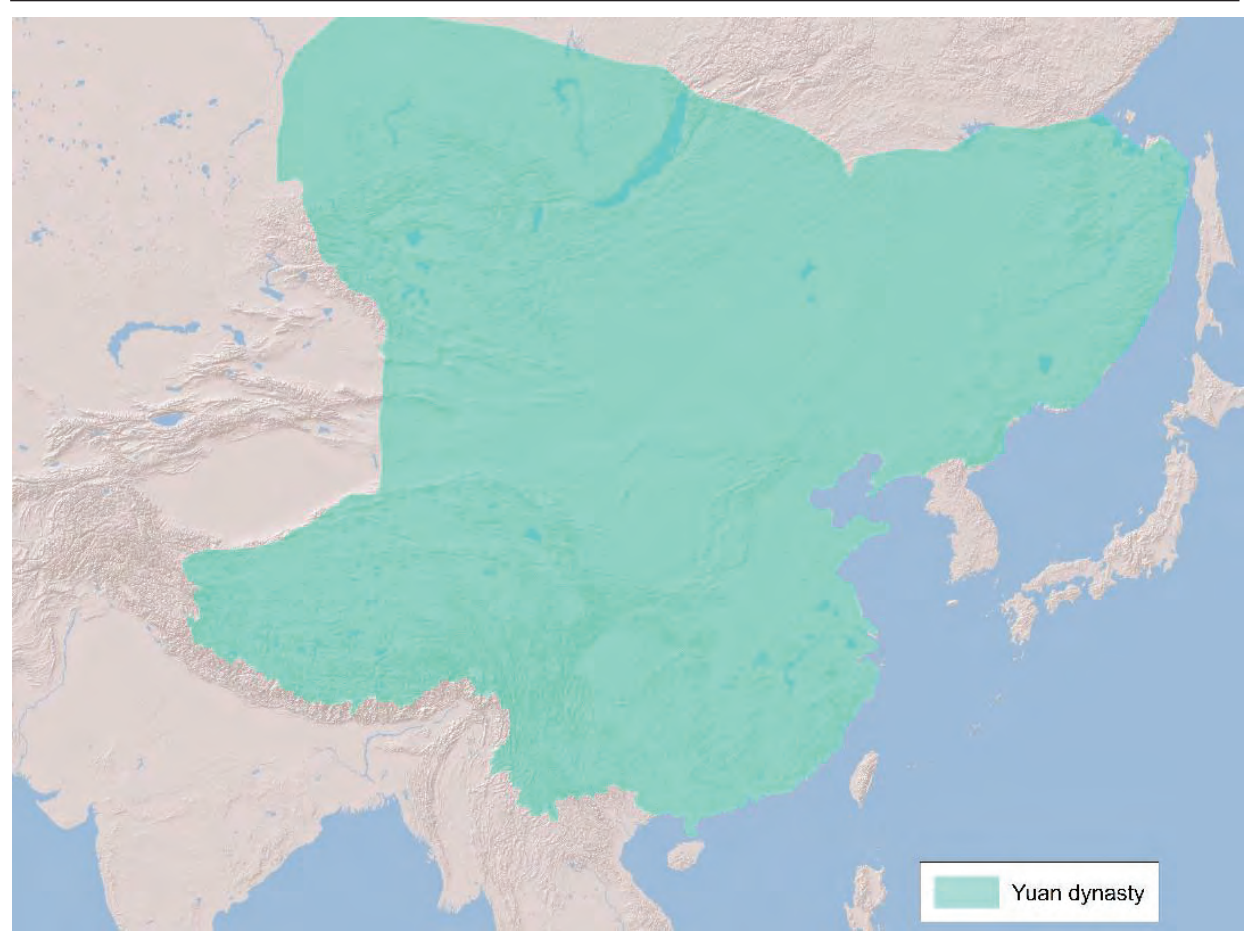

Map 6: China in the thirteenth and fourteenth centuries

Source: Edited by ÁGNES VARGA

Eventually the Mongol Empire penetrated European territories as well, and Batu Khan's armies pushed as far as Hungary and Poland in the thirteenth century. The Black Death occurred towards the end of the Yuan era and wiped out half of Europe's population.

The Ming dynasty and Admiral Zheng He (1371-1433)

The Ming dynasty (1368-1644) represents an outstanding period in Chinese history when the technological, economic, social and cultural advancement of the Middle Kingdom achieved superiority over contemporary Europe. The economic and domestic political challenges faced by the Yuan dynasty led to rebellions across the country; Zhu Yuanzhang (1328-1398), a peasant turned into military leader gained control over the southern regions, then pushed towards the north and brought an end to the Yuan reign of Mongolian origin. Zhu declared himself Emperor, established the Ming dynasty in 1368 and set up its capital in Nanjing. He gradually strengthened his power in the Han periphery regions, crushed the ethnic rebellions of South-Southwest China and demolished the 
remaining Mongolian forces in the northern region of Manchuria. His successor relocated the capital to what is now Beijing and built a new settlement in the years from 1407 to 1420 centred around the imperial palace complex, the Forbidden City. A recurring element of the studies written on China is the global superiority of the empire over the past two thousand years and its civilisational and technological advancement in comparison to Europe in the centuries following the collapse of the Roman Empire. So, the question is: why did not China become a world superpower? Due to the colonisation process starting in the 1600s there was hardly any part of the world not controlled by Europe in the early twentieth century. There are several explanations on the matter, and each one of them is likely to have influenced the course of world history. Although the theories based on geographical determinism rather simplify the picture, comparing China with Europe may lead to some interesting conclusions. An obvious difference is that while the core territory of China constitutes a vast homogenous, almost continental region (i.e. the eastern-north-eastern plains suitable for cultivation and the southern region with the greatest concentration of population), Europe is rather varied geographically. Think of Africa: although it is three time larger than Europe, its coastline is actually shorter. The territory of Europe is divided by many seas forming peninsulas and islands, as well as mountain ranges such as the Pyrenees, the Alps, the Carpathian Mountains and the Scandinavian Mountains. This might have contributed to the fact that Europe has never been organised into a single state despite the efforts of numerous military leaders, monarchs and dictators in recent centuries; in fact, the last permanently successful attempt in this regard was that of the Roman Empire. The geographical and topographical borders contributed to the formation of independent nation states and hindered large scale conquests. The map of modern-day Europe shows that most of its geographical units represent individual countries, and this structure led to permanent interstate conflicts and wars in an era when land and territory were viewed as the major source of state power and wealth. For the European monarchies the only way to expand territory was to engage in zero-sum machinations at the expense of one another; according to some estimates there was not a single peaceful year in Europe in the four and a half centuries between 1500 and 1945. War is also viewed as a contest fought with ultimate weapons resulting in technological development in military as well as in any other aspects. In terms of international order, it led to the evolution of the Westphalian system and the concept of state sovereignty, a European invention which spread in the world as a result of colonisation and globalisation, or else by use of force.

Meanwhile, China's perception of world order was completely different; since its unification in 221 BCE China had not seen an international system comprised of similarly powerful entities opposed to one another. Remember China's 
geographical isolation and its core territory consisting of easily unifiable larger plains. Thus, China experienced no challenges posed by foreign enemies (or else assimilated them) and required no new territories to support its population. According to the theoretical aspect of the explanation, China had no equal competitors and thus viewed the world as a set of concentric circles, the centre point representing the Emperor surrounded by the court, the capital and imperial territories. This mentality is also reflected by the name of the country, which is completely different in Chinese than in any other languages: Zhongguo, or Middle Kingdom. Theoretically it implies that the territories actually situated outside the borders of China also belong to the Empire. This concept is called tianxia, which means that the entire world 'under heaven' formed part of the Empire, but the people living outside the actual borders were less advanced and thus not worthy to share Chinese wealth, culture and standard of living. This concept fundamentally influenced the Chinese world view which, contrary to Europe and the Westphalian system, regards the world not as a liberal community of sovereign equal nation states, but as a set of concentric circles. The centre of this world represents China, surrounded by hierarchical circles made up of periphery states, that is the tributary system.

All this probably contributed to the fact that the imperial fleet of 317 enormous vessels commanded by Admiral Zheng He set out from South China in 1405, almost 90 years before Columbus carrying 28,000 crewmen towards Southeast Asia, India and perhaps as far as East Africa, and returned without conquering any of them. The purpose of the altogether seven expeditions lasting until the 1430s was merely to inform the local population of the Emperor's message regarding the future collection of symbolic taxes or tributes. China's subsequent rulers strongly believed in imperial superiority and regarded the fleet unnecessary as the 'barbarians' had nothing to offer to the mighty Empire, while the threat of another northern Mongol invasion was imminent. According to Angus Deaton, Nobel laureate in economics, the imperial court viewed these expeditions and the resulting increase in maritime trade and merchant prosperity with jealousy, and eventually put an end to exploration, in fact, attempted to erase all documented memory as an outstanding example of protectionism, machination and intrigue. This decision was guided by faith in the mighty Empire and determined China's fate for the next five hundred years. While China chose voluntary isolation, Europe's technological advancement and situation necessitated the start of colonisation, leading to European economic and military superiority over China in the coming centuries. The bitter awakening came in the nineteenth century, bringing a hundred years of humiliation, devastation, death and partial colonisation for China. 
The Ming era was concurrent with the start of European colonisation and the early phase of industrial revolution. The age of Reformation and Renaissance significantly contributed to the greatness of Europe and the evolution of global trade and world order. Further points of reference include the work of Machiavelli and the expansion of the Ottoman Empire.

\section{Qing dynasty (1644/6-1911)}

The last Chinese imperial dynasty came to power as a result of the northern Manchu invasion, after defeating the Ming dynasty (Map 7). The ruling Qing elite, invariably assimilated into Chinese society, extended its power over current day Xinjiang, Tibet, Mongolia and some parts of South Siberia. China's failing dynastic power in the mid-1800s as a result of internal processes coincided with the arrival of the European (and subsequent American and Japanese) invaders. In economic terms this weakening process was mainly attributable to the so-called high-level equilibrium trap. According to the theory developed by historian Mark Elvin, in spite of China's centuries long economic and social superiority over Europe it never underwent an indigenous industrial revolution, as the Chinese economy had reached an equilibrium point where supply and demand were wellbalanced within the empire due to its highly efficient systems.

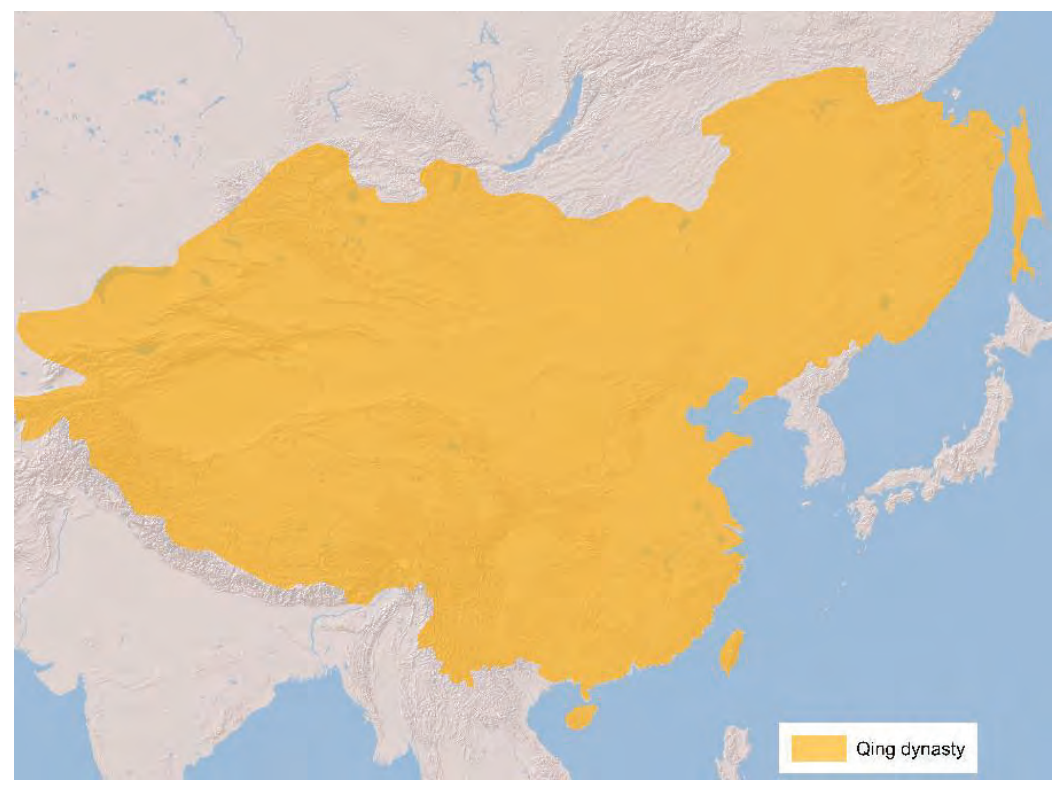

Map 7: The territory of China during the last dynasty Source: Edited by ÁGNES VARGA 
Thanks to the enormous size of China's economy and its highly developed road and canal networks local shortages could be easily balanced with surpluses produced elsewhere. At the same time, labour was very cheap; farming had been extended to all cultivable territories by the seventeenth century which, considering the sheer size of China, was sufficient to supply the steadily growing population, and as agriculture was unable to absorb more workers, the increased supply of labour at repressed wages. Due to the combination of these factors investment in capital to improve technology and efficiency would not have been profitable. In Elvin's view a philosophical change at the time also contributed to the situation, including a shift from Taoism and interest in natural sciences and the natural world to Confucianism focused on social philosophy and morality. This transformed intellectual environment failed to promote technological development. In addition, the wealthy merchants exercised control over state officials, and made them change laws for their own benefit with the result that the actual producers were left with no accumulated profit, and thus had no capital to improve technology and efficiency. Moreover, we should recall the already described geographical features, and the fact that China had no opponent on a similar scale to pose challenge and competition for several millennia. In other words, high-level equilibrium trap means the kind of situation where relative welfare, lack of competition and protectionist measures by a selfish elite prevented further progress and improvement. Stopping Zheng He's expeditions inflicted similar damage on China.

The above processes happened to take place at the worst possible time; no matter how far from Europe, the Western powers eventually reached the shores of China and set out to partially colonise the Heavenly Kingdom.

In 1793 Lord Macartney, the envoy appointed by King George III approached the imperial court in Beijing in order to open new ports for British trade, relax trade restrictions, establish a permanent embassy and obtain a small island for British use off the coast of China. The Canton system gradually developed in the seventeenth and eighteenth centuries controlled Western trade through thirteen appointed factories until 1757, when Emperor Qianlong (1711-1799) introduced trade restrictions out of concern for changes in Chinese society as a result of foreign influence. The Chinese subjects were not permitted to teach the Chinese language to foreigners, and European traders were forbidden to bring women into China. Frustration with the system increased, along with a growing deficit in balance of trade; in exchange for tea, porcelain and silk the British had to make payment in silver. Finally, the traders convinced the king to send a mission led by George Macartney to Beijing. The journey lasted almost a year, and the huge differences between Chinese and Western thinking became apparent already in ceremonial matters. While the imperial court considered Macartney's mission as 
a tributary visit, the British viewed it as an exchange between two sovereign and therefore equal monarchs. The Emperor expected Macartney to perform the kowtow (koutou), a ceremonial greeting (made by an inferior by kneeling and touching his head to the ground nine times to show respect), which shocked the British. After lengthy debate the Emperor graciously conceded to Macartney perform the act only once instead of nine times; however, the British suggested that a highranking Chinese official did the same before the portrait of King George. The idea was unthinkable: no one could equal the Son of Heaven. The Emperor was about to cancel the meeting, but eventually agreed that Macartney greet him the British way by getting down on one knee. Eventually, the letter from King George was delivered with the British requests, but like his predecessors, Emperor Qianlong saw no benefit in trading with the barbarians, despised the products of British industry provided as gifts and rejected the idea of opening an embassy. Instead of deliberating the requests, the Emperor sent a message demanding the British monarch to kneel before the Son of Heaven in Beijing. The humiliated delegation returned to England without achieving anything; the war with Napoleon in the following years left no room for worries about China.

With Europe's stability restored, however, the Western powers turned their attention to the East once more. Although China was much farther than India, its precious goods including tea, porcelain, silk and spices made it a highly attractive target. Eventually the Chinese facilitated trade with the West through a number of ports, but the situation turned out to be rather one-sided. The Europeans purchased a great deal of luxury items, with hardly anything passed the other way round - a bit like today. This led to significant deficit in the British balance of trade, and the increased use of silver accepted in payment caused financial difficulties. Assessing the situation, the British decided to introduce a new product to the Chinese market relying on its Indian colonies and labour. The British East India Company began to ship opium from South Asia to China with immediate popularity, which improved the balance of trade and facilitated the flowback of silver into European economy.

Naturally, the court quickly realised the threat posed by addiction among the population and banned the importation of opium into China by imperial decree. These measures remained in place despite Britain's protests; the situation escalated, and eventually the First Opium War broke out in 1839. Faith in the mighty Middle Kingdom was immediately crushed when a handful of British vessels destroyed the imperial fleet without suffering major losses and moved along the coastline bombarding Chinese ports. The balance of power is well illustrated by the fact that while the British lost 69 men, the conflict cost almost twenty thousand lives for China. Aware of its powerless situation, the empire concluded the unfavourable Treaty of Nanking with the British in 1842. Hong Kong (Xiang- 
gang) came under British control as a result of the treaty. The Second Opium War broke out in 1856 when the Chinese seized a British smuggling craft, and the British soldiers besieged the city of Canton (Guangzhou). The following year the English and French warships destroyed the Dagu forts at the mouth of the Hai (Bei) River near Tianjin on the way to Beijing. In 1858 the Qing government was forced to sign the Treaty of Tientsin, which ended the first phase of the war, opening ten additional ports to European trade with concessions and requiring China to pay war reparations. The Second Opium War ended with the signing of the Convention of Beijing in 1860, which granted further concessions to the Western powers, including the opening of the port of Tientsin and additional reparations. In economic terms it was extremely beneficial: the British were finally able to sell textile products to China free of duty and the foreign warships were free to navigate China's rivers. Europe's modern manufacturing industry soon became influential thanks to China's compliance with the terms of the Convention. China lost control over tariffs and customs to the benefit of the British.

Western invasion and the serial humiliating defeats and treaties shocked the Chinese society convinced of its own superiority. The foreign powers had far more advanced weapons than China, and Christianity was also used as a means to conquer the empire. The foreign privileges obtained by force had disastrous effects on China's economy. Although the open ports attracted capital and labour, this led to simultaneous inequalities in contrast to the inland territories. The goods imported from the developed industrialised countries and the introduced subsidies afflicted China's industry in many ways, and China became increasingly dependent on imports, and consequently on world economy and world trade dominated by the West.

Western dominance had a similarly negative impact on China's society. The conflicts between the newly arrived or settled foreigners and the local population became increasingly frequent. As a secondary consequence, the enmity to the Westerners gradually extended to Western values as well, leading to a dismissive attitude towards innovation and reform. Moreover, the frequently observed arrogance and richness of the foreigners further increased the sense of inferiority among the Chinese population developed as a result of military defeats inflicted by the Westerners. Due to a combination of these impacts China found it difficult to accept the inevitable and necessary changes. Although the foreign military, economic and cultural pressures certainly had some positive effects on China, its several thousand year old social structure and cohesion began to crumble in the late nineteenth century, and eventually collapsed with far more severe consequences than in any other colonised country owing to the sheer size of the empire. 
Frustration among the Chinese elite and the population in the middle of the nineteenth century increased, demanding reforms and progress for the country. The internal turmoil led to a series of rebellions, each one with terrible consequences. An outstanding example is the Taiping Rebellion (1851-1864), a Christian movement of the Heavenly Kingdom which caused devastation to a third of China and claimed up to thirty million lives. A number of other rebellions followed (e.g. Nian Rebellion, Muslim religious war). The civil disturbances and the defeats suffered at the hands of foreign powers reflected the helplessness of the Qing administration. In 1899 the Boxer Rebellion (initiated by the Militia United in Righteousness known as the Boxers because many of their members practised martial arts) opposed foreign influence; the Boxers set fire to the embassies in Beijing, lynched foreign diplomats and killed two hundred missionaries and over thirty thousand Chinese Christians. In response an Eight-Nation Alliance (Britain, Germany, France, Austria-Hungary, Italy, Japan, Russia and the United States) launched a revenge campaign against Beijing. The fifty thousand strong allied forces disembarked at Tientsin (Tianjin), marched to the capital, defeated the imperial army, and finally liberated the besieged diplomatic quarter and ransacked most of Beijing and the Forbidden City.

Nevertheless, even more shocking was the defeat inflicted on China by Japan. Japan, a feudal tributary despised for hundreds of years underwent fundamental changes in the second half of the nineteenth century; the Meiji Restoration in 1868 led to rapid Western style industrialisation and modernisation across the country. Consequently, the demand for natural resources increased, which was to be met by territorial expansion dictated by the spirit of the age. The obvious target was China; the first Sino-Japanese War in 1894 and 1895 ended with Japan's spectacular victory, and the Treaty of Shimonoseki ceded the Liaodong Peninsula, Taiwan and the Penghu Islands to Japan. In addition, the Qing Empire was to pay war reparations on a staggering scale: $260-340$ million taels (10-15,000 tons) of silver to Imperial Japan.

The serial defeats naturally led to numerous attempts to modernise China. Military improvements began after the First Opium War, but the purchased Western weapons and warships proved insufficient. The aim after the Second Opium War was to modernise China's government introducing the Hundred Days of Reform by Emperor Guangxu (1871-1908). These measures included the abolition of the traditional civil service examination system, the establishment of the University of Beijing and agricultural schools across the country, a shift from absolutism to constitutional monarchy, the introduction of a capitalist economic model and further industrialisation. However, real progress was prevented by the conservative forces within the court. The dynastic empire's inability to revive 
became increasingly apparent with a growing need for modernisation represented by Sun Yat-sen's movement (born Sun Wen, 1866-1925).

\section{The Wuchang Uprising}

The fall of the Qing dynasty was finally brought about by another wave of uprising. The Qing government planned to nationalise local railway companies and transfer control to foreign banks. The proposal was met with anger and rebellion. The military forces deployed against the armed rebels of Sichuan left the city of Wuchang in the neighbouring Hubei province unguarded, where an uprising broke out and the locals managed to expel the Qing government functionary. The imperial court dispatched a modernised army unit led by General Yuan Shikai (1859-1916) to crush the uprising, but the General had different ideas and engaged in secret negotiations with the rebels instead. Meanwhile, Sun Yat-sen, an emblematic figure of the Chinese revolutionary movement returned from the United States, having sought to find wealthy Chinese supporters for the fight against imperial power. Due to rapidly escalating events eighteen southern and central provinces voted to secede from the Qing dynasty in December 1911, and shortly afterwards Sun Yat-sen was elected as provisional president of the republic. The seceding provinces proclaimed the establishment of the Republic of China on 1 January 1912 supported by Yuan Shikai's army. The then six-yearold emperor was forced to abdicate on 12 February 1912, ending 2,000 years of dynastic rule in China.

\subsubsection{Traditional Chinese strategic culture and its sources}

China's traditional strategic culture and international political approach have been deeply influenced by ancient Chinese philosophy and historical experiences. The Seven Military Classics (Wu jing qi shu) is a major study of warfare compiled in the eleventh century that represents the most important sources of Chinese military and strategic knowledge. The Seven Military Classics comprise Jiang Ziya (Taigong)'s Six Secret Teachings, the Sima Rangju Art of War, Sun Tzu's (Sunzi) The Art of War, Wu Qi's Wuzi, Wei Liaozi, the Three Strategies of Huang Shigong, and Questions and Replies between Tang Taizong and Li Weigong. The work of Sun Tzu and Wu Qi is discussed below. 
Philosophical foundations - Confucianism and Legalism

In order to understand China's current strategy and international approach it is important to be familiar with Chinese philosophical tradition and thinking. This philosophical tradition, which, in a sense, has turned into religions, is so ingrained in everyday life and thinking that it often influences China's (foreign policy) decision making in an almost unnoticeable way. That is to say, it is a most fundamental and most profound aspect of Chinese culture. The two most widespread and most influential philosophical schools are associated with Lao-Tze (Laozi, sixth century BCE) and Confucius (see above).

\section{Sun Tzu and The Art of War}

Sun Tzu (Sunzi) (544-496 BCE) was a highly successful, still influential Chinese military strategist in charge of the Wei king's army. His expertise and instructions were collected in The Book of War (alternatively translated as The Art of War), which has grown to be a fundamental work not only in a military sense, but in every aspect of decision making, whether business or political, all over the world. According to Sun Tzu, knowledge wins wars without fight and overthrows governments without prolonged military operation.

It would be difficult to overestimate the significance of Sun Tzu's work; his book is now considered a major study not only for the military academies, but also for all major Western universities and institutes of economic management and training. This is primarily due to Sun Tzu's fundamental principles which can be successfully applied to all kinds of strategies. The instructions of the book written in the sixth century BCE are still recognisable in modern Chinese leadership principles. Think of the famous quote from Deng Xiaoping (1904-1997): 'Observe calmly; secure your position; cope with affairs calmly; hide your capacities and bide your time; be good at maintaining a low profile; and never claim leadership' (quoted by Kissinger, H. 2014, p. 458).

Wuzi

Wuzi is a major classic Chinese work on military strategy written by $\mathrm{Wu}$ Qi (440-381 BCE), a talented military leader and politician of the Warring States period. The opposed forces of the Warring States period tried to form vertical and horizontal alliances as a means to balance power among the states and to temporarily pacify the affected regions. As seen above, the solution was finally brought about by creating a unified empire in 221 BCE led by the Qin state. Although Wu Qi was educated by Confucian philosophers, he turned out to be one of the earliest 
major Legalist thinkers. His work contains revolutionary ideas on warfare, directly opposed to the military techniques of patriarchal Confucianism.

Wu Qi's book follows the process of transition from Confucian terminology, with all major concepts gaining new meaning and wider interpretation in military aspects.

These changes laid the foundation for subsequent terminology applied in political philosophy. The surviving stories on Wu Qi's life contain numerous references characteristic for a very powerful legalist-minded individual. Wu Qi, who similarly to Cao Cao (155-220) displayed some Machiavellian qualities, did not shy away from any means to achieve his ambitions. According to some researchers a much more substantial original version of the Wuzi written by Wu Qi himself may have got lost and the currently known version comprising six chapters is a summary originating from the Han era. Others believe, however, that certain parts of the text describe the Warring States period with such accuracy that they are more likely to be contemporary. The truth probably lies somewhere in the middle; the original work recovered in fragments during the Han era must have been completed according to contemporary military science and technology. Studying the book used to be mandatory for all military leaders and statesmen for many centuries; in fact, the Wuzi was selected as a major source for the Seven Military Classics compiled in 1080 during the Song dynasty.

\section{The concept of tianxia and the tributary system}

Throughout its history China preferred to think of itself as the centre of civilisation, with all outward entities considered barbaric and therefore necessarily inferior to the Middle Kingdom. This view is represented in urban planning as well; think of the Forbidden City, the centre of Beijing. According to China's concentric approach the power and influence of the Middle Kingdom is radiated from this centre point.

The holistic perspective of tianxia ('all under heaven') is an important element of Confucianism that provides the philosophical foundation of the tributary system. All under heaven in traditional Chinese thinking means not only the physical world; it is a cultural concept that also incorporates morality and the workings of the universe. The tributary system is essentially based on inequality, with a simultaneous aspiration towards 'Great Harmony' (Datong). Although difficult to explain in Western terms, it essentially means that the beings in the world (in this case individuals, peoples and countries) are unequal: 
China is at the centre point, surrounded by all else arranged in concentric circles. All under heaven form part of a great hierarchy which, by definition, is without any conflict and comprises every country dominated by China. Thus, nothing is far away, and there is nothing to be conquered; everything is part of a single whole, with the Middle Kingdom at its centre. Datong, the aspiration toward harmony of man and nature is another important element of the Chinese world view. Hierarchical order, on the other hand, is essential for the survival of society, and it forms the basis of the tributary system as well. However, this hierarchy is not based on 'strong versus weak' in the Western sense but resembles more like a father-son relationship. Administration and authority based on bonds and relationships within Chinese society (father-son, emperor-minister, elder brother-younger brother, husband-wife, friends) was termed 'Li Zhi', essentially the equivalent of government based on morality and ethics.

As seen above, traditional Chinese thinking distinguished no individual sovereign states, but considered all under heaven to be part of a single whole, which is why it lacks the concept of international relations in the classical sense. The countries within this system (the Korean Peninsula, Japan, Vietnam and parts of Central Asia, their status changing from time to time) were all tributaries, or taxpayers loosely connected with China, comparable to satellites orbiting around a bigger and stronger entity. International relations were viewed according to the principles and rules applied to society and the relationships of individual people. This sort of universalistic approach, very much unlike the Western one, was further encouraged by China's geographical conditions. Indeed, China resembles a vast remote island in many aspects. As discussed previously, the country is difficult to access due to numerous characteristics including dense rainforests and the Himalayan mountain range in the south, the coastline in the east, the Siberian and Mongolian wilderness in the north, and the Taklamakan Desert and the Central Asian Mountains in the west. The enormous distances are to blame for China's low-level intercultural relations and lack of experience with an international system of equally powerful entities until the start of European invasion in the nineteenth century. 
Civilisations from East to West

\subsubsection{Chronological table ${ }^{7}$}

\begin{tabular}{|c|c|}
\hline Date & Event \\
\hline $8000 \mathrm{BCE}$ & Emergence of the earliest Chinese cultures \\
\hline 2207-1766 BCE & Xia dynasty \\
\hline 2000-1500 BCE & Emergence of literacy \\
\hline 1765-1122 BCE & Shang dynasty \\
\hline 1122-256 BCE & Zhou dynasty \\
\hline $604 \mathrm{BCE}$ & Lao-Tze \\
\hline 453-221 BCE & Warring States period \\
\hline 551-479 BCE & Confucius \\
\hline 544-496 BCE & Sun Tzu \\
\hline 440-381 BCE & Wu-Qi \\
\hline 221-206 BCE & Qin dynasty \\
\hline $221 \mathrm{BCE}$ & Unification of China by Qin Shi Huangdi \\
\hline 206 BCE-220 CE & Han dynasty (Eastern Han and Western Han) \\
\hline $220-265$ & The Three Kingdoms \\
\hline $618-907$ & Tang dynasty \\
\hline 907-960 & Five Dynasties and Ten Kingdoms \\
\hline $960-1127$ & Northern Song dynasty \\
\hline $1127-1279$ & Southern Song dynasty \\
\hline $1279-1367$ & Yuan dynasty \\
\hline $1367-1644$ & Ming dynasty \\
\hline $1407-1420$ & Construction of the Forbidden City \\
\hline $1405-1433$ & Expeditions by Admiral Zheng He \\
\hline 1644-1911 & Qing dynasty \\
\hline 1793 & Mission led by Lord Macartney \\
\hline 1839-1842 & First Opium War \\
\hline $1856-1860$ & Second Opium War \\
\hline $1851-1864$ & Taiping Rebellion \\
\hline 1894-1895 & First Sino-Japanese War, Treaty of Shimonoseki \\
\hline 1899-1901 & Boxer Rebellion \\
\hline 1911 & Wuchang Uprising, fall of the Empire \\
\hline 1 January 1912 & Proclamation of the Republic of China \\
\hline
\end{tabular}

${ }^{7}$ The historical dates associated with Ancient China are rather varied; this brief chronology relies on the dates established by Jacques Gernet. 


\subsubsection{Bibliography}

DAWSON, RAYMOND 2000: The Chinese Experience. London: Phoenix Press

Feng, HuIYen 2007: Chinese Strategic Culture and Foreign Policy DecisionMaking - Confucianism, Leadership and War. London \& New York: Routledge

Friedman, GeORGe 2006: The Geopolitics of China. Stratfor, 2006. April 26. https://worldview.stratfor.com/article/geopolitics-china - 20 January 2020

GEERAERTS, GUSTAAF - Jing, MEN 2001: International Relations Theory in China. Global Society, 15(3) 251-276.

GERNET, JACQUES 1996: A History of Chinese Civilisation. Oxford: Oxford University Press

HUI, VICTORIA TIN-BOR 2005: War and State Formation in Ancient China and Early Modern Europe. Cambridge University Press, Cambridge.

JIANG, RONG 2008: Wolf Totem. New York: Penguin Press

KANG, DAvid C. 2007: China Rising - Peace, Power, and Order in East Asia. New York: Columbia University Press

KISSINGER, HENRY 1995: Diplomacy. New York: Simon \& Schuster

Kissinger, HENRY 2012: On China. London: Penguin Books

LAO-TSE 2016: Tao Te Ching. Madrid: Verbum

QIN, YAQING 2010: Why is there no Chinese international relations theory? In: ACHARYA, AMITAV - BUZAN, BARRY (eds.) 2010: Non-Western International Relations Theory, Routledge, New York

Song, XINNING 2001: Building International Relations Theory with Chinese Characteristics. Journal of Contemporary China, 10(26) 61-74.

Sun, Tzu 2007: The Art of War. Minneapolis, Minn.: Filiquarian 


\title{
2.2. The J apanese Civilisation
}

\author{
MÁRIA ILDIKÓ FARKAS
}

\subsubsection{J apan as an independent civilisation?}

The existing civilisations of the world today are units of varying size over time and space, covering larger areas and multiple nations, ethnicities, languages, and cultures, among which the Japanese civilisation of a single country, nation, and culture seems rather unusual. What factors justify comparative civilisation history studies viewing Japan as an independent civilisation?

Where does Japan belong? Undoubtedly one of the most advanced industrialised countries in the world, with its highly developed industrial - or even post-industrial - economy, society and democratic political and institutional system, it is part of the group of most developed countries (G7). At the same time, it is very different from the West in terms of its location, its cultural identity, its religions, its writing system and many other cultural traditions, and is linked to Asia, where some elements of its civilisation come from.

The latter may suggest that Japan is in fact the periphery of Chinese civilisation, which has had a great and significant influence on Japan throughout history. Japan was geographically and politically located on the fringes of Chinese civilisation for millennia, occasionally adjusting to and adopting the results of the China-centred East Asian order, but at times closing itself away, remaining outside the scope of the Chinese civilisation, with its development taking a different direction. Although, it moulded the adoptions to its own image until they were 'Japanised', and more in tune with Japanese characteristics and the internal conditions created by development that varied widely from those of China. It is a bold statement, but we dare to state that Japan has never been an integral part of the China-centred East Asian world order.

The island nature of the country and the possibility of isolation (from Asia) is likely to play an important role in this. Located alongside the Asian continent, it has taken on many elements of Chinese culture throughout its history (which were then transformed according to its own traditions to create Japanese Buddhism, Japanese Confucianism, and many art genres), but Japan differs significantly from Chinese civilisation, in its religious and cultural life, and especially in its history. Shintō as an independent Japanese religion, Japan's unique family system, medieval feudalism, the successful nineteenth-century modernisation, the modern statehood in Asia before 1945 and the democratic statehood after 1945 are all elements that are significantly different from the 
characteristics of Chinese civilisation, and more closely resemble those of Europe.

This comparison is particularly valid from the mid-nineteenth century, when Japan became the periphery of Western civilisation. Japan lived in isolation until the 1850s and, after the invasion of Western powers (from 1868), was successfully modernised, avoiding a colonial fate. Japan thus achieved a unique position for itself as a country which joined the West: from some aspects it is considered 'western', but in some important dimensions it is clearly not, therefore in relation to Japan the terms of 'dual civilisation' and 'mix of two civilisations (western and Chinese)' have been used.

The success of Japanese modernisation during the nineteenth century, and its unparalleled existence in Asia, has raised the possibility that Japan is not a part of the Asian (Chinese) civilisation, but is an independent civilisation due to its uniqueness (EISENSTADT, SH. N. 1996; HUNTINGTON, S P. 1998). For Japanese traditions and characteristics have always broken through in any system of foreign influence and takeover, whether Chinese or European. The geography of the Japanese islands and the way of life it defined (cultural ecology), Shintō, Japanese feudalism, Bushido, special ethnic and cultural homogeneity, combined with the adoptions, ensured the unique nature of Japanese history: the strange unity of permanence and change. Japan's difference from Asia is not the result of modernity (that is, the influence of Western civilisation), but it has much deeper roots. The unique development of Japan has always taken a different direction from that of the continent and the West, even in the case of Chinese and Western adoptions, facilitated by the cyclical phenomenon of Japanese history: periods of isolation. All this together rightly raises the possibility of an independent Japanese civilisation that explains the peculiarities of Japanese development.

So we can say that Japan is an independent civilisation, which is a very unique phenomenon, because in this case one country, one state, one people (98 percent Japanese), one nation, one culture and one language has created one of the world's civilisations existing today. Although related to Chinese civilisation (adopting cultural elements such as Tao, Buddhism, Confucianism, writing system), it has taken an independent path in its historical development (medieval feudalism, successful modernisation in the nineteenth century) and cannot be considered part of Chinese civilisation. However, it is neither an integral part of Western civilisation, mainly due to its cultural heritage and identity. This is explained by the fact that the creation of modern Japan followed the then European development pattern of the second half of the nineteenth century, but that it was based on the Japanese cultural tradition that preceded western-style modernisation. With this cultural identity, Japan took the 'non-western' path of modernisation, first and for a long time (until the mid-twentieth century) alone. 
2.2. The Japanese Civilisation

\subsubsection{Sources and foundations of the J apanese civilisation}

How, when, and under what circumstances was Japanese civilisation established? From what elements, on what basis and based on the effect of what factors was it established? How did the natural environment shape the way of life and consequently the culture of the population living here? What kind of beliefs and world views were generated from it? What external influences prevailed in the cultural changes? How did the specific nature of the culture that emerged influence historical changes?

\section{Natural environment}

Obviously, the formation of an independent Japanese civilisation was greatly influenced by the country's island nature, which was an obstacle to positive or negative influences from outside, and to some extent and at times kept the population of the Japanese islands isolated.

Japan is actually a volcanic archipelago that stretches over the Eastern border of East Asia for a length of 2,400 km (Map 8). Today's Japan is made up of 4 main islands (Hokkaidō, Honshū, Shikoku, Kyūshū) and more than 3,000 inhabited and uninhabited islands, covering an area of $377,923 \mathrm{~km}^{2}$, which in Europe represents a territory larger than Germany, similar to Norway. (About four times the size of Hungary.) The difference in the data from some sources (a few $\mathrm{km}^{2}$ ) is explained by the fact that the number of small islands is constantly changing, due to tectonic movements they continue to sink into the sea or rise above the water level. There is a significantly larger difference due to the socalled 'Northern Territories' (part of the Kuril Islands, about 5,000 $\mathrm{km}^{2}$ ), which is currently occupied by Russia (with the Soviet Union occupying the Japaneseowned islands in the Second World War) but which Japan considers theirs and counts as its official territory.

The natural environment is characterised by the fact that 72 percent of Japan's territory is mountainous, and the islands are made up of a chain of mountains, practically rising from the sea, with a mountain chain extending throughout the country (its highest point above sea level is the peak of Mount Fuji, at 3,776 metres). Due to the high mountains, steep hillsides and narrow valleys, almost three quarters of the country's territory is unfit for human settlements and agricultural cultivation. In addition to very few cultivated areas, they have also attempted to use the hillsides with terraced cultivation, the creation and maintenance of which has meant and continues to mean additional work for agricultural cultivation. The country has a small inhabitable area, which means that people's living space is tight and crowded, with 127 million people living in an area 
equivalent to only one quarter of the country (i.e. the approximate area of Hungary). Even if calculating with the entire territory, the population density of Japan is still part of the world's leading countries (18) with a number of 337 persons $/ \mathrm{km}^{2}$ (Belgium has one of the highest population densities in Europe, 339), but this population is very unevenly distributed on the islands: over half of the country's population (57\%) lives on less than $2.2 \%$ of its territory, with $90 \%$ living in cities. With a population density of more than 5,000 persons $/ \mathrm{km}^{2}$, the metropolitan Tokyo Region ranks below the most densely populated cities in the world (Monaco, Macao, Singapore and Hong Kong) and is the most populous urban agglomeration by population (34.5 million).

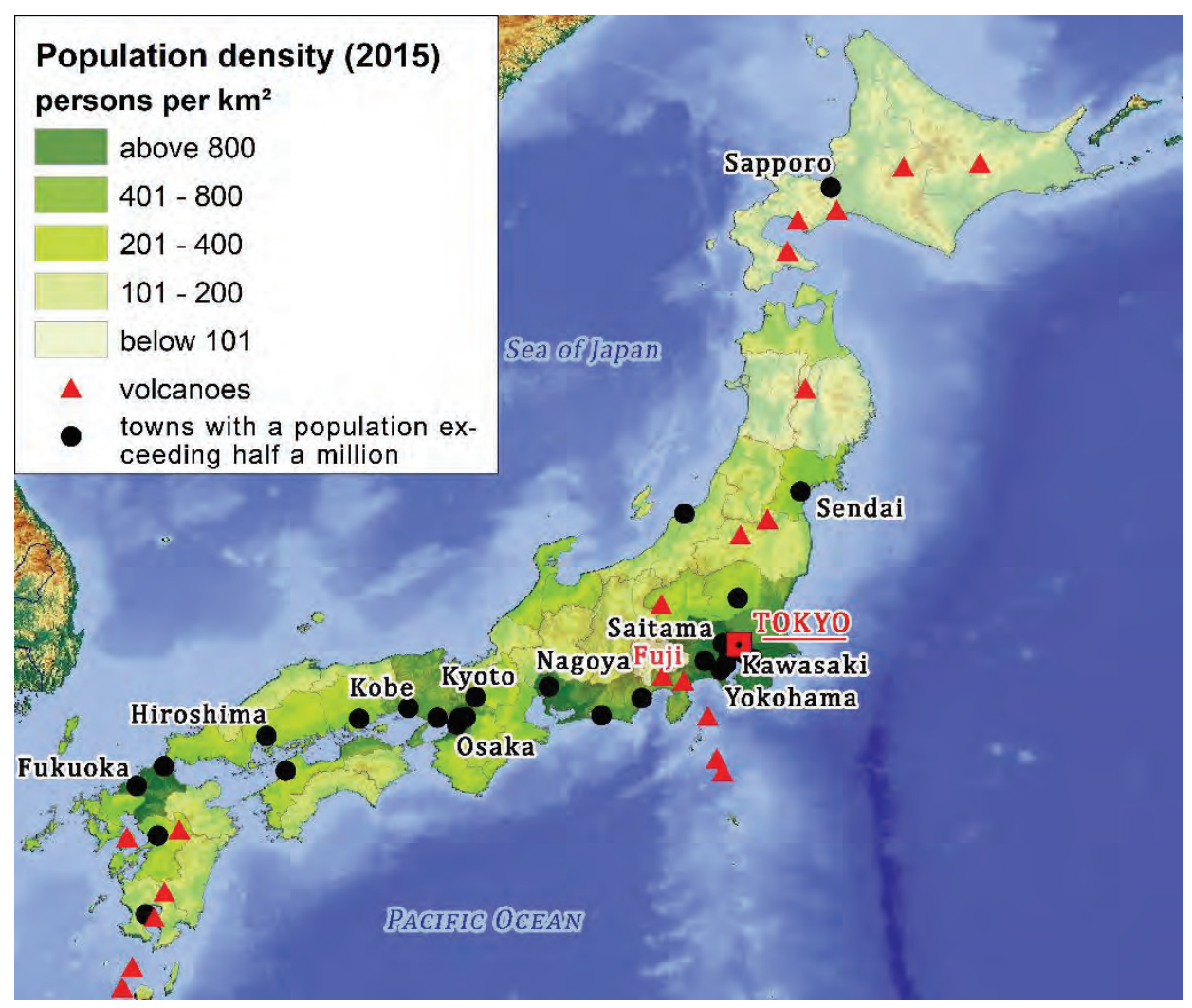

Map 8: Japan's topography, major volcanoes and cities Source: Edited by ÁGNES VARGA

In terms of natural resources, Japan is an extremely poor country, and it seems rather contradictory that it still has the world's third largest economy (behind the US and China if the European Union is not considered a single economy, because then it is 'only' the fourth). This means that Japan's economic 
success was not due to favourable natural conditions (such as areas with oil or rich coal and iron ore deposits), but other factors may have played an important role. Japan has virtually no raw material, minerals or energy sources, even if there is a small amount of coal, iron ore, copper, zinc, gold, silver, lead, gas, sulphur, because of the natural environment it is either completely impossible to extract and mine, or it would be very uneconomical. Thus, the country has been in need of imports of all important commodities since the beginning of the modern industrialised era, and the ever-threatening foreign trade deficit has created (and still creates) a strong incentive to establish and sustain an export-oriented economy.

What impact did this natural environment have on the characteristics of the human culture emerging here? Throughout history, unfavourable and difficult natural conditions for maintaining human life have meant that continuous, hard, and persistent work was required to survive. The small cultivated area required a lot of difficult human labour in order to utilise the land: the construction of dams, canals and irrigation systems, the terraced construction, continuous maintenance of the hillside, and the constant maintenance of the system.

Japan is in the temperate zone, but has a vastly variable climate, ranging from cold temperate to subtropical. The reason for this variability is the large north-south extent of the islands (equivalent to the distance between Montreal and Miami on a map of North America, or the distance from Kiev to Cairo setting off from Europe) as well as the climate and water drainage effects of the mountain chain running along the centre of the country. Because of the latter, the climate differs on the Pacific Ocean and the Japanese Sea: along the Sea of Japan the influence of the continent can be felt (there is no monsoon in summer, but it is cold during winter with significant snowfall), while on the Pacific coast in winter there is little snow and milder weather due to the oceanic influence, but in summer there is rainfall and hot, humid weather. With the exception of Hokkaidō, the islands are in the monsoon zone, the summer rainy season (6 weeks) means high rainfall, heat and high humidity. At the same time, ocean currents are also affecting the islands: cold from the North and warm from the South are cooling or warming the islands, further increasing the temperature difference between the North and South. For example, Sapporo is located on the same latitude as Milan, but its climate is much colder due to the effect of the cold current, but Tokyo's climate is warm, similarly to that of Athens but, due to the ocean current and the monsoon, it is a lot more humid.

Climatic differences and, not infrequently, extreme weather (heavy rains, floods, snowfall, typhoons) have created the need and ability for continuous adaptation in the human communities that live here. One particular example of this is traditional Japanese architecture, which has favoured non-solid materials (wood) over solid (stone), since a wooden building (and an entire village) was 
more easily destroyed by the natural disasters described below, or as a result of extreme weather, but it could also be rebuilt within a few days permitting a return to everyday life.

\section{Natural disasters}

The natural environment also has catastrophic effects on the population of the islands.

1. Volcanoes: The territory of Japan is actually a volcanic arch, which was the result of volcanic activity due to the collision of earth-moving plates, the Eurasian plate containing the Japanese Sea, the Pacific plate in the north and the Philippine plate in the south (Figure 12). The islands are divided approximately in the middle by a break line, along which the volcanoes are located. In Japan, besides the 150-200 extinct volcanoes, they have recorded 36 active volcanoes. Ten percent of all active volcanoes in the world are located in Japan.

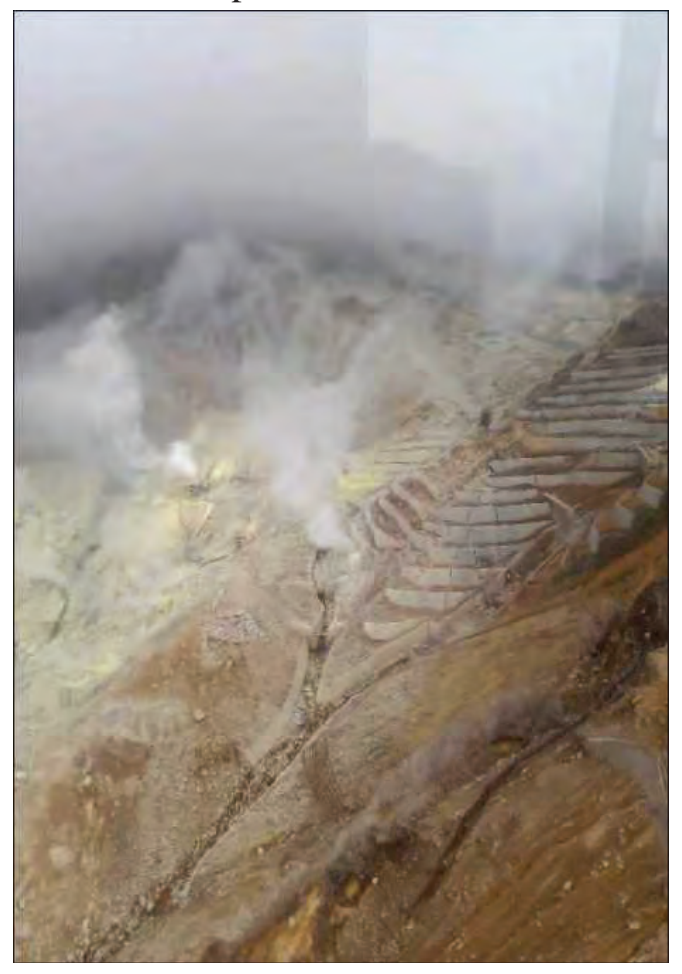

Figure 12: The still active sulphur vents of the volcanic Mount Hakone Source: Photograph by ANDREA PÓR 
2. Earthquakes: Japan is one of the most active and volatile areas in the world from a tectonic point of view. Due to the movement and collision of the tectonic plates, this area is the most vulnerable to earthquakes. Every year, 1,500 earthquakes, usually earthquakes between magnitude 4 and 7 , are recorded, which means that small earthquakes are commonplace in Japan and that the earth is always moving somewhere. Unfortunately, devastating earthquakes regularly afflict the population of the islands and a tidal wave (tsunami) can be the catastrophic consequence of an earthquake in the sea. In the twentieth century, the Great Kantō Earthquake of 1923 claimed more than 100,000 lives and almost completely destroyed Tokyo (today's city is the result of subsequent reconstruction). Japan is the most prepared country in the world for earthquakes, and thanks to special construction, monitoring, security and alarm systems, human and material losses can be significantly reduced, but devastating natural disasters cannot be completely prevented. In 2011, along the north-east coast of Japan, there was one of the largest earthquakes ever recorded in human history (with a magnitude above 9), triggering a massive 40 metre tidal wave that hit the Japanese coast. As a result of the earthquake, the island of Honshū shifted two and a half meters to the east, and the axis of the Earth swung 10 to $25 \mathrm{~cm}$. The disaster claimed some 24,000 lives (we have to add, that the major earthquake in Indonesia, which triggered a similar tsunami in 2006, claimed more than 300,000 lives). The worst consequence of the disaster was the damage to the Fukushima nuclear power plant. Although in Japan, nuclear power plants are built with serious safety systems that shut down the power plant in the event of an earthquake, the tsunami's waves of more than 30 metres could not be stopped even by the several metres of shore-side concrete defences, and the tidal wave travelled almost $10 \mathrm{~km}$ into inland Japan, destroying everything in its path and damaging the nuclear power plant.

In addition to major catastrophes, other, less devastating, but sometimes very serious, natural phenomena endanger the lives and well-being of the Japanese population. From August to October, typhoons from the South Pacific can reach the south-eastern part of the country, and in the winter, heavy snowfall from Siberia can reach the north-west, causing severe floods and landslides as the snow melts. Except for Hokkaidō, the islands are in the monsoon zone, and heavy rainfall in the early summer can also cause flooding, but it is also not good to have low rainfall, which could threaten the crops with drought.

The harsh natural environment had consequences for people's livelihoods and relationships with the world: the constant uncertainty and emergency made 
the ability to adapt to the circumstances, and flexibility, the constant, hard and persistent work in everyday life, and the naturalness of a repeating start vital. Humans have learnt to live with unpredictable and often dangerous environments, exposed to nature. Communities have emphasised the importance of organisation, collaboration, emergency preparedness from the early ages, and have maximised the use of resources and human labour.

\section{Religion}

Beliefs, world view and religion play a decisive role in shaping the nature of a civilisation. Japan is unique in this also, because the coexistence and even syncretism (the certain degree of merging and intertwining) of several different religious traditions has defined - and defines - Japanese religiousness, which, moreover, does not manifest itself in religious (theological) teachings, but rather, it shows an approach to life, tradition and lifestyle for the Japanese people. The internal, own tradition (Shintō) and the religious and philosophical tendencies adopted from outside (Tao, Buddhism, Confucianism) coexisted, complemented and influenced each other to a certain extent, and practically constituted a unified system for the Japanese, which embraced religion, the world view, morality and ethics. Community religious practice also determined the individual's life.

Exposure to natural conditions may have resulted in the Japanese having a special relationship with their environment and the formation of their own natureloving religion, the Shintō. Because they were so vulnerable to geographical and weather elements, the Japanese saw the leaders of their lives in nature, in its gods (kami), who are almost innumerable, and reside within natural phenomena. One's life depends on them, the kamis can help or become angry, but they can be reconciled with rituals, sacrifices and prayers. The Shintō is thus an archaic natureloving world of beliefs; a set of ceremonies, spells, local cults, originally without moral teachings and metaphysical sayings (Figure 13). It was characterised by the reverence of the ancestors, the adoration of natural phenomena, and the belief in the immortality of the spirit, with millions of kami.

Buddhism came to Japan in the sixth century, but did not displace Shintō, instead it complemented and broadened religious life by caring for the dead, the concept and image of the afterlife, Buddhist philosophy, theology, and morality. To this day, it is common for the Japanese to feel that Shintō deals with this life (birth, children, weddings, agriculture-related rituals, ceremonies, and celebrations in shrines), and that Buddhism deals with the soul and the afterlife (that is, according to our concepts, more religious matters). The Japanese practice the rituals of both and visit a Shintō shrine or Buddhist temple at different stages of their life and in connection with different celebrations of the year. The rituals 
and celebrations are very important in today's world, even though they are no longer closely linked to religious beliefs, still, on the one hand, they represent important turning points in an individual's life and, on the other hand, celebrations are major community events and manifestations of community belonging.

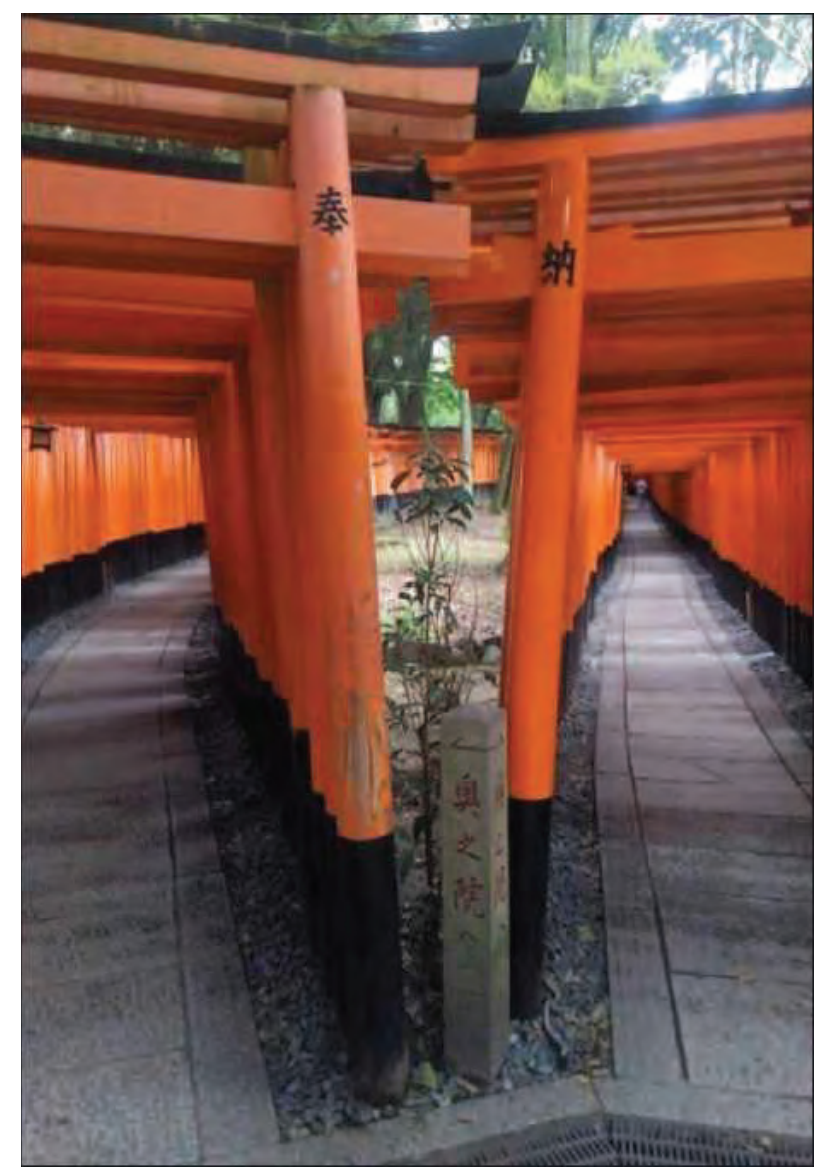

Figure 13: The row of gates of one of the biggest Shintō shrines, the Fushimi Inari Shrine

Source: Photograph by ANDREA PóR

Also, in the fifth and sixth centuries, Tao and Confucianism were introduced into Japan and became part of the Japanese religious tradition. From the Tao tradition, the yin and yang doctrine, the astrology, the habit of divination and magic, the doctrine of the arrangement of space (predecessor of today's feng shui) and the five elements, the belief in fortunate and unfortunate places, times, 
actions, signs etc. (according to the stars), i.e. the elements of the Tao, were deeply embedded in the system of popular religiousness.

Confucianism had more of an influence with its ethics and moral message, by which it provided guidance to life, defined relationships between people (hierarchy), the functioning of society (harmony), the duties of the individual (respect for authority, moral and disciplined life, importance of self-education). Buddhism in Japan has undergone a unique development, emerging and still operating today, with its own message (Figure 14). Based on the Amida (Buddha) faith, the Jōdo Shinshū direction is the most powerful and most followed branch of Japanese Buddhism to date; Japanese Zen Buddhism is the dominant spirit of the arts, aesthetics and philosophy considered to be the 'Japanese'; and the Nichiren (Hokke-shū) direction, founded in the thirteenth century, which emphasises 'Japanese' (national) Buddhism (it also has a cultural association, several schools and a political party), are still practised today.

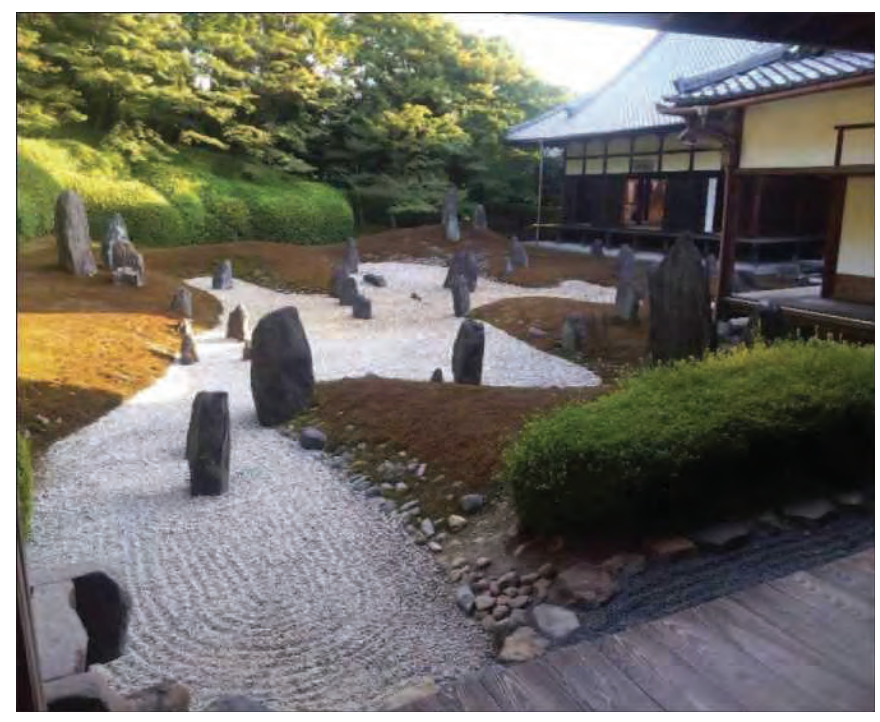

Figure 14: Garden designed according to the principles of Japanese Zen Buddhism (Kōmyō-in, Kyoto)

Source: Photograph by ANDREA PÓR

\section{Society}

Japanese society is fundamentally regarded as a collectivist society (as is generally the case with East Asian societies), as opposed to individualist 'Western' societies. In collectivist culture, the basis of social existence is the 'we consciousness', the individual can only define themselves in the community. 
The interest of the group takes precedence over the interest of the individual, because the individual depends on the group, the well-being of the group ensures the well-being of the individual, therefore the well-being of the community is paramount. The relationship between the individual and the community is bidirectional: the individual shows loyalty to the group and the group cares for its members (paternalism), and that is the benefit of the collectivist culture for the individual: protection for life. In contrast, in individualistic societies (Europe, North America), the foundation of the individual's prosperity is seen in individual abilities and performance, with freedom and independence emphasised. Society rewards individuality, individual challenges, competition and performance, whereas in a collectivist culture, the individual is almost non-existent, merely a member of a group and less valued in their individual excellence, but rather based in their value within the group. Human relationships and the system of relations is important within the group, which is usually hierarchical and designates the position and tasks of each individual, the fulfilment of which provides the basis for the individual's perception (this is also called a 'duty-oriented' society, as opposed to the western 'goal-oriented' society). One of the foundations of community survival and proper, successful functioning is intra-group harmony, cooperation, conflictfreeness, collectively referred to as 'harmony', and its sustaining is considered to be an important task for individuals, which even includes the restraining of their own emotions and suppressing their own interests. East Asian Confucianism emphasises precisely these values: collectivism, harmony, respect for hierarchy, loyalty, care, suppression of individual interest and cooperation. Is it possible to trace a common origin to the similar organisation of these societies, formulated by a common set of values, Confucianism, which still strongly determines the world view of these countries? There is a theory that the difference between collectivism, which is mainly 'Eastern' (Asian) and the more 'Western' individualism, is rooted in the diversity of agricultural production, primarily under the conditions of rice production (the difference between 'rice culture' and 'wheat culture'). In East Asia, basic food grain, rice, is produced by irrigation, flood management, which requires organised, managed, disciplined teamwork (construction and maintenance of dams and canals, shared and simultaneous work on planting, flooding, etc.) and a high degree of cooperation from group members. And working together requires a leader who everyone obeys and who is responsible for the community as a whole. Individuals experience that they can only achieve their goal, a good harvest, by working together, and that the common goal is in the interest of them all. In contrast, wheat (and rye, barley, oats, which are the most common cereals in Europe) do not need to be flooded or irrigated, and the different producers do not have to coordinate their work processes, which 
means that there is no need for teamwork in production. Farmers could cultivate their land individually. Rice cultivation spread to the Japanese islands during the period of the third-second centuries BCE, became a major agricultural activity and had a decisive influence on the community organisation of the Japanese people. The system of Japanese community organisation thus established has become the model for the functioning of society as a whole (not only agricultural production), and in fact still defines the social organisation and collectivism of the Japanese.

At the same time, measured by East Asian standards, Japanese society is 'more individualistic' than the surrounding cultures, the reason for which is rooted in history: in the Samurai tradition. The independent small landowners, hereditary private ownership of the land, the personal nature of feudal relations (overlords and vassals), and individual combat capabilities all reinforced the importance of the individual in an otherwise truly collectivist society. The traditional Japanese extended family was not a large extended family, but only a paternal descent hierarchical family with a father-to-son inheritance and wealth. In other Asian societies, loyalty to a group was more a 'birth right' (as defined by the family or the local community), whereas in Japan it was often a matter of choice (choice fidelity, adoption in families), which in today's Japanese society also explains the importance of the loyalty shown (or expected) for the (chosen) workplace. The Japanese society is also considered 'masculine', not only because the roles of men and women are still sharply distinguished, but because traditionally considered values of masculinity are of primary importance: competition, performance, workmanship, success are the main motivating factors, with 'conditioning' beginning in infancy and lasting a lifetime. However, coupled with Japanese collectivism, this does not mean individual competition, but competition between groups, which in fact puts a greater burden on individuals, because if one member of a group falls behind because of their inferior performance, that member is not confronted with their own failure (as in Western societies) but with the failure of their entire group. And the fact that they failed because of them is a great shame that an individual can wash off themselves and their group by committing suicide according to the old system of values. Japan is also called 'shame society' (as opposed to the 'sin-oriented' views of western culture), which means that society does not judge individuals' actions by general moral norms, but by fulfilling its obligation to its group properly and, if that does not happen, they bring shame onto the entire group. So, the individual does everything they can to prevent unsuccessfulness due to them, often much more than they would for their own good (this is the basis of the notorious Japanese "workaholism" and unhealthy overtime work).

The use of collective praise and punishment is a very effective motivation from an early age. This is accompanied by the need for excellence and perfection 
in Japan every day (cleanliness, packaging, behaviour). In a hierarchical society, everyone performs a function appropriate to their position, with responsibilities in terms of behaviour, etiquette and even language.

Japan's individual civilisation has built a strong sense of unity within the population, a sense of a 'homogeneous society' (in to some opinions, this is only an illusion), according to which Japan is an ethnically, linguistically, culturally, globally unified country with less inequalities in society, wealth, education and lifestyle, and where societal discipline is very high, precisely because of shared values and homogeneity. It is especially significant that Japan is one of the world's most secure countries with a very low crime rate. Reasons for this include not only the values (social exclusion of the offender) of a homogeneous, disciplined collectivist society, harsh punishments and a very strict ban on arms (i.e. crime prevention and fear of retaliation), but also the low level of unemployment, poverty and drug abuse (i.e. social factors contributing to crime).

\section{History}

Despite the external adoptions, the individual development of Japan has always taken a different direction from that of the continent, facilitated by the cyclically recurring phenomenon of Japanese history: periods of isolation. Japan's history shows a peculiar mixture of continuity and change with the cyclical alternation of opening-related adoptions and the internal development of the periods of isolation. The periodisation of its history does not fully correspond to the periods used in European historiography.

\section{Prehistory}

Jōmon period (13000-300 BCE):

The Japanese islands are practically made up of a mountain chain that rose up along a fault line, which was connected to the Asian continent during the Ice Age. The earliest findings of human presence are approx. 130,000 years old. There are finds proving the existence of prehistoric and Palaeolithic cultures from 32,000 years ago. Today's Japanese archipelago was formed 13,000 years ago as a result of the warming following the last Ice Age. Then, in the Holocene period, a larger, more sophisticated, hunter-gatherer society emerged. The Jōmon culture got its name from its distinctive braid pattern decoration on clay pots. The people of the Jōmon period (from the fourteenth millennium BCE to the beginning of the third century BCE) made the world's first earthenware and clay figures (Figure 15). The uncovered settlements have the characteristics of a semi-settled Mesolithic - or, in some opinion, Neolithic - lifestyle. Stone tools, dating back to this period, are the world's first polished stone tools. Based on all of this, there 
is an opinion that the Japanese civilisation, with the establishment of a settled lifestyle, use of advanced tools and the very first clay pots, preceded the emergence of the Middle Eastern civilisation.

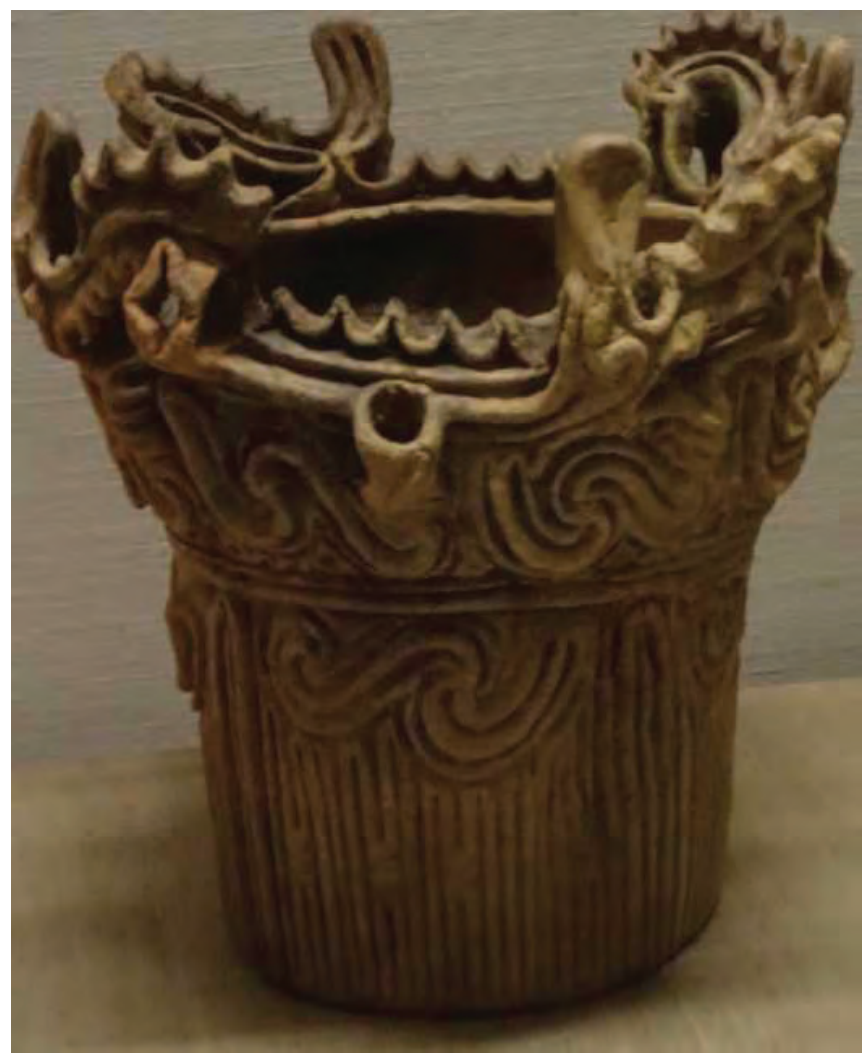

Figure 15: Ceramics from the Jōmon period Source: Photograph by MÁRIA ILDIKÓ FARKAS

Whether this population - or populations - are the ancestors of today's Japanese people, or whether they are related to the Ainu living on the islands (who have been recognised by the Japanese state as 'indigenous people' from of 2008, with a population of only 20,000 in Hokkaido), are issues that are still being debated. Scientists disagree about the origin of the Japanese people, and these questions are still fundamental to Japanese prehistory research. According to some, the first inhabitants of the Japanese archipelago, including probably the ancestors of today's Ainu, came from North Asia and East Asia to this area through the then existing earth bridges, approx. 35,000 years ago. Other research suggests that some ethnic groups also came to this area by boat from South-East Asia during the great migration period in the Pacific. According to the most 
widely accepted opinion, the Japanese people were formed by a mixture of ethnic groups coming from several directions.

Yayoi period (300 BCE - $300 \mathrm{CE}$ ):

During this period, a new type of man came from the continent to the islands and the modern Japanese people began to form as a result of mixing with the Jomon period population. Owing to the rice cultivation and irrigation techniques from Asia and the knowledge of metalworking, we can now speak of an established farming society. This agricultural society began to expand, its internal structure became more and more complex, and as a result of regional organisation territorial units were formed under the leadership of powerful landowner families (clan, tribe). The heads of the local communities were buried in huge burial mounds (kofun). Wars and emerging alliances opened the way for larger and more organised units.

Heritage: rice cultivation, metalworking, strong continental influence, migration, new types of people on the Japanese islands, the formation of today's Japanese nation.

\section{Ancient history}

Yamato period (300-538):

The first state formation was established in the Japanese Islands during the third and fourth centuries, a tribal-clan organisation based on the alliance of the strongest clans, led by the most powerful tribe, the Yamato clan. The tribes (ujis), as warrior aristocracies (Figure 16), owned their own territories, cultivated by the working and tax paying common people. The heads of the clans held ranks in the court of the great king (ōkimi). Due to the continental influence, strong parallels can be seen with the culture of the Korean Peninsula (tombs, costumes, architecture, spread of equestrian combat tactics, weapons).

Heritage: armed aristocracy, hereditary private ownership of lands, sacred nature of the ruler, clan system. 


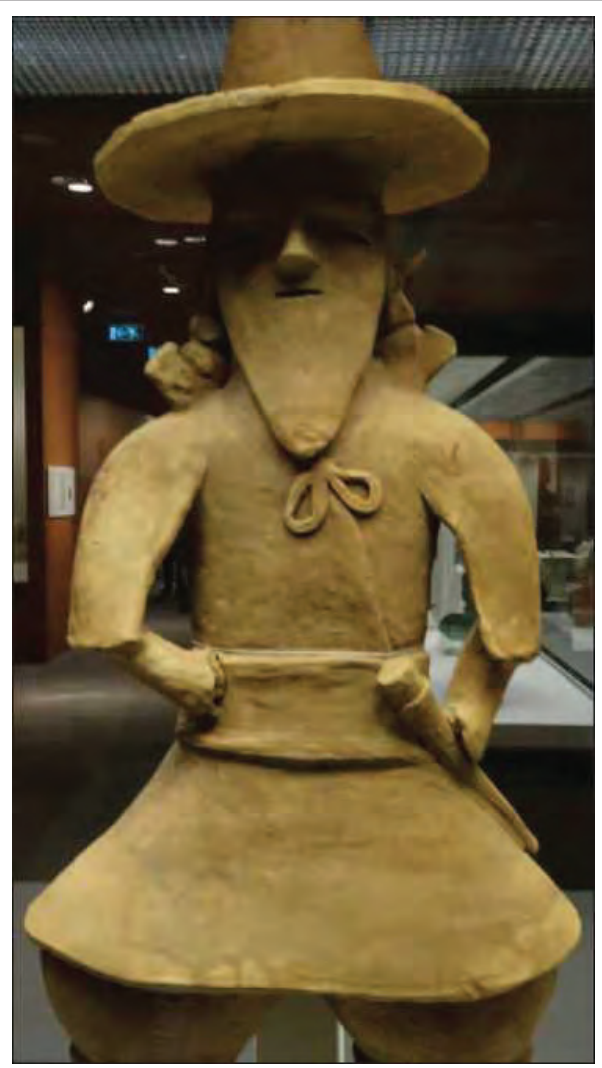

Figure 16: Terracotta statue (haniwa) showing the contemporary warrior costume Source: Photograph by MÁRIA ILDIKÓ FARKAS

Asuka period (538-710):

The emerging state made contact with the continent and became acquainted with the power centre of its surroundings, the even then millennia old Chinese Empire, whose culture, civilisation, and well-organised state served as a model for the Kingdom of Yamato (Figure 17).

During the seventh century, this relatively loose state alliance, the Kingdom of Yamato, was transformed into a centralised, strictly organised state on the Chinese model. New state offices were created, they introduced the concept of the emperor as the absolute ruler, the system of state-owned lands instead of private property, a new tax system, and they established court ranks. The founders and supporters of the reform (members of the Imperial House and some of the more powerful clans) felt it important to create a strong centralised state, partly to end internal power struggles and partly because of external threats from China and the Korean Peninsula. Owing to Korean and Chinese relations, every element 
of continental culture appeared in Japan: Buddhism, Confucianism, Tao, Chinese writing system, sciences (astronomy, medicine, and architecture).

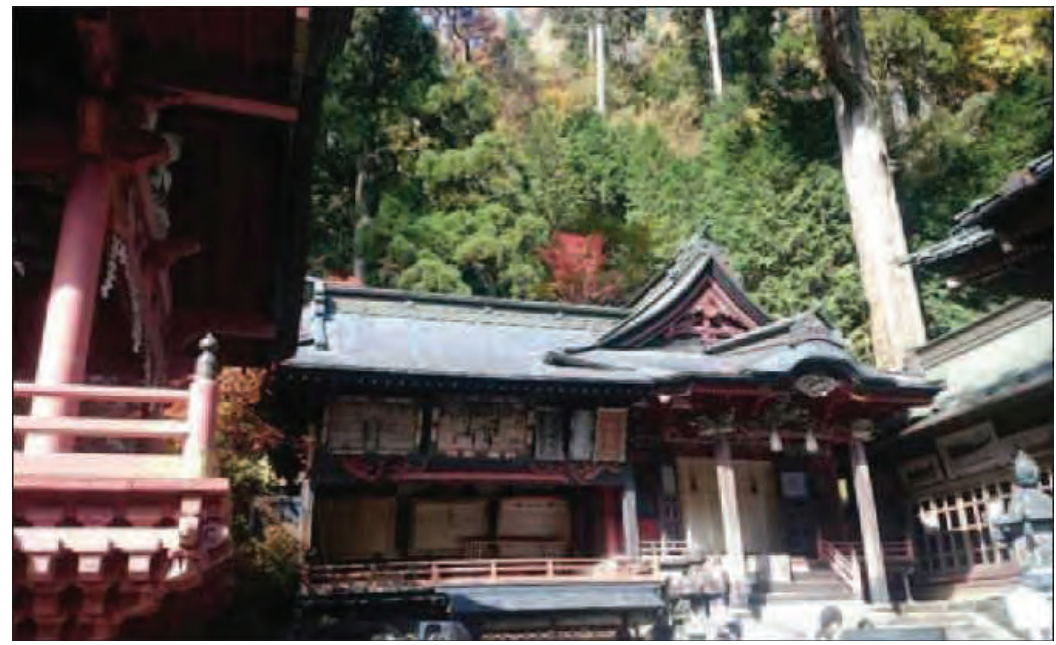

Figure 17: The Haruna Shrine, founded in 586

Source: Photograph by ANDREA PóR

Heritage: large burial mounds (kofun), adoption of elements of Chinese civilisation, close relationship with the states of the Korean Peninsula and with China, the influence of continental culture.

Nara period (710-794):

The eighth century legal collections (Ritsuryō) defined the structure of the new state and regulated its operation. According to these, the ruler, then called the 'heavenly emperor' (tennō) based on the Chinese example, ruled over the whole territory and the people of the country with absolute power, like a god. $\mathrm{He}$ exercised his power through the law, through institutions and appointed officials, and all land became his property as state land (thereby eliminating private property, as in China). The Nara period was a period of transposition and Chinese culture in Japan (Figure 18). This system was thus the adoption of a foreign pattern: the Chinese Empire, as the region's most powerful power, was counted as an example in its political structure, ideology (Confucianism, Buddhism), culture (Chinese writing system), art, and even fashion. During this period, Buddhism, following the continental pattern, also developed into a highly advanced theological and philosophical trend in Japan.

Heritage: Nara Buddhism 


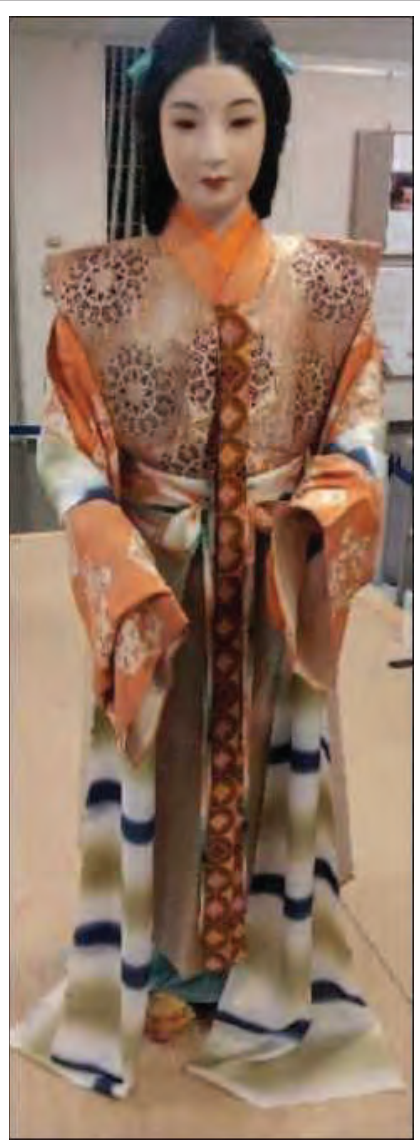

Figure 18: A woman's dress from the Nara period Source: Photograph by ANDREA PÓR

Heian period (794-1185):

The Ritsuryo State (a state structure based on the Chinese-type legal system) was not rooted in Japanese development of the time, and therefore there was also nothing that would have really sustained the sense of foreign threat at the time it was introduced, and as a result, the centralised monarchy remained only an ideal in Japan. Inheritance, private ownership of land and the clan principle did not disappear, and sooner or later it guided the movement of society. With hereditary titles and court ranks, the lands also became privately owned, thus creating a court aristocracy. In order to increase tax revenues, the state allowed the formation of tax paying private estates. Estates, such as wealth and power, were transferred from the central government to large landowners in the countryside. With the decline of state lands - and the taxes coming from them - 
the law enforcement power of the central power was increasingly weakened, and by the tenth century the central army had virtually disappeared, therefore the organisation of defence and law enforcement began in the countryside, i.e. they began to arm themselves. Some smallholders armed themselves, and some larger landowners hired armed men, thus creating an armed warrior class, the Samurai. By the end of the tenth century, power was based on private ownership, and the various classes of landowners were linked by a complex system of dependence, most characterised by a feudal hierarchy and the formation of feudal relations.

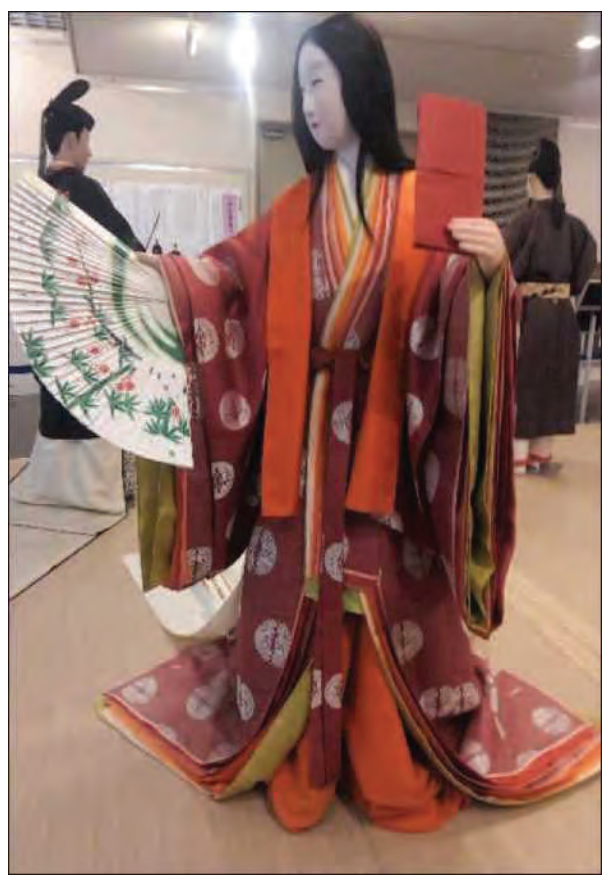

Figure 19: A woman's dress from the Heian period

Source: Photograph by ANDREA PóR

With the weakening of the Chinese Empire, interest in the culture of the continent diminished over the course of the ninth century, and Japan did not react to changes in East Asia - the emergence of new states on the Korean Peninsula, the emergence of a new Chinese Empire -, did not establish official relationships or deal with the continent until the second half of the twelfth century. This provided an opportunity for the birth and development of the individual Japanese culture. During the Heian period, the dominance of the Chinese model in all aspects of state life gradually disappeared, national culture emerged and special 
genres of Japanese language and Japanese writing reflecting the Japanese taste appeared (Figures 19-20).

The Heian period can be considered the epoch of the emergence and one of the highest standards of representation of Japanese national culture.

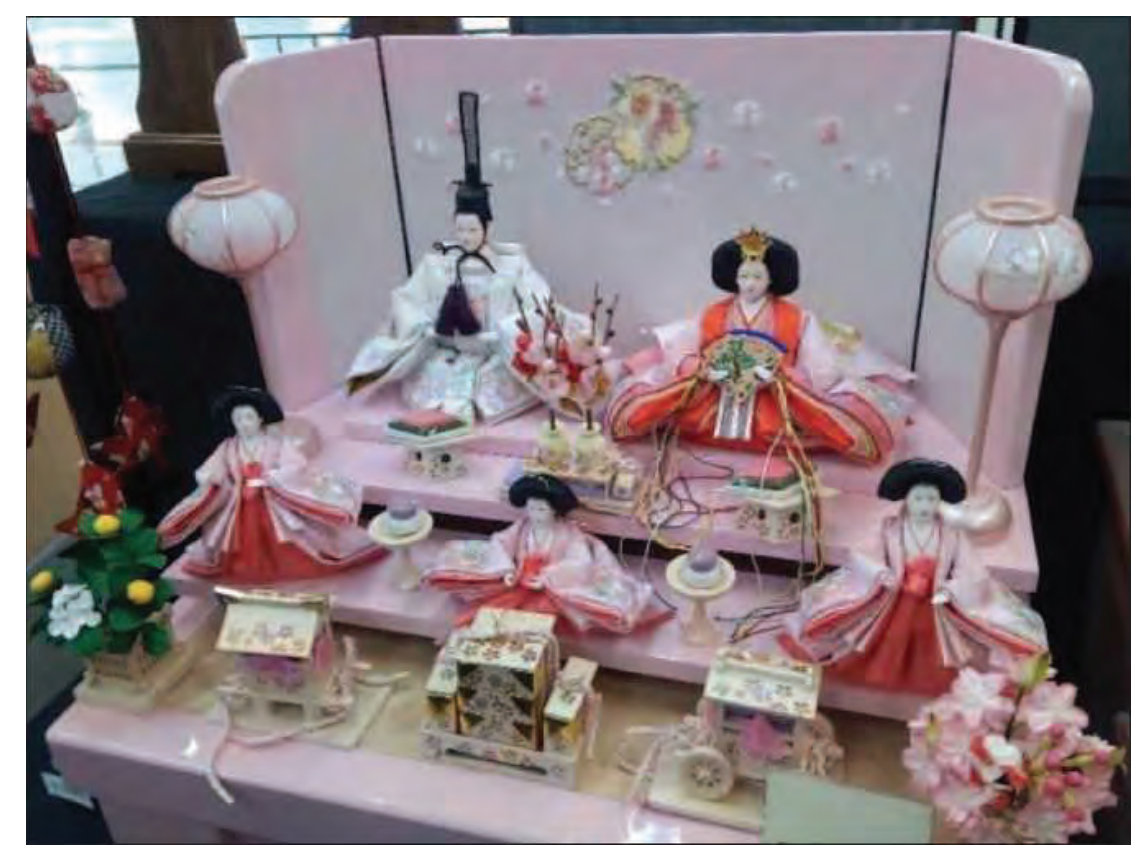

Figure 20: Dolls depicting the emperor, the empress and three ladies-in-waiting in Heian period costume for Hinamatsuri (Doll's Day)

Source: Photograph by ANDREA PÓR

During the ninth and eleventh centuries, the situations in the provinces became increasingly turbulent. The central power was less and less able to play its law enforcement role, and large estates, temples, and provincial offices were increasingly relying on the emerging armed forces for self-defence and law enforcement. Soldiering clearly became the task of the rural elite warrior, samurai or bushi (Figure 21). This process then led to the end of the twelfth century, when the Samurai, under the leadership of a distinguished family (Minamoto), formed their own 'government' and took the political power out of the hands of the court aristocracy.

Heritage: Chinese influence, then Japanisation - birth of national culture, great period of national culture, the emergence of feudal relations, the establishment of the samurai. 


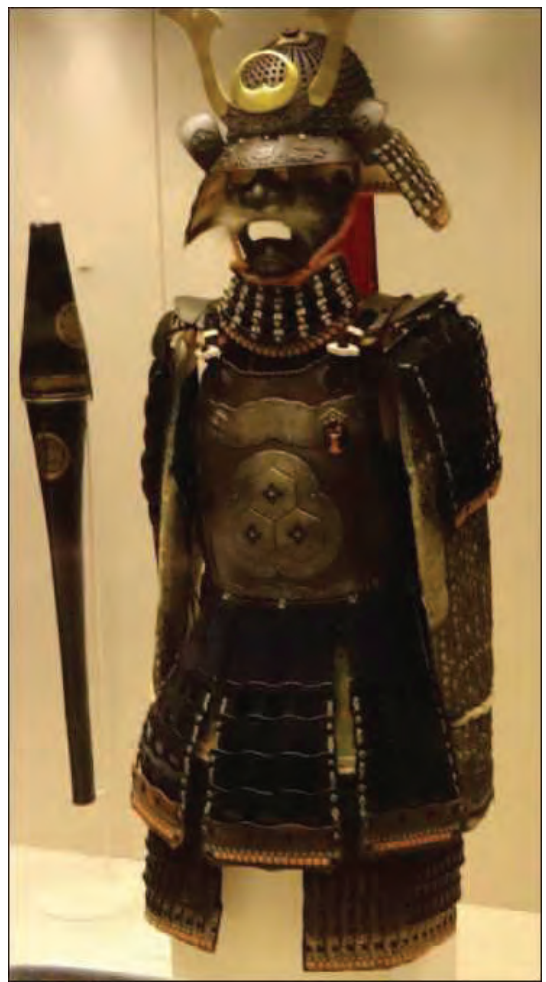

Figure 21: Samurai costume

Source: Photograph by MÁRIA ILDIKÓ FARKAS

\section{Middle Ages}

Kamakura period (1185-1333):

In the Kamakura period, the shoggun, the supreme overlord of the Samurai, with the (militarily forced) authorisation by the emperor, built a nationwide executive and control system with its headquarters in Kamakura. The basis of his power was land ownership and the feudal hierarchy built upon it, in which personal loyalty linked the overlord and the vassal. With the institutions - the Shōgun State Council, the treasury, the provincial patron (actually the shōgun governor of the province) and the shoggun administrator assigned to the private estates(!) - he was able to manage and control all provinces, private estates, the land owners, the samurai, the court noblemen and the imperial court. The emperor and the supremacy of court aristocracy became nominal, and their main activity remained the practice of the arts. The Bushi empire prevailed in Japan up until 1868. The appearance of the class of warriors not only brought about a change in the political structure, but also a change in artistic taste, the emergence of new 
trends in philosophy and religion (zen) (Figure 22), and the formation of the new forms of social organisation (the so-called ie, the Bushi family model and the feudal system).

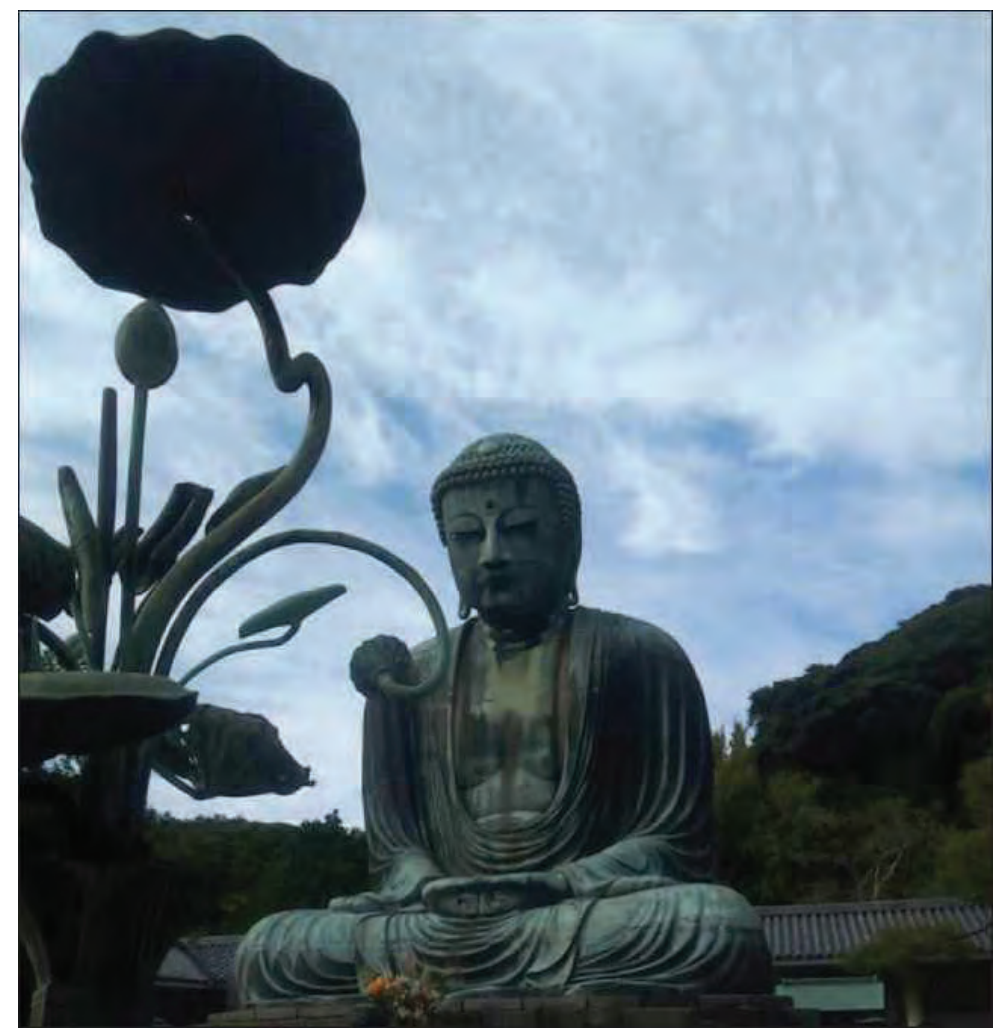

Figure 22: The Great Buddha of Kamakura Source: Photograph by ANDREA PÓR

The Mongol attacks on Japan $(1274,1281)$ were repressed by the Japanese (with the help of the 'divine wind', the kamikaze), but the many years of unprofitable war preparedness put the Samurai into financial difficulty, thus weakening loyalty to the central power and lords began to become independent of the shōgun, which led to the fall of the Kamakura military government (bakufu) in 1333.

Heritage: samurai, shōgun (military government), Japanese feudalism, ie society, Zen Buddhism. 
Muromachi period (1333-1573):

The attempt of the imperial court to regain actual power failed (13331336) and the domination of the samurai continued, but the Ashikaga family receiving the shōgun title was unable to bring the entire country under its control, therefore the power of the bakufu in Muromachi was limited to the central provinces, but that also weakened over time. From the fifteenth century onwards, more provincial unrest and local warfare erupted, and the central power slowly lost its management and control power. During the almost constant warfare in the provinces, a lord eventually became the sole ruler of the area, and the samurai in the province became his vassals. The lords of the area were independent of the shōgun and ruled entire provinces as kings (daimyo). Part of the period is also called the 'warring states period' (1467-1560), implying that the independent estates thus created were in a constant struggle for territory and often there was a struggle for power within the provinces also. By the first third of the sixteenth century about 250 independent provinces had emerged, each with its own ruler. The fifteenth-sixteenth centuries were the 'classical' period of the samurai. However, the period of fragmentation did not only mean warfare for the country. In addition to commercial articles, new knowledge and cultural flows came from the continent. Agricultural productivity increased, and individual products from different areas changed hands in steady markets - in the emerging cities - through a growing number of merchants. Larger cities were formed around the central castle of the provincial rulers in particular, with a large population of craftsmen and merchants, as a significant independent class. In the countryside, which was forced to become independent - but left to pay its taxes - rural communities began to form, which included the lives of peasants in closed, hierarchical and self-governing units.

At that time (1543), the first Europeans (first Portuguese merchants and Jesuit missionaries, then Spanish and Dutch) arrived in Japan, and although the rifles and tobacco they brought soon became established, their effects could not be lasting and significant because, after several decades of presence, the foreigners were expelled from the country, along with the Christianity they spread.

Heritage: feudalism, samurai warfare, cultural flourishing, castles, castle towns, merchants, urban culture, village communities, Europeans and Christianity in Japan.

Unification of the country (1573-1600):

The time of fragmentation was inevitably followed by a period of unification. By the beginning of the seventeenth century, the three great leaders had succeeded in uniting the country within fifty years and, the last unifier of the 
country, Tokugawa Ieyasu and his successors, the Tokugawa Shōguns established the most solid power structure in Japanese history, which stood for two and a half centuries (Figure 23).

Heritage: moving from the conditions of the middle ages into those of the early modern age, organisation of a militarily, administratively, economically and politically united state.

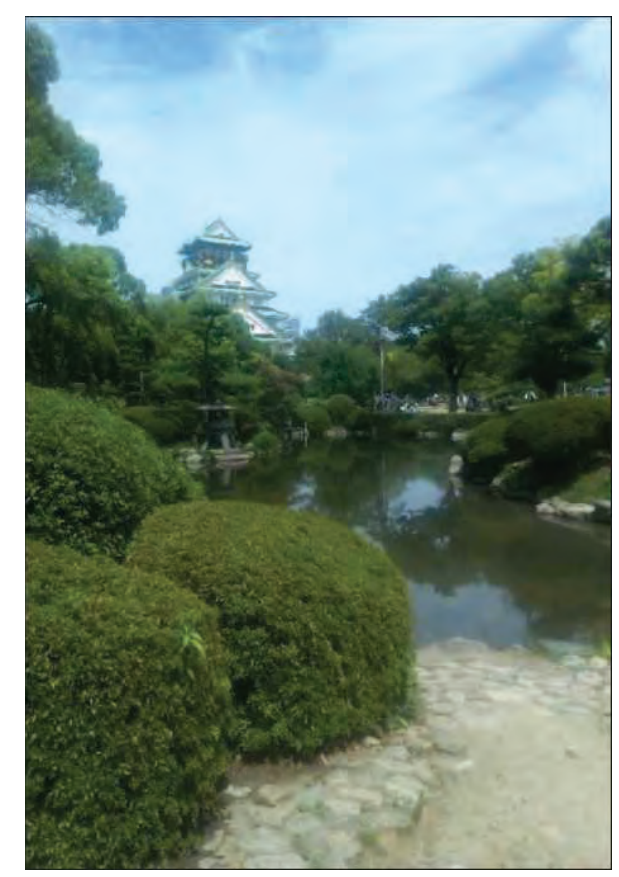

Figure 23: The Osaka castle and garden originally built in the sixteenth century Source: Photograph by ANDREA PÓR

\section{Early Modern Period}

Edo period (1603-1867):

The Tokugawa (or Edo) period (1600-1868) was the most peaceful period in Japanese history, with the completion of unification after medieval anarchy and the gradual exclusion of the outside world (Spanish, Portuguese missionaries and merchants) there was an opportunity for peaceful development without external influences.

The Tokugawa ruled the country from the centre of their estates (Edo, today's Tokyo), with their stable power based on their vast private estates (military force) and the vassal system with land redistributed on the basis of loyalty, in which the lords were personally dependent on the shoggun (Figure 24). 
Stability was also served by a hierarchical, strictly regulated social system, with classes also separated by place of residence, strongly emphasised by the Neo-Confucian ideology, as well as the high-level institutional system and administration. The task of the samurai in peacetime, could not be fighting, but they still had a duty to practice their fighting skills and to continue their cultural and artistic training, which, along with the development of the townsmen, resulted in a high level of education. In the long peacetime, the samurai class virtually became civil officials.

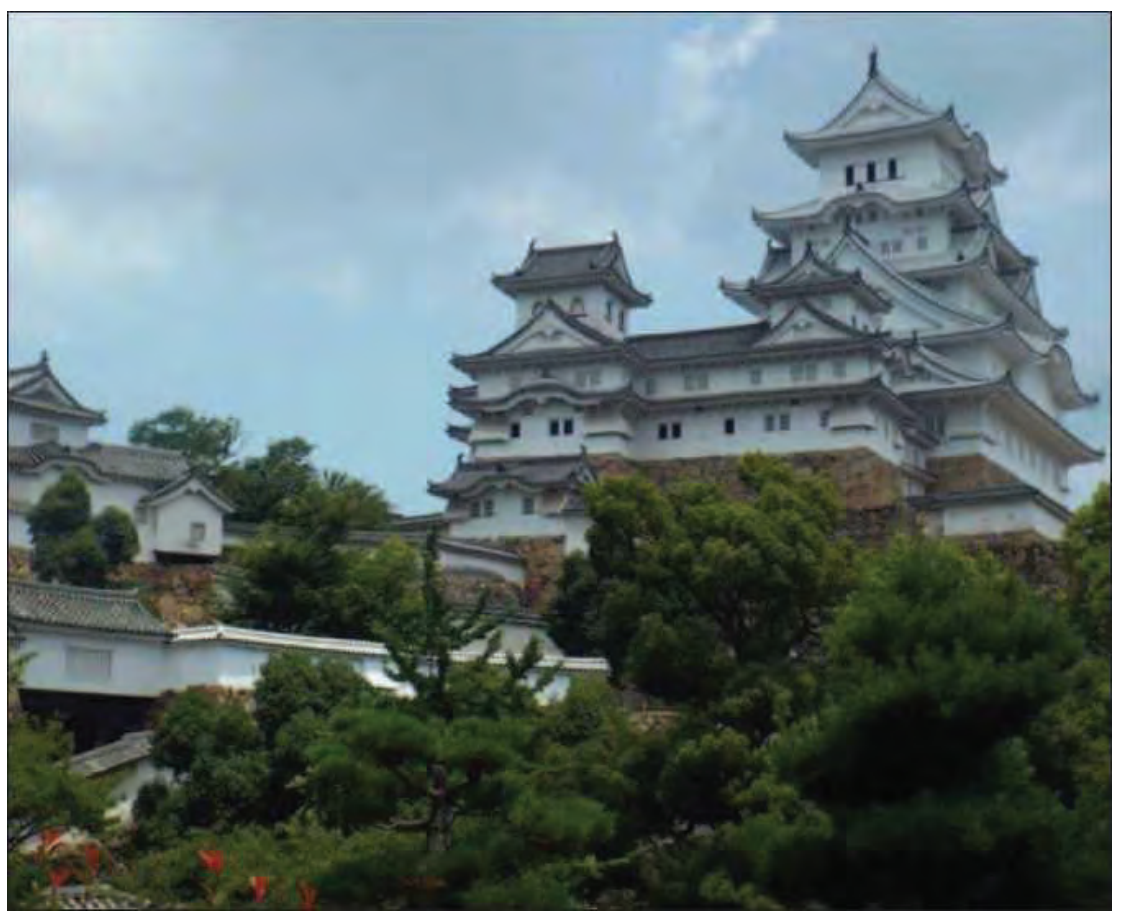

Figure 24: Castle built at the beginning of the Edo period in Himeji Source: Photograph by ANDREA PóR

The compulsory alternate residence of the court nobility (and their household and companions) in Edo gave a strong impetus to urban development, which was also supported by the development of trade and the moving of the samurai to cities (Figure 25). While the vast majority of the thirty million people (approx. 85 percent) were basically part of an agricultural society, the autonomy of the villages, the wealthy farming class, and the rent system provided an almost unparalleled rise in living standards in Asia, and produced a large surplus of labour. Existing sophisticated financial management (trading houses of city merchants acting almost as banks) had also gone beyond the framework of 
agrarian economy. People living in cities created their own genres of art (theatre, puppet theatre, urban popular literature, famous Japanese woodblock prints), which also became part of the national cultural tradition.

Isolation did not only mean disadvantage to Japan (a lack of technical progress), it also resulted in a high level of undisturbed internal development that created the financial and material conditions for transformation, while creating a homogeneous national culture with strong traditions. A strictly controlled hierarchical society, a strong central state organisation, an agricultural economy, advanced financial management, significant urbanisation, an independent urban culture, a high level of legal understanding, statutory regulation and education. At the beginning of the nineteenth century, the literacy of the Japanese population was at the same level as the most advanced areas of Europe at that time. In the midst of intellectual development and the emergence of new ideological and political concepts, the emergence of Japanese traditions (especially Shintō) helped to define Japanese cultural identity. Together with economic development, this laid the foundations for modern Japan.

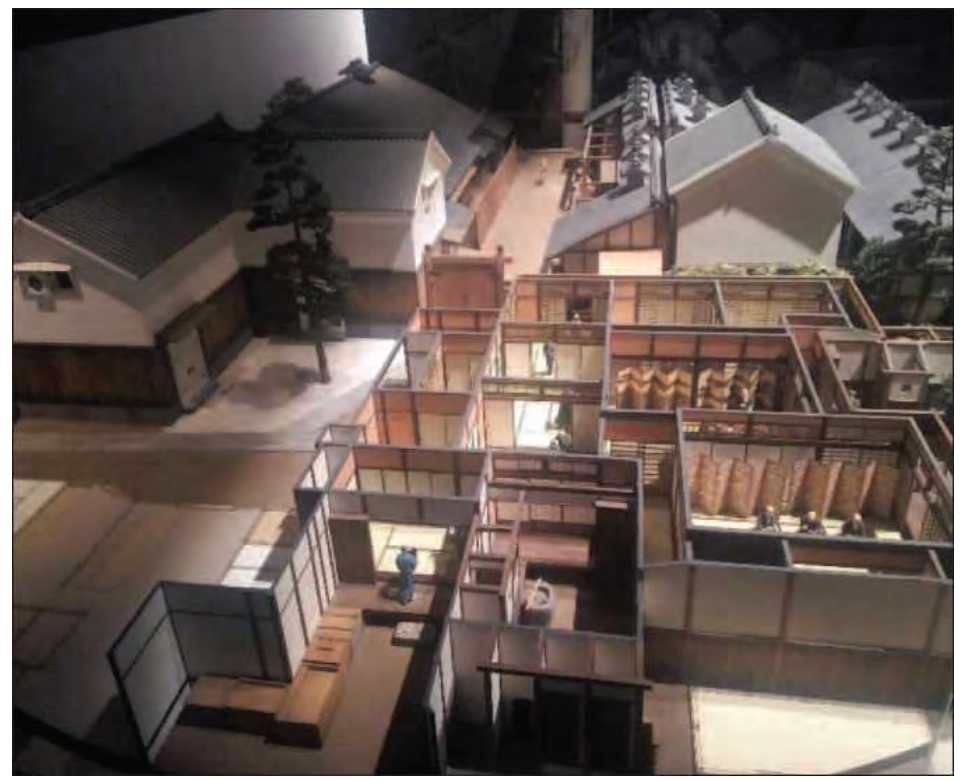

Figure 25: Interior of a house from the Edo period Source: Photograph by ANDREA PóR

By the nineteenth century, however, internal problems and external threats threatened the stability of the Tokugawa system. The financial situation started to worsen due to natural disasters, a series of bad harvests and other problems, causing general discontent. Social order also began to disintegrate, besides the 
impoverishment of samurai and the enrichment of merchants, money and wealth stratification also penetrated into traditional villages.

In the mid-nineteenth century, the disadvantage of isolation was apparent: Japan was lagging behind in technical development. When the American, English, French and Russian ships calling for the opening of the country appeared on the Japanese coasts in the 1850s, the West's technical superiority became apparent, and Japan could not go against them. In 1853, the US forced Japan to open the country, who were then followed by the great European powers. The discontent with the Tokugawa intensified after the appearance of foreigners and a strong anti-Tokugawa coalition was established coupled with the idea of an emperor-centred state in Shintō tradition, whose members recognised the dominance of the West and acknowledged the need for opening. After approximately one and a half decades of internal power struggles the samurai group, which gained power in 1868, declared a new era of openness and modernisation through its 'restoration of imperial power' programme (i.e. the abolition of military rule over the emperor that had existed for centuries). Meiji ('Enlightened Governance').

Heritage: foundations of Modern Japan - homogenisation of elements of Japanese culture, Japanese identity formation. 250 years of peace, peaceful internal development free from outside influences. Proto-industrialisation, economic development.

\section{Modern period}

Meiji period (1868-1912):

In 1868, a group of court noblemen and anti-Tokugawa samurai, with imperial support as their legitimacy, announced the transformation the country's economic and state structure in a western pattern. The primary purpose of the reforms was to avoid becoming a colony or semi-colony, to remain independent, and to strengthen the country to become an equal power with the West. After the 'opening' of Japan, it began a tense, controlled modernisation to eliminate its technical backlog and to build a modern state that occupies the same position in the world as all other powers at that time.

The new government enacted fundamental reforms in all areas of life, with the help of foreign experts and consultants in the early years. Social restrictions and privileges were abolished, paving the way for the transformation of society. The feudal provincial system was abolished, and a modern administrative system was introduced, and, with the abolition of large estates, an extensive land reform was implemented. They also organised a modern public education system, announcing general compulsory education, with the establishment of secondary schools and universities. The introduction of general military conscription served 
as the basis for setting up a new, modern, regular state army. The first measures included the construction and development of infrastructure: the establishment of a postal and telegraph network, the construction of railways and ports, and the establishment of the first industrial facilities (mines, textile factories). In 1871, the national currency (yen) was unified and the Japanese banking system was established.

The Japanese Industrial Revolution began in the 1860s with the mechanisation of the textile industry and increased productivity. The period from 1868 to 1884 laid the foundations for industrialisation, and the next period, from 1884 to the end of the First World War, became a period of rapid economic growth. After the surge of the light industry (1887-1896), the main objective was to establish and develop the heavy industry (1897-1906). The first iron and steel works were founded in 1890, when shipbuilding, including mechanical engineering, and mining began. The first $30 \mathrm{~km}$ line between Tokyo and Yokohama opened in 1872 and was followed by the construction of 7,800 km of railways by 1905 .

The development was mainly through public investment, i.e. most of the industries were set up as state-owned enterprises (light industry, railways, mines, shipbuilding, heavy industry), which were privatised after a decade, and therefore industrialisation was largely realised by the private sector. However, the government continued to play an active role in economic development and directly supported Japanese business and industry in the emerging private economy. The Edo period provided a good foundation for economic development, with a large, educated population, an agricultural surplus, a monetarised economy, a financially strong trading class, and an educated samurai class performing managerial and organisational work.

At the beginning of the Meiji period, there was intense Westernisation, Japan trying to adopt everything from the West, including ideas, cultural currents, and artistic styles. The advanced knowledge of the West fascinated the Japanese, and they wanted to learn everything: delegations travelled to Europe and America to study the relations, laws, economies, and political life of developed countries. Foreign experts were invited to Japan to conduct the transformation and Japanese students flocked to European universities. The knowledge accumulated in this way was put into practice immediately. However, from the 1880s, the issue of Japanese identity and the importance of traditional values came gradually to the foreground. Based on Confucian ethics, important documents and guiding declarations of the period named traditional Japanese virtues as the most important principles: subject loyalty, filial piety, striving for harmony, modest and moderate conduct, diligent study and work, living morally, respect for the law, self-sacrificing love for the homeland. This was accompanied by the elevation of the Japanese national mythology and emperor cult to an official ideology, defining 
Japan's unique identity, while retaining its national character, spirituality, cultural traditions and heritage.

The transformation of the political system accelerated in the 1880s. The constitution, largely based on the Prussian model (1889), stated that the emperor was the supreme power, but at the same time created a parliamentary system: the responsibilities of the bicameral parliament, the cabinet, ministers and the prime minister. The parties were formed in the 1880s, and in 1890 the first election was held in Japan. On the basis of limited voting rights (1.6 percent of the total population could vote), however, for the first time in Japan (and virtually in the whole of Asia for the first time), parliament could be convened on the basis of the principle of popular representation. The parties underwent several transformations, renamed themselves, but represented certain interests, thus influencing political development with their voters. True, they were closely associated with some economic interest groups from the outset, and this interweaving of politics and business (and corruption) became a feature of Japanese public life. However, despite all its faults, the Japanese parliamentary system became operational in less than a decade, having completed a journey that took centuries in other countries.

By the turn of the century, the establishment of the modern state structure and economy was complete, and this was where the golden age of modern Japanese history began and continued until the end of the First World War: with continued economic development, prosperity and victories.

However, the country's lack of raw materials caused difficulties. Japan was self-sufficient for centuries, but for the creation and development of modern industry it became heavily dependent on foreign trade. At the beginning of the Meiji period, it could only export agricultural products (tea, rice, tobacco, silk) in limited quantities, thus, the value of imports always exceeded that of exports. It was only after 1890 that the export of finished products began, but the shortage of raw materials remained a serious problem, the solution for which was increasingly seen in expansion and external conquest. The economic question, the equilibrium of the foreign trade balance, became a question of national security, which was partly solved by peaceful trade and partly by land acquisitions, i.e. by military means. The closest solution seemed to be China, with its vast area, raw materials, minerals, and outlets. This led to the Sino-Japanese War of 1894-1895, in which Japan had a seemingly smooth victory in ten months, and in addition to recognising its estates (Taiwan, Okinawa) and its interest (Korea) with China, it also received a huge indemnity and Chinese territories. Japan defeated the former civilisation centre and, in its place, became the great power of Asia. Japan was already, by international standards, clearly considered a conqueror and not one to be conquered. The island country's distant goal was to replace China by estab- 
lishing a Japan-centred East Asian world order, called the Great East Asian New World Order.

However, its expansion on the continent collided with Russian expansion, and this conflict lead to the Russo-Japanese War of 1904-1905, in which Japan was once again victorious. This placed Japan on an equal footing with the Western powers and concluded a series of equal treaties with them. The main area of interest for Japan was Korea and Manchuria, with the establishment of a protectorate in Korea in 1905 and the annexation of the country in 1910 without any international complications. From then on, Japan regarded itself as the eighth power of the world, which was also published in the contemporary international press. From this time on, European newspapers began to write about the 'yellow peril', stressing that other Asian countries could follow the example of Japan by modernisation and 'self-awakening', which could become a serious threat to the rule of the 'whites'. In Asia, the victory of Japan was welcomed with ambivalent feelings: on the one hand, the victory of Japan was indeed encouraging for Asians, confirming that the West can be defeated, while, at the same time, Japan's conquest was rightly regarded as the same imperialist aggression as of the Western superpowers. Japan already behaved as a colonising power in Asia, and this conduct of modern Japan (1890-1945) and its memory, heavily burden the relationship between Japan and its East Asian neighbours to this day. By the beginning of the twentieth century, Japan had clearly become a Western type modern state, it belonged to the great powers, and Asia considered it to be Western (imperialist).

By the turn of the century, Japanese society had also changed. Society, though remaining hierarchical, opened up and equal education, in principle, ensured equal opportunities for all. Learning (just as it is today) and the education of children played a central role in the life of society, especially that of the middle class, because careers and all later life were dependent on exams (just as it is today). Although the samurai status and practically its entire class ceased to exist, their spirituality and legends (authoritarianism, loyalty, self-sacrifice, heroism) became an integral part of Japanese national consciousness. In spite of western ideas, which mainly affected the lives of intellectuals and upper classes, Japanese society remained fundamentally collectivist. The Japanese family system, which had existed for centuries, continued to exist not only in the countryside and not just among the peasants - the urban population, the former samurai, the economic elite all followed the traditional pattern, and even the newly formed companies were built on the family model. Japanese society itself is based on this pattern, and the state emerged as the highest level of community.

Heritage: rapid modernisation, westernisation, modern nation state, industrialisation, urbanisation. From a feudal system to a modern industrial state, from 
seclusion to catching up with the western powers. Westernisation AND a strong Japanese national identity based on Japanese tradition. Japan as a western power in Asia, nationalism.

Taishō period (1912-1926):

The death of Emperor Meiji in 1912 marked the end of an era. The great transformation was complete, the great generations that had gone through it were extinct, and there were generations living in Japan, who were already born into the new world. Power was held in delicate balance by various elite groups (court officials, civil servants, the army, the fleet, parliamentary parties, economic elites).

The parliamentary system in Japan was barely a few decades old at the time, and for that reason it lacked the 'roots' of centuries-old systems: the broad social embeddedness, stable voting base and background of the parties were not yet established. Although the parliamentary system seemed to work well, the parties had an intellectual circle, an ideology and a consistent political agenda, but did not really have a broad social base and support behind them, making political life virtually an arena of rivalry between elite groups. The various government crises, changes and transformations (no government lasted more than half a year) were inconceivable to the average person and they saw politics, which were increasingly intertwined with economic interests, as being useless, with subsequent serious consequences. The power of the parliament was not yet solid, the power of the emperor was absolute, which, however, could be taken advantage of at any time, not by him, but by the groups acting on his behalf (which did occur).

For the new generations, the western form was natural in political life, in the structure of the state, in the economy, in foreign policy, and even in society. The successes achieved so far were attributed to westernisation, therefore the worshipping of the West was inevitable. The Taishō period, from 1912 to 1926, was referred to as the 'liberal twenties', a period of western-type parliamentary, civil governance. It is true that economic development decreased, slowed down compared to its flourishing during the World War, with bank failures and 'rice riots' also occurring, but these did not yet seem to be a threat to stability. The period saw the appearance of the western lifestyle, style, fashion and feeling in Japan, and the old norms began to loosen. Still, we can say that it was rather superficial because the core values remained intact: family model, hierarchical society, Shintō. All these later reappeared prominently in the life of the society after turning away from the 'West' as a result of the global crisis.

The First World War also provided an opportunity for Japan to further expand its territories in East Asian. He used the war that broke out in Europe for his own purposes and made his own conquests under the pretext of the British 
alliance. Japan attended the Peace Conference ending the World War, on the side of the victors, as one of the five great powers. It could retain his Chinese conquests and unquestionably became the leading power in the Far East.

However, this was not a clear success for the country. The end of the wartime boom (1918) was a major blow to Japanese industry. After the war, Europeans returned to Asian markets, making it difficult for the growing war industry to adapt to the changed circumstances. Japan's modern-day economic development (between 1880 and 1945) was the slowest in the 1920s, and moreover, serious crisis situations emerged on several occasions, even before the global economic crisis. Increasing dependence on foreign markets and commodities was a growing problem for the emerging Japanese industry. All this became a matter of national security, that is, military expansion and land acquisition clearly served the purpose of obtaining raw materials and markets. In the 1920s, however, the international situation based on peaceful negotiations and agreements was not conducive to aggressive foreign policy, and within Japan advocates of peaceful solutions prevailed (for the time being), therefore the Japanese economy was based on open world trade (globalisation), which then collapsed in 1929.

Despite all its success, Japan was not treated as an equal party by the victorious powers, which led to growing anti-westernism in Japanese public opinion. Its former allies, especially the English, followed Japan's growing conquest of the Far East with increasing suspicion and fear, and they no longer viewed them as an ally but as a major rival. In particular, US behaviour became threatening to Japan, making it clear that in the Pacific, Japanese expansion was contrary to US interests, and a number of restrictive measures were introduces against the Japanese (restricting the Japanese fleet, suppressing Japanese interest in China, prohibiting Japanese immigration in the US). Japanese public opinion was not only dissatisfied with the government because of the inadequate management of the internal crisis, but also because it felt that the government did not sufficiently represent Japanese interests against the superpowers. Dissatisfaction with the government was accompanied by frustration from the West and a return to Japanese values, which led to a strengthening of nationalist tendencies.

Heritage: Taishō democracy: new democratic, liberal trends in politics and society AND: the roots of radical nationalism, expansionism and anti-liberalism. 
Shōwa period (1926-1989)

Before 1945:

From 1926 a new era began: the reign of Emperor Shōwa (up until 1989). In 1930, Japan was hit hard by the crisis, foreign markets were lost, banks collapsed, production slumped, and Japan's exports abroad protected domestic markets with high tariffs. In addition to the economic collapse, this also created a crisis of consciousness in the country: disillusionment with the West.

Japanese values, national characteristics, elements of self-development came to the forefront, and western ideas and practices were increasingly rejected. Extreme political ideologies emerged and conquered that uniquely blended Japanese tradition with modern radical, extremist ideas (e.g.: the 'Shōwa restoration' theory, in which they wanted to achieve state socialism by a military dictatorship, and according to which the rich should sacrifice their wealth for the benefit of the public, and the politicians should return power to the emperor). The delicate equilibrium of the twenties was disrupted, and the increasingly powerful army began to fill the gap in power. During the 1930s, military leadership gained control of the civil government and by 1940 established a military dictatorship.

In 1931, Japanese troops launched an offensive in China, initiating a nearly 15-year long battle between China and Japan. In 1932, the Japanese puppet state Manchukuo was established in the occupied territories of Manchuria, which was not recognised by the League of Nations, in fact, it even excluded Japan from its members. In 1936, Japan signed the Anti-Comintern Pact with Germany, which made it part of another federal system, but regardless thereof, it was fighting its own war. In 1937, the Japanese Empire occupied parts of China, launching the Second Sino-Japanese War. Internal politics became increasingly dictatorial: persecution of political opposition, nationalist and militarist propaganda, and a ban on parties (1940). The European War broke out in 1939, in which Japan did not interfere, but as a result of the German successes, in 1940 it became general opinion in Japan that Germany would be victorious, which led to the conclusion of the Tripartite Pact in September 1940.

Japan's strategic goal was to gain naval supremacy in the Pacific, followed by beneficial peace deals with the United States and Great Britain by acquiring strategic raw materials deposits. On 7 December 1941, Japan attacked the US Naval Base at Pearl Harbor and sent a message of war to the United States. Japan expanded continually in the Pacific region and reached the largest expanse of its empire by 1942: controlling most of China, Korea, almost all of South-East Asia (Indochina, Malaysia, Burma, Thailand, the Philippines, Indonesia) and the Pacific archipelago all the way to the coast of Australia. The Americans initiated a counterattack and, during 1943-1944, reoccupied the Japanese territories. In February 1945, the US Air Force began a systematic bombing of Japanese military sites and cities. After the US deployed the atomic bomb against Japan 
and the Soviet Union entered the war against Japan, Japan surrendered unconditionally to the Allies on 15 August. The war in Japan claimed millions of lives and destroyed the country's economy and infrastructure.

Heritage: Militarism, wartime expansion, ultranationalism, war atrocities, kamikaze.

American occupation (1945-1951):

The country was in ruins, the war devastation was greater than in Germany, the industrial districts were completely bombed, and industrial production stopped. The number of war casualties was over two million. During the Second World War, the country lost 26 percent of its national wealth, all its major cities were destroyed, and agriculture did not work due to lack of equipment and manpower. The country was facing famine and the status of its healthcare was catastrophic. However, the imperial speech (14 August 1945) announcing the war defeat contained an important inspiring thought and the programme for the Japanese was set out already among the ruins: 'endure the unbearable'. Surviving, rebuilding, enduring humiliation, American occupation, and changing everything that led the country in the wrong direction.

After the World War, Japan was essentially occupied by the US. Six and a half years of military occupation and guardianship followed, running smoothly without incident. The main goal was Japan's transformation, i.e. to create a country that poses no threat to the US or to world peace and operates according to the principles and practices of Western democracy. The Americans initially expected resistance to reform efforts, but the Japanese enforced the invaders' orders. By this time, the collective purpose of the Japanese people, which had always been able to mobilise society, was to rebuild and recover, and the Americans helped with that. This motivated Japan's willingness to cooperate.

The occupation was aimed at demilitarising and democratising Japan and meant reform and transformation of the same scale as the Meiji period modernisation. Land reform, human rights in the constitution, universal suffrage, limiting the emperor to a symbolic role, administrative decentralisation reform, education transformation, demilitarisation, political purging, secret free elections, parliamentary reform and renunciation of war. Today's democratic Japan was created under this American leadership. The new Constitution, which came into force in 1947, and was written by American occupiers, is still the fundamental law of Japan. Its renowned Article 9 is the only one in the world to contain a provision for the renunciation of war, which, at the time, reflected the goals of the Americans with Japan ('to become a peaceful state') and coincided with the Japanese situation assessment ('no more war'), but after a few years it started 
causing problems ('Is Japan allowed to have a defence force?'), with this problem still persisting today, as Japan has not yet amended its Constitution.

However, in 1948, a change in world politics highlighted the value of Japan's role for the US, which made it take an interest in Japan's economic strengthening. The US partly released Japan's war reparations, and partly helped with reconstruction with financial stabilisation policies and specific aid-opening the US market to Japanese goods, transferring technology, granting loans and providing machinery. On 8 September 1951, 48 states signed a peace treaty with Japan in San Francisco, which recognised Japan's full sovereignty, but withdrew Japan's territorial claims in Asia and recognised Korea's independence. The peace treaty entered into force in 1952 and marked the end of the American occupation. At the same time, Japan was defenceless and in need of US defence. Thus, at the end of the occupation, a bilateral security agreement was concluded between Japan and the United States, under which American bases remained on Japanese territory with troops stationed there. Japan is still the cornerstone of the US military system in East Asia.

Heritage: formation of modern-day Japan, democratisation, demilitarisation, American alliance.

The 1950s - beginning of the 'Japanese miracle':

Japan regained full sovereignty and set about adapting its transformed economy and its entire organisation to its national characteristics. The Korean War between 1950 and 1953 boosted the Japanese economy, Japanese commodities were in demand, and the pre-war heavy industry could be re-launched. State control played an important role in the rebuilding of industry, pushing for the development of key sectors in the first phase of industrialisation, such as steel, shipbuilding, coal mining and the chemical industry. These industries were also supported by tax breaks, well-considered lending, soft government loans, and export incentives. The Japanese economy grew more than 10 percent annually, with GNP growth of 8.6 percent between 1951 and 1955, and 9.1 percent between 1955 and 1960. Japan rapidly increased its exports, the main characteristic of which at that time was its cheapness and not its quality.

In the 1950s, Japan became an independent, sovereign state within the US security system (UN member from 1956), with parliamentary democracy, a booming economy, and a clearly positive national strategy: now by peaceful means (strengthening the economy, increasing foreign trade), but Japan once again wanted to become one of the most advanced states. In this, the government was a worthy partner of a well-disciplined, hard-working Japanese society that was well mobilised for the common cause, which made the achievement of economic success all the more important, as it hoped not only to strengthen the 
country - and, of course, to improve its own living conditions - but also to regain the prestige and favourable image of the country lost in the World War.

The 1960s and 1970s:

At the 1964 Tokyo Olympics, the world marvelled at the rapidly developing country (Figure 26). It was then that it became clear that Japan was to be counted on as an economic power. The competitiveness of Japanese goods on the world market continued to increase with the improving of their quality. In the second half of the sixties, the production and export of cars started off at a tremendous pace and the electronics industry began to boom. Thanks to the export promoting policies and the still stable, low exchange rate of the yen, Japanese products flooded the world. The growth of the Japanese economy exceeded 10 percent annually.

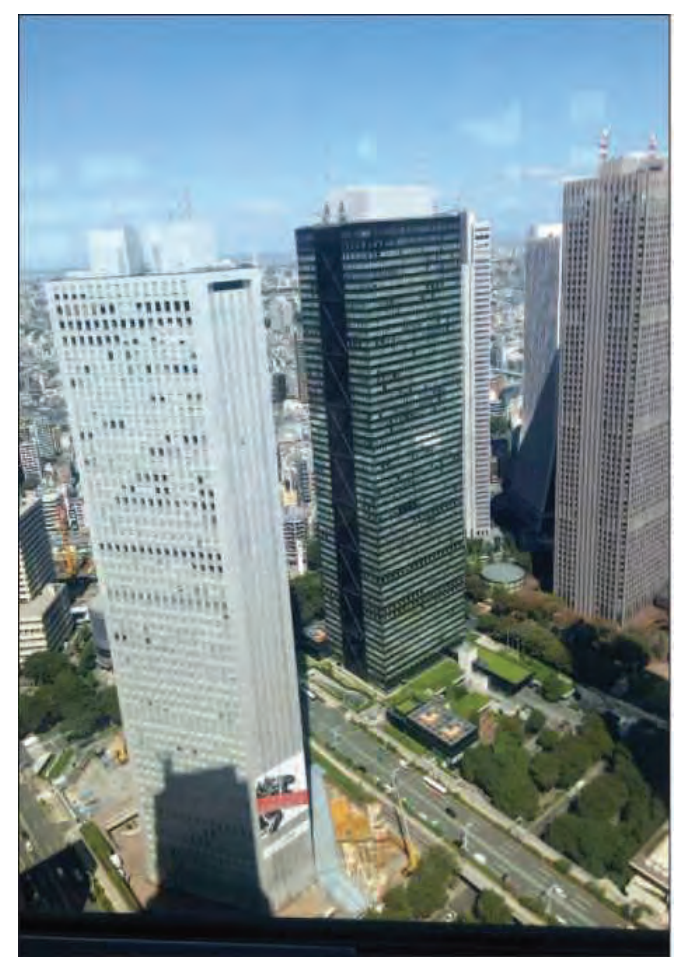

Figure 26: Skyscrapers in Tokyo Source: Photograph by ANDREA PÓR

By 1965, Japan was one of the most advanced industrialised countries, and by 1968, it had become the world's third most advanced market economy, with virtually no mineral resources or energy sources. High economic growth was 
facilitated by the role of the state in increasing, stimulating and managing the economy (providing favourable loans or subsidies, investments that are important for industrial development; export subsidies to increase Japanese exports) and industrial development activities of the Japan National Bank (utilising household savings). It played an important part, that Japan kept its military spending low (under 1 percent, while other countries spent more than 10 percent of GDP on military spending) thanks to its 'peace constitution', and that the thus 'remaining' financial resources could all be spent on industrial development. Most of the profits were reinvested and used in innovation and technological development, which kept the Japanese industry steady and able to use the latest technology. This was the time when the 'Japanese-type' management and employment system was solidified, which, based on collective (Confucian) values - cooperation, workplace harmony, loyalty and paternalism was able to manage and reconcile the interests of employers and employees without conflict, thus ensuring a consistently high level of production. The large number of well-educated, well-trained, diligent and hard-working population also contributed to the success, since after the war there was virtually a social consensus on the importance of economic development as a way to make Japan successful again, and to regain its good reputation and positive international image lost during the war. There is no doubt, however, that the state kept social spending low, meaning no welfare state was established, and although the standard of living of Japanese workers increased with the enrichment of the country, their quality of life (social welfare system, housing quality, infrastructure, leisure, health, pension, working time) was far lower than that of the population of similarly developed countries.

In response to the energy crisis of the 1970s, Japanese industry responded by restructuring: launching industries that are less energy intensive but require a high degree of technical development and expertise: high technology, electronics, computing etc. The special Japanese management system and the employer system, which followed the traditions of Japanese community and family organisation, also played a significant role in the success. From the 1970s onwards, the government treated the improvement of living standards and then the quality of life for the Japanese population as a programme. Strict environmental laws were enacted from the 1970s to offset, halt and reverse serious environmental pollution.

Heritage: economic growth, development, establishment of the post-industrial economy, 'high-tech' industries, Americanisation, unique Japanese culture and lifestyle. 


\section{Japan today}

Japan is now the world's third largest economy, representing 14 percent of the world's GNP. 7 percent of goods traded internationally on the world market come from here. More than 10 percent of all foreign direct investment in the world is owned by the country.

The development of Japan after the Second World War is clearly dominated by elements of Western democracy, not only in the institutional system but also in everyday life. Changes have occurred in dressing and eating habits, housing conditions, and everyday life is also aided with the use of modern tools, and, of course, the forms and means of entertainment have also become 'Westernised'. By the turn of the millennium society had begun to change, with the behavioural habits and the language also changing; nowadays, the traditional framework of the Japanese lifestyle also seems to be changing. Social changes have resulted in the transformation of traditional living conditions, with large families disbursed due to internal migration and urbanisation, and small families taking their place; the ageing of the population is becoming increasingly worrying. Popular culture (fashion, film, entertainment, media, pop culture) became clearly Americanised (Figure 27). Today, Japan is most often described as follows: a modern (or even postmodern), highly developed, high-tech, democratic, pacifist and rich country. In this sense, Japan is part of the Western world.

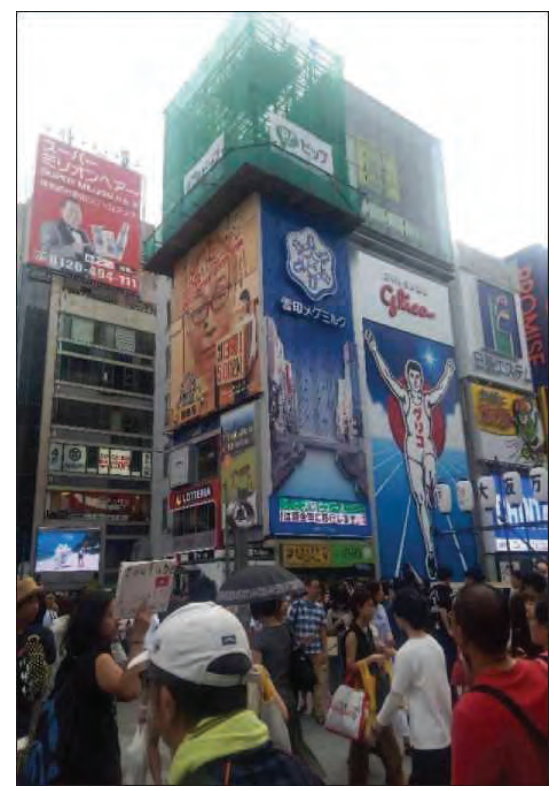

Figure 27: Advertisement in the Dōtonbori district (Osaka) Source: Photograph by ANDREA PÓR 
At the same time, in today's Japan we can see that traditional elements of Japanese culture are still important today, Confucian values (diligence, hard and persistent work, loyalty, respect, responsibility, paternalism) are decisive in work, education and social life (behaviour, etiquette and language use determined by hierarchy). All this continues to show the importance of the Japanese cultural tradition and thus the uniqueness of Japanese culture, the existence of an independent Japanese civilisation (Figure 28).

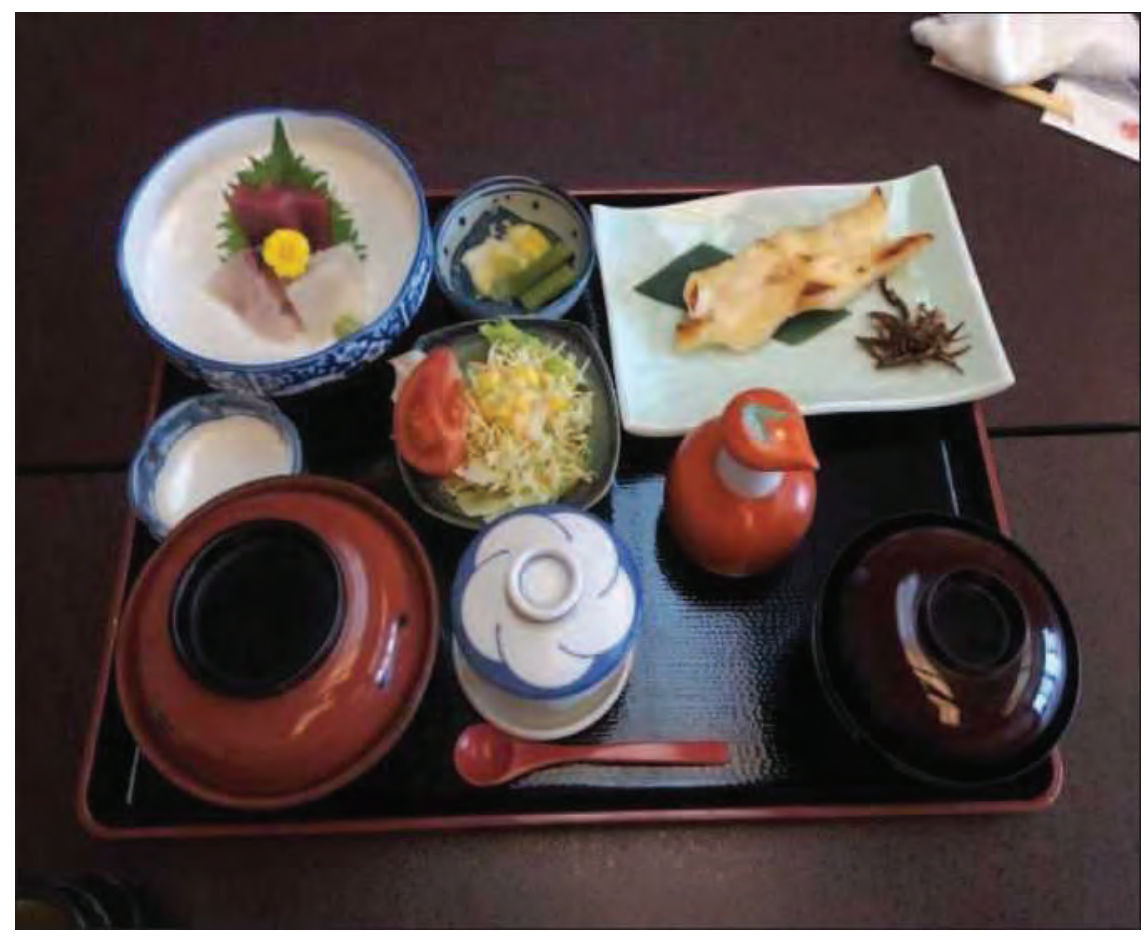

Figure 28: Traditional yet modern Japanese serving Source: Photograph by ANDREA PÓR

Based on its own cultural tradition, Japan was able to carry out modernisation in a 'non-Western' way, and thus pioneered the possibility of a 'nonWestern' modernity, the existence of a non-Western development model. In the second half of the twentieth century, the development of the 'little tigers' (several East Asian states began to develop economically, then socially and politically) was also realised similarly to the Japanese model by following, in part, the path of Western modernisation and partly, in a very different way. All this proves, quite convincingly, that there is a 'non-Western way' of modernisation, which was already mentioned in connection with Japan's development. It is now widely 
accepted that these states did not simply replicate the 'Western model', but, through their own system of social and cultural traditions, they implemented a modern form of capitalist development, thus demonstrating a new form thereof. Today, we can clearly speak of the existence of Asian capitalism, in which the Japanese example, explicitly or implicitly, played a major role in the region.

'Asian capitalism' (based on Japan's example, South Korea, Taiwan, Singapore, and partly Vietnam) is a non-individualistic version of capitalist modernity, based on Confucian values such as collective solidarity and discipline, reinforced by the characteristics of network capitalism and family values. Economically, it means the control of public finances, the dominance of stateowned companies in the strategic sector, the support of large "national' private companies, heavily dependent on the export market, with a high proportion of retail savings (the latter is necessitated by the underdevelopment of the welfare state and the shortcomings of the social system).

As a result of economic successes, Japan's diplomatic prestige increased by the turn of the millennium, and there was a demand both domestically and abroad for a more active foreign policy and, possibly, for its military power, which would be more proportionate to its international significance. In recent decades, Japanese culture has become an 'expanding', exporting culture, mainly from the inclusive culture, which after the Second World War, in particular, saw the influx and often unrestricted spread of American mass culture. This phenomenon is known as soft power, which is an influence on the consciousness (culture, sports, science, fashion) of the people against the hard power of military and economic power. However, soft power is no less important, in fact it is economically significant. This was also recognised by the Japanese government when it announced the Cool Japan programme, Japan's programme to become a cultural superpower. Elements of Japanese traditional and modern culture fashion, music, history and philosophy, martial arts, pop culture, trends, design, manga and anime, modern electronic devices and forms of communication - are increasingly appearing in Western culture, creating trends and finding followers. Once considered an isolated, exotic civilisation, Japan has become a part of everyday life for today's generations.

The main question going forward is how Japan, after the Second World War, clearly committed to the West (and primarily to the United States), defines its current and future position, task and identity in Asia and the world. 


\subsubsection{Chronological table}

\begin{tabular}{|c|c|}
\hline Date & Event \\
\hline 13000-300 ВСЕ & Jōmon period: prehistoric cultures \\
\hline 300 ВСЕ - 300 СЕ & $\begin{array}{l}\text { Yayoi period: Rice cultivation, metalworking and metal use, settled } \\
\text { lifestyle, agricultural production, social stratification, regional } \\
\text { organisation }\end{array}$ \\
\hline $300-538$ & $\begin{array}{l}\text { Yamato period: the first state formation, a tribal alliance, with close } \\
\text { ties with the Korean Peninsula and China. Kofun culture }\end{array}$ \\
\hline $538-710$ & $\begin{array}{l}\text { Asuka period: adoption of the Chinese civilisation - Buddhism, } \\
\text { Confucianism, Tao, writing, sciences, legal system, state } \\
\text { organisation, concept of absolute imperial power }\end{array}$ \\
\hline $\begin{array}{l}538 \text { (according to } \\
\text { some } 552 \text { ) }\end{array}$ & Introduction of Buddhism in Japan \\
\hline 645 & $\begin{array}{l}\text { Taika reforms: introduction of a new governmental and } \\
\text { administrative system based on the Chinese model. New state offices, } \\
\text { the concept of the emperor as absolute ruler, state land system instead } \\
\text { of private property, tax system, court rank system }\end{array}$ \\
\hline $710-794$ & $\begin{array}{l}\text { Nara period: the era of the centralised bureaucratic monarchy built on } \\
\text { the Chinese model }\end{array}$ \\
\hline $794-1185$ & $\begin{array}{l}\text { Heian period: the emergence and development of Japanese national } \\
\text { culture, the flourishing of court culture. With the transformation of } \\
\text { the land tenure system, the formation, strengthening, empowerment } \\
\text { of the samurai class, the emergence of feudalism }\end{array}$ \\
\hline $1185-1333$ & Kamakura period: the emergence of samurai power, feudalism \\
\hline 1232 & New samurai legal system \\
\hline 1274,1281 & Mongol attacks on Japan \\
\hline $1333-1573$ & $\begin{array}{l}\text { Muromachi period: feudal fragmentation, 'age of warring states', } \\
\text { flourishing of the samurai culture. Trade and urban development. } \\
\text { Formation of village communities }\end{array}$ \\
\hline 1543 & The appearance of Europeans in Japan \\
\hline $1573-1600$ & Unification of the country \\
\hline $1603-1867$ & $\begin{array}{l}\text { Edo period: Early Modern Period. Internal unity, peace, confinement, } \\
\text { economic and cultural development. The establishment of the } \\
\text { foundations of modern Japan }\end{array}$ \\
\hline 1853 & $\begin{array}{l}\text { The USA forces Japan to open the country - internal controversy over } \\
\text { its opening }\end{array}$ \\
\hline $1868-1912$ & $\begin{array}{l}\text { Meiji period: Announcement of the opening. Rapid modernisation, } \\
\text { westernisation, creation of a modern nation-state, industrialisation, } \\
\text { urbanisation. From a feudal system to a modern industrial state, from } \\
\text { seclusion to catching up with the western powers. }\end{array}$ \\
\hline 1889 & Western type constitution \\
\hline $1894-1895$ & Sino-Japanese War (Japanese victory, Taiwan becomes part of Japan) \\
\hline
\end{tabular}


Civilisations from East to West

\begin{tabular}{|c|c|}
\hline Date & Event \\
\hline $1904-1905$ & $\begin{array}{l}\text { Russo-Japanese War (Japanese victory, further acquisitions in East } \\
\text { Asia and China) }\end{array}$ \\
\hline 1910 & Annexation of Korea \\
\hline $1912-1926$ & $\begin{array}{l}\text { Taishō period: Taishō democracy: new democratic, liberal trends in } \\
\text { politics and society. AND: the roots of radical nationalism, }\end{array}$ \\
\hline 1926-1989 & Shōwa period \\
\hline Before 1945 & $\begin{array}{l}\text { 'Dark valley'. Militarism, wartime expansion, nationalism ('Japanese } \\
\text { fascism') }\end{array}$ \\
\hline 1929 & $\begin{array}{l}\text { Global economic crisis results in a huge crisis in Japan, the rise of } \\
\text { radical movements, the army gradually takes over }\end{array}$ \\
\hline 1932 & Occupation of Manchuria \\
\hline $1937-1945$ & Sino-Japanese War (Japan occupies territories in China) \\
\hline 1940 & $\begin{array}{l}\text { Japanese-German-Italian Alliance - Establishment of the 'Axis } \\
\text { Powers' }\end{array}$ \\
\hline 7 December 1941 & Japan attacks US (Pearl Harbor, Hawaii) \\
\hline 6 and 9 August 1945 & $\begin{array}{l}\text { US drops nuclear bomb on Hiroshima and Nagasaki, Japan surrenders } \\
\text { unconditionally in a few days }\end{array}$ \\
\hline $1945-1951$ & $\begin{array}{l}\text { American occupation: the formation of modern-day Japan, } \\
\text { democratisation, demilitarisation, American alliance }\end{array}$ \\
\hline 1947 & $\begin{array}{l}\text { New (modern day) Constitution: the Emperor is only a symbol. } \\
\text { Fundamental human rights, general secret ballot, the principle of } \\
\text { popular sovereignty. Democratic political system. Article 9: }\end{array}$ \\
\hline 1952 & $\begin{array}{l}\text { Treaty of San Francisco: Japan regained its sovereignty but requires } \\
\text { US military defence, Japan is strategically important to the US: US- } \\
\text { Japan Security Treaty. Japan is an important member of the US }\end{array}$ \\
\hline $1950-1953$ & $\begin{array}{l}\text { Korean War: Economic benefit for Japan: its heavy industry could be } \\
\text { revived, followed by other industries }\end{array}$ \\
\hline 1950s & $\begin{array}{l}\text { The beginning of the 'Japanese miracle'. Economic growth, } \\
\text { development, Americanisation, unique Japanese culture and way of } \\
\text { life. GNP growth: 1951-1955: 8.6\%, 1955-1960: } 9.1 \%\end{array}$ \\
\hline 1968 & Japan is the third largest economy in the world \\
\hline 1970 & Japan is the leading manufacturer in the world: ships, radio, television \\
\hline 1973 & $\begin{array}{l}\text { Oil crisis - Japan: successful transition, restructuring to less energy- } \\
\text { intensive, high-tech industries. Post-industrial economy, }\end{array}$ \\
\hline 1980 & Car, high-tech electronic products \\
\hline
\end{tabular}




\subsubsection{Bibliography}

ARnason, Johann P. 2010: Social Theory \& the Japanese Experience. The Dual Civilisation. New York: Kegan Paul International

Benedict, Ruth 2006: The Chrysanthemum and the Sword: Patterns of Japanese Culture. Boston \& New York: Mariner Books

COLLCUTT, MARTIN - MARIUS JANSEN - ISAO KUMAKURA 1988: Cultural Atlas of Japan. London \& New York: Phaidon Press

EARHART, BYRON H. 1982: Japanese Religion: Unity and Diversity. Belmont, Calif.: Wadsworth

EISENSTADT, SHMUEL N. 1996: Japanese Civilisation: A Comparative View. Chicago: University of Chicago Press

FUKUTAKE, TADASHI 1989: The Japanese Social Structure, Its Evolution in the Modern Century. Tokyo: University of Tokyo Press

Huntington, SAmuel P. 2011: The Clash of Civilisations and the Remaking of World Order. New York: Simon \& Schuster

Jansen, Marius B. 2000: The Making of Modern Japan. Cambridge, Mass.: Belknap Press of Harvard University Press

KIDDER, EDWARD 1977: The Ancient Japan. London \& New York: Elsevier \& Phaidon Press

KIDDER, EDWARD 1985: The Art of Japan. London: Guild Publishing

Morishima, MichIO 1994: Why Has Japan Succeded? Western Technology and the Japanese Ethos. Cambridge: Cambridge University Press

NAKANE, CHIE 1972: Japanese Society. Berkeley: University of California Press

ReISCHAUeR, EDWIN O. 1999: The Japanese Today. Change and Continuity.

Tokyo: Tuttle Publishing

TOTMAN, CONRAD 2005: History of Japan. New Jersey: Wiley-Blackwell 


\section{The Indian Subcontinent}




\title{
3.1. The I ndian Civilisation
}

\author{
ZSUZSANNA RENNER
}

\subsubsection{Introduction}

The Indian civilisation is one of the oldest civilisations in the world which, unlike other ancient civilisations, still exists today. It was established and formed in the Indian subcontinent as a result of the diverse socio-economic-political processes that took place here. It includes the specific Indian phenomena of society and culture, Indian religions (Hindu, Buddhist, Jain and Sikh), Indian languages, philosophy, literature, architecture, fine arts and sciences - all the material and spiritual values that the peoples living here created during the existence of civilisation. Although essentially unique to the geographical region of the Indian subcontinent, from the fifth century India also spread to much of Southeast Asia. Its cultural radiance is even broader: it has had a lasting impact through Buddhist religion and art in Central Asia and the Far East. Indian philosophy has found its way into the West in modern times, and its popularity is now experiencing its renaissance.

After the prehistoric antecedents lasting to the middle of the second millennium BCE, the early period of almost a millennium of Indian civilisation included the appearance of the Aryans and their dispersal on the Indian subcontinent (from about 1500 to $600 \mathrm{BCE}$ ). Its typical features evolved between $600 \mathrm{BCE}$ and $1200 \mathrm{CE}$. The beginning of the thirteenth century was a milestone in the history of the subcontinent when the Islamic conquest and the ensuing Islamic statehood of India put an end to the exclusivity of Indian civilisation on the subcontinent. In the long term, this new situation has perpetuated the problem of coexistence, interaction and conflict between Indian and Islamic civilisation. Although the Indian civilisation did not cease to exist, with the expansion of Islam, its regional kingdoms were integrated into the political organisation of the subcontinent's sultanates with the exception of the southernmost part of the subcontinent. With colonisation, another civilisation, the West, also appeared in the region. Between 1858 and 1947, the British Government of India first politically united the whole of the subcontinent, exercising its power partly directly and partly through semi-sovereign Hindu and Muslim principalities under the authority of the British Crown. Although colonial politics did not intervene in religious matters, it brought about so much change in economic, social, administrative and political terms that the foundations of civilisation could not remain intact, either. Indian civilisation survived but continued to bear the traces of coexistence with both Islamic and Western civilisation. 
Independent India has a large part of the subcontinent and the heritage of all three civilisations. Its constitution states the complex nature of Indian culture. The traditional Indian civilisation exists within the geographical-political framework of the Republic of India, forming a majority but not a single culture. The destruction of the subcontinent's self-sustaining economy and the deepening of Hindu-Muslim conflict under the British is a major legacy of India's colonial past. At the same time, the political system, the use of the English language and the subcontinent's basic communication system (train, post, roads, telecommunications) inherited from British India proved to be a significant resource in the modernisation efforts in which India achieved significant success.

India is today the world's largest functioning democracy, a dynamically developing economic power. By 2050, its per capita GDP is projected to be close to that of the United States. At the same time, its explosive population growth, which has tripled the country's population since 1947, represents a huge burden. Other major problems include social inequality, rural poverty, environmental degradation and illiteracy (27.9\% according to UNESCO data in 2011), which is particularly high among women. Due to the coexistence of the Hindu majority and the Muslim minority, the definition of being Indian is constantly on the agenda, and the enormous increase in the Indian diaspora also calls for new approaches to the concepts of being Indian and being Hindu.

\subsubsection{The role of geography and climate}

The geographical environment in which Indian civilisation emerged and evolved is the Indian subcontinent or, in present-day terms, South Asia. This vast area, which is about the size of Europe, is now shared by several countries: India, Pakistan, Bangladesh, Nepal, Bhutan, Sri Lanka and the Maldives; sometimes north-eastern Afghanistan which played an important role in the history of the subcontinent is also considered part of it (Map 9). It is separated from the rest of the Eurasian continent by natural frontiers: the 2,500-km stretch of the Himalayas to the north, the Hind Kush to the north-west, the extensive, almost impassable tropical forests to the northeast, and the Arakan Mountains. The peninsula is surrounded by seas: the Arabian Sea in the west, the Bay of Bengal in the east, and the Indian Ocean in the south. These geophysical features of the subcontinent provided for the distinct but not isolated development of the subcontinent. River valleys and high passes through the Himalayas, crossed by Tibetan ethnic groups, were a link with the Tibetan Plateau. In the northeast, the Manipur river valleys provided links to China, Burma (Myanmar) and Southeast Asia. In the west, the Bolan Pass opening on the Indus Valley on the edge of the desert mountainous region of Balochistan was used as a trade route and population movements also 
took place there. But the most important link with the outside world was the Haibar (Khyber) Pass in the north-western corner of the subcontinent, in the Kabul River valley, the main transportation route for peoples and ethnic groups to the subcontinent, where most conquerors: Aryans, Persians, Greeks, Parthians, Scythians, Kushans, Afghans, Turks, Pathans entered Indian soil.

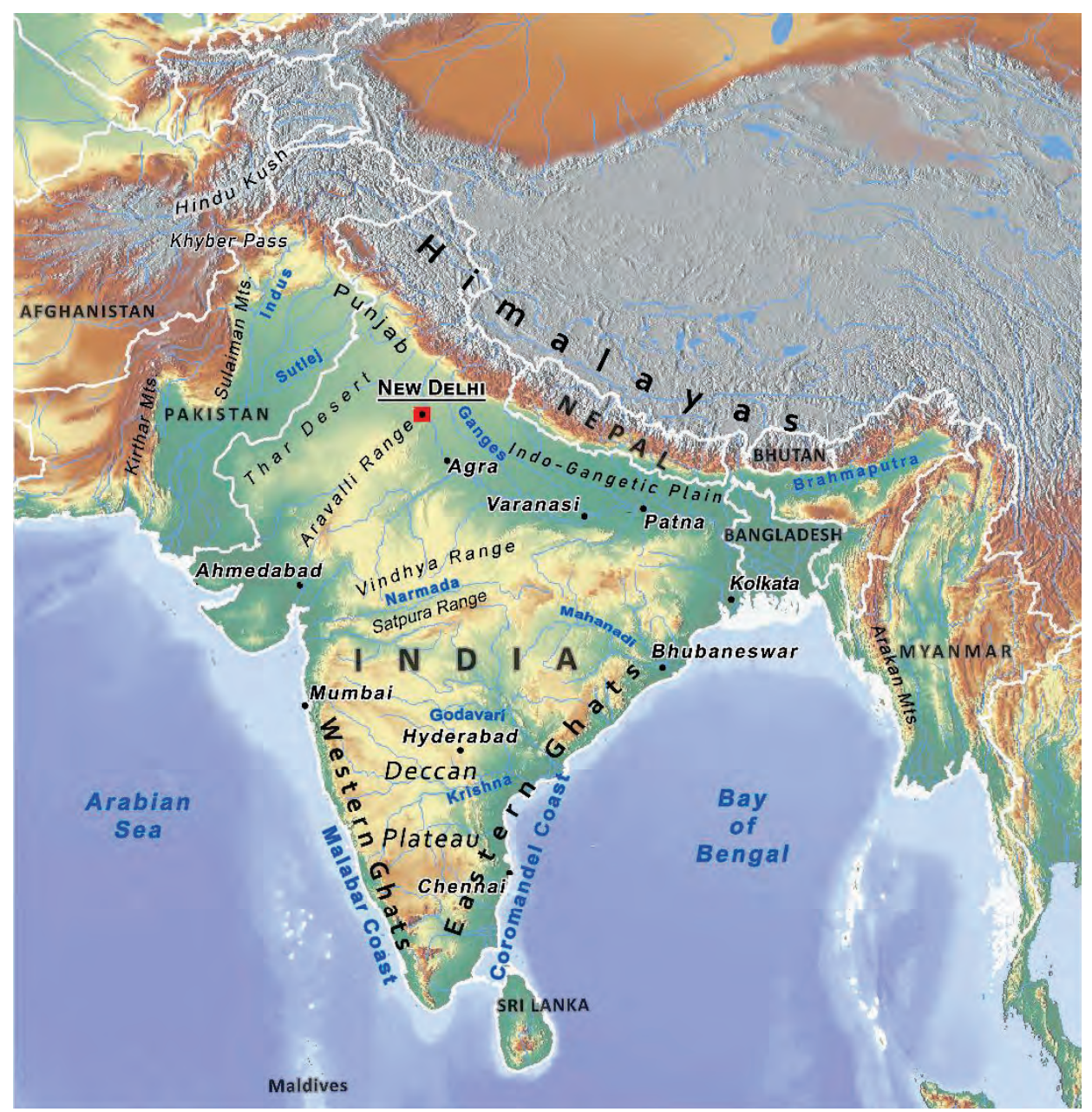

Map 9: The Indian subcontinent

Source: Edited by ÁGNES VARGA

The Indian branch of the Silk Road, the main continental trade route beyond the subcontinent, which proved to be crucial not only for trade in commodities but also for the spread of ideas, also led there. This was the 
direction of the spread of Buddhism to the north and with it, the authoritative forms of Buddhist art that had evolved in India.

The peninsula surrounded by seas has been involved in preserving relations with the outside world from prehistoric times through longitudinally passable beaches and maritime shipping and trade. The Indus Valley Civilisation had already established a maritime trade relationship with Mesopotamia by coastal shipping. The Indus Valley merchants transported their goods to Oman and Bahrain, from where they were transported by local merchants to the cities of Mesopotamia. Subsequently, there was regular traffic between the eastern provinces of the Roman Empire (primarily Egypt) and Indian ports. The emergence of early Southeast Asian kingdoms - Suvannabhumi in today's Myanmar, Mon Kingdom in southern Thailand, Funan and Chenla in Cambodia, Champa in Vietnam, Srivijaya in Sumatra and Java - was largely facilitated by the development of maritime relations. Early connections were made from the port on the west coast, Bharukachcha (now Bharuch, Gujarat), and this role was later taken over by the ports on the east coast.

The interior of the subcontinent is divided by rivers and mountain ranges, and archaeology has shown that the main cultural regions have closely followed these natural geographical boundaries since prehistoric times. The northern region, bounded on the north by the Himalayas, to the south by the Narmada River and the Vindhya Range, covers the vast plains of the Indus and Ganges. The Indus Basin was the cradle of the Indus Valley Civilisation, and then its upper stream region, the Punjab ("five rivers"), was the first settlement area of the Aryans arriving on the subcontinent. Historically, the alluvial plain of the Ganges and its tributary, the Yamuna, played a key role. This fertile river valley is India's most prolific region, creating favourable conditions for the emergence of largescale states due to both its economic strength and the better accessibility to the lowlands. The central region is the difficult-to-cross mountainous forested area of the Deccan Plateau divided by ravines, stretching between the rivers Narmada and Krishna. It was a scene of strong regional kingdoms and prominent dynasties, where the political and cultural influence of the northern and southern regions prevailed to varying degrees, and the indigenous tribal culture survived until recently and even to this day, in closed spots. The region south of Krishna carries the typical South Indian cultural features that have established and still maintain the traditional distinction between North and South. Longitudinal zones have formed in the coastal strips have developed longitudinal zones, which are defined by the cultural features of the narrow coastal strips with the hinterland of the West and the East Ghat behind them.

In addition to the physical geography of the subcontinent, there is a sacred geography in Indian tradition where the hills of India are celebrated, primarily the 
snow-capped peaks of the Himalayas (Sk. 'the land of snow'), where Indian mythology places the heavenly abode of the gods.

The rivers that ensure the fertility of the earth are religiously honoured and personified by goddesses. Their water is also closely related to ritual purity, so immersion in rivers and scattering of the ashes of the dead into the river are among the best-known Hindu rites. The holiest river, the Ganges or Gangá, originates in the Himalayas and flows into the Bay of Bengal. Its course is accompanied by a chain of pilgrimage sites: Haridwar, where it leaves behind the Himalayas and enters the plains; Prayagraj, formerly known as Allahabad and still earlier as Prayag, where it meets the Yamuna, and where the great Kumbh Mela pilgrimage takes place at the confluence every 12 years (it is estimated that 120 million pilgrims attended it in 2013); and above all, Varanasi or Kashi, the holiest Hindu city, the centre of Hindu culture (Figure 29). To the conceptions of the sacred geography of the subcontinent, as old as the Hindu religion itself, a new one was added during the nineteenth-century independence movement, when the whole of India began to be regarded as the holy land of Hinduism and personified by the Hindu goddess Bharat Mata (Mother India). This symbol was fraught with political overtones and provoked protest from religious minorities due to the association of Indian land with the Hindu religion.

The subcontinent's climate is warmer than its geographical location would justify it, as the Himalayan mountain range hampers both northern winds and monsoon winds from the south-west. The monsoons drive heavy rain clouds over the subcontinent for three months. After months of scorching heat, people rejoice at the arrival of the much-awaited, life-giving rain. The lakes and ponds, now filled with water, are covered with lotuses, lands turn green, trees bloom, and intoxicating scents float in the air. Traditional topoi in poetry and painting: screaming peacocks, the beautiful young lady hurrying in the rain or doing her make-up before meeting her beloved indicate that this is the season of love in India.

However, precipitation is not evenly distributed across the subcontinent. Most of the rain falls on the southern side of the Himalayas and the coastal side of the Western Ghats and the heavy rainfall may cause devastating floods, while there is a tropical savannah inside the Deccan Plateau and hot desert climate prevails in the Thar Desert of the north-west. Due to the imbalance of climate and rain, a major duty of kings in the Indian civilisation was to ensure the fertility of the lands. In the royal capitals, artificial water reservoirs and the construction of dams on the rivers provided the necessary amount of water between monsoon periods. Their design and operation required a high level of technical knowledge and was among the fundamental achievements of civilisation. Wells served as an additional source of water. Most villages had a simple dug well from where 
women carried the water. At the same time, large stepwells specific to Indian civilisation were built in the driest western parts of the Indian subcontinent. These multi-storey underground palaces provided access to groundwater throughout the year, cooling during the hot season, and the opportunity to thank the gods for all of this, so their socio-religious significance was not negligible either.

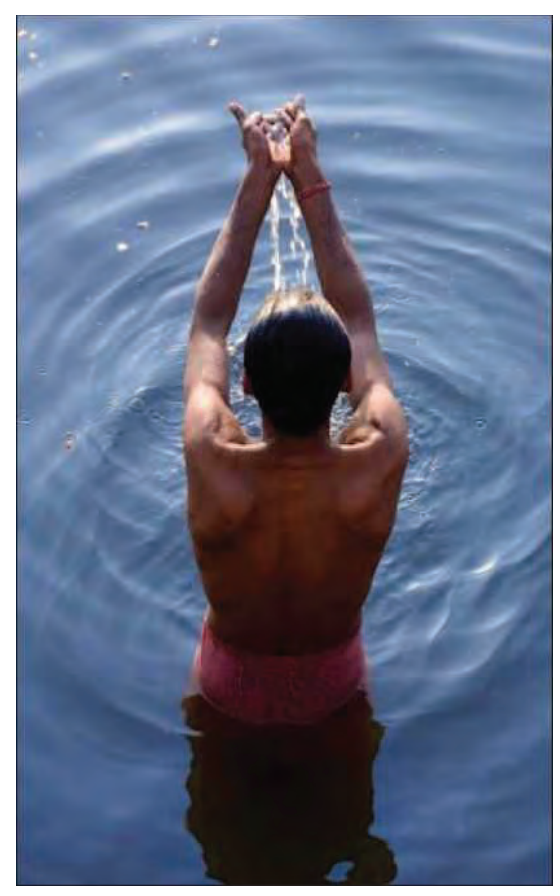

Figure 29: Morning rite on the Ganges in Varanasi

Source: Jorge Royan. https://commons.wikimedia.org/wiki/File:India_-_Varanasi_ ba\%C3\%B1o_Ganges_-_0072.jpg

Routes across the subcontinent played a huge role in the settlement of the region, the development of Indian civilisation, trade and the spread of religions, especially Buddhism. The main trade route was the 'northern road' connecting the Ganges Valley with Gandhara and further with Silk Road in the north-west, with branches in the east to China and the old port of the Bay of Bengal, Tamralipti (now Tamluk, West Bengal). An important land route connected the royal capital Pataliputra (now Patna, Bihar) in the eastern Ganges basin, with the west coast port city, Bharukachcha, from where merchants headed to the Arabian and East African coasts.

Inside the peninsula, the "southern route" initially led through pre-Aryan areas. However, land roads could only be used during the dry season as they became impassable during the monsoon. The traveling monks sought shelter in 
caves until the end of the rainy season. These were the places where the first rockcut Buddhist caves were established and the shrines themselves the first manifestations of this form of sacred architecture so characteristic of Indian civilisation. There were many dangers to land trade, therefore, gaining control over trade routes and junctions was a major driving force behind the expansion ambitions of the kingdoms in the subcontinent.

The physical conditions of the subcontinent persisted, although this does not mean that there were no changes. In the last two and a half millennia, the rivers that irrigated the plains of the subcontinent, which are still unregulated, have changed their course from time to time, and have thereby profoundly influenced the existence of early cultures and state formations established on flood-based economy. Due to the deposition of large amounts of sediment, shifts have also occurred in the river estuaries. The significant change in the direction of the Indus and the desiccation of the Sarasvati River, coupled with the change in the direction of the monsoon wind, played a decisive role in the decline of the Indus Valley Civilisation. The eastern shift of the monsoon may have contributed to the gradual expansion of the Thar Desert and the drying up of the forests surrounding the lower Indus. The great Indian epics, Ramayana and Mahabharata testify that most of the subcontinent was once covered with dense forests. In ancient literary works, the forest, as an abode of hermits, forest animals and demons, as a scene of wars and battles, appears symbolically in contrast to the sacred world of cities and villages involved in civilisation.

\subsubsection{L anguages of the subcontinent}

Among the language families present in the Indian subcontinent, the IndoEuropean languages, which have been present since at least the second millennium $\mathrm{CE}$, are the predominant languages through the Indo-Aryan languages, which are part of the Indo-Iranian languages. This includes Sanskrit ('complex', 'ornamented'), the archaic form of which was spoken by the Aryans coming from the north-west on the subcontinent. Aryan (meaning "noble") is the selfdesignation of the speakers of the Indo-Iranian branch of the Indo-European language family; it does not refer to ethnic belonging. India's oldest sacred texts, the Vedas, and the vast religious, philosophical, scientific literature of ancient India were written in Sanskrit. Sanskrit grammar and phonetics were described in the world's first regular grammatical work (Astadhayayi) by Panini, who lived in the fifth century CE.

With the spread of the Aryans, the Sanskrit language became widespread throughout northern India, and as they continued to spread, simplified local variants, the Prakrit languages developed. The best known of these is Pali, the 
sacred language of Southern (Theravada) Buddhism and the Pāli Canon. The Indo-European languages spoken today in the subcontinent originate from the Prakrit languages: Hindi in North and Central India, Gujarati and Rajasthani in the west, Punjabi and Sindhi in the north-west; the Dardic languages including Kashmiri in the northernmost corner, Pahari languages in the Himalayas, Bihari Bengali, Oriya and Asami in the East, Marathi in the South and Singhalese in Sri Lanka. The Iranian languages are represented by Balochi and Pashto in the west and north-west, and Kafiri or Nuristani in the far north-west of the subcontinent. The official language of the Mughal Empire was Persian. Among the IndoEuropean languages used on the subcontinent, the widespread use of English as an official language and modern lingua franca is worth mentioning.

The languages belonging to the Dravidian language family, which have inscriptional evidence from the beginning of our time, are concentrated in the southern part of the subcontinent, but their remains can also be found in Central India (Gondi) and Balochistan (Brahui). The South Indian Dravidian languages include Tamil, Kannada, Malayalam and Telugu, in all of which rich literature has been produced. We know very little about the early history of Dravidian speakers. It is believed that the population of the Indus Valley Civilisation was made up of Proto-Dravidian speakers who migrated there around 4,500 BCE from the Iranian plateau and were gradually pushed south by the settling Aryans. However, since the Indus Valley writing remains undeciphered as yet, this question cannot be answered with certainty based on our current knowledge. What is certain is that the Dravidians, like the Aryans, have no clear ethnic characteristics, which virtually excludes their archaeological identification. At the same time, Dravidian names and loanwords in Sanskrit confirm the presence of the Dravidians from the earliest stages of Vedic literature, suggesting that they had arrived in the subcontinent earlier than the Aryans.

The Austro-Asiatic languages (Munda in Central and Eastern India, Khasi in Assam) have written evidence only from the last few centuries. Judging from loanwords, however, their speakers are likely to have arrived in the subcontinent before the Dravidian and Aryan language groups. Ethnic groups representing the Tibeto-Burman branch of the Sino-Tibetan language family crossed the Himalayas into the northern and north-eastern peripheries of the subcontinent. Their presence is indicated by inscriptions in the Kathmandu Valley since the fourth century CE. Tibetan and Newari of the Tibetan-Burmese branch are spoken today in the Himalayas. 
3.1. The Indian Civilisation

\title{
3.1.4. Chronology of the H istory of Indian Civilisation
}

\author{
Concept of time, chronology, sources
}

Establishing the historical dates of Indian civilisation has been difficult since the beginning of the research. In Indian tradition, there was no systematic historiography such as in Europe, China, or Islamic culture. Little or no importance was given to the timeliness of the events and the historical role of the individual. Although there is a historical tradition, mainly in the form of royal lists and ancestry lines (genealogies), which, however, are embedded in the myths and legends of the Puranas ("old stories", encyclopaedic works of the Indian cosmological, mythological and historical tradition), often contradictory and rarely relate to specific persons, dates, events, or locations. The reason for this lies in an approach that relativises the earthly world of phenomena. There is a cosmic logic in the narratives of Indian civilisation about the past, which places terrestrial time and man on earth in the perspective of the operation of the universe, so it is understandable that its significance becomes relative or dwarfed from this point of view. In the world conception of the Indian civilisation, time is not linear, but cyclic, where the cycles of existence and destruction (withdrawal or dissolution) of the universe are eternally interchanged. Cosmological time is measured in the days and years of the gods. A cycle of existence (Sk. kalpa, 'eon') corresponds to one day of the god Brahma, which is equal to 4.32 billion earth years, followed by Brahma's night of the same length (cycle of dissolution). A kalpa is made up of 1000 great periods (mahayuga), each of which consists of four epochs (yuga). They (Satya, Treta, Dvapara and Kali Yugas) are not of equal length, but gradually decreasing duration, and are characterised by the gradual deterioration of order, law, and morality. The longest is Satya Yuga or the Golden Age when people were closest to the divine laws, and the shortest and morally most corrupt is Kali Yuga when the world is ripe for renewal. The latter occurs as a result of divine intervention and is followed, after an interval of dissolution, by a new cycle of the four yugas. In one single day of Brahma, the four yugas revolve a thousand times. The events that take place in them - including the incarnations of the gods, the appearance of Buddhas and Jinas, the great wars and the turning points in history - are identical, so the events that the man on earth experiences in his or her life had already taken place infinite times in the past and will occur again in future world epochs. One year of Brahma consists of 360 such days, and his life, however long it may seem, is finite with 311 trillion and 40 billion years of earth time, a mere flash for the universe as a whole. Brahma, however, is not alone, in the worlds of the universe, a multitude of Brahmas are born and disappear subject to the causal relationships of the material world. 
The traditional Indian view of history is primarily shaped by the Puranas and the great epics. The formation of the Puranas in the first version is estimated to have taken place from the fourth to the tenth centuries $\mathrm{CE}$, but much of the stories goes back to ancient times. The epics and other literary works also contain historical references, but the dates of most of them are difficult to establish and their period of creation often spans hundreds of years. Historical research, the most important sources of which are dated inscriptions and coins, seeks to compare data extracted from Puranic and epic literature with dated persons and events, which, however, is only successful in some cases. Archaeological research has been ongoing since the establishment of the Archaeological Survey of India (1861), but the vast expanse of Indian civilisation and the continued habitation and cult use of holy sites hinders the full exploration of even the most important sites. It is estimated that most of the material and artistic heritage of Indian civilisation is still buried underground today, so any major discovery may profoundly change our view of civilisation in the future.

\section{Periodisation}

There are no universally followed periods in the history of the Indian civilisation. Its main phases used to be described earlier as Hindu, Muslim and British periods. However, this was misleading because it may have seemed as though the periods of Hindu, Islamic and British civilisations were consecutive eras in the history of the subcontinent, yet the Indian civilisation did not cease to exist with the advent of either the Islamic or the European civilisation. The division of antiquity, medieval times, and modern times is also widespread and is still partly used today, despite the fact that the Indian socio-economic features associated with the great historical periods differ significantly from those of the West. Another common method is periodisation by royal dynasties, the main disadvantage of which is that no period in the history of Indian civilisation can be linked to any single dynasty since the whole of the subcontinent was first united by British India (official English name: the Indian Empire). Therefore, recent and present historiography usually apply periodisation with a mixed set of criteria, taking into account the tendencies of social and economic processes that span dynasties. However, in the absence of a generally accepted system, periodisation can vary from one school of history to another, or even from one historian to another. The major periods in the history of Indian civilisation, using a mixed set of criteria, are: 
Prehistory until c. 1500 BCE

- Indus Valley Civilisation c. 2600-1900

Antiquity

- Vedic period c. 1500-600 BCE

- Second urbanisation c. 600-200 BCE

- Early classical period c. 200 BCE - 320 CE

- Classical period c. 320-650

Middle Ages

- Early Middle Ages (Hindu dynasties in the north) c. 650-1200

- Late Middle Ages (Delhi Sultanate) c. 1200-1526

Modern history

- Early Modern Age (Age of the Mughal Empire) 1526-1858

- Modern Age (British Empire in India and Independence) from 1858 to the present

The main features of the historical periods

Human settlement has left archaeological traces on the Indian subcontinent since prehistoric times. The first significant civilisation was the Indus Valley Civilisation, one of the great river cultures of the ancient East, besides Mesopotamia and Egypt. Its immediate antecedents were the Neolithic settlements on the eastern side of the Bolan Pass, dating back to around 7000 BCE. The prehistory of the Indus Valley Civilisation began around 3300 BCE, and its mature urban phase dates back to 2600-1900 BCE. In its vast territory, comprising areas of today's Pakistan (Sindh, Punjab, Baluchistan), north-western India (Punjab, Haryana, Gujarat, Rajasthan) and north-eastern Afghanistan, more than two thousand cities have been detected. Its total population is estimated at two to five million. The decline of the civilisation is probably due to climatic reasons, with its cities abandoned by 1700 BCE.

The decline of Indus Valley Civilisation coincided with the emergence of Indo-Aryan speaking ethnic groups on the subcontinent, followed by the rise of Vedic culture (c. 1500-600 BCE) parallel with the expansion of the Aryansin northern India.

At the time of the Second Urbanisation that took place in the Ganges Valley (c. 600-200 BCE), the Buddhist and Jaina religions emerged, Hellenistic and West Asian impacts could be felt as a result of Greek and Persian conquests and contacts, the first great empire of the subcontinent, the Maurya Empire was created (Map 10) and the Tamil culture fist flourished in South India. 


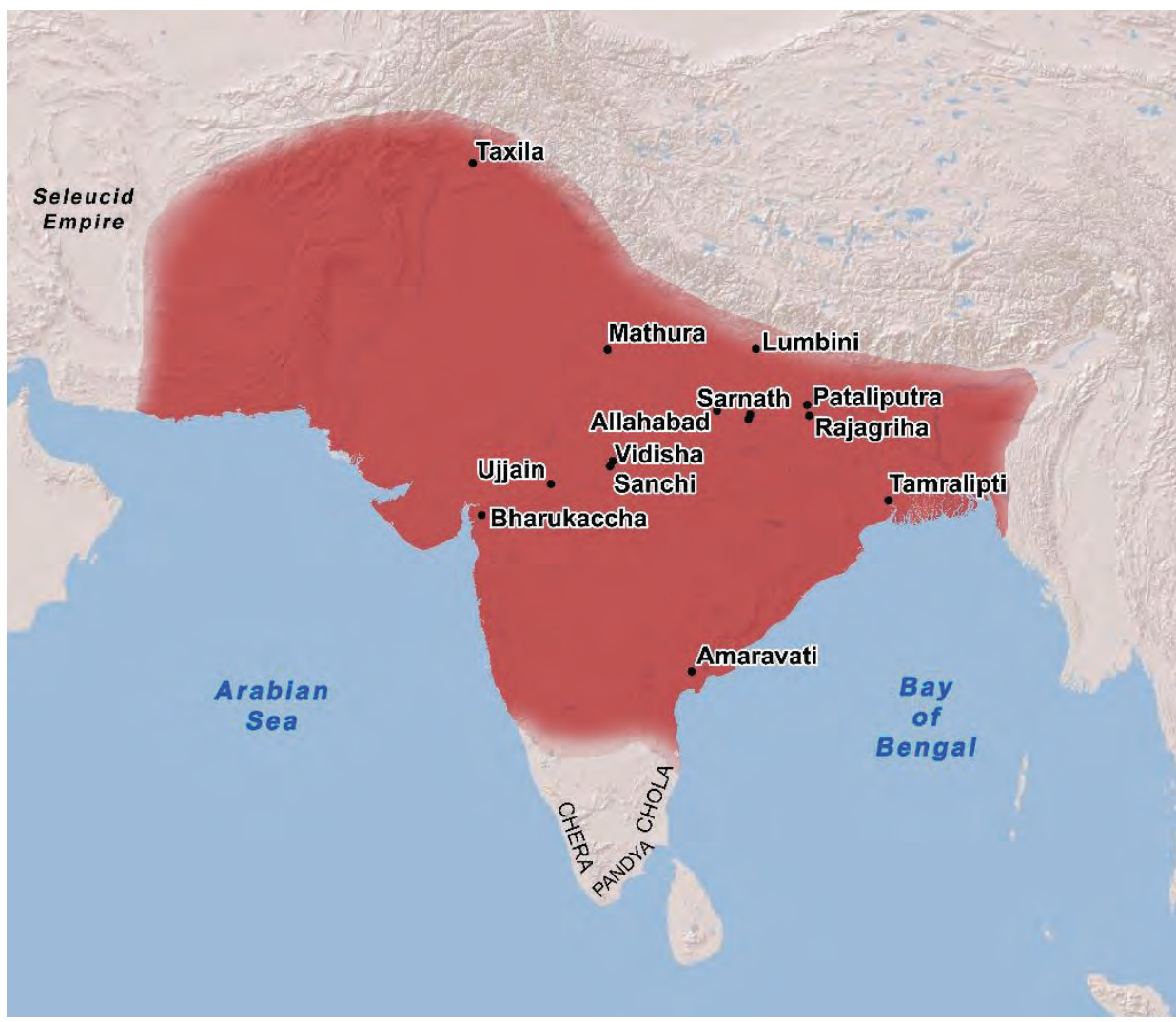

Map 10: The Maurya Empire c. 250 BCE Source: Edited by ÁGNES VARGA

The early classical period (c. 200 BCE - 320 вCE) added Central Asian impacts to Hellenistic influences and the second period of prosperity for Buddhism under the auspices of the Kushan Empire. The classical period (c. 320650) witnessed the first imperial flourishing of Hindu religion and culture within the Gupta state (Map 11).The period hallmarked with the Gupta-Vakataka dynasties is also known as the Golden Age of North India, which brought the unparalleled flourishing of science, fine arts and literature within a sophisticated urban culture. In South India, the Pallava dynasty gained power by establishing maritime relations with Southeast Asia. 


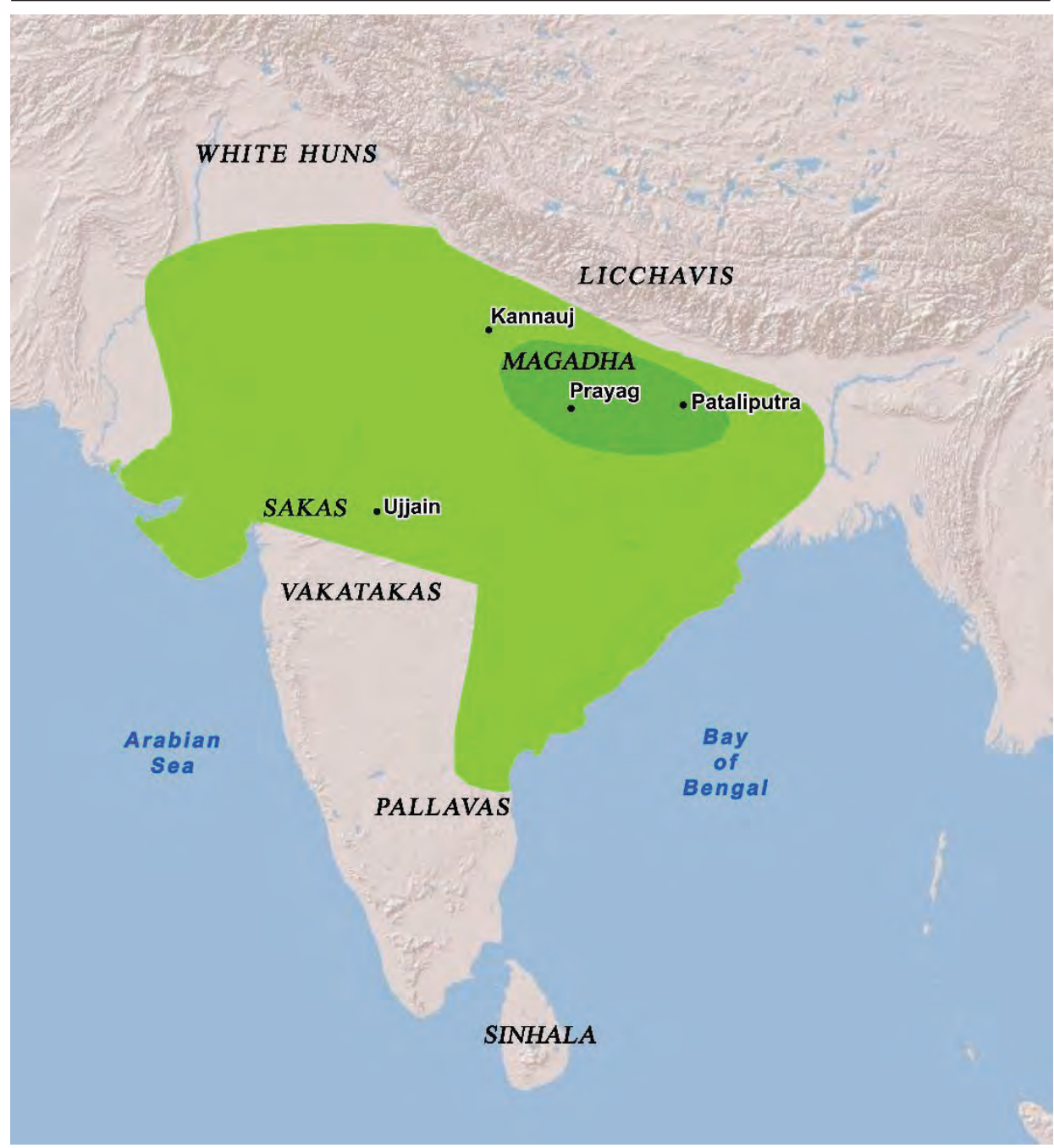

Map 11: The Gupta Empire and its neighbours c. 400 CE Source: Edited by ÁGNES VARGA

The early Middle Ages (c. 650-1200) were characterised by political fragmentation and the rise of Hindu dynasties, with increasing invasions of Islamic conquerors in the north. The late Middle Ages (c. 1200-1526) bring the foundation and expansion of the Delhi Sultanate and its successor states as well as an increase in the proportion of Muslim population. Hindu religiosity was characterised by the spread of the bhakti movement which focused on a personal devotion to god. The rise of the Sikh religion in Punjab was partly related to the bhakti movement. In the South, the Chola Empire emerged as a dominant power, 
whereas during the spread of Islam in North India, Vijayanagar became the representative of Hindu statehood. In the north, the Rajput principalities fought against the expanding Islamic power.

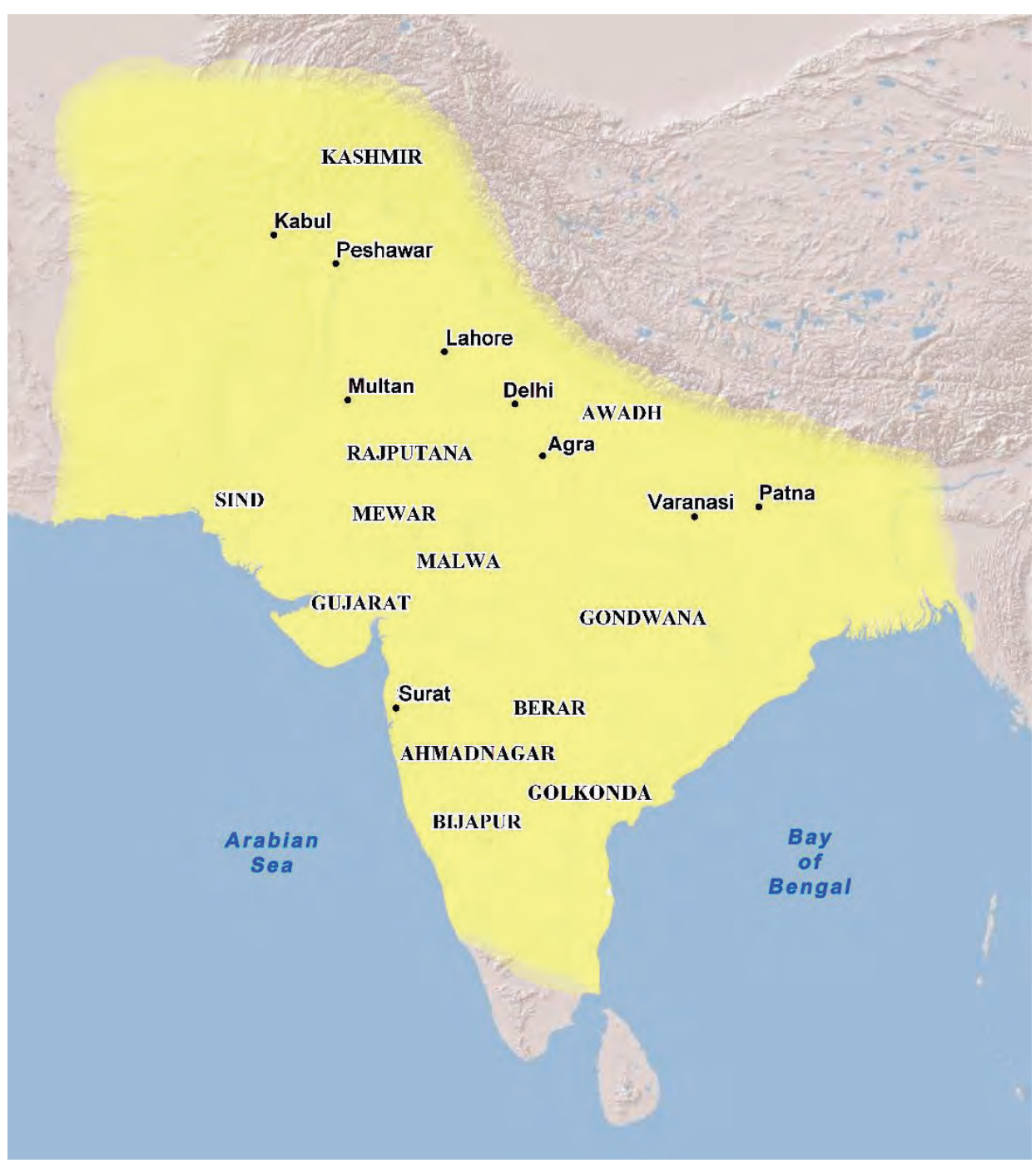

Map 12: The greatest expansion of the Mughal Empire (late seventeenth, early eighteenth century)

Source: Edited by ÁGNES VARGA 
In the early modern age (1526-1858), new Islamic conquerors, the Mughals, created an Islamic empire that was more powerful than its predecessors stretching over almost the entire subcontinent (Map 12), against which, however, resistance emerged in the form of the Sikh and Maratha states.

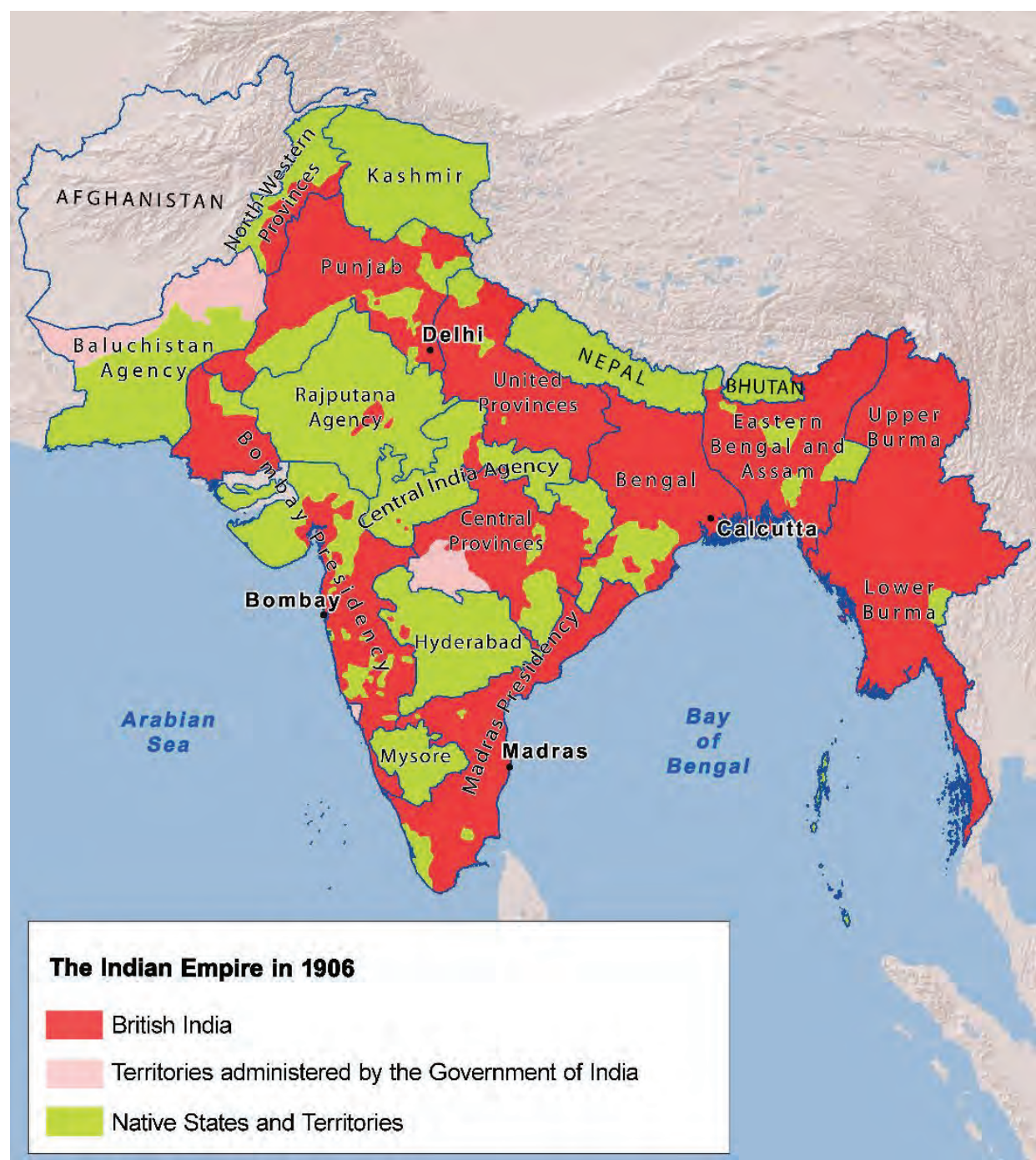

Map 13: British India in 1906

Source: Edited by ÁGNES VARGA 
This was also the age of colonisation: this is when European traders set foot in the coastal areas. The British emerged victorious from the rivalry of Western powers here, leading straight to the formation of the British colonial empire in India. The suppression of the Indian Rebellion in 1858 was a milestone as the British Crown took over the colonial government from the East India Company (Map 13). The unfolding independence movement led to the proclamation of the independence and the partition of India and Pakistan after World War II in 1947.

\subsubsection{The main chapters in the history of Indian civilisation}

\section{Material culture of the Indus Valley Civilisation}

Known for its large and well-planned cities, the Indus Valley Civilisation represents the first period of urbanisation in the history of the subcontinent. Although the connection between the achievements of this civilisation or its creators and the later civilisation of the subcontinent is not known, the large number of comparable phenomena allows the assumption of some continuity that has not yet been clarified. Answering the open questions is hindered by the fact that our knowledge is based almost exclusively on the interpretation of archaeological evidence. The Indus script is still undeciphered, and there are contradicting views even about its nature. According to one hypothesis, it is pictographic and syllabic and was used to record an early Dravidian language, while according to another assumption its symbols do not constitute a writing system. Although the number of known symbols is over four hundred, they are inscribed on seals, small tablets, and ceramic pots, and the average length of the inscriptions is only $4-5$ characters. Thus, the question of whether the Indus Valley Civilisation had a writing system to record a language cannot be answered beyond any doubt. Many researchers believe that a civilisation of such size and organisation could not have existed without writing, and they presume that some perishable material was used for writing, as a result of which all written records have been destroyed.

Across the whole expanse of the civilisation, we can observe a high degree of planning and regulation, indicating the existence of strong central power. However, we have no information about the nature of that power. The most important cities (Mohenjo Daro, Harappa, Lothal, Kalibangan) were divided into a citadel and a lower city, both surrounded by walls. It is assumed that the citadel may have served as the residence of the elite, but no trace of a ruler's palace or large tomb was found. The most famous structure in the citadel of Mohenjo Daro, known as the Great Bath, a brick-covered tank made water-resistant with bitumen, triggers an association with South India's temple tanks for many. We 
3.1. The Indian Civilisation

can probably assume that the builders of the Great Bath were driven by some ritual goal. Tiny cells surrounded the tank that might have been used by priests. However, no building was found in any of the cities that could be clearly identified as a temple.

In the lower town, the streets running north-south and east-west formed a regular mesh and intersected at right angles. This kind of urban planning, and even the hierarchy of streets, can be recognised much later in the descriptions of the Vastu Shastras (architectural manuals) and the urban planning based on them. In the lower city stood most of the residential buildings, often two-story buildings and almost closed to the street, with living quarters built around an inner courtyard, much like the typical medieval and early modern dwellings of wealthy North Indian urban merchants (haveli). The water supply and the drainage system unmatched in the era are striking. There were public wells in the cities, but the larger houses had their own wells inside the gate (a medieval example for this is the old city of Ahmedabad, Gujarat). Many houses had bathrooms, and sewage was drained into covered underground sewers on the main streets. The flat roofs of the houses were used for various purposes, like today. The lower town was inhabited primarily by traders and craftsmen who lived in well-defined neighbourhoods. The crowded residential quarters of craftsmen, shopkeepers, workers, and peasants were located in the outer parts of the cities. Occupational (caste) organisation is a typical feature of South Asian urban morphology in historical periods, as are city walls and the city gates at the end of the main roads. In Harappa, workshops of various craftsmen were discovered: potter's kilns, textile dyers' vats, metalworkers' smelters, shell carvers' workshops and bead drills. Jewellery recovered from burials - belts, necklaces, etc. made from multiple rows of beads - closely resemble jewels depicted in female figures of early Buddhist art (e.g., on the balustrade of the Bharhut stupa in Madhya Pradesh). Among the figurative representations, the humped bull (zebu) was very common, which is also of great importance in the later cultures (zebu was domesticated on the Indian subcontinent). A small number of bronze figures unearthed in Indus cities testifies to the knowledge of the lost wax method of bronze casting.

The Indus Valley Civilisation was highly advanced in measuring height, weight, and time. A uniform system of weights and measures was in the entire area of civilisation throughout its 700 years of existence. The massive walls surrounding the cities, the huge brick platforms, large grain storages, warehouses and dockyards on the riverbank reflect the advanced level of architecture and construction technology. The design of port buildings testifies to an accurate knowledge of tides and currents. 
Despite the high degree of urbanisation, most of the population lived in villages. The dominance of the countryside and the role of the villages as the main promoters of Indian civilisation continued in the historic period. Based on the excavated human skeletons, the anthropologically mixed population was dominated by the Proto-Australoid and the Mediterranean types. The primary source of living was agriculture, with wheat, barley and legumes as the main food. Domestic animals included cattle, buffalo, sheep, goats, pigs and possibly poultry. The harvested crops were transported on ox or buffalo-drawn twowheeled carts, similar to what we see in India today. The annual flooding of the Indus and Sarasvati water systems, as well as the water from the wells, were used in farming. The plough had been known before the urban phase of the civilisation.

Trade played a key role. This ensured the connection of the towns with the hinterland and the supply of the necessary raw materials - soapstone (steatite), lapis lazuli, carnelian, copper, tin, gold. The cities of the civilisation were linked by the rivers, as evidenced by the granaries built on the banks of the rivers, where the produce of the land for urban consumption was delivered. Judging from the occurrence of the Indus Valley finds, land-based trade relations were established with the interior of the subcontinent, Afghanistan, the coastal region of the Persian Gulf, and Mesopotamia.

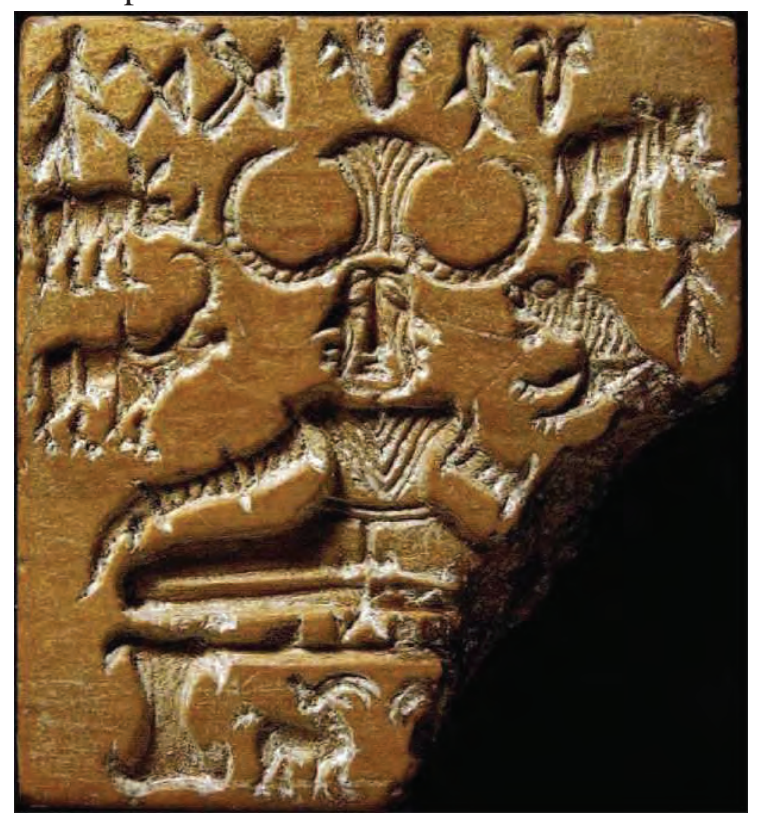

Figure 30: Male figure sitting in yoga pose. Indus Valley seal, Mohenjo Daro (Pakistan), 2600-1900 вСE

Source: https://commons.wikimedia.org/wiki/File:Shiva_Pashupati.jpg 
The religion of the Indus Valley Civilisation cannot be reconstructed, but it is certainly noteworthy that many elements of Indus Valley culture reappear in the later religions of the subcontinent. The striking presence of water in the cities and the "Great Bath" may suggest that water may have played a ritual role already at that time. The terracotta female figurines can be related to the mother goddess figures of the farming communities in Balochistan. The female figures depicted in of some of the seals - the female figure among the branches of a tree or the group of seven female figures - indicate the Indus Valley roots of the Mother Goddess, who was to play a major role in later Hindu cult, and the Indus Valley origin of the ancient symbolism based on the parallelism of female fertility and the reproductive capacity of nature. Phallic representation, the basic symbol of the later Shiva cult, and ring stones indicating female fertility appear already in the Indus Valley. The figures of the seals sitting in yoga posture suggest the ancient roots of the mode of sitting, and perhaps the meditation technique, used in later Indian religions (Figure 30). Representations of the seals include the short-stemmed cross and the swastika. The broken or angled cross, or swastika in Sanskrit, (from the words su + asti, 'well-being'), is an ancient symbol of the sun and fertility in Asia, a sacred symbol used in the religions of Indian civilisation, Hinduism, Buddhism and Jainism; its original meaning had nothing to do with the racist power symbol in twentieth-century Nazi Germany. The Indus Valley people initially buried their dead, and later cremation and placement of the ashes in urns spread.

\section{The Vedic Aryan lifestyle, religion and literature}

The Aryans - tribes, clans, ethnic groups - arriving in the Indian subcontinent brought radical changes: horseback riding, shepherding and fighting with horse-drawn carts, which secured their superiority over the local population. In their religion, brought with them from outside India, they worshipped many gods and goddesses. Hymns, prayers, songs addressed to their gods as well as magical formulas and commentaries to the sacred texts resulted in extensive oral poetry and prose literature, which was later organised into and handed down in collections. These literary works are the main source of reference to the Vedic age, i.e., the age of the Aryans appearing in India and their dispersion of North India. The loose tribal alliance of the Aryans covered a mixed population which only had its language in common, so their anthropological identification is not possible from archaeological finds. Apart from this, their archaeological traces are small, as they were nomadic shepherds and did not build cities. Their main occupation was cattle breeding, initially, they left farming to the local population. Their round or rectangular huts were built of bamboo and straw, and their houses 
and pens were surrounded by walls built from a palisade and rammed earth. Texts dating back to the period of settling the Ganges Valley already refer to larger, wooden, multi-room houses surrounded by gardens and settlements fortified with ramparts. However, there is no archaeological evidence to support this data.

The textual sources of the Vedic age are the Vedas (hence the name), the oldest and most sacred religious and literary works of the Aryans. The core of the four Vedas - Rigveda, Yajurveda, Samaveda, and Atharvaveda - consisted of a collection of hymns, to which later extensive commentary literature was added. Some of this included the rules and explanations of sacrificial rites (Brahmanas), others explained the symbolism of the sacrifices (Aranyakas), still others contained theoretical and philosophical speculations (Upanishads). The oldest hymns of the Rigveda were composed around 1500 BCE in the Punjab, while the geographical horizon of the three later Vedas reflects the process of settlement of the Ganges Valley. The Vedas originated and preserved in the oral tradition, and their most authentic versions are still passed on verbally. While manuscripts were written since the Middle Ages, the continuity of oral tradition has ensured the preservation of the over three thousand years old texts in their unaltered form. Complex recitation systems were created that provided for the literal memorisation of texts, including precise pronunciation of sounds, pitch, and accent. This system, which is unique in the world, was declared by UNESCO in 2003 as part of the Oral and Intangible Heritage of Humanity. Even later well into the historic period, orality remained a deeply rooted tradition of the Indian civilisation.

At the heart of Aryan religious practice were sacrificial rites that involved the sharing of sacrificial offerings with the gods and members of the community. During the fire sacrifices, animals or other sacrificial offerings (milk, purified butter) were offered to the Vedic gods (devas). There were other types of sacrifices, such as the rite of consecration of the ruler, or the great horse sacrifice, which strengthened or extended the ruler's power, or the ritual of soma pressing and consuming. The sacrifices were accompanied by a recitation of hymns addressed to the gods. The members of the populous world of gods and goddesses embodying natural forces and abstract notions inhabited the three spheres of the hierarchically structured world: the earth, the atmosphere, and the sky. Among the gods of the earthly sphere are Agni, the fire god, the embodiment of the sacrificial fire and mediator between men and the gods; Brihaspati, advisor of the gods and heavenly prototype of the earthly brahman priests; and Soma, the god of the intoxicating fermented drink used in ceremonies. The gods of the air are the warrior Indra, king of the gods; Vayu, the wind god; the unpredictable and destructive Rudra and the violent Maruts embodying storms. The heavenly gods include the celestial god Djaus, the Vedic equivalent of the Greek Zeus; Mitra 
and Varuna, the guardians of cosmic order; Surya the sun god and Ushas, the goddess of dawn moving before the sun; and Vishnu, personifying the pervasive power of the sun, who had not yet risen to the rank of chief god. Some of the sacrifices were extremely complicated and took several days or weeks to perform. The details of the construction of the sacrificial altar, the setting of auspicious times, the exact performance of the rites, the texts to be recited required knowledge, which was possessed only by the Brahmin priests, who gained great power by their indispensability. Among the patrons on whose behalf of the sacrifices were performed were Kshatriyas (warriors, kings) and wealthy Vaishyas (free commoners), who prayed for childbirth, wealth, or fertility of the land. Some of the sacrifices have survived in modern Hinduism, but the Vedic gods were replaced by later gods of Puranic mythology (primarily Vishnu and his incarnations, the manifestations of Siva and the various forms of the Goddess). The Vedic gods live on in an altered role as guardians of the directions.

\section{Formation of the characteristic social structure of Indian civilisation}

The supremacy of the Aryans soon led to the emergence of the distinctive Indian social structure, the Varna system, which strengthened and conserved their dominant position. Four hereditary social classes (Sk. varna, 'colour') evolved: priests (Brahmins), warriors (Kshatriyas), farmers, merchants (Vaishyas) and servants (Shudras). The members of the upper three varnas were Aryans, whereas the fourth varna was made up from members of the majority substrate population. At the top of the social hierarchy stood the Brahmin priests, the exclusive custodians of the sacred texts and sacrificial rites, and later the main practitioners of all spiritual activity. The kings came from among the Kshatriyas who held the leadership of the army and thus the actual power. While the Kshatriyas created the state power that protected the Brahmins and endowed them with donations, the Brahmins alone were called upon to ensure the sanctity and legitimacy of the royal power. As a result, as early as the late Vedic age, an interdependence developed between the two upper varnas, and their rivalry for leadership in the social hierarchy can be traced throughout the history of Indian civilisation. The Vaishya class was much more populous than the previous two and included those occupied with commerce, agriculture, and crafts. The members of the three upper varnas were the so-called 'twice-born' who underwent an initiation ceremony as they reached adulthood and received the sacred thread as a token of their ritual status. By this, they were born a second time and became full members of Aryan society: they could study the sacred texts and attend ceremonies and feasts. The task of the Shudras was to serve the other three classes. They were economically subordinate labourers or servants who were excluded from the ritual privileges of 
the 'twice-born'. Subsequent laws sought to prevent the intermingling of the varnas by prohibiting marriage between them, thus preserving the hierarchy formed during the Aryan conquest.

Manusmriti (Laws of Manu), which originated around the first century CE, already reflects a much more complex social system that emerged with the differentiation of the varna system. In this structure, there were a large number of jatis (later known as caste, a word of Portuguese origin), which were hereditary occupational groups or guilds practising endogamy (intra-group marriage). The caste to which the individual belonged by birth not only assigned his place in the hierarchy, but also his life task and opportunities. In addition to the four varnas, a large stratum emerged from the untouchables outside the varna system, which was associated with the development of the concept of ritual purity or impurity, which was not yet present in the Vedas. The untouchables (also known as Dalits, or Harijans, the children of God, a name given by Mahatma Gandhi,) pursued ritually unclean occupations and also included tribal ethnic groups, and nomads, who were subject to strict restrictions on contact with the dominant groups in society. The leader of the struggle for their rights during the independence movement was B.R. Ambedkar, a lawyer, politician, social reformer, who himself came from an untouchable caste. The caste system and untouchability were abolished by the constitution of independent India, but both still exist to this day.

\section{Late Vedic Age: Conquest of the Ganges Valley}

The Rigveda tells how the Aryans burned and destroyed the forests of the Ganges Basin to obtain cultivable land. In addition to the fire, horses, buffaloes, carts, wagons, vessels, bronzeware, and from the twelfth century BCE, iron tools contributed to the expansion. The late Vedic age (approx. 1100-600 BCE), the conquest of the Ganges Valley, archeologically corresponds to the Iron Age. In addition to cattle breeding, agricultural activity became increasingly important in the economic life of the Aryans. As it is mentioned in the Yajurveda, they used dozens of oxen to plough their land. Rice first appears in the Atharvaveda, geographically in the central Ganges basin. It seems likely that it was domesticated in China or Southeast Asia, from where it was transferred to the Indian subcontinent as a crop. In some of the centres in the Ganges Basin royal dynasties emerged (eighth-sixth centuries BCE). Four states: Kuru, Panchala, Kosala and Videha existed during this period. Along with the Ganges Basin, the Aryans were expanding south of the Jamuna River in what is now Madhya Pradesh, Gujarat, Maharashtra, Orissa, but in these regions, there seems to have been a closer interaction with the settled pre-Aryan farming population. 
The memory of the wars and conquests of the Vedic era is preserved in India's great epics, the Ramayana and the Mahabharata. Their text as known today was formed much later, between $400 \mathrm{BCE}$ and $400 \mathrm{CE}$, but, according to some researchers, the core of their story goes back to the Vedic period. In the focus of the Mahabharata is the great battle of the Kaurava and the Pandava tribes, which according to tradition may have taken place in the upper GangesYamuna Doab, around 1000 BCE. Through the exile of King Rama and his recapture of the throne of Ayodhya, the Ramayana narrates the conquest of the peninsula by the Aryans, all the way down to Sri Lanka. During the long period of their formation, the original length of both epics considerably increased due to the bardic tradition that allowed for amendments, interpolations and updates according to the current situation. In the process, the two epics grew into a veritable encyclopaedia of Hindu tradition and culture, a repository of examples of religious duty and morals to follow. Their historical authenticity is not questioned by Hindu tradition, although research has so far failed to substantiate this with archaeological data beyond any doubt.

Towards the end of the Vedic period, exponents of philosophical thinking formulating in the latest explanatory texts on Vedic sacrificial rites, the Upanishads, sought a connection between the microcosm of man and the macrocosm of the world. Upanishads have continued to be composed hundreds of years after the end of the Vedic period, but the oldest works of the genre, the Brihadaranyaka and the Chandogya Upanishads (between 800 and $600 \mathrm{BCE}$ ), are the most important from the point of view of the essence of Upanishad philosophy. The new thoughts emphasise the possibility of individual cognition, and the ultimate unity of all phenomena, which are only seemingly different. The supreme doctrine of the Upanishads is the identity of the absolute reality (brahman) and the inner soul of the individual (atman), which laid the foundations of later Indian philosophy of religion and mysticism. Many of the sages who appeared in the Upanishads were Kshatriyas, and the esoteric doctrine of rebirth (reincarnation) is also explained by a Kshatriya teacher. Experiencing identity with the divine essence can put an end to the chain of rebirths - this hope expresses the ultimate goal of every Indian religion. The birthplace of Upanishadic philosophy is the eastern Ganges Basin, Videha, the new centre of Vedic culture in which the religion of the substrate population in all likelihood had played a role. The ideas formulated here later gained their final synthesis in the highly influential philosophy of Sankara (eighth century CE). The diversity of the philosophical search in the late Vedic age is indicated by the fact that the doctrines of Sankhya and Yoga, two of the later Hindu philosophical systems, which were only written down as late as the first centuries CE, had already formulated by this time. Sankhya derives the creation of the world from the 
duality of two creative principles, Purusa (consciousness) and Prakriti (matter) whereas the philosophical and practical system of Yoga strives to eliminate this duality through meditation. Sankhya, Yoga and Vedanta are among the six orthodox schools of ancient Indian philosophy (darshana).

\section{The Age of Second Urbanisation: Jainism and Buddhism}

In the period between 600-200 BCE, the central Ganges basin, called Madhyadesha, the 'middle country', became the central area of Indian civilisation. An increasing proportion of the water-rich, fertile regions was brought under agricultural cultivation; rice cultivation expanded, and the population increased in both number and wealth. One millennium after the demise of the Indus Valley Civilisation, another process of urbanisation began. At the same time, in the region of the former four states, sixteen so-called Mahajanapadas or 'great countries' emerged which extended beyond the central Ganges Valley to Gandhara in the north-west and Bengal in the east and penetrated peripheries of the Ganges Valley and the areas to the south between the Jamuna, Narmada and Tapti rivers. The flat regions of the river valleys favoured the formation of kingdoms, while the typical state form in the mountainous areas was the oligarchic tribal republic. Roads between the cities were full of lively trade, as a sure sign of which minting began.

While from the Late Vedic Age but especially from the Second Urbanisation period society reached a higher complexity, the old Vedic religion became stiffened into excessive ritualism and the religious monopoly of Brahmin priests became unquestionable. Townspeople, particularly their affluent groups (merchants, officials) increasingly felt the need for a more personal religious experience. Some of the Kshatriyas were also receptive to non-mediated religious teachings precisely because of the excessive power of the Brahmins. In the forests, hermits, mendicants and self-mortifying ascetics proliferated whose religious ideals denied the ritual orthodoxy represented by the Brahmins. This religious fermentation is referred to as the Shramana movements (from the word shramana, 'ascetic'). In these were born the ideas that are among the popular concepts of later Indian religiosity, including emerging Hinduism: renunciation of the world, the chain of rebirths (samsara) imbued with suffering and liberation from it (moksha). Among the shramana movements, Jainism, which still exists today, and Buddhism, which has become a world religion, stood out and became independent religions.

Jainism is somewhat older of the two religions. Its founder, Vardhamana Mahavira lived between 599-527 or 540-468 BCE. He did not consider himself the founder of Jainism, but the twenty-fourth in the line of the Tirthankaras (Sk. 
'path-maker', 'ford-maker'). Like his younger contemporary, Siddhartha Gautama, he was born into a royal Kshatriya family. Resigning from the rank of a prince, he became a wandering monk, and after twelve years of self-mourning asceticism, overcoming the constraints of the body and the senses, he attained a state of enlightenment and was freed from the chain of rebirth. Henceforth, he was called Jina ('Conqueror'). During the three decades of his teaching, he organised his disciples into a strict monastic order and laid down the rules of conduct for lay believers as well. The cornerstone of his teaching is the perfection and perfect purification of the soul from the material impurities that cling to it as a result of deeds and bind it to the physical body through a multitude of rebirths. Consequently, eliminating such impurities also means escaping rebirth. The soul (jiva) from then on exists in a state of eternal splendour of omniscience. It may take a long time, probably a series of rebirths, however. Therefore, the purpose of earthly existence is not to seek direct enlightenment, but to practice a disciplined, meritorious, moral way of life and the supreme principle of nonviolence, with respect for all life, human and animal. Monasticism was accompanied by the observance of monastic vows and an ascetic lifestyle. In the latter, Jina set an example: he died at the age of seventy-two by starving himself to death.

Later, two main sects of the Jain monastic order emerged: the Digambara (Sk. 'sky-clad', i.e., naked), whose members went so far in suppressing the needs of the body as to give up clothing; and the Shvetambara, i.e., 'white-clad', whose monastic regulations are less stringent than those of the Digambara. Both sects still exist today. The Jain religion forbids all forms of violence and harm. The monks sweep the path at their feet so as not to extinguish life by stepping on some tiny creature and wear a mask in front of their mouths to prevent creatures from being inhaled inadvertently. For the same reason, lay followers avoid farming occupations, as animals in the ground may be injured during ploughing. Both monks and lay believers follow a strict vegetarian diet. Due to the ban on agricultural occupations, it was primarily the city dwellers, including many traders, who became followers of the Jain religion. The religious confirmation of the aspiring, active life may also have contributed to making the Jain trading community one of India's most successful trading communities. Their donations contributed to the maintenance of monastic communities and the flourishing of Jain temple architecture and art. Jainism has many important monastic centres and sites of religious pilgrimage, concentrated in the West and South of India. An image of Jina is placed in the main sanctuary of Jain temples, often built of white marble and abundantly decorated with carvings. The Jain religion also has a vast literary heritage whose works were written in Magadhi Prakrit, Sanskrit and New Indo-Aryan languages. The canonical texts of Jainism are called Agamas. The 
Jain religion did not engage in missionary activities but remained within India for a long time, and only expanded beyond the borders of India with the emergence of the diaspora. In India, it has a firm standing despite the relatively small number of its followers (less than $0.4 \%$ of the total population, around 4.5 million). In 2014, it was granted national minority status.

The founder of Buddhism, Siddhartha Gautama, later known as the Buddha (the 'Enlightened') (Figure 31), supposedly lived between 563 and 483 BCE. (There are considerably differing Buddhist traditions and scholarly opinions regarding the exact dates of his life.) There is little definite information about his life. His biography (Buddhacharita) interwoven with legendary and miraculous elements was written by Ashvaghosha in Sanskrit in the first century CE. He was a historical figure, born in Lumbini, on the border of present-day India and Nepal, as the son of the king of the Shakya clan. The latter is indicated by his later titles Shakyamuni ('Sage of the Shakyas') and Shakyasimha ('Lion of the Shakyas'). Miraculous signs accompanied his conception and birth, and, on the basis of his bodily signs, the visionaries predicted that he would become a world ruler or a prophet who saves the world. He received an education worthy of the heir to the throne; he studied, married, had a son, but was not satisfied. According to tradition, in the face of old age, sickness and death he realised suffering as the true nature of worldly existence, whereupon he became a monk to find a way out. He joined various monastic schools and pursued an ascetic life until he realised that excessive asceticism leads nowhere. As a consequence, he rejected the extremes of both self-mortification and worldly pleasures, seeking to follow the 'middle way' instead. After seeking the answer to the problem of suffering in vain for a long time, he decided to sit under a tree and meditate until he found a way out of suffering. After seven times seven days of fasting and deep meditation, he recognised the cause of suffering and found a way to be liberated; that is, he attained enlightenment.

The Buddha delivered his first sermon at Sarnath, near Benares, where, in the words of tradition, he 'turned the Wheel of Law'. For the remaining fortyfour years of his life, as a wandering teacher, he preached the truth he had recognised, the basic tenets of which are the 'Four Noble Truths' and the 'Noble Eightfold Path'. The 'Four Noble Truths' are as follows: existence is suffering; the cause of suffering is craving and attachment; suffering can be ended by eliminating desires; the way to end suffering is to follow the Noble Eightfold Path. The latter includes right view, right resolve, right speech, right conduct, right livelihood, right effort, right mindfulness, and right meditation. In everyday life, the Buddha considered moral conduct a must. He set out five precepts for lay followers: do not kill, do not steal, do not commit adultery, do not lie, and do not get drunk. In addition to this, monks were subject to a vow of celibacy and 
poverty. The community of monks (sangha) and its lay followers grew rapidly, and it also had wealthy supporters. The Buddha rejected the absolute authority of the Vedas and the birth privileges of the Brahmins. Although most of his disciples belonged to the Brahmins and Kshatriyas, this did not rule out that persons of lower origin join the community. By creating an order of nuns, the Buddha also allowed women to be admitted into the order. Some of his disciples had already set out by this time and preached the doctrine throughout India. With his enlightenment, the Buddha cut off the chain of his rebirths and with his death in Kushinagar, he attained Nirvana (Sk. 'extinction', liberation from the constraints of worldly existence). His body was cremated, and mounds of earth (stupas) were raised above his body relics distributed among the chiefs of eight countries.

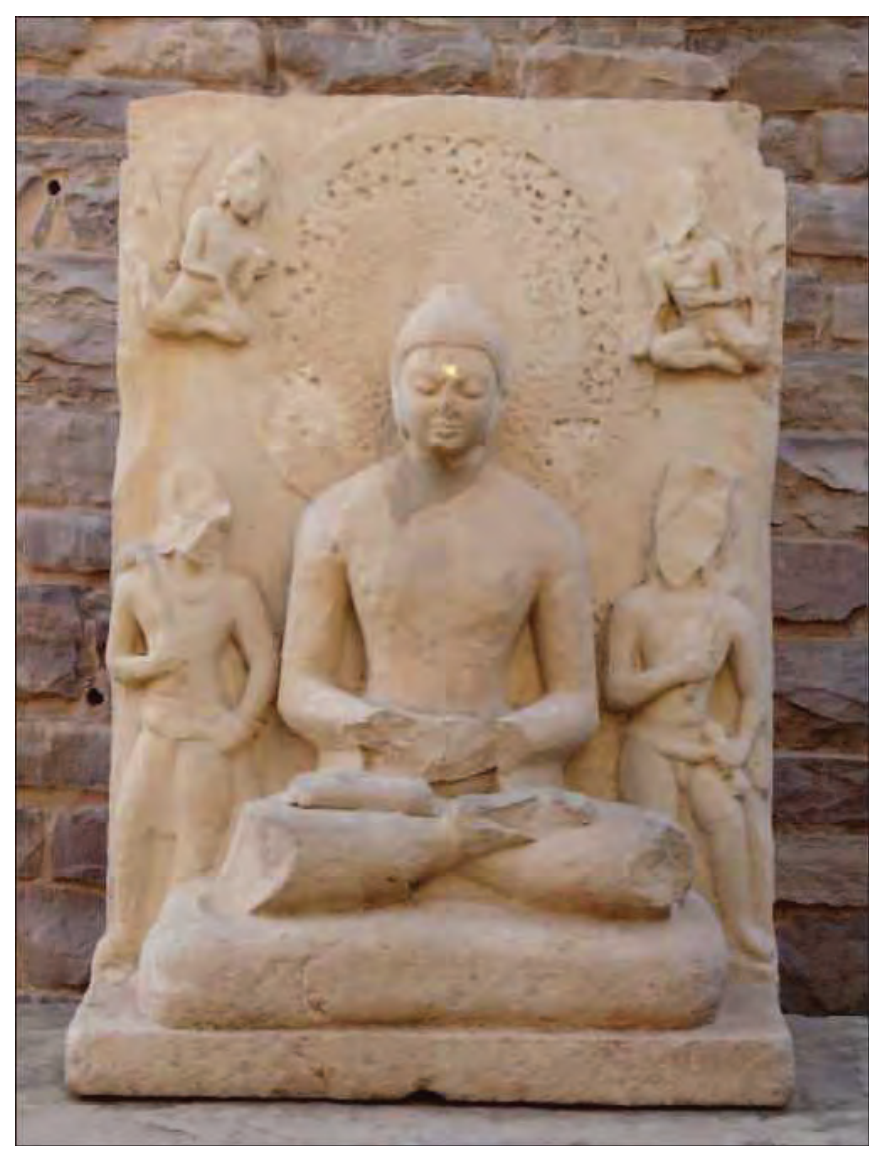

Figure 31: Meditating Buddha. Relief panel at the eastern side of Stupa I (Great Stupa). Sanchi (Madhya Pradesh), Gupta period, c. mid-fifth century Source: Photograph by ZsUZSANNA RENNER 
The Buddha did not write down his teachings, nor did he appoint a successor. The sangha, that is, saffron robe, regular meetings and the decisions made unanimously ensured the separation of the Buddha's disciples from his lay followers. According to the Buddhist tradition, after the Buddha's death, the members of the order gathered in Rajagriha to establish the main points of the doctrine (Pali Dhamma) and monastic discipline (Vinaya) as it lived in the memory of the disciples. The doctrine was preserved in oral tradition for a long time. The Councils that were convened from time to time sought to affirm the Buddha's teachings considered authentic, but differences of opinion increased, and Buddhism split into sects. The Canon was first committed to writing in Pali in the first century CE in Sri Lanka, and in Sanskrit in Kashmir, which sealed the splitting between the two main branches known today, Theravada and Mahayana Buddhism. Theravada Buddhism, the doctrine of the Thera (Pali 'elders') or the direct disciples of the Buddha, spread south of India, in Sri Lanka and Southeast Asia: Burma, Thailand, Laos and Cambodia, hence it is also called Southern Buddhism, while Mahayana (Sk. 'great vehicle', 'wide path') spread north of India: in Ladakh, Nepal, Tibet, Mongolia, China, Korea and Japan, and is therefore also known as Northern Buddhism. A relatively late development which grew out of Mahayana is Vajrayana ('diamond vehicle', 'diamond path') or Tantric Buddhism where spiritual emanations and a large number of Bodhisattvas including terrifying deities and their female counterparts form a complex esoteric system. In addition, mantras (magical formulas), mandalas (cosmograms) and other rites play an important role. The ideal of the Theravada is the arhat, the monk who has attained Nirvana, who, through individual self-perfection, is already freed from the bondage of desires on earth and is completely destroyed in death. However, this path is only open to a select few, which is why this trend has been called Hinayana (Sk. 'lesser vehicle', 'narrow path') with some mockery by the Mahayana devotees who, on the contrary, believed that they could attain enlightenment themselves. The ideal of the Mahayana is the compassionate and selfless Bodhisattva (Sk. 'enlightenment being') who has attained enlightenment but renounces Nirvana to help believers on the path to enlightenment.

The scriptures of Southern Buddhism is the Tipitaka (Pali 'Triple Basket'), i.e. a triple collection, which includes: 1. Vinaya Pitaka ('Basket of Discipline'), a collection of rules of the monastic community; 2. Sutta Pitaka ('Basket of Discourse'), which contains the speeches and sayings of the Buddha, and as such is the principal source of the Doctrine; 3. Abhidhamma Pitaka ('Basket of Special Doctrine'), the scholastic interpretation of the Doctrine. The canon compiled by the Theravada school had been preserved for centuries in oral form, until, according to Sri Lankan tradition, after the Third Council it was brought by Mahinda, the son or brother of King Ashoka, to the island of Sri Lanka, where it 
was written down in the first century CE. The teachings of the Mahayana are contained in texts called sutras, the most important which are the Mahavastu, the Lalitavistara, the Divyavadana and the Saddharma Pundarika. A significant portion of the original Sanskrit texts has survived in Chinese and Tibetan translations. Both the Theravada and Mahayana traditions see themselves as preserving the original teachings of the Buddha.

\section{Early Classical Age: the Maurya Empire}

Magadha, the easternmost of the sixteen Mahajanapadas, south of the Ganges (in what is now the state of Bihar), with its capital Pataliputra, became the starting point for the imperial aspirations of the subcontinent and expanded rapidly at the expense of the other Mahajanapadas. During this time, the areas of the north-western part of the subcontinent beyond the Indus River fell under the control of the Persian Achaemenid Empire for two centuries. Vedic and Iranian culture was equally present in Takshashila (Taxila), the capital of Gandhara. Persian rule here ended with the military campaign of Alexander the Great, who broke into India in 326 BCE. Crossing the Hydaspes River (today: Jhelum), he defeated the Indian armies marching against him, but due to the rebellion of his soldiers, he abandoned his plan for further Indian conquest. He advanced with his army along the Indus, then, leaving governors behind, he left India with some of his troops by land, the rest of his army returning to Persia by sea. However temporary, Alexander the Great's stay in India had far-reaching consequences, opening up the channel of communication between the Hellenistic world and India through which Greek and Persian cultural influences were to arrive on the Indian subcontinent for centuries.

The creation of the first great empire of the subcontinent is attributed to the Maurya dynasty. Chandragupta, the founder of the dynasty was originally from Magadha and ruled between 321 and 298 BCE. He united North India by expelling the successors of Alexander the Great. According to tradition, Chandragupta was assisted in establishing the empire by Kautilya (also known as Chanakya), author of the Arthashastra ('Textbook of Advantage'), a treatise on statecraft and political science. This classical work is considered by many to be of later origin, but some parts of it certainly date back to the Maurya period. Kautilya, prime minister and advisor to Chandragupta, covers every detail of governance in his work from warfare to the organisation of the empire and taxation. Its basic premise is that the state can overcome its neighbours by virtue of its economic power because it allows for the maintenance of a strong army. Kautilya recognised the importance of obtaining information; in his work, the system of couriers, spies and messengers is given appropriate emphasis. Chandragupta's 
grandson, Ashoka (268-232 BCE), extended his rule to the entire subcontinent except for the southernmost parts, and his empire stretched from Bengal to Afghanistan. However, during the war for Kalinga in East India, he felt remorse about the excessive bloodshed and converted to the Buddhist faith. Across the empire, he erected columns and placed rock edicts on which he had Buddhist religious teachings as well as principles of governance engraved.

Ashoka's royal support marked a turning point in the history of Buddhism. The converting activity of Buddhism outside India dates from the Third Council, which was convened on his initiative. Ashoka sent monks across the borders of India in all directions: Gandhara, Kashmir and other countries at the foot of the Himalayas in the north, Sri Lanka and modern-day Burma in the south. Although of these missions, so far only the Sri Lankan missionary activity has been proven as a historical fact, the Burmese Buddhist tradition also firmly preserves the memory of monks from India. The first and, for a long time, only Buddhist kingdom in Sri Lanka later became the source of the spread and many renewals of Buddhism in Southeast Asia. However, the Third Council did not involve the entire Buddhist community, so the separation of the northern and southern branch of Buddhism is likely to have taken place by that time.

\section{Literacy}

After the disputed Indus Valley antecedents of the literacy of Indian civilisation, the earliest coherent historical writings are the pillar and rock inscriptions of Ashoka (third century BCE), written everywhere in the local Prakrit languages. To encode them the so-called Brahmi script was used, from which all the writings of India and Southeast Asia are derived, including the Devanagari, which is used to record Sanskrit and Hindi. Short Brahmi inscriptions also survived on pottery fragments from the fourth century BCE. The Brahmi and its derivatives are syllabic scripts, in which syllable-forming vowels are indicated by diacritical marks linked to the consonants. At the same time, the north-western inscriptions of Ashoka were written in Kharosthi, another script which was used in Gandhara, Pakistan, Afghanistan, and later in Bactria and the Kushan Empire. Inscriptions, engraved in stone and later on copper plates, are among the most important written relics of Indian civilisation until the end of the Hindu dynasties. Inscriptions on coins have survived from earlier times. The lifespan of organic medium (palm leaves, birch bark, paper) under the tropical climate is in most cases not very long. The earliest surviving copy of palm leaf manuscripts, dried and smoked, pierced and bound with a string into a book, is a ninth-century Shaiva text preserved today in the Cambridge University Library. The average lifespan of manuscripts written on paper in India is usually only 200-300 years, 
therefore collections which contained this type of manuscript (e.g., the genealogical records of Brahmin communities) were constantly copied. The earliest manuscripts on paper have survived from the Middle Ages. The oldest manuscript of the Rigveda, also on paper, dates from 1362 and is held by the Library of the Asiatic Society of Bengal.

\section{The emergence of Buddhist art}

After a gap of about one and a half millennia following the prehistoric antecedents of the Indus Valley Civilisation, art reappeared in the Maurya period. The surviving fragments of the palace of Pataliputra (the capital) reflect Persian and Greek influence; this is not surprising since the north-western parts of the subcontinent, Bactria and the upper Indus region, that had been conquered earlier by the Achaemenid Empire and then by Alexander the Great came under the rule of Maurya Empire through the conquest of Chandragupta. North Indian territorial unification had a stimulating effect on trade and diplomatic relations. Megasthenes, a Greek historian and diplomat, spent four years at Chandragupta's court in Pataliputra as the ambassador of Seleucus I Nicator. In the wake of these relationships, Persian artistic influence appeared in the power symbols of the imperial art of the Mauryas. Soon after the most famous of these, the Lion Capital

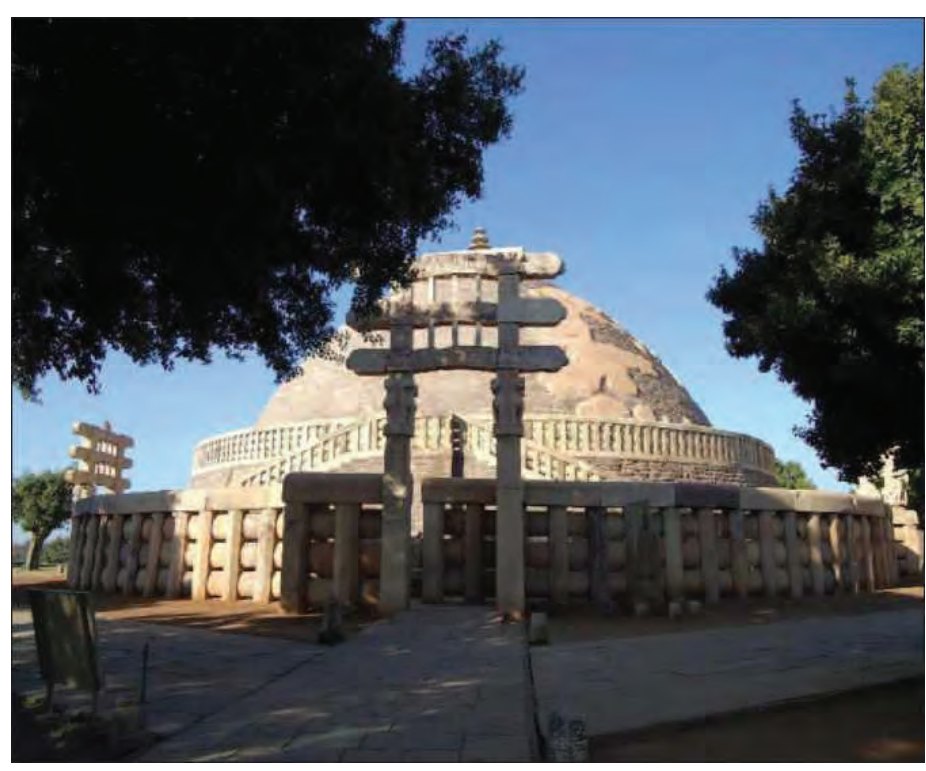

Figure 32: Stupa I (Great Stupa) at Sanchi (Madhya Pradesh), third century BCE through first century CE

Source: Photograph by ZsuZsAnNa RENNER 
of Ashoka, gained a new symbolic content, simultaneously manifesting the glory of the emperor (Sk. chakravartin) and the Buddha.

Emerging Buddhist art took on many foreign elements, but was also nourished by local sources: oversized, heavy and corpulent depiction of nature spirits and demigods of the folk cults (yakshas and their female counterparts, the yakshis) played an important role in the development of the Indian-style Buddha and Bodhisattva depictions.

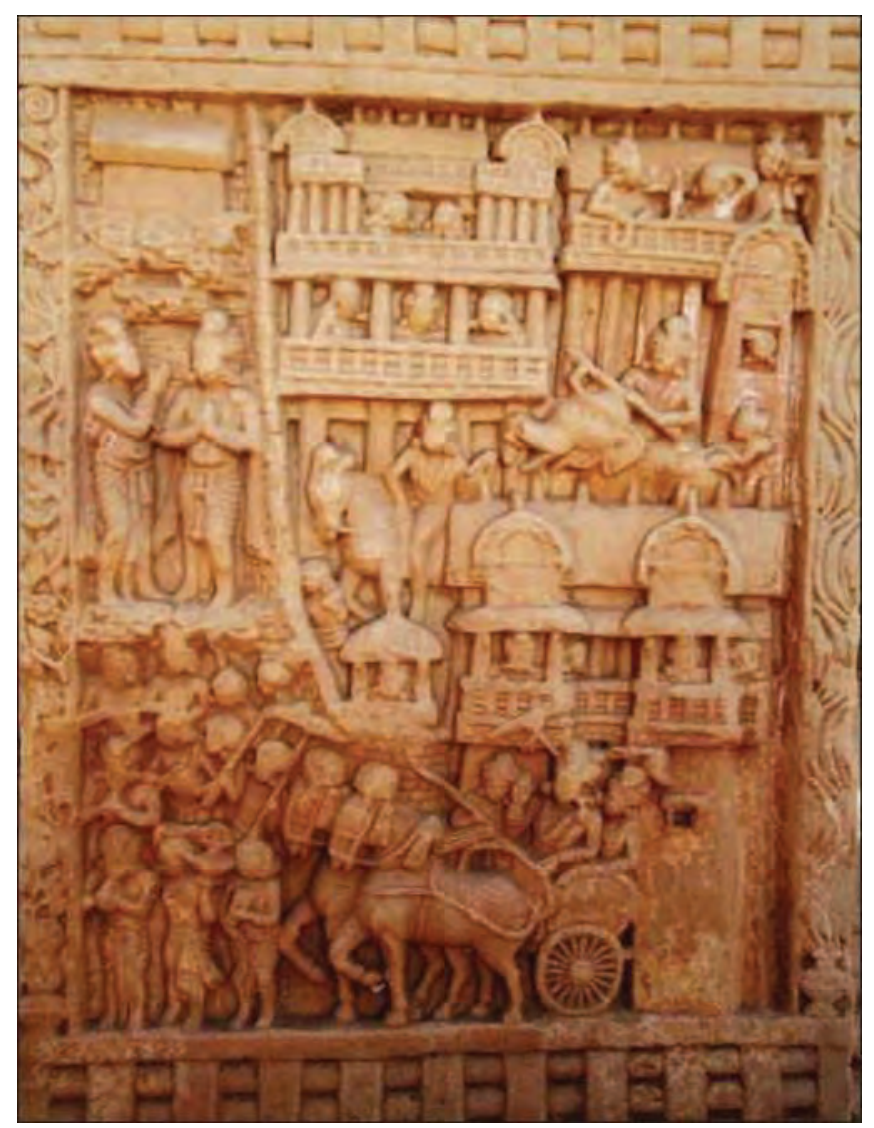

Figure 33: Bimbisara, the king of Rajagriha emerging from the royal palace to visit the

Buddha. Relief at the eastern gateway of Stupa I (Great Stupa). Sanchi (Madhya Pradesh), c. second-third decades of the first century CE Source: Photograph by ZsUZSANNA RENNER

The most characteristic edifice of the Buddhist cult is the stupa. The first stupas were used to house the bodily relics of the Buddha. Initially, they were simple mounds of earth, later they were covered with bricks or stone and surrounded by a railing. The hemispherical body of the stupa symbolised the sky, 
the column in its centre represented the world axis (axis mundi). The path of ritual circumambulation (Sk. pradakshina, 'to the right', that is, the object of reverence always has to be to the right of the worshiper) referred to the apparent orbit of the sun. The ornate gateways opened to the main directions in the railing separating the sacred area from the secular environment, and the plan of the stupa formed a swastika, a cross with broken arms, the ancient symbol of the sun. Of the early stupas, the stupa at Sanchi (Madhya Pradesh) can be seen today in its former glory (Figure 32). Its gateways are covered with carvings from the first century CE, depicting stories of the life and previous incarnations of the Buddha, embedded in bustling scenes of contemporary urban and rural life (Figure 33).

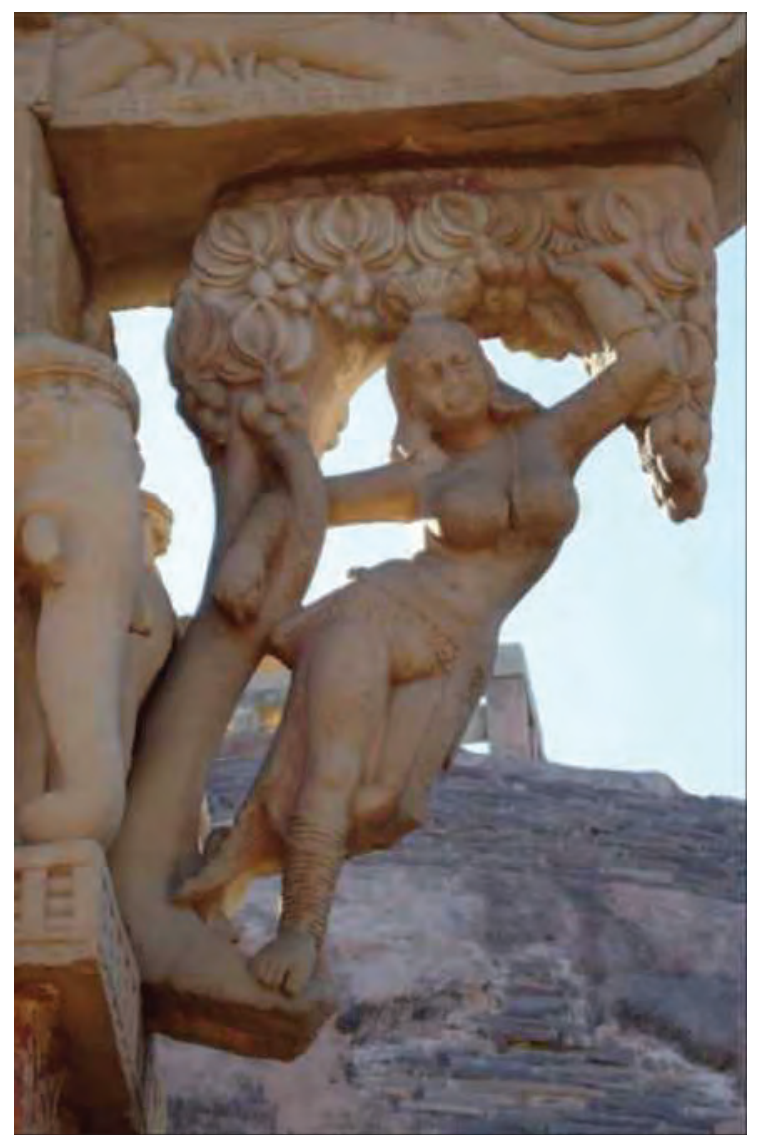

Figure 34: Tree goddess at the eastern gateway of Stupa I (Great Stupa). Sanchi

(Madhya Pradesh), c. second-third decades of the first century CE

Source: Photograph by ZSUZSANNA RENNER 
The inscriptions on the reliefs record that the Sanchi monastic centre and Buddhist community were supported by many wealthy merchants, guild leaders, male and female city dwellers, thus contributing to the maintenance of a religious set-up that benefited them. The seductive female figures appearing in the surroundings of the stupas, yakshis and tree-goddesses, whose voluptuous forms are scarcely covered by their veil-like garments, underline a conspicuous feature of Indian culture. Sacred art in India is not restricted to religious images and symbols, but encompasses, for instance, fertility symbols and erotic depictions that are regarded auspicious, sanctifying and fortune-bringing. As such, they are not alien to the religious context, be it a Buddhist monastic complex or later, a Hindu temple (Figure 34). The shrines and gathering places of early Buddhism were often set up in caves. In addition to their obvious climatic role in providing protection from the heat of the tropical sun and the monsoon rains, caves naturally carry the basic symbolism of Indian temple architecture which is based on the relationship between the mountain and the mountain cave, the temple tower and the main shrine below, standing for the heavenly abode of the gods and the place of their earthly incarnation respectively.

In early Buddhist art, there is an absence of the portrayal of the Buddha himself; his presence is merely indicated by symbols: an empty throne, an umbrella, footprints, the tree of enlightenment, etc. The reason for this is not quite clear. It has been long assumed that the Buddha himself forbade his depiction, and this ban remained in force as long as his human nature was a living tradition. When, with the intensification of theistic religious tendencies, people began to worship him as God, his anthropomorphic form appeared in reliefs. This happened at about the same time in Gandhara in the north-west, and in Mathura, on the banks of the Yamuna River. By supporting Buddhism, the Central Asian Kushans, who united Hellenistic Bactria and North India to Mathura under their rule, gave an impetus to the consolidation and spread of the Buddhist religion toward China and Central Asia. This is also the period of the consolidation of Buddhist iconography, which has become a common ground for the symbolic depictions of the Buddhas and Bodhisattvas not only in the Indian subcontinent but throughout the Buddhist world. The Buddha is always depicted as a monk, with a shaved head, in a monastic robe, while the Bodhisattvas appear in princely attire, richly adorned. Body postures and hand gestures are fixed and mostly reminiscent of important events in the Buddha's life, e.g. the meditation posture refers to the weeks of the Buddha's deep contemplation before enlightenment, the teaching gesture symbolises his first sermon, and the reclining posture his passing to Nirvana. Of the auspicious marks on his body, the elongated ears, the triple fold of skin on the neck, the cranial protuberance at the top of the head, and the tuft of hair between the eyebrows are almost always depicted, as are 
sometimes the wheels (chakras) on the palms and soles, the arms reaching to the knees or the huge body size. In the Kushan era, two traditions of Buddhist art developed: the Gandhara school, which, under the impact of Hellenistic style, gave birth to almost Apollo-like Buddhas, and the school of Mathura, which grew out of the local tradition of flesh-and-blood yaksha depictions. The masters of the Gandhara school created the giant Buddhas of Bamiyan in Afghanistan on the north-western fringe of the subcontinent in the fourth-fifth centuries CE, which were demolished in 2001 by the Taliban, who belong to the radical branch of Islam. The Gandhara style, spreading north along the Silk Road, left a deep imprint on the art of northern Buddhist countries. In Southeast Asian Buddhist art, some new iconographic types of Buddha depictions have also emerged, and they often portray giant Buddhas as well as the Buddhas of past world eras. In the countries of northern Buddhism, the innumerable Bodhisattvas of the Mahayana and Vajrayana pantheon serve as an inexhaustible source of representations. The images of Avalokiteshvara, the Bodhisattva of Compassion is particularly popular.

\section{The culture of the classical era}

The classical era of Indian civilisation begins with the closure of the Maurya period and last up to the end of the Gupta period. During this time, the significant events in the history of the subcontinent took place in four major regions. The eastern Ganges basin remained the starting point for unification and imperial ambitions within the subcontinent. It was the core area of the Shungas who succeeded the Mauryas and then of the Gupta dynasty. Both dynasties were Hindu. The northeast region continued to be the base of the subcontinent's conquests, a scene of cultural interactions and blending. The Indo-Greek, IndoScythian, Indo-Parthian and Indo-Sasanian kingdoms (second century BCE to first century $\mathrm{CE}$ ) and then the Kushans (first to third century $\mathrm{CE}$ ) gained prominence here, and their power sometimes penetrated further into the subcontinent. In the Deccan, an independent kingdom emerged under the rule of the Satavahana dynasty, whose sway spanned the peninsula from the Arabian Sea to the Bay of Bengal. In South India, Tamil-language literature flourished (Sangam era, c. 300 $\mathrm{BCE}$ to $300 \mathrm{CE}$ ), reflecting the social structure of the South free of rigid caste constraints and the emergence of a classical culture that was still to a great extent independent of the North. By the end of the Sangam period, the three dominant kingdoms of South India: the Chola, the Chera and the Pandya, were formed. 


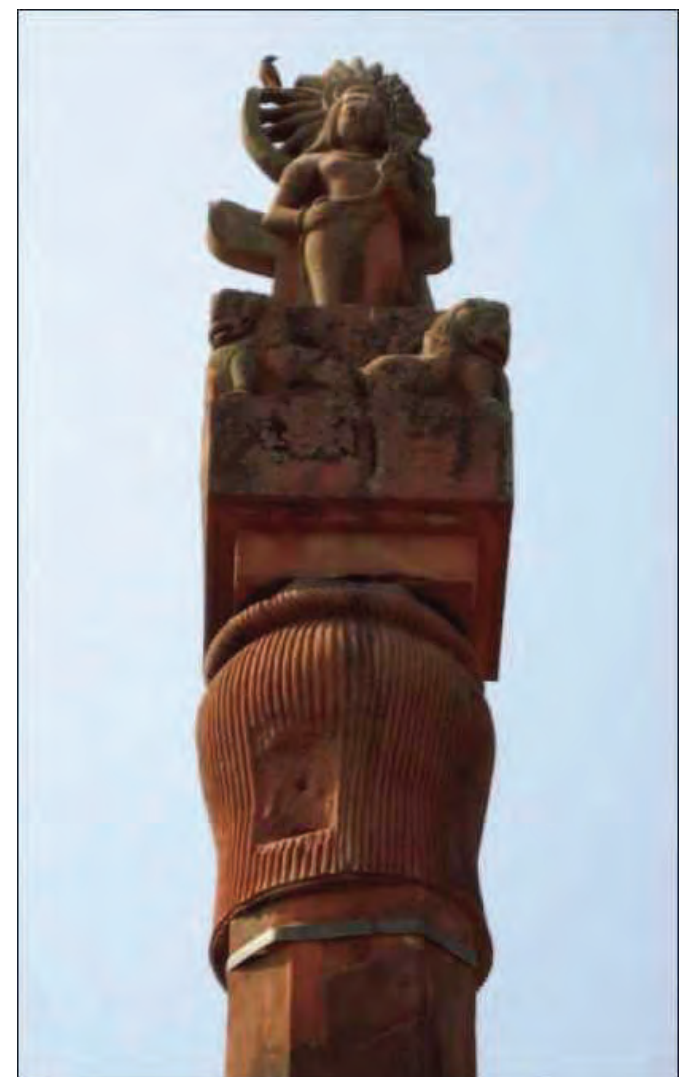

Figure 35: Upper part of a pillar from Budhagupta's reign depicting the mythical sunbird Garuda. Eran (Madhya Pradesh), Gupta period, 484 CE

Source: Photograph by ZsUZSANNA RENNER

The Gupta Dynasty, whose reign (c. 320-550 CE) is commonly referred to as the golden age of Indian civilisation, ruled over northern India and the Deccan, including the territories of the allied Vakataka dynasty. Owing to the military successes of the Gupta rulers, for the first time in centuries it was possible to subjugate foreign tribes and power centres and centralise the empire. The long development of the preceding periods and the stability of domestic politics brought with them outstanding civilisational achievements and an unprecedented, sophisticated urban culture, to the financial basis of which extensive longdistance trade largely contributed. From this age, the first temples dedicated to Hindu gods survived, and due to royal support, the Brahmins once again came to prominence. The sciences (medicine, mathematics, and astronomy), philosophy, Sanskrit literature and the arts flourished. Kalidasa, the most distinguished ancient Indian playwright and poet who raised Sanskrit court poetry and prose 
(kavya) to unprecedented heights, lived in the fifth century. His works started to be translated into English and German in the late eighteenth century. Gupta arts sought the ideal forms. The language of kavya is ornate, full of poetic images, puns, ambiguities. Not only the performing arts (music, dance, theatre) but also the literature were to a large extent influenced by the Natya Shastra, a handbook of dramatic art attributed to Bharata, believed to have been written between the first century BCE and third century CE. The Natya Shastra laid the foundations of Indian aesthetics by formulating the theory of rasa ('taste'). According to this, the aesthetic taste or essence of any work, be it music, drama or visual representation, evokes the desired feelings and helps the viewer to reach a kind of catharsis aimed at experiencing transcendent reality. Rasa aesthetics was meant for an educated, receptive audience, thus indirectly referring to the high cultural standards of urban society in the Gupta era.

A remarkable aspect of urban life in the fifth century is revealed by the Kama Sutra ('Textbook of Love'), which, in addition to its erotic motive, displays a surprising level of sophistication and an interest in human relationships and women's literacy. Sanskrit literature also abounded in popular stories and tales. The Panchatantra, a collection of tales that reached Europe as early as the eleventh century, originally belonged to a series of works on political ethics (nitishastra) and, as such, was intended as a code of conduct for kings. In its aphorisms, cunning and wits appear as essential virtues. In the south, the Pallava kingdom (fourth to ninth century) supported the adoption of Sanskrit culture, which was accompanied by donations to the Brahmins and a unifying effort to replace the tribal fragmentation of the previous era. At the same time, Tamil secular and religious literature reached its zenith. The development of poetry proclaiming devotion to Shiva and Vishnu, which spread the devotional bhakti cult and poetry throughout India, had a profound impact in the history of Hinduism.

In the fine arts, purity and harmony prevailed. It is at this time that sculpture created in the representation of the human body a classical Indian tradition masterfully combining aspects of asceticism, spirituality, and sensual beauty. Similar to Buddhist depictions, Hindu iconography had also reached its full-fledged form by this time: Vishnu and his avatars (incarnations) and the various manifestations of Shiva are all depicted with their regular postures, gestures, attributes and mounts. Multi-armed and multi-headed images are frequent as symbols of omnipresence and omniscience. Vishnu wears a high headgear, a garland of forest flowers around his neck, and royal jewellery; in his hands, he holds a discus, a conch and a mace. His mount is the mythical Garuda bird (Figure 35). In a typical iconographic form, he is reclining on the coiled body 
of the Serpent of Infinity, a lotus growing out of his navel with the god Brahma, the creator of the world (Figure 36).

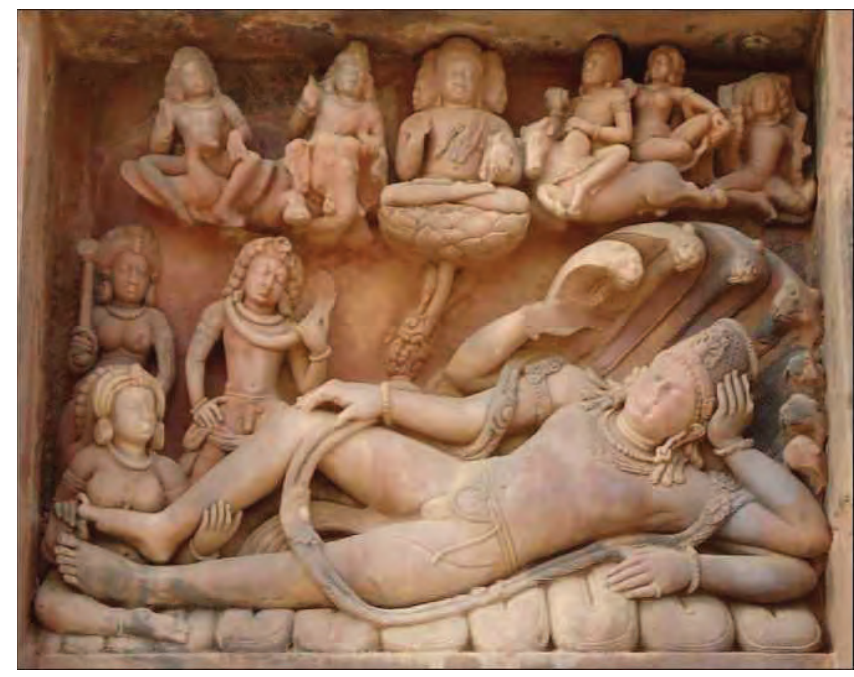

Figure 36: Vishnu lying on the Serpent of Infinity (detail). Dashavatara Temple, Deogarh (Uttar Pradesh), early sixth century Source: Photograph by ZsUZSANNA RENNER

Vishnu's female counterpart, Shri Lakshmi, the goddess of good fortune, abundance and happiness, whom he is often portrayed with, largely contributed to his popularity. His ten avatars - Fish, Tortoise, Boar, Man-Lion, Dwarf, Parashurama (Rama with an axe), Rama, Krishna, Buddha (or Balarama) and Kalki are depicted on their own, in groups of ten, or around Vishnu. Shiva, known as the Lord of Yoga, often appears as an ascetic. He does not wear a headgear but has the crescent moon pinned to his matted locks of hair piled up on top of his head. The third eye in the middle of his forehead is the sensory organ of transcendent vision. A tiger's hide is thrown over his breast, and a cobra curls around his neck. As the Lord of the Dance (Nataraja), he destroys the universe with his violent dance. His main attributes include the trident and the hourglassshaped drum; his mount is Nandi, the white bull. His spouse is Parvati, daughter of the Himalayas; his children are the elephant headed Ganesha, remover of obstacles, and the war god Skanda (Kartikeya). He is most often represented in the aniconic form of his phallic symbol, the linga (Figure 37). The creator god Brahma has four heads; he sits on a lotus throne or a white goose, in his hands holds a book (the Vedas), a sacrificial spoon, a rosary and a jar full of the nectar of immortality. The earliest surviving Hindu temples date back to the Gupta era. 


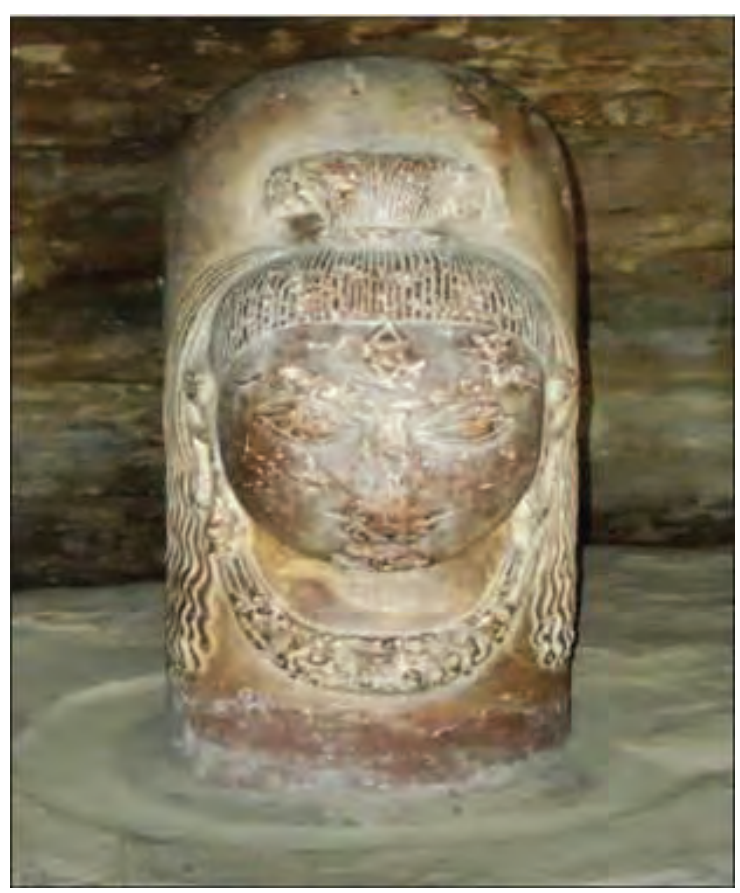

Figure 37: Linga with the head of Shiva. Udayagiri (Madhya Pradesh), Cave 4. Gupta period, early fifth century Source: Photograph by ZsUZSANNA RENNER

\section{Hinduism}

The Hindu religion does not have a founder; therefore, it does not have a starting date either. Its origins are mixed and complex; during its formative period of about two thousand years, countless layers and impacts contributed to its evolution. Historically, it was formed by incorporating local traditions, cults and rites during the expansion of the Aryan civilisation on the subcontinent. The two main strands of these are the Sanskrit literature of the Vedic Aryans and their pantheon of many gods who often personify natural phenomena, and the religion of pre-Aryan peoples, centred on the cult of the mother goddess and fertility. Hinduism that is comparable to its today's form developed in the first centuries of our era and reached maturity in the Gupta period. Vishnu and Shiva then emerged as principal deities, and the tradition of the Goddess (Devi) of various names appeared.

The characteristics of Hinduism are difficult to define in general. Not only a founder but a holy book obligatory to all believers, teaching accepted by all, cannot be named; it has no common church, no elaborated dogmas. It well 
accommodates ardent devotion to the godhead and atheism; exalted philosophies, folk cults, tree and snake worship; non-violence (ahimsa) and animal sacrifice. Given the circumstances and history of its formation, it is not surprising that Hinduism is not a religion, but a mixture of countless religions and cults that have never been forged into a homogeneous system. The name Hinduism itself is recent and not even Indian; it was coined by the nineteenth-century British scholarship to denote the typically Indian religious ideas and practices. The name Hindu is much older: the peoples living beyond the Indus River were so named by the Persians and Greeks. In the Middle Ages, the inhabitants of the subcontinent began to apply it to themselves, as opposed to the Muslim conquerors of North India, and from there it was only one step for the word to acquire a religious meaning. Ever since the concept of Hinduism was accepted in India, its followers have named their religion as Hindu Dharma, a version established in Indian languages. The term Sanatana Dharma ('eternal religion'), which emphasises the eternal spiritual nature above the differences in the religious practices of Hinduism, is also widespread.

The most striking feature of Hinduism is probably the multitude of gods, so it seems to be a polytheistic belief. However, since the Hindu believer only reveres as supreme god the one whose worship is established by tradition in his family, we can speak of religious pluralism rather than polytheism. On the other hand, Hindu believers do not deny the existence of the other gods either. They believe that the divine essence can manifest itself in an infinite variety of forms, so the path to it is also many. Religious practices can also be different. Going to the temple is not obligatory, nor is faith in God; one can be a Hindu as an atheist simply by being born into a Hindu caste.

Despite the prominent role of spirituality, the social aspects of Hinduism are remarkable. The social hierarchy (varna and caste system) interwoven and reinforced with the rules of ritual purity and impurity inseparably intertwined with the precepts and practices of the Hindu religion. The support of the ruling dynasties, on whom not only the construction of temples symbolising the divine origin of the kingdom but also the royal donations for the maintenance of the priestly class depended, decisively influenced the history of Hinduism. Religion and society are profoundly interrelated through a system of basic concepts such as the four aims of human life, the doctrine of the duties of social classes and life stages (varnashrama dharma), or the observance of customs associated with rites of passage (sanskaras: birth, name-giving, first haircut, marriage, etc.). The four purposes of life are dharma, a set of religious and ritual prescriptions for one's own life situation and social group; artha, meaning money, wealth, or simply livelihood; kama, meaning sensual, marital pleasures; and moksha, union with the transcendent. The doctrine of the four goals of life gave justification to living the 
various aspects of life, whereas the concept of varnas and phases of life contributed to their balance by designating the emphases of the particular life periods. The task of youth was to learn, of an adult man to establish a family, support it and have children; of the ageing man to retire and, in the final phase of his life, to wander about as a homeless renouncer, preparing to exit worldly existence. The most emphatic Hindu concept is the dharma, which means the religion itself and, more broadly, the whole system of rules which includes the individual's own life tasks and the duties arising from belonging to different social groups. The latter primarily include caste obligations, but others as well, such as the duties of women or kings. The most authoritative source of Hindu law (dharma) in Ancient India was the Code of Manu (Manusmriti, also known as the Manava Dharmashastra), created around the first century CE. Topics discussed in it include the ordinances prescribed for each period of life, the rites of passage, the duties of castes and the ruler, and the administration of justice. Thus, in addition to the criminal law exercised by the ruler, the dharma as religious law, religious practice, duty, virtue, a norm of conduct is given a focal role in the work. The Code of Manu is thus primarily a collection of prescriptions for lifestyle and behaviour. In subsequent codes (dharmashastras) the purely legal nature came to the fore.

Another fundamental concept of the Hindu religion is karma, which means destiny as determined by the actions of a previous life. Hindu believers who follow the precepts of their religion strive to earn a better fortune in their next life and, through a series of rebirths, to get ever closer to salvation (moksha). Indian religions (Hinduism, Buddhism, Jainism) accept the concept of the transmigration of the soul, and for all of them, salvation means getting out of the cycle of life called samsara, breaking the chain of rebirths. In the context of Hindu religion, the only way to live a virtuous life is by following one's dharma, that is, by strictly adhering to the regulations concerning one's social status. If one is a king, should excel at performing royal duties; if one is a tanner, should excel at finishing leather. The caste system stiffened precisely because individuals could only complete their life goals at the very place of the social structure they were born, and only by obeying their destiny could they hope to have a better rebirth in their next life.

For most Hindus, the Bhagavad Gita ("The Song of the Lord") is one of the most sacred texts. Presumably, it was created between the fourth century BCE and the second century CE and has survived as part of the Mahabharata. The decisive battle between the opposing Kauravas and the Pandavas is imminent but Arjuna, who is leading the army of the Pandavas, is in despair as he is about to shed the blood of his cousins and relatives. At this point, his charioteer, Krishna, reveals his supreme divine form to Arjuna and addresses him a speech. Man must 
fulfil the task society imposed on him. It is warrior's duty (dharma) to fight but driven by a sense of duty, not out of hatred, knowing that only the body can be destroyed, the soul (atman) is immortal; it wanders through a multitude of rebirths in the cycle of life in search of liberation (moksha). In his theophany, Krishna presents himself as the Ultimate Reality (Brahman), from whom all living entities and all phenomena of the world flow out at the beginning of creation, and eventually fall back there. The phenomenal world is nothing but magic, illusion (maya); Krishna offers devotion (bhakti) felt for him as one of the ways of liberation.

The doctrines and cults of Hinduism were elaborated and affirmed in the Puranas that gathered together myths, legends, and oral traditions. One of the concepts put forward was the cyclical creation of the world and, related to it, the figure of the almighty deity who created, sustained, and destroyed the world. The main cults, Vaishnavism, Shaivism, and Shaktism developed around Vishnu, Shiva and the Goddess (Devi) respectively but over time the cult of Krishna also grew into an independent religion. Theologians sought to reconcile the divergent traditions of Vishnu and Shiva in the construction of the Hindu Trinity (Trimurti), in which the sustaining role of Vishnu and the destructive role of Shiva were complemented by Brahma as creator, and in which all three deities were seen as the manifestation of the supreme transcendent essence, the Brahman. However, this remained largely at the level of speculation, partly because the significance of the cult of Brahma was negligible compared to that of Vishnu and Shiva. The ancient female principle of the mother goddess (Magna Mater, 'Great Mother') was manifested in the many different names and forms of Devi, in her independent cult and her role as the female counterpart of the main gods. Mother goddesses (matrikas 'mothers') were also worshipped and depicted in groups. The Puranas devote ample space to the description of temples and images, as well as to the benefits to be gained from visiting holy sites, thus consolidating the Hindu tradition of temple cult, visual representations, and pilgrimages.

The tendencies of Hinduism changed over historical periods. As the members of the Gupta Dynasty were devotees of Vishnu, during their reign, Vishnu cult strengthened with royal support. In the age of the Hindu dynasties that replaced the Guptas, the prevalence of Shaivism can be observed as a general phenomenon, which, however, did not mean at all the complete marginalisation of Vaishnavism. Often within the same dynasty, either Shaiva or Vaishnava rulers took the throne. The Islamic rule in India, most powerful between 1200 and 1750, is characterised by the increasing strength of the bhakti movement and the enhanced role of the community's cohesive power. The age of colonisation had a decisive impact on the development of modern Hinduism. On the one hand, Hindu thinkers and reformers began to look at their own traditions through the 
lens of European authors and critics, which sparked revival movements. First, Ram Mohan Roy's movement (Brahmo Samaj, 'Society of Brahma', 1828), and then the Arya Samaj ('Society of Aryans', 1875) set the goal of reforming Hinduism. On the other hand, due to its intertwining with the independence movement, Hinduism took on a political hue at this time. The adoption of the concept of Hinduism came handy in forging a national unity that had a Hindu character from the outset. The emphasis on the sanctity of the Vedas (another concept emerging from the West) and the idea of a 'mystical India' also proved to be a useful tool for counterbalancing religious differences. The patriotism of the Hindu revival movement, which made India the holy land of Hinduism, intertwined with the cult of bhakti, and the mysticism of the Bengali Ramakrishna was vested with the role of a new nation-building force. Ramakrishna's chief disciple, Vivekananda, who spread his ideas in the West, and the Theosophical Society founded in South India but relocated to New York in 1875, played an important role in spreading Indian religious and philosophical ideas to the West.

Hindu religious practice and the Hindu way of life traditionally involves several other deeply-rooted phenomena and habits such as religious festivals that often last for several days, vegetarianism which is based on the principle of noninjury (ahimsa), respect for cows, the living tradition of the caste system, and arranged marriages based on caste compliance and horoscope matching. However, in the practice of all this, significant social and regional differences can be observed, which are also influenced by the urban or rural environment, and the cultural background of the practitioner.

\section{Early Middle Ages: The age of Hindu dynasties}

The disintegration of the Gupta Empire was followed by centuries of political fragmentation in the subcontinent. Next time it was the Muslim Mughal Dynasty to establish a centralised state, bringing almost the entire subcontinent under its sway in the mid-sixteenth century. Regional Hindu kingdoms emerged and were continuously at war for supremacy over the numerous local vassal states. In the north-east the Palas (eighth to the twelfth century), in the north-west the Gurjara-Pratiharas (seventh to the tenth century), in the south-west the Rashtrakutas (eighth to the tenth century), in the Deccan the Chalukyas (seventh to the eighth century), in the south the Pallavas (seventh to the ninth century) and the Cholas (ninth to the thirteenth century) ruled over extensive territories. Unlike the Western-type state, the states of the subcontinent were defined by their centre, not by their territorial extent. The capital city was the seat of the divine ruler and the focus of cosmogonic concepts regarding world order. The power of the ruler, in its entirety, prevailed only in the immediate vicinity of the centre and with 
distance, it gradually decreased. The dependence of the peripheral areas was loose or nominal. The kingdom may have been encircled by secondary and tertiary centres of vassal areas in multiple rings. This type of state structure, whose exercise of power was already described in Kautilya's Arthashastra, has been called mandala state by researchers (the mandala being a diagram depicting the universe with a presiding deity in its centre surrounded by multiple rings of protection). In the sacred centre of the kingdom, the king had his temple built, and in its sanctuary, he had the image of the deity he worshipped erected, thus proclaiming the divine origin of his power. Rooted in India, the concept of devaraja (Sk. 'god-king', i.e. deified monarch) and its cultic and architectural dimensions took a mature form in the Southeast-Asian kingdoms; however, the need for a charismatic exercise of power also resulted in the emergence of a multitude of sacred centres in India. This gave a huge boost to the development of Hindu architecture and sculpture. Buddhism was pushed back to Northeast India in the eighth century, where it experienced its last Indian heyday during the Pala dynasty. In the early thirteenth century, conquering Islam destroyed its thriving monastic centres and famous universities (Nalanda, Vikramashila). Its monks fled abroad, and Buddhism practically ceased in India. South India was first united by the Chola kings. The dynasty of Tamil origin emerged as a land and sea power in the eleventh century through its conquests in Southeast Asia. Chola kings had a large fleet and army, and their imperial ambitions were backed by considerable economic power. In the cultural field, they left lasting impressions in both South India and Southeast Asia. As unconditional adherents of the Shaiva Hindu religiosity, the Cholas also spread this form of Hinduism in Southeast Asia. In South India, they erected grand-scale temples in honour of Shiva. The first temple cities (Thanjavur, Chidambaram) emerged as a result of their quest for monumentality. With their generous donations, they established the temples as independent economic actors in the life of the kingdom.

The Hindu temple itself is actually a three-dimensional mandala: a symbol of the universe, with the divinity at its centre. Its primary symbolism refers to the mountain and the cave hidden inside it, translated into architectural forms by the tower and the sanctuary. The image of the deity (always the linga in the case of Shiva temples) is erected in the closed, dark, cell-like main sanctuary (Sk. garbhagriha, 'womb chamber'). After the ritual circumambulation of the temple, the worshipper arrives here through the antechamber and the pillared hall (mandapa) to see the deity (darshana) and place the offerings (puja). The cosmic symbolism of the Hindu temple is enhanced by the images of deities and celestial beings covering the walls. Hindu temple architecture, in contrast to Indian secular architecture, was characterised by the use of durable materials (brick, stone) and conservative construction technologies. The ritual precepts of Hindu architecture 
prohibited the use of arches and domes; they were replaced by beams, false arches and domes, and towers built of horizontal layers. As this construction technology is not suitable for covering large spaces, the interiors of Hindu temples are sometimes distinctly narrow, not allowing many believers to be accommodated. The temples of Khajuraho in Madhya Pradesh, built in the tenth and eleventh centuries, manifest the purest form of North Indian (nagara) architecture (Figure 38).

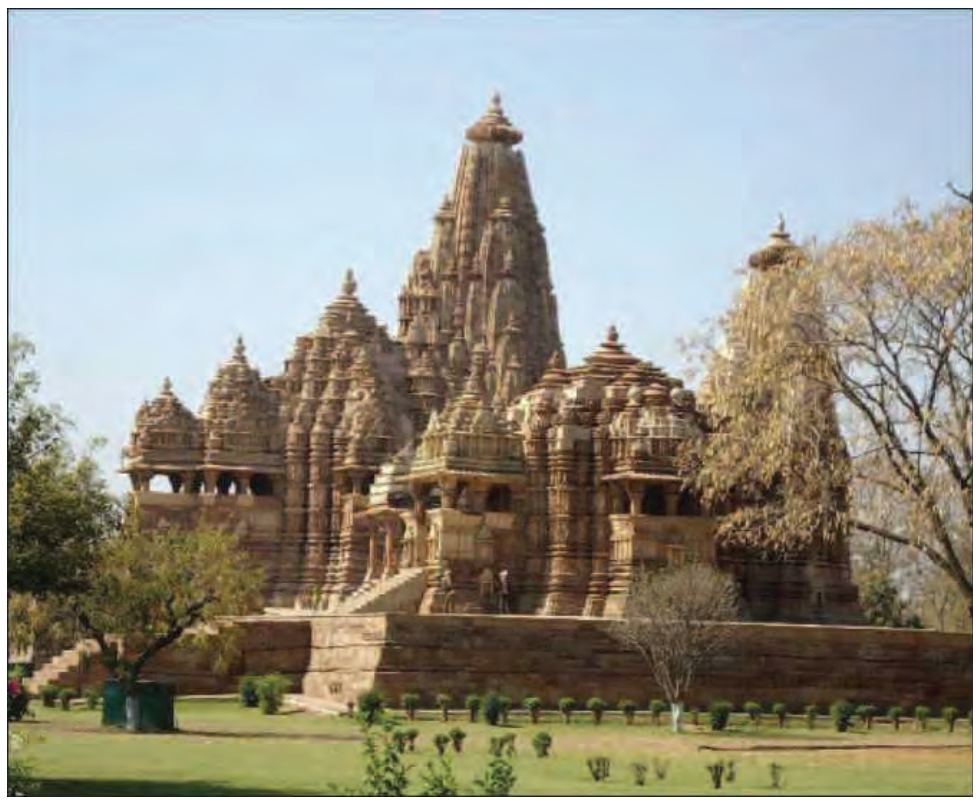

Figure 38: Temples of Khajuraho. Chandela dynasty, eleventh century Source: Photograph by ZsUZSANNA RENNER

In South Indian (Dravidian) temple architecture, the sanctuary and its superstructure, symbolising the celestial vehicle of the deity, are dwarfed by the impressive gate towers rising above the entrances of the walls surrounding the temple district. The most important pilgrimage centres in the south from the sixteenth century onwards were transformed into large temple districts, whose maintenance and operation were ensured by generous royal donations, large areas of land and a big staff. An indispensable part of the temple is the sacred tank used for ritual baths and other temple rituals. In the courtyards enclosed by the walls of the temple, pillared halls (mandapas), shrines, pilgrims' dormitories, kitchens, warehouses and other service buildings are located. The great temple cities of South India: Thanjavur (formerly Tanjore), Madurai, Rameshwaram, Tiruvannamalai took their present form in the last flourishing period of South 
Indian temple architecture between the sixteenth-eighteenth centuries (Figure 39).

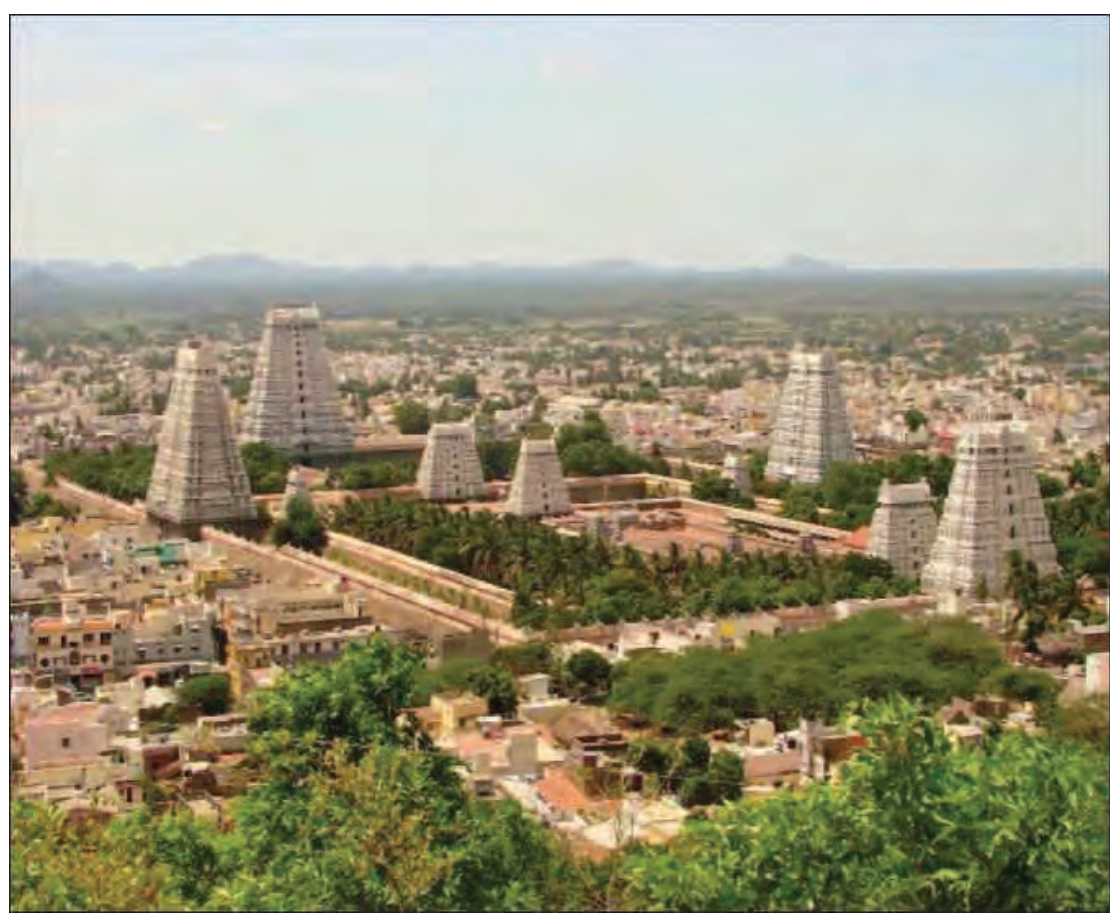

Figure 39: Arunachalesvara Temple, Tiruvannamalai (Tamil Nadu)

Source: Adam Jones adamjones.freeservers.com. https://commons.wikimedia.org/wiki/ File: View_over_Arunchaleshvara_Temple_from_the_Red_Mountain __Tiruvannamalai_-_India_01.JPG

In the context of medieval Indian art, it is imperative to mention bronze sculpture, which culminated at this time thanks through the iconic works of Chola art. The temple cult of South India required many bronze statues, which were placed in shrines of the temple halls and carried around the city on holidays. The production of the large, solid Chola bronzes not only testifies to the high standard of artistic creativity, the perfect sculptural realisation of spiritual beauty but also to the economic strength of the kingdom, due to the huge amount of metals used. In addition, the casting technology applied (the so-called cire-perdue or lost wax process) assumed a high level of metal casting and metalworking knowledge. South Indian temple art is a prime example of the fact that the primary resourcemobilising activity in Indian civilisation was, in technological, economic and aesthetic terms, sacred art, which used the noblest materials, the highest available technology and the best of human creativity. The images had to comply with the 
rules of iconography and had to be perfect in a technical sense; only this way could they become suitable for cultic use. However, the creators of works of art aspiring to such perfection remained unknown in most cases. In the art of India, the names of creators have survived only as a rare exception. The recording of names was ruled out both by the perception of art whose only real aim was to approach transcendental reality and the low social rank of builders, stonemasons, sculptors, and bronze founders.

In Southeast Asia, between the fifth and thirteenth centuries, Indian-type kingdoms and later vast empires emerged. Indian impacts arrived through direct relationships (e.g., the presence of Indian Brahmin priests in the royal courts), sacred texts and literary works, including the Mahabharata and the Ramayana. At the beginning of the Middle Ages, trade relations with the Mediterranean still existed but were soon replaced by relations with southern China. Increased maritime traffic boosted the inclusion of Southeast Asian areas along the sea route to China into India's commercial and cultural sphere of interest. The Mon Kingdom, which existed in southern Thailand and Burma until the eighth century, was replaced by new centres of power. Their power structure was modelled on the mandala-type kingdoms of India.

In present-day Cambodia, Chenla was replaced in the ninth century by the Khmer Empire with its capital at Angkor, the most powerful kingdom in Southeast Asia. Its power was counterbalanced by the Kingdom of Pagan in modern-day Burma. In the conflict zone between the two, the Thai kingdoms of Haripunchai, Sukhothai and Ayutthaya fought with varying outcomes against their neighbours. The eastern half of the mainland was dominated by Champa, which had long resisted Chinese pressure from the north. The Malay Peninsula, Sumatra, and West and Central Java were part of the Kingdom of Srivijaya. In the eleventh century, the Chola Empire conquered Sri Lanka and successfully intervened on the side of the Khmer Kingdom in the power rivalry between Srivijaya and Angkor, occupying parts of Srivijaya in the process. Hindu culture was dominant in this period in the Khmer and Cham areas, as well as in East Java (a unique local variant of Hinduism still exists on the nearby island of Bali). Hinduism in other kingdoms existed alongside Buddhism as the predominant religion. Within Hindu religiosity, Shaivism, Vaishnavism, Bhakti and Tantric cults focusing on creative energy were all present, albeit with varying weights. The great Indian epics in all kingdoms had a fertilising effect on local literature and the arts, especially narrative depictions, dance, and puppetry. Building complexes in Southeast Asian power centres (Angkor, Pagan, My Son, Prambanan, Borobudur, etc.) are among the most important sites for sacred art in Asia and the world. In addition to the dominant Indian character, local style influences and creative ideas prevailed in their art. In a sense, the temples of Angkor can be 
considered the pinnacle of Hindu temple architecture. Through the concept of the temple mountain, the Indian perception of the structure of the world with the world mountain (Meru) in its centre and the surrounding lands and oceans was fully translated into architectural forms here. The construction of reservoirs and water systems required a high level of engineering knowledge, whose antecedents can also be found in India. The largest Buddhist stupa in the world was built in Borobudur, Java. With the decline of the great kingdoms, the influence of Hindu culture ceased in Southeast Asia. However, the heritage of Indian culture in the form of Theravada Buddhism fundamentally defines the image of the mainland part of the region to this day. An exception is Vietnam, where the 'Pure land' school belonging to Mahayana Buddhism gained popularity.

\section{Islam in India}

The Islamic conquest was a watershed in the medieval history of the subcontinent. Less than a hundred years after the hijra, Islam gained its foothold in the north-western part of the Indian subcontinent, in the areas west of the Indus, through the Arab conquerors and later the converted Persians, Afghans, and Central Asian Turks. From there, Muslim chiefs led increasingly frequent campaigns to northern Indian territories. In 1203, breaking the resistance of the Rajput principalities, the Muslim forces took Delhi and established the first Islamic state in North India. The crucial difference from earlier nomadic invasions in the history of the subcontinent was that while former settlers had been rapidly assimilated by the socio-political and cultural system of the subcontinent, Islam introduced its own legal and administrative system, religion, and ethical principles. The Delhi Sultanate expanded rapidly, and successive dynasties extended their power to northern India and much of the Deccan. The conquest took many casualties and caused significant destruction. Hindu temples on the routes of conquest were demolished and mosques erected in their place, and a head tax was imposed on the Hindu population. Although forced conversion also took place, due to the benefits of embracing Islam, the Muslim population of the subcontinent also grew though voluntary conversions, especially from the lower strata of Hindu society. The vast majority of Muslims in India came from the converted local population. In contrast to Hindu civilisation, Islamic culture concentrated in the cities, where large-scale construction works took place, soon transforming the Indian cityscape. Typical Islamic building types emerged: fortresses indicating the military character of power, mosques and minarets essential to the practice of religion, as well as tombs, gardens, madrasas. Although the Muslim land and public administration system left the rural foundations of Hindu society intact, the interruption of Hindu statehood led to the 
gradual decay of former royal centres even in areas not directly affected by the military conquest. However, the emergence of Islamic statehood in India also gave rise to resistance. The West Indian fortresses of the Rajput dynasties, famous for their military virtues, were the main base for resistance and military operations of varying success (Figure 40). In the southern part of the peninsula, the power of the Delhi Sultanate was counterbalanced by the Hindu Vijayanagara Empire where Hindu culture flourished undisturbed until the mid-sixteenth century.

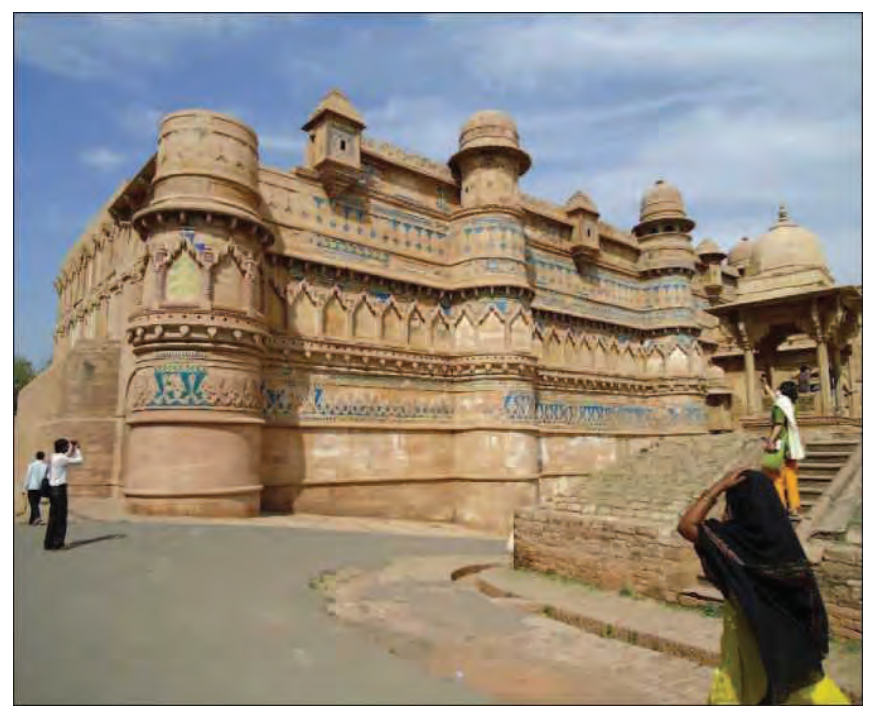

Figure 40: Gwalior Fort, Madhya Pradesh. In its present form it was built in the fifteenth and sixteenth centuries

Source: Photograph by ZSUZSANNA RENNER

The Delhi Sultanate was in fact only a prelude to the creation of the Mughal Empire (1526-1858), which, at the zenith of its power, united the entire Indian subcontinent under its rule, except for the southern tip of the peninsula. According to researchers, the enormous empire, ahead of China in its day, was the world's largest economic power, driven by growth in agricultural production, the accumulation of commercial capital, and a relatively high level of urbanisation. The official language of administration which operated from three capitals was Persian. Akbar (1556-1605), the most prominent ruler of the Mughal Dynasty, married a Rajput princess and sought to bring Islamic and Hindu culture closer in other ways too. He studied Indian religions and merged some of the elements of Islam and the trends of Hinduism known at that time in a syncretic religion which he called Din-i Ilahi, the 'Divine Faith'. His successors did not follow Akbar on the path of religious tolerance, but a kind of synthesis of Islamic and the Hindu culture was nevertheless achieved, especially in architecture. 
Massive constructions took place under each of the Mughal emperors; however, the most outstanding builder among them was Shah Jahan (1628-1658) at whose order the fortress of Delhi and Agra, and the world-famous tomb, the Taj Mahal was built. Muslim edifices of the time display elements of Hindu architecture that mark the creation of the distinctive Indo-Islamic style. The synthesis is even more evident in Rajput architecture, which not only embraced stylistic elements of Islamic art (e.g., lobed arches) but also building types (fortress, palace), technologies (vault, arch, dome) and structural features (multi-story, contiguous interiors). In terms of religion, Islamic mysticism and the presence of Sufi saints had an impact on Hindu religiosity; linguistically, the development of Urdu was due to the interplay of Persian and Indian languages. In music, Hindustani (North Indian) classical instrumental and vocal music bears the stamp of Persian and Arabic influences. In art, the sophisticated Mughal miniature painting, which did not prohibit human portrayal, had a lasting impact on local Indian miniature painting. Islam introduced many branches of applied arts and crafts, hitherto unknown in India: the making of glazed pottery, brocade and carpet weaving, metallic embroidery, gemstone carving, many varieties of metalwork, including the production of ornamental weapons, and the list could go on. These handicrafts, the finest creations of which were produced in the workshops (karkhana) of the Mughal court, are still practised in India today.

Islam meant a counterpoint for the civilisation of India. Its cosmopolitan culture, the monotheism and congregational nature of its religion, the simple and pure architectural forms and vast spaces of its buildings, the complete absence of sculpture and the importance of writing in general and calligraphy in particular, the linear perception of time and the role of historiography - only to mention a few of the most striking differences - were in sharp contrast with the thousandyear-old cultural patterns of India. The diverse cultural output of Islam in India, however, has infiltrated the fabric of the subcontinent's civilisation over the centuries of coexistence. In the age of colonisation and modernisation, Indian civilisation underwent further changes in the context of the Hindu Renaissance and the Indian Independence Movement charged with Hindu religious hue. Today, when religious antagonisms, unfortunately, do not diminish but intensify and become a factor in arousing passions in political battles, we can only hope that India's still living civilisation, drawing on its long tradition of tolerance and reconciling diverse cultural phenomena, will be able to accept its multifaceted past in the best sense of the word and use it as a resource for its benefit. 
3.1. The Indian Civilisation

\subsubsection{Chronological table}

\begin{tabular}{|c|c|}
\hline Date & Event \\
\hline c. $2600-1900 \mathrm{BCE}$ & Indus Valley Civilisation \\
\hline c. from 1900 BCE & Arrival of Aryans in India \\
\hline c. $1500-600$ BCE & Vedic Age \\
\hline Around 1500 BCE & Origin of the Rigveda \\
\hline sixth century BCE & The rise of Magadha with its capital at Rajgir, later Pataliputra \\
\hline $\begin{array}{l}\text { c. } 599 / 570-527 / 489 \\
\text { or } 468 \text { BCE }\end{array}$ & Vardhamana Mahavira, the Jina \\
\hline c. $563-483$ BCE & Siddhartha Gautama, the Buddha \\
\hline 327-325 BCE & Alexander the Great's campaign in India \\
\hline c. $323-185$ BCE & Maurya Age \\
\hline c. $268-231$ BCE & Ashoka Maurya \\
\hline $180-130$ ВСЕ & Indo-Greek kingdoms in the north-west \\
\hline first c. BCE -first c. CE & Saka and Parthian kingdoms in the north-west \\
\hline $\begin{array}{l}\text { C. second C. BCE - } \\
\text { second century CE }\end{array}$ & Satavahana dynasty in the Deccan and Central India \\
\hline first-third centuries & Kushan era in the north-west and Central India \\
\hline c. $320-550$ & Gupta Empire \\
\hline c. third-sixth & Vakataka dynasty in northern Deccan \\
\hline $\begin{array}{l}\text { c. } 600-1200 \text {, in South } \\
\text { India until } 1761\end{array}$ & Hindu dynasties \\
\hline $\begin{array}{l}\text { c. mid-sixth century- } \\
\text { mid-eighth century }\end{array}$ & Early Western Chalukya dynasty in the Deccan \\
\hline $\begin{array}{l}\text { seventh-ninth } \\
\text { centuries }\end{array}$ & Pallava dynasty in Andhra and Tamil Nadu \\
\hline eighth-tenth centuries & Rashtrakuta dynasty in the Deccan \\
\hline $\begin{array}{l}\text { eighth-twelfth } \\
\text { centuries }\end{array}$ & Pala dynasty in Eastern India \\
\hline $\begin{array}{l}\text { Mid-ninth-thirteenth } \\
\text { centuries }\end{array}$ & Chola dynasty in Tamil Nadu \\
\hline $1206-1526$ & Delhi Sultanate \\
\hline $1526-1858$ & Mughal Empire \\
\hline $1556-1605$ & Akbar \\
\hline $1627-1658$ & Shah Jahan \\
\hline $\begin{array}{l}\text { fourteenth to the } \\
\text { nineteenth century }\end{array}$ & $\begin{array}{l}\text { Rajput principalities in Rajasthan, Central India, and at the foot of the } \\
\text { Himalayas }\end{array}$ \\
\hline $1336-1565$ & Vijayanagar \\
\hline $1858-1947$ & British Indian Empire \\
\hline 1947 & Declaration of independence and partition of India \\
\hline
\end{tabular}




\subsubsection{Bibliography}

AlbaneSe, MARILIA 2001: Ancient India: from the Origins to the XIII century $A D$. New Delhi: Om Book Service

Albanese, MARILIA 2013: Angkor: splendors of the Khmer civilisation. Vercelli: WhiteStar

The Bhagavad Gita 2014: Translated from the Sanskrit by Juan Mascaró. London: Penguin Classics

BRoCKIngton, JoHn L. 2000: The Sacred Thread: A Short History of Buddhism. Delhi \& New York: Oxford University Press

IONS, VERONICA 2004: Indian Mythology. London: Bounty Books

JOHNSON, GORDON 1996: Cultural Atlas of India. Abingdon: Andromeda

Mahabharata 2019: Retold and translated from the Sanskrit by William Buck. Oakland, Calif.: University of California Press

RAWSON, PHILIP 1977: Indian Asia. Oxford: Elsevier Phaidon

SANyal, SAnjeev 2013: Land of Seven Rivers. A Brief History of India's Geography. Penguin

SchwartZBerg, JosePh E. 2006: A Historical Atlas of South Asia. Second impression. Copyright 1978 by the Regents of the University of Minnesota, assigned 1988 to Joseph E. Schwartzberg, Digital South Asia Library.

SINGH, UPINDER 2009: A History of Ancient and Early Medieval India: From the Stone Age to the 12th Century. Delhi: Pearson India

WOOD, MICHAEL 2007: The Story of India. BBC Books

WoOD, MichAEL 2007: The Story of India. BBC documentary series, Episodes $1-6$ 
4. The Middle East 


\subsection{J udaism}

\section{DÓRA ZsOM}

Judaism is the oldest monotheistic religion, which precedes both Christianity and Islam. Unlike these, the origins of Judaism are not linked to a particular historical event - like the activity of Jesus Christ in Christianity, or that of Muhammad in Islam -, which would clearly mark the beginnings of Judaism. Moreover, contrary to Christianity and Islam, Jews do not promote their faith, and they do not aim to convert the different peoples of the world to Judaism. In fact, Jews consider themselves to be members of a large family, or distant relatives, and regard Judaism as the religion of this particular family, tribe, or people. Jewish descent (that is, belonging to the Jewish people according to Jewish law) is traced through the maternal line. In addition, converts were accepted since the beginning of Jewish history through a procedure similar to "adoption", - nonetheless, this was rather uncommon. Jews have never actively promoted their religion and sought to increase the number of converts among non-Jewish people.

The origins of Judaism date back to the nomadic tribes that wandered between ancient Mesopotamia and Egypt worshipping and offering sacrifices to their tribal gods. These tribes traced their lineage back to a mutual ancestor, named Israel. Hence, they called themselves "children of Israel" (Israel being an alternate name of the forefather Jacob). The alliance of these tribes settled in Canaan between the thirteenth and twelfth century BCE. Today, this territory comprises Israel, Palestine, Lebanon and Jordan. They founded their kingdom with its centre being the city of Jerusalem, however, the kingdom was soon divided into two, a northern (Israel) and southern (Judah) kingdom in the tenth century BCE. As a result of the conquests by the surrounding empires, both kingdoms lost their independence: Israel, as an independent kingdom, was eventually eliminated by the Assyrian Empire in the eighth century BCE, and Judah first came under the rule of the Assyrian, then the Babylonian, Persian, and finally the Roman Empire. The Romans demolished the Temple in Jerusalem (in $70 \mathrm{CE}$ ), the central place of worship of the ancient Israelites, which resulted in a complete transformation of the religion. As a consequence, we shall distinguish between the religion of the biblical age (Biblical Judaism) and the Judaism of later times (Rabbinical Judaism). 


\subsubsection{J udaism in Biblical Times}

The term "Judaism" does not appear either in the Hebrew Bible (i.e. the Bible used by the Jews) or in other ancient Jewish sacred texts. The Greek original of the word was used by Jews in the Hellenistic era to refer to their particular religious practices. (See 2 Maccabees 2:21, 8:1, 14:38. The Hebrew Bible is not comprised of the same books as the Catholic Bible, the Books of the Maccabees are not part of it.) The word "Judaism" is derived from the name of Judah, one of the great-grandsons of Patriarch Abraham, to whom the tribe of Judah traces back its lineage to. The English term "Jew" also originates in the name Judah through a variety of adoptions. The word "Hebrew" is the English equivalent of the biblical term "ivri", which derives from the verbal root meaning "to traverse, to pass over, to wander". The Bible denotes Abraham, one of the nomad ancestors of Israel as "ivri". Abraham's son was Isaac, father of Jacob, who was later given the name Israel. They are regarded as the Patriarchs of the Jewish people. Israel (Jacob) had twelve sons, and these sons were the ancestors of the twelve tribes of Israel, including the tribe of Judah. In modern English the term "Jewish" is used for the people and the religion, while "Israelite" refers either to a member of the ancient Hebrew nation or to a person having Jewish religion, and lastly, the word "Hebrew" is primarily used to denote the language.

The principal source of knowledge about Biblical Judaism is the Bible itself. The Hebrew Bible roughly corresponds to the Old Testament of the Protestant Bible, i.e. it contains the same books but in a different arrangement. The Hebrew Bible is divided into three sections (Torah, Prophets, Writings). The Torah (meaning: "Law", consisting of the five books of Moses) is primarily a legal text, but it also contains a description of the creation of the world and the first human couple, the Flood and Noah's Ark, the Tower of Babel and the confusion of languages, the migrations of the Patriarchs, Israel's Exodus from Egypt, the miracles of Moses, the Ten Commandments, and the description of the Jewish people's wanderings in the wilderness. The continuation of the history of ancient Israel, that is, the conquest of the land of Israel and the history of the two kingdoms, is written in the books of the so-called Former Prophets (Joshua, Judges, Samuel, and Kings) and Latter Prophets (Isaiah, Jeremiah, Ezekiel). These books and the books of the Twelve Minor Prophets are included in the book of "Prophets", the second main division of the Hebrew Bible. The third section, "Writings", consists of both poetic and historical books: Psalms, the Book of Proverbs, the Book of Job, Song of Songs, the Book of Ruth, Lamentations, Ecclesiastes, the Book of Esther, the Book of Daniel, the Book of Ezra and Nehemiah, Chronicles. The three divisions do not reflect the chronology of the text, which itself is a very complex problem: biblical stories were initially 
passed on orally and were only written down later on. The biblical text, in its present form, is the result of a combination of different sources and several stages of editing. The sources that were combined into a single story are of different ages, origins, and genres. In terms of genre and content, they fit into the literary tradition of the surrounding peoples, and many well-known biblical stories and motifs (the creation of the world, the flood, etc.) are present in other ancient Middle Eastern literary traditions, as well.

\subsubsection{The Biblical Story of I srael}

According to the biblical story, God commanded Abraham to leave his country, his people and his father's household and go to the land he will show him (Gen. 12:1-3). Abraham and his family wandered from the southern Mesopotamian Ur to Egypt through Canaan, and in the course of their journey God promised Abraham to give the land of Canaan to his family and descendants (Map 14).

To confirm this, God made a covenant with Abraham, according to which each male must undergo circumcision (Gen. 17:1-14). In the time of the Patriarchs, namely Abraham, his son Isaac, and Isaac's son Jacob, God repeated this promise to the family; however, during that time the family (tribe) had not yet settled in Canaan, but led a nomadic lifestyle, wandering between Egypt and Mesopotamia, while crossing several times the land that later became Israel. The Bible explains the name Israel with a mysterious story: Patriarch Jacob struggled until dawn with an angel who, at the end of their struggle, gave him the name of Israel "for you have striven with God and with men, and have prevailed" (Gen. 32:29) ${ }^{8}$. According to popular etymology, the Hebrew name Yisrael means "he who struggles with God". Jacob's twelve sons escaped from the famine that affected Canaan and fled to Egypt where they settled and multiplied. The twelve sons of Israel (Jacob) are the ancestors of the twelve tribes of the people of Israel, who united into a single people upon their Exodus from Egypt.

\footnotetext{
8 The translations of Biblical passages are given, with slight modernisation, according to the so-called JPS Tanakh 1917, i.e. The Holy Scriptures According to the Masoretic Text: A New Translation. Philadelphia, PA: The Jewish Publication Society, 1917.
} 


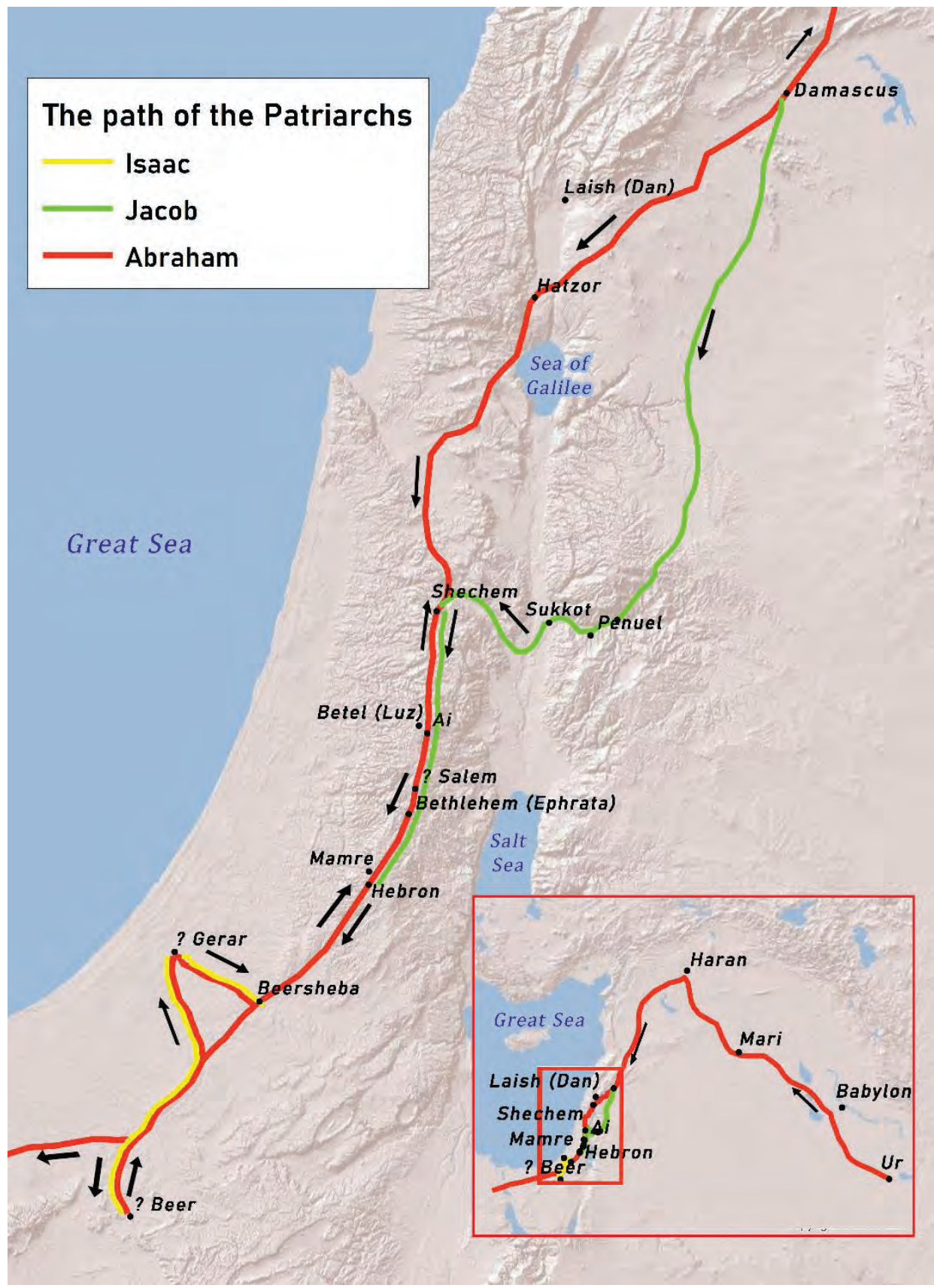

Map 14: Migration routes of the Patriarchs according to the Bible Source: Edited by ÁGNES VARGA 
The Second Book of Moses (Exodus) tells the story of the hardships the people of Israel had to face in Egypt when the Egyptians forced the nation into slavery. Moses became their advocate, and obeying God's command, he demanded that Pharaoh release his people, and allow them to return to Canaan. Upon the Pharaoh's refusal to grant this request, God struck Egypt with ten plagues, the most serious of which was the death of the firstborn. According to the story, God commanded the people of Israel to slaughter sacrificial lambs, to eat the meat with unleavened bread, to smear the blood of the lamb on the doorposts, and to remain in their houses at night, because: "For the Lord will pass through to smite the Egyptians; and when He sees the blood upon the lintel, and on the two side-posts, the Lord will pass over the door, and will not suffer the destroyer to come in unto your houses to smite you. (...) And it came to pass at midnight, that the Lord smote all the firstborn in the land of Egypt, from the firstborn of Pharaoh that sat on his throne unto the first-born of the captive that was in the dungeon; and all the first-born of cattle." (Exodus 12:23, 29) Seeing this the Pharaoh gave his consent to the Israelites to leave Egypt, but soon after he had a change of heart, and pursued the nation of Israel with his chariots, and overtook them at the Red Sea. Holding out his staff, Moses separated the Red Sea and the Israelites walked on the passage of dry land with walls of water on both sides; however, their pursuers drowned as the waters rushed back. After their Exodus from Egypt, the people of Israel wandered in the wilderness for forty years, while God taught them how to serve him. The revelation at Mount Sinai took place at the beginning of these wanderings: Moses received the Ten Commandments engraved on tablets of stone; God disclosed his other commandments and laws as well, and finally, God made a covenant with the people (Ex. 20:1-17, 24:3-8, 12). The divine revelation was very frightening for the people, therefore they asked Moses to represent them before God. However, since Moses spent such a long time on the mountain, standing before God, the people thought that he had been consumed by the unbearable power of the divine presence. So, they made a golden idol, a calf of moulded gold for themselves.

Upon descending from Mount Sinai after forty days, Moses found the people practicing idolatry, and in his exasperation, he broke the tablets of stone onto which God himself had inscribed His laws. However, after the people repented, at God's command Moses remade the tablets of stone, but this time he inscribed the commandments on them instead of God. God himself led the people during the wondering in the wilderness; his place of worship was a portable tabernacle. The Ark of the Covenant (also known as the Ark of Testimony) with its winged cherubim was the tangible throne of the invisible God, the place of manifestation of the divine presence. 


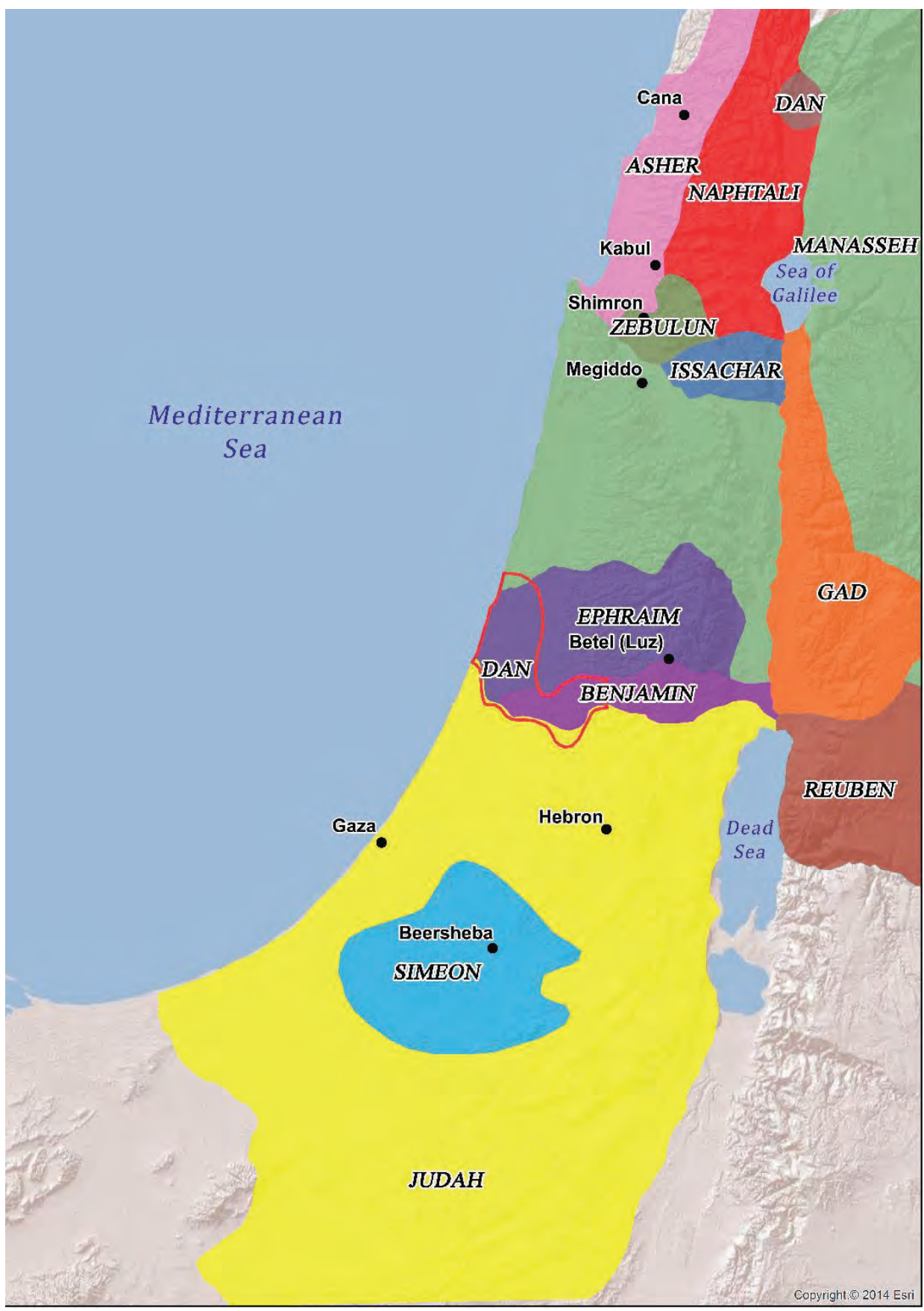

Map 15: Map of the twelve tribes of Israel Source: Edited by ÁGNES VARGA 
Canaan was conquered only after a long period of wondering in the wilderness, after that had Moses died and Joshua assumed the role of leading the people. The territories they occupied were divided among the twelve tribes, who then sought to protect them from the invasions of neighbouring peoples (Map 15). The tribal alliance soon became a kingdom, headed first by Saul and then by David (first half of tenth century BCE), followed by his son, Solomon (second half of tenth century BCE). David occupied Jerusalem and made it the capital of his kingdom. The central place of worship, the Temple of Jerusalem, was built by Solomon. The cult was based on offering sacrifices in the Temple, and the rituals connected to the offerings were carried out by the priestly orders (Kohanim and Leviim). After Solomon's death, the kingdom split into two. Ten tribes in the North established an independent kingdom called Israel, while two tribes in the South (the larger tribe of Judah and the smaller tribe of Benjamin) together formed a kingdom called Judah. During the next two centuries (ninth and eighth centuries BCE), the two kingdoms fought against one another as well as against the surrounding peoples, and the two dominant empires of the region (namely Egypt and Assyria), until Israel was eventually conquered by the Assyrian Empire (721 BCE) (Map 16). In line with the politics of the Assyrian Empire, while a large part of the population was deported to other parts of the Empire, ethnic groups from other parts of the Empire were moved to Israel. Soon Judah also came under Assyrian rule. After the fall of the Assyrian Empire, Judah became part of the Neo-Babylonian Empire. Nebuchadnezzar (Nabu-kudurri-usur), Babylonian ruler conquered Jerusalem in 597 BCE and deported a part of the population (socalled "Babylonian captivity"). Approximately ten years later, the kingdom of Judah revolted against Babylonian rule. In response to that, the Babylonian army again sieged and conquered Jerusalem, and finally destroyed both the city and the Temple (587 BCE). King Cyrus of Persia defeated Babylon in 540 BCE and granted the deported Jews permission to return to Jerusalem, but the restoration of the Temple was only completed in 516 BCE ("the Second Temple"). The Hebrew Bible does not report the events of the centuries that followed: Judah became part of the spheres of interest of new empires; after it was conquered by Alexander the Great, the land remained under Greek military and cultural influence, against which the Jews rebelled (the Maccabean Revolt) in 167 BCE. Pompey the Great led a successful military campaign against Judah in 63 BCE, after which the supremacy of the Roman Empire prevailed over it. Judah was ruled by successive Judean kings and Roman governors (procurators), until it finally came under direct Roman administration, and became a province of the Roman Empire. In response to the Jewish revolt against the Roman rule in $70 \mathrm{CE}$, the Roman army destroyed Jerusalem and the Second Temple, which was never rebuilt. 


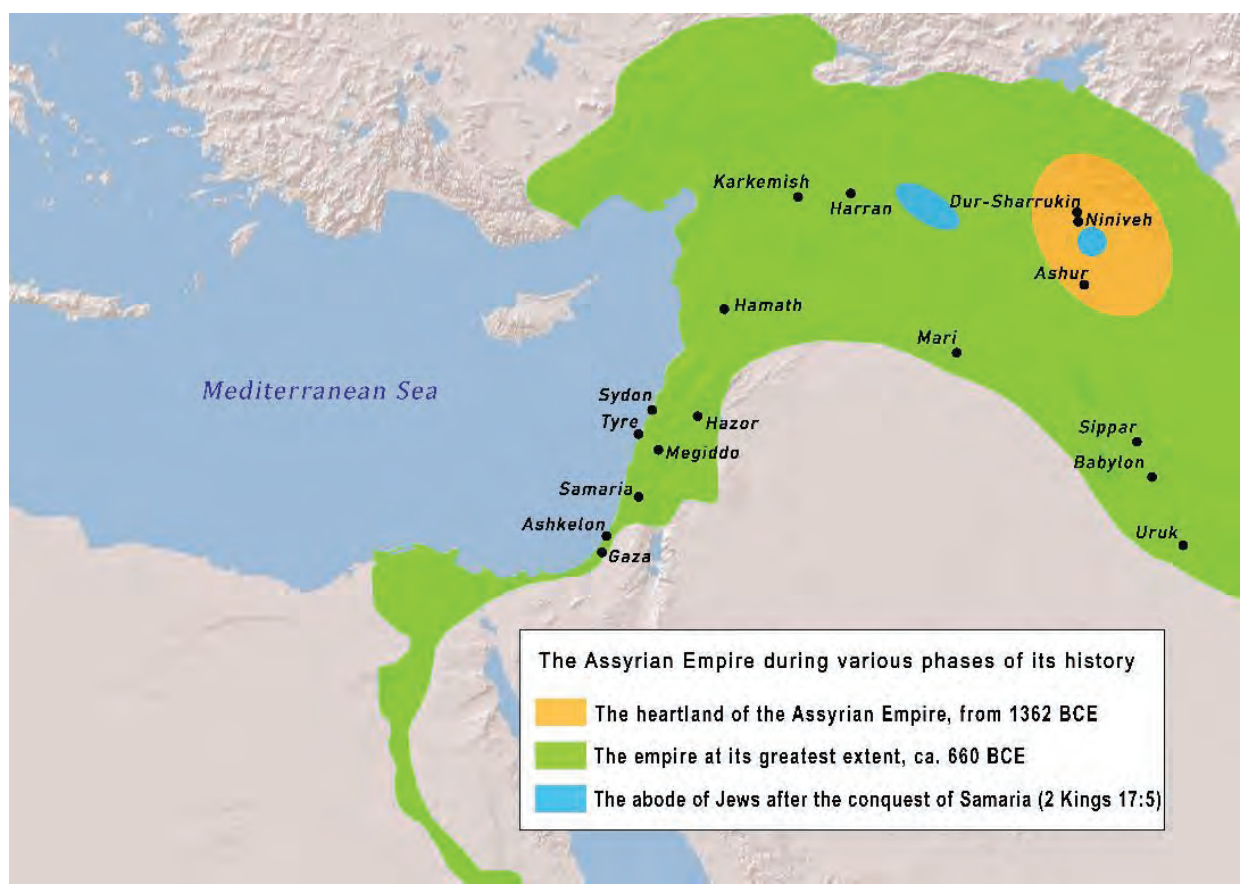

Map 16: The Assyrian Empire following the annexation of Israel Source: Edited by ÁGNES VARGA

The only original wall still standing in the area of the Temple Mount is the Wailing Wall (also known as the Western Wall), which is not, however, a wall of the Temple's building but a section of the wall surrounding the Temple area, built by Herod the Great (ruled between 37-4 BCE). Its significance is due to the fact that in practice a religious Jew cannot get closer to the site of the former Temple, which also became a holy place for the Muslims following the Islamic conquest. Nowadays, the Dome of the Rock stands on the site of the former Temple.

\subsubsection{Religious rituals and cult in the Biblical Period}

The tribal cult of ancient Israel was slowly transformed into a centralised religious practice, which was based on the notion of covenant: first between God and a specific person (Abraham), then between God and a tribe (descendants of Abraham), finally between God and a people (Israel). A covenant is a contract between two parties with well-defined terms and conditions in which the parties to the contract assume certain obligations. According to the biblical history, God promised to consider the people of Israel as his chosen people, whom he leads into Canaan, which he gives to his people. In turn, it is Israel's duty to observe 
God's laws: "And Moses went up unto God, and the Lord called unto him out of the mountain, saying: 'Thus shall you say to the house of Jacob, and tell the children of Israel: You have seen what I did unto the Egyptians, and how I bore you on eagles' wings, and brought you unto Myself. Now therefore, if you will hearken unto My voice indeed, and keep My covenant, then you shall be Mine own treasure from among all peoples; for all the earth is Mine'; [...] And all the people answered together, and said: 'All that the Lord has spoken we will do'." (Exodus 19:3-5, 8)

The religious practice consisted primarily of offering sacrifices and observing certain religious festivities, three of which required the whole people to make a pilgrimage to Jerusalem where they had to offer sacrifices in the Temple. The Temple was divided into different parts according to the degree of sanctity: the outer court of the Temple was open to everyone, even to non-Jews. To the inner court Jewish women could enter but non-Jews could not; and only Jewish men could go any further, while only priests had access to the innermost halls and chambers. The holiest area was the so-called "Holy of Holies", where no one was allowed to enter except the High Priest, but even he could enter only once a year, on the Day of Atonement (Yom Kippur). In the Holy of the Holies the invisible God himself dwelled above the Ark of the Covenant. The Day of Atonement was the only occasion on which the High Priest uttered the name of God. According to Jewish tradition, it is forbidden to pronounce the four-letter name of God (the Tetragrammaton), which therefore has to be substituted by names such as "Lord" or "Eternal". God's four-letter name was a taboo due to the tremendous power attributed to it, which was life-threatening even for the High Priest himself, who pronounced it once a year in obedience to the divine ordinance.

After the destruction of the Temple, the religious practice was radically transformed, as its central element, the offering of sacrifices, was no longer possible to perform. Its role was assumed by studying, reciting, commenting and discussing the sacred texts.

\subsubsection{The M ajor Branches of J udaism}

After the destruction of the Second Temple (70 CE), most of the Jews were forced into diaspora; that is, dispersed throughout the world. Jewish history is, therefore, extremely diverse, as it forms an integral part of the history of each country in which Jews settled. Each community followed their own traditions, always living as part of the minority within the majority population, assimilating to a greater or lesser extent to the majority (for example with regard to language, local customs, clothing, and legal system). The congregations did not form a 
single hierarchical organisation and enjoyed a high degree of independence. On the basis of origin, customs and rituals, we can distinguish between three large groups: the Ashkenazi, the Sephardi and the Mizrahi Jews.

The name Ashkenazi ${ }^{9}$ refers to the Jews who come from Germany or Northern-France and follow the religious rites and customs that evolved in those regions, regardless of where they currently live for example in the United States, in the State of Israel, or in Budapest. In the Middle Ages Germany and France were intellectual centres of Judaism, and therefore, the Ashkenazi form of Judaism became prevalent in Europe. Ashkenazi Jews spoke, and to some extent, still speak Yiddish, which belongs to the Germanic language group. Ashkenaz is the term referring to Germany in medieval Hebrew texts.

Jews who originally come from the Iberian Peninsula are called Sephardi ${ }^{10}$ Jews. Up until the end of the Middle Ages, Jewish culture flourished in that region, but in 1492, when Isabella of Castile and Ferdinand of Aragon, known as the "Catholic Kings" (Reyes Católicos), expelled the last Muslim conquerors from their kingdoms, the rulers decided to establish a united, monoreligious nation. Therefore, the Jews under their rule were compelled to choose between converting to Christianity and leaving the country. The communities that decided to emigrate were given a three months' grace period to fold up their livelihood, sell their properties, and leave Christian territory. Of course, property prices immediately plummeted, since it was commonly known that Jews would be forced to sell their properties regardless of the low prices once the grace period ended, since after that deadline, Jews remaining in the countries of the Catholic kings faced death penalty. Furthermore, the export of wealth was severely hindered, since Jews emigrating from Spain were forbidden to take precious metals with them. Some emigrating Jews settled in North Africa and the Ottoman Empire, while others moved to nearby Portugal, where they soon had to face new hardships. Portugal, similar to Spain, also issued an expulsion order in 1497, with the exception that the grace period was only one month. However, the Jews were eventually not expulsed from Portugal: when they gathered in the ports designated for boarding on the day of the departure (after having liquidated their shops and sold their houses), they were simply surrounded by Christian priests and soldiers, who forcefully baptised them. After their forced baptism as fresh Christian subjects, they were forbidden to leave the country. This was because, in the meantime, the Portuguese ruler had realised, that expelling the Jewish craftsmen, traders and bankers from the country would have grave economic consequences. Although Jews converted to Christianity were prohibited to leave

\footnotetext{
${ }^{9}$ Also known as Ashkenazic Jews, or Ashkenazim, by using the Hebrew plural.

${ }^{10}$ Also known as Sephardic Jews, or Sephardim, by using the Hebrew plural.
} 
Spain, and their religious observance was supervised by the Inquisition both in Spain and Portugal, Christians of Jewish descent kept secretly emigrating from the Iberian Peninsula in the next centuries. Jews who descended from those who left the Iberian Peninsula, whether at the time of the expulsion or later are called Sephardi Jews (Sepharad is the name for Spain in medieval Hebrew literature). Most of them spoke Ladino until recently, which means that they continued to use the Spanish language for about five hundred years after they had been expelled from the country.

The Hebrew term Mizrahi, meaning "Oriental", refers to the Jews who settled in Muslim countries before the expulsion of the Jews from the Iberian Peninsula. Mizrahi Jews lived among other places in the Middle East, Iraq, Iran, the Caucasus, India and Pakistan. However, since the vast majority of Sephardi Jews also lived in Muslim countries, Mizrahi, or Oriental Jews are often confounded with Sephardi Jews.

\subsubsection{J ewish $L$ anguages}

It has been common for Jews to speak, in addition to, or instead of the Hebrew language, the dominant language of the area where they live. When Aramaic became the lingua franca across Syria and Palestine, it was also adopted by the Jews, to the extent that the use of Hebrew was mainly reduced to the sphere of religious life and scholarly production, while Aramaic became the commonly spoken language. When the Jews were dispersed across the world, the native language of each Jewish community became the language of the country where they settled. In fact, they would even carry on using the assimilated foreign language when moving to another language region. For example, in the Middle Ages, Jews who settled in the Iberian Peninsula spoke Spanish (the form of Spanish used at the time), and they carried it on after they had been expelled from Spain in 1492 and had scattered throughout North Africa, the East coast of the Mediterranean Sea and in Asia Minor. Only the three major languages are mentioned below.

\section{Aramaic}

During the Neo-Assyrian Empire, Aramaic became a kind of lingua franca in Mesopotamia and the Middle East, including the region of Syria and Palestine. Parts of the Bible were written in Aramaic (Book of Daniel, Book of Ezra), and around the beginning of the Common Era, Jews (including Jesus) spoke Aramaic. A large portion of post-biblical Jewish literature is written in Aramaic: a 
considerable part of the Talmud, various exegetical collections (midrashim), and of course the Aramaic translations of the Bible (targumim).

\section{Yiddish}

Yiddish is a dialect of German, which is written in Hebrew letters, and contains a lot of foreign words of Hebrew and other origins. It evolved in the Middle Ages and was used by European Jews. It mostly became widespread when the Bible and its commentaries were translated into Yiddish for the masses who no longer spoke Hebrew. Today, modern Hebrew has gradually overshadowed Yiddish, nevertheless, it is still spoken by many Orthodox communities, most of which have long been living outside of Europe.

\section{Ladino}

Ladino is the language of the descendants of the Jews who were expelled from the Iberian Peninsula in 1492. It used to be a widely spoken language, primarily among Jews living in Turkey, up until a couple of generations ago. (Following their expulsion from Spain, Jewish people migrated to the Ottoman Empire in large numbers). Upon the foundation of the State of Israel, almost the entire population of Jews from Muslim territories immigrated to Israel and, in just a few generations, they have lost the Ladino language, used for centuries. In many respects, Ladino has preserved the Spanish language of the fifteenth century, while it has also been enriched with Hebrew and other foreign words. It is written in Hebrew letters.

\subsubsection{Rabbinic J udaism}

The word rabbi (master), which plays a central role in the Jewish religion, is not mentioned at all in the Hebrew Bible. However, it appears in the New Testament as well as in Jewish religious texts, such as the Mishnah, dating back to the beginning of the Common Era. The rabbi did not only teach Jewish religious law, he also decided controversial cases and litigations, both in religious, civil and criminal matters. After the Jews spread throughout the world (diaspora), the role of the rabbi changed, because in each country, besides the Jewish religious law, the laws of that country had to be observed as well. In many cases this did not allow the application of a different system of criminal law. Initially, the rabbis also had a secular occupation in order to provide for their families as they were not allowed to accept payment for their rabbinic functions. Rabbis still head each Jewish community today. Their roles are to manage the 
affairs of their community in collaboration with other community officials. Each Jewish community is autonomous, which means that another community cannot intervene in its affairs or override its decisions. This means, there is no such hierarchy in Judaism as in the Catholic Church, where the Pope who leads the entire organisation exercises supreme power. Nevertheless, this does not mean that all religious communities are of equal weight; for political, economic or cultural (intellectual) reasons, a given congregation may prevail over others. When this happens, other congregations begin to align themselves with the leading religious community and follow its practice, at least as long as the congregation in the leading position maintains its status. Due to the characteristics of the Jewish diaspora, there are usually several leading congregations existing parallelly, but these do not constitute a hierarchic system in which the communities are subjected to a supreme authority.

\subsubsection{The M ost Important J ewish R eligious Texts}

The most important texts of Judaism besides the Bible are the Mishnah and the Talmud, and their commentaries. Within the Bible, the Torah (meaning teaching, doctrine, law), which consists of the five books of Moses (Figure 41) is of special significance. According to Jewish tradition, the Torah was "given" by God to Moses on Mount Sinai, and God revealed to Moses at the same time its oral interpretations and commentaries. According to this tradition, a distinction is made between "written law" (Written Torah) and "oral law" (Oral Torah). The latter is mainly included in post-biblical collections of religious law, namely the Mishnah and the Talmud.

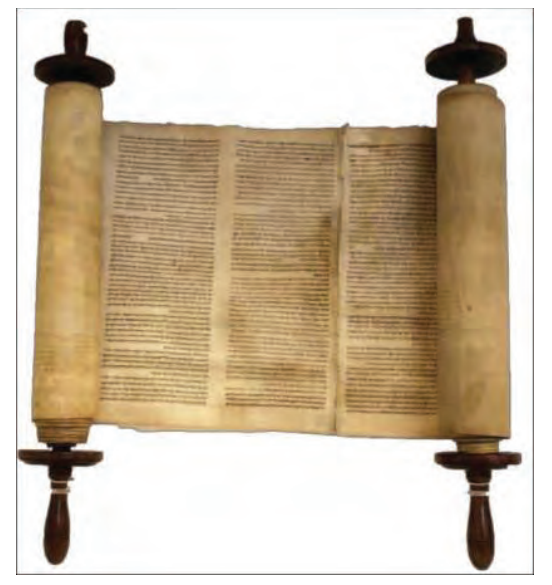

Figure 41: Torah scroll from the Munk-Munkácsi collection, MILEV (XIX-69) http://collections.milev.hu/items/show/31795 - accessed 20 April 2020 
Each week (on Monday, Thursday, and Saturday) a longer passage is read from the Torah in the synagogue, called the weekly Torah portion. The Torah is divided into 54 weekly portions; in this weekly division, the entire text is read publicly each year. (Because of the specific features of the Jewish calendar and holidays, there are more weekly portions than the number of weeks in a year, therefore, on certain weeks two weekly portions are read.)

The text is read with characteristic intonation and chanting, while following the text with a silver Torah pointer, featuring a small hand at the end of the stick (Figure 42). It is not mandatory to use a silver Torah pointer, but it is not allowed to touch the sacred text with bare hands.

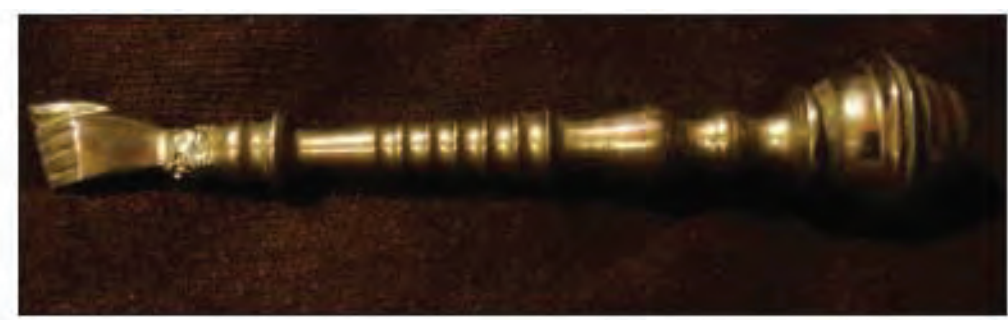

Figure 42: Torah pointer, Marrakesh, Jewish Museum Source: Photograph by KINGA DÉVÉNYI

The Torah is handwritten on a single parchment scroll, with rollers attached to the two ends of the scroll used to roll the parchment up. The parchment is made from the skin of an animal that is ritually pure, and therefore, it is quite expensive.

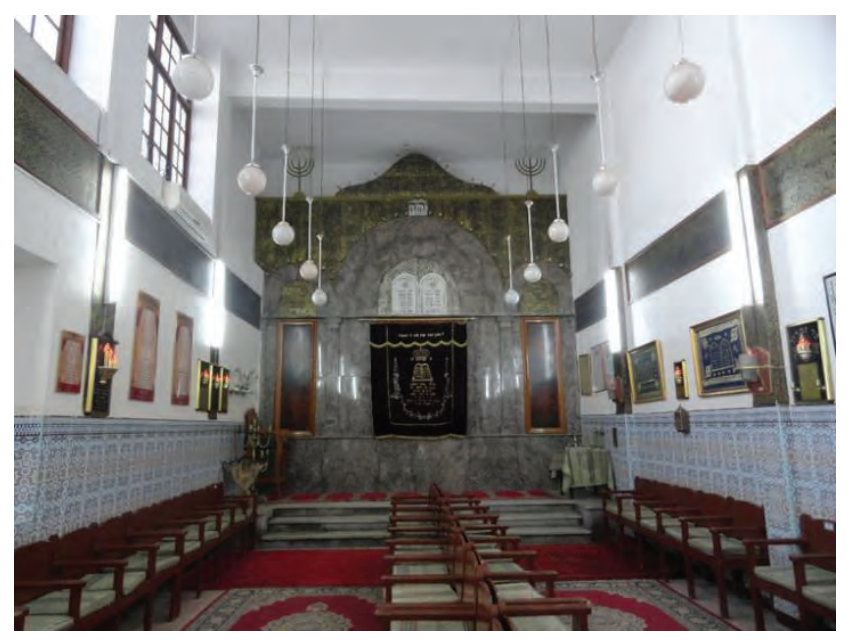

Figure 43: Lazama Synagogue in Marrakesh Source: Photograph by KINGA DÉVÉNYI 
The text is organised into columns, the size of each column is well defined (usually 42 rows per column, with minor variations in some communities). The copyist is a trained scribe who works under strict rules and copying the text usually takes more than a year. The completion of the Torah scroll is a cause for great celebration, during which it is carried to the synagogue while dancing (Figure 43). The scroll is kept in a case; the type of the case (shape and material) depends on the customs of the specific community. Torah scrolls are stored in the synagogue in the ornamental Torah ark, normally located in the middle of the wall facing Jerusalem (members of the congregation turn towards the Torah ark when reciting prayers, in the direction of Jerusalem). At the end of the Torah reading, the open scroll is lifted so that the community may see the script.

The Mishnah is a legal collection of the so-called "oral law", which was passed down orally in Hebrew until the end of the second century CE and was then written down. The Mishnah is a fundamental source of Jewish religious law, however, besides legal texts it also contains other types of narratives, commentaries, exegetical texts and masterpieces of the wisdom literature. The Hebrew word Mishnah means "repetition", "learning". The name Mishnah does not only refer to the entire collection, but also to the individual sections, traditions (i.e., a given mishnah is a law or a certain passage of the collection called Mishnah).

The Talmud (meaning "learning") is also a collection of the oral law, but it is more recent than the Mishnah, and also comprises it (Figure 44). The Talmud is basically a commentary and explanation of the Mishnah, which is reflected in its structure as well: each mishnah passage is followed by a long discussion on it, mostly in Aramaic (the Talmud is thus a bilingual text). The genre of the interpretation of Jewish law is basically the debate that the Talmud captures almost as a dialogue, however, often without identifying the participants. Since both Hebrew and Aramaic scripts only record consonants, and the text lacks interpunctuation, Talmudic debates are difficult to follow, since the reader may not always be sure where a particular sentence begins and ends. Since the Talmud was initially passed down orally, its text was deliberately concise. Therefore, the Talmud is usually not studied alone, but in pairs or groups, where the students may reconstruct and continue the discussion of the Talmudic sages. By studying the Talmud, one can master dialectics, the art of debate. Talmud study is a religious duty of every adult male to this day. The genre of the Talmud (i.e. debate) and its continuous study over the centuries probably influenced the image and character of Judaism. The Talmud has often been the target of anti-Semitic outbursts and it was publicly burnt several times in history along with other books. 


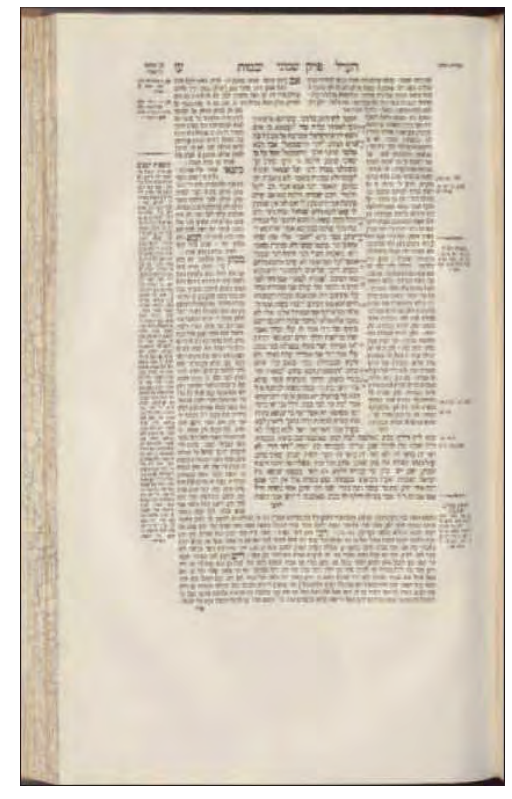

Figure 44: Babylonian Talmud. Prague: Landau, 1832.

Source: The Oriental Collection of the Library of the Hungarian Academy of Sciences

\subsubsection{Stages of J ewish Life, C ertain Religious R ules}

The Jewish religion is based on the observance of the 613 commandments (mitzvah) from the Torah. The commandments are not listed in an itemised way in the Bible but were deduced and recorded by rabbinical authorities. The commandments are divided according to the following aspects: There are 248 active (positive) commandments corresponding to the number of members of a human body and 365 negative commandments corresponding to the number of days in a year. (The number of bodily members is 248 according to Jewish tradition.) Division is also made between commandments referring to the relation between man and God, and to others referring to the relation between man and the fellow people. Jewish law also distinguishes between commandments related to a specific time and the ones that are not. A commandment related to a specific time is, for example, the Torah reading on Saturday, which is done on Saturday morning in the synagogue. Commandments related to specific times do not apply to women because, according to the traditional perception and explanation, they primarily have to look after the family and children, and it is often impossible to reconcile childcare with specific times. 


\section{Circumcision}

On the eighth day following the birth of a boy, it is mandatory to circumcise him. According to the Bible, circumcision is a sign of the covenant between God and Israel: "This is My covenant, which you shall keep, between Me and you and your seed after you: every male among you shall be circumcised. [...] and it shall be a token of a covenant between Me and you. [...] My covenant shall be in your flesh for an everlasting covenant." (Gen. 17:10-11,13) Circumcision is performed by a trained specialist (mohel) within the framework of a religious service. The child is given a name during this ritual. (Girls are named in the community following the Torah reading: the father is called to the Torah and this is when he announces his daughter's name to the community.) The ceremony is concluded with a festive meal.

\section{Bar Mitzvah}

Boys are required to observe Jewish religious laws from the age of thirteen (girls are required to observe the laws from the age of twelve, but they are subject to fewer rules than boys). Bar mitzvah (which literally translates to "son of commandment") on the one hand refers to a boy who has turned thirteen years old, and also to the festive occasion, when the boy observes a commandment in front of the community for the first time in his life. This usually means the boy will read a passage from the Torah in the synagogue, but depending on his skills, he may also be entrusted with additional honorary duties.

\section{Marriage}

A couple wishing to contract marriage sign a document in which the man undertakes to provide for his wife. The ceremony commonly includes the following: The groom is led to the bride and covers her face with a veil, then he steps under the wedding canopy (huppah). The bride is led to him, and she walks around the groom seven times, while those present hold candles in their hands. In the Ashkenazi tradition the canopy is set up in the open air, because the sky reminds those present to the promise that God made to Abraham: "Look now toward heaven, and count the stars, if you be able to count them'; and He said unto him: 'So shall your seed be'” (Genesis 15:5). The groom lifts the bride's veil and they both drink a sip of wine. The groom gives the bride a ring and recites the declaration: "Behold, you are consecrated to me with this ring according to the Law of Moses and Israel". They listen to the seven marriage blessings then they take another sip of wine, and the groom breaks the glass with his foot. 
At this point, the guests cheer, and the dance begins. The traditional explanation for breaking the glass is that no joy can be complete until the Temple in Jerusalem is not rebuilt: "If I forget you, O Jerusalem, let my right hand forget her cunning. Let my tongue cleave to the roof of my mouth, if I remember you not; if I set not Jerusalem above my chiefest joy." (Psalm 137:5-6) Breaking the glass is a symbol of bitterness affecting the joy of the festive occasion. Afterward the newlyweds retreat to a private place: in traditional societies and in older ages, this was the first time the couple was left alone. Sex within marriage is also regulated by religious rules.

It is worth noting that Jewish religious law permits divorce: the divorce is to be conducted before a body of three rabbis (rabbinical court), as civil divorce is not recognised according to Jewish law.

\section{Prayer Shawl, Phylacteries, Mezuzah, Covering the Head}

One of the positive commandments of the Torah is that fringes must be attached to any garments with four edges: " "Speak unto the children of Israel, and bid them that they make them throughout their generations fringes in the corners of their garments, and that they put with the fringe of each corner a thread of blue. And it shall be unto you for a fringe, that you may look upon it, and remember all the commandments of the Lord and do them; and that you go not about after your own heart and your own eyes, after which you use to go astray" (Numbers 15:38-39). Accordingly, Jewish men wear a so-called tallit katan over their undergarments, which is rectangular and fitted with four fringes on its corners to comply with the rules. This is worn all day. During the morning prayer, a larger, ornate piece of cloth is also worn called tallit, a prayer shawl (Figure 45) with four fringes as well.

During weekday morning prayers, Jewish men wear phylacteries (tefillin). The tefillin is a set of two small black leather boxes containing scrolls of parchment inscribed with passages from the Torah. These boxes are fitted with leather straps to the head and to the left arm. 

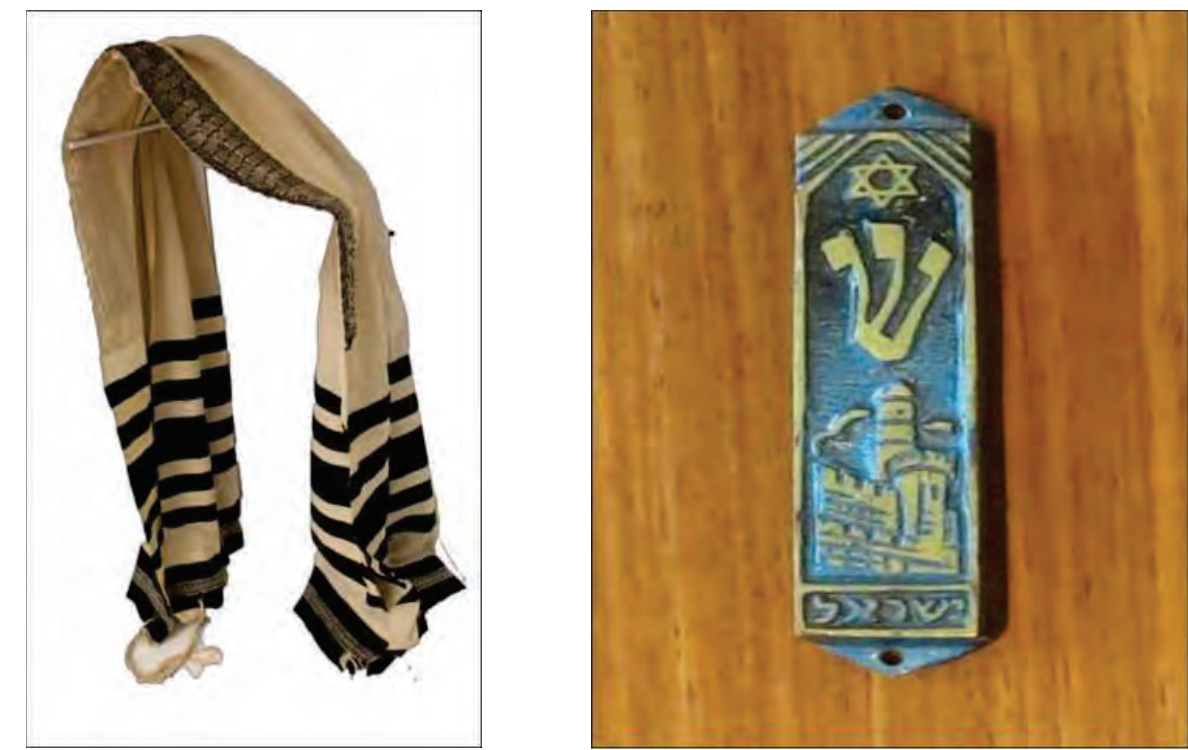

Figure 45: Prayer shawl (tallit) with silver embroidery, MILEV http://collections.milev.hu/items/show/32623 - 20 accessed April 2020 Figure 46: Sephardi mezuzah from Macedonia

Source: PretoriaTravel, https://commons.wikimedia.org/w/index.php?curid=23829644

The passages from the Torah cite the principles of the Jewish faith, and they are tied to the body to symbolise total acceptance and subordination. The text inside the tefillin also mentions God's commandment to wear the passages on the body: "Hear, O Israel: The Lord our God, the Lord is one. And you shall love the Lord your God with all your heart, and with all your soul, and with all your might. And these words, which I command you this day, shall be upon your heart; and you shall teach them diligently unto your children, and shall talk of them when you sit in your house, and when you walk by the way, and when you lie down, and when you rise up. And you shall bind them for a sign upon your hand, and they shall be for frontlets between your eyes. And you shall write them upon the doorposts of your house, and upon your gates." (Deuteronomy 6:4-9) This passage is the most concise statement of Jewish monotheism; it is one of the most important prayers of Judaism, which has to be repeated five times in the daily prayer. In order to observe the last sentence of this passage of the Torah, a mezuzah is placed on the (right) doorframe in Jewish homes (Figure 46). It consists of a small case and a parchment scroll inside it inscribed with specific verses from the Torah. It is usually a decorative case, made of metal, wood, or plastic, and on the outside, it bears the name of God: Shaddai (Almighty). It is customary to touch (or kiss) the mezuzah when passing by. 
Covering the head is such an essential part of the appearance of religious Jews that it is perhaps the best known sign of Judaism for outside observers. However, wearing a hat, cap, or other headgear is not a commandment of the Torah, it is rather a custom, a way of showing respect for God. According to the traditional explanation, in the Roman Empire, covering the head was a symbol of slavery; free people walked with their heads uncovered. Jewish people cover their heads to remember that they are servants of God. In addition to hats and other headgear, the so-called kippah is a common headwear, consisting of a small round cap, often made of black silk, velvet or coloured crocheted yarn. Its size, material, and colour vary by religious congregation, consequently the kippah (along with other pieces of clothing) indicates the congregation its owner belongs to.

\subsubsection{M ajor Holidays}

Given the fact that Jews have lived in diaspora throughout history, and, to some extent, they are still living in diaspora today, and the fact that religious communities are not hierarchically organised, holiday customs are diverse and the interpretation of holiday rules varies from one congregation to another. Therefore, the following overview is limited to the most basic features that a particular congregation may significantly deviate from.

The dates of holidays are determined by the Jewish calendar, which is lunisolar, meaning that it takes into account both the Sun and the Moon as it revolves around the Earth. Jewish months are lunar months (from New Moon to New Moon), nevertheless the length of the full year corresponds to the length of the solar calendar year. Because the lunar year is 11 days shorter than the solar year, an extra lunar month is added to the year at specific intervals (every second or third year) to compensate for this difference. Each day lasts from sunset to sunset, meaning that the day begins in the evening.

\section{Sabbath}

The Ten Commandments includes the Sabbath as a holy day: "Six days shall you labour, and do all your work; but the seventh day is a Sabbath unto the Lord your God, in it you shall not do any manner of work, you, nor your son, nor your daughter, nor your man-servant, nor your maid-servant, nor your cattle, nor your stranger that is within your gates; for in six days the Lord made heaven and earth, the sea, and all that in them is, and rested on the seventh day; wherefore the Lord blessed the Sabbath day, and hallowed it." (Exodus 20:9-11) However, this passage does not explain exactly how it is to be made holy. Only one of the 
Sabbath prohibitions, the prohibition of fire, is mentioned explicitly in the Torah (Ex. 35:3).

Since according to the Jewish calendar, each day begins at sunset, Sabbath also begins on Friday evening. Work is not allowed after the beginning of Sabbath, therefore all preparations for the holiday must be done by Friday afternoon: cleaning the apartment, cooking the festive food, setting the festive table, taking a shower, putting on festive clothes, etc. The Sabbath officially begins when the housewife lights the two Sabbath candles about twenty minutes before sunset and blesses the lit candles while covering her eyes. Two loaves of Challah bread are placed on the table covered with a tablecloth, along with glass of wine, called kiddush cup because a blessing is recited over the wine to sanctify the Sabbath (this is called the Kiddush - "sanctification" - ceremony).

The beginning of the Sabbath, which is called "the welcoming of Sabbath" is celebrated in the synagogue, where men and at least the older children are usually present, but women (especially wives having children) are not required to attend the synagogue service since they are supposed to take care of the smaller children and the celebration at home.

Women are usually happy to rest a little after the Sabbath preparations and before the Sabbath dinner, or to be with their smaller children before the family and Sabbath guests arrive. However, many women also attend the Sabbath service in the synagogue; this depends on each woman's individual circumstances and decision.

After the synagogue service the family gathers at home around the festive table, often inviting guests, too. They sing religious songs together, the father blesses his children before dinner, and then he recites the kiddush with the cup of wine in his hand, after which everyone drinks from the wine (the children drink grape juice, which is considered ritually to equal wine). After that, they wash their hands while reciting the corresponding blessing, the father recites the blessing over the bread (Challah), cuts it into slices and distributes it among those present. This is followed by the festive meal, during which it is customary to talk also about religious topics. The meal ends with long blessings that are recited or sung together.

The Sabbath morning service in the synagogue is much longer than the weekday services, it lasts almost for the whole morning. Women are not required to attend this service either. The second festive meal is at noon and it follows a similar ritual as the Sabbath dinner. The afternoon is mostly spent relaxing, walking, chatting, playing games, or perhaps studying. Studying in this context means studying the Torah in its broader sense: individual reading or in-group discussion of the Bible, its commentaries, or Jewish legal texts (like the Mishnah or the Talmud). Studying the Torah is compulsory for men on the Sabbath, but this obliga- 
tion is fulfilled by everyone when attending the synagogue service, where a portion of the Torah is read out loud as part of the service. Spending some time with studying during the Sabbath is a widespread practice, but not mandatory. The Sabbath ends after the third meal with the "separation" (havdalah) ceremony at sunset, after full darkness. This ceremony involves reciting a blessing over wine again, smelling some spices held in an ornate spice container, and finally, lighting a candle with several wicks and blessing its flame. This is followed by the recitation of the havdalah blessing: "Blessed are You, Lord our God, King of the universe, Who distinguishes between the sacred and the secular, between light and dark, between Israel and the nations, between the seventh day and the six days of labour. Blessed are You, Lord, Who distinguishes between the sacred and the secular."

The main feature of the Sabbath is the tranquillity provided by the intricate system of prohibitions to work. The religious concept of work is not the same as the everyday meaning of the word: work is not equal to occupation (job, profession) or physical effort. The Torah does not interpret the nature of work that is forbidden on the Sabbath, nor does it list the activities prohibited. These are explained in later rabbinical literature. The prohibition of certain activities was established by applying a specific Jewish exegetical principle, which attributes an additional meaning to the succession of passages in the Torah. Even if two passages seem to be unrelated to each other, the mere fact that the second follows the first establishes a connection between them that may have consequences from the point of view of religious law. The rules for preparing the wilderness tabernacle in the Torah are immediately followed by a call to observe the Sabbath (Ex. 31:1-13). Already in ancient times, this was interpreted as an intimation to which activity is actually forbidden on the Sabbath: all the activities, direct or indirect, that are necessary to build the tabernacle (since works for building the tabernacle were suspended during Sabbath). The Mishnah (Sabbath 7:2) lists thirty-nine such activities. However, hundreds of additional labours can be derived from these activities (these are the so-called "primary labours"), which makes the system of Sabbath prohibitions very complicated. For example, there were sacrificial breads in the tabernacle, and as a result all activities necessary for making bread, such as ploughing, sowing, reaping, binding sheaves, threshing, grinding, kneading, baking, are forbidden on Sabbath. Since in the tabernacle there were canvases, garments and priestly vestments as well, sheep-shearing, carding, laundering, dyeing, and sewing are also among the forbidden activities. However, these categories should not be understood in their ordinary sense but interpreted in an abstract way. For example, sheep-shearing in the broader, abstract sense of the word means to separate from the body itself something that grows from the body. This is where, among other things, the prohibition to comb the hair on Sabbath 
comes from: because a few strands of hair may also fall out while combing, one may, even if unintentionally, separate from the body things (strands of hair) that grow from it.

The prohibition to switch on the light originates in the prohibition to light fire. Naturally, this does not mean that Jews would spend the festive day holed up in the dark, they simply make sure to turn the lights on already by Friday afternoon, and set a timer to switch them off at a certain time. Before the invention of electricity, this was done by preparing a sufficient amount of lamp oil, etc. in advance. Sabbath prohibitions, therefore, do not depend on whether an activity can be regarded as work in the ordinary sense of the word, but solely on whether it is included among the primary labours listed in the Mishnah, or among the activities derived from them. To the outside observer, it may seem as though there were many difficulties in observing the Sabbath; nonetheless, this is not so: throughout all eras and circumstances in history there have been well-established and well-known methods of observing the Sabbath, which were followed by the different congregations.

It should be noted that according to Jewish religious law, the sustenance and protection of life is more important than any of the commandments, and in case of such necessity, all commandments must be violated (with the exception of three special commandments). That is, if a person's life can only be saved by not observing a Sabbath prohibition then every Jew is obligated to violate the Sabbath. For the same reason a variety of emergency services, such as hospitals, ambulances, firefighters may operate on Saturday, and this is the reason why members of various armed bodies are exempt from the laws of Sabbath. (The three commandments that are not to be violated despite any life-threatening circumstances are those prohibiting idolatry, murder and illicit sexual relations.)

\section{The Days of Awe: Rosh ha-Shanah and Yom Kippur}

The first ten days of the Jewish year are called "The Days of Awe". The period begins with the Jewish New Year (Rosh ha-Shanah) and ends with the Day of Atonement (Yom Kippur).

Rosh ha-Shanah marks the anniversary of the creation of the world; it is the beginning of the Ten days of Repentance. This is the time when the shofar, the ram's horn used to summon the people, call for war, and intimidate the enemy in biblical times, - is blown in the synagogues. (Figure 47). There are three modulations of sounds produced on the shofar: a long, unbroken blast, a three-part blast, and a seven-part blast. The sound of the shofar is not pleasant, on the contrary, it is rather alarming and shocking. 


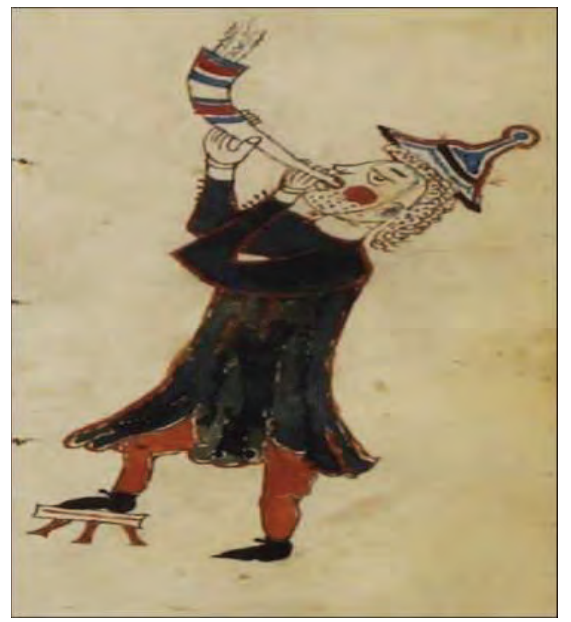

Figure 47: Man blowing a ram's horn (shofar). Festive prayer book (mahzor), South Germany, end of the thirteenth century

Source: The Oriental Collection of the Library of the Hungarian Academy of Sciences, Ms Kaufmann A. 388/II. fol. 12v

On the eve of the holiday, symbolic foods are consumed to ensure a good new year: challah bread or apple dipped in honey (symbolising a sweet new year), a meal served with fish or lamb head (to make the diners the "head", meaning to make them leaders rather than subordinates), pomegranate (just as the fruit is full of seed, one may be full of merits in the new year), etc.

Yom Kippur is the Day of Atonement for all the sins, when members of the congregation engage in rigorous fasting: they do not consume any food or drink for approximately 26 hours, do not pursue any pleasant activities (for example, they only wash themselves to the extent which is absolutely necessary, do not wear leather shoes, etc.). Fasting begins in the afternoon, before sunset, and ends in the next evening, after dark. The Yom Kippur service grants redemption for one's sins committed against another person, but only if the person against whom the sin was committed also forgives the sinner; therefore, before the ceremony, members must apologise to anyone who may have been hurt by them. In other words, the Day of Atonement is also the day of repairing relationships. Sins committed against God are forgiven by God when one repents sincerely. Worship begins with a prayer that has a heart touching melody, called Kol Nidre ("all vows"), which is actually a legal formula that annuls in advance any vows made to God in the next year, which cannot be upheld by the believer for whatever reason. Since the persecution of the Jews in medieval times, this ceremony gained particular significance, and has been charged with emotional undertones. As a result of the medieval persecution of Jews and the forced conversion to Chris- 
tianity, masses of Jews were forced to abandon their religion (the extent of forced conversion was so great that in some countries the majority of Jews or even the entire Jewish population was forcibly baptised). Christian religious practices of the converted Jews were overseen by the Inquisition, a special institution of the Catholic Church, which sentenced tens of thousands of baptised Jews to death for trying to observe certain rules of the Jewish religion in secret. However, fasting and repentance on the Day of Atonement was considered such a strong religious obligation that even people who were regarded to have broken the Jewish law by being baptised wanted to observe it to its possible extent, and hence many of them joined the celebrating Jews on this occasion. According to some interpretations, this is the historical reason why, before singing Kol Nidre, the cantor recites out loud: "By the authority of the Court on High and by authority of the court down here, by the permission of One Who Is Everywhere and by the permission of this congregation, we hold it lawful to pray with sinners (that, is Jews converted to Christianity forcefully)."

The entire Day of Atonement is spent with prayers for forgiveness in an increasingly intense state. According to the widespread tradition, the Day of Atonement is the only day of the year when the Satan cannot accuse man in front of God. According to the traditional interpretation, this is indicated by the numeric value of the Hebrew letters in the word Satan (meaning the Devil), which is 364, one less than the number of days in the year. Therefore, the Day of Atonement is an exceptional opportunity to ask for forgiveness. The congregation concludes the service by reciting a final prayer, called the Ne'ila ("locking") before sunset. This prayer was originally recited while the gates of the Temple in Jerusalem were locked, but today the name refers to locking the gates of Heaven. While the gates of Heaven are open, God is listening to the prayers of repentance, and as the time for locking the gates approaches, the congregation makes final efforts to seek forgiveness. According to folk tradition, this is the moment when God closes the "Book of Life and Death", in which he inscribes each person's fate: whether they will still live the next Day of Atonement, or whether they will depart from this life by then.

\section{Sukkot ${ }^{11}$}

Sukkot means "tabernacles, or tents", in which the Jews dwelled after the Exodus from Egypt for forty years in the wilderness (Figure 48). The Feast of Tabernacles commemorates this event and is symbolically relived as believers

\footnotetext{
${ }^{11}$ Also spelled Sukkoth.
} 
"dwell" in tents or tabernacles for a week; that is, they spend as much time there as possible.

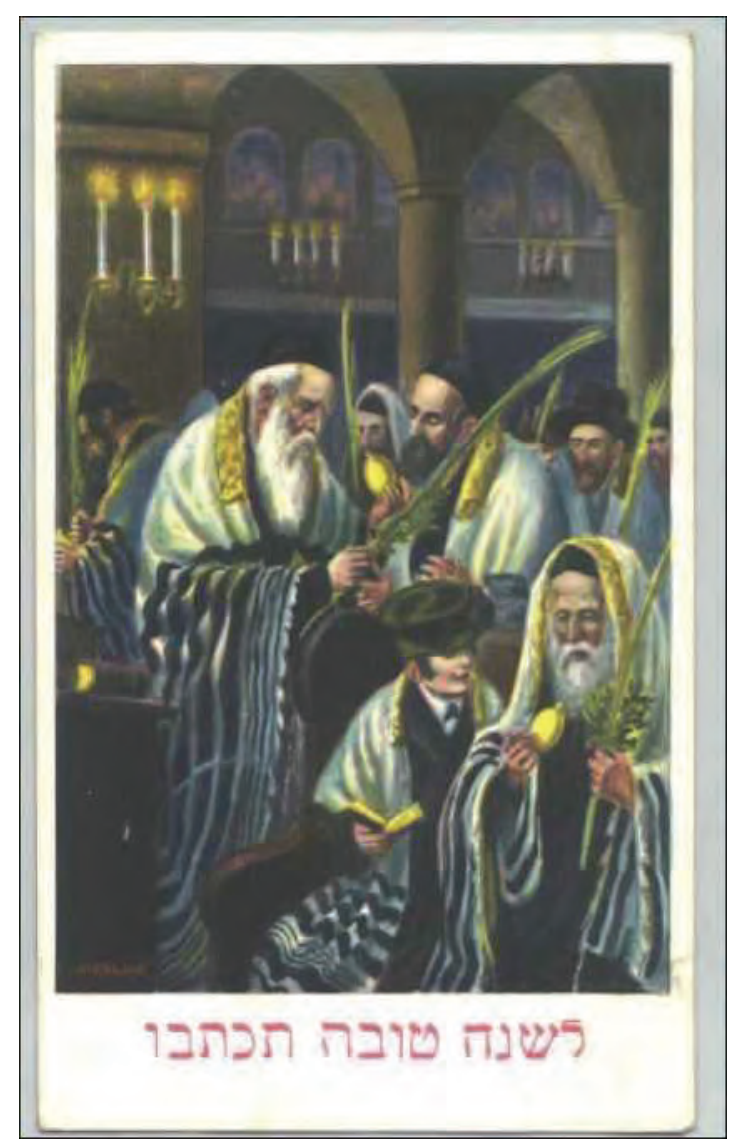

Figure 48: F. Kaskeline, Celebrating Sukkot in the synagogue, MILEV

Source: http://collections.milev.hu/items/show/31846 - accessed 20 April 2020

Nowadays the tabernacles are actually booths that are installed in the garden or on the balcony, and meals are always served here. The booth must be a temporary structure, and its roof constructed of organic materials grown from the earth, such as tree branches, straw of cereals, reed, but the branches or stalks cannot be bound together. The Holiday of Sukkot is celebrated in early autumn, when the temperature in Israel is mostly pleasant, so it is not uncomfortable to stay in the booth. However, in many European countries it is already very cold and rainy around this time; therefore, only the first two evening meals of the holiday period must be served in the booth under any circumstances. During the ceremony of Sukkot prayers are recited while waving a special bouquet called lulav, which is 
composed of a type of citrus (etrog), myrtle leaves, branches of willow tree and palm tree.

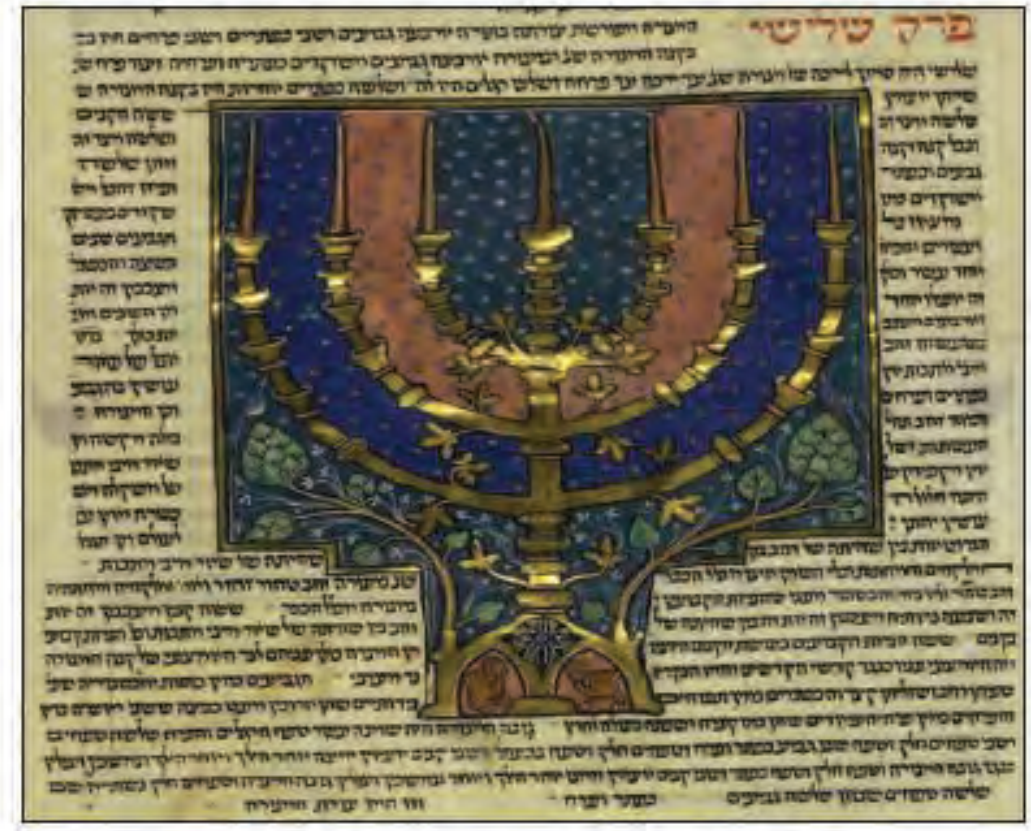

Figure 49: Depiction of the menorah in a manuscript of Maimonides's Mishneh Torah, North-East France, 1296

Source: The Oriental Collection of the Library of the Hungarian Academy of Sciences, Ms Kaufmann A. 77/III. fol. 3v

\section{Hanukkah}

Hanukkah (meaning: "dedication", i.e. of the temple in Jerusalem) is a winter holiday commemorating the rededication of the Temple in Jerusalem at the time of the Maccabean revolt against the Seleucid Empire. The Maccabeans defeated the Seleucid army in 165 BCE. Since the Temple was desecrated by the Seleucids, it had to be purified and rededicated (this is where the name of the festival originates from).

According to the ancient tradition the seven branches of the candle holder, the menorah had to be lit with oil in the Temple, however, there was only enough sealed (consequently, not desecrated) oil left to fuel the flame of the menorah for one day (Figure 49). Miraculously, the oil burned for eight days, the time it took to press the new oil. To commemorate this, each day an additional candle is lit in the eight-plus-one-branched hanukkiah during the eight-day holiday. It is not prohibited to work during this holiday. There are a variety of customs accompanying 
the holiday, such as eating deep fried doughnuts, giving gifts to children, as well as games associated with it, for example playing with the spinning top, called dreidel (Figure 50).

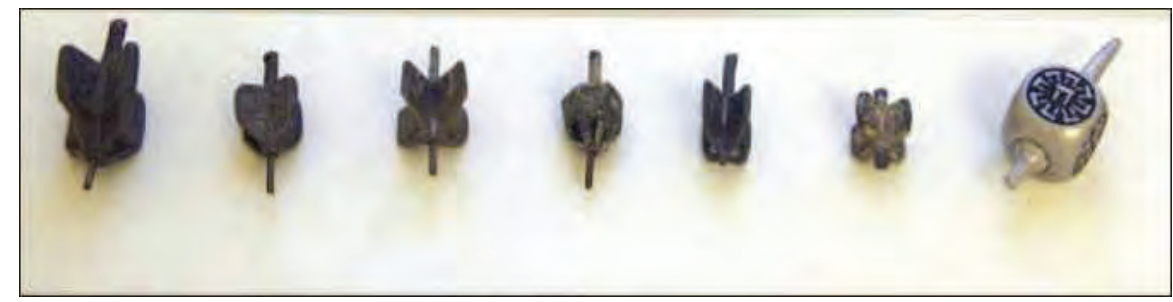

Figure 50: Spinning top (dreidel) played during Hanukkah, MILEV

Source: http://collections.milev.hu/items/show/29761 - accessed 20 April 2020

\section{Purim}

Purim (meaning: "fate") commemorates the story told in the Book of Esther included in the Bible. In the Persian Empire, during the reign of King Ahasuerus, Haman, one of the leaders of the ruling political elite, persuaded the king to order the extermination of Jews in the empire on the grounds that the Jews did not adhere to the central religion of the empire. Haman cast lots to choose the date on which the Jews would be exterminated, hence the name "purim". Although Queen Esther of Jewish descent persuaded the king to change his heart, the decree against the Jewish people could no longer be annulled. However, the king allowed the Jews to defend themselves on the day designated for their extermination, and the Jews eventually won against their enemies. Purim, similarly to Hanukkah is a particularly happy holiday, when one must send food and drink to at least two people, donate to the poor, serve a festive meal and read the Scroll of Esther (this book of the Bible is also traditionally written on parchment scroll). It is not prohibited to work during the holiday, and it is characterised by a carnival atmosphere (the festival is celebrated at the end of the winter). People are dressed in costumes, and publicly burn a puppet symbolising "the evil Haman", and each time Haman's name is read out loud (54 times in total) during the reading of the Scroll of Esther, the congregation engages in noise-making with Purim graggers to blot out his name (in order to erase his memory), which is especially fun for children. The tradition of wearing costumes, according to some explanations, is a hint to the fact that God does not control history in an explicit, obvious manner, but in a hidden, disguised way. 


\section{$\operatorname{Pesah}^{12}$}

The "Jewish Passover", Pesah is celebrated in spring. It is the festival of the Exodus from Egypt, and of the unleavened bread. It commemorates the Exodus of the people of Israel from Egypt following their slavery in Egypt for centuries and despite the Pharaoh's prohibition and resistance. The Exodus was led by Moses and accompanied by miraculous events. Its significance is due to the fact that, according to tradition, the Exodus from Egypt shaped the nomad tribes subordinated to states and empires into one autonomous people, for this reason Pesah is actually a celebration of freedom.

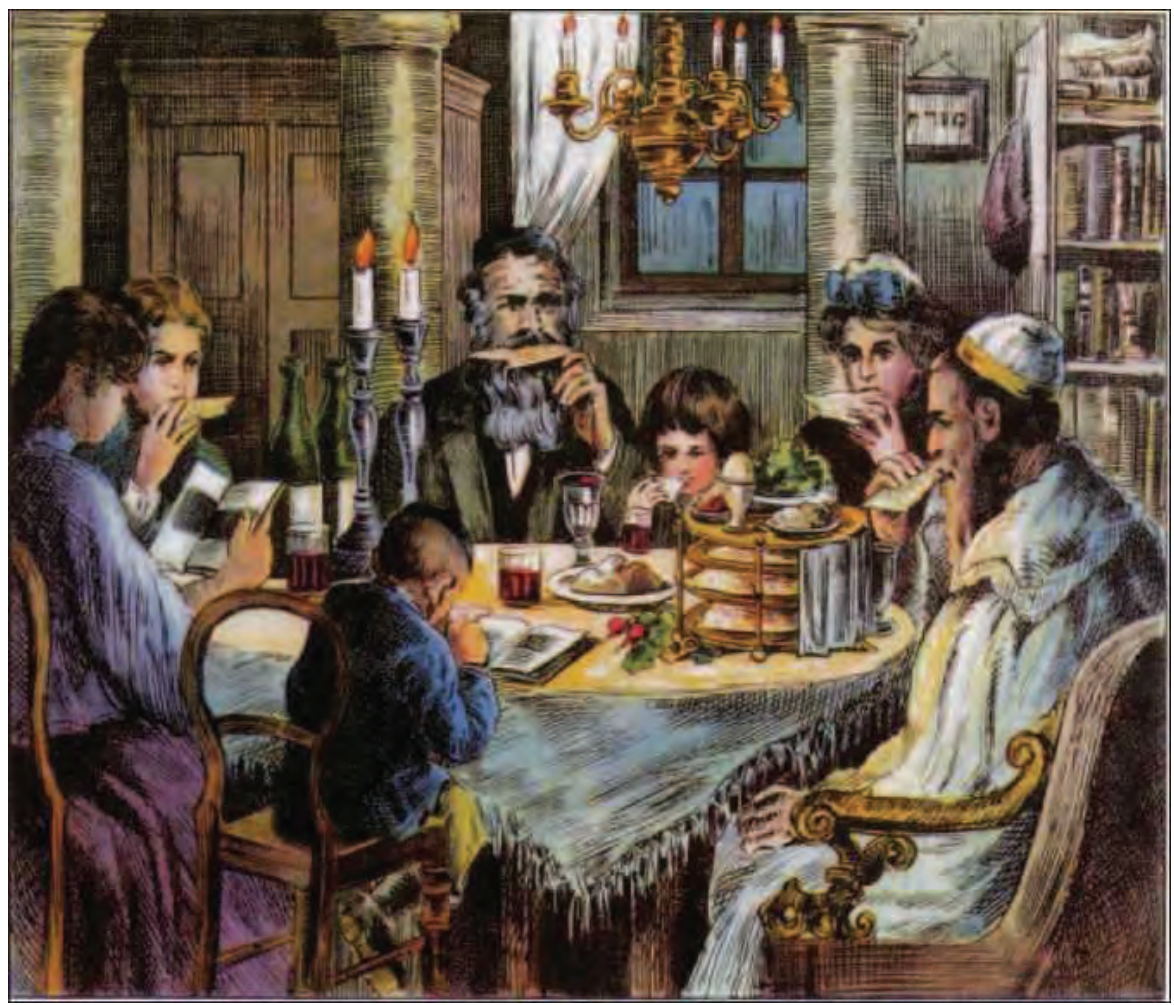

Figure 51: Table set for the Seder meal

Source: Leó Singer: Haggadah shel Pesah. Budapest: Schlesinger, 1917

The first Pesah, held in Egypt, fell on a Thursday. On that evening God commanded every Jewish family to slaughter and serve a sacrificial lamb and smear the front door of their house with the blood of the lamb. The lamb's blood

${ }^{12}$ Also spelled Pesach. 
protected the Jews from the Angel of Death sweeping through Egypt that night and taking the lives of every first born. However, God "bypassed" or "passed over" (pasah), the doors marked with blood. This is where the name of the holiday pesah (Passover) originates from. Then the Jews had to leave the country in such a hurry that they had no time to let the bread rise. To commemorate this, it is forbidden to eat or own anything leaven during the festival (for seven days in Israel, for eight days in the diaspora). The story of the Exodus from Egypt is told in Exodus 1-15.

The main event of the holiday is the Seder eve, a ritual feast conducted on the first night of the Pesah involving retelling the story of the Exodus with symbolic acts and dishes (Figure 51). The order of ritual of the Seder dinner is set forth in the richly illustrated text, called Haggadah (meaning "telling"), which is read (and in part sung) together by the family before the dinner. The text of the Haggadah is not rigidly followed, it only serves as the framework for the main points of the narrative; that is, in the spirit of the text of the Haggadah, participants themselves make commentaries about the biblical story and its subsequent rabbinical interpretations. In part, this discussion takes the format of questions and answers, because telling the story of the Exodus is actually a learning process, meaning that it assumes that participants enter into a dialogue or even a debate (juxtaposition of viewpoints). The reading of the Haggadah, including the verbal commentaries takes several hours. Meanwhile, symbolic foods are consumed: bitter herbs (for example horseradish) symbolising the bitterness of slavery; hard-boiled eggs (as a reference to the mourning for the destruction of the Temple); parsley or celery (as a symbol of renewal, spring, fertility); salty water (as a symbol of suffering and tears); grated apples mixed with nuts, cinnamon and wine representing the mortar (another reference to slavery). In addition, a lamb shank bone or a roast chicken wing is also placed on the Seder plate but it is not eaten. It symbolises the sacrificial lamb, which, however, cannot be properly offered since the demolition of the Temple. The meaning of unleavened bread is explained by the Haggadah (in Aramaic) as the following: "This is the bread of poverty which our ancestors ate in the land of Egypt. Anyone who is famished should come and eat, anyone in need should come and partake of the Pesah sacrifice. Now we are here, next year we will be in the land of Israel; this year we are slaves, next year we will be free people." The Haggadah is mostly written in Hebrew, but some parts are in Aramaic because in the first centuries $\mathrm{AD}$ Aramaic was the spoken language of the Jewish people. According to Jewish tradition, everyone must consider himself to be led by God out of Egypt; that is, one must personally experience the move from slavery to liberation. 
Shavuot

The Revelation on Mount Sinai took place seven weeks after the Exodus from Egypt, when God gave Moses and the people the Tablets of Stone of the Ten Commandments and revealed the written and the oral Torah. This was the moment when God entered into a covenant with Israel: "that He may establish you this day unto Himself for a people, and that He may be unto you a God, as He spoke unto you, and as He swore unto thy fathers, to Abraham, to Isaac, and to Jacob." (Deut. 29:12) According to Jewish tradition, all the Jews, whether born later or even converted, that is, every single Jew until the end of time were present when establishing this covenant. As it reads in the following portion of the Torah: "Neither with you only do I make this covenant and this oath; but with him that stands here with us this day before the Lord our God, and also with him that is not here with us this day." (Deut. 29:13-14). It is customary to stay up all night on Shavuot to study.

\subsubsection{Dietary L aws}

The notion of "kosher" (kashrut in Modern Hebrew), meaning conforming to religious requirements, is the basic concept of Jewish dietary laws. Religious Jews can only eat food that is kosher. The Bible distinguishes between clean and unclean animals: for example, beef, goat, and chicken are clean, but rabbits and pigs are unclean (Leviticus 11, Deuteronomy 14:2-21). It is forbidden to eat unclean animals. Even a clean animal should only be consumed if it has been slaughtered in accordance with the rules of ritual slaughter and examined for any disease that renders the animal unfit for consumption, in which case the clean animal is not considered kosher. The blood must be completely drawn out of the meat because the consumption of blood is forbidden. Likewise, vegetables intended for consumption must be carefully examined for maggots and worms, because if they are present, the consumption of the vegetable is prohibited.

Foods are divided into three categories: meat products, dairy products, and neutral (neither meat nor dairy). Meat and dairy products also include everything that is made of meat or milk, as well as the fats derived from them. It is prohibited to mix meat and dairy foods. This seemingly simple rule has many consequences: meat and dairy products cannot be mixed during cooking or consumption, nor during digestion inside the stomach. Therefore, one must wait a certain amount of time between eating meat and dairy foods (less time is required if meat is consumed after dairy foods, since it is easier to digest milk, but dairy food can only be consumed several hours after eating meat). Different dishes and cutlery must be used for dishes containing dairy or meet, for example, it is forbidden to use a butter knife to cut meat or to cook meat dishes in a pan that was previously 
used to cook dishes with dairy products. Neutral foods (such as vegetables) can be mixed with either dairy or meat dishes, but one must make sure that the cutlery does not transmit any meat or dairy onto the neutral (called parve in Hebrew) food. For example, mustard is a parve food: it is neither meat nor dairy, and it can be mixed with both categories. However, if a knife used to eat cooked frankfurters is dipped into the mustard jar, the cutlery will transfer the meat character over to the mustard, which will in turn become "meaty", and hence it can no longer be consumed with dairy products (e.g. cheese). Therefore, it is customary for Jewish kitchens to also have separate cutlery and dishes for parve products, the third category of foods. Different types of cutlery are usually colour coded (for example, knives with red handles are for meats, while for dairy foods knives with blue handles are used) or otherwise distinguished. Dietary laws are extremely complex, therefore a more detailed description of these is not in the scope of this chapter.

\subsubsection{Schools of Thoughts in J udaism}

\section{Kabbalah}

Kabbalah is the main (but not the only) manifestation of Jewish mysticism, which seeks to explain God's unknowable essence. The Kabbalah is an extremely diverse and multifaceted mystical doctrine, with many different schools; for this reason, this short summary must be confined to the most general principles. According to the Kabbalistic teaching, no positive statement can be made about God, because in essence God is absolutely unknowable. For the same reason, the Kabbalist does not approach God by means of his intellectual faculty but intends to gain an intuitive knowledge of God by attaining to God's intimate closeness. Communication with God is made possible through the system of sephirot, which are emanations through which God's unknown essence reveals itself. The use of Kabbalistic language is highly anthropomorphic, and it does not refrain from sexual connotations. The feminine principle of the Divine plays a critical role in the Kabbalistic tradition, and in this respect, the Kabbalah is unique among other Jewish schools of thought. The most important Kabbalistic work is the Zohar (Book of Splendour) written in Aramaic in the thirteenth century in Spain.

According to the teachings of the most influential Kabbalistic master, Isaac Luria (1531-1572), during the creation God contracted, i.e. withdrew to a certain extent his divinity in order "to make space" for the world to be created. The divine light poured into the material forms of the world, but they were too weak to bear it, and so they all burst, shattered, and sparks of the divine light became enclosed in the shells of the shattering forms. By obeying the commandments of the Jewish 
religion, sparks of the divine light can be released, whereby the faithful Jew completes the act of creation. God remains passive in this process; the fate of creation and the evolution of the world depends on human activity.

\section{Hasidism}

The Hasidic movement started in Poland and Ukraine in the eighteenth century. Hasidic Jews assimilated and further developed elements of the Kabbalistic concept of intimate proximity to God. According to the Hasidic view, personal connection with God entails a feeling of enthusiasm and pleasure that manifest itself in the zest for life. Hassidic Jews seek to get into God's closeness through intuition rather than trying to comprehend divinity using their rational faculty. Their teachings are primarily transmitted through stories, tales, and parables. Hasidism soon became a mass movement. For ordinary people, the "holy" rabbi, the rebbe or tzadik ("righteous man"), transmits the will of God, becoming a kind of mediator between God and men, who stands above the order of creation and can even perform miracles. The Hasidic movement continues to this day, primarily in Israel and the United States.

\section{Zionism}

In Europe, the emancipation of Jews began during the French Revolution. Christianity was not considered a prerequisite of citizenship anymore and Jews were gradually recognised as entitled to equality and citizenship rights. Emancipation entailed assimilation: Jews began to assimilate into the majority society by adopting its customs and culture. Efforts were made to modernise the Orthodox Jewish religion, and many turned away from the religion, and led secular lives. Secularisation culminated in Zionism, which aimed to make the Jewish people equal to all other nations living in independent states and disposing of the right to self-determination. The chief ideologist of Zionism was Theodor (Tivadar) Herzl (1860-1904), born in Hungary, the founder of the international World Zionist Organisation. Zionists began to purchase lands on a large-scale in Palestine, and followers of the movement settled in those territories with the purpose of creating a new Jewish culture independent of Rabbinic Judaism, and with the ultimate aim of founding an independent Jewish state. Initially, Orthodox Jews opposed Zionist aspirations because they regarded the movement as turning away from God. However, the Holocaust greatly changed the attitude of Jews regarding the concept of a secular Jewish state. Owing to the trauma of the Holocaust, masses of Jews believed that only their own state could guarantee their safety, and hence, after the end of World War II an increasing number of Jewish 
people immigrated to Palestine. Following the UN's resolution, the State of Israel was established on May 14, 1948.

\subsubsection{Chronological table}

\begin{tabular}{c|l} 
Date & \multicolumn{1}{c}{ Event } \\
\hline $\begin{array}{c}\text { BCE thirteenth- } \\
\text { twelfth centuries }\end{array}$ & Israel settles in Canaan \\
\hline BCE 721 & $\begin{array}{l}\text { Israel becomes part of the Assyrian Empire, the end of the Northern } \\
\text { Kingdom }\end{array}$ \\
\hline BCE 587 & $\begin{array}{l}\text { Siege of Jerusalem by the Babylonian army; destruction of the city } \\
\text { and the First Temple }\end{array}$ \\
\hline BCE 167 & Beginning of the Maccabean Revolt \\
\hline BCE 63 & $\begin{array}{l}\text { Siege of Jerusalem by Pompey the Great, end of the independent } \\
\text { Jewish kingdom (the Hasmonean Kingdom) }\end{array}$ \\
\hline 70 & The Roman army destroys Jerusalem and the Second Temple \\
\hline 1492 & The expulsion of Jews from Spain \\
\hline 1948 & Foundation of the State of Israel
\end{tabular}

\subsubsection{Bibliography}

ArIEL, DAVID S. 1996: What do Jews Believe: The Spiritual Foundations of Judaism. New York: Schocken

Borowitz, Eugene B. 1987: "Judaism". In: Eliade, Mircea (ed.): The Encyclopedia of Religion. New York: Macmillan, Vol. 8, 127-205.

BRIGHT, JoHn 2000: A History of Israel. Louisville, KY: Westminster J. Knox Press. (4th ed.)

DAVIES, W. D. ET AL. szerk. 2008-2017: The Cambridge History of Judaism. 8 vols. Cambridge: University Press

Donin, Hayim HaLeVy 1972: To Be a Jew: A Guide to Jewish Observance in Contemporary Life. New York: Harper Collins

JACOB, LOUIS: 1984: The Book of Jewish Belief. West Orange, NJ: Behrman House

JaCOB, LouIs 1987: The Book of Jewish Practice. West Orange, NJ: Behrman House

Milgram, Abraham 1971: Jewish Worship. Philadelphia: Jewish Publication Society of America

Rogerson, JoHn 1985: The New Atlas of the Bible. London: Macdonald 


\title{
4.2. The I slamic Civilisation
}

\author{
KINGA DÉVÉNYI
}

\subsubsection{Introduction}

The religion of Islam was the last of the three major Middle Eastern monotheistic religions to be established, in the seventh century. Islam, however, has been more than a religion to this day; it regulates and influences all areas of life. Up to the first decade of the twentieth century, Islam almost exclusively determined both intangible and tangible culture. This is why in the world of Islam the period between the seventh and twentieth century is referred to as the era of Islamic civilisation. The past 100-150 years have already witnessed a growing, partly positive, partly negative and alienating impact of Western culture and civilisation, in view of which we shall limit the examination of Islamic civilisation to the above 1300 years.

At the moment there are some 1.7 billion Muslims, i.e. followers of Islam in the world. Most of them live in countries where Islam is either the only religion or that of the decisive majority of the population. It is the totality of these countries that is referred to as the world of Islam, but even outside the world of Islam a significant number of Muslims live in minority (Map 17). Countries of the Islamic world are situated from Southeast Asia to North and West Africa. These are:

In Southeast and South Asia:

- Indonesia, Brunei, Malaysia, Bangladesh, the Maldives

In Central Asia:

- Tajikistan, Kyrgyzstan, Kazakhstan, Uzbekistan, Turkmenistan, Azerbaijan

In the Middle East:

- non-Arab countries: Afghanistan, Pakistan, Iran, Turkey

- Arab countries: Saudi-Arabia, Yemen, Oman, United Arab Emirates, Qatar, Bahrain, Kuwait, Iraq, Syria, Lebanon, Jordan

In North Africa:

- Republic of Sudan (North-Sudan), Egypt, Libya, Tunisia, Algeria, Morocco, Mauritania

From the other African countries, at the time of writing, there is a Muslim majority in Mali, Niger, Djibouti, Somalia, Senegal, Gambia, Guinea, Sierra Leone, Burkina Faso and the Comoro Islands, while about half of the population is Muslim in Chad and Nigeria. In Europe, Albania, Bosnia and Kosovo are considered to have a Muslim majority. 


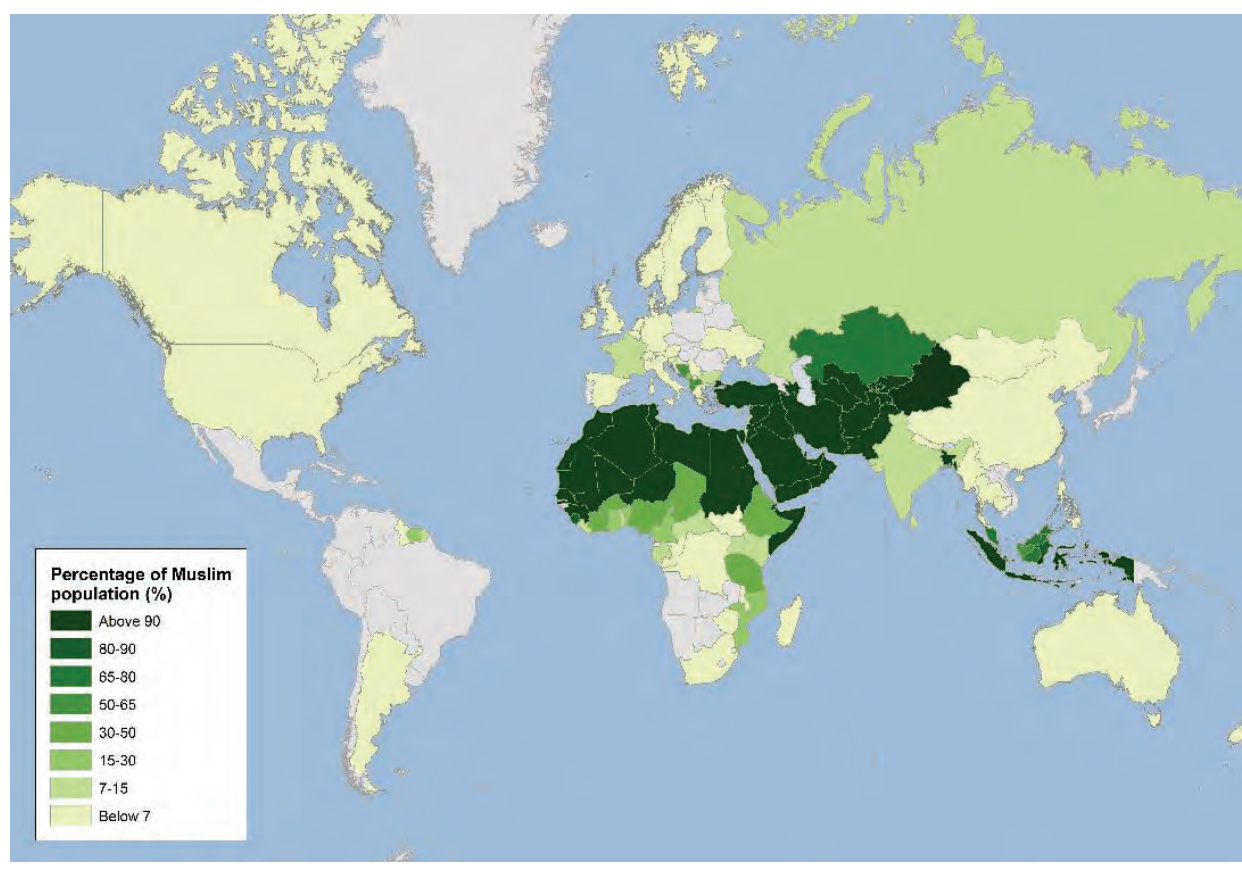

Map 17: The world's Muslim population in 2018

Source: Edited by ÁGNES VARGA

In numerous other countries Muslims live in minority. Some of them have always lived in the same area but converted to Islam at some stage, contrary to the majority of the population. This includes among others, in Asia, Muslims in the Philippines and India, Uyghurs in China, and Muslims in certain areas of Russia like Chechens and Tatars. In many countries in Africa, Muslims comprise a certain percentage of the population (for details cf. the chapter on African civilisation). Another large group of Muslims living as minorities are those who immigrated to Europe and North and South America in the past century, in various ways and for a number of reasons. They used to refer to themselves as living "in emigration"; today they call themselves "Muslim minority". Their number is currently estimated to be 25 million in Western Europe and some three to four million in North and South America together. Afro-American Muslims who converted to Islam after 1950 should be distinguished from the former. The Muslim use of "the world of Islam" is different and is used to refer to any area or country with some Muslim population.

In view of the above, what is referred to as the world of Islam, whether in the broader or narrower sense of the term, comprises a colourful diversity of ethnicities (ethnic groups) and languages, even though originally the "mother tongue" of Islam used to be - and has remained to be - Arabic (Map 18). Arabs 
still comprise the largest group of Muslims with over 400 million people. The second largest ethnic group are Indians living in Pakistan and India, followed by Indonesians, Malays, various Turkic peoples and Persians. Others include a multitude of African ethnic groups as well as Afro-Americans. As regards language, Arabic is once again the major and most important language in the Islamic world, followed by Urdu (in Pakistan and India), Indonesian and Malay, Turkic languages and Farsi. Arabic and Farsi have been the two most important languages in the history of Islamic civilisation, having a great impact on the other languages, primarily Ottoman Turkish and Urdu.

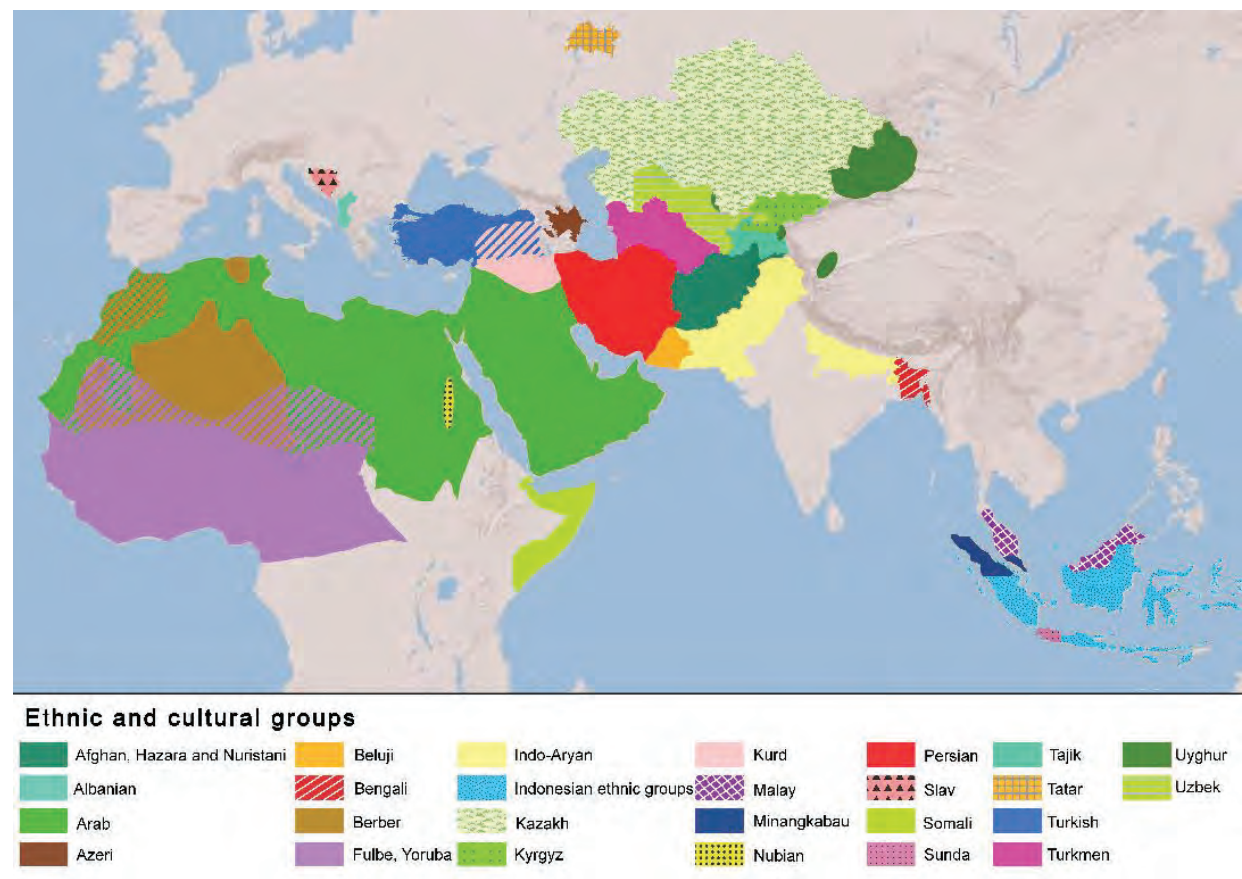

Map 18: The major ethnic and cultural groups in Islam in 2018 Source: Edited by ÁGNES VARGA

The impact of Arabic has been great not only on the vocabulary of the languages of Islam, but also on the spread of Arabic script. For example, some 35-40 percent of the vocabulary of the East-African Swahili language, while 3035 percent of modern Farsi words are of Arabic origin. From among the languages Farsi, Urdu, Azeri, Pashtu as well as Iraqi and Iranian Kurdish have continued using Arabic script until today, Swahili and Turkish switched to Latin script in 1870 and 1926 respectively, while Central Asian Turkic peoples adopted the Cyrillic script during the years of Soviet reign, after 1921. For a long time, 
the two related languages, Malay and Indonesian only differed in that Jawi, a variety of the former, retained Arabic script until the end of the twentieth century, while the latter adopted the Latin script during the Dutch colonisation in the nineteenth century. Arabic script is one of the major writing systems besides Latin and Chinese.

As a geographical characteristic, the first five hundred years of the foundation and spread of Islam took place in a clearly identifiable area: a zone spreading north to the Tropic of Cancer in the Northern hemisphere (Map 19). A major characteristic of this area (with the exception of Pakistan and North India) is little precipitation producing vast deserts, in many regions (e.g. Arabia) interrupted only by bare mountains and highlands. The area also features the Eurasian mountain system referring to various mountain ranges in Afghanistan, East Iran, Turkey (Anatolia) as well as the North-African Atlas mountain range.

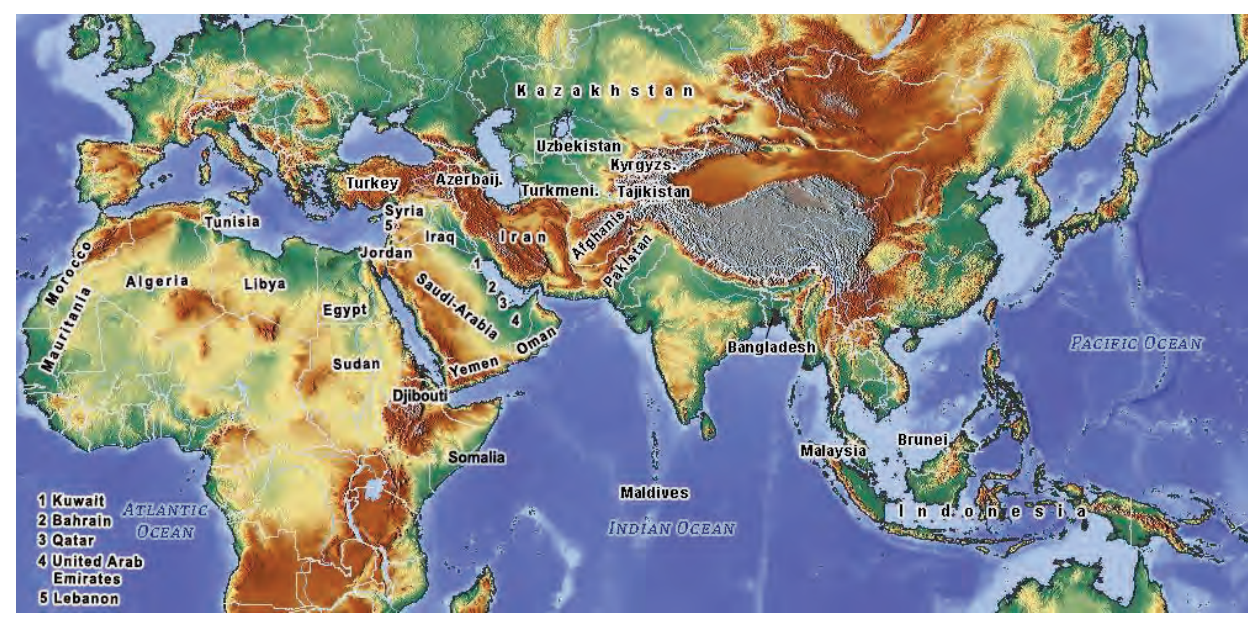

Map 19: Geographical characteristics of the Islamic world Source: Edited by ÁGNES VARGA

Up to the last third of the twentieth century, the characteristic way of life in the desert had been nomadism for thousands of years, based on sporadic water sources and complemented by systems of oases where garden-type agriculture and small domestic animal husbandry (sheep, goats) could be established near permanent wells (Figure 52). Desert nomads were referred to as camel breeding nomads as camels are able to withstand the shortage of water and walk great distances without drinking. 


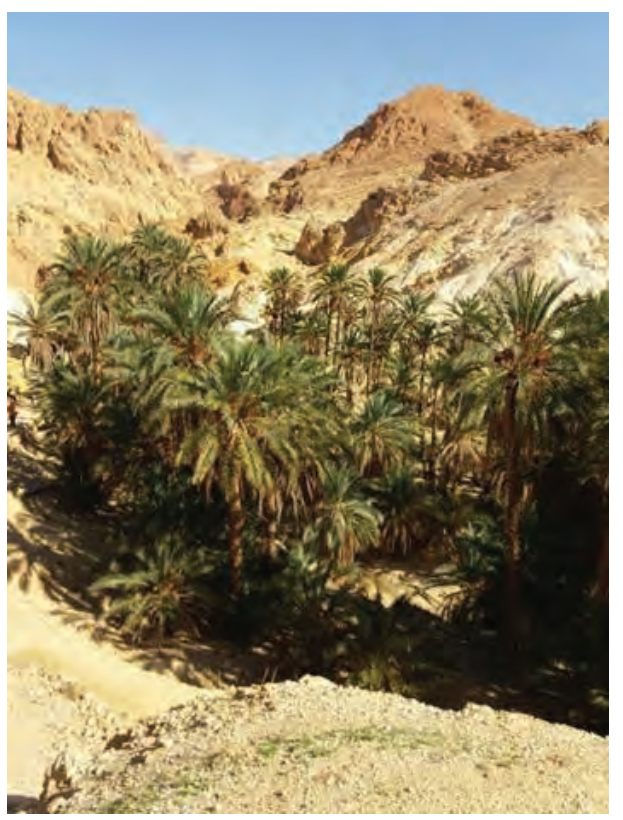

Figure 52: In the barren countryside, date palm oases continue to be a major source of living to this day

Source: Photograph by KINGA DÉvÉNYI

Geopolitically, most of the Islamic world - irrespective of geographical location (with the exception of Pakistan, Indonesia, Malaysia and Muslim countries in West-Africa) - has been referred to as the 'Near East' in the past, while 'Middle East' essentially supplanted Near East in the early twentieth century, although the two are now used interchangeably among English speakers. Both of these terms are Eurocentric, meaning that the historians named the region on the basis of its position relative to Europe. The significance of the Middle Eastern region grew to a large extent after 1930, when vast oil reserves were discovered in several countries in the region (Iraq, Iran, Saudi-Arabia, United Arab Emirates, Qatar, Oman, as well as Libya and Algeria in North Africa), continuously increasing exploitation as well as the wealth of especially those among the above countries that have a smaller population size. The region has recently attracted international attention once again due to the political changes ongoing there ("Arab Spring", "Islamic State") as well as the migration originating from there, which, considering the proximity, poses special tasks for border protection in the European Union (Map 20). 


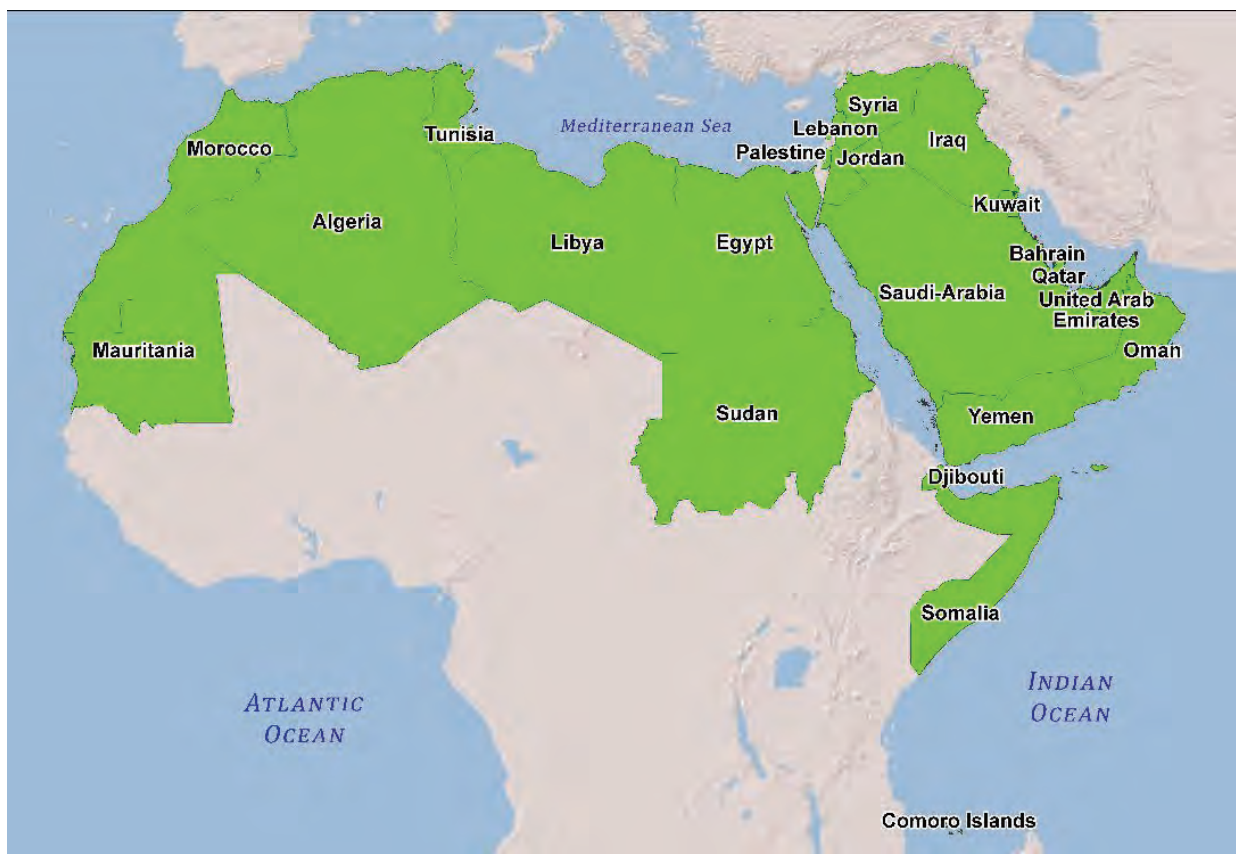

Map 20: The Arab League, established in Cairo in 1945 and comprising 22 countries today, incorporates the Arab states situated in the central areas of the Islamic world Source: Edited by ÁGNES VARGA

\subsubsection{H istory}

\section{Muhammad and Islam}

\section{The origin of the religion of Islam}

The religion of Islam emerged in the first third of the seventh century; its founder was Prophet Muhammad (d. in 632). Muhammad, son of Abdallah, was born in Mecca, Arabia, in around 570. He was orphaned at an early age, whereby he developed social sensitivity, and this is also expressed in the holy book of Islam, the Quran. While traditional tribal society tried to take care of orphans and widows, this was given less focus in Meccan society based on trading activity and a higher degree of individualism. Muhammad was, however, more fortunate than fellow orphans. After his first guardian, his grandfather Abd al-Muttalib also died, according to tribal traditions he came under the guardianship of his eldest uncle Abu Talib. Until his death, Abu Talib defended the Prophet from the attacks that were to grow increasingly stronger against him, even though Abu Talib himself did not convert to the new religion. 
As another fortunate circumstance, Muhammad had the chance to marry the wealthy tradeswoman Khadijah, which secured him employment and subsistence by her side, and she, too, tried to protect him herself, being much older. In that society based on polygamy, Muhammad did not take another wife as long as Khadijah was alive. During his trading trips Muhammad probably met with the teachings of Judaism and Christianity, as well as with Biblical stories.

The best-known story from Muhammad's travels in his young age is what is referred to as the Bahira legend. According to Arab historians, his uncle took the 12-year-old Muhammad on a trading trip to Syria, where they met a Syrian Christian monk, Bahira. Bahira invited the traders into his cell to cool down, but they left the boy outside in the heat of the sun to look after the camels. However, a cloud unusual at that time of the day provided shade for Muhammad. The monk declared this event a miracle and foretold that Muhammad would become a prophet.

It is assumed that at that time many places in Arabia and thus Mecca, too, were regularly visited by preaching Christian monks. What was known as the Fertile Crescent surrounding Arabia, as well as the southern part of the peninsula, were populated by Christian Arabs. There were Jews, on the other hand, living in several oasis towns such as Yathrib and Khaybar. It is clearly apparent from the text of the Quran and some of its linguistic turns that Meccans were familiar with Biblical stories, prophets and with monotheism itself.

Muhammad is assumed to have been around 30 years of age when he started wondering about the questions of life, about justice, the meaning of life and spiritual purity. While he continued to respect Meccan traditions and rituals, year by year he visited a cave in the nearby Hira Mountain where others, too, had withdrawn to meditate. In the course of these visits in 610-611, at the age of forty approximately, Muhammad underwent dramatic experiences. During one of his withdrawals he heard a voice and had a vision, which summoned him to worship God who had created the world, the only God whose name was Allah, whom Arabs respected but who did not have a special cult among them. Encouraged by his wife Khadijah, Muhammad realised that the voice had really come from God himself and was brought down by archangel Jibril (Gabriel) to him, God's chosen prophet. From then on, he continued receiving new messages in his visions, summarised under the name Quran, which originally means "recitation". For some time, Mohammed shared the divine messages only with his wife and some close friends, but three years later he felt that he had a prophetic mission for his people and started openly spreading the new cult in Mecca. The Meccan tribe Quraysh was mostly mistrustful and rejecting towards the new teachings, which they saw partly as Muhammad's individual pursuit of power and partly, due to the similarity to the known Christian teachings, as an intrigue by the Byzantine 
Empire attempting to exercise control over Meccan trade as they had done before. At the same time, they feared to lose the pagan cults and idols which, together with the annual Meccan pilgrimage and fairs as well as the right to designate the holy months when fighting was forbidden, ensured Mecca's superiority over the tribes of Arabia. Muhammad was therefore often insulted and ridiculed during his public preaching, which, however, could not dissuade him. The number of his followers slowly grew to a few dozen, primarily among disadvantaged orphans and slaves, and soon a group of literates formed who followed him and recorded his teachings. These notes on palm leaves, bones, pieces of papyrus and leather as well as soft sand stones were to form the basis of collecting what was to become the Quran.

Numerous events recorded in his biography show that neither the occurrence of the revelations nor their contents were under Muhammad's conscious control. After the early revelations he received no divine guidance for a long time, which made him severely depressed, and was helped through only by the unceasing encouragement and faith of his wife Khadijah. Later on he received the longed for revelations as required but even so it happened sometimes that he did not receive the divine decision in some important issue and interpreted this as his humiliation by God for his mistakes. Such remarks occur in the Quran itself, which often quotes God's words to Muhammad.

Arabs were not unfamiliar with accounts of people who claimed to have been taken over by a being beyond their control, putting words into their mouth, and the rhymed prose of the early parts of the Quran could be familiar, too, as such was also the register of soothsayers (kahin) in their ecstatic statements. At the same time, poets (shair) also claimed that their words of military motivation and glorification for their tribes were inspired by spirits (jinn). Therefore, both Muhammad and later Muslims made great efforts to distinguish the revelations of the Quran from soothsayers' and poets' statements.

Meccans watched Muhammad's missionary activity with growing hostility and after they failed to persuade his clan, the Banu Hashim, to deny Muhammad the protection obligatory according to tribal morale, they took measures against the whole clan in 616 boycotting them for three years. It was prohibited to keep contact or trade with the Banu Hashim clan. In 619, however, there were two events which negatively affected Muhammad: his wife Khadijah and his protective uncle Abu Talib died.

\section{Accounts of the Night Journey and Heavenly Ascension of the Prophet Muhammad}

It is assumed that the tragic events with a great impact on his life, the death of his wife and his uncle, left Muhammad in despair and a loss of certainty about 
the success of his mission. Then, in around 619 he received a vision, which is referred to only by half a sentence in the Quran but is described in detail in dozens of the traditions. The quotation from the Quran is as follows (17:1): "Glory to Him who journeyed His servant by night, from the Sacred Mosque, to the Farthest Mosque". On the basis of the word used here, the first part of the story is referred to as the "night journey" (Isra) and every Muslim religious scholar accepts it as authentic. The details are outlined in the Hadith with reference to Muhammad's account. One night, Muhammad was taken by archangel Jibril from the roof of his house in Mecca to the farthest mosque, which, based on the identical name, scholars identify with the al-Aqsa mosque in Jerusalem, built much later. According to the accounts Muhammad was awake and followed the angel travelling on the back of the mule Buraq. In the mosque he prayed together with the earlier great prophets Moses and Jesus, who asked Mohammed to lead the prayer as an imam. The vision may have thus reinforced Muhammad's sense of mission. For the second part of the story there is no evidence in the Quran and has thus not been accepted by all religious scholars, although its assumed date is celebrated throughout the Islamic world. This is the heavenly journey (Mi'raj). The story says that Jibril led the Prophet "from the farthest mosque" to the seven levels of Heaven, where in every level he was awaited and greeted by prophets known from the Bible and finally he proceeded to God's throne.

\section{The hijra (emigration)}

As the head of the clan Abu Talib was succeeded by another uncle of Muhammad who is referred to in the Quran as Abu Lahab ("Father of Flame"), which metaphorically means "destined for Hell". He did not wish to protect Muhammad, who thus had to find support outside Mecca. He did find the support from the side of the population of Yathrib, $320 \mathrm{~km}$ north of Mecca, later called Medina. The inhabitants of Yathrib engaged in agriculture and primarily date cultivation. The three Jewish tribes who lived there were later joined by two pagan Arab tribes, the Aws and the Khazraj, who were in constant fight with each other. According to ancient Arabian tradition they were to welcome a neutral arbitrator in town who had the necessary moral dignity and wise understanding, and this they found in Muhammad. Negotiations went on in the years 621-622, after which they signed the two so-called Agreements of al-Aqaba, in which they accepted the new religion and Muhammad as the leader, and at the same time they promised him, Meccan Muslims and their families the protection granted to the members of their own tribes, their wives and children. Thereafter, in September 622, a group of some 70 Muslims left Mecca, and Muhammad followed them. This emigration is called hijra in Arabic, and this was to mark the beginning of Muslim calendar. The emigration had to be fast and secret, because between 
Mecca and Yathrib (Medina) Muslims could not enjoy either the old or the new protection, anyone could have killed them without a consequence.

\section{Islam in Medina}

In the new town Muslims, who had no understanding of agriculture, first of all had to face economic and financial difficulties. Initially, the solution was that the new Medinese Muslims, the Ansar ("supporters"), accepted the emigrants (muhajirun) as their brethren. In early 624 Muhammad adopted a method that helped to solve financial difficulties and, by weakening Meccan pagans, advanced the cause of religion at the same time. In a holy month (when fighting was not allowed) they attacked the Meccan caravan carrying goods on their way to Syria. Although many even among the Muslims disapproved of violating the holy month, a Quranic revelation (2:217) said this was allowed in the fight against the greater evil, paganism. The greatest success Muhammad had was in the Battle of Badr (March 624), where Muslim forces who were of a smaller size succeeded in robbing a well-guarded, bigger caravan. The success was significant not only financially, but it also reinforced Muhammad's authority, which was also indicated by the fact that he succeeded in expelling one of the Jewish tribes who had been intriguing against him - the Banu Qaynuqa - from Medina. These battles were also of ideological significance, since there were clan members fighting against clan members and even Muslim family members against pagan family members. Muhammad declared that the old tribal system was over; Muslims formed a single super-tribe called umma. Members of the umma were not allowed to keep contact with former fellow tribesmen, were not allowed to inherit from them and vice versa. The following year, the too hot-headed young people persuaded Muhammad into a battle that was to end in a severe defeat at Uhud, but Meccans were unable to exploit their victory and destroy Medina. At the same time, Muhammad succeeded in expelling the other Jewish tribe supporting the Meccans, the Banu Nadir as well. They were not allowed to take their property with them, which were thus passed down to Muslims. Hostility with Meccans also continued who, in order to protect their trade, decided for a decisive step in 627. They recruited a force of thousands of Bedouins from among their allies, joined also by many Meccans, and went to Medina to attack and seize it. Muhammad was, however, informed of their plan in time and had deep trenches dug in order to protect the city, while the removed earth served as a protective wall. The Battle of the Trench (khandaq) lasted as long as a month and Meccans had to retreat without results. This led to the reinforcement of Muhammad's position in Medina. After the battle, the last Jewish tribe in Medina collaborating with Meccans, the Banu Qurayz, were massacred under the pretext of a conflict with Muslims. Thereby both external and internal resistance was dissolved, and 
Muhammad's attention could now turn to organising the Muslim community, now including all inhabitants of Medina acknowledging Muhammad's leadership, on a religious basis.

In the initial years of Islam in Medina, Muhammad did not make efforts to pass universal regulations guiding the new community. It seems that in the atmosphere of waiting for the end of the world, he considered Muslim life in this world would be ephemeral. As his authority and power grew, however, there was growing need for passing laws, and this became increasingly clear in the Medinese chapters of the Quran as time passed. Certain laws referred to performing various forms of worship: creed (the profession of faith), prayer, compulsory almsgiving, fasting and pilgrimage. Since these are, however, not always comprehensive instructions, these were later complemented with the traditions of actual religious practice as performed by Muhammad. Another category of laws dealt with relationships between people: marriage, divorce, inheritance, trade agreements. These, too, were described only to the extent they diverted from the existing habits and norms. A third category focused on moral requirements like declaring sexual relationships outside the new marital relationship approved by Islam as sinful. The Medinese revelations stipulated ways of punishment for certain major sins (hudud): murder, theft, adultery, and defamation. At the same time, they specified the most important prohibitions in diet and marriage.

Not everyone welcomed the Prophet's growing prestige in Medina; for example, his enemies misused the rumours in connection with one of his wives, Aisha. The Quran therefore contains numerous instructions that refer only to Muhammad and his household. Finally, it was important to legalise the fight against members of the old Meccan tribe and clan who remained pagan and order the struggle (jihad) against those prohibiting exercising Islam. The Quran mentions at the same time that this fight - literally "struggle" - must take root in the soul of Muslims in order to reinforce their faith. In the world of Islam marked by the Quran, individuals may, however, reach happiness in this and the other world only as members of the Muslim community, the umma, in view of which it encourages Muslims to try to keep to the "straight path" by supporting and guiding one another to the right path.

In 628 Muhammad decided for a bold step: with his followers including Bedouins from the neighbourhood he went to Mecca unarmed to perform the pilgrimage. Meccans offered peace, as a result of which Muslims were allowed to perform the pilgrimage the next year, in 629. In 630, however, an incident provided an excuse for Muhammad to denounce peace and seize Mecca. The conquest was bloodless, Meccans surrendered to Islam and six weeks later they already fought together and won in the Battle of Hunayn against hostile Bedouin tribes. The year 631 witnessed the final breakthrough when all tribes in Arabia 
sent delegations indicating their intention to join Islam, while at the same time smaller raids and campaigns were launched to border areas of the neighbouring Sassanid Persian Empire and the Byzantine Empire. In 632 Muhammad, who decided to stay in Medina, performed the pilgrimage to Mecca once again referred to as the "farewell pilgrimage" - and soon, unexpectedly even for his close companions, he died.

\section{The question of succession}

Muhammad failed to appoint a successor (caliph), whose election was therefore preceded by heavy disputes. Medinese Muslims felt they had enabled the success of Islam and therefore they should provide the successor, while the Meccans argued for the principle that the successor should come from Muhammad's tribe, the Quraysh. Tribal traditions made two kinds of succession possible. Either an experienced and wise leader was appointed by election or the most prominent member of the family or household (Ahl al-Bayt) of the deceased chief became the new chief of the tribe. Finally, at the initiative of Umar, who had played a significant role in governing the life of the community in Muhammad's life already, the oldest and one of the first Muslims, Abu Bakr, was elected the first caliph. This was, however, unwelcome by some of the Muslims who wanted Ali, the Prophet's cousin and at the same time the husband of his daughter, Fatimah, to be the caliph. These Muslims called themselves "party of Ali" (Shiat Ali) and were to form a branch of Islam still existing today, Shii Islam.

\section{The Caliphate in Medina: the reign of the four rightly guided caliphs}

\section{The caliphate of Abu Bakr (632-634)}

Abu Bakr's most important task was to defeat the separatist efforts of Bedouin tribes from Islam (ridda, "apostasy"). These tribes considered joining Islam as a traditional contract of tribal alliance, which was related to Muhammad as a person and for them his death made it invalid. Abu Bakr's armies were victorious at several points of Arabia, so he was able to reunify the peninsula. His efforts to maintain power and unity were facilitated by the circumstance that, continuing the external conquests started by Muhammad, he sent troops against the Byzantine Empire and the Sassanid Persian Empire. The allocation of the booty obtained in the victorious battles enhanced the loyalty and fighting spirit of Bedouin tribes. Abu Bakr rose to power at an old age and died two years later, but before that he designated Umar ibn al-Khattab as his successor in order to avoid disputes similar to those preceding his appointment. 
4.2. The Islamic Civilisation

The caliphate of Umar (634-644)

The second caliph Umar had achievements important from the point of view of Islamic history in three areas. First, he reinforced the organisation and internal order of the new and growing empire. Umar used to be the guardian of order when Muhammad was still alive; he applied much stricter measures against phenomena he considered immoral or anti-Islamic than Muhammad himself. Tradition says that he was the one who urged a total ban on wine drinking, too, towards the end of the Medinese era as drunken behaviour led to disorder. During his reign he was quick to ban the so-called pleasure marriage, which was a temporary relationship allowed also by the Quran. The explanation he gave for the ban was that pleasure marriage had only been allowed temporarily during the lengthy siege of the oasis of Khaybar when fighting Muslims were unable to keep contact with their wives for a long time. The other area where Umar had the greatest success was his fast and huge military victories. In 635 Muslim forces occupied Damascus and by 636 the whole Syrian and Palestinian province of the Byzantine Empire became part of the Muslim Caliphate. Finally, between 638 and 641 they seized Egypt, too, from Byzantium. Fast military success also continued towards the East. At the Iraqi al-Qadisiyya in 637, they had a decisive victory against the Persian Empire whose capital and central areas were in the Western border zone of the empire, in Iraq. Arab conquests continued after the victory and within a few years the whole vast Sassanid Empire was in Muslim hands. Umar appointed his own loyal men to the top positions of all the armies and newly occupied provinces and in this way, he was able to maintain control of the caliphate that had grown at an unexpected pace. The third area where Umar's activity has had significance to this day was collecting and organising the various parts of the Quran. Umar assigned the Prophet's scribe Zayd ibn Thabit to perform this task and it was through the activity of this scribe that the current structure of the Quran, the order of the verses (aya) and chapters (sura) was established. As a consequence of an assumed personal injury, Umar was murdered while praying in 644.

\section{The caliphate of Uthman (644-656)}

Umar was succeeded by Uthman ibn Affan, a member of the most prestigious Meccan clan - the Banu Umayya - and husband of one of Muhammad's daughters. Uthman also understood the significance of the Quran and assigned a committee led by Zayd to collect all the existing copies of the Quran and make the script uniform by eliminating the various linguistic versions. Uthman then had the various versions burnt and the uniformised version copied in enough copies to be sent to all the provinces. 
During Uthman's reign conquests continued both in the direction of the eastern provinces of the Persian Empire and in that of Libya in North-Africa. At the same time, there was growing dissatisfaction over the fact that the caliph appointed the members of his family and clan to all important positions. This is how Muawiyah, son of the pagan Meccan leader opposing Muhammad and the later caliph became the commander of the important Syrian province. At the same time, the supporters of Ali (the Shia) had a growing community as well. Finally, Caliph Uthman was killed in his own house by rebels in 656. Muslims were unable to reach an agreement on the question of succession.

\section{The caliphate of Ali (656-661) and the first civil war (fitna)}

In Medina, Ali was elected caliph, but he was not recognised by the Syrians, who had elected Muawiyah. The armies of Ali and Muawiyah met at the bank of the Euphrates (at Siffin, today's Raqqa) in 657, where following ancient Arab tradition they decided for arbitration, on the basis of which the western territories remained under Muawiyah's and the eastern territories under Ali's rule. Some of Ali's supporters did not accept this and broke away from the camp claiming that Ali became caliph because God ordered it to be so, and people were not allowed to change this. They established an independent state in the central parts of Arabia. They were referred to as Kharijis ("those who leave") by later generations. In the meantime, Ali and his followers moved to a new military town in South Iraq, Kufa, where Ali was assassinated by a Khariji when coming out of a mosque. Thereby Muawiyah became the only ruler.

Kharijis formed the first sect of Islam. According to their strict views, anyone who committed a major sin was to be punished by death, while the most suitable Muslim was to be appointed caliph, irrespective of his origin. Those who did not follow their teachings were not Muslims and could be freely killed. These tenets were revived in extremist political Islam in the twentieth and twenty-first centuries once again. After the eighth century, Kharijis were forced out of the central areas of Arabia and established countries on the edge or more hidden parts of the Islamic world. The most significant of these was the Rustamid Imamate in the territory of today's Algeria in the ninth century. A more moderate branch of Kharijis are the Ibadis, who founded an independent state in Oman still existing today. There are smaller Ibadi communities in today's Algeria, in the Mzab Valley, as well as Libya, Tunisia and Zanzibar (Map 24).

\section{The Umayyad Caliphate of Damascus (661-750)}

Muawiyah's reign marked the beginning of the Umayyad dynasty, who governed the vast empire from Damascus. The first era (661-683) is referred to 
4.2. The Islamic Civilisation

as the Sufyanid Umayyad dynasty since the caliphs came from among descendants of Sufyan within the Umayyad clan. The first of them was Muawiyah (661680), who reigned with the support of Syrian Arab tribes. After the first so-called civil war (fitna) of the Islamic Empire ended with the death of Ali, the majority of Muslims, striving for unity, supported the Umayyads. The remaining internal resistance, Ali's supporters and the Kharijites were successfully defeated by military force, and at the same time external conquests continued primarily with the help of a strong and successful fleet established against Byzantium, which occupied the island of Cyprus. At that time, the influence of the new provinces on the Islamic Caliphate became clear since desert Bedouin tribes had no understanding of shipping, for which Syrian, Palestinian and Egyptian Muslims were used. In all areas of state administration, the Umayyad Caliphate strongly relied on Christians in the conquered Syria who continued Byzantine traditions and performed public administration in the Greek language. The currency at the same time was adopted from the Sassanid Persian Empire: the Arabic version of the silver drachma was dirhem. It was also a Byzantine effect that hereditary reign was adopted as a custom after Muawiyah's death, so was followed by his son Yazid I. Ali's supporters - the Shia - who were in majority in South Iraq tried to use the disputes regarding succession and led by Husayn - Ali's son and Muhammad's grandson - they went to attack the Umayyad governor. The battle of Karbala fought against a much larger enemy ended in the defeat of Husayn and his martyrdom together with that of most members of his family. The commemoration of his death has become a Shii mourning holiday called Ashura and is celebrated on the tenth day of the first month (muharram)of the lunar calendar year.

The second civil war (fitna) (683-692)

After the death of Yazid, Marwan I from the other branch of the Umayyad clan rose to power (683-685). As succession had never been regulated in principle and chieftains always took their loyalty oath to the caliph in person rather than the dynasty, there were once again several claimants to the caliphate when Yazid died.

Zubayr gained power in a Medina of diminished prestige and tried to reign from there, while Mukhtar became the Shii candidate in Kufa. The fights finally ended only after the military success of Marwan's son Abd al-Malik (685-705), who became the actual and acknowledged ruler of the whole empire only after 692. There were three significant characteristic features of his reign that affected the later development of Islam. 
- On the one hand, influenced by great empires in the region and following their example, he put an end to the caliph's dependence on tribal and military leaders and became a ruler with absolute power.

- On the other hand, relying on strong military governors, he solidified his power in the new provinces, primarily in the territories of Iraq and Iran. The governor here was Hajjaj for decades, who not only continued expanding the empire further east but also succeeded in introducing an effective taxation system. Islam never obliged the population of the conquered territories to convert, but for reasons of taxation Hajjaj wished to explicitly block Islamisation. While Muslims only paid land tax (kharaj), the followers of acknowledged religions referred to as dhimmis (Jews, Christians and in Iran Zoroastrians) were also obliged to pay poll tax (jizya). He was therefore considered anti-Islamic by later generations as he tried to prevent conversion and keep peasants from leaving their villages and move to the new town. He had one more reason for doing so: the disgruntled population of the new military garrison towns like Kufa and Basra in South Iraq were Shii and forever in opposition.

- The third feature of the reign of Abd al-Malik was the Arabisation of the state. Arabic replaced Greek as an official language, new coins - gold dinar - were minted to replace Greek ones, with a quotation from the Quran instead of the sovereign's image, while public administration was gradually transferred from Christians to educated Arab Muslims.

During the reign of Abd al-Malik's successors the empire expanded towards the West and reached a decisive stage in 711 (Map 21). Led by Tariq ibn Ziyad the Muslim troops reinforced by the conquered North African Berber tribes who had converted to Islam, crossed over to Europe at a place called the Gibraltar pass today. The name of Gibraltar (Jabal Tariq, Tariq's Mountain) has retained the name of this commander until our days. From then on, they rapidly advanced and with the exception of the northern mountain range took control of the whole Hispanic Peninsula (today's Spain and Portugal). They called the area al-Andalus (Andalusia), which was larger than the province of Andalusia in today's Spain. The Umayyads' reign was basically based on the support of the Arab tribal system, which guaranteed certain stability to the caliphate, but was at the same time prone to the negative effects of inter-tribal discord primarily between the Northern and Southern Arab tribes: the relatively recent immigrant Qays, and the Qalb whose members had arrived earlier in Syria. With the troops, this rivalry was transferred to Andalusia as well, where fights were recorded for centuries. It was because of its nature of being based on the Arab tribal system that later Arab historians referred to the Damascus Caliphate as the "Arab Kingdom". This, 
however, generated dissatisfaction among non-Arab Muslims. If they wanted to be acknowledged in urban life, they needed the protection of some Arab tribe, clan or family and to become their protégée (mawla, "client"). It was this dissatisfaction that led to the strengthening movement and later open rebellion that is referred to as the Abbasid Revolution which led to the fall of the Syrian Umayyad Caliphate in 750 and the establishment of the Iraqi Abbasid Caliphate.

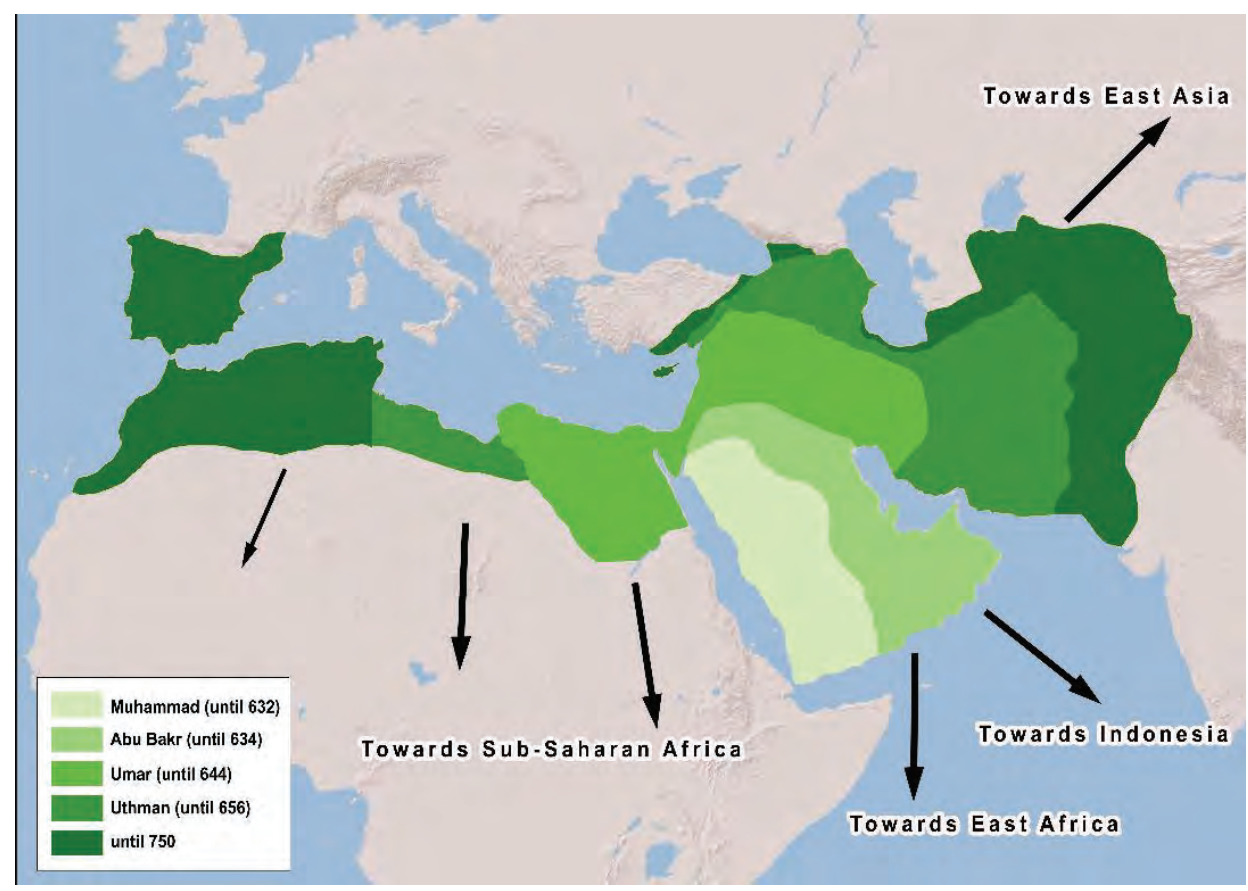

Map 21: The expansion of Islam Source: Edited by ÁGNES VARGA

\section{Religious movements in the first half of the eighth century}

The growing dissatisfaction in the second half of the Umayyad era also manifested itself in various religious movements. Although apart from the Shiis and Kharijis who clearly rejected the dynasty, the followers of numerous other religious movements and views accepted the existing rule, they did formulate critical views. The Murjiah ("those who postpone") were dissatisfied with the religiousness of the system, they postponed their judgement and left it up to God to judge sovereigns on Judgement Day. The Qadariyah asserted God was just, and humans followed the good or the evil exercising their free will. In the Quran they studied the concept of divine decree (qadar) and came to the conclusion that God did not arrange everything in advance. Their followers were mainly members of the South Arabian tribe Kalb who were disillusioned with the 
Umayyads. The Jabriyah (jabr meaning coercion) on the contrary believed in divine predestination and taught that human intention had no role in determining our deeds. Another teaching that became of decisive importance in the ninth century was also established under the name Mu'tazila. The Mu'tazilites did not make a stance in political issues and accepted the concepts of free will and divine justice. They, however, were not active in Syria but in Basra in South Iraq.

The son of Caliph Muawiyah, Yazid I (r. 680-683) who died at a young age in a horse-riding accident had special respect among some of the Northern Iraqi Kurds. Their followers, the Yazidis separated from Sunni Islam. The closed endogamous community of Yazidis have lived in Northern Iraq until today.

\section{The Abbasid Caliphate of Baghdad (750-1258)}

Although the members of the dynasty used the title "caliph" between 750 and 1258, their actual power lasted much shorter, until 945. From then on, power shifted away to various military dynasties, while the caliphs symbolised the lawfulness and legality of these dynasties' reign in the eyes of their subjects as the military governors (emir) of the time always pledged allegiance to the caliph. The members of the Abbasid dynasty were descendants of Abbas, one of the Prophet Muhammad's uncles. They regarded themselves as God's delegates on Earth ("God's shadow on Earth") and, accordingly, after rising to power, they adopted regnal names alluding to God's will. The first who helped the family to power had himself called al-Saffah ("the blood-shedder") indicating that God had chosen him to eradicate the Umayyads as well as their followers, all held for disbelievers, which he, worthy of his name, in fact did. There was only one member of the Umayyad family who was able to escape, who went to Andalusia and there, relying on friendly Arab tribes and breaking away from the Abbasids, established an independent Umayyad Emirate under the name Abd al-Rahman I. The reason why al-Saffah was, despite the brevity of his reign (750-754), able to efficiently eradicate his enemies and later even some of his supporters who became dangerous, was that he did not rely on tribal Arabs among whom even a caliph had to think twice before killing a dangerous rival as according to tribal tradition he had to fear obligatory blood feud. The Abbasids, however, primarily relied on East-Iranian, mainly Khurasani mountain-dwellers and the Iranian-Iraqi peasantry in their movement. Understandably, they were to choose their capital also in this region, close to the capital of the former Sassanid Empire.

Al-Saffah's successor was Caliph al-Mansur ("the one supported by God") (754-775), who first moved to his South Iraqi castle of al-Hashimiyya near the river Euphrates, but soon planned to establish a new capital further North near a small Persian village on the river Tigris, Baghdad. This place was extremely 
suitable from the military, the public administration as well as the trade aspects. Here the two large rivers, the Tigris and the Euphrates are close to each other; they were connected by a huge canal system which surrounded Baghdad as well, and since ancient times this was the place where the East-Western (Silk Road) and the North-Southern trade routes crossed each other. The old Sassanid capital Ctesiphon was nearby, and south to it lay the huge agricultural area providing also for the Persian Empire, the Sawad ("black soil"). The original idea was that the imperial seat surrounded by a double castle wall system and called, because of its form, round city, would only be inhabited by the caliph and his court: the clerks running public administration, the treasury and first of all the caliph's large community of bodyguards. Caliph al-Mansur moved into the city in 762 and although officially it was called Madinat al-Salam, in everyday life it was called Baghdad from the very beginning. The caliph's original idea was that tradesmen and manufacturers would only deliver the required goods to the round city, but it would be prohibited for them to settle there in the fear of potential clashes between the population and the military or the negative effects of potential riots. Soon, however, various small towns were established around the capital lying on the right bank of the Tigris, which, gradually growing into one, were to form the vastest city in the Middle Ages. Thereby the weight of the caliphate irrevocably shifted towards the east, which was one reason why they were unable to keep the Western provinces with the exception of Egypt. Besides the Umayyad Emirate in Iberia, independent emirates were formed also in the areas of today's Tunisia, Algeria and Morocco (Figure 53).

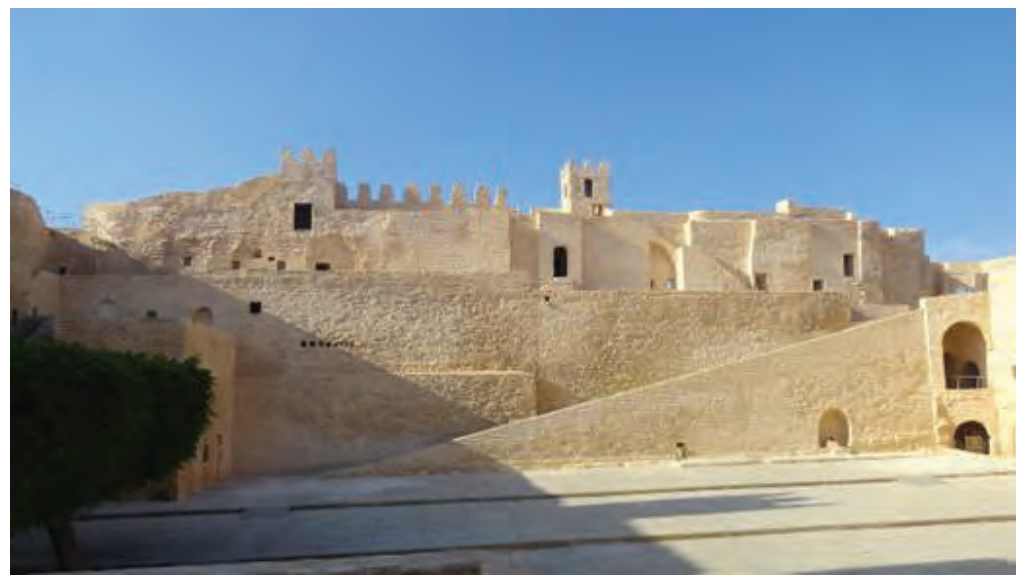

Figure 53: The fortress of Monastir (Tunisia) originally built by the Abbasid governor in the late eighth century, later used and enlarged by the local dynasties Source: Photograph by KINGA DÉVÉNYI 
The main difference of the Abbasid Caliphate (or Caliphate of Baghdad) from its predecessor in Damascus was that putting Syria into the background, Iraq became the centre in every respect. It was here that agriculture was developed; it was here that new crafts like paper manufacturing came into being, and in the administration, Syrians were replaced by descendants of officers of Iraqi or Iranian origin. The caliphs of Baghdad adopted the system of the earlier offices (diwan) but complemented it with a new office, that of the chief minister (wazir), whose duty was to carry out the caliph's instructions but in numerous issues he was able to decide individually and he had his own staff of clerks. The caliph was no longer the highest-ranking Arab sheikh, but the protector of Muslims entrusted by God.

The Abbasid rise to power inevitably involved a change in the composition of the army. The military victory over the Umayyads was mainly thanks to the mercenaries hired from the province of Khurasan, and for half a century they became the major support of the caliphate. When, after 820 , the province became semi-independent under a military commander called Tahir and his dynasty and they did not give more soldiers, the caliphs relied on an army of mercenaries from various Turkic tribes rather than on Arab tribal armies like the Umayyads. The only exception were border areas where troops of voluntary warriors were formed from locals who bore the title Ghazi ("warrior against disbelievers") and were given some of the booty of possible raids.

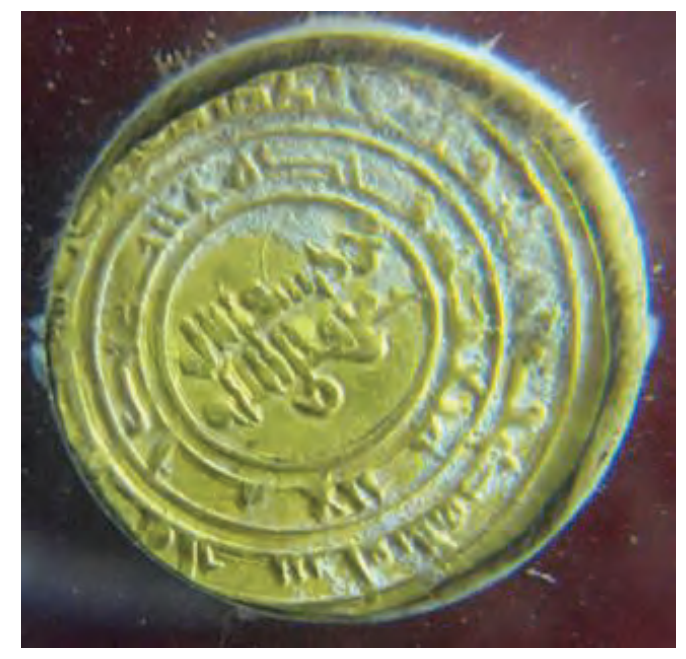

Figure 54: Gold dinar with an Arabic inscription, Museum of Mahdia (Tunisia) Source: Photograph by KINGA DÉVÉNYI 
The first Abbasid era between 750 and 830 witnessed great economic booms. The uniform and vast empire provided a huge market for the agricultural and handicraft products, and the caliphs reigning according to the Meccan traditions tried to facilitate trade, which marketed the goods as far as the Atlantic Ocean in the West and India in the East. All these made it necessary to establish a well-developed financial as well as a commercial letter of credit distribution system. Money changers had to be up to date about the exchange rate of the silver dirham used in the Iranian part of the empire and the gold dinar meeting the Byzantine traditions (Figure 54). In order to avoid that the tradesmen carry a huge amount of silver or gold, the credit system based on cheques was established, and these were accepted from tradesmen from Baghdad everywhere from Morocco to the Province of Sindh at the bank of the Indus River. The word cheque itself is also of Arabic origin (sakk). As Islam prohibits that money should beget money considering it as usury, most monetary institutions were operated by Jews and Christians.

The age of Harun al-Rashid (786-809), the golden age of the Caliphate of Baghdad

After crushing internal riots, the caliph's attention turned to the organisation of the empire. The caliph who was also the "commander of the faithful" at the same time, personally commanded a troop every year. On one occasion he supervised the Meccan caravan, the following year the usual raid against Byzantium. He considered guaranteeing public security to be the highest priority task of the central authority; he made efforts not to interfere with the private sphere and usually left legal and religious issues up to scholars of law and religion. The caliph and his court, however, effectively supported culture and science all the time. Even for a long time after his death, the name of Harun alRashid still well known among the population of Baghdad; he became one of the main characters in the oldest versions of Arabian Nights as the just sovereign who in disguise mingles with the people so as to listen to and resolve their complaints. One of the real manifestations of this was the special court held every week under the supervision of the caliph to remedy unlawfulness (mazalim courts), where anyone could bring their complaints to the caliph. This tradition, which originally was adopted form the court of the Persian king, survived for centuries but from the tenth century it was headed by the chief minister rather than the sovereign. As an advantage, the sovereign or the chief minister were not bound by the complicated provisions of Islamic law and could make instant judgements as they liked. After the seventeenth century, a separate office under the name Diwan almazalim was established in the Ottoman Empire where judges examined the complaints lodged against decisions. 
The court of the Caliph of Baghdad was famous for its splendour and opulence. The only reason why we cannot experience the beauty of the buildings and gardens is that in the thirteenth century the Mongols destroyed everything; only the establishments in Andalusia modelled on the Iraqi examples can give us a picture as those were not destroyed by the Christian armies during the reconquest (reconquista; twelth-fifteenth centuries).

\section{Caliph al-Ma'mun (813-833)}

Al-Ma'mun, who occupied Baghdad in a fraternal war, tried to limit the authority of religious scholars who relied on traditions and with reference to the eternal Quran tried to lay down the rules of religion, law and social life. He therefore made the Mu'tazilite teachings the official dogma, whose representatives taught about the created - i.e. not eternal - Quran and free will. The "created" nature of the Quran means that God could have created it differently from the way we know it today, which gives room for the sovereign's or the government's intention in the interpretation of divine laws as the Quran no longer has an absolute nature. Under al-Ma'mun and his successors this dogma became obligatory for state officials and religious leaders in mosques, and those who did not share the teaching of the created Quran were imprisoned. This was called inquisition (mihna).

\section{The beginning of the fragmentation of the empire}

In the second half of the ninth century Abbasid power weakened; the huge empire was impossible to govern by directly appointed governors. Provincial governors' growth of power is primarily indicated by the fact that local dynasties were formed which, although they acknowledged the caliphs of Baghdad, governed independently and most of the time kept the collected taxes as well. First it was the eastern territories that became independent from Baghdad. The Saffarids governed Iran and the Province of Sindh (today's Pakistan, Afghanistan), later the Samanids who defeated them moved their centre to Central Asia making Bukhara their capital. They considered themselves the descendants of the pre-Islamic Persian dynasty and regarded the dissemination of new Persian literary language and Persian culture against Arabicate culture as their main task. They were deprived of their power by their own Turkish mercenaries, who established the Ghaznavid Empire with Ghazna as capital after 1000. They, too, were supporters of Persian culture. It is to the credit of their first sovereign Mahmud (997-1030) that he sponsored one of the greatest works of Persian culture: Firdawsi's historical epic, the "Book of Kings" (Shahnameh) was dedicated to him by the author. 


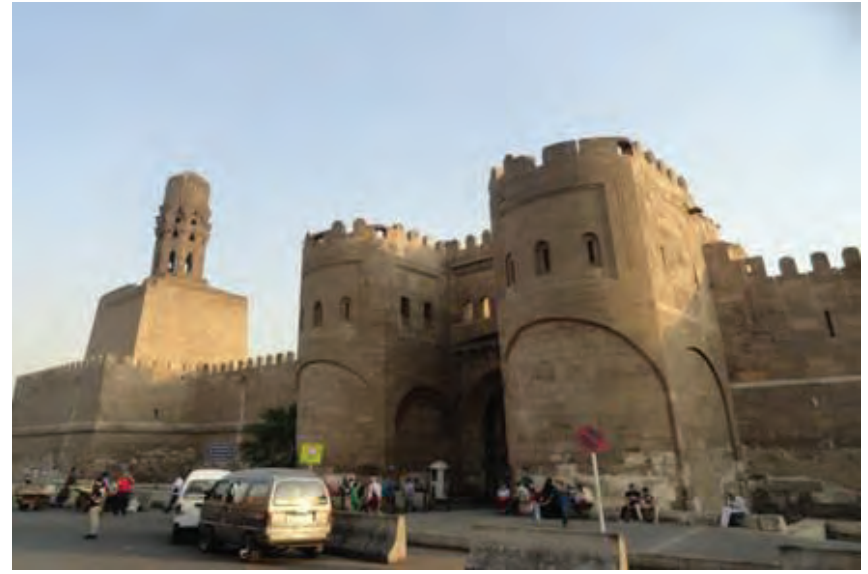

Figure 55: The Bab al-Futuh (Gate of Conquests) built by the Fatimids in the eleventh century, in Cairo. In the background, a minaret of the Hakim Mosque named after the sixth Fatimid Caliph

Source: Photograph by KINGA DÉvÉNYI

In the central territories of the Caliphate of Baghdad, in Iraq and Western Iran, the Iranian Shii Buyids (also called Buwayhids) took control of actual power in 945 for about half a century and used the Caliph of Baghdad for authorising their power.

In Egypt as well as in the areas of today's Tunisia, Algeria and Morocco, dynasties of military governors reigned in the ninth century. These dynasties, however, all acknowledged the Caliph of Baghdad as the head and the religious leader of the Islamic Empire and did not launch a fight against him as they had no religious-ideological differences of opinion. The Umayyad Emirate in Spain also acknowledged the Caliph of Baghdad as religious leader despite political differences. In the tenth century, however, a new power emerged in North Africa: the Shii Fatimids (Figure 55).

\section{The disintegration of the Abbasid Caliphate}

In 1095 Pope Urban declared the First Crusade to liberate the Holy Land, i.e. Jerusalem, and the crusader troops - whom Arabs called Franks irrespective of their origin - soon established several smaller or larger principalities near the Mediterranean Sea in the region of Syria and Palestine, of which the Kingdom of Jerusalem was the most significant one.

The crusaders fought heavy battles with the Seljuk Emirate that initially took control of Syria and later of Egypt as well. The most famous of these was the battle fought at Hattin in 1187, where Emir Saladin defeated the crusader troops and regained control over Jerusalem as well for some time. Smaller 
crusader states, however, resisted for another one hundred years until as long as 1291 when the last Palestinian town Akko, too, was lost. Despite their final lack of success, the Crusades nevertheless had a great impact on the history of the Middle East. They opened the eastern region of the Mediterranean Sea to European, primarily Venetian traders, while Islamic civilisation made a significant material and intellectual impact on the Europe of the Middle Ages.

\section{Islam in Spain}

Islamic troops, which by then included the indigenous inhabitants of North African regions - the Berbers - as well, invaded the Hispanic Peninsula in 711 and formed various Islamic states there until the fall of Granada in 1492. The Umayyad Emir who fled from Damascus and his descendants reigned in much of the peninsula with Córdoba as the capital from 756 to 1031. In 929 Abd alRahman III proclaimed himself caliph and thus broke with Baghdad from a religious point of view as well, but he did not launch hostile actions, either ideologically or militarily, against the Eastern caliphate. The Caliphate of Córdoba did not only leave marvellous material heritage - building, gardens and various smaller objects - behind, which stand as witnesses of the highly developed civilisation of the age, but constituted the first channel via which the products and achievements of the culture and civilisation of the Islamic East reached Europe. This is proven among others by the hundreds of cultural terms that were adopted from the Arabic via the Spanish to European languages. Examples for these words include adobe, algebra, alchemy, estrade, magazine, tariff, and giraffe. During the Muslim reign large numbers of Christians and Jews were allowed to freely practice their religion, while at the same time they mixed with the Arab-Berber population both linguistically and culturally.

The Caliphate of Córdoba survived until 1031 when after the death of the last Umayyad sovereign it fell apart into small regional city-states. This is referred to as the age of "petty kingdoms" or "reyes taifas" with a Spanish-Arabic term. This age passed with small kingdoms fighting against one another, in which the Northern Christian principalities supported various Muslim sovereigns alternately in the military sense as well. At the same time commercial and cultural relations were continuous among both Muslim principalities and the territories under Christian rule.

\section{The reconquista}

At the end of the eleventh century there was a turn in the political relations in the peninsula. Using the fragmentation of the Western Islamic world, Christian kingdoms started to launch attacks; marking the beginning of the fights called 
reconquista ("reconquest"), which were to last until 1492, the centre of the Northern Muslim territories Toledo fell under Christian rule in 1085. After the Castilian conquest Toledo remained to be an important cultural centre. Its Arabic language library suffered no harm; at the school founded there Muslim and Jewish scholars translated the Arabic and Hebrew philosophical, logical and mathematical works to the Castilian language, to be later translated by Spanish scholars into Latin, the language of European science at the time. Thereby the ancient Greek sciences that had been lost for Europe for a long time could spread in the Christian Europe.

As another consequence of the fall of Toledo, the Muslim small kingdoms invited in the troops of the Berber dynasty reigning in the territory of Morocco, the Almoravids, to prevent Christian conquest. This proved a doubled-edged sword however, because the Almoravids, after halting the Christian conquest, stayed in the Muslim-ruled areas of the peninsula and joined these territories to their own empire. Originally the Almoravids formed a religious alliance of nomadic Berbers living in North-West Africa. Even their name itself means "those who live at a monastery-fortress (ribat) and spread Islam in a militant way". Men veiled their faces the way like their late successors, the North-African Tuaregs do. Starting from Senegal they occupied Morocco, where in 1062 they established the city of Marrakesh, which remained to be their capital. Between 1086 and 1147 they gradually occupied Muslim Spain.

Their leaders called themselves "commanders of the faithful" (amir) and in religious issues they accepted the authority of the caliphs of Baghdad. They left behind significant heritage especially in the field of architecture. Their capital in Iberia was Sevilla instead of Córdoba.

At the beginning of the twelfth century a new Berber religious movement was launched from North-Western Africa, which by 1147 conquered the Almoravid Emirate. They were the Almohads, which name is the Spanish version of the Arabic al-Muwahhidun, the strict interpreters of divine unity. By 1146 they occupied the Spanish territories of Almoravids and in 1147 their capital, Marrakesh, as well. Their religious doctrines were formulated by their first leader, Ibn Tumart who led an ascetic life, disapproved of music, dance and wine drinking, the last of which was widespread despite being prohibited by Islam. He regarded himself as mahdi, God's messenger. His successors adopted the title of caliph and separated from Eastern Islam in the religious sense as well, although they claimed to be Sunnis. They extended their power to the whole of NorthAfrica, up to the Egyptian border. They made Seville the capital of their whole empire not only of the Spanish territories. Although the Almohad's primary goal was to block the advance of the holy war and of Christian troops in Spain, from the end of the twelfth century they gradually suffered military failures and finally 
in the battle at Las Navas de Tolosa in 1212 their whole huge army was annihilated by the united troops of Christian kingdoms, whereby the united Islamic Empire ceased to exist in the Iberian peninsula. Only a single Muslim state was able to survive for another 250 years, the Emirate of Granada.

\section{The Middle East after the collapse of the Caliphate of Baghdad}

\section{The Mamluk Sultanate}

A southern line of the Mongol invasion gradually conquered and devastated the areas of the Caliphate of Baghdad, then in 1258 the armies of the Mongol leader Hulagu destroyed Baghdad and killed most of its inhabitants including the last caliph. Various Mongol successor states were established in the Middle East afterwards, the most significant being the Iranian empire of Timur (or Tamerlane) in the fourteenth century. At the same time, after 1250 the Mamluk Sultanate was established replacing the Ayyubid Emirate and survived until 1517 in Egypt, Syria, Palestine and the holy places of Hijaz, Mecca and Medina (Map 22).

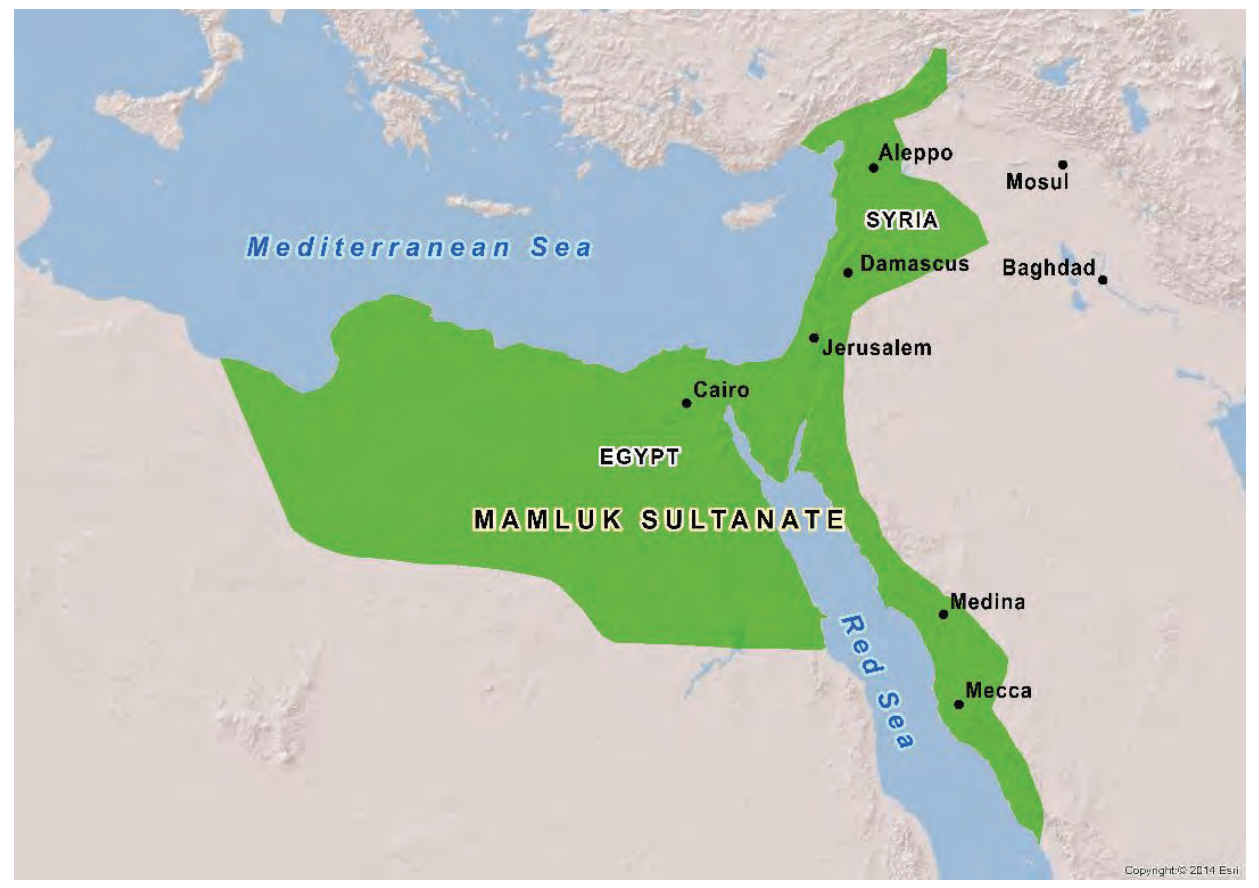

Map 22: The Mamluk Sultanate at its greatest extension Source: Edited by ÁGNES VARGA 
The word Mamluk means a "slave soldier" who was bought at a very young age and trained to become a soldier primarily in the barracks of Central Asia and the citadel of Cairo. As they did not have social contacts of any kind, their loyalty to the sovereign could be counted on. The various emirs, commanders and even the sultan himself were Mamluks originally. Their sons could not become mamluks as only imported young slaves could become soldiers. The leading Mamluks not only dominated the army but the economy as well, as they owned most of the arable land.

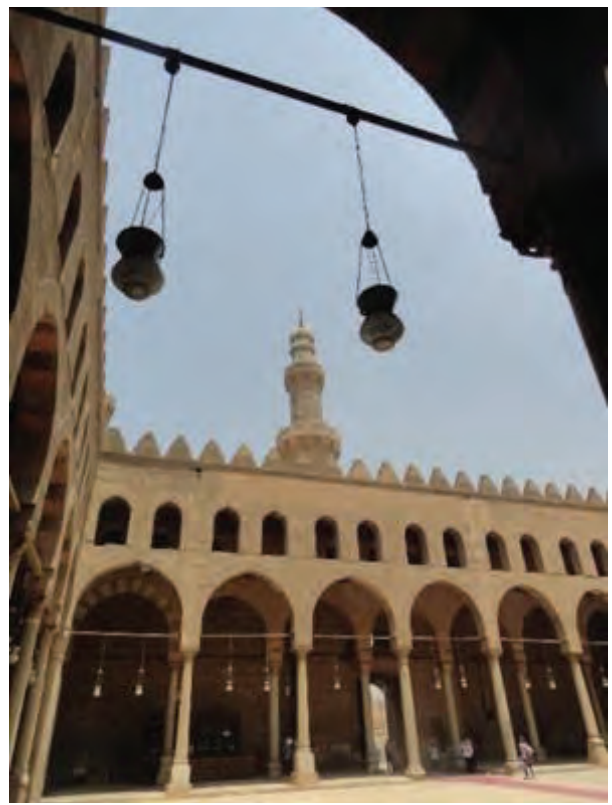

Figure 56: The mosque built in the territory of the citadel of Cairo by the Bahri Mamluk Sultan al-Nasir Muhammad ibn Qalawun in the early fourteenth century

Source: Photograph by MÁtÉ L. IVÁNYI

In the first period between 1250-1382 Mamluk sultans governed the empire from the Roda Island on the Nile, to which they owe their name Bahri (river) Mamluks (Figure 56). They were mainly of Turkish nationality. Later on, between 1382 and 1517, the sultans moved over to the citadel built by the Ayyubids, after which they were named Burji (castle-dweller) Mamluks. They were mainly of Circassian origin. Mamluks were primarily proud of their cavalry. Their favourite pastime was polo. This was also the reason why they were ultimately defeated and lost their empire in 1517 when against the Ottoman Turkish army that used canons, they were only able to fight with a cavalry armed with spears and arrows. 
The lasting heritage passed down by the Mamluk age, especially in Egypt, was created in the field of architecture. As regards science, development was greatest in medicine and especially in ophthalmology and veterinary medicine.

\section{The Muslim conquest of India}

During the first four caliphs, up to 660, Muslim armies got as far as the area of today's Afghanistan in the East, and in the second half of the seventh century they proceeded further on in Sindh province to the area of modern Pakistan, up to the river Indus. Peace was, however, not restored after the initial conquests, either, as the various local sovereigns kept on fighting against the Muslim governors of the eastern provinces (Sistan, Khurasan and Sindh) on the heavy and high mountain terrain for decades. Thus, the Arab strategy in the border regions was to collect taxes rather than consolidate their power. The conquest of the Province of Sindh was finally completed only during the caliphate of Damascus in 720 .

In the Province of Hind in the area of today's India, only temporary success was achieved at that time. From the direction of Central Asia, Turko-Afghan Mamluk warriors succeeded in invading the territory of India and founding the Delhi Sultanate only at the beginning of the thirteenth century. The famous Moroccan traveller Ibn Battuta visited there in the first half of the fourteenth century and gave us a detailed description of Indian Muslims, also available in an English translation. The greatest merit of the sultanate probably was that it prevented the invasion of Mongol herds - which had caused much devastation in the areas of Afghanistan, Iran and Iraq - to the territory of India.

\section{The Indian Mughal Empire}

Some parts of the Central-Asian Empire established by Timur survived as long as until 1507 under his successors. In 1398 Timur conquered and ravaged the Delhi Sultanate under the pretext that the Muslim sultan had been too lenient with his Hindu subjects. Under his successors the empire fell apart, until at the beginning of the sixteenth century Babur ("Tiger"), who claimed to be a descendant of Genghis khan and Timur, having lost his predecessors' estates in Uzbekistan and their capital Samarkand, turned south and occupied North-India. There he founded the Mughal Empire, which lasted for more than 300 years, between 1526 and 1857, even though in the last 100 years it existed only in name. Their capital was the city of Agra, East to Delhi. In the sixteenth century the empire only extended to North India, but later today's Afghanistan, Pakistan (Sindh) and Central India were also under their control up to 1739 when the Persian Nadir Shah occupied Delhi together with much of the Mughal Empire. 
The Mughal culture left lasting traces primarily in North India. Outstanding of its architectural heritage is Taj Mahal, which is considered to be one of the most beautiful buildings in the world. The Mughal era was an outstanding stage of Indian culture in the areas of both fine arts and literature.

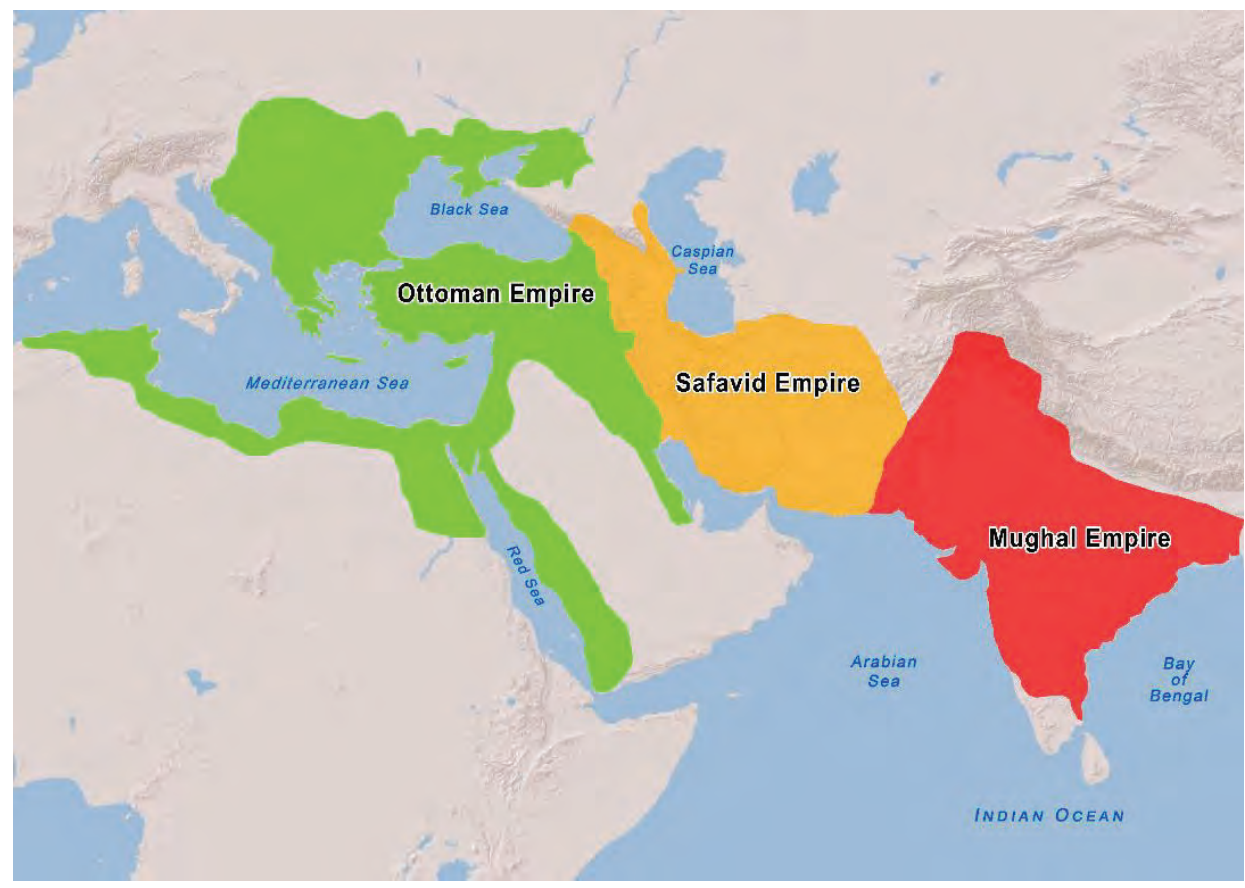

Map 23: The so-called Gunpowder Empires

Source: Edited by ÁGNES VARGA

Iran after the sixteenth century

After the collapse of the Timurid Empire which included Iran as well, the Safavids who had an army organised from various nationalities in the area of Azerbaijan established an empire in the region in 1502, which included besides today's Iran the areas of Azerbaijan, Georgia, North-Caucasus and Afghanistan and, for a hundred years, also those of Iraq, Bahrain and some parts of Syria and Anatolia as well. Originally the Safavids were members of a Sufi order who felt that they would be able to complete their religious mission only by gaining political power. Their first sovereign Shah Ismail I converted to the Twelver Shii branch of Islam, which he made the state religion. This has had a lasting impact until today as the great majority of the populations of Iran, Iraq and Azerbaijan are Shii. The Safavids tried to extend towards the West in Anatolia, where they had clashes with the Ottoman Empire. 


\section{The Ottoman Empire}

By defeating Seljuk Turks in Northwest Anatolia in the last years of the thirteenth century, the chief of the Oghuz Turk tribe Osman established an empire, which after 1354 extended to the Balkans as well, embracing the Byzantine Empire. Finally, in 1453 Sultan Mehmed the Conqueror (r. 14511481) occupied Constantinople and put an end to the one-thousand-year-old East Roman Empire (Map 23). When the Persian Empire started recruiting soldiers from among Anatolian Turkmen, the Turks started a war against the dangerous neighbour and using cannons they made a great victory against the Safavids in 1512, thereby halting their advance and forcing them out of Asia Minor.

Similarly relying on their cannons, they defeated the Egyptian-Syrian Mamluk army in 1517, thereby putting an end to the 250-year-old Mamluk Sultanate. After that they not only occupied Egypt, Syria, Palestine and Hijaz, i.e. the Mamluk Empire, but North-African Arab territories as well, i.e. today's Libya, Tunisia and Algeria with the exception of today's Morocco. The greatest sovereign Suleiman the Magnificent died in Hungary in 1566 during a siege.

The more than 100 year-long war against Iran ended in the occupation of Iraq in the sixteenth and seventeenth centuries. The Turks led this war not merely with the purpose of gaining territories but as the leaders of the Islamic world as well, since the sultans had adopted the title of caliph and regarded themselves as protectors of Sunni Islam against the "heretic" Shiis.

After the Peace Treaty of Karlóca in 1699 the Ottoman Empire was pushed out of Hungary but kept its territories in the Balkans and Greece until the first third of the nineteenth century. From Arab countries Algeria and Tunisia got under French colonial reign in 1830 and 1891 respectively. Egypt, Syria, Palestine and the Hijaz broke away from Turkey at the end of World War I. The Sultanate was abolished in 1922 and Turkey became a republic.

Turkish civilisation basically developed under a Persian-Arabic influence; the Ottoman Turkish language, too, was written in Arabic script. Literature was influenced by the Persian literature, religious life and religious literature by the Arabic language. As regards clothing, habits and various fields of everyday and social life in general, upper classes were fundamentally under a strong Persian influence. 


\subsubsection{Religion}

\section{The fundamentals of the religion of Islam}

\section{The pillars of Islam}

The belief system of Islam, its fundamental teachings and system of law regulating private and social life crystallised throughout centuries. The rituals affecting the whole community were consolidated quite soon, however. These are called the five pillars (arkan) of Islam to this day. These are the following:

1. The profession of faith (shahada), i.e. repeating that "There is no deity except God and Muhammad is the messenger of God." (Figure 57). According to the teaching of Islam prophets with whom God sent revelations laid down in books are regarded as messengers (rasul). These are Moses with the Torah, Jesus with the Gospel and Muhammad, the seal of prophets, with the Quran. The first part of the profession of faith distinguishes Islam from idolatrous pagans, while the second half from the other monotheistic religions: Judaism and Christianity.

2. Prayer (salat) five times a day: before sunrise (morning prayer), immediately after noon (noon prayer), in mid-afternoon (afternoon prayer), before sunset (sunset prayer) and in mid evening (evening prayer).

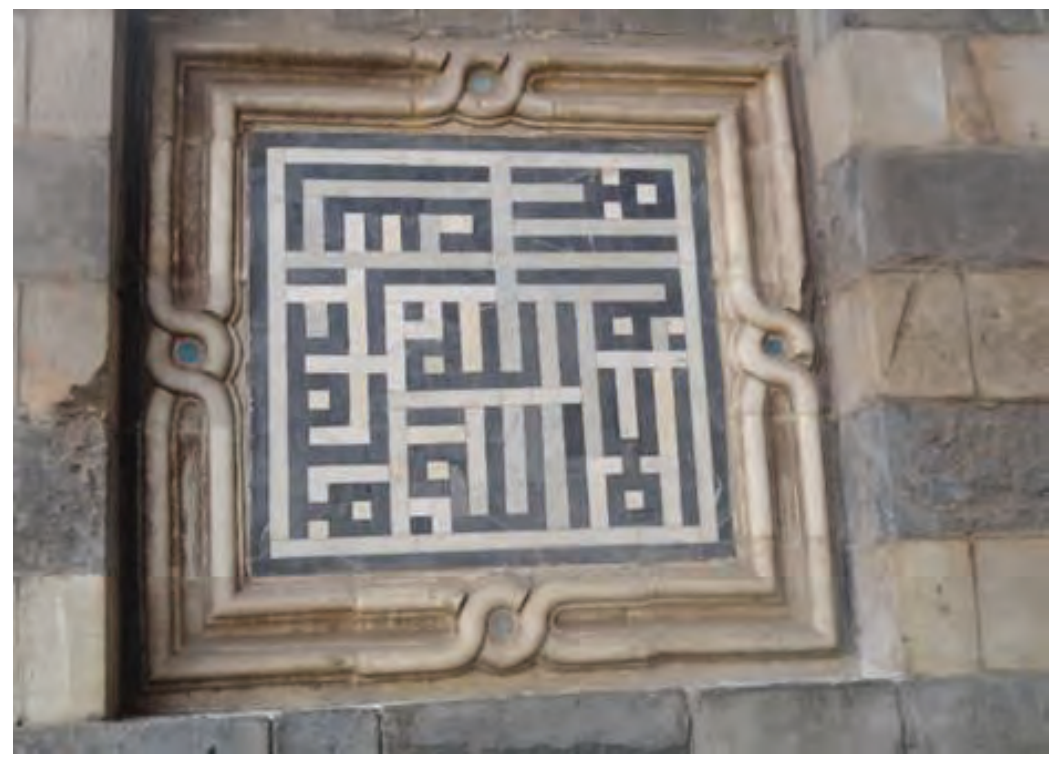

Figure 57: The profession of faith in calligraphic form on the wall of a Cairo mosque Source: Photograph by KINGA DÉvÉNYI 
The exact times, of course, change seasonally and geographically. As we can see, three prayers are closely related to the movement of the Sun, but it is not allowed to pray exactly at sunrise, noon or sunset so as to avoid resemblance to the pagan cult of Sun worshipping. Prior to the prayer, the call to prayer (adhan) warns Muslims of their religious obligation. Traditionally the adhan was chanted by the mu'azzin who went up to the top of the minaret, the tall tower forming a part of the mosque, every time so as to be better heard by the inhabitants of the neighbourhood. Nowadays usually a pre-recorded adhan is transmitted via loudspeakers. The prayer can be performed anywhere, not only at a mosque, but only after ritual ablution (wudu), which means washing the face, the hands and the feet according to a precise instruction. At a mosque, this can be done at the well (mida') in the courtyard of the mosque (sahn). Another important requirement of the prayer is that the person praying should face the qibla, i.e. the direction of the sacred shrine in Mecca called the Kaaba. The text of the prayer comprises specifically chosen quotations from the Quran, which are to be recited in the Arabic language even by non-Arabs. The prayer always includes the profession of faith, which forms the basis of Islam as well as a so-called Takbir formula, i.e. the profession that God is the greatest (Allahu akbar). Each prayer is made up of two or more rakaa, which are a series of bowing and prostration movements. It is recommended to perform the prayer at a mosque where believers stand in rows and led by an imam (leader of the prayer), who recites the prayer with the same wording as the others a little ahead of them, they pray together. In the inner space of the mosque the direction of prayer is indicated by a semi-circular niche in the wall, the mihrab (Figure 58). Of special importance is the prayer at Friday noon, which, where possible, should be performed by all adult male inhabitants of a community (town) at a Friday congregational mosque (jami') where the prayer is followed by a sermon (khutbah). This in the Middle Ages was in the Arabic language all the time and its political significance is indicated by the fact that it had an established form in which the name of the acknowledged Muslim ruler, usually the caliph, was mentioned.

Very often the subjects learned about the political changes only by the change of the ruler mentioned in the sermon. Its political significance has been kept to this day, e.g. the Friday sermons also played a major role in preparing the Islamic Revolution in Iran before 1979. The sermon is delivered by the preacher (khatib) from a pulpit (minbar) located next to the mihrab, to be reached via a few steps. 


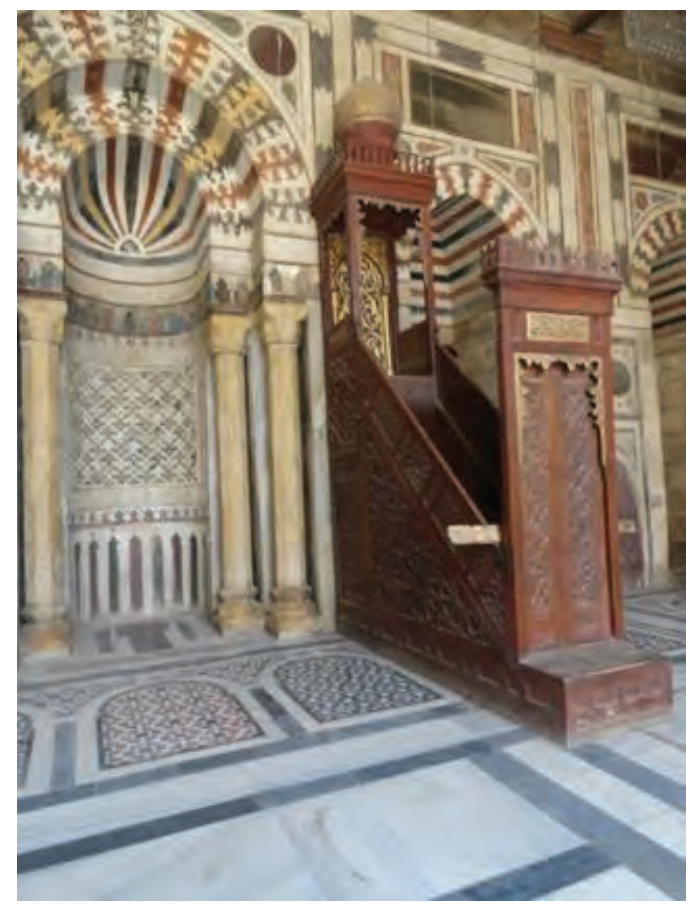

Figure 58: Mihrab and minbar in a Cairo mosque Source: Photograph by KINGA DÉVÉNYI

3. Fasting (sawm) in the ninth month of the Islamic calendar, the month of Ramadan, partly to commemorate the fact that the revelation of the Quran began in that month. In each country, the beginning of the fasting month is announced by the highest religious dignitary after he has caught sight of the crescent moon at a high point in the sky. Fasting lasts from dawn to dusk every day, which means that fasting is longest in the summer months when it is the most difficult to make it through without drinking in these countries of hot climate. During fasting you are not allowed to either eat or drink, to smoke or to engage in sexual intercourse; according to the stricter interpretation you are not allowed to swallow even your own saliva. Only healthy men and women above the age of 12 are required to fast. Fasting may be broken for various reasons (like travelling, menstruation, etc.) In such cases the days without fasting must be made up for later on. Traditionally, in many places up to a few decades ago, believers were informed of the beginning and the end of fasting by firing a cannon. When fasting is broken in the evening it is followed by a social meal (iftar), which has a strong community building effect. According to the Prophet's tradition, the first food to be eaten after fasting should be dates and if dates 
are not available, fasting should be broken by water. This is usually followed by entertainment and street celebrations until late at night, on which occasion it is a custom to decorate the streets with lampions. Many people spend some of the night at a mosque reciting special Ramadan night prayers (tarawih). Most people get up early for a meal before fasting. The end of the fasting month is celebrated by a three-day post-fasting festival (Eid al-fitr or "smaller feast"), which is opened by a special communal morning prayer.

4. The alms or religious tax (zakat), whichnowadays is generally the moral obligation of only those who can afford to donate for the poor. Originally and throughout the Middle Ages it was an obligatory tax to be paid by everyone every year, based on the value of all of one's possessions. Traditionally Muslims had to donate one fortieth part (2,5\%) of all their wealth and savings beyond the minimum required for subsistence. The collected tax (which did not necessarily mean money) was distributed among poor Muslims, religious officials and mosques. Today religious tax is collected on a voluntary basis in most countries, usually by mosques. In some Muslim countries it is an obligatory tax collected by the state, e.g. in Saudi Arabia, Pakistan or Malaysia. Unlike in Sunni Islam, for the Shiis paying the zakat has always been voluntary and collected by mosques.

5. The pilgrimage to Mecca (hajj) in the twelfth month of the lunar year (dhu l-hijja), between the seventh and ninth days of that month, when all those who are able to afford it considering their health and financial status should once in their lives make a pilgrimage to God's House, the Kaaba (Figure 59). Today, when the number of pilgrims is almost three million a year, the quota system per country may be an obstacle for people to perform the pilgrimage at least once in their lives.

Pilgrims enjoy great respect all their lives and have the prestige to be called a hajj (if a man) or a hajja (if a woman). Pilgrims may enter the holy district of Mecca only wearing special attire (ihram), which for men are two white robes without stitches, while women are not allowed to wear gloves or veils covering their face. It is characteristic for the pilgrimage that, while in mosques women are always separated from men, here they perform the rituals together. The pilgrimage starts and finishes with the tawaf, i.e. fast circumambulation around the Kaaba seven times. After that the pilgrims make the distance between two hills near the Kaaba - nowadays this is an outside corridor of the great mosque - seven times ( $s a^{\prime} i$ ) by running (or walking very fast) to commemorate that Hagar, the wife of the Prophet Abraham had tried to find water in the desert here for herself and her son Ismail. According to the Quran the Kaaba was built by Abraham, while 
Ismail is held to be the ancestor of Arabs. The next day the pilgrims proceed together to the plain of Muzdalifa near Мecca, where they pray and spend the night in tents. On the ninth day of the month they proceed from here to Mount Arafat where they throw small stones and pebbles at pillars symbolising the devil. The next day the feast of sacrifice (Eid aladha) or the "greater feast" begins, which once again starts with a special communal morning prayer and continues with a ritual animal sacrifice whereby pilgrims slaughter sheep in Mecca and other Muslims do the same at home.

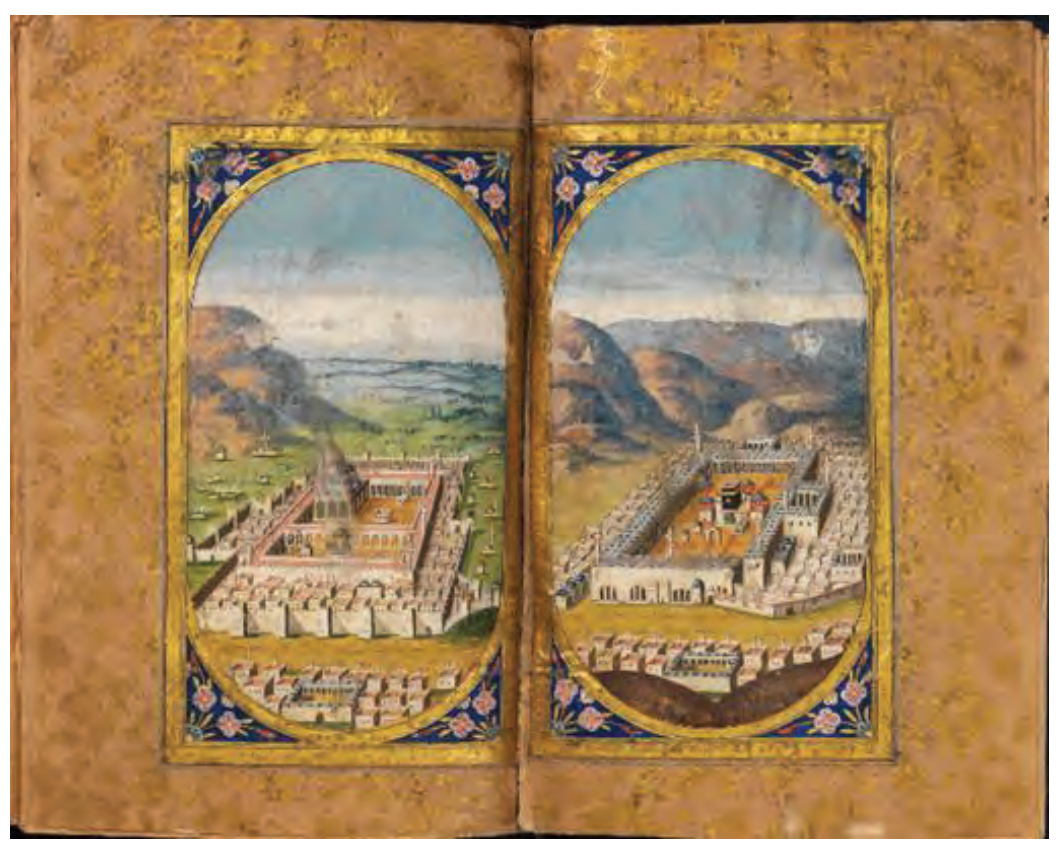

Figure 59: Mecca and Medina in a Muslim prayer book copied in the eighteenth century Source: The Oriental Collection of the Library of the Hungarian Academy of Sciences,

Ms Arab O. 54, fols. 11v-12r

According to many, the sixth pillar of Islam is jihad, which has a double meaning based on the interpretation of the Quran. The great jihad means the strife in the believer's soul for true faith, while small jihad means the fight for the protection of Muslims and for practising the religion of Islam.

\section{Mosques and madrasas}

While the primary function of mosques was to serve as the place where the five prayers per day could be performed, in between praying times they also served as sites for socialisation. It was here that you could meet, have a talk, sign 
contracts, engage in reconciliation, and arrange marriages. It was not only the sacred nature of the place but the presence of men of religion - primarily the imam of the mosque - that played a role in this. Before and after praying the Quran reader recited extracts from the holy book. It was here, too, that you could ask scholars of religion for legal advice. The cool and airy prayer room covered with carpets was also suitable for an afternoon siesta. In every bigger town there was a larger, central mosque where Friday noon prayers and sermons after that were held in the presence of the local ruler or leader. This mosque was called a jami ("congregational mosque") alluding to the Arabic name of Friday meaning ("the day of gathering").

From the very beginning, mosques were also placing of teaching. The teaching activity was carried out for a small circle of disciples (halka); the teacher (sheikh) sat down with his back against a pillar and was surrounded by his disciples. The teaching method was uniform until the twentieth century: disciples memorised concise texts which were sometimes arranged in rhymes, to which explanations were provided by the teachers. The basic education of children writing, reading, Quran recitation and memorising - also took place at the mosque or a school attached to the mosque called maktab or kuttab.

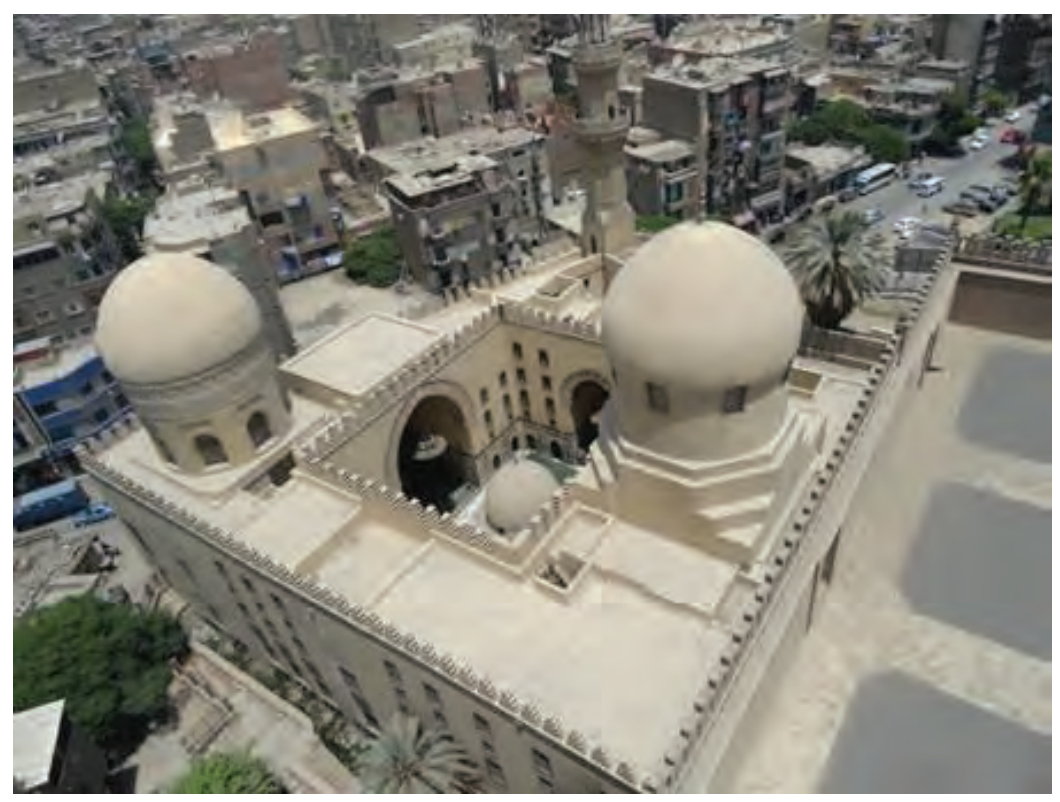

Figure 60: The madrasa of Sarghatmish in Cairo built in 1356. It houses a mosque and a mausoleum as well

Source: Photograph by KINGA DÉvÉNYI 
Demand was highest for teaching experts of law, considering which a unique institution, the madrasa ("school" or "college") was established and disseminated in the world of Islam; here Islamic law was taught primarily, the second most important subject being linguistics as the basic tool for interpreting texts (Figure 60). The first college of that type (the Nizamiyya) was founded by the chief minister of the Seljuk Empire Nizam al-Mulk (d. 1092) in Baghdad, and later in other cities of the empire.

\section{The development of the legal system of Islam}

In the new empire, the moral and legal system regulating all areas of life started to become consolidated in the span of over two centuries, by the ninth and tenth centuries only. While the rituals of religion were regulated rather soon on the basis of the texts of Islam, the Quran and the tradition of the Prophet (Hadith), it took much longer for the instructions guiding everyday life, human relations and family law to crystallise and often the earlier habits of a given territory contributed to shaping them.. The interpretation of specific Quranic places started to develop only by the ninth century. The collection of the Hadith began in the mid eighth century, while the arrangement and critical analysis of the hundreds of thousands of traditions took another century.

These traditions were expected to reveal how the Prophet Muhammad, guided by divine inspiration, lived, how he behaved, acted and how he made judgements in the thousands of issues of life. The sunna (literally "custom") was a totality of the customs followed by Muhammad, which could serve as models for later generations.

What is Sharia? What we refer to as Islamic law is in fact the totality of instructions guiding the whole life of Muslims and all their actions. This sharia (literally "way" or "path") designated by God to follow is actually the divine law. The divine intention is, however, not clear to everyone; it must be understood. Interpretation should be carried out by those who devote all their lives to studying the divine resources in depth, with true faith and good moral conduct, i.e. make individual efforts (ijtihad). The way they understand, describe and teach Sharia to people is called fiqh (literally "understanding"): this is what Islamic law in the narrower sense is, and the expert, the scholar of law is called faqih. Thus, while Sharia is the one and only divine law, fiqh is the product of the colourful human activities which are sometimes completely different from one another and which are carried out by the faqih. 
The establishment of schools of law

In initial times, the scholars of law of the various fields often worked completely independently, providing interpretations and legal regulations for judges in a region as well as for the Muslims living there. By time, the number of the various legal tendencies was reduced to four. They are called madhhab, which is usually translated as school of ritual and law. The earliest of these schools were established in the second half of the eighth century at two important places, Medina and Iraq. The Iraqi school was later named after its first master, Abu Hanifa, Hanafi madhhab, while the one in Medina was named Maliki madhhab after the great Medinese teacher Malik. At the beginning of the ninth century Shafi'i madhhab became the third of these schools. This was named after alShafi'i who, having made long study tours, settled in Egypt. The fourth one, the Hanbali madhhab, was named after Ibn Hanbal who lived in the first half of the ninth century. When the Hanafi School was established, it could rely on the Hadith only to a limited extent, so Hanafi faqihs considered the individual opinions $\left(r a^{\prime} y\right)$ of scholars of law also as a means of legislation beyond Iraqi customary law. Malik relied on Medinese traditions primarily, but he also took into consideration the Hadith already available to a significant extent. His handbook with the title al-Muwatta ("Well-trodden path"), although it does contain traditions, is not a collection of Hadith but a collection of teachings including hadiths serving as explanation for legal issues, put down later by his disciples. It should be noted that Abu Hanifa did not put down his legal interpretations, either, it was left to his disciples to do it. One reason for this could be that in the Islamic Empire paper manufacturing became widespread only after 770 , i.e. after the death of Abu Hanifa and in Malik's last stage of life, and it became possible only later to write books of a large size. Al-Shafi'i developed a theory according to which legal decisions could be exclusively based on the Quran. Hence it fundamentally differs from the two earlier schools of law, the one complementing the words of the Quran with those of the Hadith only and the school complementing the missing implications from the Quran on the basis of individual opinion. This theory stipulates that it is the Quran itself that encourages using the Prophet's tradition when saying "obey the Prophet" and by extension it is obligatory to obey Muhammad's sunna as a source of law as the exclusive supplement to the Quran. At the same time, instead of using unregulated individual opinion ( $\left.r a^{\prime} y\right)$, he worked out rules for using analogy (qiyas), with the help of which a solution could be found on the basis of a case inferred from a written text to a case not included in Islamic texts (nass). He claimed the method was justified on the basis that the Quran also used analogies. 


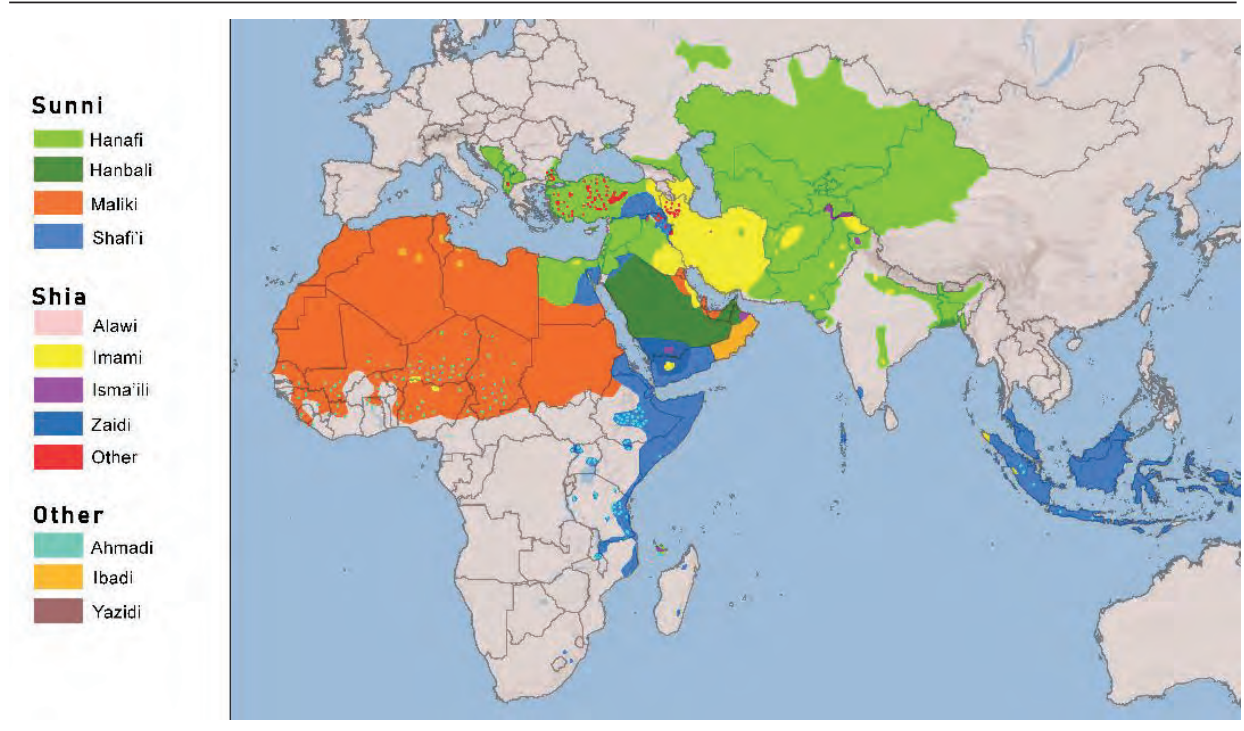

Map 24: The major branches and schools of law of Islam Source: Edited by ÁGNES VARGA

\section{Analogy}

The most important tool of interpreting religious texts has become analogy (qiyas), which solves the problem described by a religious scholar in the Middle Ages the following way: the number of texts is finite, but the number of cases in life is endless, and the only way to bridge this gap is to use the rules of analogy. The result depends on what the school of religious law (Map 24) considers as the basis of the analogy. The way to determine it is by attempting to establish what the intention of the lawmaker (God or Prophet Muhammad inspired by God) could have been when formulating the original text, i.e. follow the spirit of the law. Let us take an example of extending the scope of a hadith based on analogy. When conquering the Arabian oasis Khaybar, the Prophet left the original landowners on the lands as sharecroppers in return for their taking care of the date palms. It was this that the so-called "shared irrigation farming" (musaqat) contracts in Islamic law were based on, but the respective schools of law interpreted this tradition in different ways. Abu Hanifa opposed using it under the excuse that it was unpredictable how much yield there would be and how much profit the two parties would have. Malik in contrast extended the scope of the contract to all horticultural products: fruit tree cultivation, grape growing and vegetable growing. Al-Shafi'i permitted sharecropping contracts only for grape growing and date palm cultivation because they were traditionally cultivated in the same garden. Those, however, who were willing to interpret the texts only 
literally (the Zahiris) did not use an analogy and said that, based on the Hadith, such contracts could only be signed for date palms.

\section{Islamic law and state law in the nineteenth century}

Islamic law (Sharia) has never been an exclusive legal source in the history of the world of Islam. There has always been need for ordinances and instructions by the rulers in issues that were not regulated by Islamic law or the discussion of which would have been complicated at the Sharia courts, e.g. where a case required support by two or four witnesses. In the Ottoman Empire these regulations by the sovereign were called qanun; these dealt with the issues of taxation, public administration, finances or criminal law. Often these only complemented, in other cases replaced the provisions of Islamic law. At the same time, the qanun system helped cope with the problems caused by the fact that Muslim religious law relied on the interpretations of religious scholars to a great extent, which made uniformly regulated court practice impossible.

In the second half of the nineteenth century the legal system of the Ottoman Empire underwent a significant reform, which was referred to as reorganisation (tanzimat). This was influenced by the Napoleonic Code, while the pressure of European powers could be felt on the laws that targeted granting equal rights to persons of various religions and trade rights to Europeans. It was a further significant change that these state laws were enforced by newly established state courts independent from the Islamic religious council.

In the Arab world it was first in Egypt, more or less under Ottoman reign and yet controlled by the English, that the system of courts was modernised in the last decades of the nineteenth century based on the Ottoman example. With the exception of family law (Personal Status Law) the role of qadi courts was taken over by state courts, and legal regulations were laid down in state laws. The pyramidal structure of courts - lower courts, higher courts and courts of appeal was established in Egypt as well. Islamic law does not have a concept of higher court where you can appeal against a judgment, and neither the charge, nor the defence have representatives: the judge makes his decision single-handedly.

Simultaneously the office of the state-appointed national mufti was established, and the approval of death penalties was transferred to his scope of authority. The Chief Mufti in Egypt has exercised this scope of authority to this day. Let us illustrate this with an example taken from 1987. A man admitted at the police to have kidnapped, detained and raped a woman. As there were no witnesses, the man was sentenced to death on the basis of that confession, even though he withdrew his statement at court. Based on Egyptian law, testimonies made at the police are also conclusive. The judgement was brought before the Chief Mufti, who rejected it on the grounds that he had found a case among the 
Prophet's hadiths that, using analogy, could be used for this case. A man who had admitted having kidnapped and raped somebody's wife was brought before the Prophet. There were no witnesses. The Prophet ordered that the man be brought away and stoned to death. Half a day passed when those commissioned with executing the stoning returned, and when the Prophet asked them what had taken so long, they said the convict had run away and it took long to catch him and stone him to death. The Prophet said in response that they had acted wrong: by running away the man had withdrawn his testimony and he should not have been stoned.

\section{The science of Hadith}

In 750 the Abbasid dynasty rose to power with the ideological background that they would restore genuine Islam and rule on the basis of its laws. One of the signs of this was that they supported collecting the Prophet's traditions, the Hadith. The word hadith means "report, communication" and contains the Prophet's words and the words of his companions who were present when the Prophet guided Muslims through his actions. The significance of the Hadith is based on the principle that everything the Prophet said was inspired by God. According to the scholars of religion, the Prophet's whole life, his deeds and words, if compiled in the form of hadiths provide an explanation for the Quran at the same time. Thus, a hadith is a saying that those of the Prophet's companions who heard it shared with others later on and they, after Muhammad's death, passed down to later generations. Later on, it became a real fashion to learn these and try to find the companions who knew such verbal sayings. As in the course of the conquests the companions disseminated to various provinces of the empire, many such hadith collectors made lengthy travels in order to acquire still unknown traditions. After some time not only the saying itself was remembered or written down but also the person they heard it from and the person that this person heard it from, back to the person who had stood next to the Prophet when he said it. The chain of these narrators or transmitters makes up the first part of the hadith called "support" (isnad), while the saying itself makes up the other part, which is called the "text" (matn). While imitating the Prophet became a requirement in all areas of life, the significance of collecting hadiths grew. As a consequence, however, many invented hadiths partly in order to narrate as many traditions as possible, since this had become a profitable job, and partly in order to underpin their views and political stances.

In Iraq, two military garrison towns were established after the Prophet's death, Kufa and Basra. In the centuries to come, these developed into important political, religious, scientific and cultural centres and started rivalising with each 
other. In order to reinforce their own significance and excellence, the inhabitants of both cities falsified hadiths in which the Prophet praised their city, even though these had not even existed in the Prophet's life. The narrators and collectors of traditions also committed numerous benevolent falsifications. Among others, they attributed many well-known wisdoms and proverbial sayings to the Prophet. There are also many hadiths that contradict one another, which does not necessarily imply falsification but indicates only that the Prophet reacted differently to certain issues depending on the occasion and the necessity. On one occasion, for example, he forbade visiting and honouring graves, while he recommended it at another time. In many cases it easily turned out that a hadith was falsified because the alleged narrators had not lived at the same place or at the same time so they could not have passed on the tradition to one another, or the first narrator had not lived in the Prophet's age. The falsifications were also detected by the representatives of the science of Hadith that developed in the ninth century, therefore, as the first step, they collected the narrators' names and tried to find out about their biographies, examining what intellectual and moral characteristics had been recorded about them. Based on these they made critical remarks concerning the hadiths these narrators had passed on. The traditions were, however, qualified primarily on the basis of their isnad, the chain of narrators, and not on the basis of their contents. As the next step in the second half of the ninth century, the major Hadith collections that have been respected as holy books until today were compiled. Initially hadiths were arranged based on the narrators, an example for which is Ibn Hanbal's book containing 28 thousand hadiths, while later they were organised based on their content. Six such books were compiled, the most famous of which are the books by al-Bukhari and Muslim with the title Sahih ("healthy, sound"), which include some seven thousand hadiths considered to be authentic. Al-Bukhari said he had selected from some 600 thousand traditions the sound ones, i.e. those accepted by everyone. The basis of selection was the chain of narrators. It was a basic requirement that the tradition should be based on a connected chain of perfect men with an excellent character, trustworthiness and a good memory. It was another aspect of the selection that a narration should rely on several chains of narration. If there was information that many had listened to the Prophet but only one narrator passed on the story, the hadith was discarded. Certainly, there were some principles set also for the acceptability of the content (matn): a hadith must not contradict the teaching of the Quran and the fundamental principles of Islam, must not contradict the laws of nature or the common experience of Muslims and it must not glorify a person, place or tribe - which many hadiths did. A hadith must not make reference to future events by specifying the place or the time, and a hadith must not claim that the Prophet says or does things or acts in a way that 
contradicts the holiness of the Prophet or the teachings of Islam about prophets. As the respect for the Hadith grew, the teaching developed - which has retained its importance until today - that the first three generations of Muslims constituted the group of "pious predecessors" (salaf) who were to be followed because they were the depositaries of the traditions of the Prophet.

The following hadith can be found in al-Bukhari's collection, which is divided into books and chapters, and is No. 1. in the first chapter of the book with the title "Revelation": "al-Humaydi Abd Allah ibn al-Zubayr related to us saying: Sufyan related to us saying: Yahya ibn Sa'id al-Ansari related to us, saying: Muhammad ibn Ibrahim al-Taymi told me that he heard 'Alqamah ibn Waqqas al-Laythi say: Narrated by Umar ibn al-Khattab say on the pulpit: I heard the Prophet saying (here ends the isnad, the chain of narrators going back as far as the Prophet): "The reward of deeds depends upon the intentions and every person will get the reward according to what he has intended. So, whoever emigrated for worldly benefits or for a woman to marry, his emigration was for what he emigrated for." (This part is the matn, the actual text of the tradition).

Hadiths usually have several versions. There is one more sentence in another version: "He who emigrates to God and his Messenger, reaches God and his Messenger." This tradition has been passed down via another chain, too, which proves its correctness. A hadith that has been passed down via only a single chain is usually viewed as suspicious.

\section{Islamic mysticism: Sufism}

Towards the end of the Umayyad and in the first century of the Abbasid era, in certain provinces of the Islamic Empire - primarily in Iran and Iraq ascetic trends advocating withdrawal from the world and movements embracing the mystical concept of the world grew increasingly stronger. Ascetics did not live in communities; they withdrew from secular life individually to live as hermits or wayfarers, longing for the afterlife, having been sickened with the perversity and purposelessness of the world. Mystics, too, shared the belief about the purposelessness of worldly efforts, relations and goals, but unlike ascetics they wished to attain happiness already in this life by getting closer to God in their heart. They strove for getting to know God and feeling love for God, thinking this would guide them on their path leading to God's proximity. As a fundamental characteristic of any mystic concept and not only Islamic mysticism, it is believed that it is impossible to get to know God's world ("the absent world") by rationally interpreting texts. Thus, every sentence and every word in the Quran as well as all the facts in the world have another, concealed meaning, which can only be accessed in a state of mystical immersion, speculation and trance. 
In the second half of the eighth century those who were later respected as the early mystics still considered that turning away from the world was the most important step. One of them was a noble prince who under the influence of a vision seen at night dressed up as a beggar; another was the leader of a gang of ruffians who upon hearing a Quranic recital he quit his trade and became a wayfarer. Yet others heard voices while in the solitude of a graveyard. This is the first stage of the mystical journey called repentance and its essence is to sever worldly ties. It was in the middle of the ninth century that mystics were first called Sufis after the long, coarse, woollen (suf) robe that they wore. After repentance, the Sufi withdrew from worldly life for some time, either by locking himself up in his home or by staying at a faraway barren place to meditate. After that, however, he immediately looked for companions and a master so as to find the right path leading to God. This is what distinguishes a Sufi from a hermit. On the one hand, the master demonstrated among disciples (murid, "one who seeks") ready to embark on a mystical journey the rituals through which a Sufi could get into the desired ecstatic condition (hal), and on the other hand within the framework of a personal conversation with the individual disciple selected the spiritual practices suitable for that particular disciple. This is how "those who sought" could advance via the stages of their journey, which include turning away from the world - and this here is not the ultimate goal but a transitional stage and a means to advance - and poverty, which simultaneously means renouncing worldly goods and "being in need" in the sense of having a need for God. This was such a typical characteristic of the majority of the Sufis that the Arabic word faqir (poor) and the Farsi word dervish (beggar) referred to devoted mystics in general. Sufis, who respected the law, did not reject the provisions of Islamic law, the Sharia and respected religious sciences as well, but were of the opinion that this external knowledge was only the beginning and disciples who proceeded by following the tariqa, i.e. the mystical path would ultimately reach the level of masters (haqiqa), God's truth.

At the same time, humbleness and humility are very important characteristics of a true Sufi. Bistami, one of the most famous Central Asian mystics in the ninth century, had a disciple, a rich and elegantly dressed merchant, complaining to the master that he had been attending mystical gatherings and rituals for twenty years, but he had never once had either Muhammad or God appear even in his dream, and he had never had the feeling to have discovered God in the bottom of his heart. Bistami looked at him top to bottom and advised him to dress up in rags, hang a beggar's bowl around his neck and put nuts in it so that they would make noise by each step, and dressed up like that stand outside his shop at the market where everyone knew him. Then God would help him 
4.2. The Islamic Civilisation

towards his proximity. The merchant certainly refused to humiliate himself in this way.

Not having a master caused suffering to these pious Muslims who longed for God's love, so if they were unable to find a master - Arabic: sheikh, Farsi: pir - in their own city, they embarked on a long wandering. Sometimes they even left to find another master to learn from if they already had one, and their master himself encouraged them to do so. There has been a saying among them that "the master of those who do not have a master is the Satan". The various masters mark the respective stages of the Sufi path in different ways but believe that every path leading to God was equally good. After poverty and the severing of earthly ties the Sufi usually reaches the stage of intoxication (saqr), which causes satisfaction and joy, but this is soon followed by sobriety (sahw), a kind of disillusionment and sadness when the Sufi realised that God is at an unattainable distance above him. First, this causes fear (khawf), followed by the hope (raja) that it is nevertheless possible to make it to the end of the journey, to get to know God and reach the state of divine love. The Sufi who consolidated these stages indicating spiritual conditions, reached an important stage in his mystical existence: the stage of spiritual expansion and joy (bast), to be followed by compression and anxiety ( $q a b d$ ). The first was the phase of long-lasting happiness and joy, the second the phase of prolonged despair.

It was narrated of Bistami that he spent twenty years in the state of anxiety, in the course of which he avoided city life wandering in forsaken places. It was acceptable of a Sufi to say in the condition of trance things that would have qualified as unlawful and forbidden in the case of everyday people. Bistami asserted among others: "Glory be to me! How great is my glory!" In Islam this quality was allowed to be assigned only to God. Those who interpreted Bistami's words maintain, however, that what he said should not be understood as selfdeification but in a way that he had had room in his heart only for God and his heart became one with God's glory.

To this day, Bistami has remained the example for an intoxicated Sufi, while Junayd, who lived in Baghdad at the turn of the ninth and tenth centuries, was a sober Sufi. The later mystical organisations - the so-called dervish orders - considered both their "heavenly" masters. A Sufi, however, reaches his ultimate goal only when he reaches God's proximity and forms spiritual intimacy (uns) with God. This is called "attainment" which, however, can only be achieved with God's will and help. Those who reach that stage feel obliged, after their "return", to become masters and guide others. Such masters with this attitude, regarded as Sufi sages, have been given the designation, based on a quotation from the Quran, "God's friends" (awliya Allah), the singular of which is wali and is usually translated into European languages as "saint". 
Once the fame of a wali spread, Sufi disciples came from faraway places in order to learn from him. In exceptional cases the wali tried to flee from popularity seeking solitude. There were whole groups of them, primarily in Nishapur in East-Iran, who concealed their deep mystical religious devotion or even took the blame (malama) by outsiders that they were not religious enough and were therefore referred to as malamati. They despised those who called themselves Sufi and walked the streets in groups, praising God and begging for subsistence as they had quit their original job. The Malamatis in contrast were craftsmen and tradesmen probably brought together by their profession and the guild as they did not openly look for followers or disciples.

The further development of Sufism was greatly affected by a dramatic event in the first third of the tenth century. With his statements uttered in trance, the influential Baghdadi mystic Hallaj, disciple of the moderate Sufi Junayd disturbed the peace of mind of the inhabitants of the streets and markets of Baghdad, while considering the high number of his followers he probably became suspicious politically as well. After a long period of confinement, he was executed under brutal circumstances in 922: he was butchered, and his body was set alight. Hallaj was primarily charged with heresy because of two of his statements. One was his teaching of "incarnation" (hulul), i.e. that God had moved into his soul and therefore he said among others: "I am the Truth" (Haqq), which is God's most important name among Sufis. The other was his saying that the pilgrimage could be performed anywhere, even around his body as if it was the Kaaba in Mecca or could be performed in one's heart. The martyrdom of Hallaj had a sobering effect on Sufis for centuries and their handbooks usually began with a lengthy argumentation confirming that Sufis adhered to Islamic provisions and Sharia law in every aspect. Their rituals and religiosity were not meant to replace the provisions of Sharia but to complement them. The Sufi desire to unite with God, to adopt godly characteristics instead of earthly human ones, also raised criticism. As a reaction to this criticism, the Sufis emphasised that they wished to follow the example of Muhammad and imitate his life; he is the example of the "perfect man" and it was via him that they wished to get closer to God. One of the signs of this was that several Sufis made their own "celestial journeys" to the Seven Heavens, to the pedestal of God's throne, but while Muhammad had done so while being awake and in his body during his celestial journey (miraj) (which is not accepted by all religious scholars), the Sufis, e.g. Bistami only claimed they had advanced in their dreams and in their hearts via the Seven Heavens to God.

One of the earliest pieces of written evidence for the outstanding role of the Prophet Muhammad in Sufism that has survived is found in the mystical biography of the ninth century Persian mystic Hakim Tirmidhi ("Sage of 
4.2. The Islamic Civilisation

Tirmidh"), and is the description of dozens of dreams. In one of his first dreams Muhammad takes Tirmidhi by hand and leads him into the city mosque where people are waiting for the Friday prayer, leading him up to the pulpit. At the highest step of the pulpit stands Muhammad, pointing with his right hand up to God, and holding with his left hand Tirmidhi's right hand, while with his left hand Tirmidhi points at the people in the mosque. This on the one hand symbolises the chain that helped the sage advance to the proximity of God and on the other hand it symbolises the mission that Tirmidhi should lead Muslims on the Sufi path.

\section{The role of the Quran in mysticism}

While various external influences, including the eighth century Christianity in Syria, certainly had a major role in the development of the Islamic mysticism, Sufis tried to derive every idea and teaching from the Quran and trace them back to a Quranic verse. Good examples for this - certainly special interpretation are the above concepts of qabd and bast. In the Quran, these two words are in the following verse: "God straightens and enlarges" (2:245). It means that God may give "opening His palm" (basata) - the way one gives money to a beggar with an open palm - while "straightening" is expressed with the verb qabada, i.e. "close His palm". Sufis have interpreted this saying that God opens their hearts to be receptive to God's grace and inspirations, and later closes them, whereby a condition of doubts and anxiety follows.

\section{The golden age of Sufi or dervish orders between the thirteenth and nineteenth centuries}

The identity and character of the mystical Sufi movements that developed in various parts of the Islamic world in the ninth-twelfth centuries changed rapidly and somewhat unexpectedly after the thirteenth century. The oftenconcealed religious practice of individuals and small groups grew into organisations of brotherhoods - called dervish orders in Europe - that mobilised and in one way or another attracted to their membership whole city quarters and even whole cities.

An important step towards the establishment of orders was that the relations between the leaders (masters, sheikhs) and the seekers (disciples, murid) became regular, in the course of which the latter, guided by their masters, strove to reach various stages of the mystical path (maqamat). Early masters tended to guide rather than teach; practice was more important than theosophy and it was of secondary importance to summarise the teachings.

The Sufi orders used the word tariqa (way) for specifying themselves. Tariqa is a practical method for guiding the seeker by proceeding along a certain 
(tested) system which ensures, in addition to reaching the mystical stages, experiencing the spiritual-intellectual (trance) conditions as well. Initially, two ninth-century Sufi schools were distinguished as guiding lines: Junayd's sober contemplation and Bistami's intoxicated ecstasy, and the various orders usually respected both and regarded both as their masters. Deceased masters, too, constituted parts of the "order" as parts of the chain, i.e. the series of living and deceased masters that leads back to the Prophet Muhammad, whose intercession before God they hoped for.

The orders started to develop around outstanding masters in the twelfththirteenth centuries. Abd al-Qadir al-Jilani (d. 1166) was the founding wali of the Qadiriyya order, while Abu l-Hasan ash-Shadhili (d. 1258) was the founding wali of the Shadhiliyya order - both of these disseminated primarily in North Africa and Egypt - while Mu'in al-Din Chishti (d. 1236) is regarded as the founder of the Indian Chishtiya order. The initial groups were loose and flexible associations. Their members could travel, they looked for masters or stayed at one and the same place; they worked as craftsmen or lived on alms. The usually lived at a khanqa or ribat built for them from donations, which housed, besides some alcoves and a mosque, storerooms, a kitchen, a bathroom and a well, and was provided with a full catering staff. As long as the dervishes lived at such an accommodation, they had to comply with strict requirements, e.g. they were not allowed to have a worldly job; they were allowed to perform only religious tasks like copying the Quran and other religious books. They had to attend three or four remembrance ceremonies (dhikr) per week and five prayers per day. They constituted the inner circles of orders which grew larger and larger and it was them who were called dervishes. Being a member of an order did not mean at the same time that a dervish was not allowed to find accommodation with another order in another city. The members of the outer circle, whose number could be a hundred times bigger than the number of the dervishes, did not attend the masters' individual or group activities, but several times a week they could attend the Sufi rituals held at the mosques or houses of the order, could learn the order's prayer book and recite it or chant it together. They also helped the dervishes with donations and felt a bond towards them.

An increasing number of dervish orders were established later on all over the Islamic world, and they were often assigned serious political roles. The Bektashi Order founded in the fourteenth century was the official Sufi institution for the Janissaries in the Ottoman Empire, the Mevlevi order was the official order of the Ottoman sultan and his court, while the Halvati order had commoners as members. The members of the Mevlevi order follow the teaching and mystical practice of the Persian Sufi writer and poet Jalal al-Din Rumi, who lived and 
worked in thirteenth century Anatolia, by performing a special dance at the rituals, after which they are called Whirling Dervishes.

\section{Shii Islam}

With respect to most religious and legal regulations there are just insignificant differences between Sunni and Shii Muslims. The significant difference concerns the person of the Imam, who is required to be a descendant of Ali. At the same time, the Imam acquires his infallible knowledge not by learning but by inherited divine inspiration. Since the last Imam disappeared in the ninth century, during what is referred to as his "occultation", this knowledge is inherited by the highest Shii religious scholar.

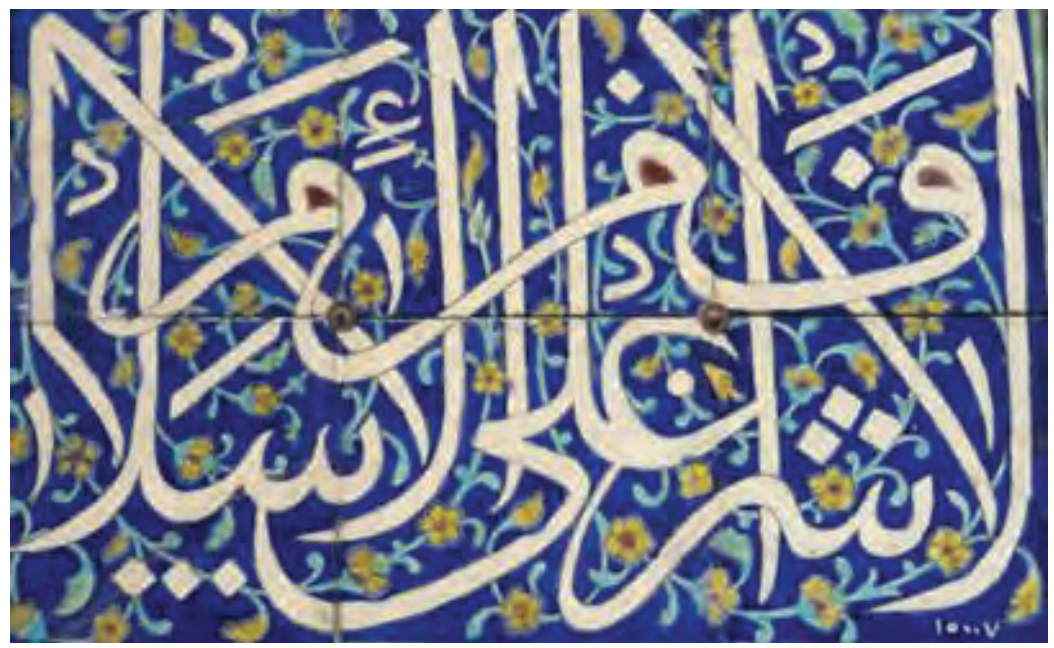

Figure 61: Ali's wise saying in a calligraphic arrangement on six tiles: "There is no higher nobility than Islam".

Source: Photograph by KINGA DÉvÉNYI

\section{Imami or Twelver Shiis}

Shii Islam developed from Ali's party in the course of centuries. Their fundamental teaching is that Ali (Figure 61) should have followed Muhammad as a caliph and his descendants, i.e. the Prophet's closest relatives - his "household" - were to follow after him. In view of this, Shiis soon developed a habit of cursing "usurper" caliphs, primarily Uthman. In the course of centuries, the dogma developed that Ali had received secret teaching from Muhammad or that God had given Ali special knowledge which his descendants the Shii Imams also inherited. Sunni religious scholars held that Islamic law, Sharia, was an autonomous body of norms accepted as authentic and independent of any earthly 
power, maintained and preserved by the community as a whole even, where necessary, against the ruler's will. Contrary to this, according to Shii teachings, the continuity of divine law should be guaranteed by the authentic representative of the divine will, i.e. the true Imam, similarly to the age of Muhammad. The loyalty to Ali and his family guarantees this chosen person. In their view, Ali was not simply the fourth caliph, but the person who had been around Muhammad all his life and had thus acquired special knowledge, and so a person who abandons Ali's camp in fact abandons divine justice. Loyalty to Ali, on the other hand, guarantees a kind of esoteric knowledge that others are unable to attain. This secret, hidden knowledge is possessed by the Imams and only Shiis have been able to evaluate and get to know it. This coupled with awaiting the "pre-appointed leader", the Mahdi, who would guide society to the straight path before judgement day. For the Shiis, the secret explanation of the Quran is also about Imams and their fate. These Imams were Ali's descendants through his two sons, Hasan and Husayn. In their lives they usually did not have either a political or a religious role with the only exception of Jaafar al-Sadiq ("the truthful") whose religious teachings are respected even by the Sunnis. He was the sixth Imam. The majority of the Shiis acknowledged his son, Musa al-Kadhim as Imam after him. His descendants are the Twelver or Imami Shia who make up the majority of the Shiis in Iran and Iraq still today. The ninth and tenth Imams died in their childhood and their imamate was accepted. In their case it is evident that it had to be assumed not only that their words were the truth as a result of divine designation and that an imam was infallible, but also that an imam possessed divine inspiration and passed it on to his descendant without the need to acquire earthly knowledge. What the imam passed down to his descendant was the special divine light that God placed in him, as a consequence of which he was aware of the truth following from his nature. The eleventh Imam Hasan al-Askari was assassinated at the caliph's court in 873 . He did not have a son that was known of but a certain Muhammad who disappeared in a cave as a child is allegedly his descendant. He is the Imam in occultation whose return the Shiis have been awaiting to this day. He was represented by four deputies until 940, who ensured that the divine knowledge would be maintained. This is what is referred to as the "minor occultation". As the last deputy did not name another deputy, the major occultation (ghayba) when the Shii community does not have a leader guided by God, began. When the Twelver Shiis rose to power in Iran later on in the sixteenth century, the dogma was established that in the absence of the Imam the leading religious scholar, the Ayatollah inherited the divine inspiration and became the infallible leader of the community. According to Shii historical descriptions Imams, who were endowed with cosmic values, were always persecuted, imprisoned or poisoned by Umayyad and Abbasid rulers. Shii holidays, 
4.2. The Islamic Civilisation

anniversaries and pilgrimages therefore are held in order to mourn them and most importantly Husayn who suffered immensely from thirst in the desert, was betrayed even by his own supporters and was finally killed by his enemies in the Battle of Karbala. However, on legal and social issues the Shiis do not differ considerably from the Sunnis. They usually stick to the wording of the Quran more strongly and reject the practice that a Quranic verse might abrogate another or that a tradition might abrogate a Quranic verse. As regards their traditions traced back Muhammad the main difference from Sunni traditions is that the Shiis prefer traditions going back to Muhammad's family and especially those that support Ali's right of heritage and his excellence.

\section{Ismaili or Sevener Shiis}

There were, however, Shiis who held that the descendants of Jaafar's other son Ismail, who died still during Jaafar's life, were the true Imams. Their followers are the Ismaili or Sevener Shiis, who established the Fatimid Caliphate and ruled in North Africa and the Middle East from the tenth to the twelfth century. As their major characteristic they launched a dynamic social and intellectual movement which supported numberless riots. The first member of the Fatimid dynasty that claimed descent from Muhammad's daughter Fatima, Ubaydallah Mahdi, occupied the capital of the governor who supported the Abbasids in today's Tunisia in 909 and proclaimed himself caliph. This was the first case that Muslims had two caliphs, i.e. representatives of God on Earth at the same time. One weapon that Ismaili Fatimids used was sending out missionaries, who converted even the population of far-away territories to their teachings. In 969 they conquered Egypt, a great part of Syria as well as the holy cities of Hijaz, Mecca and Medina. They transferred their centre to Egypt and built a new capital, Cairo, and were in constant conflict with the Caliphate of Baghdad.

In their teachings they relied on the hidden meaning of the Quran understandable only to initiates, while Twelver Shiis only party did so. Another difference between them is that according to the Ismaili teachings the seventh Imam Ismail has always had hereditary Imams. At the moment (since 1957) the forty-ninth Imam Aga Khan IV has been the leader of the Ismaili communities scattered around the world.

At the end of the eleventh century Nizar, a candidate of the Fatimid Caliphate was killed during the debate for succession and his supporters, members of the Nizari Ismaili community fled from Egypt to the Middle East. One of their groups established the Druze sect, who today live in Lebanon, Syria and Israel in the area of the Mountain of the Druze. Others, occupying several high mountain castles, established a system of fortresses from Syria to East Iran, 
from where for 150 years they kept the states of the surrounding plains in dread. After their assumed practice of smoking hashish, they were called "Assassins" (Arabic hashshashin). Since they committed suicide murders against renowned statesmen, their name means "murderer" and "to murder" in several European languages (e.g. assassinate in English).

Owing to its internal strives the Fatimid Dynasty was unable to resist the new military systems that arose in the role of the protectors of Sunni faith and restorers of the Abbasid Caliphate. The Syrian province of Fatimids was first occupied by Seljuk Turks; later the Kurdish Ayyubid Army occupied Cairo and the whole of Egypt in 1171. The leader of the new Ayyubid Empire became Saladin (Salah al-Din, reign: 1171-1193), who took Syria from the Seljuks but, just like Seljuks, took the oath of loyalty to the Caliphs of Baghdad.

\section{Further Shii branches}

From the fifth Imam the moderate Zaydi Shia branched off, who considered Zayd ibn Ali rather than Muhammad al-Baqir the fifth Imam. Today the largest Zaydi community is in Yemen where the Northern part of the country was governed by Zaydi Imams as long as until the end of the twentieth century.

Mention must be made also of the Alawi branch, who are an extremist sect that broke off from the Twelver Shiis. As they keep their religious documents secret, only their previous name "Ali ilahi" tells us about their central teaching, i.e. that Ali is divine. At the moment they form a significant minority in Syria but have communities in Turkey and Lebanon as well.

\section{Branches of Islam in the modern age}

\section{The Wahhabi branch of Islam}

In the eighteenth century a new, puritan Hanbali-based movement emerged which interpreted the teachings of Islam in an extremist way and which soon gained popularity in Arabia. After its founder, Muhammad Ibn Abd al-Wahhab (1703-1791), who lived and taught in Najd in central Arabia it is called the Wahhabi branch. Ibn Abd al-Wahhab felt that the darkness of ignorance reigned, because of which he taught that the true arms were books and knowledge. He fought against various popular practices and superstitions like asking the intercession and the help of the Prophet at his tomb, , adoring holy trees, stones and tombs. His purpose was, as he explained, to restore Islam the way it had been during the time of the Prophet and the first caliphs by eliminating elements adopted from other religions. Thereby he can be regarded as the founder of modern fundamentalist Salafi Islam (following ancestors). In the first part of his life his enemies were plentiful; he considered everyone who contradicted him a 
heretic, and this became a characteristic of the extreme religious branches of the twentieth and twenty-first centuries. He was convinced that both public and private life had to be controlled by religion. At the same time, he also had positive teachings that are not followed by his late successors: he spoke up for social justice, the equality of Muslims, the protection of women, the poor and property, and spoke up against corruption. He advocated that fighting was allowed only in justified cases; the instruments of persuasion were teaching and preaching. $\mathrm{He}$ called his teaching the doctrine of the unity of God (tawhid); his followers have called themselves muwahhidun ("those who profess the unity of God") until today.

It was a decisive change in the history of the Wahhabi branch when, in 1744, Ibn Abd al-Wahhab signed an agreement with the militant chieftain of Najd, Muhammad Ibn Saud. Accordingly, the latter became the secular commander and emir, while Ibn Abd al-Wahhab the Imam, i.e. the Islamic religious leader. Thereby he legalised the tribally-based kingdom - the Saudi state of Najd - from the religious aspect, whereby the tribal raids multiplied. Although the jihad - religious war - became a duty of the new state, according to the Wahhabi teaching the conquered must first be demanded to convert to "true" Islam and may only be killed if they refuse to do so. As the troops did not follow this but murdered, looted and destroyed everything instead, Muhammad Ibn Abd al-Wahhab became disappointed and retired from direct engagement in governing after 1770. His doctrine survived and was influential in many regions, e.g. Egypt and India, already in the nineteenth century; of, while it became the official religion of Saudi Arabia established in the first third of the twentieth century.

\section{The nineteenth-century reform age of Islam (nahda) in Egypt}

During the European - English and French - colonisation in the second half of the nineteenth century religious scholars and intellectuals in several Arab countries got in contact with Western civilisation. The influence of the West was double: on the one hand it awakened the desire to catch up with the West and restore the old glory, and on the other hand the anti-Islamic, secular external power also aroused rejection. It was as an effect of this double reaction that the Islamic reform movement (islah) developed first of all in Egypt, and alongside with that an effort - called Renaissance (nahda) - appeared to renew the secular culture. The father of religious reforms was primarily Muhammad Abduh (18491905) Egyptian jurist, religious scholar and liberal reformer, who is considered to be the most important figure of the modernisation of Islam. He broke away from rigid dogmatism, advocated the new doctrine that the gates of religious renewal and new interpretations did not close in the Middle Ages. As a young man he was strongly inspired by and learned a great deal from Jamal al-Din al- 
Afghani (1838-1897) who stayed in Egypt in the 1870's and who was a reformer, an agitator, liberal and an extremist at the same time. It was in the course of their activity that the intellectual strife for restoring the power of Islam and blocking the European advance first took a more or less coherent shape. This reform movement was characterised by the influence of Western rationalism, efforts for the unity of Islam, the criticism of Western imperialism and the adoption of modern civilisation. Al-Afghani emphasised Pan-Islamic efforts and envisaged the Ottoman Sultanate as the caliphate uniting the world of Islam. Abduh restricted his activity to Egypt, where he was regarded as a reformer and reviver who, in addition to adopting the achievements of Western civilisation, wanted to deepen religious practice. This effort was facilitated by the fact that towards the end of his life he was officially appointed the Grand Mufti of Egypt. In that function he advocated women's equal rights and launched a fight against the activities of Sufi orders which he considered an obstacle to development.

\section{Major tendencies of Islam in the twentieth century}

Towards the end of the nineteenth century the followers of an influential Sunni preacher Mirza Ghulam Ahmad (1835-1908) formed a separate group in Punjab in India. They regarded their leader as a second Prophet after Muhammad and referred to themselves as Ahmadi Muslims. As a result of persecution, they live scattered around the world today and engage in zealous missionary work.

In the twentieth century, in the years following World War I, various tendencies of political Islam developed in several parts of the Islamic world. The most important of these is the Movement of Muslim Brethren established in the Middle East, primarily in Egypt and Syria. The movement was launched by the Egyptian Hasan al-Banna murdered in 1949, the goal of the movement was to attain power and its main characteristic was that it did not rely on men of religion but on lay intellectuals.

The most influential figure of political Islam in the Indian subcontinent and after 1947 in Pakistan was Abul Aala Mawdudi (1903-1979). His goal was to propagate the teachings and legislation of Islam among the Muslim masses. In his view, organisations based on Islam should only take over power provided that the above concepts were shared by the people.

The ideas of Hasan al-Banna and Mawdudi were further developed and published in a simple, reader-friendly manner by the Egyptian Sayyid Qutb, executed in 1966, whose fundamental idea, which later became popular, was that modern-age Muslim countries actually lived in the pagan age (jahiliyya). It was not enough if somebody claimed to be a Muslim; everything must be done, if necessary, by force, so that the world would be governed, according to God's will, by the teachings of Islam. The same principle in Shii Islam was implemented 
by Ayatollah Khomeini (1902-1989) via the Iranian Islamic Revolution in 1979. In the thus established Iranian Islamic Republic, political leadership was transferred to religious scholars (velayat-e faqih).

In the world of Islam, the view that the legal order based on the divine law of Islam (Sharia) must be restored is widely shared even by non-extremist Muslim religious movements. Sharia as the state law in Sunni Islam was clearly implemented in Saudi Arabia where both political and religious power is held by the king. This means that the questions in which religious scholars have the authority to make judgements on the basis of sacred scriptures are not laid down in state laws. In spite of this, state laws must be passed for two thirds of the legal issues as those are outside the scope of Sharia. In the second half of the twentieth century extremist Muslims called themselves Salafis claiming they followed the lifestyle and morals of the age of the Prophet and the three generations after him (salaf meaning "pious predecessors"). They consider everyone who does not share their views - which is the majority of Muslim societies - as a nonbeliever. This charge of unbelief is called takfir. This has relevance because according to the Quran a Muslim must not fight against another Muslim except if the latter has been declared a nonbeliever.

Another widely used concept of contemporary Islam is jihad, which has become the slogan of extremist Muslim political activists in the meaning of "holy war" mainly in the past forty years. This fight, they believe, must be fought both within and outside the world of Islam.

\subsubsection{The secular civilisation}

\section{The secular sciences in the East}

In the first decades of the ninth century, Harun al-Rashid's son, Caliph alMamun became famous for further extending the House of Wisdom established by his father in order to support translations from the Greek and Syriac languages, and for giving significant financial subsidy for its operation. By this, he partly attempted to counterbalance the advance of religious sciences. In addition to housing translators, the institute provided premises for a huge library. Several hundred works by some 80 authors were translated there, primarily in philosophy and natural sciences, which had a great impact on both intellectual and religious life.

The works of the most prominent representatives of Greek science were translated into Arabic language during what is referred to as the second translation era in the second half of the ninth century, by the Syrian Christian scientists living in North Syria who had earlier translated these from Greek to 
Syriac language. The most significant of them was Hunayn ibn Ishaq who translated Aristotle, Plato as well as works in medicine. Qusta ibn Luqa translated Aristotle, Plutarch's historical works and Euclid's Elements, a fundamental book of mathematics into the Arabic language. As all these works were later translated into Latin, Mediaeval Europe has become acquainted with Greek science due to the Arabs. Arab philosophers and natural scientists not only interpreted Greek works but, in many cases, developed them further. The philosopher and logician al-Farabi (d. ca. 950) and the philosopher and physician Avicenna (Ibn Sina), (d. 1037) were the greatest scientists. Avicenna provided a complete system of sciences in his multi-volume work The Book of Healing, while he summarised medicine in his work The Canon of Medicine (al-Qanun fi t-tibb). The activity of scientists writing in the Arabic language also had a great impact in the field of mathematics. The word algebra is of Arabic origin: al-jabr meaning "the reunion of broken parts", i.e. ways to find the wanted unknown. It was the Arabs that added the zero to the sequence of numbers: the Arabic sifr is chiffre in French, and this is also where the English "cipher" come from. The first great mathematician and astronomer was al-Khwarizmi (d. 850); the word "algorithm" in the European languages originates from his name.

From the great number of valuable works in Arabic historiography, a world history by al-Tabari (d. 922), entitled Annals (Tarih) is outstanding. The greatest figure in scientific historiography, who had a great impact on modern European historiography as well, is Ibn Khaldun whose Introduction (Muqaddima), written to his world history provides both theoretical and practical fundamentals for historiography.

\section{Achievements of Islamic civilisation in Spain}

After the end of the reconquest in 1492, in the field of material culture it was primarily architecture and landscape architecture that influenced, via the Kingdom of Spain, the European civilisation in the centuries to come. The former Muslims who had seemingly converted to Christianity were allowed to stay in the peninsula for more than a century but were constantly suspected by the Spanish of practising their old faith. They were called Moriscos (Spanish for Moorish). They constituted the craftsmen stratum of society in the new Spanish Kingdom and transmitted the products of science and culture from the Middle East towards Europe. The most influential Muslim scholar was the philosopher Ibn Rushd (Averroes) living under the Almohads in the twelfth century, whose works were translated to Latin and were used by Christian theologians as well, e.g. the greatest figure of Christian theology in the Middle Ages, St. Thomas Aquinas. It was also in Spain where Arabic medical literature was translated into Latin, of 
4.2. The Islamic Civilisation

which the above-mentioned work by Ibn Sina was still taught at European universities at the beginning of the nineteenth century. When in 1609, at the demand of the inquisition Philip III, King of Spain ordered that the Moors and the Jews be expelled from Spain, they fled primarily to North Africa, causing a great shortage of experts in the kingdom. According to Spanish historical resources more than half a million Moors were expelled at that time. The number of Arabic books they left behind, which were burnt as heretic documents, is estimated to have been around 600 thousand. Mosques were transformed into churches, while the thousands of baths that were viewed as the symbols of "pagan" Muslim culture were destroyed. Between the fall of Granada and the first decade of the seventeenth century some three million Moors were expelled or executed for the sin of falling back to Islam.

\section{Literature in the central parts of the Islamic world}

\section{Arabic literature in the Middle Ages}

The most important genre in Arabic literature in the Middle Ages was poetry. On the one hand genres were kept which preserved traditions from preIslamic poetry - panegyrics, elegies, satires - and on the other hand new genres were born like wine poems, love poems and religious poems. Since there are very strict formal conditions for classical Arab poems as well as due to an abundance of paronomasia, they cannot really be translated.

The first fiction in the Arabic language is Kalila and Dimna, a collection of fables from the eighth century, written as a mirror for princes. The majority of the tales are of Indian origin. A more widely known collection of tales and also of a larger size is the collection without an author and with the title Arabian Nights, which took five hundred years to compile from Indian, Persian and Arabic sources. A special Arabic genre is the maqama, which came into being in the tenth century, and in which the permanent narrator tells in first person singular about his adventures with a permanent trickster, which happened to him in various cities of the Arab world. The most renowned maqama writer was al-Hariri in the twelfth century. An outstanding figure of Arabic literature in Andalusia, also from the twelfth century, is Ibn Tufayl, whose novel Hayy ibn Yaqzan, a philosophical tale has been published in English, too. One of the most interesting sources about the times of the crusades is the work of Usama ibn Munqidh which is also available in English: An Arab-Syrian Gentleman and Warrior in the Period of the Crusades: Memoirs of Usama Ibn-Munqidh (Kitab al i'tibar). The most prominent piece of travel literature is a travelogue about the journeys of Ibn Battuta in the fourteenth century, also translated into English. The author travelled some 20 thousand kilometres around the world. 
Persian poetry in the Middle Ages

At the time of the early Muslim empires the use of Arabic in the written language pushed Farsi into the background. The first literary accomplishment in the New Persian language written in Arabic script, which has been one of the most influential ones until today is Firdausi's (ca. 940-ca. 1021) historical epic Shahnameh ("Book of Kings"). Poetry was the most famous genre in the Mediaeval Persian literature. Besides the four-line (rubaiyat) wine verses and love verses by Umar Khayyam (1048-1131), the poems of Hafiz from the fourteenth century stand out. These have become also very popular in Europe from the eighteenth century on. An outstanding poet in the twelfth century was Nizami, whose major work "Five treasures" (Panj ganj) comprising five long epic poems had been a favourite for illustrators for long centuries. Similarly, important works are the rhyming couplets (masnavi) of the great mystical poet of the thirteenth century Jalal al-Din Rumi as well as Sadi's Rose Garden in which he made a systematic compilation of wisdom based on his experiences, adventures and the knowledge and experience gained by travelling. The works of Jami who was born in the territory of today's Afghanistan and lived in the fifteenth century spread primarily via the mystical Naqshbandi order to the whole Persianate region, including Central and South Asia. His best-known work containing seven works bears the title Haft awrang ("Seven Thrones"), one story in which (Yusuf va-Zulaykha) tells the story of Joseph and the wife of Potiphar based on the twelfth chapter of the Quran.

\section{Ottoman-Turkish literature}

The literature of the Ottoman period, written in the Ottoman Turkish language includes both folklore material based on oral tradition and written texts not related to the former. Ottoman literature, which was written in Arabic script, was to a great extent influenced by Arabic and Persian literature. Just like in these two, the main genre was the so-called diwan poetry, while prose was less significant. Both oral and written poetry were permeated by mystical notions. The first poet of significance was Yunus Emre (1238-1320), an outstanding figure of Sufi mysticism, who had a great impact on Ottoman literature in all of its ages. He belonged to the poets of his time who did not write in a literary register which was under Arabic and Persian influence - but used a vocabulary much closer to spoken language. Fuzuli (1483-1556), who was of Azeri origin, wrote, following the traditions of his age, significant works both in Ottoman Turkish and Persian. A representative poet of the age of Suleiman the Magnificent was Bâkî (1526-1600), who is considered a great master of style. Nedim (1681-1730), the poet of the "Tulip Age" who brought revolutionary innovations, intertwined the literary language of the elite with linguistic turns from folk poetry. An 
outstanding genre in prose was that of travel books (Seyahatnâme), whose most excellent representative was Evliya Çelebi (1611-1684).

\section{Islamic art}

The diversity of art in the region gives a true picture of the diversity of Islam in place and time. The framework of this chapter does not allow the presentation of all branches of art, therefore only a brief mention is made of the two most significant ones: mosque architecture and calligraphy.

\section{Styles of mosque architecture}

Hypostyle mosques

This is the simplest type, which reminds Muslims of the first mosque, the house of Prophet Muhammad in Medina. This layout was built most frequently all over the Islamic world (Figures 62-63) before the four iwan mosque became widespread in the twelfth century. The best-known mosque built in this style is in Qayrawan, Tunisia.

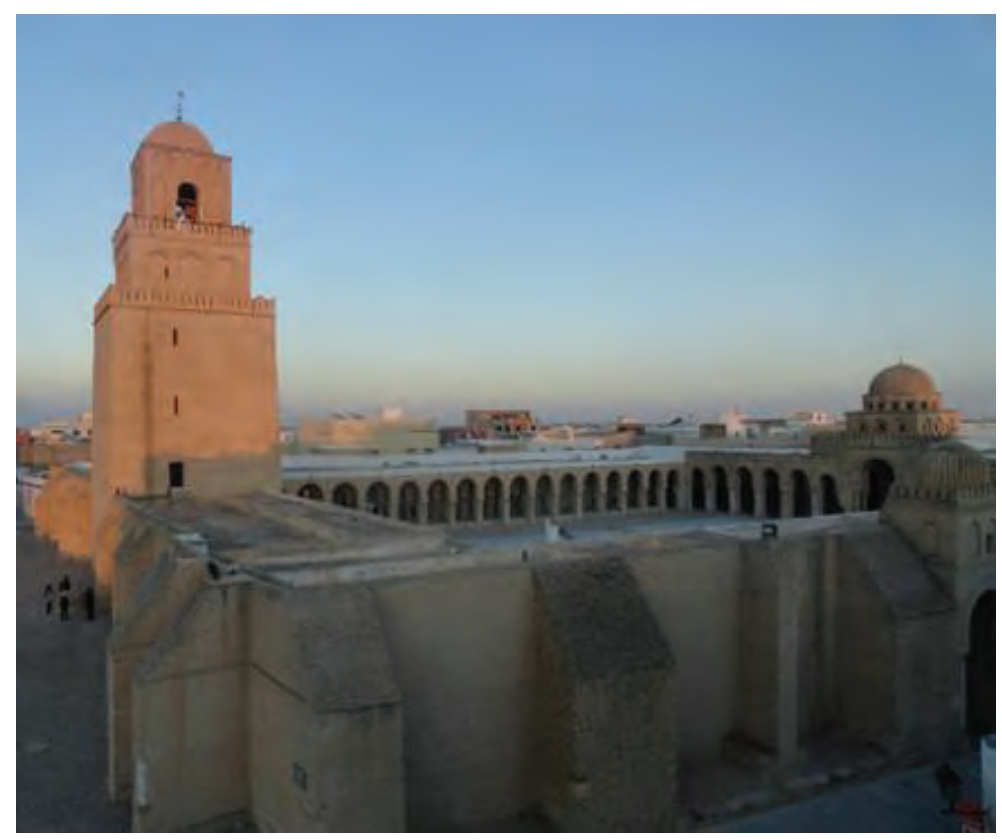

Figure 62: The Great Mosque of Qayrawan founded by Uqba ibn Nafi in 670, which gained its final form during the reign of the Aghlabid dynasty in the ninth century Source: Photograph by KINGA DÉvÉNYI 


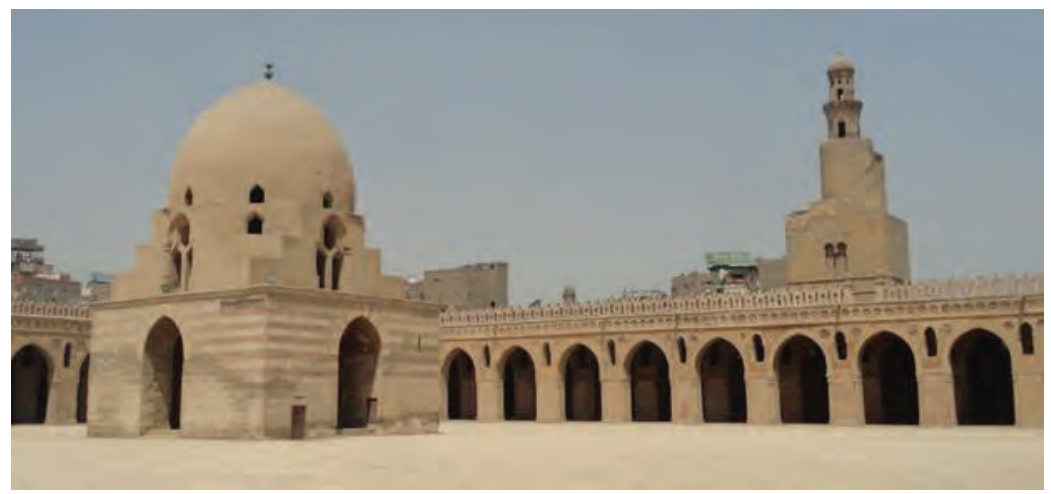

Figure 63: The Mosque of Ibn Tulun in Cairo built in 879 and its minaret Source: Photograph by KINGA DÉVÉNYI

Four-iwan mosques:

An iwan is a large, vaulted hall that opens to a courtyard (Figure 64). Just like in the case of a hypostyle mosque, the walls enclose a vast courtyard. The biggest iwan is the one facing praying direction (qibla). Although it developed in Iran under ancient Persian influence, it later spread everywhere from India to Cairo both in sacred and secular architecture.

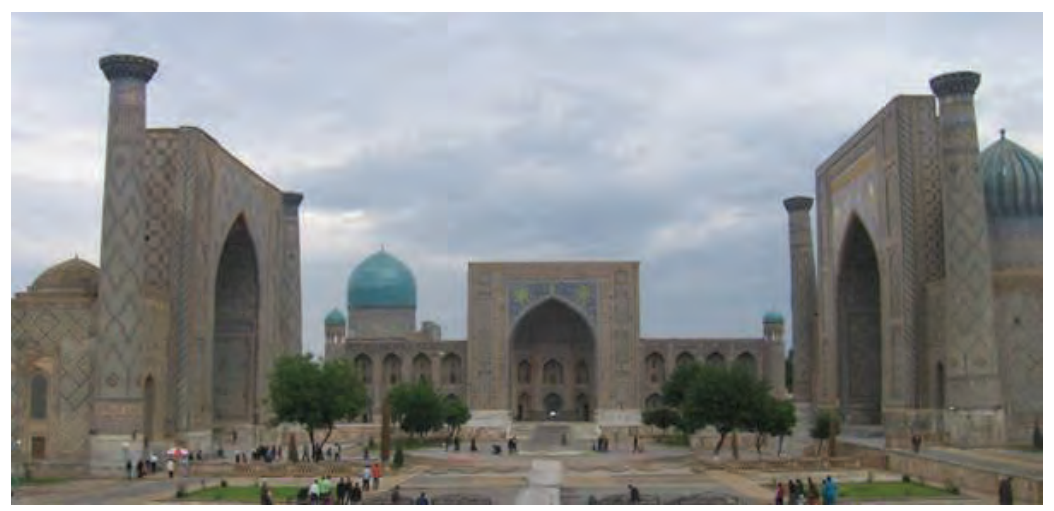

Figure 64: The iwans of three madrasas built between the fifteenth and seventeenth centuries in the Registan, the main square of Samarkand in the Timurid period Source: Photograph by MIKLÓs SÁRKÖZY

Centrally planned mosques:

Ottoman Turkish architecture was to a great extent influenced by the church Hagia Sophia in Istanbul, which was the largest of all Byzantine churches, and whose main characteristic feature is the monumental central dome above the huge nave. Turkish mosques mostly copied this example. 
Calligraphy (khatt)

Before modern age, the most important and in many places the only field of fine arts in the Islamic world was Arabic calligraphy. Striving for beauty had such importance in writing - probably with the exception of much of the book copying - that the Arabic word for writing, khatt, means calligraphy at the same time. Engaging in calligraphy constituted a part of high-level knowledge and the most famous calligraphers (khattat) came from among high-position clerks like Ibn Muqla (d. 940), the chief minister of several Abbasid caliphs.

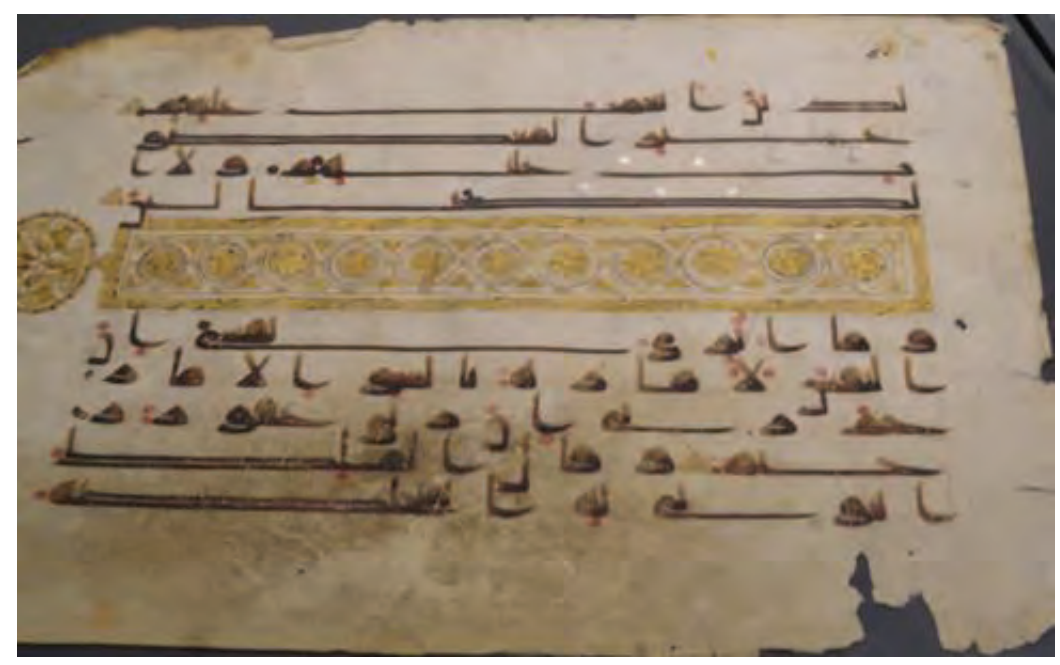

Figure 65: Quran excerpts $(1: 7 ; 12: 53)$ in Kufic script from the eighth century, with a decorative sura dividing panel. Museum of Islamic Art, Istanbul Source: Photograph by MÁTÉ L. IVÁNYI

Arabic script developed in two geometrically different versions in the sixth and seventh centuries. The square Kufic script was named after the city of Kufa in South Iraq (Figure 65). This was used for inscriptions on buildings as well as for copying the Quran until the tenth century; for decoration it was frequently used later as well.

The Maghrebi script developed from the Kufic and was also used by book copiers before book printing was invented, and the Quran was written in Maghrebi script even in its printed form. The other type of writing was the round naskhi script, which was the "script of copyists" and was used for writing manuscripts until the middle of the nineteenth century. This script was developed into several decorative scripts, too, e.g. thuluth, diwani, muhaqqaq, and this became the script of the Quran, too, after the year 1000. Naskhi script was the basis for various Persian scripts like taliq and nastaliq, which latter developed 
from the former (Figure 66). In offices shikaste, characterised by tiny and thin letters, was used, which was also adopted by the Ottoman Empire.

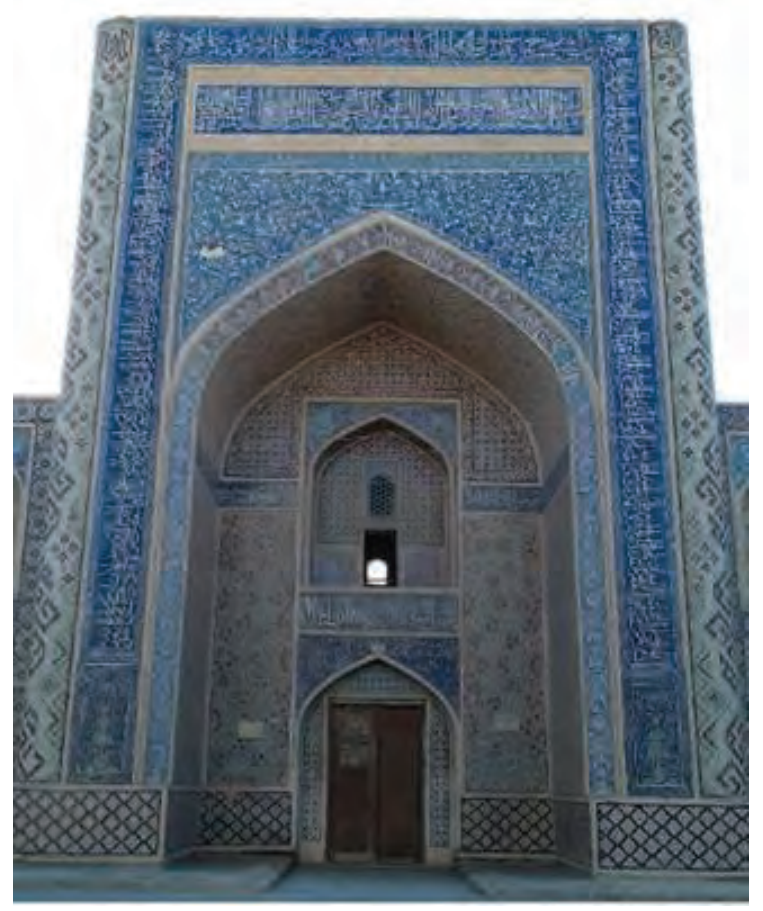

Figure 66: The tiles on the facade of the Abdullah Khan Madrasa covered with inscriptions, Bukhara, sixteenth century Source: Photograph by MIKLÓs SÁRKÖZY

Calligraphy has retained its artistic function in modern art as well (Figure 67).

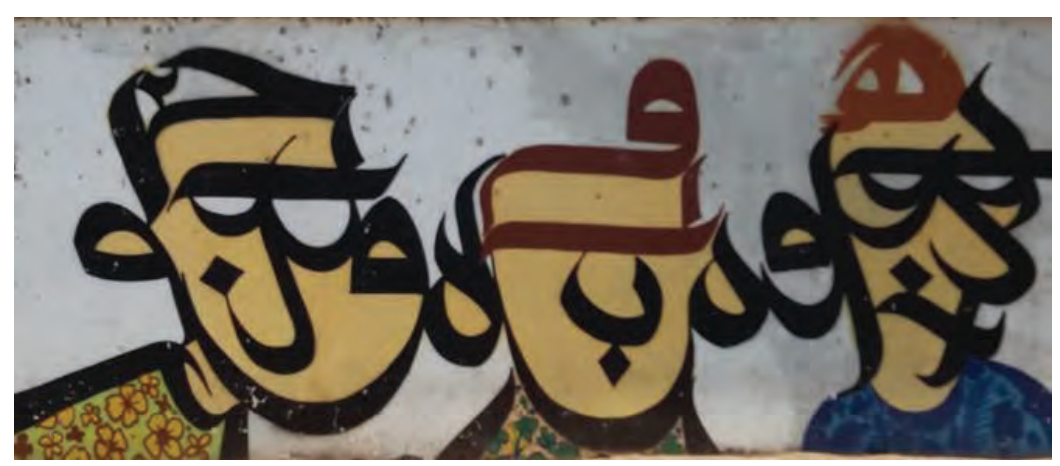

Figure 67: Modern street art in Cairo making use of calligraphy Source: Photograph by KINGA DÉvÉNYI 


\subsubsection{Chronological table}

\begin{tabular}{|c|c|c|}
\hline Date & Era & Event \\
\hline c. 570 & \multirow{12}{*}{$\begin{array}{l}\text { Muhammad } \\
\text { and the } \\
\text { formative } \\
\text { period of } \\
\text { Islam }\end{array}$} & The birth of the Prophet Muhammad \\
\hline c. 611 & & The start of the revelation of the Quran \\
\hline 622 & & $\begin{array}{l}\text { The hijra, Muhammad's emigration from Mecca to Medina, } \\
\text { marking the beginning of the Islamic calendar. }\end{array}$ \\
\hline 624 & & $\begin{array}{l}\text { The Battle of Badr, Muhammad's first great victory against } \\
\text { Meccan pagans }\end{array}$ \\
\hline 630 & & The conquest of Mecca \\
\hline 632 & & The death of the Prophet Muhammad \\
\hline $632-661$ & & The reign of the first four, "rightly guided caliphs" in Medina \\
\hline $632-634$ & & Abu Bakr, the first caliph \\
\hline $634-644$ & & The reign of Caliph Umar \\
\hline $644-656$ & & The reign of Caliph Uthman \\
\hline $656-661$ & & The reign of Caliph Ali, with Kufa as the centre \\
\hline 657 & & $\begin{array}{l}\text { The Battle of Siffin between Ali and Muawiya, arbitration, the } \\
\text { secession of Kharijis from Ali's camp }\end{array}$ \\
\hline $633-651$ & \multirow{5}{*}{ Conquests } & The conquest of Mesopotamia and Persia \\
\hline $634-641$ & & The conquest of Syria \\
\hline $639-642$ & & The conquest of Egypt \\
\hline $647-722$ & & The conquest of North-Africa (Maghreb) \\
\hline $711-722$ & & $\begin{array}{l}\text { The conquest of the southern and central parts of Hispania } \\
\text { (Andalusia) }\end{array}$ \\
\hline $661-750$ & \multirow{2}{*}{$\begin{array}{c}\text { Arab } \\
\text { dynasties }\end{array}$} & Umayyad Caliphate in Damascus \\
\hline $750-1258$ & & Abbasid Caliphate in Baghdad \\
\hline 756 & \multirow{7}{*}{$\begin{array}{l}\text { Further } \\
\text { dynasties } \\
\text { in Arab } \\
\text { territories }\end{array}$} & Umayyad Emirate in Córdoba \\
\hline $929-1031$ & & Umayyad Caliphate in Córdoba \\
\hline 909-1171 & & Fatimid Caliphate in North Africa and the Middle East \\
\hline $1174-1260$ & & Ayyubid Sultanate in Egypt and Syria \\
\hline $1040-1147$ & & Almoravid reign in North Africa then Andalusia \\
\hline $1147-1269$ & & Almohad Caliphate in North Africa and Andalusia \\
\hline $1251-1517$ & & Mamluk Sultanate with Cairo as capital \\
\hline
\end{tabular}


Civilisations from East to West

\begin{tabular}{|c|c|c|}
\hline Date & Era & Event \\
\hline 819-999 & \multirow{11}{*}{$\begin{array}{l}\text { Other } \\
\text { Muslim } \\
\text { dynasties }\end{array}$} & $\begin{array}{l}\text { Emirate of Samanids of Persian origin in the areas of East Iran, } \\
\text { Afghanistan, Central Asia and West India, with Samarkand and } \\
\text { later Bukhara (Central Asia) as capital }\end{array}$ \\
\hline $945-988$ & & $\begin{array}{l}\text { Emirate of Iranian Shii Buyids in West Iran and Iraq } \\
\text { acknowledged by the Caliphs of Baghdad }\end{array}$ \\
\hline $977-1186$ & & $\begin{array}{l}\text { Ghaznavid Emirate with Ghazna (Afghanistan) as capital in the } \\
\text { area of the earlier Samanid Emirate - the reign of slave soldiers }\end{array}$ \\
\hline $1050-1153$ & & $\begin{array}{l}\text { Great Seljuk Empire with Isfahan (Iran) as the centre. Their } \\
\text { reign extended to the whole Middle East }\end{array}$ \\
\hline 1299 & & $\begin{array}{l}\text { Bey, then Sultan Osman establishes the Ottoman Empire } \\
\text { bearing his name in Asia Minor }\end{array}$ \\
\hline 1453 & & $\begin{array}{l}\text { Sultan Mehmed the Conqueror conquers Constantinople, which } \\
\text { under the name Istanbul becomes the capital of the Empire }\end{array}$ \\
\hline 1502 & & Foundation of the Shii Safavid Empire in Persia \\
\hline $1520-1566$ & & The reign of Suleiman the Magnificent in the Ottoman Empire \\
\hline 1526 & & $\begin{array}{l}\text { The Foundation of the Mughal Empire under Sultan Babur in } \\
\text { India }\end{array}$ \\
\hline $1794-1925$ & & Reign of the Qajar dynasty in Iran \\
\hline $1925-1979$ & & Pahlavi dynasty in Iran \\
\hline $1922-23$ & \multicolumn{2}{|c|}{$\begin{array}{l}\text { Abolition of the Sultanate and the proclamation of the Turkish Republic, led } \\
\text { by Kemal Ataturk }\end{array}$} \\
\hline 1979 & \multicolumn{2}{|c|}{ Islamic Revolution in Iran led by Ayatollah Khomeini } \\
\hline
\end{tabular}


4.2. The Islamic Civilisation

\subsubsection{Bibliography}

BeEston, Alfred F. L. ET AL. (eds.) 1983-2006: The Cambridge History of Arabic Literature. Cambridge: Cambridge University Press, 6 vols.

Cleveland, William L. - Martin Bunton 2009: A History of the Modern Middle East. Philadelphia: Westview Press

FISHER, W. B. ET AL. (eds.) 1968-2001: The Cambridge History of Iran. Cambridge University Press, 7 vols.

FODOR, SÁNDOR 2009: Sufism and Magic: Amulets from the Islamic World. Keszthely: Helikon Múzeum

GolDZIHER, IgNAZ 1971: Muslim Studies. Albany: SUNY Press, 2 vols.

GoLDZIHER, IGNAZ 1981: Introduction to Islamic Theology and Law. Princeton: University Press

HillenBrand, CAROle 2015: Islam. A New Historical Introduction. London: Thames and Hudson

HillenBrand, ROBERT 1999: Islamic Art and Architecture. London: Thames and Hudson

HODGSON, MARSHALL G. S. 1977: The Venture of Islam. Chicago: University of Chicago Press. 3 vols.

Kamrava, Mehran 2005: The Modern Middle East: A Political History since the First World War. Berkeley \& Los Angeles: University of California Press

LEWIS, BERNARD 1972: Istanbul and the Civilization of the Ottoman Empire. Oklahoma City: University of Oklahoma Press

LEWIS, BERNARD 2002: The Arabs in History. New York: Oxford University

MANDEl Khan, Gabriel 2001: Arabic Script. Styles, Variants, and Calligraphic Adaptations. New York: Abbeville Press

Nicholson, ReYNOLD A. 2002: The Mystics of Islam. Bloomington: World Wisdom

Pedersen, Johannes 1984: The Arabic Book. Princeton: University Press

SCHACHT, JosEPH 1982: An Introduction to Islamic Law. Oxford: Clarendon

SHAW, STANFORD J. 1976. History of the Ottoman Empire and Modern Turkey: Volume 1, Empire of the Gazis: The Rise and Decline of the Ottoman Empire 1280-1808. Cambridge: Cambridge University Press

The New Cambridge History of Islam. Cambridge: Cambridge University Press, 2010-2011.

Watt, William Montgomery 1961: Muhammad - Prophet and Statesman. Oxford: Clarendon

WATT, WiLliam MONTGOMERY 1983: The Majesty That Was Islam. The Islamic World 661-1100. London: Sidgwick and Jackson 
5. Africa 


\subsection{The Civilisations of Africa ${ }^{13}$}

\section{ZOLTÁN SZOMBATHY}

The plural form in the title of the chapter - "civilisations" rather than "civilisation" - is not an accidental typo but is a form justified and used intentionally. The reason is that, as opposed to the other civilisations discussed in the book, the civilisations of Africa (and within that, Sub-Saharan Africa) are interrelated by very few characteristics to the extent which would justify considering the continent as a single, more or less uniform civilisation. Africa shows so great diversity in terms of culture, religion and society that it is in fact almost impossible to treat it as a single civilisation; however, in the absence of a better solution, we will nevertheless do so in this book. For this very reason, this is exactly the aspect that should be highlighted and emphasized right at the outset: to what extent and in what sense can we talk about an "African civilisation"; or in other words, to what extent and how does the African continent or at least the part thereof south of the Sahara constitute a civilisational entity and an independent cultural area, if it does so at all. The most important general principle to be established right away is related to the definition of African civilisation(s): Africa constitutes a single civilisation exclusively in the geographical (and racial) sense; it would be difficult to refer to a cultural unity in the case of Africa. The African continent cannot be considered as a culturally defined civilisation, not least because a significant overlap with other civilisations - discussed in this book as well - can be detected. Therefore, for instance, it would be completely absurd to discuss the Islamic civilisation as if the statements made there did not concern the Sub-Saharan African Muslim population (nearly one fifth of the Muslims of the world, which is an ever-increasing ratio for that matter). These are not minor details that can be disregarded conveniently: currently, at least one third of the population of Sub-Saharan Africa is Muslim (therefore the chapter on Islamic civilisation discusses them as well), and nearly half of the population of SubSaharan Africa is Christian (therefore the chapters about Western and Eastern Christianity as a civilisation apply to a significant extent to them as well).

\footnotetext{
${ }^{13}$ Most of the African languages now use the Latin script; spelling conventions, of course, differ from those of English. However, for the sake of uniform spelling, we use all words and names in African languages in roughly English spelling.
} 


\subsubsection{Terminological matters and the boundaries of African civilisations}

In discussing the African civilisations, it will be advisable to clarify some terminological aspects first. The first among these is the name of the region itself, which is not merely a linguistic matter but also an issue of principle, which affects the boundaries of the civilisations to be discussed as well. In the scholarly literature written in English, French, Spanish and other Western languages, compound words formed with the adjective "Sub-Saharan" (French: subsaharien; Spanish: subsahariano; etc.) are used often ("Sub-Saharan Africa", "SubSaharan region"); the advantage of this term is that it is a neutral, descriptive geographical term free from ideological overtones. Unfortunately, it has a major disadvantage as well: the expression implies that the Sahara is some kind of cultural-civilisational boundary between two completely different regions - as you will see, this is not even remotely true. In Hungarian, the name "Black Africa" is more common, and we have no reason to change this, since no systematic pejorative meaning is attached to the adjective "black" in the Hungarian language. However, it shall be noted that the equivalents of the expression "Black Africa" used to be and partially are still used in several European languages (e.g. English Black Africa; French Afrique noire; etc.); the decline in the use of these expressions may be traced back to explicitly political - ideological reasons, for these are fundamentally descriptive terms: they reflect the fact that the regions situated south of the Sahara are inhabited mostly by a population of markedly dark complexion. In any case, in what follows we will use the now usual English term "Sub-Saharan Africa", or - for the sake of brevity and unless noted otherwise - the word "Africa" will mean "Sub-Saharan Africa" throughout this chapter.

As we have already mentioned briefly, both the name "Sub-Saharan Africa" and the name "Black Africa" raise a serious - and ultimately unsolvable - theoretical problem, to wit: where can the anthropological and cultural boundaries of Sub-Saharan Africa be drawn in the north. The problem is unsolvable because these boundaries cannot be drawn anywhere in reality: although the region of the North African Arabic-speaking countries is a rather different world compared to Sub-Saharan Africa (more in terms of anthropology and much less in terms of culture), no clear boundary can be established anywhere. In other words, the Sahara is not a boundary but rather a transitional area. In most of the desert the majority of the population are of Sub-Saharan African character. Culturally however, the Sub-Saharan African links dominate in certain regions (e.g. the Saharan areas of Chad), while North African links dominate in other regions (e.g. Mauritania or certain regions of Algeria). The 
entire Saharan population is Muslim; however, this is also the case in the SubSaharan African region situated more to the south (the so-called Sahel belt) as well. Countless trade routes have run across the Sahara since ancient times, which ensured permanent relations between the two lands bordering the desert; and in the same way that populations of (partially) Arabic origin and of (mostly) Arabic culture live in Sub-Saharan Africa (the Sudan, Chad), population elements of fundamentally Sub-Saharan African origin can be found also in North Africa (this is the so-called Haratin population in Morocco and Algeria).

Another terminological matter should be briefly discussed as well. In the English language (and in other modern European languages as well) it has been a common phenomenon that the word "tribe" would be used in reference to African ethnic groups, even in cases where it is not justified at all. This reflects a prejudiced thinking: it is totally unjustified to use the word "tribe" in Africa to refer to social groups for which the word "nation", "ethnic group" or "ethnicity" would be used in Europe. A social group which in any case includes several hundred thousand or several million people, speaks its own common language, and which may also constitute a political unit and considers itself as an independent nation is a "nation" or "ethnic group" in Africa as well, and not a tribe. There are, to be sure, tribes also in Africa - the same as in Asia and as they used to exist in Europe as well - but it is a different (lower) level of social organisation. Thus, for example the Somalis are a nation or an ethnic group, but there are tribes within the nation (e.g. Darod, Isaaq, Dir, Hawiye, Rahanweyn, etc.).

\subsubsection{Cultural diversity}

As already emphasised in the introduction, Africa is exceptionally diverse in terms of culture, a degree of diversity the like of which can be observed only on the Asian continent. Despite this Asia is usually not treated as a single civilisation (it is not in this volume either). The issue of diversity will have to be stressed again and again as part of the presentation of different cultural characteristics (language, religion, social organisation, political structures, states, external cultural influences). For this reason, when discussing such specific questions, we will revisit this aspect as well; here it is noted only in general that there is hardly any area or phenomenon of culture regarding which Africa shows uniformity.

Let us start with the issue of religion. Even aside from the foreign influences - although, as we will see, these cannot be disregarded - the traditional religions of Africa show few shared characteristics present everywhere. Even more important is the fact that the religious and cultural life of numerous regions of Sub-Saharan Africa have been profoundly informed by Islam since the Middle 
Ages, while some other African regions have just as deep-rooted Christian traditions. These two religious communities show few common characteristics, and their cultural orientations could not be more different (in some cases even in spite of close geographical proximity: the Cristian Ethiopian Highlands and the Muslim East Ethiopia are geographically close, but are strikingly dissimilar in terms of religion and culture).

The linguistic map of Africa shows even more diversity. Languages belonging to several, totally unrelated language families are often spoken within the same small region; moreover, many Sub-Saharan African languages have their closest relatives on other continents. For example, most of the languages spoken in Madagascar are related to the languages of Indonesia and the Pacific Ocean region (the most closely-related languages being spoken on the island of Kalimantan in Indonesia); the languages of the central and northern belts of Nigeria are related more closely to, for example, Hebrew or Arabic than to the neighbouring languages spoken in the Nigerian regions situated directly to the south. In the southern part of Kordofan province in the Sudan, languages belonging to at least four different language families are spoken, often in mountain ranges situated in each other's immediate vicinity, thereby creating a linguistic mosaic which is perhaps most reminiscent of situation in certain regions of the Northern Caucasus.

Lifestyles, material and intellectual cultures also show incredible variety, so that it would be a futile effort to try summarising this aspect in any concise manner. A particularly interesting phenomenon is that the most primitive cultures are frequently found in the immediate vicinity of quite sophisticated states and cultures, which often had and continue to have permanent and profound cultural interactions with remote regions within the continent as well as regions outside Africa while having minimal contacts with neighbouring communities having a more primitive culture. A pertinent example is the sophisticated culture of the Christian Ethiopian highlands, and, not far from these, the remarkably primitive pastoral cultures such as those of the Muslim Afar people or the small animist peoples of the lower Omo River valley. Likewise, quite next to the Muslim high cultures and states of the Hausa and Fulani of Northern Nigeria, one finds the rather primitive cultures of the small animistic (now partly Christianised and to a lesser extent Islamised) ethnic groups of the so-called Middle Belt , the two types of civilisations having had a fairly limited interaction with each other. In the vicinity of the feudal states of the Congo Basin (including the Congo Kingdom , which has been Catholic since the sixteenth century and had maintained friendly contacts with the Portuguese), the hunter-gatherer jungle communities of the Pygmy peoples have survived to this day. 
5.1. The Civilisations of Africa

\subsubsection{Images of Africa: distortions, exoticism and ideology}

The fact that societies on very different levels of material development existed side-by-side on the African continent led to interesting and revealing distortions of the image of Africa, in popular literature as well as in part of the scholarly literature. Distortions and misconceptions on Africa can be traced to three main reasons. Firstly there was a marked tendency to emphasise the exotic aspects over characteristics that appeared familiar to Western observers, secondly, political and ideological points of view had their impact, and thirdly racism, an example of such ideologies, has unfortunately dominated discourse on Africa. The first of these factors, i.e. the overemphasising of exotic elements, is a universal human error, and while there is no reason to suspect a political agenda behind it, it can be very harmful. The so-called colonial gaze meant that the eyes of colonialists were especially keen to note what appeared alien and bizarre, albeit many features of African civilisations were by no means incomprehensible to Western observers.

Reports on the more primitive cultures of Africa are often overrepresented in descriptions of the continent's cultural life, while external cultural influences are often downplayed or neglected: the primitive and the outlandish are "more interesting" than the more sophisticated and the familiar. A ludicrous example of this tendency is the Sudanese material of the renowned photographer and filmmaker Leni Riefenstahl (1902-2003) who "portrayed" the lives and culture of the Nuba - a collection of ethnic groups having a very primitive culture conveniently forgetting to note (and, to be sure, to show in her photographs) that the majority of these people had converted or were converting to Islam and did not insist on preserving their traditional and very primitive lifestyle intact. Obviously, Sudanese Muslim culture did not seem exotic enough to be worth recording, and even of noting.

In other cases, distortions of Africa's image result from explicit ideological concerns. This observation applies especially to the issue of extent to which many African cultures, or aspects of culture, can be considered as "authentically" African. The whole issue of African "authenticity" is hopelessly beyond the reach of scholarly argumentation. Of course, civilisations have always influenced one another, and the sea not being an impassable obstacle to trade and communication, cultural influence does not stop at the shores of any continent. As we have already noted with regard to religions and languages, foreign cultural influences have been present throughout the history of Africa no less than in other parts of the world, and therefore discussions in terms of just how "authentic" or "genuine" any African civilisation or cultural feature is nonsense, making as much sense as it would be in discussions of European culture. To give a more 
specific example: the degree of the "authenticity" of, say, the culture of the Muslim Swahili trading towns of East Africa or the culture of the Orthodox Christian Ethiopian Empire is precisely as meaningful as an academic controversy as a similar exploration of the "authenticity" of Western Christianity of Japanese Zen Buddhism would be. Of course, the roots of European Christianity can be traced back to the Middle East and Zen Buddhism ultimately derives from China (and indeed from India), but "authenticity" in these cases is a patently inadequate analytical concept. Likewise, why would a mosque built in colonial Baroque style in Lagos by Yoruba slaves resettled from Brazil for their own community, be regarded as anything but an integral part of African civilisation? Yet such absurd controversies are common (to some extent even in academic works), demonstrating an implicit tendency to measure African civilisations by standards not applied to other civilisations of the world. This is entirely unjustified and betrays the impact of heavily ideologised views.

Ideologised thinking is often present among the political and cultural élite of modern Africa as well. An obvious example is the so-called autenticité ideology of the former Zairian president Mobutu Sese Seko, which required the country's élite to take "authentic" African personal names despite the fact that many Africans have used personal names of Arabic or European origin for centuries (in what was to become Zaire, for example, Christian personal names have been used since as early as the sixteenth century). The absurd question of "authenticity" has been raised by outsiders as well as Africans regarding almost every advanced culture in Sub-Saharan Africa, especially those African societies that established and maintained regular commercial and cultural contacts with peoples living outside the continent.

As a sample, one might mention a few African ethnic groups and societies that became the unfortunate subjects of fatuous debates regarding their "African authenticity" debates that sadly are still going on in some cases. Examples include the Christian peoples of the Ethiopian Highlands (Amharic and Tigrinya speakers), the Arabic-speaking populations of Sudan and Chad, the Swahili of the East African coast, the Portuguese-speaking Christian élite of Angola and Congo, the population of Madagascar, the black population of West Africa who have returned from America (Yoruba people who returned from Brazil in Nigeria, and Creoles in Liberia and Sierra Leone). The list goes on, but one specific example will suffice to illustrate the tendency. The population of the Egypt-Sudan border region, known as Nubian, are black and speak an African (Nilo-Saharan) language, but they have obviously been exposed to a variety of foreign cultural influences since Antiquity: from the powerful influence of ancient Egypt to the Monophysite Christianity of the Middle Ages to the ever-present influence of Islam from the late Middle Ages to the present day. The foreign influences that 
affected the Nubians even include a handful of immigrants originating from the Balkan Peninsula and Hungary - or perhaps legends of such immigration (the socalled Kushshaf and Majarab communities were established this way). Today Nubians still speak their own language, preserve their own characteristic culture, and it would be ridiculous to refer to them as in some way not "authentically African".

Doing justice to the varied foreign influences that have had an impact on African civilisations - or even making an overview of the major influences is beyond the scope of this book. However, a few examples will be instructive, such as the introduction of numerous plant species (including maize, cocoa and tobacco from the Americas, and a lot of plant varieties from Southeast Asia), a large number of musical instruments and musical techniques, scripts and writing systems (see below), numerous elements of folklore (e.g. characteristic legends of origin and folktale types), and of course the two world religions (Islam and Christianity) complete with all their cultural traditions. In addition to the main colonising powers (England, France and Portugal), the Arabs also had a very powerful influence on the civilisations of Africa (emanating partly from North Africa and partly from the Arabian Peninsula), as did more recently (and to a much smaller extent) the Indians. Of strictly local importance yet interesting is the influence of Jewish culture on the highland areas of Ethiopia (through the Falasha population who adopted the Israelite religion and consider themselves Jews), as well as the (limited) Chinese influence on the East African coast (visited by a Chinese fleet under the leadership of Zheng He in the first half of the fifteenth century, making the use of certain Chinese luxury items such as porcelain dishes fashionable among the Swahili élite). European (and American) influences mostly date from colonial times onwards, yet similarly to other parts of the world this influence is pervasive in Africa too, being most evident in music, films, material culture and - in the Christian parts of Africa - religion.

\subsubsection{The influence of racism and the African diaspora}

Racism is a very special - and in Africa an unfortunately quite significant - kind of ideological attitude. Its importance in discussions of Africa is enhanced by the fact that, due to the extreme cultural variety of African civilisations, race is in fact the only basis of the supposed unity of the Sub-Saharan regions. Racism left its imprint on the attitudes of the European colonisers to Africa, who tended to perceive the cultures of Africa as inferior and derived from outside sources. Examples of such views include the insistence - totally baseless yet not less tenacious for that - on attributing the huge stone constructions of the Zimbabwe state and its other cultural achievements to immigrants from outside Africa, and 
on misidentifying the Swahili city-states as "Arab trading cities". The ideas of German ethnologist and Africanist Leo Frobenius (1873-1938) about the "Eritrean" and "Atlantic" archetypes of African civilisation are further examples of the race-based approach (although in his case, the underlying sentiments were fundamentally benevolent towards Africans).

However, racism has affected not only the research done by Europeans and Americans; the impact of racist ideas is evident on the work of African and African-American scholars as well. The so-called négritude movement of the French-speaking regions and the so-called Afrocentrism, which is widespread in the work of certain university departments in the USA can be mentioned in this regard. Both trends are characterised by the celebration of African traditions, the myth of African cultural unity, as well as a good dose of racism, which are often accompanied by absurd and completely baseless statements regarding African culture and history. (These are the scholarly circles in which, for example, ancient Egypt is treated as an integral part of Sub-Saharan Africa, which then makes its achievements Sub-Saharan African accomplishments.) These ideas result from an inescapable, sad historical fact: no matter how understandable the nostalgia for the motherland, i.e. Africa, in the American Black diaspora, the fact remains that due to the nature of the slave trade, there is not a single African-American person today who will be able to identify with certainty the place within Africa where his or her ancestors originated. For this reason, a kind of pan-African nostalgia blurs more precise historical details, hence the totally erroneous idea of pan-African cultural unity.

Accordingly, the influence of African civilisations on the American Black diaspora is utterly eclectic. As iconic features of 'African culture' one finds, for instance, the kente fabrics and clothes of the Ashanti people of Ghana, the woodcarvings and masks of the Congo Basin and other areas, an assortment of elements from various of African languages, the celebrations in Harlem and elsewhere of the Senegalese Muslim sect, mass conversion to Islam among American Blacks (e.g. the Nation of Islam), the lobbying for a variety of African political causes, as well as the invention and celebration of totally imaginary 'African' festivities (e.g. the entirely fictitious Kwanzaa, which is meant to replace Christmas). The diaspora preserved few original cultural traditions, which is a consequence of the slave trade: the slaves coming from different ethnicities and areas were deliberately intermingled, resulting in the inevitable loss of their languages and cultural traditions. Some religious traditions were preserved in the diaspora (e.g. the possession cults: in the Arab world Zar and Gnawa, in Brazil Macumba and Candomblé, and in the Caribbean Voodoo and Santería). certain African words were also preserved in some dialects, such as in the Gullah dialect spoken on the islands of South Carolina; Brazilian Portuguese preserved certain 
Yoruba words, and Haitian Creole a few Ewe words, etc. However, the most important locus of African cultural influences are obviously cuisine (e.g. Caribbean Black gastronomy, soul food and Creole cuisine, in the Southern US, etc.) and music, in which the African influence is indisputable in such musical genres as jazz, reggae and several Latin American musical styles, as well as in Moroccan Gnawa music.

Just as Africa influenced the Black diaspora of the American continent and the Arab world, the Black diaspora also influenced Africa. In this regard music may be mentioned again, with numerous musical styles - which often draw on African cultural roots - returning to Africa and achieving great popularity there; such as reggae or Congolese rumba (although rumba is played in other African lands as well), popular throughout Africa. An interesting if very limited influence is the presence of the Jamaican Rastafarian cult in certain African countries. The teachings of the cult emphasise the attraction of Africa (mainly Ethiopia) as the motherland, and the desire of returning there, a goal realised by certain members of the cult. Although for historical reasons the ancestors of Jamaican Blacks simply cannot have come from Ethiopia, in the town of Shashemene in South Ethiopia a small Rastafari community has been formed of Jamaicans who settled there. As noted above, for emotional and ideological reasons Africa tends to be perceived by the Black diaspora as a distinct, unified civilisation, regardless of all the evidence that contradicts this perception.

\subsubsection{Ethnic groups and languages}

Similar to all other continents, the population of Africa can be classified according to various criteria. Genetic, somatic, cultural and linguistic criteria may equally be used, and each of these will obviously result in different divisions. For example, in certain cases populations of completely identical origins and great genetic proximity may speak very different languages; peoples of similar culture often use completely different languages and have starkly different origins, and so on. In what follows, the aspect which perhaps allows for the most objective classification is adopted: linguistic divisions will serve as the fundamental criterion for identifying the main subdivisions of the ethnicities of Africa. It bears emphasis, however, that this is not the only possible classificatory scheme. It is also worth stressing that shared language by no means implies shared ancestry: thus for example, the Arabic-speaking populations of Sub-Saharan Africa (primarily in the Sudan and Chad) - with insignificant exceptions - are overwhelmingly not of Arab origin but descendants of Sub-Saharan African Blacks who adopted the Arabic language during the last few centuries (and to a small extent intermarried with a few Arab immigrants). The "Arab" population 
of the East African countries (Kenya, Tanzania) is also of largely African origin; moreover, these communities typically do not even use the Arabic language but do trace their pedigrees back to, fictitious Arab ancestors. The Ethiopian Christian Amhara people speak a Semitic language, however, in terms of their origin the Amhara people are not a purely Semitic population but evolved from the mingling of a numerous local African population and less sizeable communities of immigrants arriving from Arabia.

The issue of assimilation and mixing is extremely important for the history and ethnography of Africa, and therefore before discussing the linguistic classification, this question has to be addressed briefly. As in Europe, in Africa too the majority of the largest ethnic groups emerged through the assimilation of a multitude of smaller ethnic communities. In many cases the process of assimilation was that the dominant ethnic group of a vast, expansionary feudal empire assimilated masses of the peoples under its domination. However, the process often took place with no centralised state exerting its influence, indeed in some cases without any kind of state structure. For example, the Fulani (or Fulbe) people, widespread throughout West Africa, established a number of large Islamic theocratic states (among others in the territory of today's Nigeria and Mali), and in these states the members of other ethnic groups adopted the Fulani language and culture on a massive scale and became Fulani themselves in this way. (The process shows obvious parallels with the emergence of several European nations, suffice here to mention only the role of the French state in the evolution of the French nation and in the assimilation of populations speaking other languages.). The Swahili population of the East African coast, or the Hausa population of North Nigeria assimilated other peoples in a similar manner within the domain of smaller local states. On the other hand, the Oromo (or Galla) ethnic group of South Ethiopia assimilated a large number of smaller ethnicities without establishing a large-scale state, thus here the assimilation process was not linked to an organised political entity. It is worth mentioning that the peoples which emerged this way include some of the largest ethnic groups of Africa in terms of demographic figures (the Hausa is now the largest ethnic group of Sub-Saharan Africa, while the Oromo is the second-largest, and the Fulani is also among the most numerous African ethnicities). It is thus difficult to overstate the significance of linguistic assimilation; moreover, such processes continue to shape the ethnic map of Africa today.

That said, brief linguistic categorisations of the population of Sub-Saharan Africa will be given (Map 25). Practical considerations will be given priority in structuring the following categorisation, i.e. language families with fewer speakers can be disposed of more briefly and will therefore be discussed first, 
while the more complex groupings that encompass numerous languages and are present in most of the African continent will be discussed last.

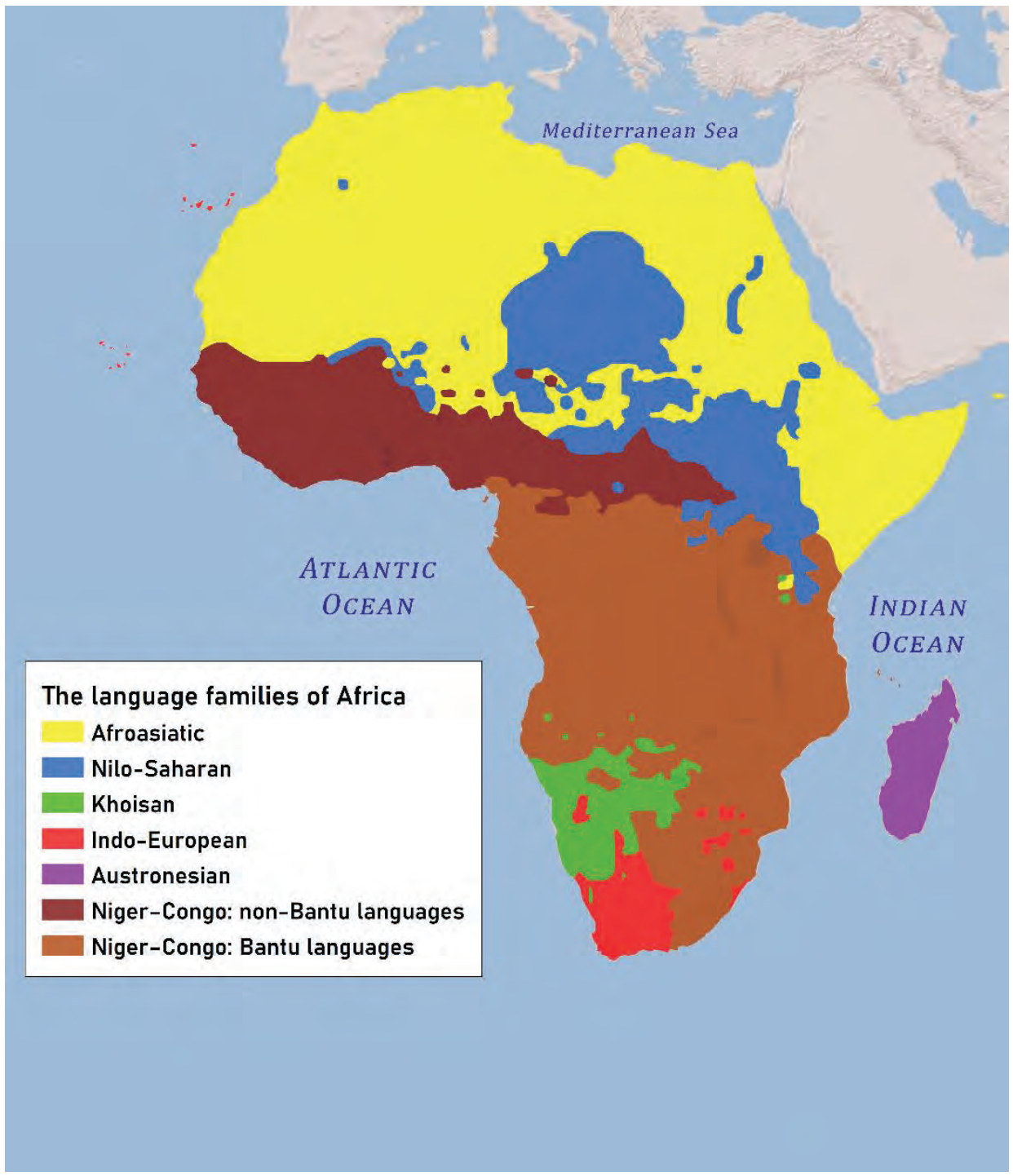

Map 25: Language families of Africa Source: Edited by ÁGNES VARGA

The Khoisan language family may be considered a curiosity rather than a crucial subject vis-à-vis the larger ethnolinguistic and civilisational landscape of Africa. The languages which belong to this language family are spoken by a few scattered hunter-gatherer communities living in the southern part of the continent 
(primarily in the territory of the Kalahari Desert of South Africa and Namibia), and for the history of the continent, these groups have had minimal significance. The two main branches of the language family are the Khoin and San languages. The Khoin-speaking nations used to be referred to as Hottentots - a name of uncertain origin - while the word Bushmen was previously used for the San peoples. The use of these names is no longer customary in the scholarly literature. The most prominent characteristic of the Khoisan languages is the use of various click-like sounds; the number of speakers of these languages is decreasing due to linguistic assimilation.

The languages of the Austronesian (former name: Malayo-Polynesian) language family, while absent from the African continent, are present on the island of Madagascar off the east coast of the continent. Most of the languages of this family are spoken in Southeast Asia and in the Pacific, and such languages were brought to Madagascar by immigrants arriving from that region. Later, the immigrants intermarried with other ethnicities arriving from the African continent, and therefore Austronesian languages are also used by populations of Black African origin there. The official language of Madagascar is Malagasy (or Malgache according to French spelling), which is a typical Austronesian language. The importance of this language family is infinitesimal with respect to other areas of Africa.

The Indo-European language family has to be mentioned too, although it is only from the twentieth century that these languages (primarily English, French and Portuguese) have been used in Africa to any appreciable extent. What accords these languages significance is in the fact that, although very few Africans use them as their native languages, most contemporary African states have preserved the official use of the language of the former colonial power. The reason usually cited to account for this is the linguistic heterogeneity of the African counties, since the latter makes it necessary to rely on a vehicular language. However, this rationalisation is unconvincing for two reasons. On the one hand, in most of the multi-ethnic, linguistically diverse African counties there is an African lingua franca as well which is understood by the majority of the people (e.g. Wolof in Senegal, Lingala in Congo, Dyula in Ivory Coast, Swahili in the East African countries, etc.). On the other hand, one must note that the language of the former colonial power has usually been preserved for official purposes even in those African countries that are practically monolingual: a good example is French as the official language of Rwanda, where everybody speaks the local Kinyarwanda language. Therefore, the multilingual situation seems rather like a mere pretext, while the real reason may be that the African political élites that emerged during the colonial period try to preserve their exclusive power and cultural monopoly, seeking to restrict social mobility through linguistic policy among other things. 
European languages have very few native speakers in Africa, although in some places unique local versions did appear (e.g. South Nigerian Pidgin English and Sierra Leonean Krio), and of course there is the Afrikaans language spoken by the white population of South Africa, virtually a variant of Dutch.

The name of the Afroasiatic (former name: Hamito-Semitic) language family speaks for itself: these languages are spoken partly in the African continent and partly in Asia; it is noteworthy that the vast majority of the speakers of Afroasiatic languages are Africans. The languages of this family may be classified into several branches; the branches that merit a mention here are the Semitic, Berber, Ancient Egyptian, Cushitic, Chadic and the so-called Omotic languages. We will not discuss the now extinct Ancient Egyptian language (which was not used in Sub-Saharan Africa anyway) and the Omotic languages, which are spoken by tiny ethnic groups in the southwestern part of Ethiopia, however, we will discuss each of the other four groups.

Many of the Semitic languages (for example, Hebrew, Aramaic, partially Arabic) are spoken by populations of non-African origin in the territory of Southwest Asia and in the Middle East. However, the majority of the Semiticspeaking populations of the world are African. Arabic is by far the most important Semitic language, being the official language of the northern zone of the African continent, and it is the mother language of countless people within Sub-Saharan Africa as well. Several million people who speak Arabic as their mother language live in the Sudan and Chad, the majority of this population originates from Africans who adopted the Arabic language. Another large bloc of the Semitic languages is also located within Sub-Saharan Africa, to be precise in the Ethiopian highlands, where the (mostly Christian) Amharic- and Tigrinyaspeaking population play a dominant role in politics. The official language of Ethiopia is Amharic. These modern Semitic languages are the descendants of the medieval $G e^{\prime} e z$ language, which has survived as a written language used in the Ethiopian Christian church to this day.

Although the Berber dialects are spoken mostly in North Africa and in the western part of the Sahara, groups which speak Berber as their native language (mainly the Tuareg people, the dialect of whom is known as Tamasheq) are also present in certain areas of West Africa (e.g. in Mali and Niger). As a result of slavery and frequent intermarriage, a significant part of the Berber-speaking populations of African are black. It should be noted that the Tuareg people developed their own writing system (the so-called Tifinagh script), although in circumstances of a nomadic lifestyle the use of this writing has always been limited. Today, the modern version of this script is taught in elementary schools in Morocco, to record the standardised Berber language. 
The Cushitic languages constitute one of the most important, most widely spoken language groups of Africa. The vast majority of the speakers of Cushitic languages are Muslim and live mostly to the south, east and northeast of the Ethiopian highlands. The largest Cushitic language is Oromo; however, Somali is spoken by almost as many people; there are far fewer speakers of Afar (or Danakil) and of the Sudanese Beja languages.

The Chadic languages - as suggested by the name - are spoken around Lake Chad, mainly in the territory of Nigeria, Chad and Cameroon. Although a multitude of Chadic languages exist, only one of these, namely Hausa, has special significance, being as it is second only to Swahili among the languages of Africa in terms of the number of speakers. Hausa is spoken as a native language mostly in the territory of Nigeria and Niger; however, it is used as a vehicular language in other areas of West Africa as well. The Hausa-speaking population is almost entirely Muslim.

The name of the Nilo-Saharan language family is also based on geographical criteria, and as suggested by the name these languages are spoken partly in the Sahara (more specifically in the southern and south-eastern extremities of the Sahara) and partly along the Nile. The speakers of the Nilotic languages live south of Egypt, primary in the Upper White Nile area, from where certain Nilotic-speaking (nomadic and pastoral) ethnicities migrated southwards to East Africa (to the territory of today's Kenya and Tanzania) in the last few centuries. The latter groups include the Kenyan Luo people and the Kenyan and Tanzanian Maasai people, while the South Sudanese Dinka and Nuer peoples are some of the more important Nilotic-speaking groups that have stayed along the Upper Nile. The most important language of the Saharan branch of this language family is Songhai, which is spoken in Mali and Niger, along the middle section of the Niger river. The languages of the Tibbu and the Zaghawa, spoken in Chad and in northern Sudan, are also among the more important languages of this group.

In geographic terms as well as, in all probability, in terms of the number of languages it encompasses, the Niger-Congo language family is the most widespread group of languages in Africa. The Niger is the largest river in West Africa, while the Congo is the largest river in the southern half of Africa, and these two geographical names roughly define the geographic expansion of the language family: the Niger-Congo languages are spoken in most of West Africa and in the southern half of the continent. A language family present over such a vast area is of course very diverse, which makes it necessary to identify subdivisions. Two main branches, and within those branches, subdivisions can be identified: the languages of West Africa form one of the two main branches, and 
the so-called Bantu languages, spoken in the southern part of Africa, form the other.

The languages of West Africa may be classified into a number of distinct groupings. The following are some of the most important divisions: the West Atlantic languages of the region extending along the ocean's coast from Senegal to Liberia (among these languages Wolof, the quasi-official language of Senegal, and Fulfulde, the language of the Fulani people widespread throughout West Africa have the greatest importance); the Mande languages in the territory of Mali, the Ivory Coast, the Gambia and Guinea (e.g. Banmana, Dyula and Mandinka); the Voltaic languages (mainly in the territory of Mali, Burkina Faso and Ghana); and the so-called Kwa languages along the coast of the Gulf of Guinea (e.g. Akan in southern Ghana and Yoruba and Igbo in southern Nigeria).

The entire southern half of Africa is the home of the Bantu languages, a group of languages with subdivisions of its own. The word Bantu means "people", and most of these languages tend to express this concept with some form of this word (e.g. in Swahili "people": watu). Among the Bantu languages Swahili, which was originally used by the population of the east coast of Africa as their native language, is by far the most important. The very name Swahili (more precisely Kiswahili) points to its geographical origins, since the word is derived from the Arabic term sawāhil ("coastal areas"). A strong Arabian cultural influence is attested by not only the Islamic religious identity of the Swahili but also by the not insignificant part of the Swahili vocabulary that is made up of loanwords of Arabic origin (it bears emphasis, however, that the greater part of the vocabulary and the entire grammar are purely Bantu). In addition to native speakers, Swahili is commonly used as a language of interethnic communication in all countries of East Africa, which has now turned it into the African language with the greatest numbers of speakers. Other important Bantu languages (also used for interethnic communication on a regional level) include Lingala and Kikongo in the Congo Basin, Zulu and Xhosa in South Africa, Kikuyu in Kenya and Luganda in Uganda.

\subsubsection{Literacy and oral tradition}

It is a frequently heard claim that literacy did not exist, or at least played a negligible role, in precolonial African civilisations. Although the claim is definitely wrong, it could hardly be disputed that writing was indeed unknown in many precolonial African cultures, and where it did exist it played a much more restricted role than in, say, Europe, the Middle East or the Far East. It is also important to note that the knowledge and practice of writing - wherever there was a written tradition at all - was typically the privilege of a small, specialised group 
of experts, and writing was never used for trite, everyday purposes. Thus, some African societies in fact did not use writing, while some other societies did use writing but only with certain limitations. The specialist literature uses the term "restricted literacy" for the latter situation. Restricted literacy characterised many African civilisations before the colonial era.

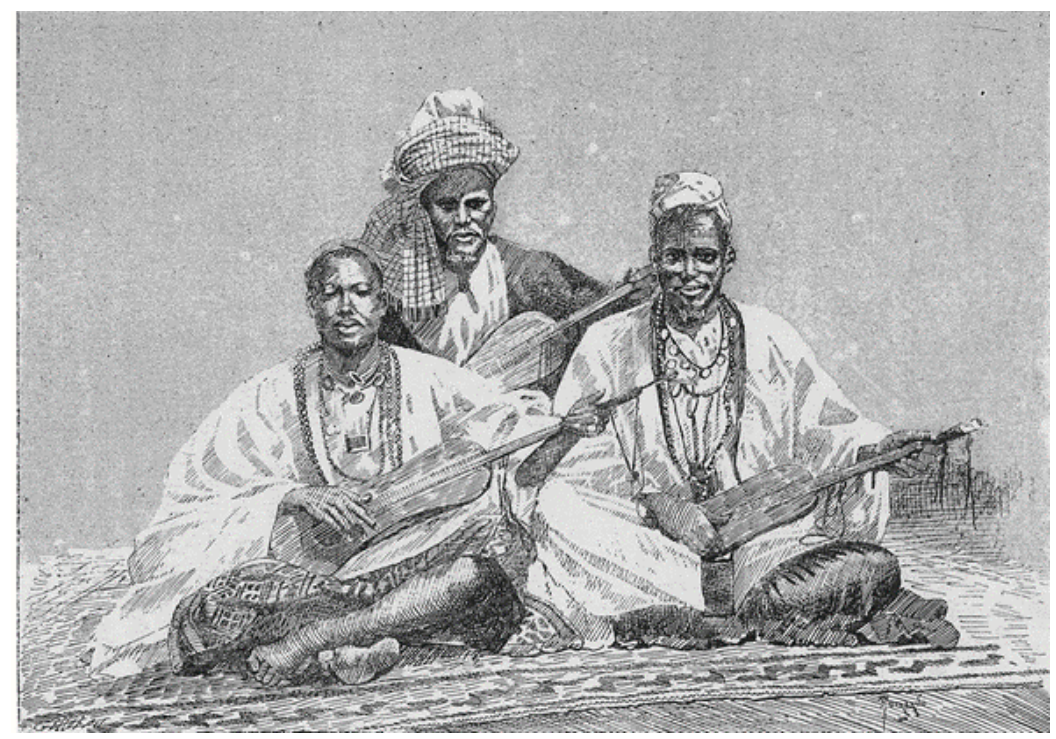

Figure 68: Mistrels (griot) from King Sambala's court (Medina, Mali)

Source: Henri-Nicolas Frey, Côte occidentale d'Afrique: vues, scènes, croquis, C. Marpon \& E. Flammarion, Paris, 1890, p. 128.

As a result, oral traditions played a crucial role in the preservation of historical memory in most of Africa. So much so that in several African societies it was the task of a separate specialised social stratum - in many cases virtually an endogamous, closed caste - to memorise oral traditions, pass them on and perform them on designated occasions. An example of such groups is the socalled griot caste that existed in much of the savannah zone of West Africa, members of which were responsible for maintaining historical memory in the service of rulers or nobles as a full-time occupation: they memorised, preserved and transmitted historic traditions, legends of origin, dynastic and aristocratic genealogies. Such traditions were often performed to musical accompaniment, therefore members of the griot caste had to excel as musicians or singerstorytellers as well. Some of the historical traditions were rather long and detailed, so much so that they can be considered as veritable epics (Figure 68). The most well-known and most influential epic of this kind is probably that immortalising the founder of the Mali Empire, the first member of the ruling 
dynasty, Sundyata Keita, a historical figure. This text is preserved to this day in numerous versions and is still performed regularly, among others on radios and televisions of the region.

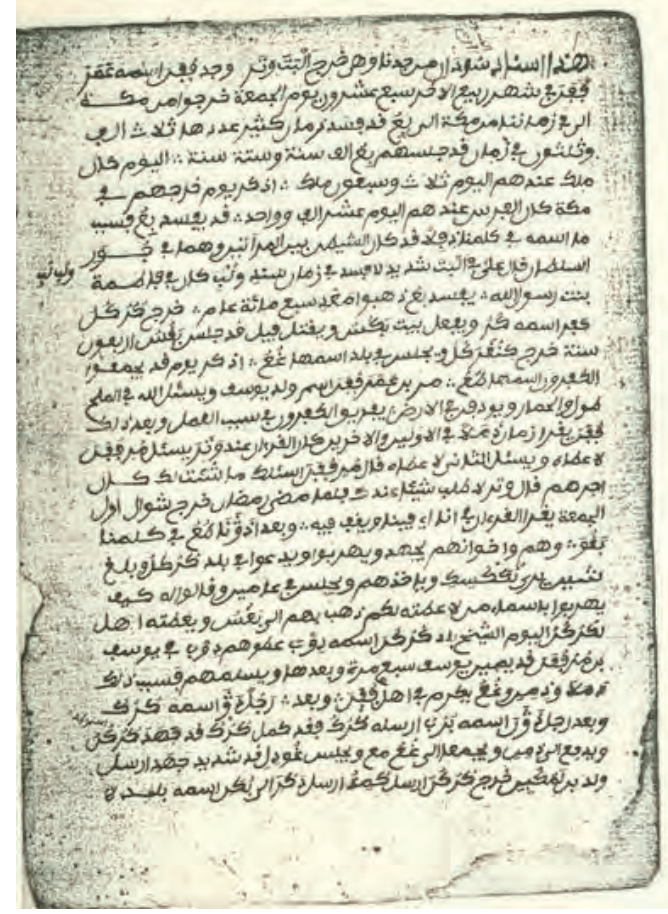

Figure 69: First page of a nineteenth-century family chronicle from Northern Ghana Source: Photograph courtesy of MUHAMMAD HAFIZ

Past works of African literacy which are extant are primarily historical works (the chronicles of states, dynasties, ethnic groups or families), administrative documents (tax documentation, documents recording estate boundaries, etc.), and works on religious topics (Bible translations, Quran copies and Quran commentaries, the hagiographies of Christian or Muslim saints, Islamic juridical works). A smaller number of literary works also survived in written form (for example, the poems of the eighteenth-century Swahili poet Muyaka bin Mwinyi Haji al-Ghassani). Written chronicles are valuable sources of African history, and wherever such chronicles exist and have survived they allow us to know much more about the historical past than in contexts in which such sources are not available (Figure 69). Exceptionally rich sources of historical information are, for instance, two local chronicles in Arabic of the medieval West African empires (see below), Mahmud Kati's work titled Tarikh al-fattash (late sixteenth century) and Abd al-Rahman al-Sa'di's work titled Tarikh al-Sudan (seventeenth century). A 
relatively great number of extant written sources are available on the history of Ethiopia, and there are numerous historical works in verse and in prose (utenzi and habari) on the East African coast as well, among others the chronicles of the medieval Kilwa (Tanzania) and Pate (Kenya) sultanates.

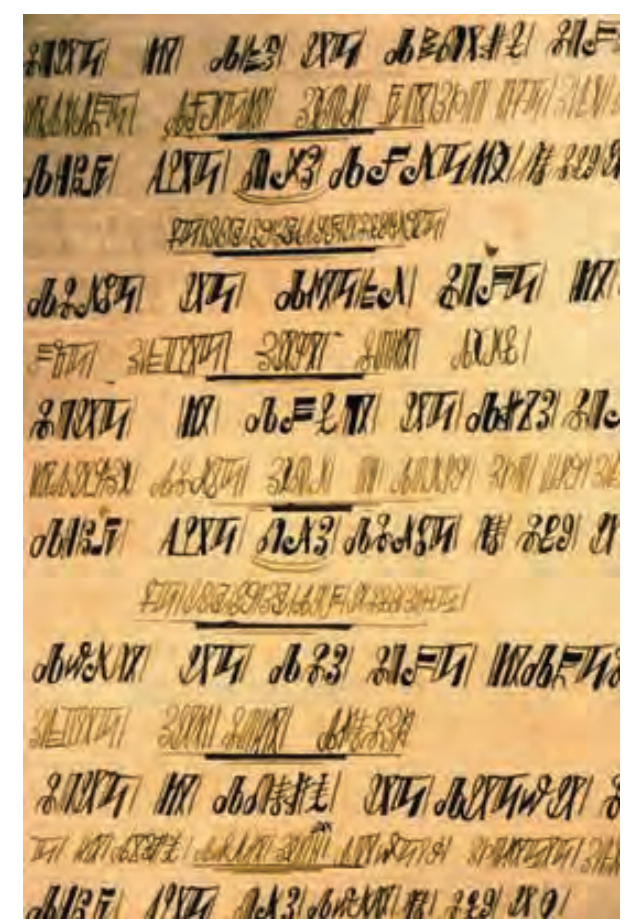

Figure 70: Book written in the script of the Bamum people of Cameroon, c. 1910 Source: Patrick Landmann/Science Photo Library

African writing can be classified into three different types, namely: 1 . the use of foreign writing systems by Africans for recording foreign languages; 2 . the adaptation of foreign scripts for recording African languages; 3 . the use of locally-developed scripts for recording African languages. This order of listing also shows the prevalence of the three types of writing: the most widespread practice was for Africans to utilise foreign languages (especially Arabic or certain European languages) for their own purposes, using the script of that foreign language. The least common practice was for Africans to develop their own writing systems in order to record their own languages. The third type (i.e. various African languages being recorded in foreign - Arabic or Latin - a characters) was not rare in certain regions, but it was far from general. In Muslim societies this type of literacy (African languages written in Arabic script) was usually called Ajami (a term of Arabic origin; meaning "non-Arabic"), and starting from the late 
Middle Ages, quite a lot of works were composed in this system in languages of Muslim African ethnic groups: in Hausa, Fulfulde, Wolof, Yoruba, Swahili, Oromo, etc. The use of Latin script for recording African languages became typical in a much later period, and initially it was linked to missionary activities and Bible translations, however, over time literacy in the Latin-script lost its religious connotations and now - for practical reasons - even most of the Muslim African peoples (including the ones mentioned above) write their languages using Latin characters. The majority of the writing systems developed locally for African languages have always been used by a select few and rarely. However, there were and are quite a number of such writing systems: e.g. the Yasini writing which was developed in the Middle Ages in what is today Mali and Mauritania, the writing system called $N^{\prime} k o$ of the Banmana people living in Mali, and the scripts of the Cameroonian Bamum people (Figure 70) and the Vai people of Liberia.

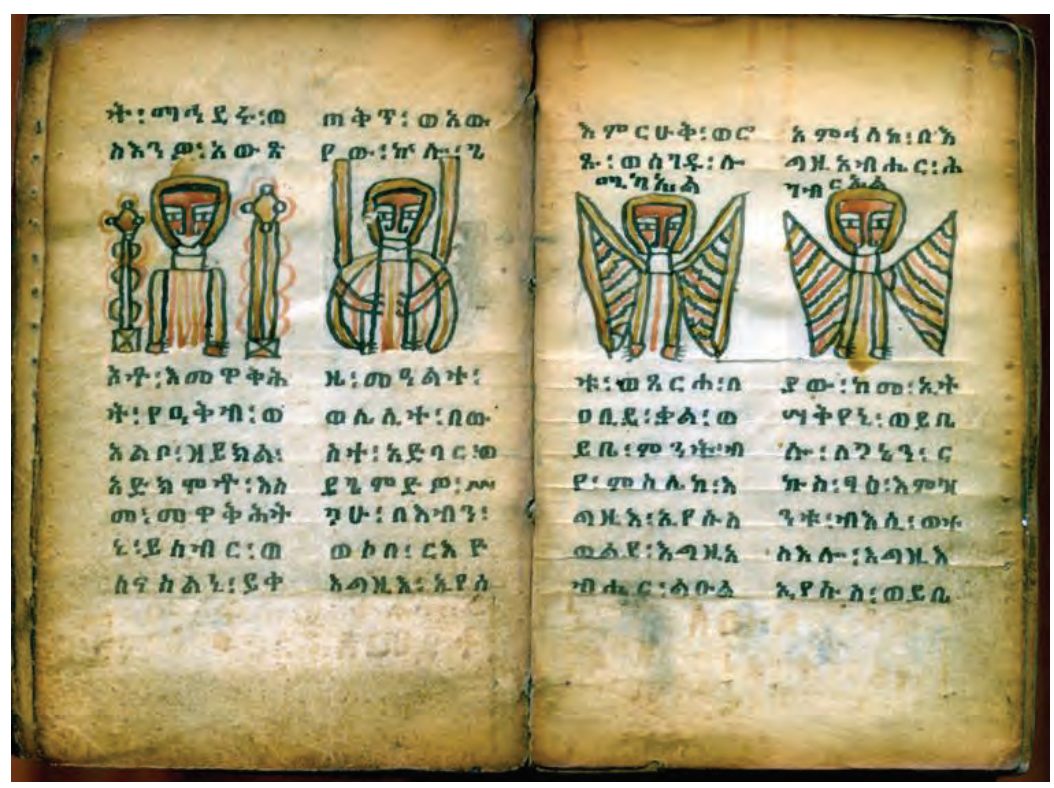

Figure 71: Ethiopian manuscript including gospel extracts and prayers in Ge'ez language. Archangels Michael and Gabriel on the right

Source: The Oriental Collection of the Library of the Hungarian Academy of Sciences, Ms Etióp 4.

There is only one African writing system which has been used since Antiquity to this day and in which a substantial quantity of texts have been composed (including nowadays newspapers, books, Internet sites, etc.): the script of the Ge'ez language, which was and is used to record much of the Ethiopian Christian religious and literary tradition (also in the Amhara and the Tigrinya 
languages) (Figure 71). Some African languages have used more than one script over time. Thus, for example, the Cameroonian Bamum people (who are mostly Muslim) have on different occasions recorded their language in Arabic script (Ajami), Latin script, and at the beginning of the twentieth century their sultan named Njoya even developed their own special writing system.

\subsubsection{Social structure}

It is difficult to discuss the political structures of African societies in generalised terms, and even more difficult to make statements valid for the whole continent. Social structures are an aspect in which the continent shows remarkable variety that allows for only very limited generalisation. One fundamental distinction is nevertheless possible to make and it is all-important: while the majority of the African population have for centuries lived in feudal kingdoms, the social organisation of other ethnic groups remained on the level of tribal organisation (e.g. the nomadic pastoralist peoples of East and Northeast Africa, such as the Cushitic-speaking Somali and Afar, and the Nilotic-speaking Maasai, Dinka and Nuer). Some African societies were more or less egalitarian, with but little socioeconomic differentiation, while other societies (e.g. the empires of West Africa) were characterised by marked class differences, and even had certain caste-like social strata. In the latter type of society, four fundamental strata tend to have been present: a nobility or military aristocracy centred on the rulers' courts, the commoners who were mostly subsistence farmers, craftsmen and other specialised castes (including where applicable the group of the literate élite and griots), and lastly the slaves. It was also typical in most of the continent that the first inhabitants of a state, a region or a settlement - the early settlers or founders of a community - enjoyed special rights, and the populations who settled there later would be symbolically considered as their "guests", while the first settlers would be regarded as the "hosts" of all later newcomers. This conception proved especially useful for long-distance trade, since a group of foreign traders who arrived in a region would thereby gain an advantageous symbolic status as "guests" of the original local population, and therefore could more easily establish amicable relationships, which facilitated successful trading activity.

Most Sub-Saharan African societies attributed special social significance to biological age. This would often result in political leadership being explicitly based on age, with supreme power over the community being the preserve of its oldest members. This social organisation is called gerontocracy ("rule of the elders"), and this term does describe the nature of political power in many traditional African societies. Moreover, some ethnic groups in fact organised all members of their society into age sets, i.e. institutionalised generational cohorts, and 
the social obligations and rights of every person were based on membership in a particular age set. This organisation has been especially characteristic of the pastoralist peoples of East and Northeast Africa speaking Cushitic and Nilotic languages. For instances, among the Oromo people a new age set came into being every eight to nine years. Members of the same age set showed special solidarity towards each other, played the same the social roles required of their age cohort, and would eventually live to fill collectively the leadership roles monopolised by the elders' set (unless, to be sure, they died before reaching that age ). The social significance of age also manifests itself in that most African peoples practised some form of the community ritual of initiation, by which the initiates would ritually - and often only after prolonged teaching and preparation - leave the status of children and acquire a new social status as adults. Initiation rituals were customary for both sexes, being strictly separate and different for each sex.

Although in the most advanced civilisations of Africa - and especially in the larger empires - the majority of the population was engaged in agriculture, a significant portion was composed of groups which pursued some kind of specialised activity. As mentioned above, caste-like groups of artisans and other professionals included people charged with the task of preserving and transmitting historical traditions. In like manner a distinct social group, or in some cases even a distinct ethnic group, would monopolise the positions requiring literacy (such as the Muslim literate élite of some parts of the West African savannah region, the so-called Jakhanke people). The castes or ethnic groups that often virtually monopolised long-distance trade had particular importance. Such specialised mercantile communities operated trading networks which often spread over vast territories; perhaps the best-known example being the trading network of the West African Wangara or Dyula ethnicity that operated from the coast of the Gulf of Guinea up to the south edge of the Sahara. This network carried Saharan salt and North African luxury items to the south, and kola nuts, fabrics, ivory and mainly gold in the opposite direction.

Gold was one of the main export items of precolonial Africa, and it was a sought-after item of trade within Sub-Saharan Africa as well. Goldmines operated in many places, but above all in the territory of today's Guinea and Ghana, Zimbabwe and Mozambique. The medieval and early modern West African empires (e.g. the Mali and Songhai Empires, and later on the Ashanti Kingdom) owed their prosperity above all to the export of gold, and the same is true of such states of East Africa as Monomotapa, which flourished in what is today Zimbabwe. Gold of African origin was exported to Europe in such quantities that according to certain etymological speculations the English word "guinea" is derived from the toponym "Guinea". In the course of his celebrated pilgrimage to Mecca the Mali emperor Mansa Musa Keita (1312-1337) passed through Cairo with his 
entourage, and he brought along such large quantities of the precious metal that the value of gold was inflated for several years' time.

In addition to gold, Africa had another export item from which traders could gain enormous profits: slaves. The slave trade and slavery have always been present in the societies of Africa - at least in stratified societies - but such activities were of relatively minor dimensions and certainly did not have a fundamental, defining impact upon the affected societies. This situation changed in the early modern age due to two factors: on the one hand, the Arab states of the Middle East were no longer able to import large quantities of slaves from Europe and Central Asia and therefore turned their attention to Sub-Saharan Africa; and an even more significant and tragic development was the increasing need of the plantation agriculture of the New World for labour, which would create a demand for tens of millions of African slaves. The latter factor - the Atlantic slave trade - in particular had consequences nothing short of catastrophic: it would destroy traditional social structures, create conditions of widespread insecurity and fuel continuous wars. The middlemen of this wretched trade made fortunes from raiding for and selling slaves, which established parasitic economies and caused immeasurable suffering to neighbouring societies. Such parasitic middlemen communities emerged on both the West African and the East African coasts; the former were mostly Christian, while the latter were Muslim Africans. (A typical example of the wealthy slave trader was the late nineteenth'century trader of Congolese origin, Hamad bin Muhammad bin Juma bin Rajab el Murjebi - better known under the nickname Tippu Tip the autobiography of whom is incidentally one of the classics old Swahili literature.) It is difficult even to estimate the exact number of Africans carried over the Atlantic Ocean, but they were many millions or even tens of millions, and further millions lost their lives during the voyage or due to warfare in their homelands. There is simply no more tragic episode in the history of Africa than the era of the slave trade.

\subsubsection{Religion}

Traditional African religious practice is so varied that very few universally applicable observations can be made. The majority of African local religions were explicitly specific to one single ethnicity, and thus can be described as ethnic religion. For example, the supreme god of the shepherding Maasai people, Ngai - similarly to the God of the Old Testament - was concerned about the welfare of this particular ethnic group only (thus He deemed it a heinous sin against the universal order of things that peoples other than the Maasai should possess cattle). Even the question of whether traditional African religions can be considered as 
monotheisms or rather as polytheisms cannot be answered unequivocally. Most African religions had one creator god responsible for the creation of the entire world, including all other deities or spirits. Such religious systems could indeed be termed monotheisms, provided that other deities are thought to be beings of lesser status vis-à-vis the creator god. Some African religions - for example, the cult of Waaq, the sky god of Cushitic-speaking peoples - display this tendency, and therefore there is good reason to consider them monotheisms. However, other African ethnic religions regarded creation as the only important act of the supreme deity, who would thereupon cease to interfere with the affairs of this world (in religious studies, creator gods playing such a limited role are referred to by the Latin term deus otiosus); therefore the focus of religious worship are the other, lesser deities whom he created and who manage the matters of the world, and who therefore must be placated. In this sense traditional African religions show the characteristics of polytheism. However, it should be noted that such definitions also depend on whether these beings are regarded as "deities" or as "spirits" by followers of the cult, since the latter interpretation is consistent with the monotheistic teachings (and therefore with Islam and Christianity as well). This allows for example the Yoruba Muslims and Christians to preserve the cult of the so-called orishas, now considering these beings as spirits rather than deities.

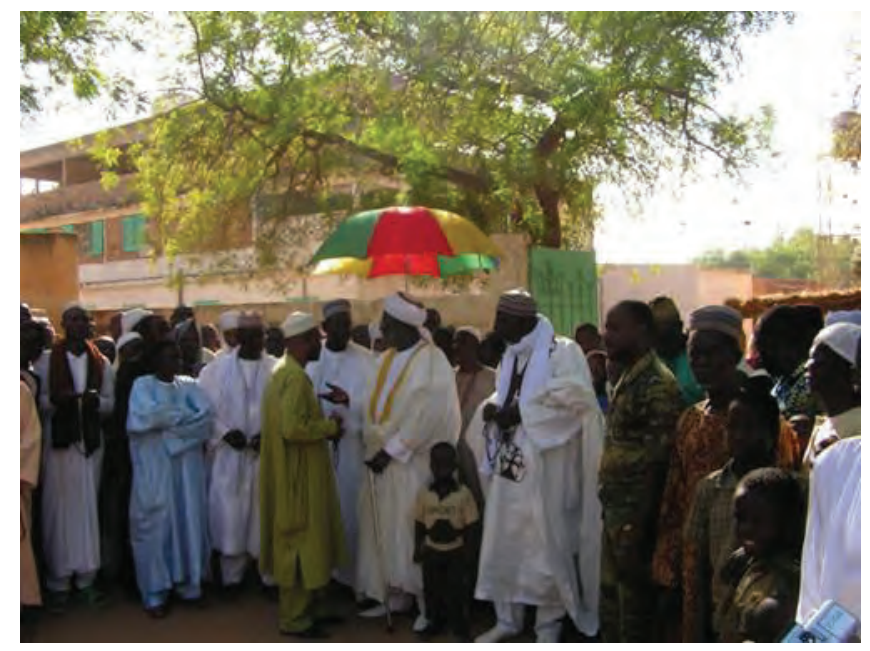

Figure 72: Local commanders of the Tijaniyyah Sufi Order in Kiota, southwest Niger Source: Photograph by ZOLTÁN SZOMBATHY 
The belief in various incorporeal, invisible beings which however interact with the people was - and still is - generally characteristic of Africa. This conception, according to which animals, plants and even inanimate objects have souls and therefore a volition of their own, is called animism. Many types of spirits (or deities) appear in African religions, and every type is the object of unique rituals. Thus certain spirits are linked to places (local spirits), others protect certain persons or communities (protective spirits), while others may invade the bodies of people (possessive spirits), Belief in the spirits of the deceased ancestors and their worship is probably more important and widespread than the cults of any other type of spirit.

The cult of ancestors may take numerous forms - one common type of ritual is the offering of food, drink or sacrificial animals at shrines designated specifically for this purpose - and an especially important type of such rituals is the phenomenon of masking cults. The use of masks in religious rituals is common in a considerable part of Africa, while it is unknown in the cultures of numerous African peoples (for example, the peoples speaking Cushitic and Nilotic languages have never used masks). Wonderful as works of art and therefore treasured possessions of many Western museums, it is important to emphasise that masks are definitely not art for art's sake in the African perception but objects which play an important cultic role. The main function of masks is to personify a spirit (or deity) and hide the person wearing the mask, and therefore the costume (made of fabric or vegetable fibres) attached to the mask and covering the entire body is always an integral part of an African mask. A famous and to this day common example of masked rituals is the cult of the Egungun spirits of the Yoruba people in Nigeria and Benin. The Egungun masks embody the spirits of the ancestors, which appear regularly so as to exhort their descendants to observe proper behaviour and respect the traditions. They address people during the rituals in a strange, high-pitched voice similar to a frog's croaking. The masked rituals live on in Christian and Muslim environments as well (the majority of the Yoruba people are either Protestant Christians or Muslims); thus the do masks of the Dyula people of the Ivory Coast and Mali, who have been Muslim for centuries, are primarily used on occasion of the two main Muslim holidays. However, over the last 100 to 200 years African religious life has undergone enormous changes: the vast majority (today more than 90 percent) of Sub-Saharan Africans have become the followers of the two great world religions, Christianity and Islam. This has not resulted in the complete disappearance of traditional religions: many elements of the older cults - for example the cults of spirits, masked rituals, etc. - have been integrated into the religious lives of Muslim and Christian believers, giving rise to heavy religious syncretism (the mixing of religious elements from different traditions). Both 
African Islam and African Christianity are characterised by a great deal of syncretistic features, although this phenomenon is the object of vehement criticism in both religious traditions.

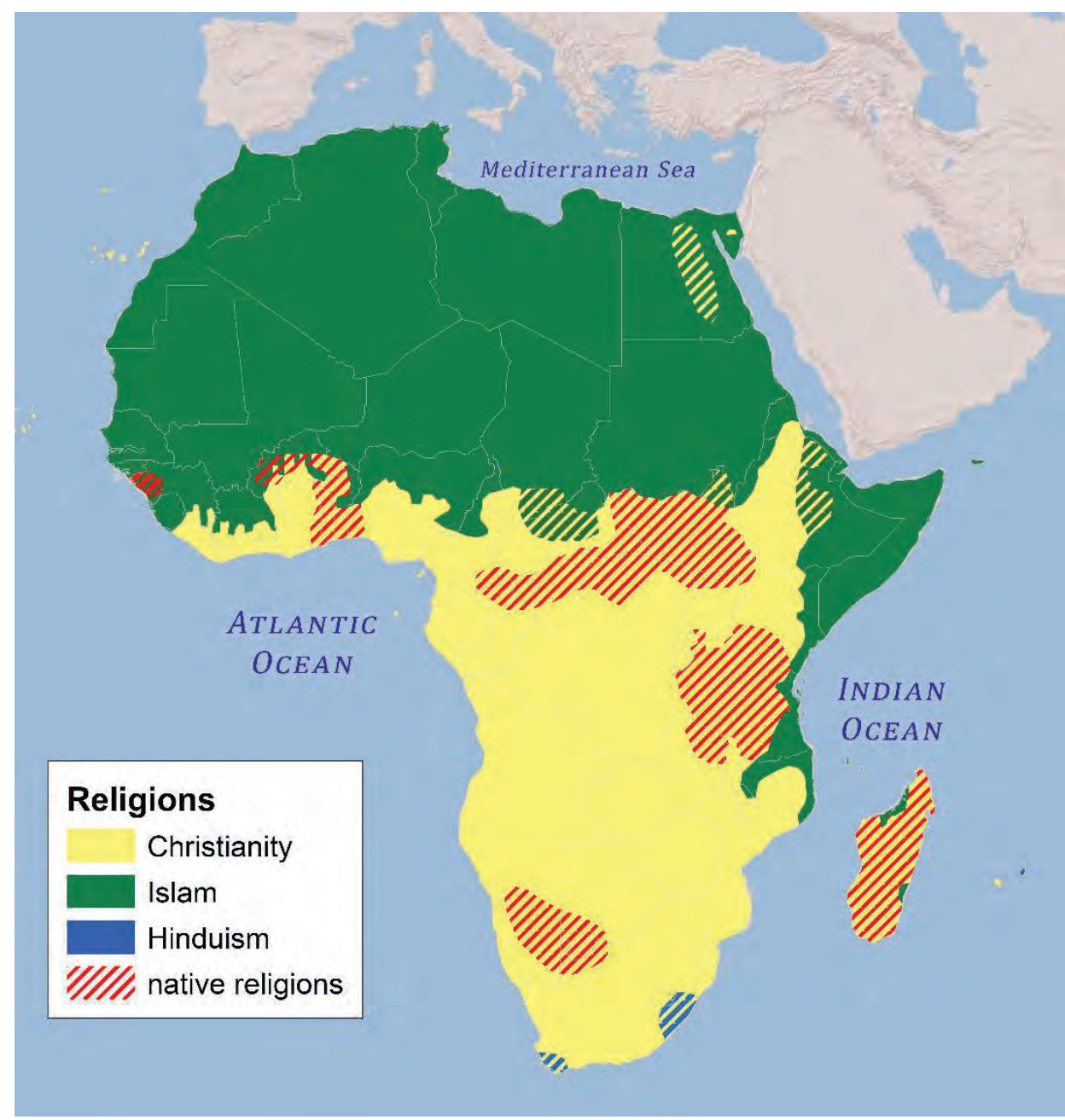

Map 26: Religions of Africa

Source: Edited by ÁGNES VARGA

The mystical tradition of Islam - Sufism - is extremely prevalent among African Muslims, and some Sufi orders show markedly syncretic characteristics (such as the Senegalese Mouride Sufi order, and even more its sub-group called Baye Fall) (Figure 72). There are also countless small churches within African Christianity, with indigenous churches often unashamedly mixing elements of African 
religious practices with Christian teachings. Well-known examples of this include the southern Nigerian Aladura ("praying") churches and the sect of the Congolese religious leader Simon Kimbangu.

Both Christianity and Islam appeared in Sub-Saharan Africa in a quite early period: Christianity was dominant in the Ethiopian highlands (and for some time in Nubia as well) during the Early Middle Ages (since the fourth century), and as is proudly stressed by African Muslims, the first Muslim community outside Mecca was formed in Ethiopia, in a settlement named Negash (this is the so-called "first emigration", or al-hijra al-ula in Arabic). In the Middle Ages Islam spread over the greater part of West Africa, in Northeast Africa and on the East African coast, however, with the exception of the latter region Islam continued to be the religion of a (substantial) minority until colonial period. The colonial period, and especially the first half of the twentieth century, was a turning point in the process of conversion, with a significant part of Sub-Saharan Africa becoming almost entirely Muslim in this period, while other parts became largely Christian. Today, half of Sub-Saharan Africans (mostly in the southern half of the continent) are Christians, and more than a third of Sub-Saharan Africans are Muslims (Map 26).

An unsettling development of recent decades throughout Africa is the increasing influence of modern religious fundamentalism (and the accompanying religious intolerance) both in Christianity and in Islam. In the Christian regions of Africa the main agents of this trend are the US-inspired Pentecostal and Evangelical churches, while in Muslim lands the they are mainly the Salafi and Wahhabi movements that often reflect the influence of Saudi Arabia as well as the extremists of such groups who propagate jihad (holy war).

\subsubsection{History, African states}

As noted above, stateless ethnic groups did exist on the African continent, but the majority of Africans lived as subjects of various kingdoms from the Middle Ages onwards. These kingdoms show considerable variety; yet the absolute power of the ruler and the existence of a feudal elite supporting it are almost universally characteristic of them. Absolute power was usually expressed symbolically through the use of magnificent regalia (thrones, parasols, palanquines, horns, ceremonial garments) and often by the custom of the king having to address his subjects only through an "interpreter." In some societies royal absolutism evolved into the institution of divine kingship. The economic basis of the feudal states was provided by the peasantry, who constituted the majority of the population, as well as by taxes and duties from the quite profitable long-distance trade. The military basis was provided by cavalry troops in the 
states of the savannah region, and by archers and (later) infantry in the kingdoms of the jungle zone, in which African trypanosomiasis precluded the use of horses. After the appearance of Europeans in the sixteenth century, firearms spread rapidly throughout Africa, and over the next centuries the armies of a significant number of feudal kingdoms (e.g. the Ashanti Empire in Ghana from the eighteenth century) relied on firearms.

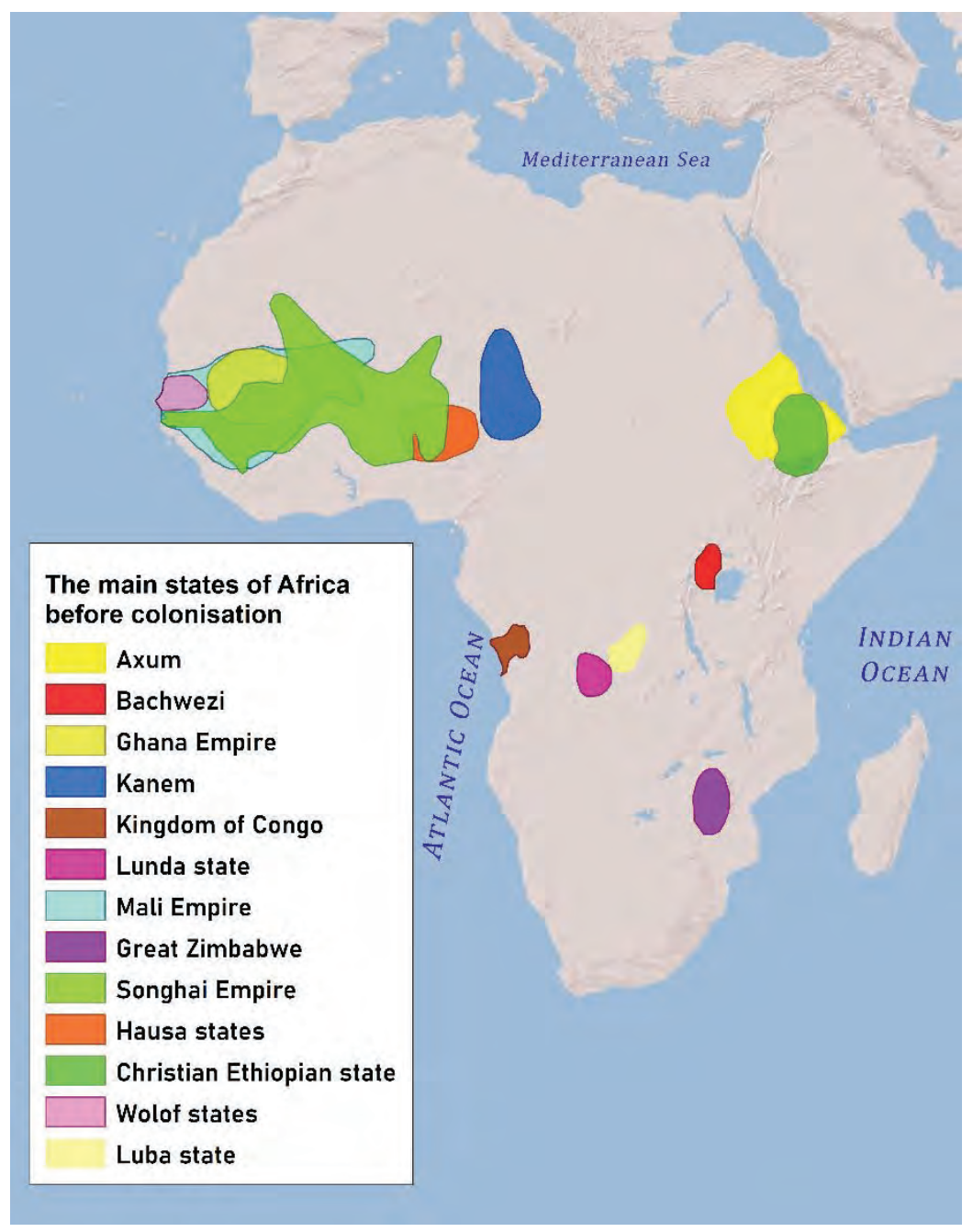

Map 27: Major pre-colonial states in Africa Source: Edited by ÁGNES VARGA 
In precolonial Africa, the majority of the most advanced kingdoms were concentrated in three regions (Map 27): 1. Northeast Africa (the highlands of Ethiopia and the regions along the Nile in the Sudan); 2. West Africa; 3. the Bantu-speaking regions (including multiple concentrations of states such as the Congo Basin; the area of today's Zimbabwe and the coast of East Africa).

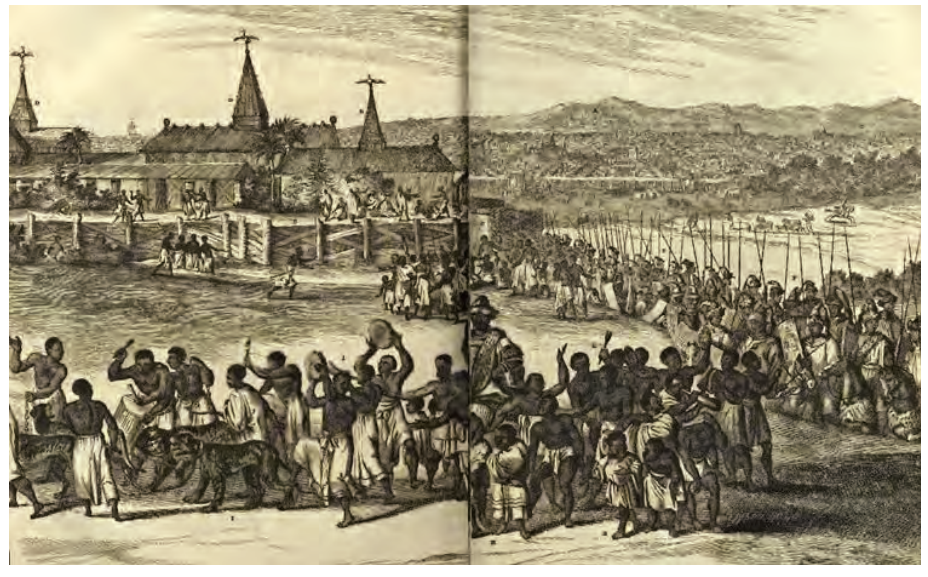

Figure 73: Dutch image of the city of Benin (today in Nigeria), 1668. Source: Olfert Dapper, Naukeurige Beschrijving der Afrikaensche gewesten. Amsterdam: Jacob van Meurs, 1678 (original edition 1668), 678-679.

The earliest Sub-Saharan African states emerged in Northeast Africa as early as in Antiquity. By far the most ancient Sub-Saharan African statehood emerged in Nubia, which was under heavy Egyptian influence. The black pharaohs of the Twenty-fifth Dynasty conquered Egypt from Nubia in the mideighth century BCE, and the Nubian states of Meroe and Napata reflect this tradition. Later too Nubia was heavily influenced by Egypt, an impact reflected in the adoption of Monophysite Christianity in the Early Middle Ages and in the emergence of Muslim states in Nubia from the Late Middle Ages. The Ethiopian highlands also saw the development of sophisticated states from Antiquity, , reflecting the powerful influence of Christian Egypt -up to the twentieth century the head of the Monophysite church was the Patriarch of Alexandria - as well as of Christian (and to a smaller extent Israelite) immigrants arriving from Yemen in the south of the Arabian Peninsula. The Ethiopian state has been Christian since Antiquity, and it was able to expand its dominion over the Muslim and animistic populations of the peripheral regions only in the last centuries. In West Africa, the first states and then empires emerged much later than in than in the northeast, but when they did there came a succession of large empires in the savannah zone. The first of the three greatest West African empires, Ghana (neither a predecessor of today's state of the same name nor even situated in the 
same area), was founded by non-Muslims but it converted to Islam before its demise. However, the other empires of the savannah region were ruled by Muslim dynasties.

Ghana was followed by the Mali Empire, which reached the apogee of its power in the fourteenth century. Then came the turn of the Songhai Empire in what is today Mali and Niger in the fifteenth to sixteenth century. East of these empires other (smaller) Muslim states flourished, for instance Bornu around Lake Chad, and the states of the Hausa people in today's North Nigeria. From the early eighteenth century until the appearance of the colonisers the history of the West African states was determined by the Muslim jihad movements which intended to "purify" Islam, and by the resulting theocratic states ruled by the Fulani people. In the southernmost belt of West Africa, on the coast of the Gulf of Guinea, a series of feudal states emerged, in which the role of Islam was far less significant, indeed quite insignificant in some cases. Such states included the kingdoms of the Yoruba people (especially Benin in what is now Nigeria - not in the modern state of the same name) and the Ashanti Empire in Ghana (Figure 73). In the southern part of Africa, numerous important kingdoms emerged in the Bantu-speaking areas: in the Congo Basin (for example, the kingdom of the Kuba people, and the Kingdom of Congo, which was under heavy Portuguese influence from the sixteenth century), in the territory of today's Zimbabwe and the neighbouring countries (for example, the late medieval Monomotapa Empire along the Zambezi River, which became rich from the export of gold), as well as the Muslim Swahili city-states along the entire East African coastline.

\subsubsection{Arts}

A lot of African societies produced large quantities of exquisite and beautiful fabrics. The types of African textiles are too varied even for a brief overview, thus a few well-known examples will suffice: the patterned adinkra and kente fabrics of the Ashanti people in Ghana, the wonderful embroidered cloth woven from the fibres of the raffia palm in the Congo Basin - which is often referred to as Congolese velvet - and the cotton fabrics produced in the city of Kano in North Nigeria and dyed with indigo.

Sculpture may well be the best-known and most iconic African art form. The very best of African sculpture is characterised by the to the tendency of abstract depictions, a feature surprisingly dominant in the sculpture all over the continent. Not that African artists were unable to create quite realistic images: for example, some of the bronze sculptures of Benin City and the Congolese wooden sculptures are astonishingly lifelike portraits. The abstraction of physical forms into geometric shapes, the almost caricature-like highlighting of certain 
accentuated formal characteristics are a conscious, deliberate method, which touched a chord with a lot of European graphic artists at the beginning of the twentieth century so much that Cubism was explicitly inspired by the approach of African art.

The most important genre of African graphic arts may be the exquisite woodcarving of the continent. In addition to various sculptures often serving cultic purposes, many African ethnic groups produced masks, whose religious role has already been commented upon. Some peoples of the Congo Basin and the East African Makonde people are particularly famous for their woodcarving. For example, in the kingdom of the Congolese Kuba people, an "official" portrait sculpture (ndop), carved from wood, was made of every ruler. Although the ndop sculptures are highly stylised portraits, they always include a symbolic object (iboi) which helps identify the king by alluding to an object associated with him: for example, Shamba Bolongongo, 93rd king of Kuba in the late sixteenth century, was fond of a characteristic African board game, and therefore his portrait statue (now in the British Museum) incorporates such a board.

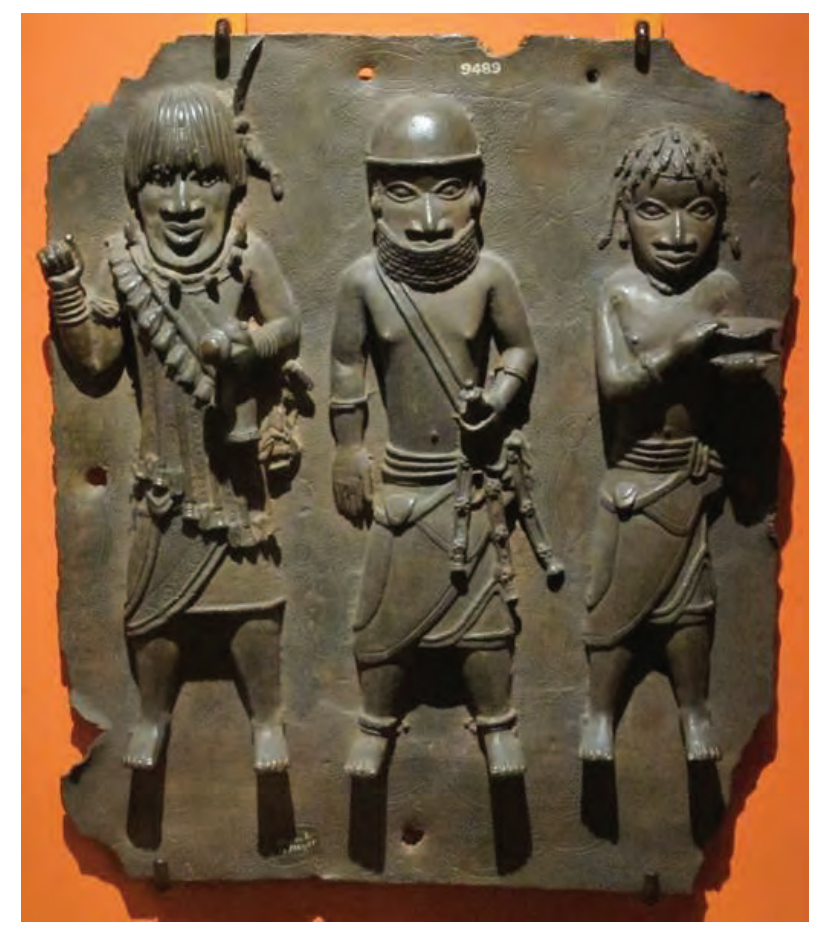

Figure 74: Three warriors, c. sixteenth-century Yoruba bronze plaque from Benin Source: Photograph by Saiko, https://en.wikipedia.org/wiki/Benin_Bronzes\#/ media/File:Benin,_placca_con_tre_guerrieri,_XVI-XVII_sec.JPG 
Apart from wood, some African peoples also used metal as the raw material of sculpture. For centuries the most important Yoruba states - above all Ife and Benin - produced a great variety of beautiful bronze sculptures using the so-called cire-perdue (lost-wax) technique; these sculptures show an astonishingly high level of artistry (Figure 74).

The subject-matter of these sculptures is quite varied. However, most of them are lifelike portraits (for example, one famous piece depicts a sixteenthcentury Portuguese musketeer) and animal figures (Figure 75). The majority of the works of this art genre have been carried away by the colonisers, and to this day Nigeria strives to no avail to recover its artistic heritage. This type of art was adapted by the neighbouring Yoruba states as well, and it is still practiced in Benin City.

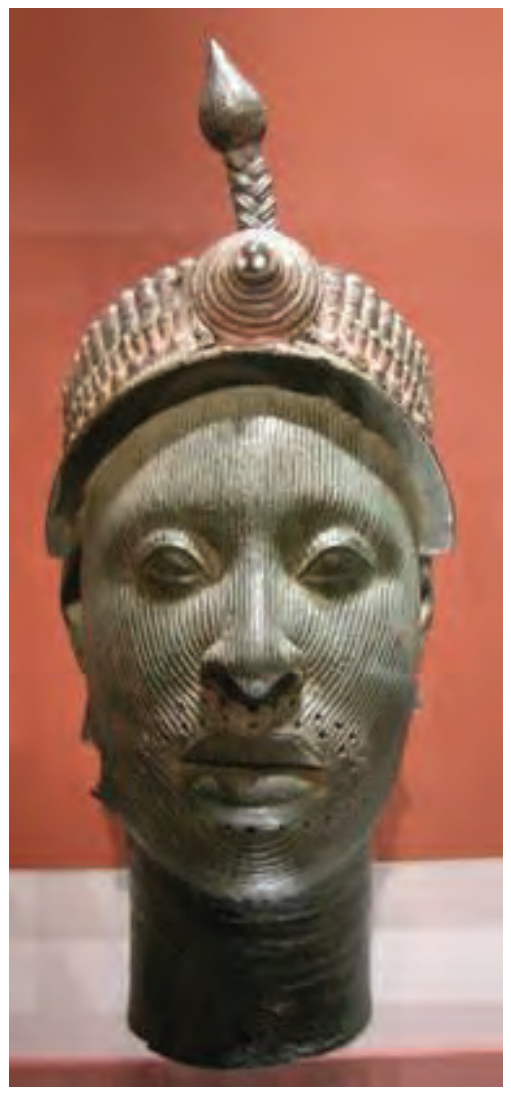

Figure 75: Yoruba bronze portrait from the city of Ife, today in the British Museum Source: Photograph by Saiko, https://en.wikipedia.org/wiki/Bronze_Head_from_Ife\#/ media/File:Arte_yoruba,_nigeria,_testa_da_ife,_12-15mo_secolo.JPG 
The typical genre of the fantastic copper and bronze sculpture of the Ashanti people in Ghana - carefully elaborated figurines, which were designated to measure gold-dust (mrammu) - may be counted among the best of African metal sculpture. (Figure 76).

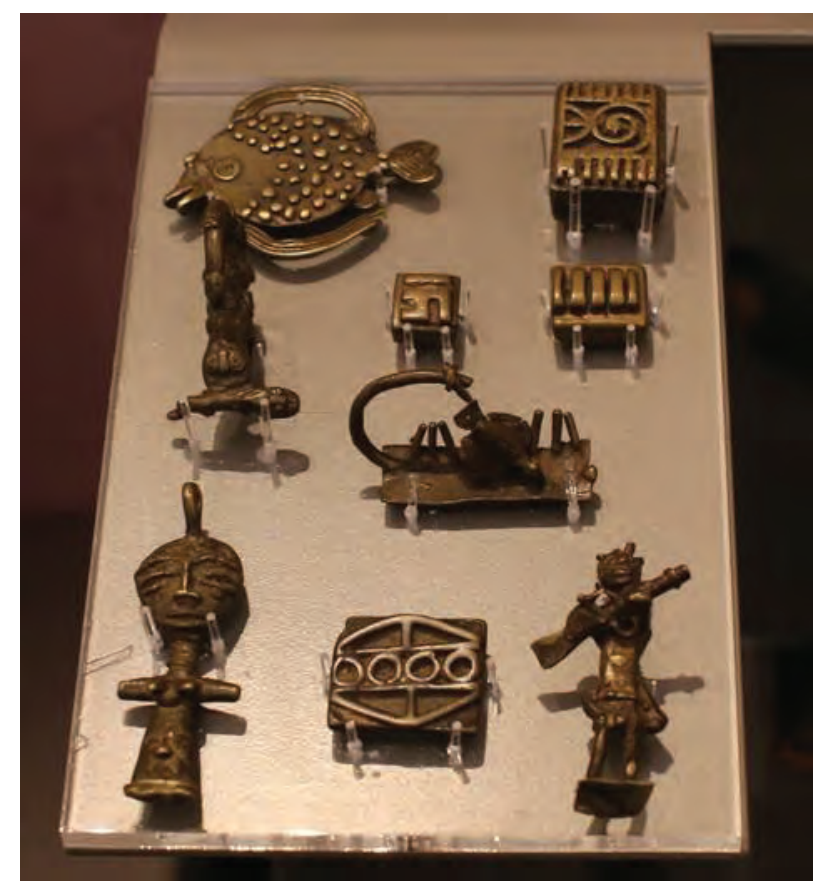

Figure 76: Ashanti copper figurines from Ghana, for weighing gold, in the British Beaney House of Art and Knowledge (Canterbury) collection Source: Photograph by Geni, https://en.wikipedia.org/wiki/Akan_goldweights\#/media/ File:Ashanti_goldweights.JPG

Whereas a significant number of African peoples did not use permanent materials for construction - in many places such materials were simply unavailable -some societies did develop architecture to a high level. The earliest examples of durable architectural works are the pyramids located in the Nubian region of the Sudan (mainly around the town of Meroe), which despite all observable differences reflect the Egyptian influence.

A little-known fact, today one finds more pyramids in the Sudan than in Egypt itself. No less fascinating are the stone-built architectural monuments of the Christian Ethiopian highlands, including the giant ancient stelae in the town of Axum, the medieval rock churches of the town of Lalibela, the rock-hewn monasteries of Tigray province, as well as the buildings (including the fortress) of the late-medieval Ethiopian capital city, Gondar (Figure 77). 
Although the Muslim regions of Ethiopia do not abound in similar architectural wonders, there is one important exception: the vast medieval old town (encircled by several kilometres of city walls) of Harar. A large number of stone-built monuments survived in the more southerly, Bantu-speaking regions of Africa, as in the Swahili city-states of the East African coast, in which the main building material was coral.

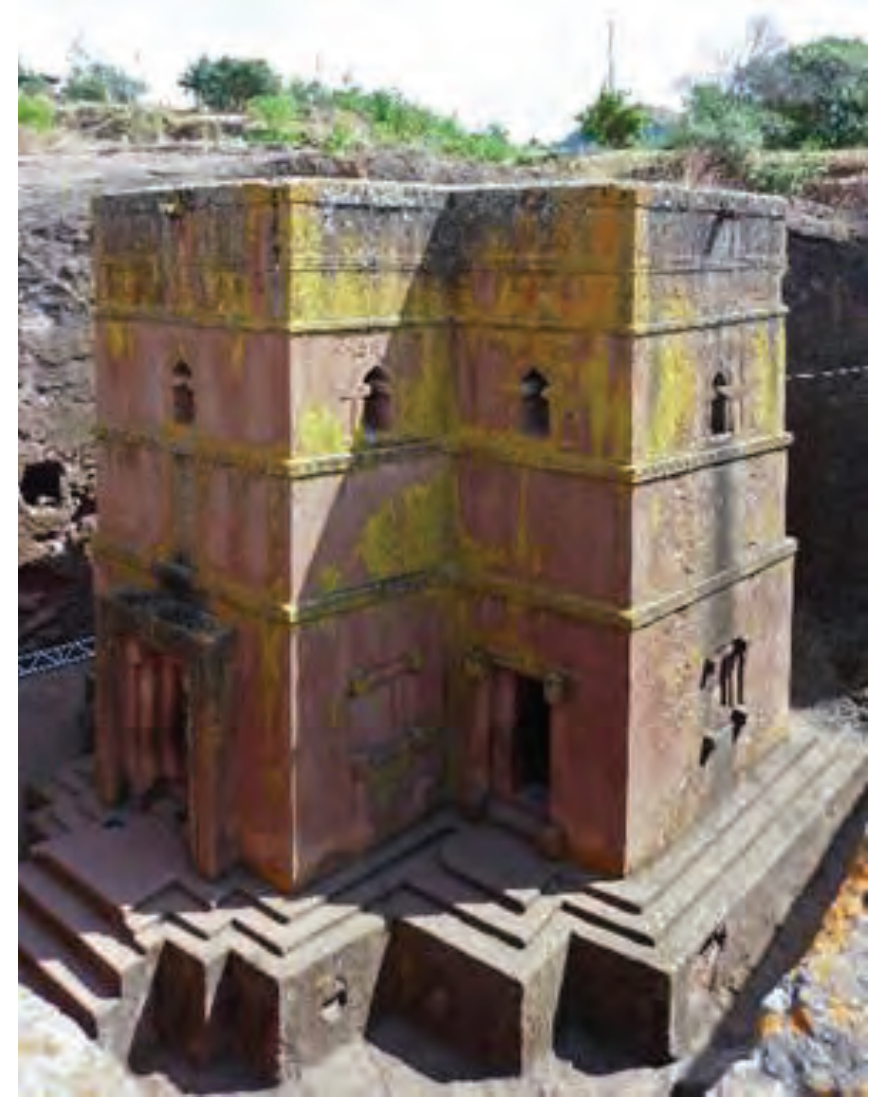

Figure 77: Bete Giyorgis (Church of St. George) in Lalibela (Ethiopia) Source: Photograph by Bernard Gagnon, https://en.wikipedia.org/wiki/Church_of_ Saint_George,_Lalibela\#/media/File:Bete_Giyorgis_03.jpg

An exhaustive list of the hundreds of these settlements is impossible here, but particularly worthy of mention are the old towns of Zanzibar (Tanzania), Lamu and Mombasa (Kenya), as well as Mogadishu (Somalia), the ruins of Gedi on the Kenyan coast, and above all the seat of the sultans of medieval Kilwa in the south of Tanzania, the most important remnant of which is the huge fortress of the sultans (Husuni Kubwa). 
Further inland, lasting architectural monuments are found primarily in the Zimbabwe region, where one can admire the ruins of numerous enormous stone complexes surrounded by walls. The most significant ruins include the so-called Great Zimbabwe - which lends its name to today's state of Zimbabwe - and Mapungubwe. According to researchers, the inspiration behind these huge round stone complexes was the simple cattle corral fenced off with thorny branches. Such structures were first built in smaller sizes, but already using stone walls (this intermediary state is illustrated by the ruins of the Kenyan Thimlich Ohinga among other places) and then later versions magnified to huge size were built (Figure 78).

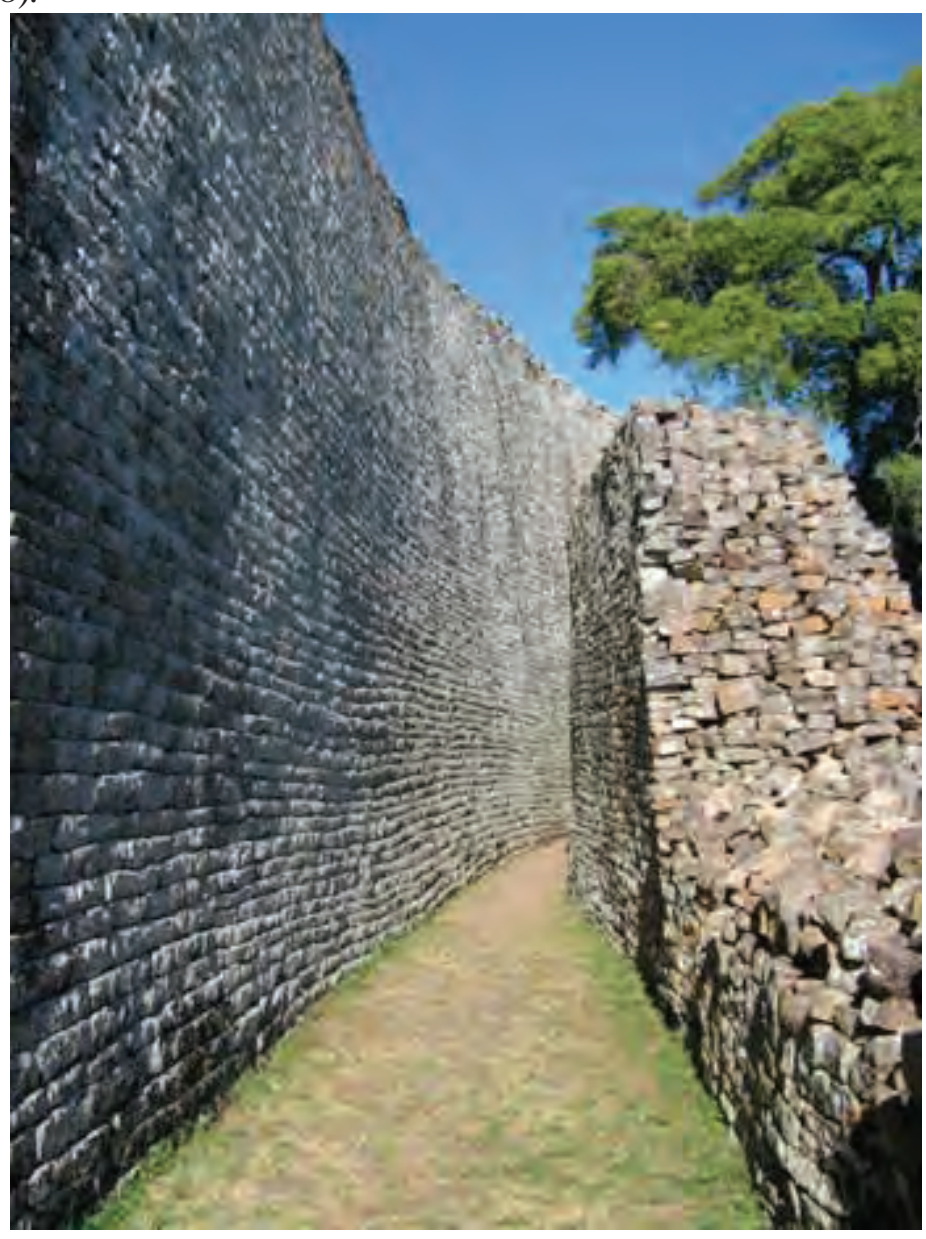

Figure 78: Part of the Great-Zimbabwe Buildings

Source: Photograph by Vinz and Korrigan, https://en.wikipedia.org/ wiki/Great_Zimbab we\#/media/File:Great_zimbabwe_2.jpg 
In most of West Africa stone is not available in sufficient quantities to allow people to use it for construction. However, in the states of the savannah belt a breath-taking architectural style, the so-called "Sudanic Gothic" style, was developed, using mud as the main building material. (The adjective 'Sudanic' refers not to today's Sudan Republic but to the entire savannah region situated south of the Sahara). Mud architecture had been developed to an advanced level by the stateless peoples living there, examples of which include the large mud houses of the Musgum people in Chad and the mud fortresses (tata) of the Tamberma people of northern Togo and Benin. Later on, developing this technology further, enormous and wonderfully beautiful public buildings were built in the great West African Muslim empires, which would be re-plastered every year after the end of the rainy season with the help of a wooden scaffolding built into the walls. Famous examples for this style are the Great Mosque of Djenne in Mali (and countless similar mosques in Mali and the neighbouring countries), the old town of Timbuktu, the emperor's mausoleum of the Songhai Empire in the town of Gao, and the minaret of the town of Agadez in Niger (the tallest mud structure in the world) (Figure 79).

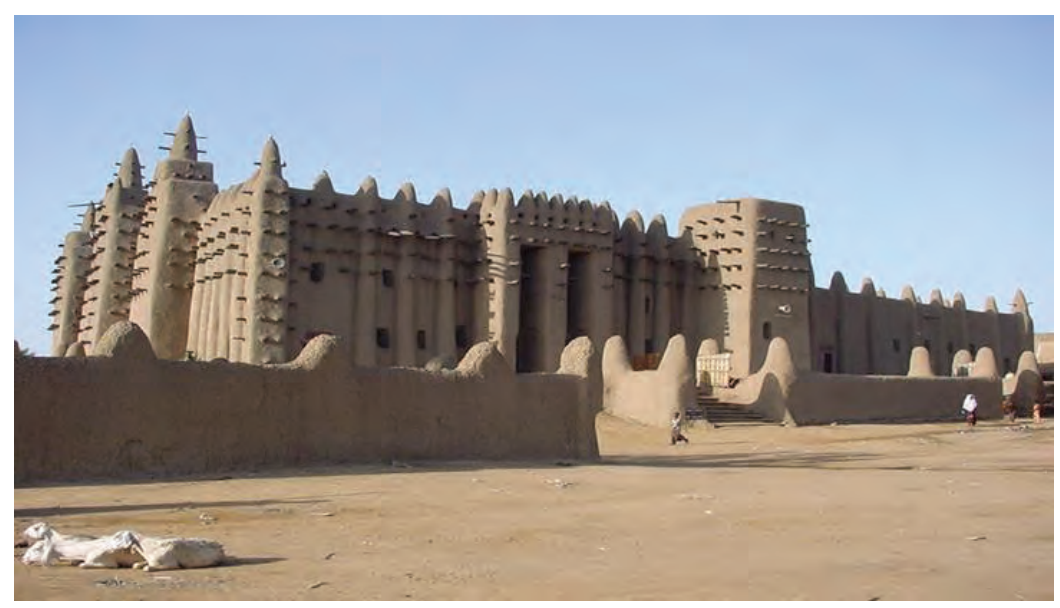

Figure 79: Great Mosque of Djenne, one of the greatest architectural gems of the Sudanese-Gothic style

Source: Photograph by Andy Gilham, https://en.wikipedia.org/wiki/Great_Mosque_of_ Djenn\%C3\%A9\#/media/File:Great_Mosque_of_Djenn\%C3\%A9_1.jpg 


\subsubsection{Chronological table}

\begin{tabular}{|c|c|}
\hline Date & Event \\
\hline from 2000 BCE & Nubian states developing under ancient Egyptian influence \\
\hline C. $500 \mathrm{BCE}-500 \mathrm{CE}$ & Meroe \\
\hline c. $300-800$ & Axum \\
\hline c. $600-1100$ & Ghana \\
\hline c. $1200-1500$ & Mali Empire \\
\hline c. $1200-1591$ & Songhai Empire \\
\hline c. $125-1500$ & Great Zimbabwe \\
\hline c. $1450-1700$ & Monomotapa \\
\hline c. 1500 & $\begin{array}{l}\text { The Portuguese arrive at the Gulf of Guinea and then reach East } \\
\text { Africa }\end{array}$ \\
\hline $\begin{array}{l}\text { eighteenth- } \\
\text { nineteenth centuries }\end{array}$ & $\begin{array}{l}\text { In the savannah belt south of the Sahara, Muslim theocratic states are } \\
\text { established. }\end{array}$ \\
\hline $\begin{array}{l}\text { seventeenth- } \\
\text { nineteenth centuries }\end{array}$ & The era of transatlantic slave trade \\
\hline $1700-1900 \mathrm{k}$ & Ashanti Empire \\
\hline $1884-1891$ & Division of Africa among the colonising powers \\
\hline $1956-80$ & The countries of Africa progressively gain their independence \\
\hline 1963 & Establishment of the Organisation of African Unity (OAU) \\
\hline
\end{tabular}

\subsubsection{Bibliography}

ADE AJAYI, J. F. - CROWDER, MiCHAEL 1985: Historical Atlas of Africa. London: Longman

BELCHER, STEVEN PATERSON 1999: Epic Traditions of Africa. Bloomington, IN: Indiana University Press

DAVIDSON, BASIL 2001: Africa in History: Themes and Outlines. London: Phoenix Press

EsleR, PhiliP FRANCIS 2019: Ethiopian Christianity: History, Theology, Practice. Waco, TX: Texas Baylor University Press

Eze, Emmanuel ChuKwUdi 1998: African Philosophy: An Anthology. Malden, MA: Blackwell Publishers

FAGE, J. D.; TORDOFF, WILliAm 2005: A History of Africa. London: Routledge

FAIRley, JAN - RIJVEN, STAN 1989: African Music. Cambridge: Cambridge University Press

FinNEGAN, RuTH 1970: Oral Literature in Africa. Oxford: Clarendon Press 
FROBENIUS, LeO 2007: Leo Frobenius on African History. In: HABERLAND, EIKE (ed.) Art and Culture: An Anthology. Princeton, NJ: Markus Wiener

GARLAKE, PETER S. 1974: Great Zimbabwe. London: Thames and Hudson

GARLAKE, PETER 1978: The Kingdoms of Africa. Lausanne: Elsevier

GOODY, JACK 1975: Literacy in Traditional Societies. Cambridge: Cambridge University Press

ISICHEI, ELIZABETH 1995: A History of Christianity in Africa: From Antiquity to the Present. Grand Rapids, MI \& Lawrenceville, NJ: William B. Eerdmans Publishing Company \& Africa World Press

LEWIS, I. M. (ed.) 1969: Islam in Tropical Africa. Oxford: Oxford University Press.

Murdock, George Peter 1959: Africa: Its Peoples and Their Culture History. New York, Toronto \& London: McGraw-Hill.

MURRAY, JOCELYN 1998: Cultural Atlas of Africa. New York: Checkmark Books

OKPEWHO, ISIDORE - DAVIES, CAROLE BOYCE - MAZRUI, ALi Al'AMIN 1999: The African Diaspora: African Origins and New World Identities. Bloomington, IN: Indiana University Press

OWOMOYELA, OYeKAN 1979: African Literatures. An Introduction. Waltham, MA: Crossroads Press

SANNeH, LAMIN 1996: Piety and Power. Muslims and Christians in West Africa. Maryknoll, NY: Orbis Books

UNESCO General History of Africa 1990: Berkeley, Paris \& London: University of California Press/James Currey

VANSINA, JAN 1975: Kingdoms of the Savanna. Madison: University of Wisconsin Press

VAnsinA, JAN; VAnsina, C. 1984: Art History in Africa. London \& New York: Longman

WiLlETT, FRANK 2002: African Art. London: Thames and Hudson

ZASLAVSKY, ClaUdia 1999: Africa Counts: Number and Pattern in African Culture. Chicago: Lawrence Hill Books 
6. Europe 


\title{
6.1. Orthodox Christian Europe: The Russian Version
}

\author{
ZOLTÁN SZ. BÍRÓ
}

\subsubsection{Identification of the area}

The boundary in Europe between Western and Eastern Christianity runs more or less along the border between Russia and its neighbours Finland, Estonia and Latvia, between Belarus and the neighbouring Latvia, Lithuania and Poland, Ukraine and Poland, Slovakia and Hungary, along Romania's western border, the borderline separating Serbia from Hungary and Croatia, as well as between Montenegro, Croatia, and Bosnia-Herzegovina. These borders are, however, of a highly relative nature since large segments of the populations living in the western parts of Belarus, Ukraine and Romania do not belong to the local Orthodox Church but some denomination of Western Christianity or the secular communities of their respective countries. Nonetheless, the above borderline clearly separates areas whose development has been dominated by the Orthodox Church rather than Latin Christianity or Islam. Of the countries to be found on the map of Europe today this category includes Russia, Ukraine, Belarus, Georgia, Romania, Moldova, Serbia, Montenegro, Macedonia, Bulgaria, Albania, greets and Cyprus. Most - but not all - of the countries listed above have autocephalous, that is, autonomous, or, with some simplification, national, orthodox churches (Map 28). The exceptions include Moldova, Belarus, Montenegro and Macedonia; they have no such autocephalous churches, because orthodox believers living in the territory of Moldova are associated with the Roman Orthodox Church or - like those living in Belarus - to the Moscow Patriarchate, while Eastern Christians in Montenegro and Macedonia are associated with the Serbian church. Ukraine is special in that not only many of the local clerics but the secular power also made considerable efforts after the disintegration of the Soviet Union to ensure that Ukraine has its own unified and autonomous Eastern Christian church, recognised by the other autocephalous churches. At the same time, in addition to those listed above, the churches of Constantinople, Alexandria, Antioch, Jerusalem, Poland as well as the jointly Czech and Slovakian are still regarded as mutually recognised autocephalous churches. There is one more Orthodox Christian church in addition to the above-mentioned ones: the one in America, but its autonomy has still not been recognised by all Eastern Churches. This is why they say that there are altogether fourteen or fourteen plus one autocephalous churches today. This then reveals that there are 
canonical, that is, mutually recognised churches even beyond the borderline separating Western and Eastern Christianity such as the Polish or the joint Czech and Slovak, just like other churches established by the apostles, whose followers have long been a minority relative to other denominations living in their respective territories. Such autocephalous Eastern Churches are those of Constantinople, Alexandria, Antioch and Jerusalem.

The word "orthodox" in the names of the eastern or orthodox churches means "righteous/correct opinion", being of the true faith. "Orthodoxy" means the correct faith - not conservatism or backwardness - as opposed to heterodoxy (different or other belief) and cacodoxy (erroneous belief). Pravoslav is none other but the Russian translation of the adjective orthodox, a word of Greek origin, which also means righteous.

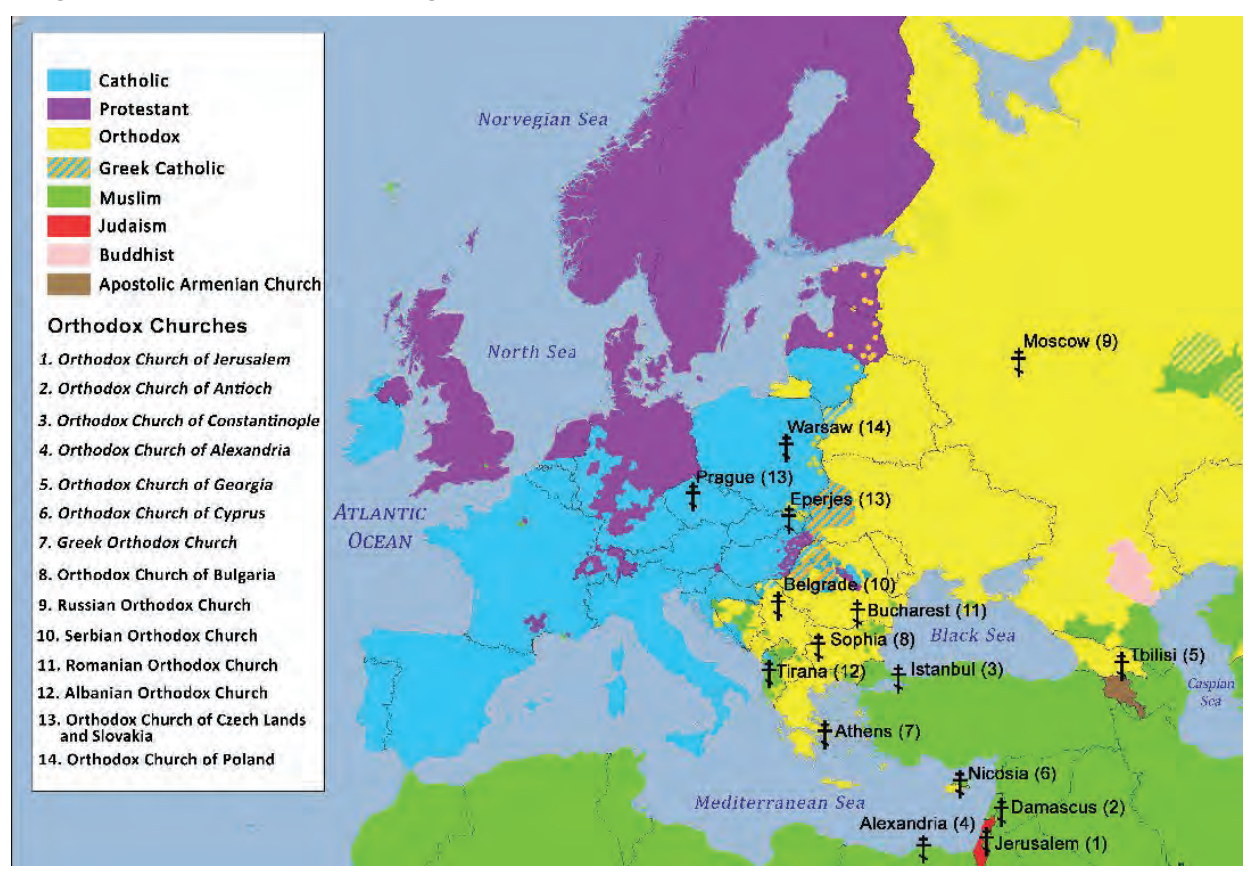

Map 28: Orthodox churches in Europe and the Middle East ${ }^{14}$ Source: Edited by ÁGNES VARGA

The tradition of calling the church of the Western or Latin Christianity Catholic and the Eastern Christianity Orthodox developed gradually after the great schism in 1054. It was a long story the way Christian community which

\footnotetext{
${ }^{14}$ The first seven orthodox churches - listed in italics - were established by apostles during the first century.
} 
used to be unified initially, split and began to drift away from each other. This process has been driven and influenced by historical and political factors as well as language, dogma and liturgy, along with differences regarding church politics and church organisation. One of the most well-known of the many debates regarding matters of dogma was the "Filioque" debate relating to the issue of the origin of the Holy Spirit. This is because the eastern churches - holding on to the universal teaching adopted by the synod in the fourth century - held that the Holy Spirit originated from the Father alone while the western church, protecting the Son's divine authority, argued that the Holy Spirit originated from both the Father and the Son too (ex Patre Filioque procedit). The differences between their respective organisational systems however, played an even more profound role in the growing distance between the two churches than did their opposing dogmatic considerations. Namely, while in the eastern parts of the Roman Empire a number of local churches came into being pursuant to the apostles' propagation of faith, linked together by the shared faith, while keeping their internal administration separate and independent of each other, in the western territories this process evolved in an altogether different direction; a new political situation evolved in the wake of the West Roman Empire in which concentration of spiritual power in a single centre appeared to be more advantageous for the survival of the church. In the east however, as the secular power managed to keep up its strength and the emperor managed to maintain order and the rule of law, the church was not forced to assume roles that are alien to the spiritual power. In the west on the other hand, the situation was different. The new Germanic kingdoms were engaged in constant rivalry with each other, creating an environment in which only the Pope represented a certain degree of unity and continuity. This provided the Pope with a role the like of which the eastern patriarchs never had. The differences between the centralised governance of the western church and the synodal, sort of collegial, governance by eastern patriarchates were growing more and more salient over time. The Byzantines never condemned the centralisation of the western church organisation as long as the Pope refrained from interfering with the lives of the eastern churches. This however, changed after a while and from the ninth century those in the west were growing increasingly convinced that the Popes' canonical jurisdiction extended over the eastern territories as well. Christians living there however - while they were ready to recognise Rome's honorary primacy and look upon the Pope as the first bishop of the pentarchy, that is, the rule of five comprising Rome, Constantinople, Alexandria, Antioch and Jerusalem, they did not accept that the Pope should have the last word concerning all matters of importance. They held that no single individual, but only the synod of all bishops of the church, could decide matters of faith. 
From the middle of the ninth century the Byzantine Church crossed the boundaries of its home ground and embarked on an intensive evangelisation campaign in Central and Eastern Europe. A particularly important role was played in this missionary activity by two monks Cyril (826-869) and Methodius (81-885). Their first mission was to the Caucasus, then on to the Moravian Principality. For the local ruler asked the Byzantine Church for missionaries who can propagate the Christian faith in a Slavic language and are able to translate the Holy Bible into Slavic. This however, required the development of a suitable written form of the Slavic language as well. It did not take long for Cyril and Methodius to fulfil both requests, laying down the foundations for Slavic Christian church culture. By translating the Bible and church service books Slavs joining Orthodoxy acquired linguistic and cultural advantages not available for western Christianity for quite some time: Slavs could read the Book and listen to church service in their own language right from the beginning.

The people of Moravia were followed by other converted communities, from Bulgarians through Serbs to Romanians. The Christianisation of the eastern Slavs started in the late tenth century. Taking up Christianity played a major role later on in enabling Eastern Slavs to maintain their identity during the centuries of the Mongol invasion (1237-1480). And when Constantinople and other eastern patriarchates - those of Alexandria, Antioch and Jerusalem - as well as the Balkan churches, came under rule while Russia then called Moscovia was no longer under Mongol control, the conditions were just right for the Russian church to play a dominant role in the orthodox world. This process took place in two phases. First the actual autonomy of the church was created by Russian bishops electing their religious leader, the new metropolitan of Moscow directly, bypassing Constantinople. This marked the beginning of the actual (though not yet recognised by others) autochefality of the Russian church. This de facto autonomy came to be recognised by the Constantinople Patriarchate only about a century and a half later, in 1589, which is when the metropolitan of Moscow was raised to the rank of a patriarch.

Another important element in the relationship between Moscow and Byzantium was that Ivan III (1462-1505), Grand Duke of Moscow, married the niece of the last Byzantine emperor in 1742. It was from that point in time that the ruler of Moscow used the title autocrator, and the Byzantine double-headed eagle in the national coat of arms. And it was also then that the ideological construct of Moscow as the third Rome appeared. According to this construct the first Rome was taken control over by the barbarians and fell into heresy; the second Rome, that is, Constantinople, got infected by the Florence Union and then fell under Ottoman rule; in other words, each of the former Romes had fallen but "the third Rome stands upright and there will be no fourth one". This concept 
was suggestive of a kind of a Russian messianism, giving rise to the perception that the Russians can justly consider themselves to be God's chosen people.

Although the Russian Orthodox Church was not exposed to Reformation with the religious wars that broke out in its wake, yet it did not mean that it was not shaken from time to time by major religious polemics. The most profound of these was related to the innovations introduced by Patriarch Nikon. The Ecclesiarch of the mid-seventeenth century revised Russian liturgy books by comparing them to original Greek scripts. At the same time, he also insisted on Russians also cross themselves with three fingers in the Greek way, not with two, the way Russians did. But Nikon went even further than this. He attempted to raise the church over the state power. This however, would have meant breaking with the diarchal system, based on the rule of two powers, adopted by Russia following the Byzantine example, i.e. the model in which both the religious and the secular power play equally major roles, since it is their symphony, or close and harmonious cooperation, that forms the basis of effective and efficient governance of the community. Nikon failed to gain the upper hand in this conflict, however, he managed to "achieve" two things though his innovations. One was a schism in the Russian church, forming a large group of those refusing to accept his reforms. They were the orthodox separatists. On the other hand, through this schism he managed to weaken the church to such an extent that a few decades later Peter I (1682-1725) could not only easily subject it to, but even integrate it in the secular power.

\subsubsection{Russia's territorial expansion}

The first state of the eastern Slavs was the Kievan Rus, an extensive, but short-lived, state formation. One reason for this was the absence of the right of the first-born in the ruling family; thus, it did not take long for the former single coherent state to fall into principalities vying even with each other. One of the consequences was a considerably reduced capability to resist the MongolianTartar forces moving towards Europe, as a result of which much of the areas populated by Slavs had come under tartar control by the middle of the thirteenth century. While the southern and central parts of the country were occupied by the Golden Horde, the western regions were conquered by the rising Lithuanian Grand Duchy. After a while the Grand Duchy of Moscow, covering the north eastern segment of the area populated by Slavs came to unite the Russian lands again. The duchy, lying at a considerable distance from Kiev, had grown from a mere 20 thousand square kilometres in the early fourteenth century had expanded to 430 thousand square kilometres by 1462 when Ivan III took the throne. In other words, it did not take more than a century and a half for the duchy to grow to 
twenty times its former size (Map 29). This dynamic process of gaining territories continued: At the time Vasily III (1505-1533) died the territory of the Moscow state was more than six times its size seventy years before.

The rise, and then the rapid growth of the territory, of the Russian state with Moscow as its centre was essentially enabled by the fall of the Golden Horde and Byzantium, the collapse of the two empires that had exercised - political or religious - power over the Russian state up to the mid-fifteenth century. Relieved of their influence, Moscovia began to expand, at an increasing rate. This process accelerated particularly after Ivan IV (1533-1584) defeated in the middle of the sixteenth century the Golden Horde's two successor clanships: the clanship of Kazan (1552) and the clanship of Astrakhan (1556).

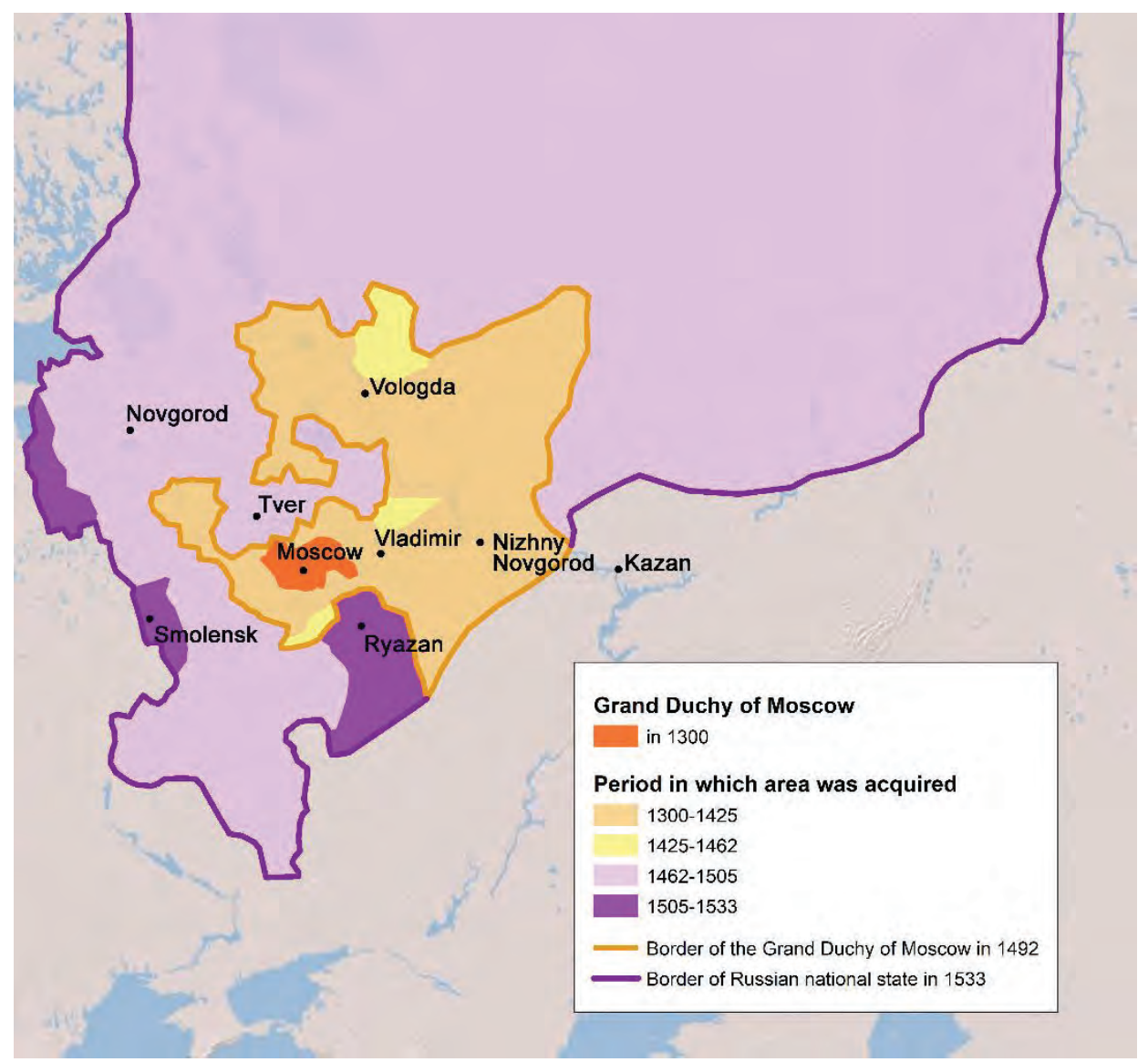

Map 29: Growth of the areas under Moscow's influence up to the sixteenth century Source: Edited by ÁGNES VARGA 
The country's territory nearly doubled under his rule, growing from 2.8 million to 5.4 million square kilometres. This was the era of the Moscovian state's great and durable triumphalism which did not come to an end even upon the death of Ivan IV. So much so, that the area of the Grand Duchy of Moscow continued to grow by an average of 35 thousand square kilometres, the size of today's Netherlands, each year during the next 150 years. Consequently, in 1600 the size of the Russian state equalled the size of the rest of Europe. The area of Siberia which it managed to conquer in the first half of the seventeenth century equalled twice the size of Europe without Russia (Map 30) However, this rapid expansion covered, for the most part, very sparsely populated areas. No significant populations lived even in the regions of the most densely populated towns of Novgorod and Pskov, let alone the territories beyond the Ural Mountains. The population density was not higher than two-three persons per square kilometre even in the European parts of the Russian state in the mid-sixteenth century, while in Western Europe it was typically about ten times as many. Although low population density enabled quick conquering of large areas against little resistance but then it made it very difficult to benefit from the opportunities offered by the territories so taken, as well as the governance of the country whose territory had increased to immense proportions.

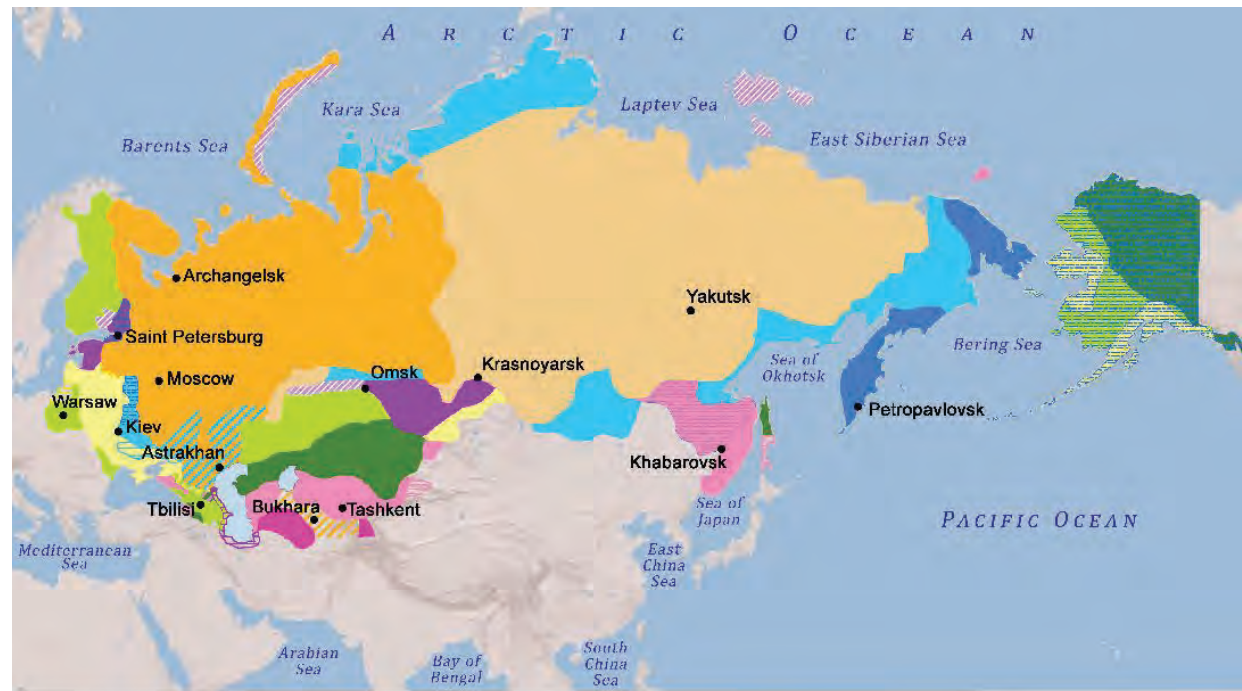

Russian areas by year of being taken control of

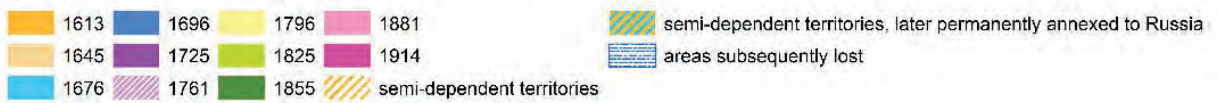

Map 30: Territorial expansion of Russia between the seventeenth century and World War One

Source: Edited by ÁGNES VARGA 
All these developments, however, took place before Peter I declared his state an empire in 1721. The new situation entailed not only practical consequences, but it also profoundly affected the ideological foundations of the Russian statehood. Peter did not refrain from laying down sacral foundations for the mission pursued by the Russian state, but he did not find it alone to be sufficient either. Therefore, he tried to combine its elements in some way with rational western traditions. This was in relation to his endeavour to create not simply a universal Orthodox empire based on the Byzantine model but rather a global empire combining the traditions of the Byzantine and the Western Roman empire. It was in this spirit that he established the country's new capital city and named it Saint Petersburg. Even the very naming of the city was a symbolic act. It was meant to remind all of Rome, the city of the apostle Peter. Indeed, even the keys in the town's coat of arms were modelled after the apostolic keys in the coat of arms of the Vatican. With the foundation of a new capital city the Russian Empire had two sacral centres: Moscow as the Third Rome, and Saint Petersburg appearing as an analogue of the ancient Rome, the city of the apostle Peter.

There is one more piece of evidence of how important it was for Peter I in addition to following sacral traditions - to lay down secular foundations for his power. This evidence lies in the way the ruler adopted the title of imperator, as his procedure differed profoundly from the way Ivan IV took the title of tsar in 1547. The latter had himself crowned when assuming the title of tsar, while Peter I did not consider this necessary when he adopted his new title. What can be rightly concluded from this is that while the adoption of the title of tsar was primarily a religious act, that of the imperator was a cultural one. The latter was not accompanied by any religious ceremony whatsoever; indeed, it may not really be regarded as an act aimed at expanding the ruler's power. The decision taken by Peter I was to change the country's cultural orientation. The renaming of the ruler's title was aimed at underpinning the general orientation - towards Europe - of the reforms adopted by Peter.

The territorial expansion of the empire continued in the eighteenth century, during the reign of both Peter I and Catherine II (1762-1796), all the more so, because the Russia had to live with its particular geographical conditions, the immensity of the territory acquired earlier, an area that had - and have - no natural borders apart from the Arctic Ocean in the north and the Pacific Ocean in the east. For this reason, the Russian state felt - just like earlier on, in the eighteenth century too - vulnerable and exposed. To suppress its fear, it started to threaten others and spared no effort to expand its boundaries as far as possible. Consequently, at the beginning of the century part of the Baltic and in the second half of the century Lithuania, along with more and more Polish areas, came under Russian control. Alaska was also gradually conquered during the reign of 
Catherine II, just like the northern shores of the Black Sea. It was then that Russian forces reached the northern edge of the Caucasus and founded in 1784 the now famous fortress town of Vladikavkaz (meaning "ruler of the Caucasus"). Nonetheless, at that time they did not yet succeed in pacifying the whole of the northern part of that mountainous area. Small local peoples continued to resist the Russian colonisation for decades to come. By contrast, Georgians, Armenians and Azeris living on the southern slopes of the Caucasus - then still referred to as Mountain Tartars - were incorporated in the empire as early as in the first third of the nineteenth century. This created a strange situation which the tsarist power wished to put an end to as quickly as possible, but it took until the mid-sixties to break the resistance of the small North Caucasian peoples and take full control over the Caucasus. And this has brought us to the moment in history when the size of the Russian Empire reached its maximum. This period was between 1864 and 1866, when the empire included the areas of the Grand Duchy of Finland, Bessarabia and the former Polish Kingdom, taken during the Napoleonic wars. At that point the entire Caucasus already belonged to Russia, but the Saint Petersburg court had not sold Alaska to the United State. The total area of the empire was already nearly 24 million square kilometres during those years but thereafter the area of the country began to shrink: partly as a result of the sale of Alaska in 1867, and partly through losing areas in north-east China as a result of defeats suffered in the 1904-1905 Russo-Japanese war, as well as through ceding half of the Sakhalin Island to the Japanese.

The administration of the vast empire was quite a challenge even during the years when there were no serious problems in its most remote areas, as no one mutinied or fought for separation. Suffice it to refer to the $9500 \mathrm{~km}$ distance between the capital city and Petropavlovsk, a fortress town in Kamchatka. Russian fortresses in Alaska, at even greater distances from the capital city, were much quicker to reach - and not only because Alaska is on another continent even during the first half of the nineteenth century by sailing across oceans, than on land through Siberia. The reason for this was that transportation on land many times more expensive than by sea. Moreover, sailing was also much safer. Therefore, the central power preferred sailing from Saint Petersburg or Odessa, nearly circumnavigating the entire globe, rather than carrying supplies including grains - to its garrisons in Alaska.

And this applied to the other way round as well. It took nearly two years for Russian traders to transport the fur of game killed in Alaska to China via Siberia even as late as in the second half of the nineteenth century. For American ships it took five months to cover the same distance. This then meant that - no matter how it was a land power - it was more complicated for Russia to reach its peripheries than other for other powers their overseas colonies: "India was closer 
to London in both technically and psychologically than many governorates of the Russian Empire to Saint Petersburg."

For, paradoxically, the oceans did not separate distant areas but rather brought them closer to one another. Alexander Etkind summed up the advantages offered by keeping in contact by sea in his work on Russia's internal colonisation along these lines: although enemies and pirates could be encountered on the sea but not subjects who were alien, poor, discontented or disobedient, for which they would have had to be placated, studied at length or perhaps relocated, enlightened, taxed, recruited from, and for whom responsibility would have had to be assumed towards the world, well, no such peoples were to be encountered on the seas (ETKIND, A. 2011, p. 15). In other words, keeping such a vast land empire together and managing its administration efficiently and effectively, were not easy tasks even "in normal mode" owing to the immense distances and in the absence of roads and railway lines.

Clearly, this circumstance must have contributed to the central power's putting off the necessary reforms for so long and when it did embark on introducing reforms at long last in the mid-nineteenth century it still insisted on keeping the empire's political system intact. Alexander II (1855-1881), who did not wish to let his power be restrained in the first place, was convinced that any constitutional limitation of the supreme power, by sharing it with some representative institution, would jeopardise the governability of the empire. In his view autocracy was the only suitable means for the effective and efficient administration of his vast country. His grandson Nicholas II (1894-1917), however, in the early twentieth century, had no choice but accept the curbing of his autocratic power. Not even that, however, was sufficient for keeping the empire together.

The governmental and then the general political crisis brought about by World War One resulted in a temporary disruption of the third largest empire of all times. Peripheries of the immense country separated, one after another, some of them temporarily, others for longer periods of time. And some even managed to quit the empire for good, like Finland and Poland. The Bolsheviks, however managed to nearly fully restore the empire, thanks to many of the peripheral countries joining it in the hope of formally keeping their autonomy. Four soviet socialist republics - the Russian, the Ukrainian, the Belorussian and the Transcaucasian - formed an alliance and created the Soviet Union at the end of December 1922. At that time however, the territory of the new federal state was smaller than that of the Russian Empire in 1914. And it remained so even after the Khorezm and the Bukharan People's Soviet Republics joined the federal state in 1923-1923. The total area of the Soviet Union was even then only 20.9 million square kilometres, smaller than the Russian Empire before World War One. It 
was not until Moscow's annexation of Eastern Poland, and the three hitherto independent Baltic states as well as Bessarabia (which used to belong to Romania between the two world wars), based on a secret bargain with the Germans in the early phase of World War Two, that the new federal state grew even larger. The territory of the Soviet Union thus exceeded 22 million square kilometres, larger than the Russian Empire at the time of its disintegration but still smaller than when it was at its peak, in 1864-1866.

Keeping the Soviet Union together entailed no difficulties as long as the constituent republic were headed by members of the same political party, the Communist Party of the Soviet Union. This set-up itself guaranteed that the soviet state structure would remain intact. However, towards the end of the Gorbachev era the communist party lost its monopoly on political power, the future of the Soviet Union also became questionable. The first signs of secession appeared in the Baltics and Georgia, i.e. where there were traditions of sovereign statehood, even if not quite from the recent past. And the coup attempt against Gorbachev, aimed at preserving the Soviet state framework, brought about the opposite result: in it accelerated the disintegration process in August 1991. The first phase of this process saw the fully legitimate and peaceful "release" of the three Baltic states from the Soviet Union, soon after the failed coup attempt. At that time no one knew what would become of the huge country, although it was already on the verge of crumbling into pieces. The final verdict was announced on 7 December 1991 when in the Belovezhskaya Pushcha in Belarus the heads of the three Slavic member republics - of Russia, Ukraine and Belarus - signed the document announcing the dissolution of the Soviet Union. Article 5 of the document declared that the "The High Contracting Parties acknowledge and respect each other's territorial integrity and the inviolability of existing borders within the Commonwealth." This principle was upheld and observed by the contracting parties and former soviet republics that had become independent and that joined the agreement a few weeks later, apart from Armenia and Azerbaijan that came to be entangled in an armed conflict back during the late soviet era. This convention was broken by Moscow when it annexed the Crimean Peninsula, part of Ukraine, in March 2014.

\subsubsection{Special features of Russia's historical development}

Even at the end of the seventeenth century Russia was still considered as a peripheral part of Europe. No European state had ever considered seriously the possibility of forming an alliance with the Grand Duchy of Moscow, before the reign of Peter I. Although the country of the tsars was here in Europe, but it was hardly taken note of, apart from its very neighbours. Or when it was taken note 
of, it was regarded as a negative example. Even Jean Bodin, who in his late sixteenth century volume on sovereignty, referred to the Moscow monarch as the only ruler in Europe - together with the Turkish sultan - who has exclusive power over not only the people living in his country but even their property and "whose subjects are called holop, that is, slave". In other words, the power of the duke of Moscow was even in Bodin's eyes, of a different nature than what was customary in other parts of Europe, in "royal or legitimate monarchies", as in the latter the "subjects obey the monarch's laws and the monarch obeys the laws of nature, leaving the subjects their natural freedom and ownership rights" (BODIN, J. 1987, pp. 135-136).

The situation was truly different in the Grand Duchy of Moscow, where the concept of ownership (dominium) was, for quite some time, not separated from that of power (imperium). The ruler not only looked upon his subjects as people over whom he exercised power but also as people in his ownership. For two substantive elements of western feudalism - conditional land ownership and the institution of vassalship - were missing in the eastern edge of Europe, or some of their elements came about at such time and under such circumstances when the western parts of the continent was already being dominated by altogether different processes. Allodial title (votchina) was replaced in Russia by the land ownership based on service (pomeste) at a time when the opposite was taking place in Europe: benefices (Latin: beneficium) were gradually turning into estates free of feudal service obligations. The primary reason for this was that the "exact replica of the Western feudal synthesis never came about" in the East. In the Moscow state the "constituents of feudalism appeared in rather confused, aslant and asynchronous combinations, none of which had the state of completion or unity of the original synthesis in full" (ANDERSON, P. 1989, p. 294). This is why certain fundamental political skills were never acquired, and some important institutions never came into being in Russia. Where feudalism evolved, however, its internal structure and reciprocity made a considerable contribution to the development of a political practice which ultimately lead to a culture of seeking for consensus. For the private contract between senior and vassal stipulated mutual commitments and obligations regardless of the respective situations and possibilities of the parties, and of the asymmetry between their respective positions. In other words - no matter how profoundly different possibilities each had - neither of them was exposed to the other: this was all the more so because the oath of fealty sworn to each other could be unsworn by both the overlord and the vassal. This was referred to as the diffidatio based on assuming and allowing that the vassal treaty can be broken unlawfully by the feudal overlord as well. And if the privilege of lawful conduct at all times does not follow from the more favourable position in the feudal hierarchy, there is a need for also an institution 
that can deliver justice in the case of a conflict between the parties - breach of trust (felony) by either party - in an impartial manner. This need, and the presence of a church separated from and rivalling the secular power, brought about in Western Europe the institution of courts, independent of the prevailing power, at a relatively early stage. Indeed, it may be argued without any exaggeration, that the right to break the fealty was that particular element of the agreement between the controllers and the controlled, those on top and those below, which - laying down the foundations for the right to resist - made a profound turn in the political, social and legal development of Europe.

However, no feudal hierarchy developed in Russia, and no system of private contracts relating to it evolved either. No agreement with mutual obligations was put in place between the duke and his boyars. The difference between their actual positions - hierarchy - was not adjusted by any contract whatsoever. The inequality between the parties rendered their relationship a oneway relation, with no place for diffidatio. Consequently, even the institutions of the administration of justice came into being in Russia under a different influence and in a different way, than in the western and central regions of Europe. The feudal contract however, fixed not only the law-governed relationship between the parties but at the same time also served the expression of mutual good will. This does not mean, however, that Western Europe during the middle ages was a world of prolonged social peace. Violence, however, was equally present in the process of development in both the east and the west, however, as a very result of the spreading practice of mutual good will, other forms of conflict resolution, not necessarily involving or threatening violence, appeared already in a relatively early stage of development. And this was immensely important, for the expression of mutual good will was a forerunner of the gradual recognition of political opponents also as representatives of the public good. This world of human interaction was the antecedent to the development of a political culture with mutual tolerance - as well as legal compliance - being a key element, together with an attitude of regarding political rivals not as enemies to be destroyed but only as adversaries or opponents. In Russia however, the absence of feudal hierarchy permitted the evolution of one-way relations even within the privileged social group. The latter group - the group of so-called "serving people" - comprised those performing military, court or administrative services around the duke, as boyars or members of the duke's entourage. Although they were in a privileged positions, even they - not to speak of the so-called "burden bearing people" "below" them in the social hierarchy - could not expect to be protected by law and unbiassed courts, in the case of a conflict.

By contrast, constitutions generalising feudal contracts and independent courts authorised to resolve feudal legal disputes appeared in the West at a 
relatively early stage, together with the claim that not only the "spirit" but the "body" should not be exposed to the will of those in power. Initially, the Habeas Corpus, or the freedom of the body, applied to a select few, even in the West. But just like the feudal agreement, as the archetype of contractual political conduct, exceeded the limits of its original purpose and validity and started to function as a generally followed example, so did the scope of the Habeas Corpus expand and apply wider and wider circles of the subjects. In the medieval societies of Western Europe, the "freedom of the body" was enforced by means of horizontal solidarity. This, however, would hardly have been possible without distinguishing in the West - based on Roman legal traditions - the concepts of political power and ownership. Because it was this very distinction from which it followed that the subjects' obedience did not mean at the same time the relinquishing of natural freedom and ownership. It was only in the systems referred to by Bodin as "despotic monarchies" that the sovereign had the right to dispose over the subjects' property and person. This is said because in the medieval and early new age Russian state there was nothing to protect the institution of private property: no customs, no laws, not even the living and accepted tradition of the Roman law. The same applied to the "freedom of the body". So much so, that up to the end of the eighteenth century even noblemen could be corporally punished. This is not surprising in a country where owing to the absence of the feudal system even the oath of fealty imposed obligations only on the swearer in the subordinated position, showing that structure of unilateral dependence in which the concept of "human dignity retained even in a subordinated position" (Szücs J. 1983, p. 30) remained unknown.

Before Peter I the orthodox church formed a close-knit symbiosis with the secular power, being neither its subordinate, nor its rival. Because the Russia's historical development took place without the medieval Western European form of distribution of power, i.e. the separation of temporal power from spiritual power. In the West, in the medium of Latin Christianity, the power of the state was curbed by the church while in the East - in the world of Orthodoxy - this role remained unfulfilled. In the western part of Europe people in the Middle Ages lived in two worlds, the world of the "body" and the world of the "spirit". While the worldly power had competence concerning the former, its supremacy was not recognised in the latter. This resulted in the evolution of a dual power and a dual subordination. This was also expressed in the evolution of dual law. While church jurisdiction followed the universal canonical law, secular jurisdiction was based on a special "national law".

What made this possible was - inter alia - that transcendence, recognised as a higher and independent principle was a legitimate tradition of the European culture: the principle of allowing and accepting that a perfect existence could be 
"placed" behind the fallible worldly existence. It was primarily this tradition that in Western Europe the church could develop into an alternative formation that could be opposed to the secular structures, restricting their power ambitions. Nonetheless, not even the ever so important spiritual tradition of the legitimate existence of transcendence - something not even known elsewhere - could have been sufficient to ensure this. This is said because although it is true that no such specific and sacred sphere of interests evolved anywhere else beyond the boundaries of the Christian world, which would have been inaccessible, indeed, forbidden for the state - because everywhere else the state itself was sacred, so religious requirements coincided with those of the state - yet this alone could hardly have turned the church into a factor imposing such strong secular restrictions on the worldly power. There was one additional necessary component, namely, the collapse of the West Roman Empire leaving a temporary political vacuum in its wake. Since however, it did come about, this situation explained at the same time why the case of Russia - which belonged to the Christian Ecumene - was so much different from that of the central and western parts of Europe.

In other words: this circumstance also explains why the joint Christian cultural tradition's legitimate capability of criticising could not develop into a true political counterforce in Russia. Well, one reason is that in the eastern edge of Europe Christianity appeared under the protection of the worldly power, in most cases with its active assistance. This could not have happened in any other way, as no Christian communities had been present for instance in the Kievan Rus, before its Christianisation. If only for this reason, the church definitely depended on the state's patronage and support. Moreover, the Byzantine christening of the country entailed the introduction of a political pattern as well, whose foundation was formed by a combination of the temporal and spiritual power, that is, the state doctrine of its symphony. While conflicts between the church and the secular community, between secular law and religious norms, were part and parcel of day-to-day life in the societies of Western Europe, only one hierarchy of values evolved in the Kievan and later the Moscovian states. The eastern orthodoxy formed a foundation for both culture and the "political community". For this very reason the medieval Russian state and its "citizens" are inconceivable outside the confines of the church framework and regulations. The symbiosis between profane and sacral in the Russia that existed before Peter I was so strong that even a political concept that is as "mundane" as despotism appeared "in the mind of the Russian people not as a legal regulation but a fact presented by God himself" (FLORENSKY, P. 1916, p. 26).

Peter the Great, however, brought about a profound change in the nature of the relationship between church and the worldly power. The close 
interdependence vanished when as a consequence of Peter's policies the church not only came under the close supervision of the worldly power but actually became a subordinated part of it. The monarch did away with the institution of the patriarchate in 1721, when the position of the Moscow patriarch had been vacant for as long as 21 years. It was replaced by a collective decision-making body called, during the reign of Peter Ecclesiastical College, and, after his death Sacred Synode, headed by a chief procurator representing the will of the worldly power, with an extensive scope of powers. Peter I radically transformed the legal framework in which the church was operating and also started to strip them of their allodial estates, on which their relative autonomy relied. This was going on for decade after decade, but it did not actually achieve its ultimate goal until the second half of the century, under the reign of Catherine II. She, on the other hand, started to disburse a remuneration to a growing part of the clergy - by way of compensation for the expropriation of the still existing ecclesiastical estates - on a regular basis, thereby turning the clergy into a serving estate, the like of nobility. Financing the clergy from the central budget however, had not become a complete and comprehensive system even by the second half of the nineteenth century. Only those working in institutions performing tasks of the administrative governance of the church and in church schools as well as those serving at small parishes on the peripheries were paid regular salaries even at that point. This treasury "alimony" however, was seldom ever sufficient, therefore clergymen supplemented their income in other ways, mostly by growing crops and relying on donations of the faithful as well as other local funding sources.

Peter I however changed not only the position of the church; he had much more ambitious plans. His aim was no less than leading Russia out of the closed and archaic world in which it existed before he had come to the throne. Having recognised the disadvantages stemming from his country's failure to have moved with the times his ambition was to develop a regulating state which would be capable of not only governing the country in an effective and efficient way but also to enforce compliance with the law and protect the population from despotic bureaucracy.

The reforms of Peter I were highly complex, aimed at making profound, fundamental changes to the Russia of the day. First of all, the tsar wished to rationalise the system of governance itself. To achieve that however, he had to transform the institutions of state power. To this end, the monarch brought down two of the main pillars of the existing system: the "boyar council" and the system of key administrative bodies - a kind of a stewardship - of central power, created in parallel with the expansion of the territory of the country, carrying out the complex tasks of the administration and management of the newly acquired lands. He replaced the first with the Senate while the latter was replaced with a system 
of colleges organised on the basis of a sectoral principle, with nationwide competence. Those then evolved into the forerunners of the ministries which were set up later, in the early nineteenth century.

In transforming the political system, the tsar focused primarily on renewing the state apparatus and the central administrative institutions, besides organising Russia's first regular army and providing it with adequate funding. The reforms were aimed not only at improving the effectiveness and efficiency of the administration of his country but also at enabling the monarch in the new circumstances to exercise reliable and firm supervision and control over both the state machinery and the army. This was the aim of a famous regulation introduced by Peter I in 1722, the so-called Table of Ranks Law requiring civil or military service to the state as a prerequisite for land ownership. Another important result of the regulation was that it rationalised the practice of performing service to the state - bringing it under a harmonised and systematic set of rules - and transformed the conditions and criteria for advancement in the hierarchy. The latter meant that the aptitude and professionalism of the candidates grew increasingly important in the course of appointments and promotions, even giving the system some measure of "democratism" since advancement in the service no longer depended exclusively on one's distinguished ancestry but more and more one's performance in the service concerned.

The rationalisation of governance entailed not only institutional changes but also standardisation and modernisation of the administrative processes. It was at this time that recording instructions on paper rolls was replaced by the use of booklets and books, a more up-to-date form of documentation. An even more profound change was the shift from the use of Cyrillic to Arabic numerals, at last. From 1700 on the years no longer started in September, reflecting the previous Russian approach, but in January, like in the rest of Europe. In all, reforms were introduced in as many areas as possible to bring Russia closer to Europe. Peter I was making very conscious and persistent steps towards adopting western values, way of life, legislation, technologies and terminologies. To accelerate the process, he even went as far as to invite large numbers of experts, professionals and advisors from the west to take important senior positions in the army, the state machinery and industry.

Nonetheless, Peter's the impatient and forced Europeanisation of his country resulted, paradoxically, in conserving social structures that not only failed to eliminate but even amplified certain Asian traits of Russia's development. "Peter the Great - as was pointed out by Ferenc Tallár - made no attempt at shifting the immense agrarian society of the village communities by relying on the potential of the towns that were developing like inclusions among the "pores « of the medieval Russian society, towards a capitalist type 
development based on market, money and commodity relations. Indeed, with his brutal tax policy, drawing extremely heavily on the resources of the taxpayer population, applied in some cases with blood violence, and with his decrees impeding the development of a free workforce base that could have formed the foundations for capitalist production, even repressing any initial forms of its evolution, structuring the entire population of the empire into estates with specific rights and obligations, assigning every single subject to a given community, Peter essentially prevented any continuation of even the very modest development that had begun in this direction" (TALLÁR, F. 1984, p. 22). Nonetheless, the reforms which Herzen called "inhuman Petrovian exercising", still achieved certain results. Russia grew stronger as a military power, capable of effectively responding to the external challenges of the day. This, however, was a costly achievement: the empire fell into an increasingly deep evolutionary trap. But none of that was perceptible at that time. What was clear however, is that by the time of the death of Peter I in 1725 Russia had become one of the five great powers of the continent. The empire he left behind was a power formation geared towards continuous development and upkeep of the country's military capabilities, as its key function and purpose, even though not of the Prussian model of "an army with a state" where the needs of the military were prioritised over any and all other needs and institutions. The reason why this was necessary was because - as Perry Andeson put it - "the unequal development of feudalism in Europe (...) was most typically and most directly expressed in terms of not the trade balance between the relevant regions of the continent but in a balance of arms" (ANDERSON, P. 1989, p. 256). Peter had no time to take any other approach. If he wanted to avoid defeat in the international competition of the day, he had to create a centralised state machinery matching those of the Western absolutisms - and fast.

While strengthening his empire in terms of its military might, for which he built up an adequate military industry background as well, Peter I also made sure that the members of the emerging privileged estate, one that was becoming increasingly uniform and unified on the basis of new foundations, are obliged to serve the state as soldiers or officers; otherwise they could own no lands. This rigorous system was functioning up to 1762 - when the nobility was relieved from the obligation of serving the state. From that point on it was up to them to decide whether they would be willing to continue to perform civilian or military services for the state. Peter III (5 January-9 July 1762) issued a letter of liberty in which he guaranteed that nobility could retain their lands and other privileges even without serving the state. Having been granted such liberty many of the nobility abandoned their positions in which they had been providing the obligatory services and returned to their estates, where some of them, having 
recognised the circumstances in which their serfs were living, found new vocations for themselves. From that point - instead of serving the state and the society - they found their role in devotion and self-sacrifice to "the people", whereby they could pay tribute in practice to the idea of European enlightenment. The enlightened part of nobility started to regard themselves in this new situation more and more as moral leaders and cultural mentors of "the people". They could do so because during the eighteenth century they gradually adopted and adapted many elements of the Western secular culture, while they themselves became organised as an estate and found their new awareness. This process was not unwelcomed by Catherine II, the most important Russian ruler of the age (besides Peter I). For she (just like the key figures of Russian enlightenment, such as Novikov, Fonvizin, Krilov, Radistsev and Karamzin) wished see the largest possible numbers of "active individuals, loyal subjects and patriots who are aware of their moral obligations not only towards the state and the empire but all members of society, including the peasants" as Marc Raeff would put it (RAEFF, M. 1990, p. 134). Meanwhile however, Catherine II spared no effort to make sure that the emerging estates are not allowed to establish foundations or charity institutions trying to help the hungry and the sick or attempt to extend education for the people independently from the state. For though the government looked with benevolence upon enlightened individuals recognising of their moral obligation, committed to social welfare and actively participating in promoting the country's material and intellectual development, it would not have the attainment of their moral, cultural and social objectives leading to any kind of independent and institutionalised activity and the evolution of a dynamic network of social solidarity. This would have entailed the risk of the administration losing control over them. Honestly devoted to enlightenment, exchanging letters with French philosophers of the age, she wished to avoid such carelessness by any means.

Catherine II tried to organise the Russian society in a system of estates known from Western and Central European feudalism. These estates in Russia however, evolved not through social progress but were created a had been intended by the monarch, therefore their members could never be confident that their privileges would last. This is one of the reasons for the still ongoing debate as to whether "real" estates existed in Russia and if they did, when did they come about. For on the eastern edge of Europe - in contrast to Western and Eastern Europe - the rights of the estates were not protected by law against the ruler's will. These rights were granted as a favour by the ruler, i.e. they were guaranteed neither by law that would have been impervious to arbitrary changes by the monarch or by the social weight and political power of the nobility or other estates' corporations. Meanwhile in the West the estates were not only part of the 
social structure but also that of the political system. Key elements of the latter included the parliament, sejm or Landtag, each established and operating on the basis of the estates' representation. However, no representative institution based on estates was present in Russia's development after Peter I. Any freedom or privilege enjoyed by anyone in Russia "was theirs only because they were allowed to have such in exchange for the services performed for the state" (BLUM, J. 1971, p. 150). The nobility owed their civic rights to the ruler's efforts aimed at "providing [its servants] with adequate moral authority and financial security to enable them to carry out their duties" (Becker, S. 1985, p. 28).

At the same time, such rights - stemming from the needs of the state and integrated in the asymmetric structure of the sharing of power between the nobility and the monarch - were rather uncertain, guaranteed by nothing other than the ruler's good will. This is clearly indicated what happened to the charter of the nobility issued by Catherine II, granting privileges to the nobility, as it was in force for hardly more than a decade after its issuance, until it was withdrawn by the ruler's son Paul I (1796-1801), meeting no resistance whatsoever, restoring the nobility's obligation to perform service to the state as well as the possibility of applying corporal punishment to the nobility, which had been banned beforehand. Although a few years later the new monarch Alexander I (1801-1825) withdrew his predecessor's decree and restored the privileges concerned, the nobility remained just as exposed to the monarch's will as they had been before, because Alexander's decision did nothing to change the fact that the ruler in power had the right - depending on the momentary needs of the state and at his/her discretion - to regulate, expand or restrict, the nobility's privileges, just like the rights and privileges of the other estates. Nicholas I (1825-1855) for instance, severely tightened the conditions applying to the nobility's travelling and staying abroad and reintroduced the obligation for the less wealthy Polish nobility, living in the western governorates of the empire, to provide services for the state on a mandatory basis. No matter how anyone would have objected to such decisions, they could not have prevented them from entering into force. The primary reason for this was that the Russian estate of nobility was lacking in corporative discipline and solidarity. And what they were most sorely lacking in was a mutual vertical loyalty. This was a result primarily of the Russian course of development without the forms of institution of the vassal system, i.e. of the fact that there had never been any firm legal foundation for any of the privileges the various estates had in Russia.

The Russian nobility could never defend their rights at court against the supreme power - in contrast to the nobility in western countries - because those rights "had always been based on political foundations" (ROMANOVICH-SLAVATINSKY, A. 1870, p. 214). The privileges of the various estates - and whether they 
were taken away from or added to - were always dominated by current political practicality. The political nature of their rights made it possible for the supreme power to grant privileges to some and strip them from others, depending on the needs of the state" (ROMANOVICH-SlavatinSKY, A. 1870, p. 214). There was nothing to control the supreme power in this, apart from the needs of state administration and the ruler's common sense. Clearly, although with some delay, but certainly by the second half of the eighteenth century, social groups that differed from each other in their legal statuses, i.e. the estates, had emerged (because they were created by the state) in Russia as well, just like they had earlier in Western and Eastern Europe, however, in Russia there was no institutional guarantee whatsoever for the rights and privileges of the estates. It was solely up to the ruler in power to decide whether to expand or restrict them; the ruler could withdraw and grant privileges at his or her sole discretion.

In the system that had evolved in the Russian circumstances the social position and status of every subject of the empire was determined essentially by the estate (soslovye) The law on estates - in force up to 1917 - provided that "four basic types of people (rod) are distinguished within the urban and rural population on the basis of the differences between their respective legal statuses: the nobility, the clergy and the urban and the rural population. The "types of people" and "belonging to estates" however, coincided only in the case of the first two estates.

By contrast, the urban and the rural population formed not specific, clearcut estates but were distributed among various estates that differed from each other in terms of their legal statuses. In terms of estates, urban residents could be honorary citizens - this estate had a hereditary and a personal version - or merchants, artisans or petty bourgeois. The largest estate of the rural population was made up of peasants of different legal statuses, but the Cossacks also counted as rural subjects, forming a separate estate. Unlike peasants, however, they enjoyed a variety of privileges. There was one more estate in the Russian course of development, that is, the so-called aliens. They were the ones to whom the scope of the empire's laws could not be extended for a variety of - ethnic, religious, way of life related - reasons, therefore such people continued to live under their own rules even after being brought under Russian control.

Privileged, that is, non-tax paying, estates among these, included the nobility, the clergy as well as the group formed of honorary citizens. They did not have to pay a poll tax. But this was not the only privilege they had. Another important privilege they enjoyed was that they could not be obliged to perform services for the state, recruited as soldiers or subjected to corporal punishment. By contrast, the estate of merchants was only a partially privileged group. Merchants forming the most affluent segment of the estate were free from the obligation to do military service, until the introduction in 1874 of general compulsory 
military service. The poorest traders however, never had such privileges. Their subordinated position is clearly indicated by the fact that they could be corporally punished just like the petty bourgeois, artisans and peasants.

Ultimately, the poll tax payment obligation main dividing line splitting the society into two fundamentally different groups: the privileged and the rest, that is, the taxpayers. The state's policy relating to society was aimed primarily not at forming estates but at determining which social groups should and which ones should not be included in the taxpayer category. And the importance of being added to the taxpayer group did not lie primarily in the tax payment obligation but in a variety of other legal consequences associated with this status. The taxpayer status entailed the possibility of corporal punishment, restricted freedom of movement and compulsory military service. Those not obliged to pay taxes, however, were exempt from such legal disadvantages. The difference between the two statuses was so significant that it was not considered as a mere status difference by anyone. For belonging to the taxpayer estates had many more other implications. Taxpayers had every right to feel stigmatised. And it was as such, that they were looked upon by the privileged. Surely, the difference between the two categories could not be eliminated by simply abolishing serfdom. So much so, that the psychological barrier between these two groups had not disappeared even decades after the adoption of the emancipation laws.

Even this artificially formed estate structure was endangered in the wake of the French Revolution. The collapse of the ancien régime brought about a new situation across Europe. The revolution raised concern among the rulers of both Eastern and Central Europe. So much so, that it was the revolution, and even more so by Napoleon's army, that convinced the latter - once they recovered from their first frightened surprise - of the need to change their policies by all means. They had two alternatives: either do so voluntarily or be forced to. Recognising this, Prussia was the first country to introduce comprehensive reforms, including the elimination of serfdom in the early nineteenth century, establishing the first institutions of local self-governance introducing general compulsory military service. In Austria however, it was not until 1848 that serfdom was put an end to. In the same year the Austrian emperor provided his people with a parliament - only to dissolve it the next year. The institution of people's representation, the Landtag, established in 1849, was permitted to continue functioning.

By contrast, nothing of the sort happened in Russia. Apart from the first waves giving rise to some concern it took quite a while for the impact of the French revolution to reach the Russian Empire. Moreover, this belated impact immediately triggered two starkly opposed responses. On the one hand, it radicalised the views of part of the nobility's elite and on the other hand it wiped away the central power's inclination to continue adopting western models. The 
conspiracy in 1825 of the Decembrists, claiming a constitution, was a consequence of radicalisation. Their failure however, also meant that Nicholas I, the tsar then taking the throne, broke with the policy of predecessors - Peter I, Catherine II, Alexander I - policy of regarding Europe as a model to follow and tried to block his empire as much as possible from impacts coming from the west. This coincided with building up a new cult of monocracy, and the birth of the conservative concept of a Russian "special way". His however, came in a number of different variants. One was represented by the Slavophiles. However, their idea was significantly freer and more open than the official doctrine based on the triad of "pravoslavie, autocracy and a form of folk nationalism". Although the Slavophiles did not accept western constitutional systems but they also considered that there was a need for the restraining of autocracy. They saw not a constitution but freedom of speech and social autonomy as the means to achieve this. By a community keeping a distance from the state power however, they meant not the society as a whole but only part of it, made up of sufficiently erudite people with qualifications following western models. For them, the future of the country would be secured not by following western individualism but by creating a spiritual community of Russian people (sobornost). They held that the latter had already been achieved in the Pravoslav (Russian orthodox) church and in the village communities (obstina), so a political system most suitable for the Russian character could be built up relying on these very traditions.

Many disagreed with this idealised self-image, rather wittily referred to as "retrospective utopia" by Petr Chaadaev. The modest branch of the westernised segment of the elite of the intelligentsia formed the group most strongly disagreeing with this. What they wished was that top-down reforms in Russia should gradually bring down the autocracy and free the serfs, and then a new constitutional system should bring the country as close to the West as possible. The modest followers of western ideas refrained from idealising Russia's historical development, which they referred to as the "haughty apotheosis of the Russian people" (CHAADAEV, P. 1989, p. 277). ${ }^{15}$ They saw nothing to be envied or followed in its peculiar nature. They thought that the only special feature of the "Russian way" lied in its belatedness, therefore they expected of the new constitutional system quite the opposite of what the Slavophiles were proposing. What they hoped was that the new system would enable Russia catch up with, and becoming similar to, the West. In fact, they - primarily: Boris Tsitserin and Konstantin Kavelin, as well as former Decembrist Nikolay Turgenev - were the ones who, as liberal thinkers, became the first proponents of the adoption in Russia of constitutional ideas. They hoped that Russia would manage to smoothly turn from an autocracy

${ }^{15}$ Chaetae's letter to Friedrich Schelling (20 May 1842). 
into a constitutional system. By contrast, the radical branch of the westernising camp did not trust reforms and saw only a revolution as the possible solution. Initially, even the radical wing was liberal but in the middle of the nineteenth century they began to become increasingly interested in revolutionary socialism. However, there were some complications in adopting in Russia the socialist ideas that had been born in the West. The reason for this was that they could not, in their original form, be adopted by Russia, a country lagging so much in terms of development, so they had to be adapted to the Russian conditions. This task was carried out for the most part by Aleksandr Herzen and Mikhail Bakunin. Having seen the failed revolutions of 1848 and disappointed in the course taken by the development of politics in Western Europe, they had already concluded by the middle of the century that socialism, the West's most progressive ideology in their view, could be implemented in Russia than in Western and Eastern Europe. Their concept was based on the argument that Russia had an institution, that is, the (obstina) which they regarded, in essence, as "socialism itself". There was no private property in the village communities and the lands owned by obstinas were regularly redistributed in accordance with the changing needs of the local peasants.

Consequently, they argued, all it would take to fully implement "socialism" is sweeping away the autocracy in a revolution and then expropriate the estates of landowners. The undertaking seemed all the more promising because the radical camp considered that the tsar's power enjoyed no support from the elite or the "people" (derided and stripped of dignity). And since the history of Russia was full of bloody peasant revolts, mobilising the masses did not seem to be much of a challenge either. They expected the intelligentsia to play a major role in the necessary mobilisation. That is, the special social group whose very existence was due to the process of Europeanisation, initiated by Peter I himself. The bulk of this group was made up by individuals of the gentry and those of mixed estates (raznochinetz). Their political views - if any - were not necessarily radical; only those held radical views who, as children of the enlightenment, could not accept the social inequalities of their age and their exclusion from political processes. This was because there had been no system of representation in place, and the press was not free either, in Russia before the reforms adopted by Alexander II. Therefore, members of the intelligentsia with an interest in public matters could participate neither in political decision making, nor in the preparation of decisions to be made. Nonetheless, they were highly popular: with their propagation of social and political emancipation it did not take long for them to build up ideological control over much of the Russian society and culture. Practically nobody but the liberal or radical intelligentsia was dealing with politics, apart from the bureaucratic elite. And this remained so as long as dealing with 
politics in opposition was treated as an illegal activity. The first substantial change in this was not introduced until as late as 1864, in the form of the zemstvo reform. The establishment of self-governments of a limited set of powers - the zemstvos - created the requisites for people to legally engage in politics, at least at a local level. This, however, still did not change the nature of politics at a national level or that of the political system. The latter continued as an autocracy in an unchanged form, in which there was still no room for any representative institution with nationwide powers, participating in the process of legislation.

The zemstvo reform was one of the sweeping reforms that resulted in a profound transformation of Russia from the 1860s and 1870s. The reform process was triggered by a number of circumstances, besides the painful failure of the Crimean war (1853-1856). The most important among them may have been the recognition that without changing its politics Russia would never be capable of competing on an equal footing - in terms its military might or economic performance - with Europe's dominant powers. The Crimean defeat made it clear that the nearly three decades of Nicholas's policy of turning away from Europe was no longer tenable. It also revealed an urgent need for quick and comprehensive changes to be adopted by the Russian Empire if it was to remain a dominant participant in the European power games of the day. First of all, the serfs' situation had to be sorted, without with there was no chance of catching up. But the abolition of serfdom was not the only thing to do. Major reforms were needed nearly everywhere. The reforms initiated by Alexander II affected society in a variety of way - from the abolition of serfdom to the development of an up-to-date judiciary system, along with the introduction of limited self-governance and general compulsory military service - but left the foundations of the political system unaffected. This then resulted among other things in a situation in which, in the absence of a central legislative body and a norm that would regulate the process of adopting laws in a standardised way, laws were adopted in private circles, exposed to political skirmishes between different interest groups, in a sluggish and over-complicated manner. Politics - or at least its legally pursued form - was still a matter of a few, even if it were the "great reforms" themselves that launched the process whereby an up-to-date political publicity evolved in Russia and politics emerged from the world of court intrigues.

The extensive and highly ambitious reforms affected a wide variety of areas and aspects, left the empire's political system practically intact. The system, though modified in many ways since the early eighteenth century, retained its autocratic nature as long as until the early twentieth century, in spite of many proposals put forth concerning restrictions to be introduced to curb the absolute power. Not only the opponents of the central power, but also its proponents, initiated restriction of the autocracy (samoderzhavie). This idea however, failed to 
meet the will of any Russian ruler, partly owing to the tsarist power's special nature, starkly different from those of western monarchies, and partly for practical considerations. And when the political actually came to be transformed - in response to the bourgeois revolution of 1905-1907 following the defeat at the hand of the Japanese - the dual system (Boris Mironov) or pseudo-constitutional monarchy (Max Weber) put in place was considered by the last Russian tsar to be a consequence of a decision made under duress, the withdrawal of which he never gave up. In his historic proclamation of 17 October 1905 Nicholas II promised to grant and respect civic rights - of religion, speech, association and assembling - and to allow from that point the free establishment and operation of parties in the Russian Empire as well. As a consequence, the first national representative body, the State Duma with a right to consult, was established during the spring of the next year. This then also meant that the subjects of the empire were given political rights, even if in a rather limited form.

The reforms introduced in the second half of the nineteenth century brought about substantial changes but the majority of them turned out to have been only partly successful, while some even produced rather contradictory results. The reasons for this were many and varied. First of all, the economy had difficulties in adapting to the new circumstances during the first decades following the adoption of the reforms, while it continued to rely primarily on agriculture. Owing to the "temporarily obliged" status of the freed peasants, the small sizes of the plots they were allocated, the heavy taxes and the costs to be paid for land ownership, their dependence on the landlord continued in many aspects. Even in villages in which peasants managed to pay off the allocated plots in good time, the economic interdependence continued to prevail, for example in various forms of tenancy. The peasants continued to depend on their landlords primarily because the rent continued to have to be paid, for the most part, by work, rather than money. The landlords had no problem in accepting this situation, for one thing because it was what they had been used to. However, many were misled by the availability of cheap labour, as only few felt compelled to seek for and use more up-to-date and efficient farming methods. An increasing number of landowners refusing to adopt innovations failed or were forced to sell their land. By the end of the nineties nearly half of all land owned by members of the nobility had been mortgaged. This was accompanied by an increasingly marked stratification of the peasant class in terms of wealth despite the fact that both this and the propensity to invest, were significantly counteracted by the ownership of land by village communities.

These were not, of course, the only reasons for the contradictory results of the reforms. Other reasons included the failure to introduce a constitution, the failure to enable people's representation, as well as the fact that the Russian 
society's estate structure turned out to be extremely resilient in spite of the "great reforms". The lack of information among the village communities and the traditions in which they were trapped also impeded progress. However, the state did not have the extensive and adequately qualified administrative apparatus with which it could have effectively intervened at the level of districts and villages and enforce its political will, as would have been required for changing this situation. These factors together formed such a strong opposite force that prevented the reforms from producing anything but limited and contradictory results. However, even in this form they managed to bring about substantial changes in that huge empire.

And it was amidst this large-scale transformation process, by this time affecting the political system as well, that Russia came to be involved in World War One. The Russian Empire was, however, too poor to bear the burdens of a protracted war. The signs of this were already evident, in major conflicts during the nineteenth century but, "luckily" for the tsarist system, both the Napoleonic and the Crimean war could be put an end to - by Russia as winner in the first one and defeated in the other - before its economic weakness became all too clear for all. The country managed to back out of the 1904-1905 war with Japan also before the complete collapse but by that time issues with the persistence and loyalty of peasants, who made up to bulk of the enlisted soldiers of the army, had become evident. Moreover, the unnecessary war generated some severe social discontent and played a substantial role in the break-out of a bourgeois revolution in Russia - decades later than in the rest of Europe -, triggering a process transforming the empire's political system. Unlike before, however, Saint Petersburg could not quit the Great War in good time. The protracted war, placing increasing burdens on the country, lead to major supply problems and then a governmental, and finally a general political crisis. And all this culminated in another revolution in February 2017 for which it did not take long to sweep tsardom away. Not long after the resignation of Nicholas II the republic was proclaimed, political prisoners were freed, the death penalty was abolished, the ethnic and religious discrimination which prevailed until the very last days of tsarist system was done away with and preparations were made for general, equal and direct election by secret ballot, to the Constitutional Assembly. Among its first actions the Interim Government then exercising power recognised the independence of the Polish territories and restored the autonomy of the Grand Duchy of Finland, which had been also part of the empire. But since the Interim Government wanted to carry on with the war and failed to recognise the importance of the land issue, it lost its political power at a dramatic speed. So much so, that hardly half a year after taking power, at the end of October they could no longer resist the Bolsheviks. 
And in the autumn of 1917 a new era began in Russia. However, it took years - of a bloody civil war of immense losses - for the Bolshevik-controlled new power to stabilise its position. The Soviet Union that was established at the end of 1922 made incredible efforts and sacrifices to overcome its economic backwardness and underdevelopment, and to rise again to be one of the great powers. This, however, was only partly achieved. Although the Soviet Union became a military superpower, yet its economic performance could not come anywhere near to that of the United States of America, even during its heyday, in the mid-1970s. And after reaching its zenith, the dynamic of the Soviet economic growth began to weaken and slow down about a decade and a half before the disintegration of the Soviet Union, preparing the collapse of the Soviet type social order and the Soviet state structure at the end of 1991.

\subsubsection{Chronological table}

\begin{tabular}{|c|c|}
\hline Date & Event \\
\hline 859 & Foundation of Veliky Novgorod \\
\hline 882 & Kiev is capital city of the first eastern Slavic state, the Kievan Rus \\
\hline 988-989 & The Kievan Rus formally adopts Christianity \\
\hline 1054 & $\begin{array}{l}\text { The great schism: Eastern Christianity splits from Western } \\
\text { Christianity }\end{array}$ \\
\hline 1108 & Foundation of Vladimir \\
\hline 1147 & Foundation of Moscow \\
\hline 1223 & The Mongolians' first appearance at the borders of the Kievan state. \\
\hline 1237 & $\begin{array}{l}\text { The Mongolian forces cross the River Volga; occupation and forcing } \\
\text { parts of the Kievan Rus into a dependent position commences }\end{array}$ \\
\hline 1300 & Transfer of the metropolitan's seat from Kiev to Vladimir \\
\hline 1321 & Transfer of the metropolitan's seat from Vladimir to Moscow \\
\hline 1380 & Moscow takes control over Nizhny Novgorod and Suzdal \\
\hline 1392 & $\begin{array}{l}\text { The Russian Orthodox church wins autonomy (not yet recognised by } \\
\text { Constantinople) }\end{array}$ \\
\hline 1448 & Ivan III storms Veliky Novgorod \\
\hline 1478 & Ivan III puts an end to Tartar dependence \\
\hline 1480 & Ivan III puts an end to Tartar dependence \\
\hline 1510 & Vasily III occupies Pskov \\
\hline 1547 & Ivan IV adopts the title 'tsar' \\
\hline 1552 & Ivan IV conquers the territory of the Khanate of Kazan \\
\hline 1556 & Ivan IV defeats the Khanate of Astrakhan \\
\hline 1582 & The conquering of West Siberia is completed \\
\hline 1589 & The Moscow metropolitan bishop rises to the rank of patriarch \\
\hline
\end{tabular}


6.1. Orthodox Christian Europe: The Russian Version

\begin{tabular}{|c|c|}
\hline Date & Event \\
\hline 1598 & Last ruler of the Rjurik dynasty, Feodor I, dies \\
\hline 1605 & Beginning of the "time of troubles" \\
\hline 1613 & First Romanov ruler, Mikhail Fyodorovich, takes the throne \\
\hline 1652 & Nikon elected Moscow Patriarch \\
\hline 1697-1698 & "Grand embassy" of Peter I \\
\hline 1703 & Peter I founds the city of Saint Petersburg \\
\hline 1709 & Peter I defeats the Swedish king Charles XII at Poltava \\
\hline 1721 & $\begin{array}{l}\text { Signing of Treaty of Nystad closing the "Great Northern War" waged } \\
\text { since } 1700\end{array}$ \\
\hline 1721 & Peter I proclaimed imperator by Senate \\
\hline 1721 & Peter I dissolves the Patriarchate \\
\hline 1722 & Table of Ranks Law adopted \\
\hline 1762 & Nobility relieved from compulsory state service \\
\hline 1772 & First division of Poland \\
\hline 1783 & Crimea taken possession of by Russia \\
\hline 1785 & Catherine II issues the Charter to the Nobility \\
\hline 1793 & Second division of Poland \\
\hline 1795 & Third division of Poland \\
\hline 1812 & Napoleon's army enters the territory of Russia \\
\hline 1825 & Decembrist revolt \\
\hline 1830 & Uprising in the Polish areas \\
\hline $1853-1856$ & Crimean war \\
\hline 1860 & Founding of Vladivostok on the Pacific coast \\
\hline 1861 & Abolition of serfdom \\
\hline 1864 & Start of zemstvo reform and court reform \\
\hline 1867 & Russia sells Alaska to the USA \\
\hline 1874 & Introduction of general compulsory military service \\
\hline 1891 & Start of construction of the Trans-Siberian railway line \\
\hline 1904-1905 & Russo-Japanese War \\
\hline 1905-1907 & First bourgeois revolution in Russia \\
\hline 1905 & Nicholas II issues October manifesto respecting civil liberties \\
\hline 1906 & $\begin{array}{l}\text { State Duma - the first national representative institution, with a } \\
\text { consultative right - elected }\end{array}$ \\
\hline 1917 & $\begin{array}{l}\text { Revolution in February removes tsardom, revolution in October } \\
\text { sweeps away the Interim Government that replaced tsardom } \\
\text { Bolsheviks take power }\end{array}$ \\
\hline $1918-1921$ & Bloody civil war in Russia \\
\hline
\end{tabular}




\begin{tabular}{l|l}
\hline Date & \\
\hline 1922 & Soviet Union established \\
\hline 1991 & Soviet Union breaks up, Commonwealth of Independent States
\end{tabular}

\subsubsection{Bibliography}

ANDERSON, P. 2013: Lineages of the Absolutist State. London: Verso Books

BECKER, S. 1985: Nobility and Privilege in Late Imperial Russia. DeKalb: Northern Illinois University Press

BiLlington, J. H. 1970: The Icon and the Axe: An Interpretative History of Russian Culture. New York: Vintage Books

Blum, J. 1971: Lord and Peasant in Russia. From the Ninth to the Nineteenth Century. Princeton: Princeton University Press

CHAADAEV = ЧААДАЕВ, П. 1989: Статьи и письма. Москва: Современник

ETKIND, A. 2011: Internal Colonization: Russia's Imperial Experience. Cambridge: Polity Press

FLORENSKY = ФлоренскИй, ПАВЕЛ 1916: Около Хомякова. . Сергиев Посад: Тип. Св.-Тр. Сергіевой Лавры

KAPPELER, A. 1992: Russland als Vielvölkerreich. Entstehung - Geschichte Zerfall. München: C. H. Beck

Milner-Gulland, R. and DeJevsky, N. 1998: Cultural Atlas of Russia and the Soviet Union. New York: Facts on File

MirONOV = МиРOHOB, Б. 2014: Российская империя: от традииии к модерну, Санкт-Петербург: Дмитрий Буланин

RAEFF, M. 1982: Comprendre l'ancien régime russe: État et société en Russie impériale: essai d'interprétation. Paris: Éditions du Seuil

ROMANOVICH-Slavatinsky, A. = РОМАНОВИЧ-СЛАВАТИНСКИЙ, А. 1870: Дворянство в России от начала ХVІІІ века до отмены крепостного права. Санкт-Петербург: Типонграфия Министерства внутренных дел

SzŰCS, J. 1983: Vázlat Európa három történelmi régiójáról. Budapest: Magvető

TALLÁR, F. 1984: Utópiák igézetében. 'Sajátos orosz fejlödés' és az orosz regényforma a XIX. sz. elsö felében. Budapest: Magvető

WALICKI, A. 1975: The Slavophile Controversy: History of a Conservative Utopia in Nineteenth-century Russian Thought. New York: Oxford University Press 


\title{
6.2. Western Christian Europe ${ }^{16}$
}

\author{
LÁSZLÓ ZSINKA
}

\subsubsection{Conceptual bases}

Europe (or the West) has its individual rank in the last 500 years of the history of civilisations. It was the Europeans that started to "discover" the world, as the voyages of Columbus and Vasco de Gama drew attention. The European continent has played an extraordinary role on the way to the global world. The industrial revolution took place in Europe that created the environment for developing a civilisation where the majority of people found alternative sources of living to agriculture. The ideas of social contract, liberalism and democracy, that remodel the relationship of the state and the society, were established in Europe which in the nineteenth and twentieth centuries have changed the political environment of states and nations globally. The values of individualism, against classical community centric societies, were also born in Europe and that allowed cultural modernity to develop. The European continent had economic, political and cultural "innovations" that did not only differentiate it from other civilisations but made the progression unique. One needs to find a response to the question why Europe became the centre of the modern world in order to discuss European civilisation in detail.

This issue of "why Europe" has been studied by the Anglo-Saxon historiography and sociology under "the rise of the West" expression over the last fifty years. Such results have significantly enhanced the better understanding of Europe's civilisation characteristics. During the period of the western hegemony the matter of the unique development of the West/Europe has proven to be appropriate. Today, with the rise of the Asian region, it is clear that the age of western dominance covered only a few centuries of human civilisations and each society finds its own way to modernity. All this favoured the multilinear views against unilinear views and instead of the historical significance of the Atlantic period, that links Europe and North America, it pointed out the world historical role of the Eurasian region that covers great Asian civilisations, too. Post-modern waves also came to effect during the last decades, that aimed to convert the exceptionality (exceptionalism) of the West into relative (relativism).

\footnotetext{
${ }^{16}$ Certain parts of this paper are shortened sections of my book Európa felemelkedése [The rise of Europe], Budapest: Typotex, 2018, with special regard to the following chapters: The beginning of the western Christian culture and The first "take-off" of Europe in the High Middle Ages.
} 
Sociological approach in the second half of the twentieth century, studying the rise of the West, aimed to find a better understanding of the dynamics of modernity. The word Europe was mostly associated with the European integration process and its spiritual and cultural background. However, the word "Europe" is rooted in earlier times than the word "West". Europe has first appeared in Greek mythology, representing the Phoenician princess with whom Zeus fell in love and then took to Crete. The myth refers to the symbolic links between the ancient eastern civilisations and the developing European culture. What seem to be a significant move, from the historical aspect of the concept, is that the concept of a mythological female figure had gone through significant changes between the eighth and the sixth centuries BCE. At the time of the creation of the Homeric Hymns (eighth century BCE) it could barely have had any geographical meaning, while at the age of Herodotus and the Greco-Persian wars (fifth century BCE) it had already been more or less located at its place which today's geography also identifies.

The antique geographical definition of Europe differs from the modern definition of geography, to a certain extent. According to the classic ancient era the edge of the European continent was by the Tanais River (today called Don), whereas by the modern-day definition the line is more to the east, all the way to the Volga. Ancient Greek and Roman people had very little knowledge of Scandinavia or the northern part of the Eastern-European Plain. The modern geographical definition of Europe was created by Volger, the German geographer, in the nineteenth century, who considered the Mountains of Ural, Volga and the Caucasus as the eastern borders of the continent.

Europe used to be a geographic category during the Greco-Roman antiques. The name was barely used in historical sources from the early medieval age, that also expresses the fact that cultural content had been in the process of changes during the end of the ancient times. As a result of the Christian state organisation this cultural content was reborn together with the Carolingian Europe and that was completed with the crowning of Charlemagne, (800). No wonder why, in sources of the times, the Frankish emperor was called the "lighthouse of Europe".

After the millennium the continent increasingly identified with "Christianity". The word "Europe" was barely in use between the eleventh and thirteenth centuries. Instead "Europe", "Respublica Christiana" became common, indicating that the European continent and Christianity are one. The word "Europe" came back in use from the late Middle Ages, along with the development of secularisation. Laicisation of the culture led to the fact that using the word "Christianity" faded out little by little by the seventeenth and eighteenth centuries. Intellectuals had been using the word "Europe" ever since when trying 
to describe the characteristics of the continent. This expresses the intent to describe characteristics of the European civilisation, of which Christianity was an integral but not the only part. Voltaire, during the French Enlightenment, had already noticed the fact that there are many diverse nations and countries in Europe. On the other hand, there is a "European dimension" that does give a common base for national entities but cannot be identified exclusively with Christian belief.

Unlike in ancient times, in the modern age the definition of Europe covered more than just a geographical concept, social and cultural content got added. During the nineteenth and twentieth centuries its intellectual reflexion deepened gradually. Political theorists of the early modern history identified Europe with "freedom" compared to the eastern "despotism". It was considered to be an exceptional scene in human history in the "long nineteenth century", where people's emancipation could come alive that also gives a guideline for the development of world history. Europe became a metaphor for Christian and civic humanist theorists during the first half of the twentieth century and incorporated the values of "freedom" and "Christianity" that can be opposed to left-wing and right-wing totalitarianism. This perspective continued during the cold war when the "free world", now accompanied by the United States of America, confronted with the communist countries. These days the word "Europe" equals the technocrat connotations of the integration process. This involves that the cultural content that makes the European continent so different from others is fading. Certain intellectual groups consider this phenomenon as a "cultural/civilisational crisis".

Compared to Europe, with a great historical background, the West is a new category, used in sociology since the end of the nineteenth century to describe the Euro-American region, as the platform that serves the creation of the modern world. Europe is distinct from the West, not only with regard to the conceptual perspective but geographically too, as the latter covers North America. Europe involves values and ideas that are the subject of humanities' interest, i. e. "freedom", "Christianity', "rationalism", "humanity", while the characteristics of the West are classical concepts of social sciences, i. e. "capitalism", "market", "private property", "rational state". With respect to the interpretation of the characteristics of western development Max Weber, the German sociologist, is eminently significant at the turn of the nineteenth century, who had a decisive influence on formulating the current basic categories of modernity. While Europe represents a cultural content, the West attempts to describe the rise, development and essential characteristics of an economic and social model. The West, geographically, links the dynamic western part of Europe and North America, yet the model it represents can be expanded universally, as it actually happened in 
politicians' statements that proclaimed the universal demand of liberal democracy and free market after the end of the cold war.

It is a must to clear the typical concepts of "modernity" and „modernisation” when introducing the West. In economic terms, modernity means rise of the market and capitalism instead of state-redistribution, formulation of industrial society and organisations instead of pre-industrial agricultural societies. Socially, modernity implied the development of class societies instead of hierarchic societies that is determined by equality by birth and individual achievements. Politically the community of the "governed" is not determined by the "governors" in modernity but the "society" wins priority against the "state", and that is expressed in the definitions of social contract and representative democracy just as much as in the citizens' freedom from the power and in their rights guaranteed. From the cultural point of view, individual-centred values (individualism) appear against community-centred and traditional societies. Modernity has multi-layer meanings and West can be interpreted as a realisation of such dimensions.

The West is not only a universal economic and social model but during the past centuries it has even evolved into a hegemonic civilisation. Today we are facing the closure of this era. Therefore, the discipline of international relations is deeply concerned about the multipolar international system that took over the place of the western hegemony. The development, existence and fall of the hegemonic West has been analysed in many scientific studies during the last decades, even in greater theoretical aspects, of which the roots of western hegemony, Western European development characteristics and the matter of the western economic and social dynamics seem to be basic issues.

Over the last one thousand and five hundred years, the western side of Europe has proven many differences from the eastern side of the continent. A major difference was that of western (Latin) and eastern (orthodox) Christianity, and more and more distinctive marks added to it over the centuries. Furthermore, the Latin West was part of the Protestant movement, the dynamism of the Atlantic world trade that came along with the great geographical explorations, the seventeenth century scientific revolution and the Enlightenment. The western expansion side, the United States of America, has gained economic and political power during the past two centuries that has reshaped power relations between Western European and North American civilisations.

However, it seeded European ideas, the North American world was still different from European ideals. In contrast with the two-thousand-year past, North American settlers have three hundred years of history. North American civilisation also took over Christian principles, representative democracy, separation of powers, the ideas of citizens' freedom and free market. Western 
Christian Europe rather relied on catholic traditions, the balance between freedom and solidarity, autonomous communities, corporative social organisation and traditions of etatism. North American societies are characterised by Protestantism, laissez faire, free market, the minimal state idea, individualism and the governing role of individual initiatives. Such factors clearly prove the boundaries of the distinction between Western European and North American civilisations.

The West is identified with the Euro American world and its two branches: Western European civilisations and North American civilisations. Some interpretations put the emphasis on the differences and highlight their autonomous nature, while other understandings point out the similarities. In this paper Western European Christian civilisation and North American civilisation are considered to be two separate and independent phenomena. At the same time, Western Christian Europe is different from the Orthodox Christian world, too and that implies the acknowledgement of the essential differences between Western Europe and Eastern Europe. Western and Eastern Christianity were not only different in their dogmas and liturgics, but they contributed to the formation of autonomous Christian cultures. These, in relation with other historical factors, resulted in formulating civilisations of different characteristics in eastern and western Europe.

\subsubsection{Basic components and limitations}

Modern science of history often uses the expression "European civilisation" instead of "western Christian Europe" or "western Christian civilisation". When determining the time frames of European civilisation, the question we are facing is whether the Greco-Roman antiquity is an integral part of the European civilisational inheritance. In case classic antiquity is considered to be part of the European civilisation, the roots of Europe reach back to the beginning of ancient Greek history i. e. the age of Homer (eighth century BCE). However, if one takes the view that the history of Europe began with Christianity and German invasions, the birth of European civilisation roots back to the second half of the first millennium CE.

Germanic neo-humanists in the nineteenth century were for the first idea and Oswald Spengler was for the second, in his work called "The decline of the West (1918-1922)". Civic and Christian humanist theorists and historians between World War I and World War II, Gonzague Reynold, Christopher Dawson and Herbert W. Rüssel, emphasised the exceptional significance of Christianity with respect to the formation of Europe. At the same time the Christian-antique synthesis was still considered to be a key phenomenon that 
represented the adoption and reshaping of the classic ancient legacy in the framework of Christian culture. In their perspective, although the history of the European civilisation started with Christianity, unlike Spengler, they did not consider antiquity being an "external" factor.

Contemporary historiography movements have not proven specific interest in defining the beginning of "Europe" as a civilisation unit. However, it is true that the majority of European cultural historians consider Christianity to be a fundamental factor. Historians are divided over the role of classical antiquity, but the recognition of the role of Christianity is undoubted. Still, modern history and social sciences are divided on which aspect of Christianity is emphasised in European history. Recognition of the historical impact of Christian belief makes it possible to speak of "Western/Latin Christian Europe", "Western Christian civilisation" or "Western European Christian civilisation" as synonyms for "European civilisation".

Certain aspects of Western Christianity allow us to define more precisely what is meant by the historical role of Christian belief. On the one hand, Christianity is not only a religion, but a faith and doctrine that has social consequences. Therefore, one can talk about a social dimension of the Christian belief, that had influence on the development of social structures and political institutions. The non-political movement attitude of Christianity, unlike Muhammad and his successors Jesus Christ did not establish a state, leads to a distinction between sacred and profane, which in long term leads to a distinction between religion and politics, and to secularisation and laicisation in European history. In contrast, in the scope of human civilisations formed by other world religions, the difference between sacred and profane as a problem makes less sense. On the other hand, although Christianity has the "social dimension", unlike Hinduism, it did not fully identify with any social system, but proclaimed a universal mission and recognised the relative autonomy of the social sector. Christians applied Roman Law and unlike Islam, no autonomous religious law was created to rule social relationships. In the English language the difference between Christendom and Christianity illustrates the phenomenon. The former refers to Christianity as a religious, social and political universe, while the latter refers to the individual's faith. The coexistence of these two concepts in itself expresses the particular feature of Christianity that it did not want to identify with any socio-political or legal-ethical system but sought to define itself as the belief of the individual. In this perspective, it must also be pointed out that in European history one can never speak of a "perfect" Christian society, or of the so-called Christian "great middle ages" as its manifestation. Although the Middle Ages (twelfth - thirteenth centuries) were a great era of Christendom, this does not mean that the faith of individuals (Christianity) was more or better, compared to 
the preceding or following centuries. Even in the brightest times of the Christian Europe, we do not encounter a homogeneous Christian society free of contradictions, which does not mean that the great achievements of the medieval Christian civilisation are questioned.

Christian faith and Christian culture must be clearly distinguished. During the last two centuries, we can talk less about a "Christian Europe", either in the sense of faith or as a social or ethical norm, but the attitudes of Christian culture still influence the development of contemporary European civilisation. Today, only ten percent of the European population are practicing Christian religion. Yet the reflexes of the Christian civilisation orientate secularised societies to some extent.

It should also be pointed out that the social dimension of the Christian belief cannot be separated from the civilisation in which it effects. It was only in the Latin West that Christianity led to an increasingly distinct separation of sacred and profane spheres, while in the field of Orthodox Christianity the close link between religion and state remained. Throughout the history of the Byzantine civilisation, Caesaropapism always existed, which meant the political power had authority over the Christian Church. This phenomenon appears also in the history of Orthodox Russia. In the Latin West, for centuries after the fall of the Western Roman Empire (476), no emperor was crowned, and that resulted in the independent status of the papacy. The early Germanic kingdoms had no sufficient authority to question the autonomy of the papal power, while in Byzantium the power and continuity of the empire was available to limit the power of the Patriarch of Constantinople. Consequently, the increasing separation of the sacred and the profane sectors was not only due to the Christian doctrine but effected in special historical context. There is a reason for the fact that the Investiture Controversy in the eleventh and twelfth centuries, in support of the distinction between the sacred and the secular spheres, took place in Western Europe and not in Byzantium.

Western Christian civilisation was not only shaped by Christian religion, but influence of other historical factors must be considered too. One of the most exciting phenomena in the first millennium $\mathrm{CE}$ is the profound mutual influence between Christian religion, antique culture and barbaric tribal traditions. The relevant views of Christian humanist historians (Dawson, Reynold) has already been mentioned, that says Greco-Roman antiquity may be defined as a separate cultural entity in relation to Western Christian civilisation, but its reception and transformation had been shaping European culture since the early Middle Ages to German neo-humanism. As a result, Classical Antiquity lost its "alterity" and became more and more integrated to Western Christian Europe, to the extent that some modern humanists, such as Humboldt, considered this phenomenon being 
the essence of European civilisation. The "implantation" of antiquity into Western Christian civilisation draws attention to the fact that Greco-Roman antiquity is not only an outward antecedent of European culture but has become an effective factor for centuries. Nevertheless, Western Christian Europe has become much more than the mere accomplishment of classical antiquity. Based on all these considerations, Western Christian civilisation can be defined as a "second-generation" civilisation whose history was influenced by the ancient legacy, but it is far from an overall determination. Despite its ancient history, the Christian West can be regarded as a fundamentally novel civilisation.

A similar phenomenon can be observed in barbaric tribal cultures. During the first millennium CE, the relationship with Christianity and antiquity and German peoples became stronger. Interactions could have evolved on a cultural level, that, for example, involved the adoption of antique culture within the framework of a Christian school in barbarian areas. Social structures could also have merged, and the "transformation" of the late Roman estates into medieval feudal estates would be a good example.

It is an established topos that the history of European civilisation is described as a combination of three fundamental factors, (1) Jewish and Christian religion, (2) Greco-Roman antiquity, and (3) tribal (then national) cultures. According to this, the essence of European civilisation is the profound interaction that has developed in the framework of these three basic elements. Such combination of basic elements of civilisation also point out that Europe is not a "uniform", homogeneous civilisation, but a result of complex socio-cultural processes, where the extraordinary depth of interaction has created the special character of European culture. Some consider that "Europe" has been existing since the interaction among the three basic elements exists. Others suggest that we must consider the medieval "melting pot" as a key, where these fundamentals were so pervasive that they have radically transformed one another. The dialectic of the resulting tensions has become a shaping factor in European history, which has had an impact all the way until the modern age.

Should one accept that the "essence" of Europe is the presence and organic interaction of these basic civilisation elements, the beginning of the European civilisation, in line with the above, would be the first half of the first millennium, when the evolution of the correlations was already noticeable in the age of Late Antiquity. This concept defines the Western Christian civilisation as a "complex civilisation" that had not been shaped by Christianity alone. However, Christianity gained exceptional significance, as it was the foundation that clamped the rest together. The "umbrella-like" Christian culture influenced and "controlled" the takeover of the antique and barbarian legacy. In this sense, one can say that the "content" of European civilisation was shaped by Christian, antique, and national 
components, but its "form" was shaped solely by Christianity. The Swiss historian, Gonzague de Reynold, also referred to this when talking about the Europe under "Christian roof". The history of European civilisation until the end of the eighteenth century can be described as the interaction of the three basic civilisation elements. But, the rise of "modernity" has reshaped the image over the last two centuries, leading slowly to the decline of Christian faith and classical culture. In this light, it is understandable that the twentieth century cultural criticism prefers to speak of the "end" of Europe. Against pessimists, it should be noted that, despite the decline of the Christian faith lots of the Christian values continue to exist in secularised form in the modern society. Such is the idea of humanism, incorporated in the absolute value of human dignity, or the strong social expectation of a desirable balance between freedom and solidarity. Although interest in classical culture has decreased, rational criticism and hermeneutical culture have remained. Based on these, we can still talk about Western Christian civilisation or European culture, although in a different aspect than before the modern age.

Western Christian civilisation is a "second-generation" and "complex" culture, of several components, dating back to the late Roman world, where Christianity first became a power to shape history and ancient societies encountered barbarian people. Opinions are divided on the "end" of Western Christian Europe. "Pessimists" emphasise the loss of old European values, while "modernists" point out that the universal model of Western modernity has been accomplished via market economy, capitalism, liberalism, democracy and individualism. The assessment of the last century depends on the interpretation of modernity in the history of Europe. It is considered to be a phenomenon accomplishing the Western European civilisation that roots in the Middle Ages or it can be the "antithesis" of modern European civilisational values. In the latter case, talking about Western Christian civilisation in the twenty-first century is still questionable.

\subsubsection{The beginning of the western Christian culture (200-1000)}

The cultural geographic boundaries of Western Christian Europe were consolidated in the early Middle Ages (between the seventh and eleventh centuries) to the north of the Alps. The prosperity of the antique civilisation, whose features formed from the eighth century BCE in the Mediterranean basin, prevented that. Classical antiquity was a coastal urban civilisation, whose economic and cultural consistence was ensured by the great maritime infrastructure of the Mediterranean. Ancient Greek polis, after the great Greek colonisation (between the seventh and sixth centuries BCE), not only covered the Aegean area but also the western basin of the Mediterranean and the Black Sea. Greek poleis were usually 
located geographically near the coast. Ancient civilisation retained its maritime nature even after the establishment of the Roman Empire. In the days of Augustus, Rome conquered the whole of the Mediterranean, which was called mare nostrum ("our sea") for a reason. Greco-Roman antiquity became identical with the Mediterranean world, and this fundamentally influenced the character of ancient civilisation.

\section{The antique legacy}

In many aspects, the ancient legacy influenced the Western Christian civilisation. Polis was an ancient Greek foundation, which, for the first time in European history, represented the idea of a self-governing autonomous community against the "up-bottom" states and empires. The antique liberty-topos has become one of the most prominent legacies of European civilisation that is barely found in pre-modern societies. Greeks were the first to formulate the idea of civic liberty against the despotic states of Asia. Although different from the liberal idea of freedom of the "moderns", as a pattern it worked in medieval and renaissance city-states (classic republicanism), and in European political tradition in general. Also, despotism was morally condemned, and arguments were put forward for taking legal actions against it. Therefore, the idea of the accountability of the power dates back to significant past in European history.

Due to their pioneering role in philosophy, education, literature, fine arts and professional sciences, the Greco-Roman legacy has fed Western Christian civilisation until modern times. Classical antiquity had the power of an aesthetic norm, which was interpreted differently throughout the periods of European cultural history but was always effective. Only the debate between "ancients" and "moderns" in the context of French classicism in the seventeenth century led to the recognition that works of the modern age have their own value and may even be better than the values of Greco-Roman antiquity. The argument between the ancients and the moderns established the progressive approach of modernity, but before that the works of antiquity proved to be dominant.

One of the great legacies of classical antiquity is captured in the development of humanism. Humanism, as an anthropocentric concept, can be interpreted as a fundamental value of European civilisation, that even in modern times was a common denominator between Christians and atheists. But it has to be seen that, the expression of "anthropocentrism" was the result of a long process in ancient times and, despite its great achievements, was only marginally accomplished. They did not use the word "humanism", this is a term of modern origin, first used by Niethammer on the part of German neo-humanists in the early nineteenth century, but the word humanitas was used. 
In the classical period of ancient Greek culture (fifth-fourth centuries BCE), literary and philosophical texts had not yet invented a consistent image of human, placing it in the centre of the cosmos wilfully, although Greek literature expressed human feelings and thoughts in a more nuanced way than ancient Middle Eastern literature. In the classical age, Greek humanism was mostly embodied in fine art, when the beautiful human body was portrayed in harmonious and live proportions. Statues did not represent the idea of human dignity but sought to carve the beauty of the gods and the Olympians, while also testifying the greatness and beauty of man. Human dignity became a subject only after the conquests of Alexander the Great, in the Hellenistic age (third-first centuries BCE), when the significance of school education increased. From this point on, the Greeks believed that human dignity can be achieved through the acquisition of literacy, the encyclios paideia, that is, through learning. The culture became known in the spirit of the valid educational ideal (paideia), which also orientated the material of education. According to the Greeks, school education will uplift and perfect a person and promote people's dignity.

The school humanism of the Hellenistic age was a late phenomenon and that is what Romans inherited. There is a reason why Cicero in the first century BCE translated the Greek word paideia into Latin humanitas, and the educational humanism he incorporated was inherited throughout the Middle Ages until the Renaissance. Despite its achievements, ancient humanism had its limitations, and even its survival would have been questionable unless it encountered Christianity, which had its own humanistic tendencies, biblical humanism, Christian humanism. By doing so, it embraced and reinforced antique humanist heritage. Antique works in the eighteenth and nineteenth centuries were not popular because the original meaning of ancient humanism was accurately understood and experienced, but due to the fact that the modern bourgeoisie preferred to discover its own anthropocentric approach in antique sculptures and literary works. That is why Greek, Roman and Renaissance works of art gained enormous popularity in the eighteenth and nineteenth centuries.

In the first centuries after Christ, during the early imperial period, a cultural geographic line was drawn with far-reaching consequences in the Mediterranean. When Rome conquered the eastern basin of the Mediterranean, many Greekspeaking cities came under its control. The Roman Empire absorbed the Eastern Mediterranean, which used to be the core of Hellenistic culture. The eastern provinces of the empire were areas of Greek culture, while Latin language and culture was spread in the western provinces like Western Europe and North Africa. The cultural differences between the Greek East and the Latin West were still obscured by bilingual schooling throughout the empire (bilingual culture) throughout the early centuries, but later the differences became more significant. When 
in 395 the western and eastern empires finally split, the establishment of a political boundary meant the separation of the Latin and Greek parts of the empire. In the early Middle Ages, the Greek identity of the Byzantine Empire got strengthened, as did the identity of the Latin West. The Greek East and the Latin West provided a cultural foundation for the differences between the Roman Catholic and Orthodox churches, which became one of the major separation lines of European civilisation.

Despite the maritime nature of the Roman Empire, the conquest of western European provinces, Hispania, Gaul, Britain, took control of large areas of the mainland from the first century BCE until the first century CE. The Romanisation and Latinisation of the Western European region was largely rooted in Celtic culture, that led to the expansion of urbanisation and literacy. Romanisation evolved over centuries, Gaul was under Roman control for about four hundred years, and it proved to be profound by laying foundations for the formation of Neo-Latin languages. In the provinces, not only Roman civilisation but also Christianity spread rapidly during the first centuries of the empire. In the process of developing the cultural-geographical boundaries of Western Europe, areas that were under Roman rule for a long time must be treated differently. In the Middle Ages, modern-day France and Spain had a different civilisation background than the areas east of the Rhine or England, where Anglo-Saxon immigration heavily overruled Roman presence. It is not a coincidence that France today, which had deep Romanisation and evangelisation bases, became the core area of medieval feudal society.

\section{Barbarian-Germanic legacy}

The encounter of antique and barbaric societies played a major role in the formation of Western Christian Europe. The Romans, in their conquest of Western Europe, came into contact with the Celtic world when Julius Caesar occupied Gaul (58-49 BCE). During the early Roman Empire, in the first and second centuries, they also encountered the Germans while protecting the Rhine border.

The Celts used to live in western Europe, parts of modern-day France, Belgium, the British Isles, Germany and Austria. They were the first Iron Age population of Western Europe, known by the name and led by armed aristocracy. On the eve of the Roman conquest their settlements had a rudimentary urban character. The Germans and the Celts lived in a tribal organisation, although it had already begun to loosen when they encountered the Romans. None of them can be considered true nomadic people who lived in the Eurasian steppe corridor and in the grassy areas north of the Black Sea. Germanic and Celtic peoples were rural, farmer groups to whom the transition to peasant societies was easy. 
In Western Europe, unlike in Eastern Europe and Central Asia, nomadism has never gained a foothold, but peasant life has played a key role since the beginning. The difference between the barbarians and the settled Romans was not that they migrated for grazing of their animals, but in general they did not live in cities and literary and other civilisation achievements were less typical for them. The great migration of people that caused the fall the Western Roman Empire did not occur because the Germans sought new pastures for their animals, but generally looked for the more favourable climate and more prosperous south, and got oppressed by other ethnic groups, mostly the nomadic Huns.

In Europe, during the "Great Invasions" (third-sixth centuries), language boundaries were created which later influenced the continent's history considerably. Romanisation on the Italian peninsula had been prevalent since the early conquests, so the Latin language spread at the end of the republic. From the first to the fourth centuries, Romanisation developed in Gaul and Britain too, but Celtic language islands had survived. The Germanic Franks from the Rhine settled down in the areas of Northern France at the time of the migration. On the southern part of France, the Romanised population preserved their language and culture, while in the north of France the Germanic influences were stronger. After the Roman legions left England, the Romanised Celtic (British) population eventually was weaker against the Germanic Anglo-Saxons attacking from the direction of Scandinavia. Thus, the Anglo-Saxon linguistic and cultural layer became dominant, and Celtic culture survived only on the Irish Island.

After the end of the migration in the late ancient times, Germanic and NeoLatin languages shared the western half of Europe. Neo-Latin languages dominated in Italy, in the Iberian Peninsula, in southern France, (later Occitania), while in Germany and England the Germanic language dominated. In the northern part of France today, Germanic and Latin elements were balanced in the early Middle Age. The Celtic population survived only in smaller language islands, mainly in Bretagne and Wales. One of the main features of the emerging language map is the dichotomy of the Germanic Northern Europe and the Neo-Latin Southern Europe. It is understood that Leopold Ranke, one of the greatest German historians of the nineteenth century, derived a characteristic feature of European civilisation from the coexistence of Germanic and Latin peoples.

The western half of Europe is characterised by the coexistence of Celtic, Germanic, and Neo-Latin peoples and languages. If Eastern Europe were to be included in the study, we should mention the Slavic languages and the Turkish populations (Huns, Cumans) in the steppe corridor north of the Black Sea, as well as the Greek language in the Balkans. In the western direction, Greek cultural influences showed up mainly in southern Italy. 
As far as the linguistic components of Europe are concerned, we must not forget the presence of the Jewish population who lived in diasporas in Christian Europe. The greatest cultural influence was exerted by the Sephardi Jews in the Mediterranean. Muslim populations also showed up in Western and Southern Europe, mainly as a result of the early medieval conquests. Some remained in the Iberian Peninsula, southern Italy and Sicily even after the Christians reoccupied these areas. The Jewish and Muslim minorities were never substantial, but their cultural significance was far greater than their number.

Of the barbarians, the Germans played the greatest role in shaping the socio-cultural circumstances of the European continent. The German myths survived in medieval and then modern culture (Wagner operas). The ideal of a German free warrior made it difficult to submit to personal dependence-in emerging feudal societies and sustained the need for political participation. In medieval England, some institutions of political participation in local governance can be traced back to old Germanic legal customs. Regarding the success of nineteenth century Scandinavian modernisation, it is usually noted that the path was clear from "tribal democracy" to modern democracy in these societies. In addition to these examples of social history, some philosophers of history, such as Oswald Spengler, have called attention to the impact of the "Germanic spirit" on European civilisation.

\section{Formation of the Latin Christian cultural community}

The greatest change of the early Middle Ages (seventh-eleventh centuries) is that the centre of the Mediterranean civilisation, that left antiquity behind, got shifted to the northwest. The formation of Western Christian civilisation took place on the territory of the Frankish Empire between the Rhine and the Loire, today north of France, between the sixth and the eighth centuries. In contrast to maritime and urban antique civilisation, Christian Western Europe was a continental agricultural civilisation controlled by the military landowner elite instead of urban middle classes. Along with the territorial shift, the consistence of the Mediterranean ancient civilisation also loosened.

The unity of the ancient civilisation remained for some time after the fall of the Western Roman Empire (476). Although the political consistency of the Mediterranean was over, sea routes provided economic and cultural circulation for a century and a half. The coherence of the Mediterranean ceased when Muslim armies occupied the eastern and southern shores of the Mediterranean in the seventh century. From that point on, two opposing cultures, Christian and Muslim, faced against each other in the Mediterranean, and significant territories of the ancient Eastern Christianity, (Syria, Egypt), had come under Muslim control. 
All this contributed to reshaping the balance of power within Christianity, which led to the fact that the significance of the Roman and Byzantine churches increased. Islam shifted the centre of Mediterranean Christianity to the north, facilitating the birth of Western Christian Europe.

The Islamic threat also catalysed the outlining of the Latin Christian identity. When Charles Martel's heavy cavalry stopped the Muslim army heading toward Tours in central France at Poitiers (732), the victory of the Frankish Mayor of the Palace became the "birthday" of the Christian Europe to the north of the Alps. Although historians do not agree on the significance of the Battle of Poitiers, some believe that the Frankish army has protected the European Christian civilisation, others consider that the battle was a minor battle, it is certain that the victory of the central power of the Western Christian civilisation, the Frankish state, prevented Muslims from invading Western Europe.

Other factors also pushed the disintegration of Mediterranean Christianity. The iconoclasm movement in Byzantium (eighth-ninth centuries) played a major role in destroying the relationship between the Pope and the Byzantine ruler. Since the fall of the Western Roman Empire, no emperor had been crowned in the West. The popes recognised the Byzantine emperor as head of the entire Roman Empire. He was accepted as the formal ruler of the Western Roman territories, including Italy, although he could not exercise his jurisdiction due to the German kingdoms. In return, the emperors acknowledged that the Pope was the head of the entire universal church, which did not mean any intervention in the affairs of the eastern churches. In Christian antiquity, the five patriarchs, Constantinople, Alexandrian (Egyptian), Antiochian (Syrian), Jerusalem, and the Roman as the "Patriarch of the West", jointly controlled Christianity. Although they had broad autonomy in governing their own territory, the pentarchy they represented, and the universal councils embodied the consistency of Mediterranean Christianity.

There have been fractures in Mediterranean Christianity already in the fifth century. Assyrian and Egyptian Christians, being Monophysites and Nestorians, had expressed objection about the Christological dogma of Rome and Constantinople since Chalcedonian Council in 451. In the long term, the Chalcedonian teaching promoted the option of Christian humanism interpreted broadly, since it considered the deity of Christ as complete as his humanity, and the two were closely linked. With regard to the Chalcedonian dogma, the Roman and Byzantine churches have, for the time being, found a common ground against the Eastern Monophysites and Nestorians.

A few centuries later, the above-mentioned iconoclasm created fractures between Rome and Byzantium. The debate sought to force the will of Byzantine emperors into the Church, where the depiction of Christ, saints, and sacred images 
was considered idolatry, similarly to Jewish and Muslim religions. The popes and the Latin West, in the view of Pope St. Gregory the Great (590-604), were in favour of the iconography. Due to the deteriorating relationship, the Byzantine emperors did not pay enough attention to give the Pope proper protection against the attacks of the Italian Langobard princes. Among other things, this justified Pope Stephen's decision, who travelled personally to Frankish territories north of the Alps in the mid-eighth century and asked Pepin the Short for support against the Langobards.

The historical alliance between the papacy and the Frankish Kingdom significantly changed the internal power lines of Christianity. On the one hand, it expressed the growing power of the Western European region, that represented by the Frankish state. On the other hand, the popes' attention, in the ecclesiastical, cultural and political sense, got increasingly directed towards Europe, north of the Alps. When in 800 Pope Leo III in Rome crowned Charlemagne to be emperor, the formation of Western Christian Europe seemed to be coming to be accomplished. After three centuries, an emperor reigned in the West again, leading to legitimacy disputes with Byzantium, who considered itself the sole representative of the Roman legacy. The growing self-confidence of the Pope and the Frankish rulers rests not only on the military victories of Charles Martel, Pippin the Short, and Charlemagne, but also on the successes of evangelisation of the preceding two hundred years, which allowed the Frankish Empire to become a spiritual and intellectual focal point and centre of power for the expanding Western Europe.

Major changes took place in Western Europe in the two centuries prior to the Roman emperor's coronation in 800. Some historians duly called this era the "birth of Europe" (the making of Europe). This term refers to the birth of the religious and cultural unity of Latin Christian Europe in the seventh and eighth centuries. Such changes are linked to the success of Christian evangelisation. At the time of Muhammad's activity (around 610), the heart of Christianity was in the Mediterranean, and the areas to the north of the Alps seemed remote. During the Roman control, Christianity was widespread in modern-day Italy, Spain and France, while English and German areas were still awaiting conversion. In the British Islands, Irish Christianity reached success since the fifth century, developing its own traditions yet isolated from Rome. In England, as a remembrance of the Roman authority, much of the Celtic British maintained their faith, but with the Anglo-Saxon conquest, Christianity seemed to recoil. As a result of the evangelisation, the Anglo-Saxon kings gradually converted to Christianity in the seventh century, and it was of great importance that the conversion took place in cooperation with the Roman Church. With the decline of isolated Irish monks, church traditions, liturgical customs, and school 
education from Rome finally linked the British Isles into the stream of Western Christianity.

Trends were similar to tendencies in Germany. The Germanic tribes to the east and south of Austria, the Franconian tribe of the Rhine, were still pagans in the fifth and sixth centuries. Although Christian monks were present in these areas, the true success of evangelisation was only achieved through the activities of St. Bonifatius in the eighth century. Bonifatius, of English descent, maintained excellent relationships with the popes and the Frankish court. In cooperation with Rome, he laid the foundations not only for evangelisation but also for church organisation and school education in German territory. There is a reason for him to earn the title "Apostle of Germany" in the tradition of the Catholic Church. Through his activities, much of Germany has become part of the Latin Christian cultural community. The evangelisation of the English and German territories expanded the dimensions of Latin Christianity north of the Alps. In about 600 Christian faith and culture was present in Italian, Spanish and French territories, but by about 800 Christian kings ruled in England, and in Germany the only challenge left was the conversion of combative Saxons. François Guizot, a nineteenth-century French politician and historian, has written about the five "great nations" of (Western) Europe in his book on the history of European civilisation, mentioning the English, French, Spanish, German and Italian nations. With reference to Guizot, around the year 600 the future of English and German lands was still doubtful, but around the year 800 the five "great nations" became Christian. The success of evangelisation has proven itself in the cooperation with the Roman Church, which allowed the culture of Latin Christianity to be consolidated. That is why we can talk about a "Latin Christian community" from the seventh-eighth centuries. These changes have occurred with the territorial expansion of the Christian West. Christianity, which rejected Islam, had gained new ground and shifted its focus. The establishment of the Carolingian Empire only crowned this tendency.

Along with this process, the disintegration of the unity of the Mediterranean was completed. When Emperor Justinian (527-565) sought to restore the unity of the Roman Empire, his idea was still based on the idea of the consistence of Mediterranean civilisation. The fact that with the expansion of Islam in the seventh century, has already been mentioned, this civilisation unit was ceased. Since then, the maritime front line of conflicts between Christians and Muslims has been a significant component of the battles between the two religions. For some time, the Roman and the Byzantine Church maintained their co-operation, as evidenced by the so-called Greco-Syrian popes, Greek and Syrian church leaders, at the beginning of the eighth century, in Rome. This was broken by the iconoclasm, which, in Byzantium, eventually ended in victory for 
iconophiles that was closer to the Roman Catholic position. Despite this, the growing religious and cultural distance between the two churches could not be reversed, although formally restored several times before the Schism of 1054. On the eve of the millennium, there were three civilisations already in the Mediterranean, Byzantine Orthodox, Muslim Arabic and Latin Christian cultures.

In spite of the victory of the iconophiles, worded by St. John of Damascus, art in Byzantium was in strict boundaries, set by theological doctrines. Western Christian art, as St. Gregory the Great put it, served to tell holy stories, while in Byzantium it proclaimed divine glory, in its strict boundaries. Given that Western art had been seeking to tell narratives since the beginning, the artistic ways to of expression were much broader, enabling the Western Christian civilisation art to be open for verism, an increasingly true presentation of reality. As a result, Latin Christianity has, compared to other civilisations in a unique way, embraced the potential for change and development of styles and opened the way for the expression of anthropocentric ("humanist") content. The broadest framework for this artistic progress was provided by the consequences of the early medieval antiiconoclast arguments.

\section{The historical role of the Carolingian Empire}

After the year 800, the Carolingian Emperor not only realised the possibilities of the development of the Latin Christian cultural community, but also constituted an exemplary experiment in Christian state organisation, which filled the unity it created with social and cultural content. The Frankish alliance with the Pope performed the unification of church liturgy, monasticism, school education, and social and political structures. All this took place in the universe of the early medieval kingdom ideal, where sacred and political functions were closely linked, although the two spheres had always been distinguished. On this basis, some historians considered Charlemagne (768-814) to be the "founder" of Europe, though this is an ambiguous statement, since the Frankish state was not identical with the entire Latin Christianity (Map 31). Yet, the social and cultural transformations that emerged within the range of the Frankish Empire served as a model for the whole of Western Europe and later at the turn of the millennium for the Central and Northern European periphery. In the history of the European civilisation, Charlemagne became the only ruler of the unity of the Christian West, a great general and statesman who promoted the organisation of the Christian church and culture. 


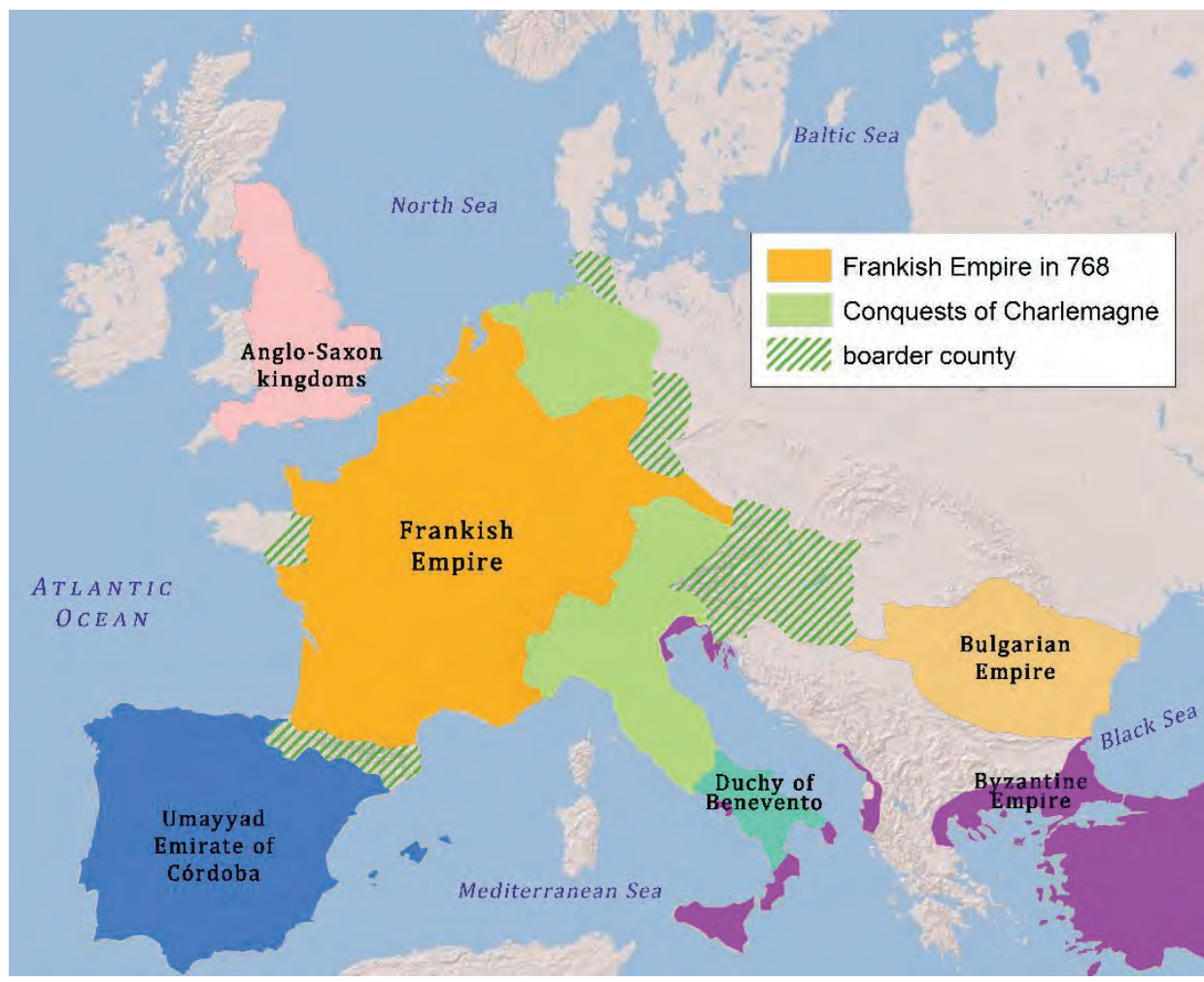

Map 31: Carolingian Europe

Source: Edited by ÁGNES VARGA

The consequences of the Carolingian church and cultural reform had an impact on the entire European culture. Charlemagne and his counsellors sought to consolidate the texts of the Bible and the liturgy in the empire. The insufficient education of the priesthood and the monks carried the risk of deteriorating the texts due to the spread of vernacular languages against classical Latin that used to be the ground of sacred texts. Christianity, due to its widespread illiteracy, has faced the challenge of becoming a verbal culture, which can make it difficult to reproduce sacred texts accurately. Carolingian reforms sought to react to this by spreading the culture of literacy and by creating normative texts that underlie ecclesial and secular education. The main tool for this was using late ancient Latin, which generated far-reaching consequences until the Reformation.

Generally speaking, Christianity is the religion of the "sacred text" and all people need to read and understand the evangel. In a larger historical perspective, the spread of Christianity has led to translating the Bible to native languages and to the rise of national literature, as is the case in Middle Eastern Christianity. Western Europe is rather the exception, where the supranational culture based on 
Latin language prevailed until the Reformation. All of this is due to the Carolingian reforms, which have had significant consequences and have given the European culture its character for centuries. Carolingian reforms allowed to preserve the ecclesiastical tradition accurately, but they created a "universal" culture separate from the local societies, which determined the university education of the entire High Middle Ages (twelfth and thirteenth centuries), and even Renaissance humanism (fourteenth-fifteenth centuries). The supranational Latin culture of the Middle Ages has become one of the most important components of the coherence of Western Christian Europe, that has no equivalent in the history of the Orthodox East. National languages began to develop relatively quickly from this initial state, and the Reformation catalysed this process in the early modern age. The universality of the Roman Church and the cultural role of Latin made it possible to interpret Western European civilisation in the dichotomy of supranational and national cultures.

The territory of the Frankish state covered most of France, the Benelux states, Italy and Germany. Charlemagne occupied eastern German Saxony, Bavarian and Austrian territories, the Transdanubia and the northern part of and the Iberian Peninsula. Not only did the emperor's coronation lead to the fact that an emperor reigned in the Latin West, but it also expressed the need to unite Latin Christianity in a single empire. Although the Anglo-Saxon kingdoms have always remained independent, for the first time in European history Charlemagne established a Christian empire centred in Western Europe and not in the Mediterranean.

The Carolingian Empire considered itself the successor of Rome. Until modern times, the idea of Rome can be regarded as the foundation of European political identity. Rome could be understood as a universal empire, which, in its height, incorporated all of Mediterranean antiquity under a single political umbrella. After its break and then the fall of the Western Roman Empire, the Byzantine East retained a "Roman" sense, which was well illustrated by the fact that Latin remained the language of administration and the army until the sixth and seventh centuries. When Charlemagne and Pope Leo III in 800 resettled the empire in the west, it was grounded on the idea of Rome, similar to the Saxon Otto the Great, who founded the Western Roman Empire in 962. In the modern age Napoleon could be mentioned, whose coronation to emperor (1804) reflected the political tradition of the idea of Rome, or Emperor Francis, who, once the Western Roman Empire ended in 1806, found it important to establish the Austrian Empire. As the empire itself adopted Christianity during the late antiquity, the demand for a political supremacy developed in the Roman idea within the scope of European Christian civilisation. 
On the other hand, it must be pointed out that the medieval empire had turned into an empty fiction over time and instead of an "imperial model" it had become a political ideology. Although the greatest rulers craved to become emperor, historians tend to point out that no real empire was created after the fall of the Western Roman Empire. The empire of Charlemagne was a temporary formation that existed only for a short period. After the decline of the Frankish Empire, the Western Roman Empire, as even its name implies, was more attached to the German nation than to the idea of universality. After the turn of the millennium, one after another Christian monarchy was founded, of which the empire was the most prestigious, but bringing together the entire Western Christian civilisation under its sovereignty had never been an option. Since the eleventh and twelfth centuries, we can speak of a Christian community (Respublica Christiana) rather than of the Roman Empire (Imperium Romanum). Despite the influence of the Roman empire idea, the direction of European history was pointing towards the strengthening of political particularism. While in nonEuropean cultures empires of entire civilisations have risen several times, in the Latin Christian Europe the emerging powers have gained greater influence. The absence of an empire is commonly referred to as a feature of European social development. In the long run, Charlemagne's empire can also be seen as a temporary phenomenon, though his contemporaries may have experienced it differently.

Historians point out that the borders of the Carolingian Europe show a striking identity with the Europe of the (Inner) Six after the Second World War (West Germany, France, Italy, Benelux States). In the history of the European civilisation, a "core Europe" can be located undoubtedly, where economic and cultural activity have been concentrated for the past thousand years. No argument that this area belongs to Western Europe, in other words part of the "West", as it was claimed in the twentieth century with political overtones. The greater part of this region benefited from the blessings of Romanisation and the early successes of Christian evangelisation. The starting point of the twelfth-thirteenth century agricultural revolution was here, in northern France, and the Rhine area, Champagne and Burgundy became one of Europe's major trading power in the late Middle Ages, characterised by high urban density. The Carolingian "Small Europe" becoming an economic core preceded the opportunities arising from great geographical discoveries and the development of the Atlantic world economy. It is also a good example of how long period tendencies (longue durée) can be maintained in history with stubborn persistence. After World War II, the economic growth lines of Western Europe also focused on the broader Rhine, the Benelux and Northern Italy, the former central areas of the Carolingian Empire (the so-called "Blue Banana" zone). 


\section{Europe under siege}

The Frankish Empire began to decline after the death of Charlemagne. The period between the disintegration of the Frankish Empire and the turn of the millennium was a period of confusion and misery in Western European history, which is well illustrated by the fact that the title of the chapter on the history of the ninth and tenth centuries in the French historian, Jean-Baptiste Duroselle's book on European history, is called "Europe under siege". The external weakness of Latin Christianity was linked to the difficulties of internal political division. The Frankish state was disintegrated by the development of feudalism. It weakened the ruler's power, and then the princes and the counties. As a result of feudal anarchy, control shifted from the princes into the hands of political society. The organisation of feudal relations and the development of relations between feudal lords and vassals became a factor in the organisation of Christian society throughout the West.

In addition to the expansion of the feudal system, another major event was the division of the Frankish Empire, of which a milestone was the Verdun Treaty of 843. The western and eastern Frankish states formed the pre-states of the kingdom of France and the German Empire. The core of Latin Christianity was therefore not united under a single state but shared by the French and Germans. The fact that the centre of Western Europe is neither German nor French, but both, yet neither one is able to overpower the other, has become an important factor for centuries to come, influencing modern national development. This feature of European history began to emerge two centuries after the end of the Frankish Empire.

Because of the internal division of Western Europe, it was unable to respond to the external (Viking, Hungarian, Muslim) attacks in the ninth and tenth centuries. The Vikings discovered the North and Baltic Seas. Many monasteries of the Irish monks in the British Isles got destroyed and there were many attacks against West Frankish lands. Heading south on the rivers of Eastern Europe and attacking the Byzantine Sea over the Black Sea, they reached the Mediterranean. Hungarian adventures were a danger from the east. The Hungarian tribes pillaged not only German territories but reached many areas of Italy and the Byzantine Empire. The weakness of the Latin Christian Europe was also reflected in the struggles with Muslims. Islam kept Sardinia and Sicily in its hands, and Saracen fleets dominated the Mediterranean. Muslim militants were robbing merchant caravans from Provence mountain settlements. 
6.2. Western Christian Europe

The significance of the first millennium

The poor agricultural world of the early Middle Ages barely provided maintenance for low population density areas. Towards the turn of the millennium, few urban settlements in Western Europe could not compete with the glorious cities of the Byzantine or Islamic civilisations (Byzantium, Baghdad, Cairo, Córdoba). With respect to that, it was difficult to imagine that the Latin Christian Europe would soon become an expansive civilisation. Yet, over the decades around the first millennium, the changes expanding the boundaries of Western Christianity were forming surprisingly fast. At the turn of the millennium, Central Europe, within a few generations, joined Latin Christianity, which implied the completion of the Czech, Polish, Hungarian, and Croatian state foundations. The Central European region became a Christian world. The unfolding European changes accelerated the process of evangelisation and state foundation in Scandinavia, resulting that the northern periphery of Europe also joined Latin Christianity.

The events of the turn of the millennium brought a significant expansion for the Carolingian's "small Europe". The ninth and tenth centuries brought a comprehensive political and cultural renewal to Byzantium that had survived the Muslim-Arab conquests of the seventh and eighth centuries and the argument on iconoclasm. The Byzantine Empire successfully evangelised Slavic peoples in the Balkans and Eastern Europe. At the turn of the millennium, the Russian state has also outlined. Although the Roman Catholic and Orthodox churches had drifted apart, the Schism has not happened yet (1054), around the first millennium the outline of a Christian "great-Europe" had been glowing faintly that covered Western, Central and Eastern Europe. Not surprisingly, Oscar Halecki, the wellknown Polish historian whose country was the subject of the break of the Western and Orthodox Europe, regarded the millennium "unity" as a significant event in European history and interpreted it in positive terms.

Since the turn of the millennium, Latin Christian Europe included the Central European and Scandinavian states. Northern and central European countries not only joined the Roman Catholic Church, but also adapted the economic-social model that evolved in Western Europe during the High Middle Ages. As a result, in Central Europe, urban autonomies, assemblies, parliaments, and universities appeared, representing the essence of "Western social development". In the meantime, there are no assemblies, parliaments or western urban development with autonomies in Russian social development.

Being part of the Latin Christian civilisation has had far-reaching cultural and historical implications. Roman Christian countries have common denominators, not only in social history but also in the history of art. In Central Europe, 
Romanesque style was followed by Gothic, Renaissance, then Baroque and Classicism, just like in Western Europe. In Russia or the Balkans, these styles prevailed within very limited frames.

\subsubsection{The first "take-off" of E urope in the High M iddle Ages (1000 1500)}

Walt Rostow, a well-known economic theorist of the post-World War II decades, developed his "stages of growth theory" in the late 1950s, suggesting that sooner or later, all societies could reach the industrialised society and enjoy the blessings of abundance for consumers. Rostow identified the commencement of industrialisation after the stagnant pre-industrial agricultural societies as sustained economic growth, which he called take-off. He used the English word that means the moment an aircraft takes off and leaves the runway. He considered the first industrial revolution in Western Europe in the 1760s being the take-off period.

Over the last half a century, economic historians have dealt a lot with the matter of how the preconditions for the economic growth between the great geographical discoveries and the Industrial Revolution in the early modern centuries (1500-1800) have developed. The influence of Protestant ethics, the rise of the market, the role of the absolutist state and the consequences of colonisation are usually listed as antecedents of the take-off. However, a more important fact should also be pointed out, that Western European historiography began to reveal since the 1930s. Modern European development would have been inconceivable without the results of the great accumulation process of the twelfth-thirteenth centuries. During the High Middle Ages (twelfth-fifteenth centuries), a series of "revolutions" took place, agricultural, urban, demographic, technical, commercial, reshaping the very image of Latin Christianity.

The historiography in the nineteenth century attached great significance to modern bourgeoise and industrial capitalism, the birth of nation-states, and rightly in a certain aspect, considered them to be the "essence" of Europe. By contrast, historians since the mid-twentieth century onward have become increasingly aware of the fact that while Western Europe has achieved enormous success since the discovery of America, European civilisation already existed in earlier centuries. Europe cannot be imagined without the results of modern civilisation, but the first great accumulation of European history was before the Renaissance and Reformation. The High Middle Age, in the words of Rostow, is rightly called the first take-off of Europe, as it has shown a strong dynamism that has had a lasting impact on the coming centuries. 
6.2. Western Christian Europe

The turning point in the eleventh century

The events at the turn of the millennium not only brought the territorial expansion of the Latin Christian Europe, but also the first steps of a spiritual renewal and material growth. The eleventh century is the beginning of the takeoff, which then got realised in the twelfth to thirteenth centuries. After the turn of the millennium, Viking and Muslim adventures stopped. Western European feudalism has been consolidated and political anarchy has diminished in some kingdoms (Map 32). Since the beginning, Western Roman emperors were the head of the church reform and supported the renewal of papacy. This was accompanied by the Cluny movement, which restored the purity of religious life in hundreds of monasteries and suppressed the secular influence. The treuga Dei (peace of God) movement was trying to get the knightage to follow Christian morals. The revival of religious life was verified by pilgrimages, Rome, Compostela, becoming popular and the birth of Romanesque style, Europe's first sacred monumental art. The huge Romanesque churches, built of white stone, were in contrast with their surroundings, even for their contemporaries, and represented a new beginning in the history of European art compared to small pre-Romanesque churches. The financial background of the growing art was provided by the slow take-off of the agricultural sector. For the first time in the history of the Christian West, it has shown significant internal energies.

Population growth created the demographic basis for the Western European expansion. Knightage also increased, and so gladly initiated military ventures, also Italian merchant towns in the western Mediterranean got constantly stronger. Before the turn of the millennium the sea was dominated by the Muslims. In the first half of the eleventh century, however, Venice succeeded just as well in the eastern basin of the Mediterranean, as Pisa defeated the Muslim fleets in the Tyrrhenian Sea. Christians cleansed Provence too from Muslims, took back Corsica, Sardinia and Sicily, and got the western basin of the Mediterranean under their control. Such naval victories were supported by the growing commercial activity of Italian cities. By the turn of the eleventh century, Italian cities had already provided logistical assistance for the crusades that had begun. When Pope Orban called the knights to conquer the Holy Land in 1096, the first major population and economic boom in Western Europe was imminent. Due to the demographic and agricultural revolution in the twelfth and thirteenth centuries, Europe "overflowed". As a sign of this, it released the Crusader armies one after another.

The influences of the Cluny movement reached Rome, and for the first time, made the Latin West theologically confident against the Greek Church of sophisticated reasoning. Thanks to the increasing militancy of the Latins and the 
church policy interests of the Patriarch of Constantinople, Michael I Cerularius, the Schism took place that completed the process of separation between the Roman Catholic and Greek churches. In 1054, the two churches mutually excommunicated each other, and that became a source of mistrust and hostility for centuries to come. It is less known that since the Schism, Latins and Greeks have attempted to restore the unity many times, as during the Renaissance, when they sought to form a Christian alliance against the growing Ottoman Empire.

The Schism deepened the civilisation differences between the western and eastern parts of Europe. In the long term, it has contributed to the formation of a religious "mixed zone" east of Central Europe, covering modern-day eastern Poland and western Ukraine. Roman Catholicism and the Orthodox Church were both active in this zone, and Western influences were also present, though weak, less than in western regions of Poland and Hungary. The Greek Catholic Church was formed in this particular area in the early modern age, which can be also seen as a compromise offered to the local Orthodox population by the Polish Catholics. Orthodox people, who accepted the Pope but retained the orthodox liturgy and traditions, became Greek Catholic.

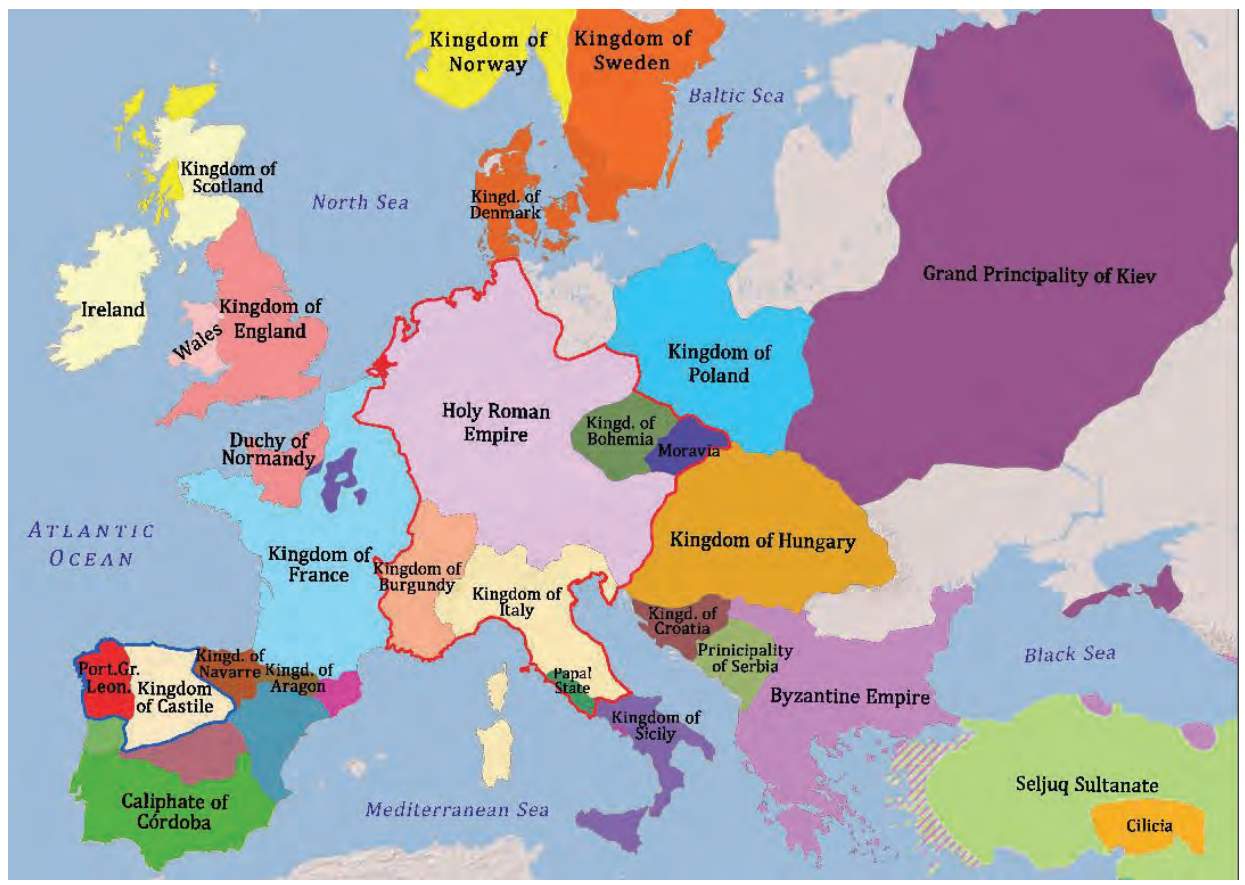

Map 32: Europe at the end of the eleventh century Source: Edited by ÁGNES VARGA 
Concerning the 1054 Schism, it should be noted that its nature changed in the second half of the twentieth century, as at the great reform council of the Catholic Church, the Second Vatican Council (1962-1965), a personal meeting between Pope Paul VI and Patriarch Athenagoras took place and they mutually lifted the excommunication of the Churches. Although the union between the two Churches has not yet been established, Catholic and the Orthodox Church got engaged in an ecumenical dialogue. In the spirit of this dialogue and of a new Christian view of Europe, Pope John Paul II defined Catholic and Orthodox religion as the "two lungs" of the continent. In his apostolic letter dated on December 31, 1980, Cyril and Method were named co-patron saints along with Europe's Catholic patron saint, Saint Benedict, as a gesture to orthodoxy.

\section{Western European "revolutions" in the High Middle Ages}

In the twelfth to thirteenth centuries, we have seen a rise in economic and demographic dynamics, which have doubled the European population. The source of the changes was the agricultural sector. Growing crop yields (one buried seed returning four to five instead of two or three) and agrotechnical innovations have opened up significant opportunities in terms of the limits of production. By applying so, Europe has closed an era of miserable agricultural conditions where starvation had been a constant problem. The "agricultural revolution" of the High Middle Ages developed in the northern French regions between the Rhine and the Loire and from there spread to Western and Central Europe.

The agricultural revolution of the twelfth and thirteenth centuries led to the flourishing of cities (urban revolution). Cities never completely ceased to exist by the disappearance of antiquity, but many of them declined. From this period on, the booming agricultural sector provided that villages could feed the reborn cities. Compared to civilisations outside Europe, medieval urban development has resulted in exceptional urban density, deeper urban-village division of labour, and increasing industrial activity. European cities were generally small in size, but their intensive presence shaped economic conditions everywhere. In the most urban areas (northern Italy, Flanders) the first signs of an early industrial civilisation also appeared. In addition to the agricultural and urban revolution, the development of a technical and commercial revolution can also be witnessed. One of the most important inventions of the era is the water mill, estimated to be up to 200,000 pieces, replacing the work of about ten million people. The growing trade in goods has created the ground of European trade networks. The achievements of the High Middle Ages created the minimum preconditions for modern capitalist development. 
The "revolutions" of the High Middle Ages led to fundamental economic development in Western Europe. The increased fertility of the earth allowed the population to grow. Along with the increasing agricultural productivity, the population density limit was close to $30-40$ persons $/ \mathrm{km}^{2}$, while the agricultural sector was able to feed around 10-15 percent of the total population living in towns. These data were outnumbered only by the consequences of the agricultural innovations in England, in the eighteenth century. Therefore, we can say that the economic history of Europe relied on the potentials of the twelfth-thirteenth century demographic and agricultural revolution until the "first industrial revolution" of the 1760s-1780s. The proportion of the urban population in some regions of the Netherlands, England, northern France and Italy in the sixteenth to the eighteenth centuries exceeded fifteen to twenty percent, but only in the industrialising England did the percentage of urban population a fundamental "breakthrough" in the first half of the nineteenth century. As a result of the Industrial Revolution, half of the English population was already living in town by 1850 .

Despite the results of agricultural and population boom, Europe in the Middle Ages did not have the level of technical and industrial superiority that could have explained modern-day western hegemony. Therefore, the interpretation of European social development should be extended to the issues of religious attitudes, social structures, and political institutions, as those have allowed the development of a civilisation that has been able to evolve faster and faster since the early centuries of the Modern Age. In this perspective, special attention must be paid to the social and cultural consequences of the Christian religion.

\section{Basic characteristics of the Christian faith}

Before presenting the impact of Christianity on Western social development, Christian faith itself should also be characterised. Christianity was the successor of the radical version of Jewish monotheism proclaimed by Old Testament prophets. Jews and Christians believe since the beginning that God took part not only in the creation but also in history, and conducts a dialogue with His chosen people, first with the Jews, then with the Church, and through His Incarnation and Redemption, seeks to give opportunity to re-open the path of supranatural existence,to eternal life, that had been closed by the original sin, the sin of the first couple of human beings that affects the entire human race. Christianity professed the theism and personalism of Jewish monotheism, that is, the concept of a personalised god, separated from the world. Through the incarnation of Jesus Christ, the transcendent God became close and accessible to men. Compared to the Jewish religion and Islam, the charm of the Christian 
religion was given by the simultaneous existence of transcendence and immanence. The distant image of God in West-Asian monotheisms became personal and experienceable.

Since the beginning, Christians had supranatural perspectives on their eternal happiness. Their earthly actions were determined by the radical command of love. Even the first Christian communities sought to support their faith with actions and to expose the requirements of Christian ethics to the world. Ancient Christian communities received the body and blood of Christ (eucharist) and read the sacred texts proclaiming the Saviour's acts. For Christians, in addition to the praxis of Communion, the intellectual reflection of faith has proved secondary, which does not mean that intellect has ever been underestimated.

Christianity, in comparison with the Hellenistic mystery religions, preached an "open tradition" and rejected the concept of esoteric knowledge accessible only to a narrow religious elite. According to Christians, two kinds of knowledge (one for the average believer and one the selected perfect ones) do not exist but everyone may get to know God's commandments from the Bible. One of the most important aspects of the Christian teaching is the belief in the goodness of creation, which has not been overruled even by the original sin. The beauty of the created world, according to Christians, proves the greatness of God. The world is not a "vale of tears" but a wonderful product of the work of God's hand. One of the essential teachings is about free will (liberum arbitrium), according to which humans have the choice between good and evil. Christians have, since the beginning, rejected any and every form of moral relativism. Catholics preached the need for the distinction between good and evil, and believed that due to divine grace, humans with free will are capable to do so, even though original sin resulted the weakening of human nature.

Despite the fact that basic teachings are identical, Christianity in the Latin West developed different from the Orthodox East. During the late antiquity (fourth-sixth centuries), the four Latin Fathers of the Church, Ambrose, St. Augustine, St. Jerome, and St. Gregory the Great, added a lot to the image of Latin Christianity. Thanks to St. Augustine, personal will in Western theology has an important role compared to intellect and emotions. The mainstream of theological thinking in the Latin West has shifted towards rational and intellectual thoughts over time - development of scholasticism - though it has also been stated that the truths of faith cannot be understood solely on intellectual grounds. Eastern theology emphasised God's incomprehensibility and therefore preached "negative theology", while Latins believed that based on intellect God could be known limitedly ("positive theology").

In Western Christianity, versions of monasticism open to the world became dominant. The Benedictine monastery of particular importance established 
practically organised communities seeking to find balance between prayer and work. In the east, the primacy of deep prayer and mystical experience was emphasised, and it became the focus of monastic life.

In the west, monks took up educational roles. The foundations of the alliance of "church" and "school" were established already in the first millennium, while the Eastern monasticism did not identify with such tasks. In Latin Christianity, rational thinking and working in the world had a greater role, which does not mean that the Latin Church did not recognise the need for mystical experiences and isolation from the world. The attitude of Western Christianity in some ways anticipated the formation of the modern world.

The role of the popes governing Latin Christianity was one of the determining features of European civilisation. Catholic tradition has always emphasised the exceptional position of the Roman Pope as successor of St. Peter with regard to the leadership of the universal church. In the churches controlled by the other four patriarchs, Alexandria, Antioch, Jerusalem, Constantinople, Roman popes practically did not intervene during the first millennium. An exception was the dogmatic debates over Christianity, where the prestige of Peter's successor was greater than that of the other four patriarchs. In the Latin West, however, the popes gained special influence in their own patriarchate. This was due to the fact that there was no emperor in the West for centuries, so the papacy had no its main competitor in power. Amidst the confusion of the migrations, the popes were often forced to take on public roles, as their environment expected them to ensure a minimum of order and peace. Therefore, the early medieval papacy in the Latin West also undertook secular tasks that enhanced its power and authority.

As the successor of the Latin-language ecclesiastical culture after the Carolingian reforms, the Roman Catholic Church, governed by the pope, expressed the cultural unity of the Western Christianity. Although it was confined to the Latin West after the Schism (1054), the name itself, "catholic" or "universal", illustrates the universal self-interpretation of the papacy and its mission of all essential values. After the turn of the millennium, the popes took powerful centralisation measures in the Roman Catholic Church in the twelfth to the fifteenth centuries. This centralising tendency continued during the sixteenth century, as a counter-reaction to the Reformation, and later in the era of liberal nation-states. Thus, the Catholic Church was able to retain its autonomy against the challenges of the modern age, but the model of governance that emerged was considerably different from the customs of the Church in the first thousand years. Since the Second Vatican Council, the Roman Catholic Church has sought to mitigate the centralisation and to create decentralised organisational solutions. 
The social dimension of Christian belief

The influence of Christianity on Western social development was the subject of many interpretations in the nineteenth and twentieth centuries. At the time of the French Revolution, an approach that regarded Christianity as the ideological stronghold of the ancien régime became general. Most nineteenth century theorists believed that Christianity could only be the opposite of modernity. Religious sociology and historical science began to rethink this simplistic concept in the early twentieth century. While doing so, the specific characteristics of Christianity were taken into account, which in the broadest sense grounded the formation of the modern world. The new history paradigm no longer considered the role of Christianity in European history as the antithesis of modernity, but as its antecedent. The changing theoretical framework also contributed to a better understanding of the socio-cultural phenomena in the High Middle Ages.

In this perspective, the fact that Christianity carried on the radicalism of Jewish monotheism, which proclaimed the existence of a personal transcendent God separate from the world, where being "sacred" could only be manifested in God, as the prophets explicitly pointed that out. On this ground could Max Weber say that, compared to "magic", Christianity facilitated "the desacralisation of the world" and that this desacralised world opened up to rational human activity. Therefore, we can say that the development of modern science and technology is, to some extent, due to Christianity. According to Christian teaching, God is completely different from the world. In contrast, the "world" as a profane sphere is immanent and distinguishable from the "sacred". This leads to the separation of the "sacred" and "profane" spheres, the political consequences of which have led to the separation of sacred and secular powers. While in Islam, Mohammed and his successors, the Caliphs, are religious and political leaders, Jesus, as we have already mentioned, did not establish a state. The Christian Church has always distinguished itself from the state, even if in Byzantium the "caesaropapist model" provided much less room for the church than the state, while in the medieval Latin West, where Pope Gelasius's (492-496) "two swords" theory that illustrates separation and balance between the two spheres, has become an integral part of political thinking and practice. In human history, it is usually either "theocracy" (= divine kingdom) or "caesaropapism", the merger of sacred and profane spheres, for the benefit of one or the other. Only in the Latin West was the social model implemented that separated and balanced the sacred and profane areas. This got manifested in the dualism of power between the Pope and the Emperor, that became one of the political features of the High Middle Ages.

The duality of the transcendent God and the immanent world proved to be an essential prerequisite for the development of modern science. The fact that the 
"secular things" have a certain autonomy and work in accordance with the laws of the created world, has, broadly speaking, provided the framework for human and scientific thinking that was gaining independence. Thomas Aquinas's thirteenth century philosophy and the professors at the University of Paris in the following two centuries greatly contributed to that since the end of the Middle Ages all the events of the world were no longer regarded as directly subject to the divine will, but as a consequence of autonomous natural law. All of this embedded the formation of secularised philosophy and science in the early modern age Europe. Overall, this led to the modern scientific revolution that established the technological superiority of the Western world over the last three centuries.

Christianity has enhanced the fulfilment of the personal dignity of the human. In addition to the Greek-Roman sources, European humanism has religious dimensions. According to Christian teaching, God created man in His own image and likeness, as the first pages of the Old Testament reads. As there are other statements on several pages of the Scriptures about the fact that man was created in God's image, we can speak of "biblical humanism" or "Christian humanism" in European religious and cultural history. It is the mission of human with freewill and open for the absolute to fulfil the potentials of creation as a companion of the Creator. Christian humanism emphasises that God does not restrict but completes people who turn to Him. A man created in God's image is the ultimate proof of human dignity. In this spirit, Christianity embraced and gave new meaning to antique humanism. The combined effect of classical and Christian humanism upgraded European civilisation to a culture of "anthropocentrism".

Christianity addressed the individuals and proclaimed a universal mission since the moment it existed. Jesus Christ brought the evangel to all people and gave his apostles the task of proclaiming the "good news" to all nations. Christianity has created the concepts of "individual" and "universal" as compared to tribal-ethnic groups that are related to one another exclusively. With Christian belief, the walls among tribal-ethnic groups have fallen or at least become secondary, and the role of the individual has increased. Max Weber regarded this moment as a fundamental feature of Western development. No individualism and universal ideals of European modernity would have been possible without Christian grounds. Exceeding the tribal ties was also a requirement for the formation of modern society, as it is clearly demonstrated in comparison with other cultures.

\section{Western European societal characteristic}

The social dimension of Christian belief has added to the development of Western European society, but not all authentic characteristics can be explained with the influence of Christianity alone. Beyond the social aspects of the Chris- 
tian belief, some other basic features of medieval political development (particularism, decentralisation) proved to be just as important as the role of Roman law or the exemplary value of the ancient municipal freedoms.

The absence of an "empire". It has already been pointed out that after the fall of the Roman Empire no empire in Western Europe had been established that would have covered the entire Latin Christian civilisation. Medieval state initiatives based on feudal relations became the ground for the later nation-states (Map 33). A wide variety of territories were created, which were not, or only nominally, under the control of sovereign princes and feudal lords, for instance the Italian city-states and the German city associations. In the High Middle Ages, Latin Christian Europe had many political and power centres that were constantly competing yet unable to defeat each other. Nowadays, historians believe that such polycentric structure is largely responsible for the dynamics that have become more and more perceptible since the second half of the Middle Ages. In contrast, civilisations outside Europe often reproduced the monolithic "imperial model".

Distinction between sacred and profane spheres. The commencement of Investiture Controversy was of great importance at the turn of the eleventh century, which led to the determination of the differences between the sacred and the profane spheres. Eugen Rosentock-Huessy called the Investiture Controversy the "first revolution" of the West followed by others until the modern revolutions. The problem of investiture became special because it was located at the intersection of religion and politics. Whether the right to appoint ecclesiastical offices is vested in the church or the secular ruler, it has forced a more common reflection on the nature of sacred and secular power. It has already been mentioned that the lesson learned from the compromise of the Investiture Controversy was the fact that neither sacred nor secular power could be questioned in European history. One of the general features of the European Middle Ages was that no sphere was able to suppress the other permanently, and the distinction between the two areas became perpetual and doctrinally acceptable. In civilisations outside Western Europe, even raising the issue of Investiture Controversy itself would have been meaningless.

Freedom institutions and autonomies. Not only economic and demographic growth took place in the High Middle Ages, but many new political institutions got established. Accelerating economic and social movements, brought to life, in the words of the political theorist, István Bibó, "circles of freedom" that transformed the network of society. At the end of the eleventh century, the church reform represented by Pope Gregory VII defended the "freedom" of the Catholic Church (libertas ecclesiae) against secular/profane society. In the eleventh and twelfth centuries, the increase in the number of cities resulted in the 
formation of city municipalities. By the thirteenth century, these autonomies had spread throughout Latin Christian Europe.

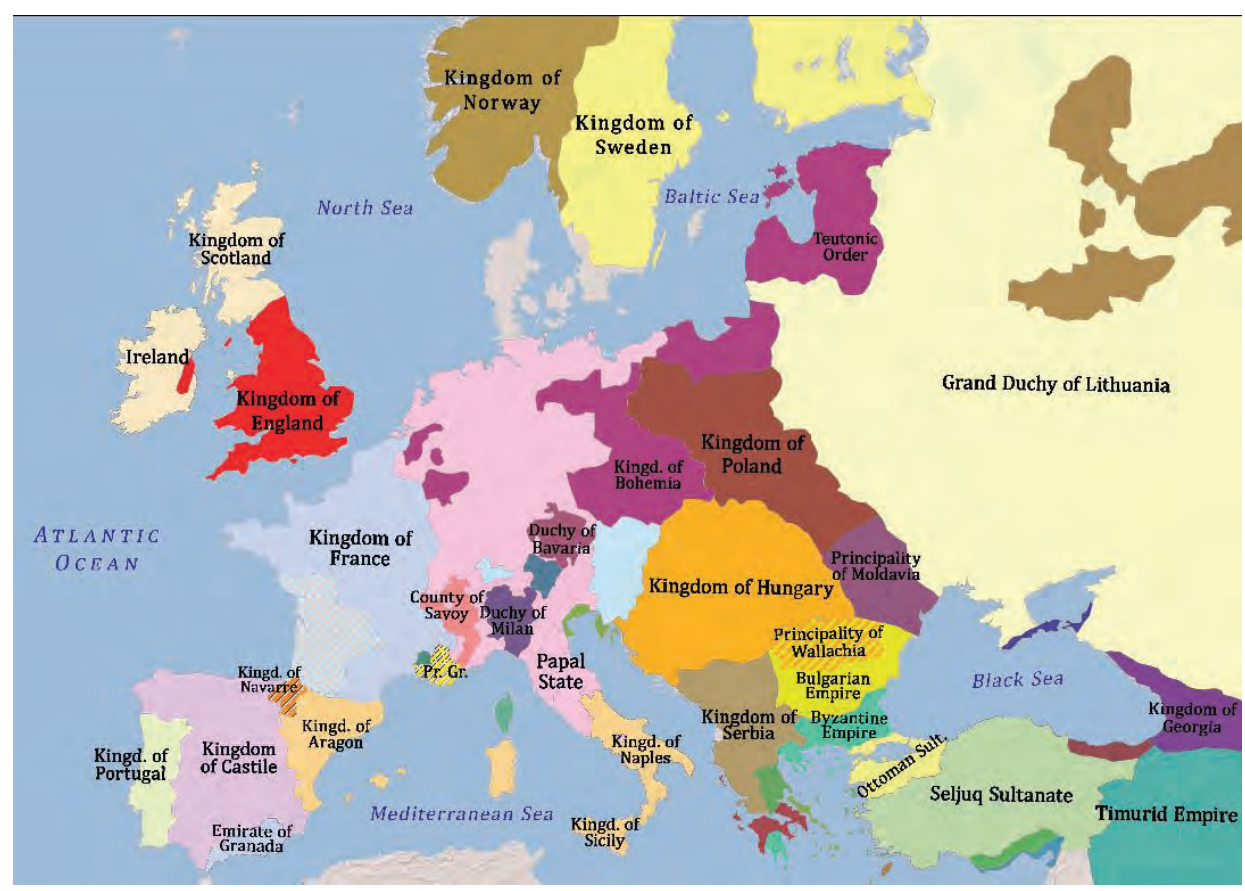

Map 33: Europe in the fourteenth century Source: Edited by ÁGNES VARGA

The High Middle Ages led to major transformations also in the functioning of political society. The system of ethical standards ruling feudal relationships provided a guarantee against one-sided forms of subordination for the vassals too. The relationship between the feudal lord and the vassal was not a patriarchal one, but contractual where not only the feudal lord had rights, but both parties made commitments. During the thirteenth century, the parliaments formed as institutionalised forms of power-sharing between the ruler and the nobility. In the thirteenth and fourteenth centuries, universities of their golden age also enjoyed considerable "freedom". Such institutions were horizontal bodies or local communities. By contrast, there are no institutionalised autonomies, legally institutionalised to the same degree, in non-European societies. It should be noted that "freedom" did not represent a modern claim of individual legal rights but appeared as a collective right of a social group (city, order) that fit into a hierarchical society. Still, the modern idea of freedom could not have been implemented without the development of medieval freedoms. 
The characteristic of Western European social development refers to the group of socio-cultural phenomena that emerged in between the eleventh and fourteenth centuries and made the Western Christian civilisation a successful precondition for modernity. Ever since the twelfth and thirteenth centuries one can see the beginnings of a social dynamic that has been repeated in more and more intense forms over the following centuries. Renaissance and Reformation started this intensifying movement, and continued with great geographical discoveries, the seventeenth century scientific revolution, eighteenth century Enlightenment, civil and industrial revolutions, and the establishment of nation-states as Europe possessed the universal hegemony.

\subsubsection{At the turn of premodern and modern (1500-1800)}

\section{Renaissance}

The economic recovery of the High Middle Ages ended at the turn of the thirteenth century. The Gothic cathedrals in northern France was a good expression of the prosperity between 1100 and 1300 . The huge Gothic temples, being built over generations, clearly expressed the available economic energies. However, the following two centuries were the era of economic, demographic crises and epidemics. With the great plague of 1348, Europe was hit by the greatest demographic disaster in history, in which the continent lost almost half its population. There is a reason for the fact that the territorial expansion of Europe also broke during this period. The Holy Land had been lost for Christians and the topos of misera Europa (miserable Europe) became frequently used by humanists against the triumphantly advancing Ottoman Empire.

Formerly, the consequences of the economic recession had been judged more pessimistic in historiography. Today it is considered that signs of economic activity reappeared in the second half of the fifteenth century. The great geographical discoveries starting in the late 1400s are great indicators of the fact that the Western European economy has found its legs. Historians used to presume that colonisation, that started with geographical discoveries, supported the economic growth in early modern Europe. Without questioning the significance of colonisation today, it is believed that another economic take-off on the European continent had already been realised around year 1450. Therefore, colonisation was not so much the reason as the consequence of the recovery. The socio-cultural structures formed in the Middle Ages that allowed greater freedom and autonomies in the Western European society have proven during the fourteenth and fifteenth centuries. Europe has given a creative response to the economic recession, leading to economic recovery in the coming centuries. 
Renaissance, as one of the most significant periods in European cultural history, dates back to the fourteenth and fifteenth centuries. Cultural historians of the bourgeois era referred to the nineteenth century as an outstanding period because they saw the revival of antique human-centred art in Renaissance art. Although historiography today is much more sophisticated and also points out many other aspects (revival of the Latin language standard, development of ancient Greek and Hebrew learning, seeds of museology by the excavation of antique ruins, spread of oil painting, appearance of perspectives in painting and the humanistic renewal of the school education programme), the individualisation and secularisation of culture undoubtedly continued in the fourteenth and fifteenth centuries.

European history reached a turning point at the turn of the fifteenth century. The verism of Renaissance art, having the works of Leonardo, Michelangelo, and Raphael, reached a peak that is barely reproducible, geographical discoveries that grounded the global role of the European continent began, the first modern states were forming, and had to face with the beginning of a balance of power within the European state system. On the other hand, this has taken place within the framework of traditional agricultural societies and thinking. In the early Modern Age, between 1500 and 1800, the phenomena of "premodern" and "premature modern" were present in European culture at the same time.

\section{Reformation}

Reformation, bringing new religious and cultural dynamism to European history, gained particular significance with regard to events in the modern age. The consistency of medieval Christianity got embodied in the hierarchical organisational model of the Roman Catholic Church. Not only did the Reformation, starting with Luther's figure, disrupt the consistency, it also challenged the hierarchy itself. There is a library of literature on the roots of Protestantism, that examine the causes of the revival of faith from various aspects, from the moral contradictions of the Catholic Church to the late medieval conversion of religious life. All Reformers were seeking the opportunity for a radical renewal of their faith. Their slogans, sola fides (faith only), sola scriptura (writing only), sola gratia (grace only), illustrate the fundamental orientation of the Reformation. Reformers believed that only faith could save, unlike Catholics who believed charity, asceticism or indulgence could too. Compared to church tradition, only the Bible should be accepted as authentic text. In the relation of divine grace and human freedom, the importance of grace at the expense of free will was appreciated greater, while the Catholic tradition emphasised the joint effect of freedom and grace. 


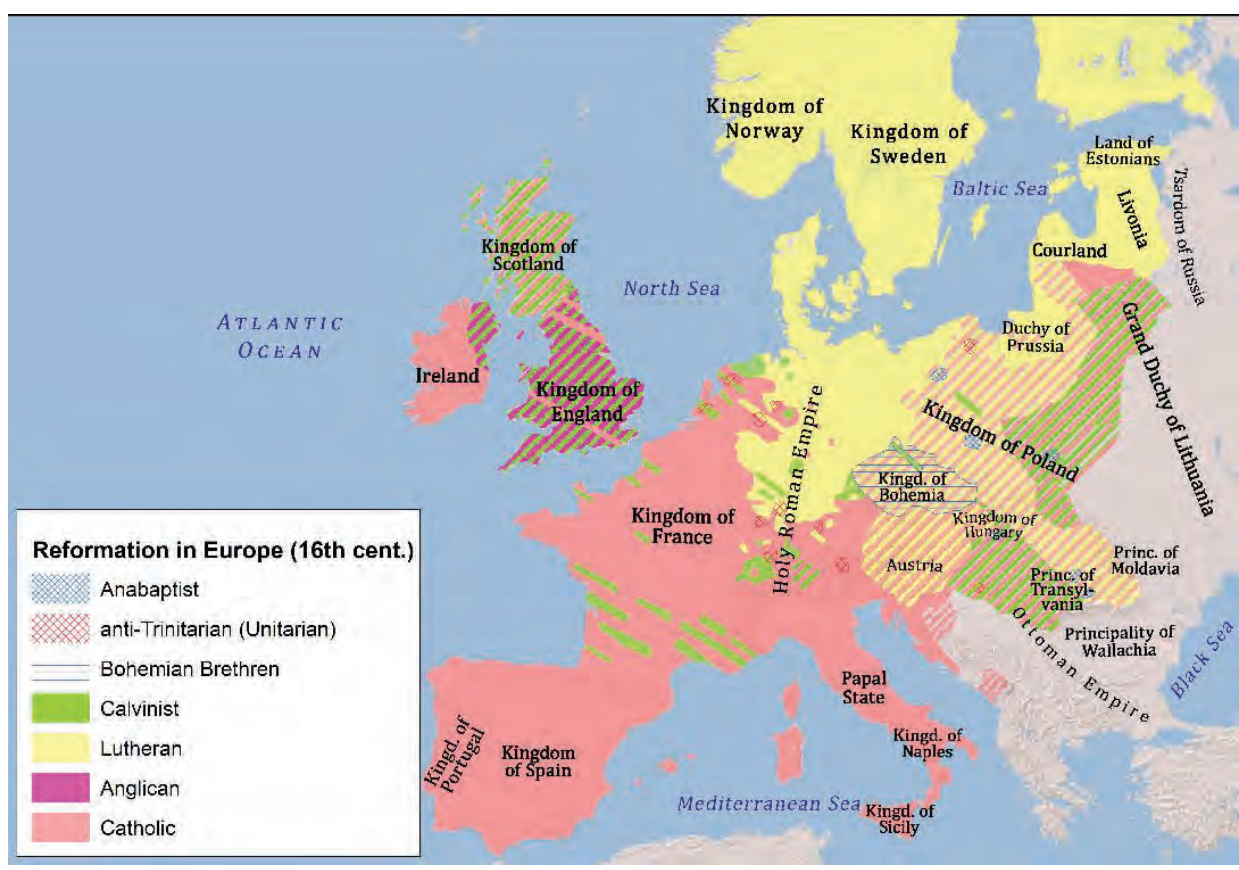

Map 34: Religious congregations in early modern Europe Source: Edited by ÁGNES VARGA

In the history of Protestantism, the constant fragmentation of religious groups and the tendency for increasingly radical groups appearing must be mentioned. In contrast, the Lutheran, Calvinist, and Anglican churches were consolidated rapidly, but to this day new protestant tendencies are emerging, especially in the United States. In countries where the reformed religions have become state churches, rulers have become heads of church, such as England, Scandinavian countries and German principalities (Map 34). Breaking with the "dual power" of the Pope and the secular rulers, Protestants accepted the concept of state church and secularised church estates.

Deprived of Catholic universalism, reformed churches got more rooted in local characteristics and gradually became national churches. This feature made them the antecedents of the emerging nation-states. In this sense, Protestantism has accelerated the process of nationalisation, which has become one of the cornerstones of the modern Europe. Compared to the Lutheran churches that accepted the prince's ruling, the more radical Calvinist church built from grassroots communities. Its "democratic" structure also had influence on the early modern political development and promoted civil revolutions against absolute monarchies. 
Reformation was considered by many religious historians to be a "modern" phenomenon due to the emphasis on individual forms of belief, the elimination of mysteries, the development of individual Bible reading and literacy. On the other hand, it is also worth to point out that Protestant radicalism was in many cases not free of contradictions. The doctrine of predestination has led Calvin to see human nature much darker (anthropological pessimism) than his Catholic debaters. Indeed, divine choice is of importance in salvation only if one's free will no longer implied. Calvin weighed the impact of the original sin on man in the defence of predestination much more dramatically than Catholics. In his view, a person, radically tainted, can be saved only by God and not by his own free choices, which is not exactly the theological doctrine that focuses on the freedom of the individual, that opens for "modernity". Nonetheless, since Luther's appearance in 1517, Protestantism has brought a dialectic into European history, that has served as a basis for historical processes towards modernity.

Reformation spread via passionate debates in sixteenth century Europe. Following the religious wars of the sixteenth and seventeenth centuries, a new fault line of religion/civilisation was emerging, the dichotomy of the Protestant North and the Catholic South. Due to Max Weber's famous thesis, economic history debated a lot about whether Protestantism really played a decisive role in the development of modern capitalism. Whether the economic increase in northern Europe and the decline of the Mediterranean was due to English, Dutch and German Protestant bourgeoise, or did the Atlantic world, economy coming with the discovery of America, put Northwest Europe in a better geographical position?

Even today, differences between Catholics and Protestants continue to impact political relations and influence the process of European unification. Empirical studies confirm that after World War II the public opinion considered the European integration as a "Catholic creation". The "statism" and "bureaucracy" of Brussels was more widely accepted by Catholic voters than the general Protestants on the north, who, in the spirit of the minimal state and Protestant national cultures, had an instinctive antipathy against officials and structures of the integration.

\section{Scientific revolution and Enlightenment}

After the Reformation, the next step in the development of modernity was the seventeenth century scientific revolution. Spinoza and Descartes opened the door to the novel use of senses and rationality. By establishing the principles of algebra and coordinate geometry, Viete, Descartes, and Euler laid the foundations of an exact scientific language, capable of expressing planar and spatial geometry 
6.2. Western Christian Europe

by using mathematical tools. In this way he provided modern physics with an apparatus which also benefited technical sciences. The heliocentric worldview created by the late Renaissance expertise, followed by Galileo's and Kepler's observations on gravity and planetary motion, required the creation of the new concepts of "infinity" and cosmos. The transformation of the scientific worldview was accomplished by Newton's elaboration and systematisation of the laws of mechanics (physical motion). From the eighteenth century, Newtonian physics slowly replaced Aristotelian physics, and remained a dominating scientific paradigm until Einstein's theory of relativity.

The great innovation of the seventeenth century scientific revolution was not only the creation of an exact mathematical language describing the laws of nature, but also the introduction of an experimental natural science method. Modern physics relied on experiments, measurements and models based on them, and then on testing and correcting them. Its standards were established in stages and formed an integral part of scientific methodology. Ancient Greek natural observations often led to brilliant conclusions, but neither exact scientific language nor experimental methods were applicable. The Middle Ages and the Renaissance surpassed ancient natural science in many areas, but the real turning point occurred only during the seventeenth century scientific revolution. By happening so, European civilisation has developed a scientific apparatus that has enabled it to achieve global industrial and technological superiority in the nineteenth century. Industrialisation in eighteenth-century England would have begun without the achievements of the scientific revolution, since the primitive machines were based on heuristic observation and the trial and error method. But the "second industrial revolution" that evolved in the last third of the nineteenth century, where the driving force was the chemical industry and electricity, could not have happened without the modern natural sciences that started with the early modern age scientific revolution.

Historians tend to discuss the seventeenth century scientific revolution in combination with the eighteenth-century Enlightenment. Together, these two phenomena were regarded by historiography as a key intellectual antecedent on the road to modern Europe. The scientific revolution has indeed been linked to the Enlightenment, but it should be noted that the latter has reformed the way of thinking about society and has made a lasting mark on human sciences. The Encyclopaedia of the French Enlightenment, on the one hand, summed up the results of the changing scientific perspective and the achievements of applied sciences (political economy, agricultural sciences, and social sciences) and, on the other hand, rethought the problem of political legitimacy radically by elaborating the concept of social contract. Enlightenment established the idea of 
monitoring "governors" and created the opportunity for the community of the "governed" to become the foundation of modern politics.

Enlightenment was the first stream of ideas in the history of European Christian civilisation that criticised not only the church but also religion. Renaissance humanists have repeatedly made critical remarks on the functioning of the Church as an institution but doubting the basic teachings of the Christian religion has never been a question. By contrast, during the French Enlightenment, the first deists, materialists appeared, who drew new philosophical conclusions from the natural scientific perspective and reached to the rejection of Christian revelation.

Enlightenment also reinterpreted Christian anthropology when it conceived man as an infinitely improvable and perfectible creature. Such anthropological optimism may have led to a "modernist" view of history focusing on "the principle of evolution", that placed the potential of European civilisation in the concept of endless progress. The increasing distance between the stream of modern ideas coming with the Enlightenment and Christian teaching has become an important feature of modern European culture. At the same time, European bourgeoise not only fulfilled the philosophical programme of the Enlightenment but preserved many of the basic values of civilisation rooted in Christianity.

\subsubsection{Splendor and decline of E urope}

\section{Europe in the "long nineteenth century"}

Eric Hobsbawm preferred to use the term "double revolution" to describe the changes of the eighteenth and nineteenth centuries. The notable English historian considered that the industrial revolution in England in the 1760s (the "first industrial revolution") led to fundamental changes in the field of economy, while the French Revolution of 1789 led to fundamental changes in politics. Prior to this, the early modern centuries (1500-1800) represented a long transitional period in European history, where pre-modern and modern elements coexisted in politics, society, and culture. Even at this time, the Reformation, the Scientific Revolution and the Enlightenment were well aware of Europe's growing dynamism, reinforced by economic and political trends, the development of the Atlantic world economy, accumulation of capital, early civil revolutions. With the "double revolution", the achievements of the human spirit and science got realised in practice and became a "mass" phenomenon. In agreement with Hobsbawm, the "double revolution" can be seen as the boundary between early modernity and modernity, which has created a civil Europe and completed the idea and practice of modernity. 
Historiography calls the period from the French Revolution (1789) to the First World War (1914) the "long nineteenth century". This part of European history is characterised by well-defined features. Economically, the "long nineteenth century" was the era of industrialisation, when growth got stabilised, in Walt Rostow's words take-off (see above). Thanks to industrialisation, Europe has gained a huge technical advantage over the rest of the world, that has grounded colonisation. The great powers of Europe became colonisers and controlled a significant part of the globe during the second half of the nineteenth century. Thanks to its exceptional industrial capacity, the European continent has reached a kind of "global role", that Europeans explained with the superiority and universal mission of "white Christian civilisation". The superiority of Europe left its mark also on the mentality of the "long nineteenth century". In line with the intellectual legacy of the Enlightenment and the economic growth, philosophers of history (Herder, Condorcet, Hegel, Marx) approached the history of European mankind as a "grand narrative", describing it as a model of human emancipation that reaches its "ideal" at the end of history.

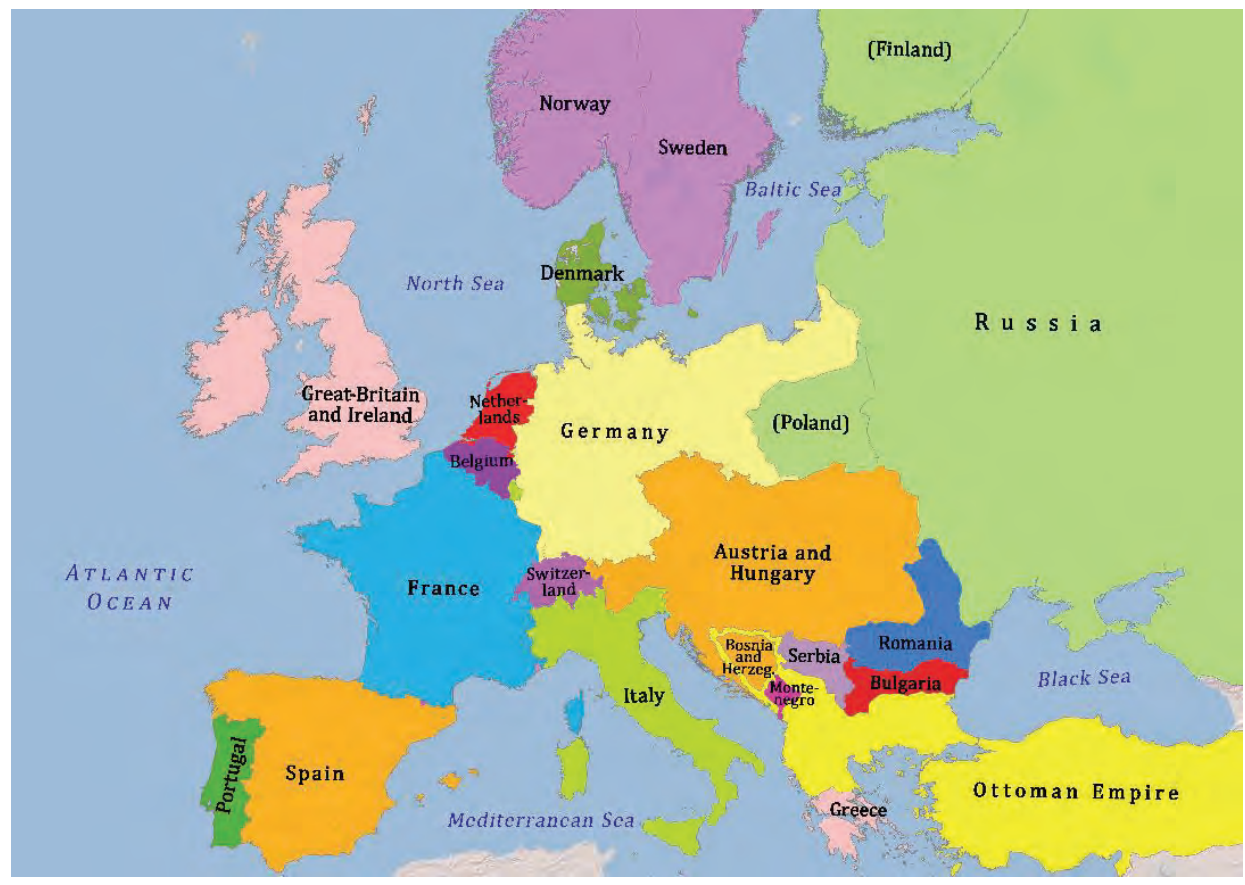

Map 35: Nation states in Europe in the last third of the nineteenth century Source: Edited by ÁGNES VARGA 
In the "long nineteenth century" one can witness the completion of a bourgeois Europe, whose dominant ideologies were liberalism, democracy and nationalism. These ideas were born with the French Revolution and, with the spread of revolutionary ideas, became dominant ideologies over the European continent. Liberalism and democracy have focused on individual and citizens' liberties, which have been implemented in more and more countries with the establishment of liberal states. Nationalism evolved along with one of the defining factors of European history, the establishment of modern nation-states (Map 35). National ideologies became the most effective vision of the "long nineteenth century" and all modern political ideologies realised their purposes within the framework of a bourgeois nation-state. The "dominant ideologies" of the nineteenth century, liberalism, democracy and nationalism, were closely linked. Their common feature was that the history of Europe and the world was approached in an optimistic and progressive framework.

The "long nineteenth century" progressivism lied on the peace and prosperity of the European continent. During this period, not only economic development had effects, but the Vienna Congress ending the Napoleonic Wars (1815) created a system of states in Europe based on the balance of power and cooperation among the great powers. Therefore, relatively few military conflicts took place during the nineteenth century. Wars usually did not last long and did not get extended to the civilian population. Disagreements have often been resolved through international conferences and congresses. The civilian Europe seemed to be a unique scene in world history, where not only economic wellbeing, prosperity and peace among states got realised, but it was also able to enforce its values all around the globe.

\section{Europe in the "short twentieth century"}

The First World War brought fundamental changes in the history of European civilisation. Not only has it accelerated Europe's economic loss against the rising United States, it has caused enormous human and material losses, that has shaken the faith in progress. As a result of World War I, "cultural pessimism" appeared in European intellectual circles, that took into account the continent's decline. The fact that the extreme right and left strengthened between the world wars resulted in the decline of liberalism and implied the development of authoritarian systems and dictatorships. This drew the line between the "long nineteenth century" and the "short twentieth century". The former was linked to Europe's world domination, faith in the future, optimism, national liberalism and the results of industrialisation, and the latter to the territorial loss of the European continent, economic, political crises and aggressive mass nationalism. 
The "short twentieth century" clearly illustrates that World War I was a turning point in both world history and European history. Compared to the ideas of the "long nineteenth century", political ideology and practice have gone through a radical transformation between the two world wars. However, the "short twentieth century" is no longer suitable for describing the history of European civilisation in the decades following the Second World War. During the decades of the Cold War (1947-1989), many colonially liberated countries outside the Western world were dominated by authoritarian regimes and dictatorships, in addition, tribal and ethnic nationalism, and bloody conflicts started. In contrast, democracies consolidated in Western Europe after World War II and extraordinary economic growth occurred between 1945 and 1973. The concept of the "short twentieth century" was originally interpreted by historians as the "cancellation" of the "long nineteenth century" values and ideas but unlike many countries in the world, Western European countries got consolidated after 1945 by liberal democracies.

Historians say the "short twentieth century" ended in 1989-1990, when the communist dictatorships collapsed, and the Cold War ended. Many people believed that liberal democracies are now unstoppably spreading around the world. On this basis, world history can finally get back on the track that characterised the "long nineteenth century". Others were more prudent and pointed out that the end of the Cold War would not necessarily lead to a worldwide victory of liberal democracies, but that the twenty-first century might be a period of bloody religious and ethnic conflicts. No matter how we interpret the events of the last few decades, a degree of ambiguity remains in the contemporary interpretation of the European civilisation. On the one hand, Europe is undoubtedly the scene of liberal democracies, economic and political freedoms, the development and preservation of individual and civil rights, and on the other hand, since the 1973 oil crisis, Western European countries have been facing a model crisis characterised by the uncertainty of civilisational values.

Between the two world wars, civic and Christian humanists sought to save both Christian and liberal values in Europe. Christian tradition was considered to be an important part of the European legacy, as well as individual and citizens' liberties. Contrary to irrational thoughts, the tradition of rationalism was upgraded to be the foundation of European culture. Far left and right were symptoms of the "barbarisation" of modern mass societies, that lead to the end of the "old" Europe. Against the extremes of nationalism and totalitarian ideologies, Europe was seen as the centre of individual and universal values that exceed the exclusivity nation-states. On this basis, after the Second World War, political elites in Western European democracies wanted to bring Christian and liberal values into line with the demands of industrial society and market efficiency. In 
their view, "Christianity", "freedom" and "modernity" are not ambivalent concepts but can be linked together. After 1945, Christian Democratic politicians began to build European integration and to adjust Western European democracies into the Atlantic community of values and interests against the communist threat.

Over the decades after the Second World War, Western European societies proved to be a successful model, that was also attractive to Eastern European socialist countries. The exceptional economic growth gave room for spectacular social emancipation, that approved economic results and legitimised the economic and social model of "regulated capitalism". The success of democracies rested on the balance between individual freedom and social solidarity, which could as well be seen as the realisation of European civilisational values in the spirit of Christian social teaching.

Despite its successes, remember that the results of the period between 1945-1973 were enabled only by economic growth, which was achieved through the adoption of American business organisation methods and the adoption of a consumer model. The US security shield, capital imports, and international financial system guaranteed by US economic power only added to this. European intellectuals between the world wars were still critical about the United States because they saw it as a negative example of an industrial mass society. After World War II, the majority of Western European politicians and intellectuals already respected the solid liberal political culture of the American society. During the Second World War the US intervention proved decisive against the Nazi Germany and that Western European democracies found a firm support in the US during the Cold War. After 1945, US financial support seemed to be essential for launching the economic growth, that seemed to be the only effective way to increase prosperity, strengthen the middle classes, and confine political extremities.

After World War II, Western European economic policies facilitated GDP increase and social well-being, but this was coupled with stronger and stronger "Americanisation". Living standards have increased and consumer society developed, but Europe's cultural identity kept decreasing. While economic growth proved to be steady, politicians and intellectuals accepted the benefits of the boom. But after the 1973 oil crisis, criticisms formulating doubts about the performance of Western European society grew. Since then, social sciences rightly represent the crisis of the European economic and social models.

In the decades after the Second World War Western Europe has set up expensive welfare systems, that have become a difficulty since the recession, hindering economic development. Cancelling them would face serious resistance, as the welfare guaranteed has become an integral part of the social values. Maintaining welfare systems makes it difficult for Europe to compete in the 
global economy, whether against American laissez faire capitalism or the Far East "developmental state". Recently, it has become a fundamental dilemma for Western Europe to adapt the models of North American neoliberalism growing since the 1980s, that would accomplish its loss of identity. Or should it preserve the welfare achievements and keep alive a comfortable European "socialism"? Over the recent decades, European countries have struggled to find successful answers to the challenges of global neo-capitalism. Current policy debates on the institutional evolution of European integration seem secondary in contract to this model crisis.

The European unity process should be mentioned in this perspective. The unity of Europe is an idea of the philosophical legacy of the Enlightenment. It is a "project" of modernity that could be embodied even in the creation of a cosmopolitan world state. European unity can be seen as the end point of a "grand narrative", that assumes the history of "humanity"/"Europe" will reach an ideal still point by the creation of a federal state. Compared to the concept of "Founding Fathers", the idea of European unity has recently evolved into a technocratic project that has hardly any contact with the general public. It suggests that the completion of the unity process can surpass all the weaknesses of Europe, while this is exactly that reveals us the fact it is an intellectual utopia. It is questionable whether the realisation of the European federation can solve the dilemmas of the economic and social model. Despite such issues, there is no doubt that the integration process has provided useful political solutions for the peoples of Europe over the past seventy years.

Finally, let us discuss the issue of the "civilisational/cultural crisis". This is not the same as the socio-economic model crisis, although apparently, there are overlaps between these two issues. "Cultural pessimism" has been engaging European intellectuals since the end of the First World War. Since the publication of Oswald Spengler's book, The Decline of the West (1918-1922), huge literature has been produced in this field. The formation of modern societies has led to a crisis of traditional values throughout the entire Western world, of which the interpretation is divided. It is also an argument whether it is a real crisis at all. If so, what is its nature and what are the characteristics? Will the crisis lead to the final collapse of Western European Christian civilisation or will it promote its renewal? In this perspective, the increasing absence of social values are usually mentioned that make collective efforts impossible, as well as the disintegration of communities, atomisation and anomie. The disappearance of families and the decreasing number of children involve deep uncertainty about the basic attitude regarding "life". A controversial issue is the result of the fading of Europe's "grand traditions", Christianity and antiquity. 
In this context, it should be pointed out that the tendency for the European continent of losing religiousness appears to be one of the most important (religious) sociological phenomena in the last half century. While in the United States we can speak of a "religious revival" within the neo-protestant churches, historic churches have not achieved a breakthrough in the field of evangelisation on the European continent. During the last decades, we see a further decline in the number of people practicing religion. Pope John Paul II (1978-2005) formulated a programme of "re-evangelising Europe", but success is still to come. A similar situation can be observed with regard to the classical heritage, as we have witnessed the decline of Latin language and literature over the last half century. The question arises whether, without "universal" Christian and classical content, national cultures can resist the temptation of nationalisms.

Today, European civilisation is threatened on the one hand by the competition of global capitalism and the effects of consumer society, and on the other by the threat of religious, ethnic fundamentalism and "national closure". To solve these problems, Europe must respond to how it can renew its "grand traditions" within a pluralistic society and fight the dichotomy of "fundamentalism" and "relativism". Given the magnitude of the dilemmas outlined, it is not surprising that "cultural pessimists" fear the loss of European values and predict the end of European civilisation, whereas "modernists" emphasise that through the realisation of the Western universal model of market economy, liberalism and democracy the evolution of European civilisation has been completed in the best sense. Although our views are largely dependent on the philosophical preconditions for approaching the "civilisational crisis", our ideologies cannot be an excuse when facing the problem.

\subsubsection{Chronological table}

\begin{tabular}{c|l} 
Date & \multicolumn{1}{c}{ Event } \\
\hline $\begin{array}{c}\text { eighth century BCE } \\
\text { fifth-fourth centuries } \\
\text { BCE }\end{array}$ & Homer's epics \\
\hline $\begin{array}{c}\text { First half of fifth } \\
\text { century BCE }\end{array}$ & Greco-Persian wars \\
\hline $\begin{array}{c}\text { fifth-first centuries } \\
\text { BCE }\end{array}$ & Roman Republic \\
\hline third-first centuries & Hellenistic Age \\
\hline BCE & Julius Caesar occupies Gaul \\
\hline 58-49 BCE & Reigning of Augustus. Beginning of the Roman Empire \\
\hline
\end{tabular}


6.2. Western Christian Europe

\begin{tabular}{|c|c|}
\hline Date & Event \\
\hline third-sixth centuries & The great invasions \\
\hline fourth-sixth cent. & Late antiquity \\
\hline 313 & Edict of Milan on religious freedom \\
\hline $354-430$ & Saint Augustine \\
\hline 395 & Roman Empire divided into West and East \\
\hline 451 & Council of Chalcedon \\
\hline 476 & Fall of the Western Roman Empire \\
\hline $590-604$ & Saint Gregory the Great \\
\hline $\begin{array}{l}\text { seventh-eleventh } \\
\text { centuries }\end{array}$ & Early Middle Ages \\
\hline $\begin{array}{l}\text { seventh-eighth } \\
\text { centuries }\end{array}$ & Evangelisation of Anglo-Saxon kingdoms and Germania \\
\hline $\begin{array}{l}\text { eighth-ninth } \\
\text { centuries }\end{array}$ & Byzantine iconoclasm \\
\hline 732 & Battle of Poitiers \\
\hline 800 & Imperial crowning of Charlemagne \\
\hline 843 & Division of Frankish Empire \\
\hline 962 & Establishment of the Western Roman Empire \\
\hline с.1000 & $\begin{array}{l}\text { Foundation of the Polish and Hungarian states. Venetian and Pisan } \\
\text { success on the Mediterranean Sea }\end{array}$ \\
\hline 1054 & Schism \\
\hline $\begin{array}{l}\text { eleventh-thirteenth } \\
\text { centuries }\end{array}$ & Age of Roman arts \\
\hline 1075 & Pope Gregory VII: Dictatus Papae \\
\hline 1096 & Beginning of the Crusades \\
\hline $\begin{array}{l}\text { twelfth -fifteenth } \\
\text { centuries }\end{array}$ & High Middle Ages \\
\hline $\begin{array}{l}\text { twelfth - thirteenth } \\
\text { centuries }\end{array}$ & Investiture Controversy \\
\hline 1054 & Schism \\
\hline eleventh-thirteenth & Age of Roman arts \\
\hline 1075 & Pope Gregory VII: Dictatus Papae \\
\hline 1096 & Beginning of the Crusades \\
\hline twelfth -fifteenth & High Middle Ages \\
\hline twelfth - thirteenth & Investiture Controversy \\
\hline $\begin{array}{l}\text { twelfth- fifteenth } \\
\text { centuries }\end{array}$ & Gothic Age \\
\hline
\end{tabular}


Civilisations from East to West

\begin{tabular}{|c|c|}
\hline Date & Event \\
\hline $1225-1274$ & Thomas Aquinas \\
\hline $\begin{array}{l}\text { fourteenth -sixteenth } \\
\text { centuries }\end{array}$ & Renaissance \\
\hline 1348 & The great plague \\
\hline 1453 & Ottomans occupy Byzantium \\
\hline 1492 & Discovery of America \\
\hline $1500-1800$ & The early Modern Age \\
\hline $\begin{array}{l}\text { Turn of the fifteenth } \\
\text { century }\end{array}$ & Art of Leonardo, Michelangelo and Raphael \\
\hline 1517 & Beginning of Reformation \\
\hline 1637 & Descartes: Discours de la méthode \\
\hline 1687 & Newton: Principia (= Philosophiae Naturalis Principia Mathematica) \\
\hline $1760-1780$ & Beginning of the first industrial revolution \\
\hline 1789 & French revolution \\
\hline 1789-1914 & "Long nineteenth century" \\
\hline 1804 & Imperial crowning of Napoleon \\
\hline 1806 & End of the Western Roman Empire \\
\hline 1815 & Congress of Vienna \\
\hline $\begin{array}{l}\text { Last third of the } \\
\text { nineteenth century }\end{array}$ & The second industrial revolution \\
\hline 1914-1918 & World War I \\
\hline $1914-1990$ & "Short twentieth century" \\
\hline $1918-1922$ & Oswald Spengler: The decline of the West was issued \\
\hline 1939-1945 & World War II \\
\hline 1949 & Establishment of NATO \\
\hline 1957 & The Treaty of Rome. Establishment of the EEC \\
\hline 1962-1965 & Vatican Council II \\
\hline 1973 & $\begin{array}{l}\text { Oil crisis. The edge of the economic growth in the developed industrial } \\
\text { world }\end{array}$ \\
\hline 1978-2005 & Pope John Paul II \\
\hline 1989-1990 & $\begin{array}{l}\text { Annus mirabilis: The fall of central-eastern European communist } \\
\text { dictatures }\end{array}$ \\
\hline
\end{tabular}


6.2. Western Christian Europe

\subsubsection{Bibliography}

BleI, KAREL 2002: Freedom of Religion and Belief: Europe's Story. Assen: Van Gorcum

BLOCH, MARC 1961: Feudal Society. London: Routledge, Kegan Paul

BROWn, PETER 1996: The Rise of Western Christendom. Triumph and Diversity. AD 200-1000. Oxford: Blackwell Publishers

Cipolla, CARlo, M. 1989: Before the Industrial Revolution. London: Routledge

DAVIES, NORMAN 1996: Europe: A History. Oxford and New York: Oxford University Press

DAWSON, CHRISTOPHER 1932: The Making of Europe: An Introduction to the History of European Unity. London: Sheed and Ward

DAWSON, CHRISTOPHER 1950: Religion and the Rise of Western Culture. London: Sheed and Ward

Duby, GeORgES 1973: Guerriers et paysans. VIIe-XIIe siècles. Premier essor de l'économie européenne. Paris: Gallimard

Eisenstadt, SHMUel 1969: The Political Systems of Empires. New York: Free Press

HALECKI, OsCAR 1950: The Limits and Divisions of European History. New York: Sheed and Ward

HALECKI, OSCAR 1952: Borderlands of Western Civilization: A History of East Central Europe. New York: The Ronald Press Co.

HASKINS, CHARLeS HOMER 1982: Renaissance and Renewal in the Twelfth Century. Oxford: Clarendon Press

HAY, DENYS 1957: Europe. The Emergence of an Idea. Edinburgh: Edinburgh University Press

HEATER, DeREK B. 1992: The Idea of European Unity. Leicester-London: Leicester University Press

HofFMAN, PHILIP 2015: Why did Europe Conquer the World? Princeton, Oxford: Princeton University Press

LE GofF, JACQUes 2007: The Birth of Europe. Oxford: Blackwell Publishing

MiLWARD, ALAN 1984: The Reconstruction of Western Europe. 1945-51. London: Methuen

Pagden, Anthony (ed.) 2002: The Idea of Europe. Cambridge University Press PERKINS, MARY ANNE 2004: Christendom and European Identity. The Legacy of a Grand Narrative since 1789. Berlin-New York: Walter de Gruyter

Rosenstock-Huessy, Eugen 1949: The Driving Power of Western Civilization: the Christian Revolution of the Middle Ages. Boston: Beacon Press 
Civilisations from East to West

Rostow, Walt, W. 1960: The Stages of Economic Growth: A Non-Communist Manifesto. Cambridge: Cambridge University Press

SAID, EDWARD 1978: Orientalism. London: Routledge and Kegan Paul

SkINNER, QUENTIN 1987: The Foundations of Modern Political Thought. Cambridge: Cambridge University Press

TOYNBEE, ARNOLD 1951-1955: A Study of History. London: Oxford University Press

Ullmann, Walter 1977: Medieval Foundations of Renaissance Humanism. London: Paul Elek 
7. America 


\title{
7.1. The North American Civilisation
}

\author{
LÁSZLÓ ZSINKA
}

At present the concept of North American civilisation mainly refers to the United States which has become the dominant pole of Western civilisation since the Second Industrial Revolution, although Anglo-Saxon colonial societies such as Canada, Australia, New Zealand show similar features. In this paper, we do not deal with the Indian societies, also known as pre-Columbian cultures, that had existed before the arrival of European people. In our study of Western Christian Europe, we have already pointed out that, compared to the at least two thousand years of European civilisation, the past 200-300 years of colonial society in North America appear to be at most the last short chapter in a book on the history of the West. We also discussed that North American civilisation embraced Christian foundations, and the ideas of individual freedom and market. Contrary to European Catholic traditions, the Protestant heritage tradition has become more prominent in North America and, compared to the continental political ideas based on the balance between freedom and solidarity, in the Anglo-Saxon tradition the main stress was put on individualism and individual initiatives and the idea of a minimal state gained importance instead of etatism and corporate society organisation. The optimism, progressivism and pragmatism of the Americans, as well as many other "values of American civilisation" can also be mentioned in this context. For this reason, in this chapter, we describe North American civilisation, another "subsystem" of the West/Euro-American world. Because its history is essentially the same as the history of civilisation in the United States, from the brief two-hundred-year history of the United States of America we highlight aspects that have become effective civilisational values and attitudes today, and present the historical environment in which they were created.

\subsubsection{Basic features}

The first colonies in North America were largely founded in the seventeenth century by English Puritans who left the island because of the harassment of the Anglican Church and royal absolutism. The diligent Puritan communities grew rapidly in the new country and, despite their disputes with the English colonial authorities, were enjoying freedom. There is a lot of literature on the influence of Protestant work ethics on the development of American capitalism, even in the early period. These included some well-known opinions of historians about the way in which Puritan communities lived their way, as prominently 
rooted in nineteenth century historiography, according to which North American Protestants were characterised by a degree of self-denial and asceticism, but their reservations about secular culture were far less powerful. The Puritans did indeed reject some "secular futilities" but did so within the framework of a sober and diligent family life, which, together with other circumstances, allowed for the accumulation of capital. This latter phenomenon was referred to in Max Weber's famous study, The Protestant Ethic and the Spirit of Capitalism (1905), which originally explored the relationship between the success of Western European capitalism and Protestant ethic. In addition to the findings of Weber's thesis on European economic history, attention should be drawn to the basic layer of American self-interpretation that was emerging at the end of the eighteenth century, known as WASP (White Anglo-Saxon Protestant). According to this, the United States was created as a Protestant country, long determined by the customs of the Anglo-Saxon middle class.

This is still embodied in many customs, such as Thanksgiving. Some of the colonists who landed with the Mayflower around Plymouth in 1620 and arrived in the New World fell victims of starvation and harsh natural conditions. The colonists were said to have been helped by the Wampanoag Native American tribe to overcome the initial difficulties. After an abundant autumn harvest, the survivors held a celebration, sharing the harvest with the Indians.

President George Washington (1789-1797) was the first to call for a Thanksgiving celebration across the country. Thanksgiving itself was a Protestant custom that can be manifested to God for many reasons in the spirit of the Psalms. With the creation of the United States, it has become the responsibility of the Member States to determine the Thanksgiving Day(s). In October 1863, President Abraham Lincoln (1861-1865) proclaimed to the whole nation the need to celebrate Thanksgiving. It was first celebrated on the last Thursday of November, and later on the fourth Thursday of November. The spread of Thanksgiving is related to the emergence of modern American identity. Its habits were formed at the end of the nineteenth century, when the consequences of the post-Civil War divisions and the large number of immigrants saw a growing need for a celebration of American national identity. Thanksgiving is good example of the close relationship between American national identity and Protestant traditions, whose living influence is still evident today.

The Anglo-Saxon Protestant heritage remained exceptional despite the growing role of Catholic Irish, Italian, Latin American immigrants since the second half of the nineteenth century, and today the United States has become a multicultural society. The role of the WASP heritage is well illustrated by the controversy between those believing in Anglo-Saxon traditions or multiculturalism. These disputes have divided the American political and cultural elite over 
7.1. The North American Civilisation

the past decades. The strength of the debate is that Americans today value the historical role of the WASP tradition as much as the melting pot culture associated with high immigration. Nowadays, conservatives refer to the importance of the WASP (White Anglo-Saxon Protestant) in protecting "original" American values, just as Liberals regard cultural diversity resulting from immigration as a fundamental phenomenon of American history.

In the thirteen colonies that make up the core of the United States, the number of settlers grew rapidly from the humble beginnings of the seventeenth century. By 1630, only a few thousand colonists had arrived, but by the early eighteenth century the population had reached a quarter of a million. Seventy years later, at the time of the outbreak of the War of Independence, at least two million people were living in North American English colonies. According to the census of 1790, the new republic had a population of 3.9 million. Ten years later, the 1800 census found that the United States had about 5.3 million people, compared to 15 million in the British Isles and 27 million in France. Throughout the eighteenth century, Europe's population was estimated to have increased by one and a half times or doubled in size due to the economic boom and more favourable climatic conditions, while the size of the future US population increased twentyfold. Comparing European and North American data, we are witnessing an extraordinary increase in the birth of the United States, which has proved to be extraordinary in later world population history. Significant growth rates continued throughout the nineteenth century.

The rapid growth was due not only to newer immigrants but also to the large number of children. From the beginning, the fact that Protestant families had a commitment to God to "multiply" and "reproduce", as well as the abundance of land that enabled the growing population to find new cultivated areas, played a role in the high natural reproduction. Available land, populations of new territories, high levels of immigration and high fertility rate continued to be important components of American culture.

As the American colonists moved westward, they were always able to acquire new lands, so no significant social differences were created. Initially, the English authorities sought to transpose solutions based on personal dependence in the medieval European agricultural economy, which would have allowed larger landlords to provide free labour. Historiography used to speak of an attempt to transpose "feudalism", but today, for two reasons, we are unlucky to use this term. On the one hand, with regard to the Western European phenomenon, historiography nowadays rather uses the term "feudal society", and since Alan Macfarlane's much-debated study - The Origins of English Individualism (1978) - it has been questionable whether we can even speak of "feudalism" or "peasant society" in the traditional sense for American colonists. Instead, it should be 
pointed out that historical sources initially refer to farmers who cannot leave their master's land without specific permission, and sometimes binding seems to be hereditary because the same applies to their children. Especially those who have already come from the motherland in debt are in a more difficult situation. It is also noticeable that in some cases attempts have been made to operate some sort of a "manorial court" because the landlord has ruled in tenants' cases. It is noticeable that in some areas the English Crown has attempted to create a kind of landlord aristocracy. However, these initiatives soon became overshadowed. In the eighteenth century, most landlords are already free owners or free tenants. Although not everyone had access to their own land, for colonists, the seventeenth-century agricultural economy of England, which was increasingly commercialised, provided the benchmark, where most farmers were owners or tenants. Ultimately, the abundance of land made it impossible for the Crown to strive for a landlord aristocracy or a system of personal dependence.

Many of the features of the European agricultural system have been the result of the scarcity of land available since the economic boom and population growth of the twelfth and thirteenth centuries. The landlord elite and farming communities organised, or privileged land use based on scarcity. In Europe, at the beginning of the twelfth century agricultural expansion, plots of land were still available for cultivation - which strengthened the possibilities of individual cultivation (hospes), but as a result of population growth solutions have been pushed into the background, and cultivations based on community regulations have generally spread (open field). In North American colonies, due to the seemingly endless prospects of abundance of land, this did not happen, but individual cultivations were consolidated. Although the English authorities attempted to protect the territory of the Indian tribes, their military allies in the colonial wars, to prevent colonists from expanding westward in the eighteenth century, which would have ended the abudance of land, their efforts were not crowned with success. In fact, strong opposition to these plans - among the richer landlords and colonists who want to expand - contributed to the outbreak of the War of Independence, the victory of which finally secured expansion to the West. The lack of European dependencies - aristocracy, feudalism - in the agricultural economy from the beginning promoted capitalist accumulation. American society, on the eve of the struggle for independence, was characterised by a broad spectrum of free owners, small holders which later played a major role in shaping social and political characteristics.

Not only the peculiarities of the social structure but also the rights of representation of the colonists played a major role in the formation of the "American values". The Puritans brought with them the bottom-up "democratic" ecclesiastical organisation of Calvinism from the Old World, and the lessons that could be 
7.1. The North American Civilisation

drawn from English political life on the basis of royal power and parliamentary debates. They took shape in the struggles of the English Civil War, partly in the Puritan army. The so-called Levellers formulated the principle of taxation linked to representation. The "Glorious Revolution" of 1688 provided valuable experience of the principles of a constitutional kingdom. When eighteenth-century colonists looked toward England, they encountered the practice of a parliamentary monarchy that served as a point of reference for them.

Even the first colonist communities expressed their need for representation in the seventeenth century. The king and his governors eventually accepted the need for colonies to form representative bodies. Different colonies applied different solutions, but the institution of representation gradually consolidated. It was true that members of the Puritan communities were empowered to elect representatives, otherwise simply "free people". From the beginning, it was important for representative bodies to have their say on taxes. In some respects, the cause of the struggle for independence can be understood as a reaction to the reduction of colonists' representation and tax rights. In the eighteenth century, towns and smaller settlements formed their local governments. The "selfgoverning spirit" of American society, as Alexis de Tocqueville (1805-1859) observed, is that the tradition of self-administration instead of administrative bureaucracy dates back as much to the pre-independence period as it did for decades after freedom was gained, when the establishment of self-governments was guaranteed by the Constitution. During the eighteenth century, the emerging elite of the East Coast had the opportunity to become acquainted with European culture and the ideas of the Enlightenment. When France lost to Canada in the Seven Years' War (1756-1763), the last link - fear of the French Royal Army that tied the Americans to England was lost. The heirs of the Puritans were no longer afraid of the Catholic French and, against the Crown, they restored the old parliamentary - Leveller - slogan of the English Civil War that "there is no taxation without representation". During the emerging War of Independence (1775-1783), the American colonists not only won the battle, but also engaged in lively debates over the constitutional system.

The formation and constitution of the United States is a fact that continues to stamp both Anglo-Saxon political thinking and American self-interpretation to this day. Not only did the American Constitution produce a legal document, but it also summed up the thinking of the European Enlightenment, and the conceptual debates surrounding the drafting were instructive. In addition to summarising the major trends of early modern political philosophy Montesquieu, Locke - they also introduced far-reaching innovations that became important milestones in Anglo-Saxon political thought development. The close interplay between the constitution and American patriotism makes the history of 
the United States just as exceptional, just as it is rare that the founding ideas of a political community so stamp their subsequent nature, and become a factor in the development of civilisation.

\subsection{2. "Establishing" freedom in the United States}

4 July 1776, in Philadelphia, at the Second Continental Congress, representatives of thirteen colonies approved the Declaration of Independence. As a result of the declaration of independence, the constitutional order of the former colonies had to be established. To this end, a committee was set up with the task of preparing a draft of the confederation. As a result of protracted debates, the Articles of Confederation were adopted in November 1777. Its creators were moved by the intention that the colonial states should have the highest degree of autonomy over the institutions of the emerging confederation. The states transferred control of foreign policy and army, the appointment of military leaders, negotiations with the Indians, and the possibility of borrowing to the Confederation. In fact, the Confederation did not have the power to enforce military or financial contributions from the States when needed. The weaknesses of this constitutional structure were already apparent in the middle of the 1780s, prompting the leaders of the War of Independence to rethink the powers between state and federal levels. The draft of the new constitution was discussed by the Constitutional Convention in Philadelphia, Pennsylvania in 1787, and was subsequently ratified by the states. The newly created federation gave federal legislation and executive powers much broader powers than the Articles of Confederation. The founding debates show that initially the Confederation had a better chance, but the United States eventually became a federation with a strong centre.

The legal disputes surrounding the American Constitution have evolved in balancing the advantages and disadvantages of the confederation which confers significant powers on each state, and the federation, which gives federal institutions extensive powers. In addition to their views on the constitution, the politicians involved in the debate - Thomas Jefferson, James Madison, Alexander Hamilton - expressed more general political philosophical ideas. The Federalist Papers the authors of which include Madison and Hamilton, dealt mainly with arguments for the federation, but also gave rise to theoretical dilemmas. The choice between federation and confederation was more than a simple constitutional issue. On the one hand, it can be regarded as a power and state organisation problem, because only the effective federal organs of the United States could enable economic development and the defence of the country. On the other hand, 
7.1. The North American Civilisation

it was a question of operating a political community, because citizen participation-based governance was first established in a large republic in history.

In constitutional debates, Hamilton became the strongest defender of strong federal powers, ahead of his time, because at the dawn of the Industrial Revolution he said that only industrial development, protective tariffs and a central bank could make his country a prosperous nation. He believed that the United States would be able to defend its interests if strong federal powers were created. Because Hamilton did not trust the people, he sought to remove government from direct forms of democracy. He was thinking of representative democracy because he did not consider the American average person, who put his own economic interests first, to be able to exercise his civil rights through direct participation. He thinks that people's actions are driven by self-love, which, in addition to economic gain, includes a desire for glory. Unlike the representatives of the Scottish Enlightenment, Hamilton did not trust that the proliferation of "trading societies" would contribute to a peaceful public relationships, because the new "utilitarianism" instead of "honour" and "power" seeks to rule as well which also marks interstate relations. Therefore, he was concluded that the new republic should have significant industrial production as soon as possible. Hamilton's thoughts are echoed in the practice of Republican federal governments after the American Civil War, which by all means focused on promoting industrialisation. His views preceded his time, but in the long run they became the starting point of a political and economic tradition which advance protectionism against liberal free trade practices, and the support to business activity by the federal government against spontaneous industrial development. The history of the last two centuries has abundantly provided examples of this practice.

Jefferson's political worldview can be seen as the opposite of Hamilton's ideas. Jefferson believed in direct democracy and wanted to empower local communities as broadly as possible. He believed that the American states, should be divided into areas approximately the size of the ancient Greek city-states, where democratic participation is practicable due to the small size of the community. Unlike Hamilton, Jefferson was optimistic about civic virtues. In his view, "natural democracy" selects citizens who are committed to public life and who are capable of handling the affairs of their fellow citizens, and the leaders of the country must be chosen from among them. Jefferson would have given the federal powers a much narrower scope because he wanted to delegate as much power as possible to the local level, relying on the self-management ability of local communities. Compared to Hamilton's sceptical utilitarianism, Jefferson's approach reflected Aristotle's view that man is by nature a social being (zoon politikon) and therefore a fundamental vocation of politics and public affairs. 
Compared to Hamilton's vision of the industry, landlord Jefferson was thinking of a society where the majority of people were farmers or urban small owners, shopkeepers and merchants. Jeffersonian democracy is founded on a broad spectrum of free owners. On the one hand, this was consistent with contemporary American conditions, and, on the other, the idyll of the traditional agricultural world came under increasing pressure as a result of the industrialisation of decades to come. Jefferson's agrarian considerations later turned the populism of rural small-ownership groups suspicious of industrial capitalism, large organisations, and Laissez-faire practices into the American political tradition. In the last third of the nineteenth century, agrarian populists have gained a significant role in American domestic politics.

Jefferson's democratic tradition has survived in American politics in a broader sense. Jefferson himself was strongly sympathetic to the plebeian ideas of the French Revolution, while federalist disputants were elitist in their thinking, and rather they regarded England after the "Glorious Revolution" as their model. They were remotely sympathetic to the idea of popular domination and were sympathetic to England in foreign policy after the end of the War of Independence. The Jeffersonian tradition expressed the fullest possible political and economic involvement of the whole people, and the need for it in public affairs against the prevailing establishment, the capitalist interest groups, or state regulation and restrictions. The Jeffersonian principles became the reference point when they wanted to make free enterprise and democratic participation accessible to a wider audience. In this respect, the Jaksonian liberalism relied on Jeffersonian tradition in the first half of the nineteenth century, as did Progressivism at the turn of the century or the Roosevelt New Deal in the 1930s, although the latter, unlike the older American ideals, strove to secure the fullest possible economicsocial emancipation after the Great Depression by increasing federal powers.

Compared to Hamilton and Jefferson, Madison's political ideas proved to be more complex and more difficult to place in the dichotomy of local or federal powers. As a committed Republican, Madison has studied extensively the ancient and modern republics. His general scepticism about achieving the best government did not stop him from expressing his position as one of the authors of The Federalist Papers. Madison was fully aware of the exceptional novelty of the emergence of the United States as a large-scale republic compared to the ancient city-states, whose governance required new conditions. For him, antique polis was a form of direct popular rule, dominated by either the stupidity or tyranny of the majority. Madison argues that a large republic makes it inevitable to use a system of representation other than direct participatory democracy. In the case of a large-scale republic, there is a greater chance that talented representatives will be in office, as larger constituencies have more capable people to choose from. 
On the other hand, interests and interest groups themselves are more diverse in large republics. This reduces the possibility of a single aspiration to power that prevents the rule of the tyranny of the majority. In this way, Madison's not only distanced himself from the Rousseau and Jefferson principles of direct democracy, reminiscent of antique polis, but also became the forerunner of modern pluralism theories.

However, the benefits of representative government and federal powers did not make Madison such a committed spokesman for the central power as Hamilton. He even elaborated the principle of power sharing by separating the roles of the three branches of power (legislation, executive, and justice) and the lower and upper branches of the legislation, and by separating states and federal powers he intended to transform the American Republic into a constitutional system that protected individual rights. Madison opposed the model of direct democracy based on local communities for indirect governance, and on the other hand he wanted to protect his country from alienated representative government and over-executive power can prevail over the people.

In his classic study of the emergence of the United States, Richard Hofstadter highlighted the circumstances surrounding the formation of the American Constitution. In his view, nothing was farther from the "Founding Fathers" than revolutionary radicalism. They were all prosperous, educated people and committed Republicans. As wealthy landlords in the East Coast, they were in close contact with European spiritual and intellectual currents. The drafting of the new constitution was intended to guarantee the power of the people, but by no means that the people themselves should take direct responsibility for governance. Therefore, they all considered representative democracy to be the best solution. Even Jefferson considered it right that the choice of Republican representatives should follow an indirect procedure following a natural selection process in local self-governing communities. Representative governance provides control, and the powers of the legislative and the executive are limited by guarantees of power sharing. The United States was born out of such a compromise: by exercising effective federal powers but by counteracting the separation of power. This solution was eventually accepted by all parties to the dispute. All with different emphases, they were all federation parties, but they respected individual freedom and rights. That is why Jefferson, in the early years, was able, without much compromise, to assume the office of president of the new federal republic, although he had previously held a minimalist view of federal powers.

To this day, this dual legacy of the constitutional tradition still influences American citizen identity, although its historical forms have changed over time. In the first decades of US history, the "Federalist" party represented the concept of a strong federal state, and against it were the "Democrats" (Republican 
Democrats) who insisted on Jefferson's local autonomy. Later, this changed, with Democratic parties taking over social programmes and the welfare state in the 1930s seeking to give federal legislation and executive powers more power, while Republicans explicitly defended state rights. Contrary to the policies of Roosevelt New Deal, which significantly expanded federal powers and the policies of Johnson's Great Society that emerged in the 1960s, Republicans, who had been in opposition until the 1980s, sought to provide economic laissez faire, low taxes, and a reduction in the power of the federal government.

In Hannah Arendt's famous book, On Revolution (1963), the United States described the emergence of the United States as "the foundation of freedom". Arendt drew a distinction between "political revolution" and "social revolution". She believed that during the French Revolution social-shaping ideas eventually took precedence, while at the founding of the United States they did not want to change social relations at all, but rather created new political institutions. That is why the United States avoided revolutionary radicalism and became a solid liberal democracy. Arendt's argument also suggests that the idea of American representative democracy developed in the same direction as Jeremy Bentham's or Benjamin Constant's ideas of freedom and democracy in nineteenth-century versions of European liberalism. There was no turning back to the "simple society" of antique polis but guarantees of freedom had to be created within "complex societies" and larger territorial states. Just as Adam Smith left behind the antique virtue in political economy in The Wealth of Nations (1776) and formulated market laws within the framework of a "complex society", politically the American constitution implemented the civil principle of modern representation instead of ancient participatory democracy.

Neo-conservative thinkers such as Irving Kristol, in the second half of the twentieth century, considered the central value of the American constitutional system - like Hannah Arendt's line of thoughts - to avoid revolutionary radicalism and formulated a conservative (or "old liberal") interpretation of the American "constitutional revolution". In this perspective, the American "revolution" was completely different from the French Revolution and other continental European revolutions, because it did not confront Christian traditions, did not radicalise, did not lead to elite change, and there was no revolutionary terror but the institutions of freedom. The War of Independence and the Constitution of 1787 created the American "demos". The American nation was not born of some common blood-folk descent, but through constitutional rights, that is, enjoyment of freedom. In this respect, the political identity of the United States can be compared to antique Greek polis created by synoikismos (co-settlement or colocation) or to ancient Rome, where the city was established as a political-legal structure while the Roman tribe or people never existed. This purely political 
structure was united by the enjoyment of rights, which was extended several times throughout Roman history. To be "Roman" was not a tribal blood relation or cultural group identity, but a legal relationship with the Roman state. The Populus Romanus, the "Roman demos" was created as a result of the acquisition of common rights. The identity of the political communities where common bloodtribal origin forms the basis for belonging to a territorial state is markedly different. Such is the case with most of the modern European nation states, which are based on historically developed forms of national identity. By contrast, the American demos could not rely on a common myth of folk descent but regarded the acquisition of "freedom" - civil and political rights - as a fundamental point of reference. As a result, American "nationalism" has become a kind of civic patriotism, where participation in constitutional rights has brought together immigrants from a wide range of linguistic and ethnic backgrounds.

Contrary to the historical-legal tradition of English liberalism, the authors of the American Constitution relied on John Locke's (1632-1704) conception of the "foundation of freedom" derived from natural law. When it was considered that the Creator gave everyone equal rights, not only the aspect of idealism, but also the prospect of universalism was included in the constitution. Contrary to English conservative liberalism, which regarded British institutions as an exceptional result of unique historical development (exceptualism), American thinking has always been tempted by universal missionary consciousness. At the same time, it became common for English and American thought that freedom itself became a tradition, both with the historical development of the English institutions of liberty and the constitutional "founding" of American freedom. This fact clarified the spiritual position of neo-conservative/neoliberal thinkers, such as Irving Kristol and Friedrich August von Hayek, who could rightly argue in the second half of the twentieth century that the preservation of political traditions implied the aged "old liberal" principles in the Anglo-Saxon world. Unconditional respect for the individual's political rights - whether from the English habeas corpus or the American Constitution - has created convergence between the English and American liberal traditions, even if there are significant differences between philosophical anthropological foundations - the empiricalhistorical foundations of the English or rational - natural law background of the Americans - were perceptible. Contrary to the tradition of English society, American thinking has always tended to be a kind of progressive optimism. The progressivism and optimism of the Americans significantly redefined the AngloSaxon liberal tradition, and then its internationalist version, during the twentieth century. 


\subsubsection{American myth - American values}

The "Founding Fathers" were considered by Hofstadter to be "conservative revolutionaries", but their political heirs were able to make significant innovations. In the decades following independence, the spirit of American democracy manifested itself in several important measures. In the United States, the state and the religion/church were separated. As early as 1786, Virginia secured free religious practice and abolished the State Church license of the Anglican Church, and more and more states followed it. The last one in 1833 was Massachusetts. The principle of John Locke on religious tolerance was taken seriously in the United States, but this did not lead to an anti-religious atmosphere. A prominent French political thinker, Tocqueville, reported in the first half of the nineteenth century that the United States is home to a large number of different churches and religious groups, and that their lively activities are an important part of civil society. In European societies, the separation of religion/church and state was the result of a long and arduous process in the nineteenth century, while Americans considered it almost natural from the beginning.

Another notable statement by Tocqueville concerned Americans' religiosity. The French political thinker travelled to the United States in 1831, marvelling at the strong influence of the Christian Bible in the young republic. It is remarkable that Tocqueville strongly argued that, in the US, unlike the continental political tradition that followed the French Revolution, religiosity and enlightenment were not opposed, but rather support and complement each other.

The religiousness and religious diversity of the United States has passed through the nineteenth and twentieth centuries and remained an important feature of the American middle classes to this day. Religious tolerance in the Tocqueville era concerned both Protestant churches and then Catholics, and only the atheist considered "morally suspicious". In recent decades, the tendency for secularisation in the US has been less pronounced than in Europe, mainly due to the "religious revival" of neo-protestant groups, and the virulence of American religiosity can be linked to significant historical antecedents.

In addition to the separation of religion and state, another early political change was the extension of voting rights in the young American republic. In European liberal societies there was a censorship of voting rights in the nineteenth century, and as a result of electoral reforms, the voting rights were gradually extended. This is why Fareed Zakaria, in The Future of Freedom (2003), rightly stated that in modern Europe, initially, it was not democracies but liberalising autocracies. Universal suffrage is not a liberal but a democratic achievement that has been prevalent in more and more countries since the last third of the nineteenth century. By contrast, American political practice is rightly called 
"revolutionary", as male voting right was introduced in more and more states in the first half of the nineteenth century. In the United States, civil "freedom" and democratic "equality" - the former Hamiltonian and Madisonian and the latter Jeffersonian - have developed from the outset in close unity. The extension of the voting right expressed the "democratism" of the American political system, which was reflected not only in the political system but also in the American spirit as a whole. The "democratic spirit" of American society was sharply different from that of contemporary England, which, as Tocqueville pointed out, remained an aristocratic society despite the constitutional arrangements that followed the "Glorious Revolution".

European liberals relied on census suffrage because they felt that pure judgment over interest could be guaranteed in the political debate if the manipulated poor could not participate in the decisions. In general, liberals sought to prevent the narrow circle of wealthy people from buying the votes of the poor, avoiding the negative experiences of ancient Greek-democracies and the French Revolution. In the United States, the democratic extension of voting rights was promoted by the fact that a society based on a broad spectrum of free owners made these reservations unjustified.

The "democratic spirit", and the work-centred way of thinking of Americans, were associated with Protestant ethics. According to Calvin's teaching, the predestination presupposes the importance of divine choice, so a Calvinist believer continually seeks the mundane signs of the afterlife for salvation. The hardworking Puritan communities wanted to experience the signs of divine choice by creating the "kingdom of God" on this earth, which released great energies for action. Moreover, all of this happened in the "Promised Land", a country to which the Puritans had migrated for a better future and where infinite perspectives preceded the construction of the "kingdom of God". The possibility of populating American territories represented a historical analogy for immigration to the "Promised Land" (i.e., "Israel") for Protestant colonists. All this was possible only through confidence in the future. Americans' optimism can be deduced from their Protestant views as well as their work-centred "decent materialism". The activities of the Protestant citizens of "America" are not only "there", but "will be" most (but by no means "were"). American optimism was tied to a strong belief in the future and trusted that there was an infinite progression in things. This progressive concept of time was consistent with the approach of the European Enlightenment, but in the United States it also formed a sense of everyday life.

During the nineteenth century, it became evident that the United States was providing opportunities for hard-working Americans and immigrants. The American dream - an expression by James Truslow Adams in his book The Epic 
of America in 1931 - also meant the experience that, after decades of decent work, the poor in the Old World could enjoy the fruits of their work as a middle class citizen in America. All of this was possible because the work-centred "American values" were associated with exceptional economic growth, a scale that surpassed all previous historical experience. The "progressivism" and "optimism" of the Americans also stemmed from the fact that socio-economic processes in the nineteenth century supported positive expectations for the future.

The "democratism" of American society did not mean equality of wealth, only equality of conditions. Because most Americans had some form of private property - land, business, etc. - the starting conditions were about equal. Relying on this, we can witness from the first half of the nineteenth century a successful emergence of broad participatory-based capitalism, which has been scarcely tempted by the risk of "proletarianisation" or "pauperising". In this context, we must also look at Jackson's concept of liberalism, which deepens Jefferson's democratic heritage. Andrew Jackson, as President of the United States (18291837), was no longer an East Coast elite like the "Founding Fathers" but was born west of the Appalachian Mountains. As a successful soldier, he gained widespread social acceptance and wanted to use his power to extend "people's rule" over the "elitism" of the founders. His attempts to suppress the old establishment may seem plebeian, but we must not forget that Jackson was not a social revolutionary for the people.

Jacksonian liberalism primarily sought to abolish government monopolies and make free business accessible to everyone. According to Jacksonian liberalism, the government should not favour any entrepreneur over another and should not offer any advantage to any businessman that it denies to the others. Jacksonian liberalism did not seek to reduce social disparities, but to promote the success of widespread popular capitalism. In doing so, he laid the foundation for the much-cited component of the American political tradition, the idea of the fruitful consequences of free enterprise and market freedom for the whole people, and the blessing of a government that actively supports business. Jacksonian liberalism clearly demonstrates that, in American political culture, extending democracy was not about equalising wealth, but about equal sharing of opportunities.

In addition to "progressivism" and "democratism", we must mention another feature of American development, the constant shift of the "moving frontier" to the west. In 1893 Frederic Jackson Turner published a powerful thesis on the role of the "frontier" in American history. According to Turner, the American people were born in a constant struggle with the wild, which significantly influenced the evolution of the folk character. Although some of the conclusions of the American historian were controversial, few theses have resulted in such a 
diverse discourse on American identity. The importance of Turner's ideas in American historiography illustrates that the Americans themselves attached great importance to the frontier, which became a symbol of infinite possibilities. As a result, at the end of the nineteenth and the beginning of the twentieth century, when the frontier in the Pacific was "closed", a crisis broke out and many commented that the exceptional development of the United States had "come to an end" (Map 36). The concept of "frontier" clearly illustrates positive judgments about the infinite perspectives of nineteenth century American rise. The frontier has shaped Protestant expectations of a "Promised Land" into concrete opportunity and fuelled American optimism.

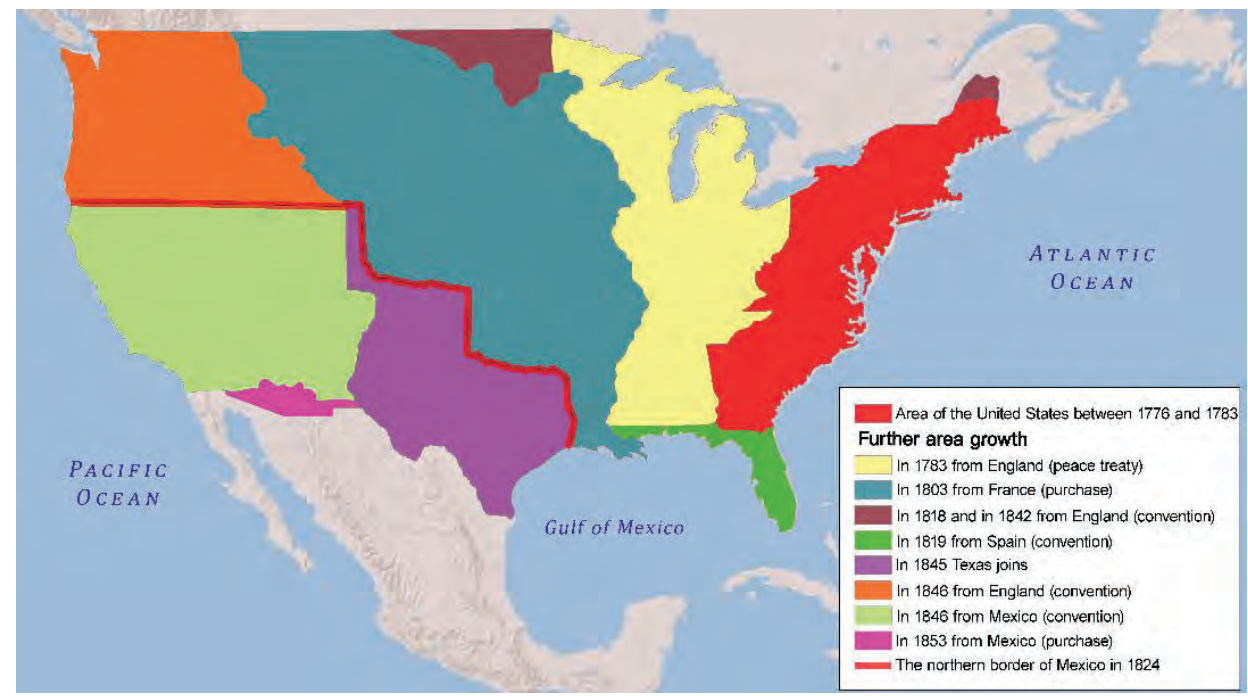

Map 36: US territorial growth between 1776 and 1853 Source: Edited by ÁGNES VARGA

Turner's reasoning seems to be instructive about the nature of historymaking forces. Concerning the relationship between geography and human society, representatives of milieu theory (Montesquieu) and geographic determinism (Ratzel) emphasised the direct social effect of the natural environment, while geographical possibilism (Vidal de la Blanche) focused on the impact of geographical factors on opportunities that society either exploits or does not use. From the point of view of American ideals, the mainstream approach emphasised the importance of Anglo-Saxon institutions rather than geographical influences. These were created through human effort and were able to establish political values, while Turner's much debated, and somewhat overwhelming thesis referred to the primacy of the environment as he attempted to explain the emergence of individualism and democracy. 


\subsubsection{The rise of the U nited States}

After the War of Independence, the United States in the early nineteenth century can be considered a factory-free capitalism or a society of free owners that not only resembled Jefferson's ideal of democracy, but also provided an example of Adam Smith's "commercial society". Smith in The Wealth of Nations considered the ownership economy based on market exchange to be ideal, where state interventions are kept to a minimum so that the idea of "invisible hand", that is, market self-regulation, can prevail. In a world of pre-factory capitalism, the commercialised agricultural economy, the broad ownership strata that determine the social structure, and the lack of etatism allowed Smith's economic idea to come close to fruition in the United States In Europe, extensive economic regulation from the traditions of royal absolutism could only be dismantled in a long struggle, while the United States from the outset provided a good example of unrestricted market and capitalism, where property and incomes were equally distributed among economic operators. Factory capitalism later reshaped original conditions, but the importance of the countryside, agriculture, and its associated small-ownership strata has long prevailed in the history of the United States.

Despite the industrial development at the turn of the nineteenth and twentieth century, the agricultural sector also played an important role, which was also reflected in the role of agricultural exports. Only after World War I did the urban population exceed the rural population, while in England about half of the population lived in cities by 1850 . When the US became an industrial power in the early twentieth century, in terms of exports, agricultural products still accounted for a very large share, compared to other industrialised countries. The importance of "rural America" was also reflected in the specifics of political culture. Compared to the vast industrial areas and major capitalists of the East Coast and the Great Lakes - and later the second half of the twentieth century California - the Midwest represented/represent the world of farmland and small towns, from where farmer "populism" may have originated, as well as the WASP consciousness of urban middle classes.

In spite of the promising beginnings of industrialisation, in the early nineteenth century, much of the capital investment did not promote industrial plant development but flowed into canal and railroad construction. In a country as large as the United States, in the pre-rail era, canals made it possible to transport large volumes of agricultural goods, which accounted for most of the goods surplus. The canals contributed to a drastic reduction in freight rates compared to land transport, water transport accounts for about one fifth - which ensured the commercial character of agriculture and, in the long run, had an exceptional impact on nation building. The United States, as an enormous 
7.1. The North American Civilisation

republic, was a unique phenomenon at the end of the eighteenth century, and many doubted whether a country of this size could last forever. The canals that were built in the first half of the nineteenth century, and a few decades later the railways not only facilitated the transport of agricultural and then industrial products, but also became an essential element of the unity of the country.

As industrialisation unfolded in the first half of the nineteenth century, the notion that tariffs were not primarily about increasing budget revenues, but about protecting young American industry from increased competition, was reinforced. The idea of defensive tariffs was not only endorsed by Hamilton, but also by economic interest groups and publicists. Protectionism was an integral part of American foreign economic practice. Although, after gaining independence, the principle of free international trade became one of the foundations of US foreign policy, the interests of industry often proved stronger. Throughout the nineteenth century, the US sought to secure its industrial and agricultural products through customs protection. It is no coincidence that the German Friedrich List, whose European economic theory owes its notion to a protective tariff and seclusion with defensive tariffs, stayed longer in the United States and was influenced by American foreign trade practices. Contrary to English trade policy, which is moving towards free trade, which has created competition for its own agriculture, the United States has been jealous of its industry and agriculture even at the turn of the century. Although Democrats have repeatedly attempted to create a multilateral free trade system in the twentieth century, the demands for protectionism have persisted in the middle-class ownership of Republicans.

It was only in the decades following the Civil War (1861-1865) that the United States became a true industrial country. By the 1880s, more people were working in industry and services than in the agricultural economy. By the end of the nineteenth century, the US had become an industrial nation, where industrial production exceeded the value of agricultural commodities. In 1890, the United States became the world's largest industrial power. During the period of economic development from the Civil War to the World War I, the value of manufacturing production increased twelve times and that of industrial capital investments increased twenty times. The number of workers in the manufacturing industry has increased at least five times. In 1830, the United States had 2.4 percent of the world's industrial output, England 9.5 percent and France 5.2 percent. In 1900, the United States had 23.6 percent, England 18.5 percent, France 6.8 percent. By 1914, American national income had already exceeded the sum of British, German, French and Russian national income. Industrialisation per capita was also well above the European average. These results were made possible by the exceptional industrial development of the last third of the nineteenth century. It is remarkable, that the United States became the world's 
first industrial power in a very short period of time, about four decades. Its rise took about the same amount of time as the period from the 1973 oil crisis to the present. During these decades, the standard of living also increased steadily.

The decades after the end of the civil war between the industrialised North and the slave-laboured South, based on free movement, are referred to as the reconstruction era and the period up to the turn of the century is called gilded age by historiography. The latter designation, also referring to Mark Twain's ironic vocabulary, illustrates well the contradiction of the era. The US economy has achieved rapid growth in industrial performance, and living standards among strong economic fluctuations, and large income disparities. This nature of American capitalism has survived to this day. From the middle of the nineteenth century onwards, the momentum of economic development illustrates the uniquely dynamic and hectic nature of American capitalism.

The post-Civil War economic policy of the federal governments greatly contributed to the recovery of the US economy. The Republican government, which embodies the "northern heritage", has sought, in the spirit of the Hamiltonian legacy, to make a positive contribution to the development of capitalism through the creation of a business-friendly environment and active measures mainly through the promotion of railway construction. The resolution supporting business also meant that the right to strike was banned by the courts as an initiation restricting the freedom of entrepreneurs, and for a while serious tensions between work and capital developed. Despite the conflicts, there were no labour parties in the United States, but wage fighting remained primarily a matter for the trade unions, who were pragmatic about enforcing wage increases and did not formulate political goals. American practice did not try to support the victims and losers of industrialisation and urbanisation with so much "etatist" budgetary means, but Protestant church and civil society, which sought to help the poor, gained a prominent role in the growing world of cities.

One of the key factors in American economic growth was that in the nineteenth century, some 60 million people left the Old World to try their luck outside their home country. About two-thirds of them have found a home in the United States. Population growth has allowed for a steady expansion of the labour market. From the 1870 s to the present, the country's population has risen from just under 40 million to about 300 million. In an era of exceptional economic growth, the United States had a population of 70 million in 1896 and nearly 100 million in 1914. Immigration proved to be strong during the turn of the century, when both skilled and unskilled labour contributed significantly to the dynamics of the prosperity.

As a result of the waves of immigration, WASP identity is facing increasing challenges. In the middle of the nineteenth century, German and Irish, 
7.1. The North American Civilisation

in the turn of the nineteenth and twentieth centuries immigrants from the Mediterranean region, mainly Italy, and Central Eastern Europe made the language of the great country more colourful. With the turn of the century immigration, the United States also had an increasing Catholic population. During the nineteenth century, assimilation tendencies became even more pronounced, largely due to the fact that most immigrants wanted to become American themselves. Sociology and history have highlighted the experiences of this period when they created the concept of the "melting pot", although research in recent decades has also pointed out that assimilation has not been so widespread in the "classic" era of immigration as previously assumed. Yet, despite increasing challenges, the Anglo-Saxon Protestant middle classes were able to integrate immigrants in their own values until the second half of the twentieth century. These tendencies have been permanently interrupted by the black civil rights movement of the 1960s and the Ibero-American immigration to the West Coast states and are still an insoluble problem.

The extraordinary dimensions of railway construction also contributed to economic growth in the nineteenth century. In the second third of the century, 50,000 kilometres of railway tracks were built, doubling in the early 1870s. At the turn of the century, the length of railroad tracks built in the United States exceeded 300,000 kilometres, overtaking the entire European rail network. By 1914, the same figure was 400,000 kilometres, when the huge Russia had a total of 75,000 kilometres of railways. The construction of transport infrastructure has stimulated GDP growth and promoted the integration of western regions' resources into the economic circulation. The growing population, the abundant supply of raw materials and the ever-expanding railway network were the three basic pillars of economic development, among which we must count on positive feedbacks. The American economy has proven to be a "expanding universe", where a significant number of players have found their way.

Thanks to the steady rise in the standard of living, consumer societies were emerging at the turn of the century, ahead of Europe. Because of the high wages, American workers could afford the consumption habits that took place in Europe only three or four decades later. The reason for the high wages is partly due to the consequences of the frontier. In continental Europe, industrialisation was promoted by the high hidden unemployment in the underdeveloped agricultural economy. After the emergence of factory capitalism, this workforce moved to industrial cities and contributed to wage cuts, allowing it to increase the profits of the capitalist entrepreneur. Therefore, there is no shortage of labour in European countries during the Industrial Revolution. By contrast, in the United States, industrial workers in the East Coast may have migrated to the West at any time if wages were not appropriate for them. There was plenty of land in the 
frontier, while labour was scarce. In addition, the modern labour organisation of farms producing for the market was not aware of hidden unemployment. All this led to attractive wages in the agricultural economy, which indirectly kept industrial wages high. Although historians have argued that migration to the West was no more of a theoretical opportunity for many, the "frontier" itself proved to be a deterrent to wage-reduction efforts.

High wages have encouraged entrepreneurs to mechanise because they have tried to replace expensive labour. Mechanisation has increased productivity and, in many cases, required skilled labour, which has further increased the value of the workforce, which again has promoted the use of labour-replacing machines. In the United States at the time of the "Second Industrial Revolution" the last decades of the nineteenth century - not only the size but also the mechanisation of factories proved to be unique, contributing to the increasing competitiveness of US exports against European rivals.

Strong economic growth contributed to the fulfilment of the American dream. In the era of the "Founding Fathers", US society consisted of a wide range of owners. The frontier made it possible for the property to be acquired and the federal government supported colonists to have access to land at affordable prices (Homestead Act). Ownership and high industrial wages have prevented significant social groups from being declassified. By the turn of the century, the United States had a large middle class of owners, well-paid employees and working classes. The structural features of economic growth ensured the preservation of the "original features", that is, the success of broad-based capitalism.

Impressive economic growth has taken place under exceptional structural conditions. American corporate and bank sizes far exceeded their European rivals. The Morgan, Carnegie, and Rockefeller families became key entrepreneurs in the US banking, steel and petroleum industries. The enormous size of the company has enabled it to produce more efficiently and to be the birthplace of professional corporate governance, management techniques and engineering, and, as monopolies capable of exerting political influence, have induced intense social debate. The United States has entered the twentieth century by gaining experience of the tensions between big capital and the middle classes, which have shaped American political culture ever since.

The enormous economic development at the turn of the century barely made it possible for the United States to stay out of world politics. The US sold most of its products on its huge domestic market but expanding exports of manufactured products had a growing impact on European national economies. US foreign trade asset vis-à-vis Europe no longer relied on agricultural exports. The capital import from the United Kingdom made it possible to raise additional funds and accelerated economic growth. The economic vitality of the United States at 
the turn of the nineteenth and twentieth centuries is well illustrated by a combination of export surplus and capital imports. While the recent foreign trade deficit is more indicative of the increasing vulnerability and competitiveness problems of the US. Cycle fluctuations of the US economic have affected European markets since the turn of the century. American speculators were able to disrupt the financial markets of European capitals. It was almost time for the United States to be forced to pursue global foreign policy if it wanted to protect its financial and export interests. European great powers and capital groups were increasingly fearful of the US becoming a world economic power.

The business with the greatest consequences of the American rise was the attempt to "internationalise" American liberal ideology. During World War I, the Wilson Principles formulated a kind of creed of liberal internationalism and sought to make them a principle of international life. In the nineteenth century, the United States pursued a largely isolationist foreign policy. The Americans did not want to become involved in the European state system based on balance of power. In their view, the United States, created by the "Founding Fathers", was also a new beginning in a moral sense, as it sought to transcend the Machiavellian power policy of the Old World. On the other hand, the Americans could afford the isolation, as no European power posed a threat that forced them to seek an alliance with another European state. In addition, the huge US domestic market has for some time led to the export of only a negligible amount of US products. This fact made it possible to preserve a receding foreign policy, even though, as a result of industrial development at the turn of the century, US export sectors began to expand. It seems that American isolationism was not only based on ideas but also on economic factors.

American "isolation" is not only the opposite of spreading American values around the world and the missionary consciousness of it, but it is about two sides of the same phenomenon. Conscious of its higher morality, the United States distanced itself from interest oriented "Old World" politics. But with the same morality, it might even have come to the conclusion that it should share its political and ethical principles with the world. The American myth included the possibility of a worldwide mission, just as the French Revolutionary nation had become a "torch" for Europe, at least according to some nineteenth-century thinkers. Not only did the Americans have an optimistic belief in progress, but they also learned, based on their frontier experience, that the lifestyle they represented could extend to larger areas, so it is not surprising that it overflows with America over time. While the United States did not have significant interests abroad and the frontier allowed expansion on the North American continent, American foreign policy idealism embodied in isolationism. But by the turn of the century, the frontier had ended - the colonists had reached the west coast - 
and on the other hand, American goods had appeared on the world market in greater quantities. When the United States showed its interest in the Pacific in the case of the Philippines and by proclaiming the principle of "open gates" that it is not indifferent to the Asian continent, and President Theodore Roosevelt (19011909), demonstratively sending the American navy fleet around the world, the public opinion in the world is beginning to understand that a new era is emerging.

On the eve of World War I, the Americans were well on their way to economically overtaking the European continent. It is estimated that by the middle of the 1920s this would have happened, but the consequences of the World War I accelerated the transformation of economic power. The United States, in the name of the Anglo-Saxon community of interests and values, gave Great Britain huge loans during the World War I. Creditors' points of view also contributed to the Wilson administration's lack of pride in its principles of not going to war and entering the war with strictly moral arguments of international law.

14 points of President Woodrow Wilson (1913-1921) announced at a joint meeting of the Senate and House of Representatives on 8 January 1918, for the first time, in the spirit of American idealism, attempted to create a radically new liberal world order. Wilson's ideas were born in a Kantian spirit when they declared the sovereignty and territorial integrity of nations. They demanded just peace without annexation, evacuation of areas occupied during the war, national self-determination and consideration of the interests of the colonial populations. Freedom of the sea shipping and the principle of unhindered international trade have been expressed. A proposal has been made to set up a community of nations capable of settling disputes peacefully. The novelty of Wilson's endeavour was not that the Americans were idealistic in their international relations, but rather, for the first time, an attempt to put their ideas into practice throughout the world.

\subsubsection{Progressivism and the New Deal}

The Second Industrial Revolution, from the last third of the nineteenth century, resulted in the emergence of an "industrial society" that was very different from the primitive factory capitalism of the First Industrial Revolution. The organisation of production has played an increasingly important role in shaping social relationships, and the manufacturing and production systems themselves have become increasingly complex. The conditions of the emerging urbanindustrial mass societies increasingly influenced everyday life, and the expanding technical civilisation manifested itself as a kind of "second nature". The emblematic theorist of large-scale capitalism is German Max Weber (18641920), who no longer spoke of free enterprise and laissez faire as representatives 
7.1. The North American Civilisation

of classical political economy in the first half of the nineteenth century, but of rational economic action and a bureaucratic state. He outlined a multi-factor model describing the emergence of modern capitalist mass production, where the market was only one factor. Since Weber, besides the (neo)classical market theories, we have to take into account the theories of industrial society, which have grown into a significant line of social science thinking in the twentieth century. It is indicative that the classic case of industrial societies created by the Second Industrial Revolution is not the Western European countries, but the United States.

The contradictions of urban mass societies resulting from the Second Industrial Revolution led to the emergence of a new social movement in the United States. At the turn of the century, the progressive era wanted to respond to social and political tensions in a unique American way. While in Europe the new democratic mass parties sought to get as many representatives into the parliament as possible and the Left announced a programme of progressive taxation and nationalisation, in the United States progressivism was seen as a civil movement, gaining a national political role. Highly capable presidents identified themselves with political goals like Theodore Roosevelt and Woodrow Wilson. Progressives at local level fought against corruption in local governments and sought to counterbalance the increasing political influence of monopolies and large-cap groups. They supported federal anti-monopoly legislation, worker protection against the employer, women's voting right, and expansion of education. Through its ideas for broadening political participation, progressivism can be considered a continuation of the Jeffersonian heritage, but its specific goals were greatly influenced by the crisis of the frontier in the last decades of the nineteenth century and the fact that industrial size and capital concentration in the United States are unique in the world. At the turn of the century, many felt that the "nation" was not moving in the right direction and that the "land of opportunity" had become a country of narrow economic interest groups that buy into the political and civil spheres.

Progressivism sought to restore faith in American values to the conditions of the industrialised world, to restore the ethos of broad participatory-based capitalism, and to expand opportunities for civic and social emancipation. Progressives have formed rather broad casual coalitions in both national and local politics, gaining support from a significant portion of urban middle classes against corrupt economic lobbyists. In the spirit of the "social gospel", many Protestant groups have also caught up. One of the emblematic figures of progressivism is John Dewey (1859-1952), whose philosophy of education has contributed to the reform of school education. By announcing a programme of pedagogical pragmatism, he wanted to suppress the teaching of classical languages, and his students developed a practical project method. Through his 
pedagogical views, Dewey became a modern apostle of American democracy, who believed in a progressive mindset with a strong belief in a better future. The progressive era pre-empted the measures of the New Deal in many areas but did not proclaim the welfare state programme and had only a loose connection with the artistic modernity of the turn of the century. It is a peculiarly "American" phenomenon where, with respect for constitutional values, it advocated on economic and social progress, and, unlike populist farmer groups who had an agrarian nostalgia for "old America", undertook to confront the problems of urban industrial mass societies.

In the 1920s, the progressive movement lost its momentum, and, on the other hand, its goals were partially realised. The decade after the World War I was the last time in American history when US citizens could still believe that they could hold the influence of the outside world beyond their borders. This was not only expressed in isolationist counter-reaction to the promulgation of Wilson's internationalist principles, but also in restricting immigration and intensifying anti-foreign views. However, the 1920s was a period of marked, but surging economic activity, which allowed the recruitment of new workers to the industry. Extremely large-scale plants (economies of scale) created by Fordist-Taylorist industrial organisation have given way to durable consumer goods - automobiles, household appliances - and could be bought by the average American family. In the 1920s, not only did American workers' real wages undergo significant growth, largely relieving social tensions at the turn of the century, US industrial production reached about 40 percent of the world share. In the 1920s, the everexpanding middle class of consumers emerged, which already included a considerable portion of urban workers. New habits of cultural consumption have evolved as household appliances have increasingly allowed women to afford reading, cinema and other forms of entertainment. In this regard, the United States overtook Western Europe, where the same consumer habits did not develop on a massive scale until after World War II.

The 1920s, on the one hand, fulfilled the potential of the industrialconsumer society and, on the other, preserved the past (old liberal) American principles of free enterprise. Republican presidents Harding, Coolidge, and Hoover all represented the traditional view of the limited role of the state. This perception is well illustrated by the public remarks of President Calvin Coolidge (1923-1929), who summarised "old" American values a few years before the New Deal was announced. These thoughts seemed a thing of the past between the New Deal of the 1930s and the Great Society of the 1960s and returned vigorously to domestic politics in the 1980s under the presidency of Ronald Reagan.

Considering Coolidge's principles, we understand why his friend and successor in the presidential chair, Hoover believed in the early years of the Great 
Depression, that state intervention was not necessary, and we should wait patiently for the recession to end. In addition, Hoover was convinced that Roosevelt and his Democrats, who proclaimed a broad public intervention programme, would win the presidential election by fundamentally destroying the values of "Americanism". Yet, when Roosevelt, with the deepening of the crisis of 19291933, won an overwhelming victory and began to realise his ideas, a single president was not forgotten so quickly by American public opinion as Hoover, who appeared helpless at the outset of the great crisis. The doctrinarian realisation of "American values" has been overridden by the material and social needs of the economic crisis.

Through his family and his education, President Franklin Delano Roosevelt (1933-1945) could have become a spokesman for the interests of the American upper classes, yet, as an exceptionally popular president, he has launched an unprecedented "revolution" in US history. Roosevelt was more of a willing and pragmatic politician and a humanist than a doctrinarian revolutionary when he sought to save the American man from hunger and seize the country from the unprecedented collapse of capitalism. In his own interpretation, Roosevelt, like Keynes, sought to save and not eradicate freedom and "free society", but his argument was never accepted by his political opponents. They saw the end of the economic laissez faire in radical social policy measures, which could, at least according to its critics, lead to decline in civil and political freedom. Roosevelt's exceptional power in the crisis made him a "radical" overriding old American values, though in his view he wanted nothing more than to transform the United States into a broad participatory-based society, where the average American can once again feel like a land of opportunity. In this respect, its programme may be conceived of as a continuation of the Jeffersonian heritage, though in a form significantly altered from its original ideals.

The interventionist measures of the Roosevelt administration - agricultural subsidies, social security, the introduction of unemployment benefits, regulation of banks and the financial sector, job creation, etc. - are well known and need not be presented. A more controversial topic is the effectiveness and awareness of the measures. It is questionable whether the recovery from the crisis was a consequence of the New Deal, or the natural movement of the market cycle, or of the military boom in the 1940s. Orthodox liberals considered the socialising results of the reforms too radical, while the (New Left) considered them too small. More important than that, the New Deal has provided hope and livelihood at the bottom of the crisis, which has restored confidence in American values and institutions. The measures in the early years were rather a series of practical ideas. Although Keynes paid a visit to American leaders who listened to his views with interest, 
it was only from the last third of the 1930s that we can talk about the beginnings of conscious Keynesian economic policy practice.

The early 1940s marked a turning point in the emergence of American macroeconomic thinking. From this time on, we could talk about the creation of national resource planning, analysis groups and national statistics, which not only optimised efforts during the World War II, but also created the economic policy approach and econometric analysis framework which led to Keynesian economists' monarchy after 1945 at the universities of the East Coast. More important was the impact of the New Deal on public thinking. The American citizen has since considered the state's helping presence on social and welfare issues to be an integral part of his life. The toughness of these views is illustrated by the fact that Reagan's economic policy did not dare to break down the fundamental achievements of the New Deal in the 1980s.

Roosevelt's successes served as a starting point for the "liberal progression" of the coming decades, where social emancipation was closely linked to etatist solutions. Roosevelt's concept was inspired by, but went beyond, Jefferson's notion of democracy, by focusing not only on broader political participation and equal opportunities, but on the distribution of wealth.

\subsubsection{American civilisation values in the second half of the twentieth century}

After World War II, Roosevelt's successor, Truman (1945-1953), due to the increasing congressional influence of the Republicans, was only partially able to pass the Fair Deal, called the continuation of New Deal - conservative criticism referred to "stealth socialism" -, but for decades Democrats have retained their leading role in economic and social policy in public life. After the World War II, the programme of democratic governance in the United States became similar in many respects to the objectives of the Western European Social Democratic and Socialist parties, proclaiming the necessity of stronger state intervention (Keynesian etatism) against the economic laissez-faire, and it identified with the programme for the creation of a social-welfare state and later with the values of the "cultural left". The politicians and voters who represented this viewpoint in the twentieth century are called liberals in the United States, while opposed to the "limited government" advocates of the Republicans, called conservatives in American terms. The term "liberal" was given new meaning by the turn of the century artistic and then by the cultural modernity of 1968, while the word "conservative" implies that republican traditions include the protection of the constitutional "old liberal" principles of free enterprise, economic laissez 
faire, the separation of powers, and the unconditional respect for a federal state with limited powers.

The "liberal" political public discourse not only promoted welfare programmes but also the emancipation efforts of blacks and supported capitalist entrepreneurs to pay attention to the social costs of their activities. To that extent, Democrats can also be seen as carrying on the Jeffersonian heritage because they wanted to promote broader political and social participation for the American man. Another important aspect that both liberals and conservatives had to bear in mind was that the emergence of industrial society changed the original nature of capitalism, which also influenced the conditions of governance. It is no coincidence that, compared to the traditional figure of the "capitalist entrepreneur" idealised by the Republicans, the Democrats were more open to the work of technocratic "social engineering" and even demanded their involvement in politics.

In the decades after 1945, the Democrats accepted without doubt the continuation of the New Deal heritage. For Republicans, the same was only possible with some restrictions, but they themselves felt that the Keynesian social engineering and social welfare programme was so popular that it was impossible to gain the confidence of voters by proclaiming the old laissez faire principles. Therefore, Republicans also used the Keynesian recipes to sustain economic growth and did not touch upon the basic achievements of the welfare state, but, in the case of the Eisenhower presidency (1953-1961) or in the case of a majority in Congress, they tried to prevent an increase in the budget redistribution. In the United States, because of the power of the "old liberal" tradition, the state's regulatory and welfare spending expansion programme has met greater resistance than in post-World War II Western Europe.

The Democrats' programme for federal regulation, the social state, and the emancipation of disadvantaged groups developed in its entirety in the second half of the 1960s. Already President Kennedy (1961-1963) had faith in the Big Government when he said that expanding governmental competences does not necessarily have negative consequences, but that the federal government can effectively contribute to solving people's problems. His successor, Johnson (1963-1969), went ahead with the announcement of the Great Society programme, which was to regulate the activities of large companies, increase welfare and education spending, fight against poverty and support the civil rights movement of blacks. Johnson was renowned for achieving these goals by significantly expanding the responsibilities and staffing of federal agencies, and sincerely believed that federal bureaucracy measures could reach social issues.

Johnson's situation was made more difficult by the fact that, during his presidency, the United States was first confronted with the limitations of its 
economic and power capabilities and the confusing domestic politics created by student movements in the late 1960s. Two decades earlier, in 1945, the US still had half of the world's industrial production and unique military capabilities the nuclear bomb monopoly, an exceptional strategic air force and a navy. Building on this economic and power superiority, President Roosevelt made an attempt to reorganise the international order after the World War II. The Roosevelt Foreign Policy Concept (Grand Design), after decades of isolationism between the two world wars, heralded a return to Wilson's liberal idealism and global engagement. Rethinking Wilson's principles, Roosevelt and his consultants sought to establish international institutional guarantees for the operation of the liberal world order through the United Nations and its specialised agencies. Liberal internationalism after 1945 was more than a mere conception of principles, since it had well-organised institutional structures.

The United States did not return to isolationism after World War II. Although its economic and political interests - its growing exports, its extensive oil interests - motivated it to pursue an active foreign policy, it wanted to reconcile its international obligations with liberal idealism, that is, the role of the "torch". Due to its role as a world power, it has undertaken such a task that it has barely been able to meet the ethical expectations of the "American mission". It is not by accident that historians emphasise that, in the eyes of the American public, there has been a constant conflict between foreign policy ideas and international power realities because of the role played by the United States after 1945. Because American values suggested an "idealistic" attitude in foreign policy, the general public reacted sensitively when faced with the opposite, as reflected in the aftermath of the Vietnam War.

In the two decades after World War II, the United States still had the economic and military capabilities that allowed it to maintain its superpower role. During the Korean War, the United States responded firmly to the communist bloc's power aspirations in defence of the free world. The US power was perhaps greatest under Eisenhower in the bipolar world, when through the creation of the "enclosing crescent", he concluded agreements with its allies on the southern borders of the Soviet Union from Japan to Turkey. In the 1950s, hundreds of thousands of soldiers stationed outside the United States to defend American interests.

In spite of its seemingly limitless possibilities, the United States faced an insoluble contradiction in the second half of the twentieth century, as the relative decline of its economic power began after the World War II. Although the signs of this became apparent only from the mid-1960s, the US showed more moderate economic growth than Western Europe, Soviet bloc countries, or Japan and East Asian countries. The United States was at the peak of its economic performance 
at the turn of the nineteenth and twentieth centuries, the late 1920s and 1945. However, due to its isolationist principles, at the turn of the century and between the two world wars, it did not want to make significant international commitments. Compared to this, the decline in economic power was observed the day after the announcement of the global role, Grand Design.

In the early 1960s, the Kennedy administration was well aware that international economic power relations were changing due to the rebuilding and rapid economic development of Western Europe. Global public opinion has been aware since the mid-1960s that the US economy is facing increasing competitiveness problems. This was also reflected in the slowing of the US GDP growth rate and the lack of a foreign trade balance. President Johnson was burdening the federal budget with Great Society spending at a time when there was a great need to reduce the tax burden on companies. Further issues were raised by the military spending of the Vietnam War, which peaked in the second half of the 1960s. Not only did the Vietnam War become unacceptable to the domestic public, but the popularity of the United States began to decline worldwide. In the 1970s, the United States was repeatedly accused by the UN under pressure by developing countries. It was an unusual situation for a superpower who, on the basis of the values of "Americanism", believed that its involvement in international affairs could only bring good for the world.

The United States' competitiveness problems also made Johnson's situation more difficult, as well as the university student movements that emerged in the second half of the 1960s. The Great Society proved to be oversized for the budget, and the New Left, on the other hand, underestimated its efforts to eradicate poverty. Student organisations under Neo-Marxist and Maoist influences criticised the Vietnam War sharply, where Johnson was trying to get out of the conflict with "keeping the face" of US, which required even greater military efforts in the short term. The black civil rights movement, which was embraced by the Liberals, reached an active stage during these years and was no free from atrocities against the majority society. Growing domestic and foreign policy difficulties have led Johnson to no longer be a candidate for the next presidential term. Despite his retirement, his actions against the Great Society provoked Republican aversion. Above all, Conservatives blamed Johnson for the decline of the American superpower. On the one hand, because he has weakened the competitiveness of the US economy through massive government spending, instead of promoting corporate prosperity through tax cuts, on the other hand, the failure of the Vietnam War has also eroded the international image of the United States, thirdly, the Democratic-backed civil and social emancipation has let go of the social valves. The rebellion of the poor and minority groups was violently 
directed against the "white middle class" (WASP), which threatened to upset public order.

In the 1970s, the United States also faced new international problems. The oil crisis of 1973 not only adversely affected American economic performance, but also created insoluble situations in foreign policy. The US has been confronted with the fact that in the world of interdependence, it is no longer capable of effectively influencing events. In the alliance with the Soviet Union, the international New Left has maintained a "blockade" of the United States in international organisations. And US foreign policy in support of Israel made it unpopular in the Arab world. The economic recession has brought years of bad domestic politics. Not surprisingly, by the mid-1970s, declinism (= a spiritual trend announcing the decline of the United States) already held prominent positions among American intellectuals when it celebrated the two hundredth anniversary of the United States.

The declinists became aware of the limitations of the American superpower and analysed the causes and nature of its decline. As the 1973 oil crisis marked the end of economic growth throughout the world economy, which raised major concerns, their perception also fit in with the global intellectual trend. This decade saw the emergence of "European pessimism" in Western Europe, and the first reports on the limits of the natural resources available to the world economy were published by the Club of Rome. Declinism was the American version of this broader trend, of which the crisis of the superpower was an important part. It was in this intellectual context that neo-conservative cultural criticism also appeared, seeking to redefine American values in the spirit of conservative values.

Since the appearance of the New Deal, intellectuals and social engineers in the Democratic sphere have dominated American intellectual life. They had in common that they believed in the possibility of social progression, they wanted to achieve social emancipation through state intervention, and they were convinced of the benefits of Big Government. Referring to the Jeffersonian branch of the American political heritage, they represented a peculiar version of the pursuit of happiness for the people that employs the toolbar of etatism. Until the 1960s, the conservatives were unable to build a powerful stockpile of intellectual weapons against them, as economic growth made it possible to extend social measures, which were extremely popular with significant sections of society. Domestic disturbances in student movements, the overthrow of US power and international competitiveness problems required neo-conservatives to form consistent views that were endorsed by the Republican political elite and the general public.

Neo-conservatives (Irving Kristol, Daniel Bell, etc.) preached the need to return to "original" American values. In their view, the successful capitalism of 
the United States rested on the entrepreneurial spirit of the WASPs, which provided the appropriate framework for the political institutions of the young American republic. The Protestant middle classes were the proponents of capitalist accumulation made possible by the political freedom guaranteed by the federal state. Emerging capitalism rested on the merits of entrepreneurs, as the state refrained from favouring some in economic life. Protestantism, as a religious pre-requisite, has become the driving force behind it, not only promoting economic development, but also creating meritocratic capitalism. As a result, successful entrepreneurs have been highly regarded for their performance. These religious and socio-cultural factors have made the United States a "land of opportunity".

According to neo-conservatives, as opposed to the "old liberal" or "conservative liberal" interpretation of American values, liberals have been increasing their role in the state since the 1930s, with devastating consequences for society as a whole. On the one hand, welfare expenditures can only be financed by rising taxes that drain energy from businesses that are the foundation of successful American capitalism. On the other hand, the growing redistribution had a detrimental effect on meritocratic capitalism because it also provided material goods to those who did not show individual performance. Third, the swelling of state bureaucracy has led to the emergence of a regulatory culture that has, in the long run, damaged social pluralism and cultural diversity.

According to neo-conservative criticism, etatism promoted homogenisation, which involved atomisation and dismantled the community forces. In this way, the cultural drivers and motivational mechanisms on which the success of traditional capitalism was based were weakened. Jefferson and Jackson still believed in broad participatory-based capitalism as they sought to expand the rule of the people. However, in the second half of the twentieth century, the Democrats gave a new interpretation to social progression. Instead of equal share of chances, the focus was on material equalisation and in a spiritual sense, they adopted the position of the 1968 cultural Left, which proclaimed value relativism. At the same time, neo-conservative criticism recognised the causes of the economic downturn and criticised the weakening of cultural drivers.

From the early 1980s, neo-conservative views became a defining element of the Republican argumentation system, which was tested when President Ronald Reagan (1981-1989) came to power. At the same time, Reagan sought to restore US superpower and boost US economic performance. This was to be achieved through tax cuts and deregulation. The Reagan era can be considered a successful foreign policy, as the United States eventually won the Cold War and strengthened US authority worldwide. From an economic and social policy point of view, however, it had mixed consequences. 
The suppression of the Big Government was in line with "old liberal" principles, the demands of urban middle classes and farmers. To that extent, it is considered a return to "original" American values. From the beginning, it has been disputed that the market-oriented transformation of the insurance system has brought many people to the point of being excluded from quality healthcare. Fortunately for Reagan, there has been an economic boom since the mid-1980s, but its benefits have not spread evenly across society. Income disparities between the richer and the poorer have not narrowed, but rather widened. As a result of deregulation of the financial system, vigorous stock market activity has contributed to the accumulation of significant wealth without any real performance, drawing attention to the contradictory nature of emerging global new capitalism.

The United States made tremendous progress towards competitive hightech sectors in the 1980s, but it is difficult to determine whether the federal government's tax reduction programme or increased military spending during the eighties facilitated the structural change. The private sector received large federal orders for military development, which had a positive impact on technical development. Tax cuts and large-scale armament could not be successfully pursued at the same time, and so the United States accumulated enormous debt in the Reagan era. Looking at the 1980s balance sheet, foreign policy achievements are obvious, but economic results and social consequences are contradictory. It is questionable whether the Reagan government's economic policy can really be considered as revolutionary as the Republicans have stressed, since there has been no radical reduction in budget redistribution.

To this day, the Reagan era has set the course for public debate in American society. Most of them are closely related to the interpretation of American values of civilisation. By winning the Cold War, the United States, as a superpower, remained alone on the international stage. This situation was described by renowned journalist and political analyst Krauthammer as an "unipolar moment". His argument was placed in a broader context by Fukuyama in his famous book The End of History and the Last Man (1992) when he came to the conclusion that by the end of the Cold War, liberal democracies had no alternative and would irreversibly spread throughout the world. Both ideas well illustrate the optimism of US foreign policy circles about US capabilities and the potential role of the "torch" in the early 1990s. However, since the turn of the millennium, international changes have become more and more evident, making it clear today that the slow loss of space of the US is irreversible and that a multipolar system is emerging.

In contrast to the rising powers of the international system, we can at most speak of a "relative decline" of the US. Undoubtedly, despite the dynamism of the American economy, it has shown volatile performance over the last three 
decades. Recently, there has been a perception of renewed power as well as structural weaknesses. The US economy has an exceptional potential for innovation but is increasingly dependent on foreign resources. The future rate of decline in the United States is not exactly predictable, nor is the rate at which its rivals are rising. The United States needs to become accustomed to its changing environment and is highly dependent on global processes. Since the role of the superpower and the belief in the universality of "American values" have been closely linked since 1945, and have become an integral part of American identity, it is not excluded that the loss of the US international space may traumatise American nationalism. Relying on historical traditions, this can lead to isolationist reactions as well as exaggeration in the push for power.

The "American values" have also been subject to multiple pressures in domestic politics. On the one hand, it is noticeable that Reagan-era "casino capitalism" had its mark on the 1990s, as noted economist Stiglitz pointed out in his studies. The deregulation and hectic operation of the US financial system is a serious risk factor for society as a whole. Slow erosion of the middle classes, widening income disparities, the emptying of public procedures and the "oligarchisation" of democracy are also problems. These tendencies call attention to the crisis of broad participatory-based capitalism, which has been at the heart of the "American dream" for two hundred years in the United States.

Finally, it must be pointed out that the deepening conflict between the conservatives and the liberals has been insoluble since the Reagan era. Republicans have developed a unique interpretation of the American tradition as well as Democrats. Today, however, it is not just about the former arguing for The Federalist and the latter arguing for Jeffersonian principles. Since 1968 and since the Great Society, etatism, progressivism, and cultural leftism have been closely united and opposed in all areas by the values established by neo-conservatives and their allies. Although pluralism of opinion is a natural phenomenon in a democracy, the disagreement these days is such that it transforms American domestic politics into a stationary warfare and undermines the minimum consensus needed to make the institutional system work.

At the dawn of American independence, Jefferson took over the presidency, though his ideas were poorly embodied in the federalist constitution. He did so because he thought the same issues as his political counterparts about fundamental issues, people's rule, freedom and citizens' rights. Despite their differences of opinion, the "Founding Fathers" had similar views on the essential values that formed the basis of American democracy. It is questionable what remains of this consensus to date and, in the absence of minimal agreement, how long the US political system is operational. American democracy must respond not only to problems of economic performance and foreign policy power, but also 
to these issues if it wants to remain attractive to the peoples of the world. The history of the United States has experienced several crises when the crisis of American values threatened and was able to respond well to the challenges. It is to be trusted that the ability of American society to renew itself, as in the past, will continue to help the country through the difficulties that it is facing.

\subsubsection{Chronological table}

\begin{tabular}{|c|c|}
\hline Date & Event \\
\hline 1492 & Columbus reaches America \\
\hline 1763 & The French lose Canada in the Seven Years' War \\
\hline 1773 & Boston Tea Party \\
\hline 1776 & The Declaration of Independence \\
\hline 1783 & Peace in Paris ends the War of Independence \\
\hline 1789-1797 & George Washington is the first president of the United States \\
\hline 1803 & Napoleon sells Louisiana to the US \\
\hline $1829-1837$ & Andrew Jackson's presidency \\
\hline 1850 & California becomes a US state \\
\hline $1861-1865$ & Abraham Lincoln's presidency \\
\hline $1861-1865$ & The American Civil War \\
\hline 1867 & Russia sells Alaska to the US \\
\hline 1869 & The first transcontinental railway line is completed \\
\hline 1898 & The beginning of the war against Spain \\
\hline 1901-1909 & Theodore Roosevelt's presidency \\
\hline $1913-1921$ & Woodrow Wilson's presidency \\
\hline 1914 & Opening of the Panama Canal \\
\hline 1917 & The US enters World War I \\
\hline $1923-1929$ & Calvin Coolidge's presidency \\
\hline 1929 & Black Friday stock market, the beginning of the global economic crisis \\
\hline 1933-1945 & Franklin Delano Roosevelt's presidency \\
\hline 1933 & The beginning of the New Deal economic programme \\
\hline 1941 & The US enters World War II after Pearl Harbour \\
\hline 1945 & End of World War II, Hiroshima and Nagasaki \\
\hline $1945-1953$ & Harry Truman's presidency \\
\hline 1947 & Beginning of the Marshall Plan to help Western Europe \\
\hline $1950-1953$ & The Korean War \\
\hline 1953-1961 & Dwight Eisenhower's presidency \\
\hline 1961-1963 & John Kennedy’s presidency \\
\hline $1963-1969$ & Lyndon Johnson presidency, Great Society programme \\
\hline
\end{tabular}


7.1. The North American Civilisation

\begin{tabular}{c|l}
\hline Date & \multicolumn{1}{c}{ Event } \\
\hline $1981-1989$ & Ronald Reagan's presidency, the US “wins” the Cold War \\
\hline 1991 & In the first Gulf War, the US defeats Iraq \\
\hline 2001 & September 11, Demolition of the World Trade Center \\
\hline $2009-2017$ & Obama is the first African-American president of the United States
\end{tabular}

\subsubsection{Bibliography}

AdAms, James, T. 2012: The Epic of America. New Brunswick \& London: Transaction Publishers

Degler, Carl, N. 1984: Out of our Past. The Forces that Shaped Modern America. New York: Harper and Row Publishers

HOFSTADTER, RichaRd 1955: The Age of Reform. New York: Alfred A. Knopf

HOFstAdTER, Richard 1973: The American Political Tradition and the Man Who Made It. New York: Vintage Books

JAy, John - HAMILTON, AlEXANDER - MADISON, JAMES 1982: The Federalist Papers. New York: Bantam Books

Kennedy, Paul 1987: The Rise and Fall of the Great Powers. New York: Random House

KRISTOL, IRVING 1972: On the Democratic Idea in America. New York: Harper and Row

LiND MiCHAEL 1995: The Next American Nation. New York: Simon and Schuster

Lind, Michael 2012: Land of Promise, An Economic History of the United States. New York: Harper Collins

MaCFARlane, Alan 1978: The Origins of English Individualism: The Family, Property and Social Transition. Oxford: Blackwell

SCHLESINGER ARTHUR M. 2003: The Coming of the New Deal: 1933-1935. New York: Houghton Mifflin Harcourt

STEINFELS, PeTER 2013: The Neoconservatives. New York: Simon and Schuster

ToCQueVILLE, AleXIS 2004: Democracy in America. New York: The Library of America

TURNER FREDRERICK J. 1921: The Frontier in American History. New York: Henry Holt and Company

ZAKARIA, FAREED 2003: The Future of Freedom. New York: W. W. Norton and Company 


\title{
7.2. Latin America: An Interactive System of Civilisations
}

\author{
BERNADETT LEHOCZKI
}

\subsubsection{Introduction}

The main dilemma with regard to Latin American civilisation stems from the fact that what we today call Latin America (the Romance-speaking sovereign states of the American continent) is actually the result of the meeting, intertwining, and centuries-old interaction of three civilisations. On the arrival of the European Conquistadors led by Christopher Columbus (died in 1506) in the Caribbean, Latin America was born at the "moment" of their encounter with the indigenous people and spread (geographically) with the European invasion into Central America and the South American subcontinent over the next centuries. It should be noted, however, that South America is a geologically autonomous continent, contrary to, for example, India, which is indisputably part of Asia.

The borders of Latin America are still changing, e.g., the states of the southern United States, which were attached to US after the end of the MexicanAmerican War of 1846-48. The population of the territories thus acquired was already using Spanish and/or native Indian languages. The rise of English in the area began then; one result of this procedure was the development of the Chicano (English-Spanish-Nahuatl mixture) language, also called Spanglish, which has its own literature. Then, in the twentieth and twenty-first centuries, the Hispanicisation of other US states has continued. Thus, before the arrival of the European (Spanish and Portuguese) conquerors, Latin America did not exist. It was created by the meeting of the two worlds, and then millions of black slaves brought in from Africa further enriched Latin America's character, adding a new dimension to the coexistence of natives and white Europeans.

Thus, an important feature of Latin American civilisation is that it cannot be considered an "original" civilisation, such as Western, Islamic, or Chinese civilisation, which (may) also exhibit important internal heterogeneity, but have common roots, religion, and values. The question, then, is whether a "new" civilisation could emerge from a meeting and already centuries of cohabitation of civilisations that had been evolving in parallel and separated from each other. And if it could, did it happen in Latin America? Is it a true "common civilisation" or is it a special hybrid system in which the members of the "original" civilisations continue to live in minimal integration, rather alongside each other in a difficult to dissolve social hierarchy? Can a Buenos Aires banker with Spanish, Italian and German ancestors, a Black shoe cleaner in the slums of Sao Paolo, and a Mayan 
Indian living in the rural areas of Guatemala be considered members of the same civilisation? What is Latin American? What are the links that unite and bind the people of the region? Do they exist at all, and are they "enough" to talk about Latin American civilisation?

In terms of civilisation, it is important to distinguish between two perspectives of Latin America: first refers to the 20 countries that historians classify as Latin America, while the second covers all the territories south of the United States border; thus, the English and Dutch-speaking Central American and Caribbean territories are also included. The "divergent areas" of the two interpretations do not only display linguistic differences, more importantly, the English and Dutch-speaking areas were independent only in the second half of the twentieth century and the closer political-economic ties with former colonists set these areas in a different path of development. Their "affiliation" is an interesting question with regard of civilisation, but it goes beyond the focus of this chapter, so I am basically dealing with Latin America in the historical sense - the first perspective described above.

The name of the region, Latin America, clearly evokes the colonial past of Europe, ignores the native heritage and the impact of the black slave culture, which have both played an important role in shaping today's Latin America and in meeting its cultural characteristics. Although alternative (otherwise one-sided and inaccurate) names existed (Indo-America, Afro-America, Ibero-America, Ibero-Indo-America), in the end (with the help of French (!) writers) the term Latin America remained and spread in public consciousness.

The one-sidedness of the term Latin America, with its strong Europeancentricity, represents one of the major challenges to the historical development of the region, a dilemma which has been regularly recurring since independence: is it right to follow the European, Western route, is it a guarantee of catching up or would it be worthwhile to "invent" an own Latin American model? A recurring obstacle on Latin American political-economic development is that members of the Creole political-economic elite view the region as Western and European (as the term "Latin America" also implies), disregarding the continued existence of non-Western, or pre-modern elements, structures in the societies, and also adapt modernisation strategies to this assumption. Of course, the question also arises whether Latin America, like the United States, can be interpreted as a subsystem of Western civilisation? Or is it just the dream of the Creole elite? In order to answer the above questions, or at least outline the main features of Latin American civilisation and place it in a system made up of other civilisations in the world, I will now consider the linguistic, ethnic, religious characteristics of the Latin American region. Then I will outline the major milestones in the history of Latin American civilisation, from the arrival of Europeans to the end of the nine- 
7.2. Latin America: An Interactive System of Civilisations

teenth century, and finally will try to analyse whether in the twentieth century Latin America tends to be moving towards unity or diversity from a civilisational perspective.

\subsubsection{Pre-Columbian cultures}

For a long time, the science of history on the American continent has not been consistent but it has now been proven that the continent was largely inhabited during the Wisconsin Ice Age (40000-7000 BCE), when the Bering Strait provided an approximately $90 \mathrm{~km}$ dry passage between the Western Hemisphere and Asia.

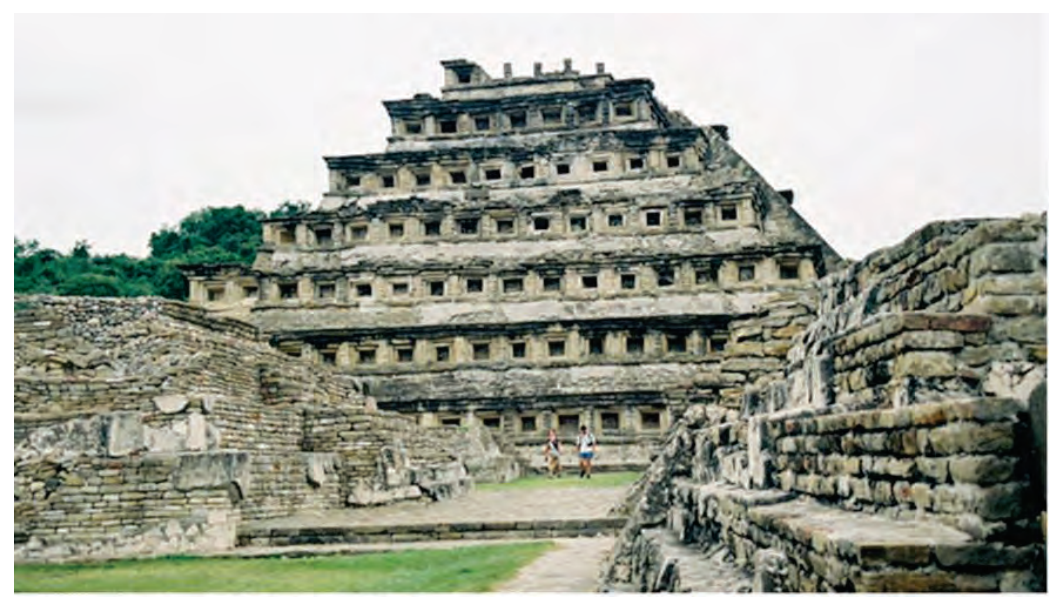

Figure 80: Pyramid of the Niches, El Tajín (Veracruz, Mexico). This edifice which was probably built in the twelfth century is rich in symbolism. Source: Photograph by LÁsZLó CSICSMANN

The history of pre-Columbian Central and South America can be divided into four major periods: archaic (7000-2500 BCE), pre-classical (2500 BCE-1 $\mathrm{CE})$, classical (1-1000 CE), and post-classical (1000-1500 CE). At the end of the archaic period, the first villages appeared that carried the novelty of settled life, and in the pre-classical era tribal organisation and agriculture-based rural lifestyle became widespread in Central America and the Andes (Map 37). In the classical era, with the strengthening of these two poles, we see entities already administered by the ruler, cities and stone-built sacred centres (Figure 80). Warfare became more common, the social status of the soldiers became stronger, and the first signs of empire building appeared. We know the most about the post-classical era, as this period is closed by the arrival of the Spanish conquerors. The major innovations of this era were the centralisation of power, the territorial growth of 
emerging empires through warfare, and a stronger social stratification than before.

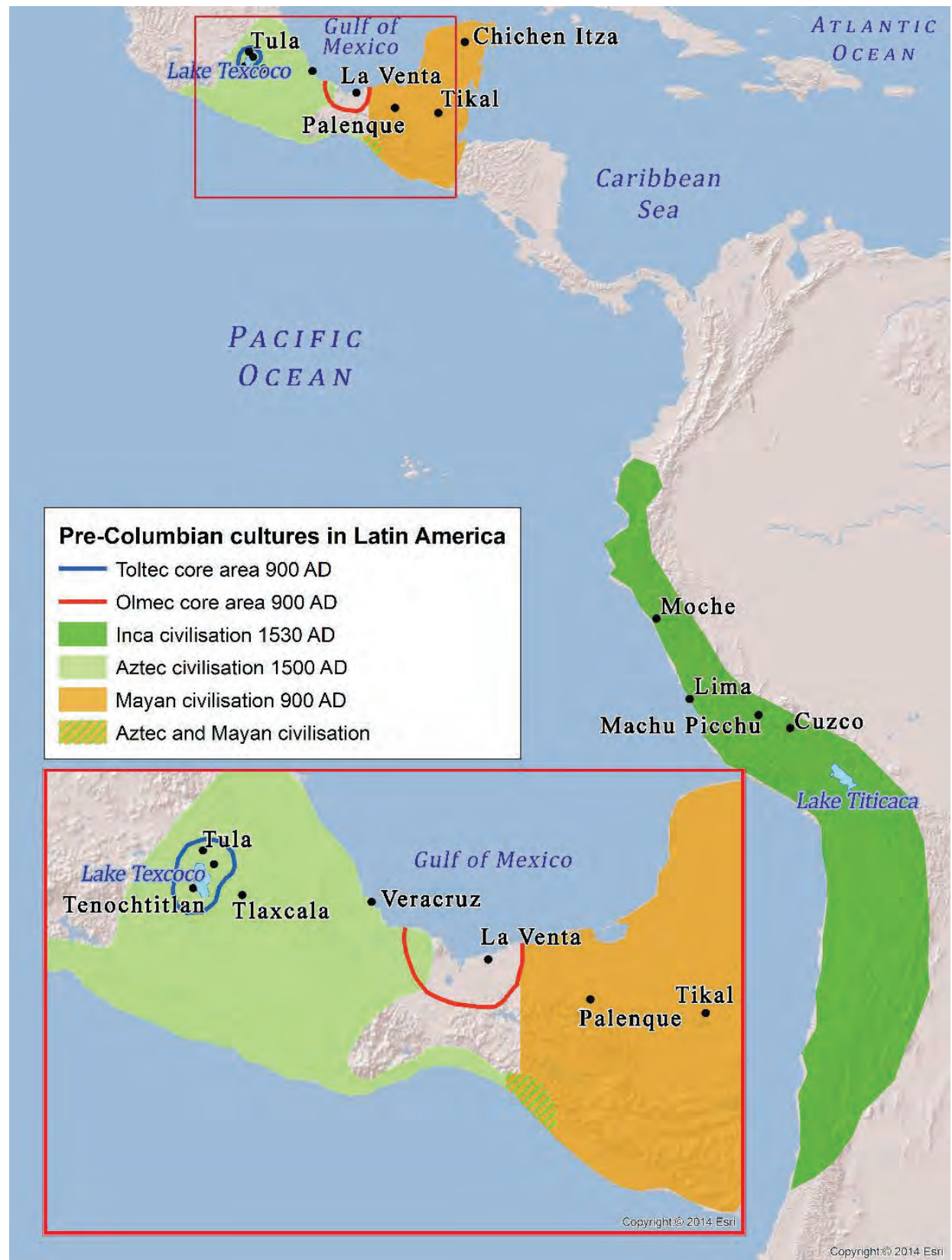

Map 37: Location of major pre-Columbian cultures Source: Edited by ÁGNES VARGA 


\section{Olmecs}

In the pre-classical era (1500-400 BCE), people living on the Gulf of Mexico were already able to trade in surplus food and the objects they made. Therefore, their craft objects are spread throughout Central America (Figure 81). Stone tools were used to erect huge buildings, including pyramids. The image of their rulers was captured on large basalt heads. Their culture influenced the Mayan culture that followed them. The cause of their decline is still unknown.

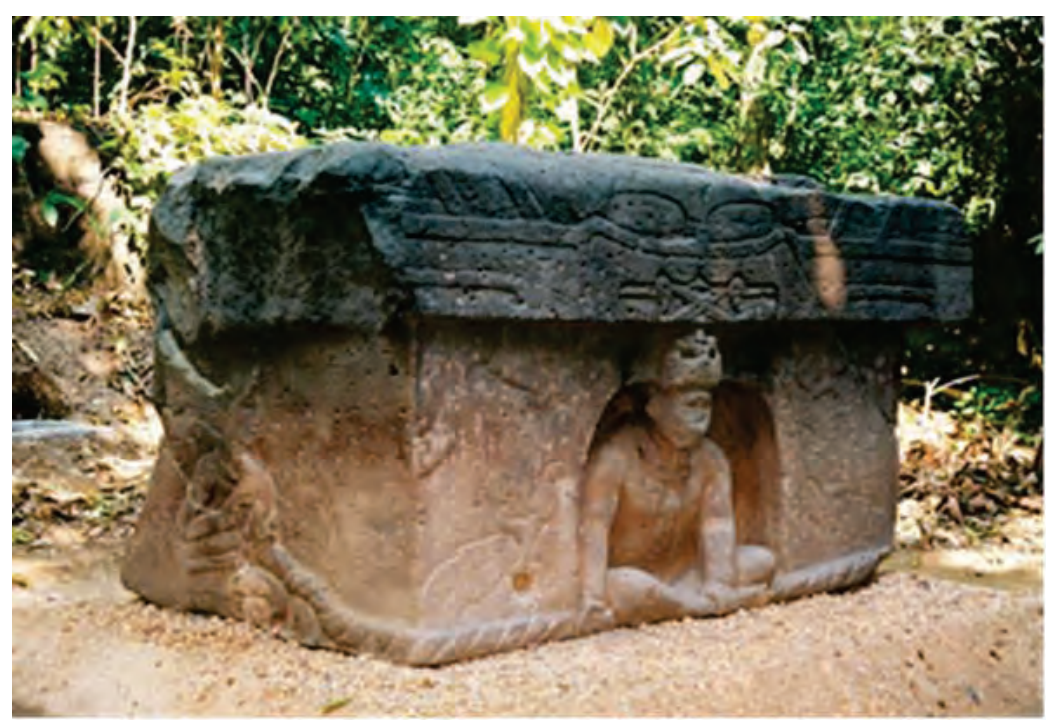

Figure 81: Olmec altar (La Venta, Tabasco, Mexico) Source: Photograph by LÁsZLÓ CSICSMANN

\section{Mayans}

In today's southern Mexico, as well as Guatemala, Belize, Honduras and El Salvador have seen the emergence of Mayan civilisation, one of its characteristics being its existence throughout the classical and post-classical eras. Unlike other post-classical cultures, the Mayans did not build a centralised empire, rather, it is a collection of cities with intensive trade relations between them. The Mayans are known for their outstanding mathematical and astronomical knowledge, as well as their monumental architecture and pyramids (Figures 8283). Their calendar system and hieroglyphic writing were adopted by several socalled Mesoamerican cultures. While they did not realise that the Earth was orbiting the Sun, they could calculate the cycles of the Moon and Venus, they also knew when the eclipse was due to the tables made by the priests. 
Their worldview was cyclical (they were thinking in 52 years), this is why they believed in the end of the cycle at the beginning of another cycle and in the coming of the end of the world.

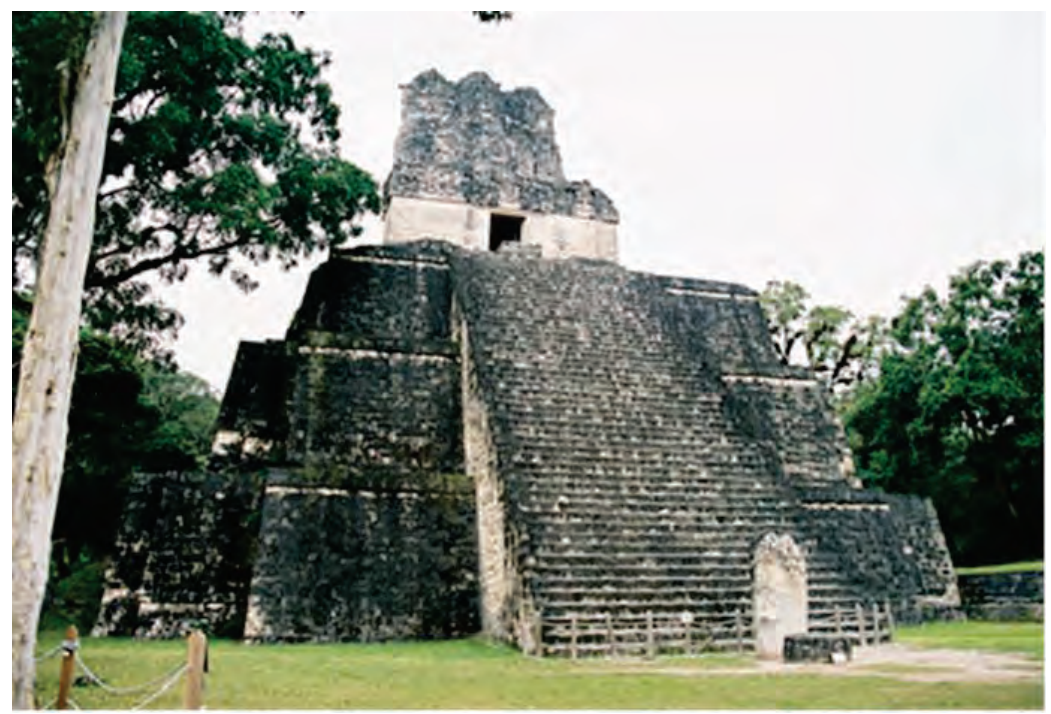

Figure 82: Step pyramid in Tikal, Guatemala, the largest city of Mayan civilisation Source: Photograph by LÁsZLó CsICSMANN

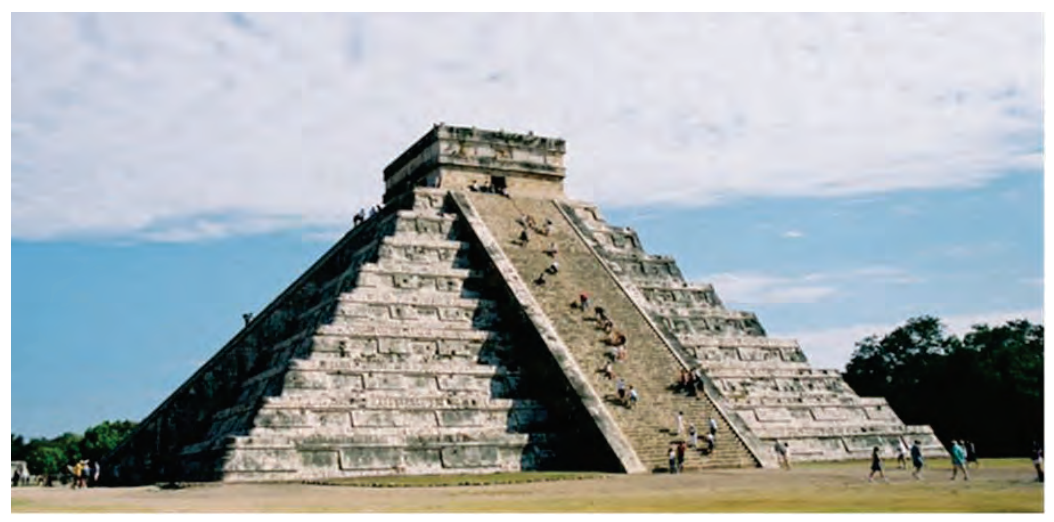

Figure 83: Mayan Toltec step pyramid, Chichen Itza (Yucatan Peninsula, Mexico) Source: Photograph by LÁsZLó CSICSMANN

\section{Aztecs}

North of the Mayan territories, in what is now Mexico, the Aztec Empire was built from the so-called Triple Alliance between the cities of Tenochtitlan (today's Mexico City), Texcoco and Tlacopán in 1428. The relatively rapid 
7.2. Latin America: An Interactive System of Civilisations

territorial expansion provided the basis for the empire in the following decades and the Aztecs became the dreaded rulers of the region. The Aztec rule was based on the taxation and labour of the enslaved peoples, and the conquered territories were divided among the Aztec nobles loyal to the centre. The Aztec was a very well organised, structured society, and the existing order was guaranteed by social hierarchy and strict law. Over the past centuries, Aztec beliefs have been the source of much controversy and has had an impact on the encounter with the Spaniards, and indirectly influenced the nature of later colonisation. The general polytheism was prevalent in the area, and today we know more than one hundred and twenty Aztec deities, but their attributes and the system of relationships between them are very complex and have not yet been fully explored. The religious, cultural, political and economic background of the large number of Aztec human scarifies has been the subject of considerable debate for centuries and there is still no consensus on their true motivations. What is certain, however, is that incoming Spaniards were exposed to the barbaric act of a heart sacrifice, which was regularly practiced by the Aztecs - when the victim's head was cut off and then his heart was taken out and offered to the gods. When Hernan Cortés landed in the Gulf of Mexico in 1519, the Aztec Empire stood at the peak of its glory, and even expanded. Nevertheless, by 1521 the empire had collapsed, and Tenochtitlan was in ruins.

\section{Incas}

The Inca Empire was located in the Andes and was an extremely well organised, highly centralised unit with a headquarters in Cuzco (today Peru). The Incas could not write, but they were outstanding in road construction, crafts, weaving and medicine. The absolute ruler at the head of the empire was the Inca, who was considered to be of divine descent as the descendant of the Sun God, but also the political legitimacy of the Inca nobility, who was related to his kinship by the divine origin. Like the Aztecs, the Incas built a vast empire in just over a hundred years and, during the conquests, imposed regular taxes on the enslaved tribes. The Inca beliefs and worldviews reflect the environmental characteristics of the Andes region: the close relationship with nature, respect for the sun, mountains, rivers, forests, etc. is deeply embedded in the Andean world of thought and continues to influence those who live there. At the same time, the Incas had a strong engineering background: during their conquests, new lands were always surveyed, plans were made to improve the land to increase taxation, and new irrigation systems, river regulation, swamp drainage, etc. specific plans have been developed. In contrast to Mesoamerican cultures, the Inca's worldview was chronological - in that sense it was closer to the incoming Europeans. With 
the arrival of the Spaniards, the Inca Empire, like the Aztecs, was at the peak of its power, but Europeans ended the Inca rule by the 1580s.

It is important to emphasise that, in addition to the most well-known PreColumbian empires described above, many indigenous groups are present in today's Latin America, with little organisation. In terms of central governance, administration, social structure, production methods, the heterogeneity of PreColumbian Latin America cannot be sufficiently emphasised. At the same time, it is worth noting that the Spaniards from Europe occupied primarily the territories of the organised empires - the first two vice-royalties (New Spain and Peru) were built on the ruins of the Aztec and Inca empires. Areas considered to be "underdeveloped" and often inhabited by fishing and hunting peoples will only be "discovered" and integrated into Latin America, known to Europeans, during the nineteenth and twentieth centuries.

\subsubsection{Components of civilisation}

The Latin American region appears to be united in both linguistic and religious terms, but as we shall see, along these dimensions we find almost as colourful a picture as it is of ethnic composition.

\section{Language features}

Despite the fact that Latin America, apart from the European colonial past, also refers to the Latin languages used in the region (Spanish, Portuguese and French), the region has a much more colourful picture. There are around 400 million Spanish speakers in eighteen states of Latin America, while Portuguese is spoken in Brazil with more than 200 million inhabitants. In the Caribbean Haiti, the official language is French. Since the colonisation, European languages spoken in Latin America have been in constant interaction with the languages of indigenous peoples and immigrants from Africa, Asia and Europe. The result of this process is the widespread use of the so-called pidgin or creole languages (English, French, Dutch and Spanish) in the Caribbean, or the Spanish-Italian mix (cocoliche) in Argentina, or Palenquero (a hybrid of African languages and Spanish) related to Colombia.

Research on indigenous languages in Latin America has shown a complex but sometimes contradictory picture. In Latin America, there are five-six hundred different indigenous languages and even more dialects. In many states of the region, such as Peru, Bolivia, there is an official native language besides Spanish, such as Quechua, Guarani or Aymara. 
7.2. Latin America: An Interactive System of Civilisations

Ethnic composition

In Latin America, the result of the meeting of these three civilisations and their active interactions for centuries, is that the people of the region display one of the most colourful/broader skin colour palettes in the world. Asian and Arab immigration has further strengthened/coloured this process. This extraordinary ethnic diversity is a distinct Latin American feature. This is referred to by the Mexican writer-philosopher José Vasconcélos' book - Minister of Education during and after the Mexican Revolution (1910-1917) - published in 1925, entitled Cosmic Race (La raza cósmica) according to which, after hundreds of years of mixing, a new fifth species was born in Latin America, Latin American.

There are widely varying estimates of the number of ethnicities in Latin America in the literature. The sources are basically based on Latin American censuses, i.e., they reflect the individual identity (or, if you prefer, the desired identity) of the people living in the region. It is difficult to show an accurate result that, given the centuries of racial mixing, the Latin American ethnic map is difficult to simplify into the categories most commonly used in the questionnaires (white, mestizo, indigenous, black, mulatto); the complexity of the issue is illustrated by the fact that, for example, hundreds of(!) terms are used in Brazil to describe different skin colour groups. This is compounded by the fact that, according to sociologists, individuals from different ethnic backgrounds see and welcome themselves in certain social spaces. For example, depending on the individual's place of residence or social embeddedness, whether they are afraid of indigenous, blacks' negative social perceptions, discrimination, or "whitening" themselves, or, in the sense of being positively discriminated against by the state, perhaps in the name of sympathising with the indigenous people or strengthening their indigenous/black identity, they are labelled themselves "more colourful". Below I refer to the figures of Ádám Anderle from 2002 regarding the ethnic division of Latin America.

The ethnic distribution of the Latin American region is mosaic-like; according to the proportion of the total population, the literature distinguishes Mestizo America (e.g., Mexico, Paraguay, Panama, Nicaragua), Mulatto America (e.g., Brazil, Cuba, Haiti), White America (e.g., Argentina, Chile, Costa Rica) and Native America (e.g., Bolivia, Peru, Guatemala). The total population of Latin America is approx. 40 percent of the Mestizos (230 million), 35 percent of Blacks and Mulattoes (190 million), native Americans and Whites are similar (810 percent), but we also need to mention the seven million Asian population for completeness.

The geographical distribution of the indigenous people of Latin America shows a varied picture; the vast majority (90 percent) of the indigenous population is concentrated in only five Latin American countries: Bolivia, Ecuador, 
Guatemala, Mexico and Peru. The largest Indian population in Latin America is made up of the Quechuas living in the Andes (10 million people), and the Mexican and Central American Mayans also make up millions of blocks, followed by the Aymara (Andes) and Nahua people (Mexico). In addition, in Latin America, we find approx. 150 native peoples. In social terms, the indigenous population can be divided into two groups: those integrated into the national economy (mainly in the Andes, Mexico, and Central America) and the natural peoples living primarily through hunting, fishing, and gathering. The proportion of the latter group decreased sharply during the twentieth century as a result of accelerated globalisation and urbanisation.

Similarly to indigenous populations, the distribution of African descendants is concentrated geographically in Latin America: Brazil has the highest number of blacks and mulattoes (according to some estimates, after all, Brazil has the highest number of blacks after Nigeria), and they also have a significant share in Ecuador and the Caribbean.

\section{Religion: the most Catholic continent?}

Regarding Latin America the term "most Catholic continent" is often mentioned. Indeed, about 75 percent of Latin Americans identify themselves with Catholicism, which is the highest compared to other Catholic regions in the world.

However, three important aspects of religious affiliation shade this picture. The first is the extent to which Latin American Catholicism is equivalent to "European" Catholicism. This aspect is also of paramount importance as to whether Latin American civilisation can be interpreted as part of the West. In the era of colonisation, Catholicism, "coming from Europe" was the folk Catholicism of the Iberian Peninsula interwoven with superstitions and beliefs. The process of Catholicisation by violent means has produced widespread religious syncretism in the Latin American region; just as the frequent depiction of animals in Latin American Catholic churches is an imprint of indigenous cultures, the Catholic faith of Latin Americans has diverse indigenous and African influences.

Another important aspect that may shape the region's Catholicism in the long run is the advancement of Protestant churches in recent decades. While Catholics are in a significant position in terms of numbers, on the one hand there is a (relatively) rapid change in the proportions and the passivity of Catholic believers, as opposed to the active participation of Protestants in the Church. Behind all this is the hundreds of years of the erosion of the Latin American Catholic Church. 
Finally, the third important point is that in many cases the practice of the Catholic faith is not exclusive in Latin America, meaning that in addition to declaring an individual Catholic, they may occasionally participate in ceremonies reflecting the faith of the indigenous people or blacks from Africa, most often blended with Catholicism. This Latin American practice is reflected in the saying that 80 percent of the Haitian population is Catholic, 15 percent Protestant and 100 percent voodoo.

\subsubsection{H istory of $L$ atin American Civilisation}

\section{Discovering America?}

As mentioned in the introduction, the birth of Latin America is linked to the arrival of the Spaniards. The memory of the discovery of the New World and its interpretation illustrate the inner challenges of Latin American civilisation. While for the European conquistadors and their descendants, Columbus's journey is an important event in the glorious past, for the indigenous people, the time of their submission and the origin of their exploitation. Thus, for the indigenous people, the "discovery" of the American continent is not only not a positive charge, but not even a discovery, since the American continent was discovered by their ancestors. (In addition, of course, the American continent was introduced to Europe by the Spaniards.) The discovery of the American continent was similarly negative for the black population of the Latin American region, for just a few years after the arrival of Columbus their ancestors began to be sailed to the continent as slaves.

Historically, the discovery of the New World can be interpreted as a continuation of the Reconquista. The Reconquista (re-conquest) marks the centurieslong process of recapturing the Iberian Peninsula from the Arabs, the final stop of which was in 1492 the Spanish re-occupation of Granada with the help of other European troops. Following the recovery of the Iberian Peninsula as a whole, the so-called Catholic kings (Isabella of Castile and Ferdinand of Aragon) intended to unify their empire with the help of the Catholic Church, developing effective central government. The discovery of America was an excellent opportunity to spread the Catholic faith and, after the Reconquista, for the derivation of the remained so-called Hidalgo nobility "unoccupied".

An important feature of colonial Latin America's nearly 350-year history is that "encounter" between the natives and the Europeans was the earliest (and "smoothest") in organised post-classical empires (Aztec, Mayan, Inca), and the indigenous hunter-fishing lifestyle later (seventeenth and eighteenth centuries), or during the colonial period they did not meet the conquistadors at all; that is, 
certain territories of Latin America will be "discovered" only after achieving independence. Thus, colonisation was not "complete", basically extending to organised empires; that is, the diversity of Pre-Columbian cultures has led to colonisation of different geographic intensities. In addition, there is an important difference between the Spanish and Portuguese colonial practices: the more active presence of the Spaniards enabled the establishment of a centralised colonial administration, while Portuguese colonisation was rather a series of sole proprietorships, with the result that only decentralised structures could be created.

Demographically, the biggest catastrophe in colonial Latin America was the drastic decline in the indigenous population. Estimates of this range are extremely wide, with most sources showing a population decline of between 50 and 90 percent. In today's Mexico, it is estimated that eleven million Indians lived at the time of the arrival of the Spaniards, of whom two million remained by 1607 . And of the estimated 3.5 million inhabitants of the Inca Empire, 1.5 million remained forty years after Francisco Pizarro's arrival.

In social terms, the colonial period in Latin America is characterised by two apparently opposite processes. On the one hand, mixing (mestizaje) was the main demographic feature. In this respect, Latin American territories are different from other European colonies, and there is nowhere near else the same regularity and volume of mixing between indigenous, captive black slaves and Europeans, resulting in the ethnic diversity discussed above. This is due to the fact that, on the one hand, the conquistadors were predominantly young, single men, and, on the other, the arrival of European women in the region was rare for decades after the discovery of the American continent. On the other hand, colonial societies organised into Spanish-controlled viceroyalties (Map 38) were hierarchically divided by skin colour: The Creoles provided the upper class, underneath the Mestizos, then the indigenous, the Mulattoes, and finally the blacks. The Spanish crown tried to enclose the colonial Latin American population in well-defined "castes", in practice, however, it has not been possible to prevent the indigenous mixing. For a long time only young men from Europe arrived in the New World, and the first conquistadors arrived in today's Latin America, inspired by the triple motivation of God, gold, glory. They did not come with their families, they came with no intention of settling down, rather, they were driven by adventure and hoped to become rich.

From the point of view of civilisation, the most significant and defining phenomenon of the colonial period is the meeting of two, or rather three, worlds on the new continent and the accompanying "civilisation shock" from virtually all three sides. Conquistadors, who were infiltrated by folk superstitions and exported zealous Catholicism, were astonished by the barbaric habits of the indigenous people, such as blood sacrifice, human sacrifice, or the consumption of 
7.2. Latin America: An Interactive System of Civilisations

human flesh (purely for sacred purposes). Europeans deeply despised and disdained the indigenous polytheist religion, idolatry. Throughout the centuries of colonialism, whites have always held a moral and civilising supremacy over indigenous people and blacks. With papal approval and a kind of (not very serious) missionary consciousness, they began to civilise the indigenous people, and to the convert them to the Catholic faith. With this activity they legitimised their conquest, and by doing so, the Catholic Church was able to establish positions similar to those of the Iberian Peninsula in the Spanish colonies.

Civilisation, or conversion to Catholicism, took place in different areas of the colonies with varying degrees of intensity, with different actors, and with varying means. The conquerors began to force the indigenous peoples to recapture them in the first areas they discovered, resulting in the destruction of much of the material and written memories of the indigenous culture. An important tool of civilisation was the encomienda system, in which the conquistadors were given a group of indigenous people from the Spanish crown to a piece of land to be used in forced labour and tax, but in return, they had to educate their labourers (i.e., educate them on how to be European). With regard to that the conquistadors who arrived in the New World were less educated and had objective to get rich, they were not prepared, nor committed to support the conversion of the natives.

Most of the Catholic Church's conversion activities were ineffective: they celebrated spectacular masses and often performed mass baptisms, which in most cases provoked the indigenous people to misunderstand. The transfer of the Spanish inquisition to the colonies did not produce the expected results.

The most effective actors in converting to the Catholic faith were the monasteries coming from Europe. Franciscan, Dominican, and Jesuit monks made serious efforts to pass Catholic doctrines to the natives. Language proved to be an important aspect: monks played an important role in overcoming linguistic difficulties, and they were the ones trying to communicate with the indigenous by learning the language of the natives. Their activities quickly highlighted conceptual challenges that transcended language, such as the absence of central concepts of Catholic practice, like confession or sin, in the language (i. e. among the: concepts) of the indigenous people. Similar efforts were made to try to consecrate the indigenous priests: the practice of celibacy proved incomprehensible and inconceivable to the indigenous people. The importance of Jesuit monks in colonial Latin America must be emphasised; representatives of this order played a prominent role in the geographical discovery of the South American sub-continent, in addition to their conversion activities, they also ventured into areas where "wild" Indians lived, which made the conquistadors not consider the exploration of these territories as a profitable investment. 
Dominican monk was also Bartolomeo de Las Casas, the most prominent Indian defender of colonial Latin America, who raised his voice in the mid-sixteenth century against the brutal treatment of indigenous people and the thesis of their born slavery. His A Short Account of the Destruction of the Indies was published in 1552, in which he presents the indigenous people as wise, benevolent, loyal peoples, and seeks to draw the attention of the Spanish crown to abuses in the colonies. Las Casas deduced the rights of the indigenous people from Christian doctrines on a religious basis, so it is interesting why he did not mention the situation of the black slaves at all. Otherwise, the Indian cause, the inhumane treatment of them, was one of the most prominent subjects of the European Enlightenment.

In any case, Europeans' conversion activity in the indigenous population has proven to be much more sophisticated than in the case of blacks. Although in the framework of plantation farming (as opposed to the indigenous population), blacks were almost exclusively under the control of the Creoles, but their education for the Catholic faith was progressing slowly. It is interesting, however, that blacks learned the language of their masters sooner, as it was a conscious Spanish and Portuguese policy to "confuse" members of certain African tribes in the colonies, to communicate poorly with each other and maintain their cultural traditions - it was primarily for economic reasons, planters considered it to be more effective for slaves.

From the very beginning, both the indigenous and the blacks had various, many forms of resistance. Escape, violent uprisings, widespread child and suicide practices were common, but the colonial period also has the problem of Indian alcoholism. The shock of civilisation was under severe psychological pressure in the lives of the coloured people: the indigenous people were deprived of their lifestyle, lands, idols and habits by the conquest of serious human sacrifices, while black slaves, after also inhumane "cruising", claiming serious human sacrifices, were forced to enter the lowest level of society on a new continent. These conflicts made life difficult for colonial Latin American societies and led to the emergence of serious stereotypes and revulsions among the various ethnicities living in the region.

The colonial period in Latin America was thus accompanied by the physical supremacy of the European conquistadors, which is also reflected in the social system; cultural life is fundamentally dominated by whites seeking to civilise and convert the indigenous and blacks to Catholic faith. This endeavour could only be partially fulfilled: on the one hand, because of the mode and means of missionary activity, and, on the other, because of the fundamental differences between the civilisations involved and the religious and cultural divides. 
7.2. Latin America: An Interactive System of Civilisations

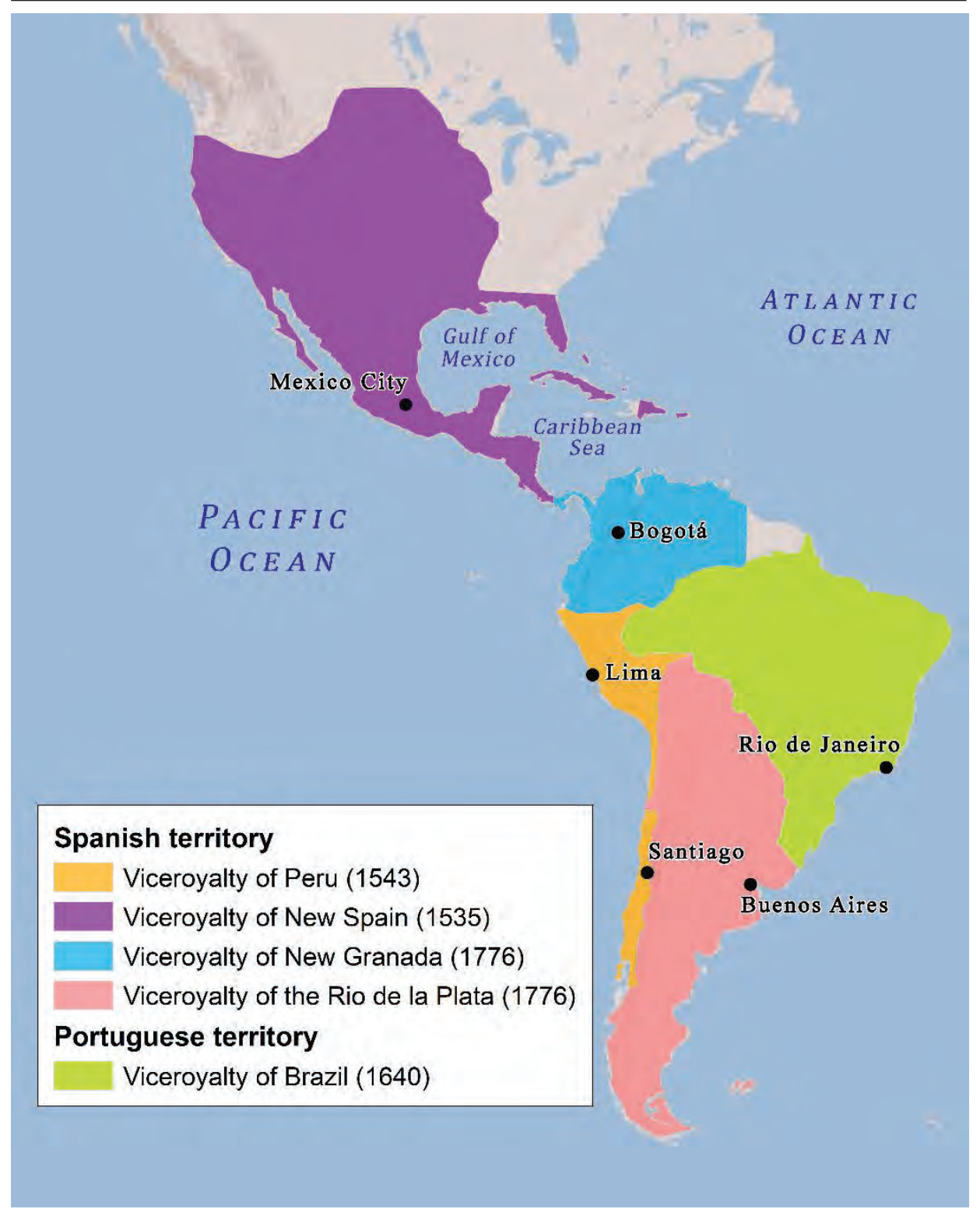

Map 38: Colonial Latin America Source: Edited by ÁGNES VARGA 
Achieving independence: common goals and aspirations?

The wars of independence in Latin America took place in the first third of the nineteenth century. The independence movements had internal and external origins. As an internal reason, we must mention the strengthening creole nationalism; for the wealthier and more and more frequently visited by the world-class Creole elite, the Spanish authorities have become increasingly burdened. They wanted to control their own destiny as newer generations born on the American continent felt less and less Spanish-born but became increasingly attached to the American continent. As an external cause, we should mention the Enlightenment of Europe and its infiltration, the independence of the United States (1776) and the decline of the Spanish Empire. After Napoleon's troops occupied the Iberian Peninsula, the Latin American Creoles, fearing a more violent colonial action on behalf of the French, saw it as time to step up their own path, and that the Spaniards occupied in Europe would not be able to resist effectively.

The struggles for independence were under the control and direction of the Creoles. Simón Bolívar (1783-1830), the main hero of the South American war of independence, was also a Creole educated in Europe. His personality is central to Latin American civilisation, because it symbolises the unity, if you will, "Latin American", which has returned to the minds of the Latin American intellectuals and politicians over and over again, but its practical realisation seems to be delayed. But this is not alone in the significance of Bolívar and the Bolivarian idea: one of the most important documents in Latin American history is the 1815 Jamaican letter. In this, Bolívar provides guidance for the future of the region: it considers democracy based on racial equality as the basis of post-independence Latin America, i.e., apart from Latin American unity and collaboration, interethnic partnership and balanced relations are a precondition for moving forward. This political agenda for nineteenth century Latin America set out a vision that seemed desirable, but reality did not allow it to materialise.

The independence wars rescued the power of the Creole elites, and the social structure/hierarchy did not change much. Independence from the ex-colonisers did not bring about the abolition of slavery everywhere in Latin America, only in the second half of the nineteenth century; most recently in Brazil (1888), where the economy was heavily dependent on slave labour. Although the constitutions of the newly independent Latin American states, as in the United States and Europe, enshrined fundamental human rights protection, the non-European descendant strata still did not enjoy full citizenship (as is the case in the United States and Europe). Historians call "conservative revolutions" the Latin American War of Independence, suggesting that it did not bring new life to Latin American social life beyond its formal independence; the highly hierarchical, skin-coloured division of the colonial age continued to exist, whereas the ruling 
7.2. Latin America: An Interactive System of Civilisations

creoles did not want revolutionary changes in social organisation. For them, the main objective was to preserve, more specifically, strengthening their political, economic, and social position, and more precisely, they had no model or idea how the non-white groups within the society could be involved in political and economic power.

The decades following independence were a painful period for Latin America; armed struggle continued to establish final state borders (Map 39), new economic partners had to be sought instead of Spain and Portugal, and there was intense competition in the political life for the new states' domestic and foreign policy formation. The Creole elite was basically divided into liberals and conservatives, that is to say, they were trying to steer the future of the new states based on ideas imported from Europe, despite the fact that Latin America did not have an industrial revolution, no middle class and the conditions for a united nation state, in the European sense, did not develop. Thus, just as during the colonial period the Spanish conquerors wanted to force the patterns of the Iberian-peninsula on their colonies, after independence the Creole elite wanted modernisation and convergence based on Western ideas and experiences.

In the last decades of the nineteenth century, the aforementioned liberalconservative struggle ended with the victory of the liberals, resulting in the suppression of the position of the Catholic Church and, in general, a departure from the colonial past. For the first time in Latin American history, Creole elite had the perception of "lagging behind", and as a response, liberal Creoles believed that "catching up" was possible by rejection of the colonial past and forced Europeanisation.

This endeavour and line of thought was represented by the civilisers of the age, also known as the romantic generation, whose members were primarily Argentine writers, poets, and philosophers. In their view, the cause of Latin American backwardness and the main obstacle to development are the presence of non-White strata in society; removing them, a European blood refresh is needed to catch up with the West. The strong political influence of civilisers is illustrated by the fact that during these decades, many Latin American countries have come to form the official programme of blanquear (whitening), which essentially sought to promote European immigration. This openly racist idea was detrimental to the future of Latin America in many ways: on the one hand, it brought deeper prejudices against indigenous people and blacks, and on the other, it refused to face the region's historical heritage, the colonial past, and that Latin America is not equal to the descendants of the conquistadors. The perception of non-White people as a "bother" or an "obstacle" has led to a strong alienation of certain groups in society, which excluded and placed in the distant future the possibility of joint development. 


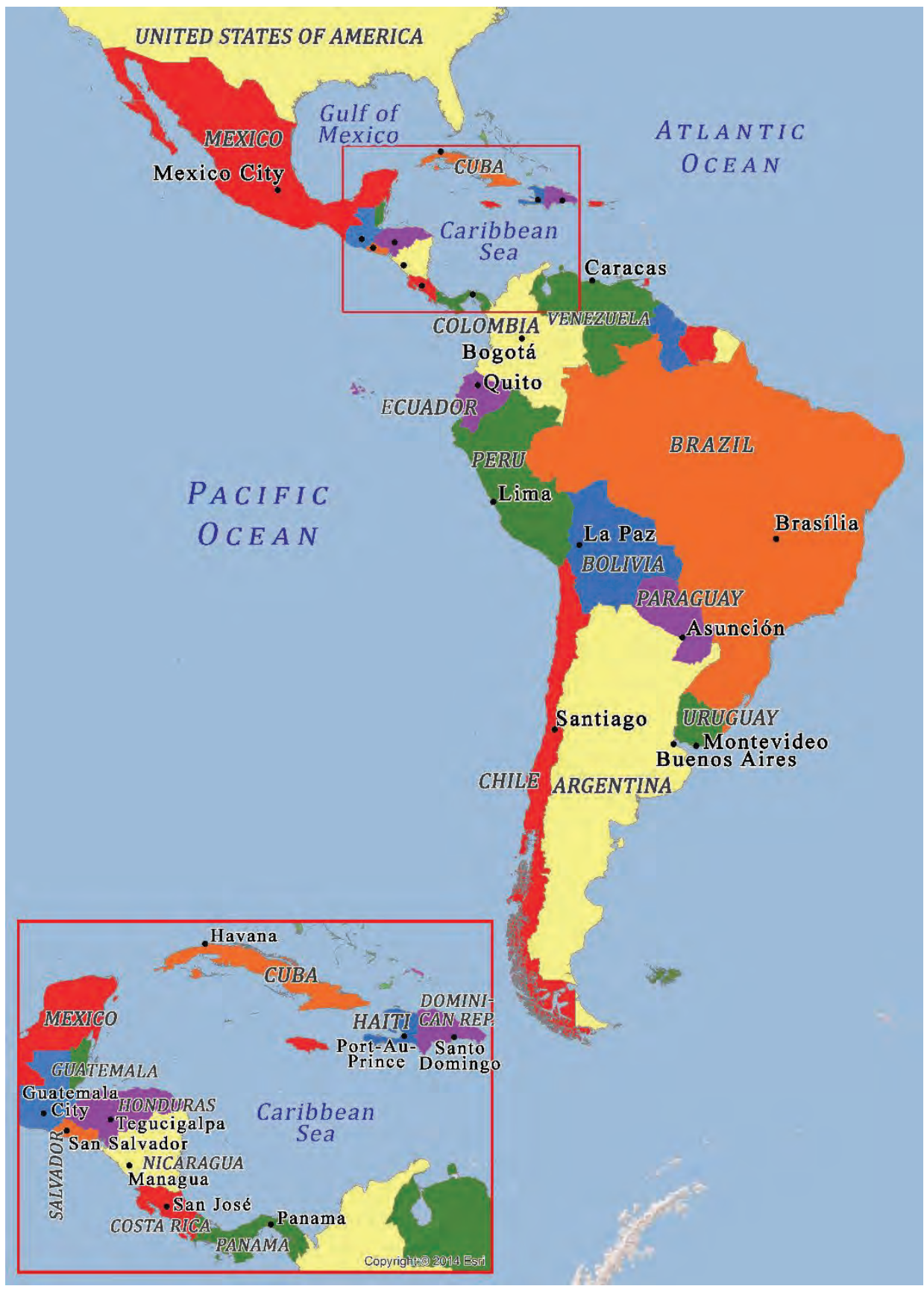

Map 39: The countries of Latin America today Source: Edited by ÁGNES VARGA 
Helping and supporting European immigration triggered a major wave of migration from the 1870s, which declined in the 1930s, and resulted in millions of Europeans (mainly German, Italian, Spanish and Central European) arriving in Latin America. The main destinations were the countries on the Atlantic coast (Argentina, Brazil and Uruguay), so this European immigration had an uneven impact on the countries of the region.

The nineteenth century thus represented an important turning point in Latin American history in several respects, but its yield and legacy were dual: on the one hand, the path to autonomous Latin American development was opened, and on the other, the way of independence and the events of the following decades worked against the Latin American unity and common social goals, influenced, strengthened, deepened internal social, ethnic divisions; making the twentieth century journey of Latin America difficult and full of challenges.

\subsubsection{T wentieth century dilemmas: A W estern or L atin American way?}

By the turn of the nineteenth and twentieth centuries, there were many fundamental changes in the future of Latin America. The final state borders were established (Panama was the last independent state in 1903), which provided an opportunity to start the process of nation-building. With the emergence of the liberal political elite, by the turn of the century, the church had been displaced from political life (separation of state and church). And in the second half of the nineteenth century, the role of the dominant European powers was gradually but surely taken over by the United States.

The process of nation-building in Latin America lasts till today and its most defining and striking feature is the constant struggle of outsiders, those on the periphery of society, the marginalised for "inclusion", social integration, equal rights, social advancement, and genuine citizenship. That is what populism in the 1930s targeted, and later on, the overwhelming majority of revolutionary efforts and guerrilla movements also attempted to accomplish these changes, with little success. Frequent coincidences of wealth and ethnic divisions are still a major obstacle to Latin American growth and the development of unified Latin American nation-states and Latin American civilisation.

The decline of the Catholic Church at the beginning of the twentieth century brought with it a weakening of Catholicism, which was further boosted by the powerful urbanisation that swept through Latin American countries. However, the Protestant advance of the last decades, which continues to this day, can also be rooted in providing active participation for its followers and fulfilling many social functions (supporting education, healthcare, helping alcoholics, the 
unemployed, etc.). The popularity of the Pentecostal movement, which embraces the poor and promises a way out for them, is becoming increasingly widespread.

The growing influence of the United States, initially primarily in economic and then in political-military terms, has a significant impact on Latin American civilisation. The size and richness of the "Northern Colossus" has created deep contrasts and asymmetry on the American continent. During the twentieth century, in Latin American self-definition and identity building, relationship with the United States became an essential element. Separation from the United States, the opposition of Latin Americanism to the culture of the Yankees (poor in Latin American reading) were basic components of Latin American self-perception.

One of the first representatives of this attitude was José Enrique Rodó of Uruguay, whose much-quoted essay, Ariel published in 1900 is still a defining work in thinking and contemplating Latin America. A prominent figure in the modernismo movement, Rodó, in his work for the "American youth", Ariel symbolises emotive, passionate Latin America, while Caliban symbolises the selfish, materialistic, individualistic United States.

According to Rodó, the United States, based on the moral principle of profitability, is the main rival of Latin America, and Latin American youth will be the main player in the resistance to US influence, so he recommends them his work Ariel because he considers the preservation of regional cultural identity as the responsibility of Hispanic-American youth.

Reducing US influence, independence from outside powers, is a recurring theme for Latin American writers, poets, philosophers and thinkers, and has become an important reference point in the definition of Latin Americanism throughout the twentieth century. All this does not mean, of course, that the purely conflicting nature of relations between the Americans will return to every thinker, but it seems fundamental to the attitude towards the United States in relation to the definition of Latin America.

After World War II, as a result of decolonisation, Latin American selfdefinition was extended by another element: it could define itself as part of the Third or developing world by engaging with the then independent African, Asian countries. Although these world regions have little affinity with Latin America in terms of civilisation/culture, similar political-economic challenges, structural difficulties and the independence of some Caribbean islands at this time activated the region's relations with a group of developing countries from the 1960s.

In the second half of the twentieth century, accelerating globalisation also reached the Latin American region. Its impact and results, like other developing regions of the world, are both the emergence and spread of technological innovation and the widening of income disparities in Latin American societies. Latin America's internal social and ethnic divisions are further strengthened by mod- 
7.2. Latin America: An Interactive System of Civilisations

ernisation as a result of globalisation, the take-over of Western production structures, financial institutions, and political arrangements, which, however, do not reach all societies; its positive benefit is enjoyed only by the upper, predominantly white strata of society.

The situation of indigenous people and blacks is twofold: on the one hand, as a result of urbanisation intertwined with globalisation, the assimilation of nonwhite people intensifies from the 1960s to the 1970s, indigenous languages and customs are on decline, while generations growing up in cities lose touch with their rising culture. At the same time, a more natural and automatic response to the trends of globalisation is the more organised presence and wider demands of the native movements. Similar processes are occurring among the black population in Latin America. An important novelty in recent decades has been the emergence - and rapid development - of endeavours that, for the first time in Latin American history, indigenous and blacks themselves have claimed their rights, demanded greater recognition, autonomy, and respect for their cultural rights. Hence, the centuries-old practice of representing the Creole elite in thinking about and disposing, social inclusion or elimination of non-white people seems to be transforming. The rise of the indigenous and black movements can certainly be regarded as a positive process in the search for identity and social advancement of these groups. However, experience so far has shown that increasingly articulate demands are pushing for further fragmentation of previously less unified Latin American societies, generating serious internal social conflicts such as those seen in Bolivia among different ethnic groups.

In the 1980s, the process of democratisation swept through the Latin American region, which, in addition to building democratic institutions, also brought about the end of censorship, the promotion of human rights and the proliferation and professionalisation of social movements and non-governmental organisations. Wider political participation and the introduction of universal suffrage are certainly positive developments in the political life of Latin American societies. At the same time, as a result of democratisation, they are gaining ever greater opportunities, building stronger networks and bringing together, in a more organised manner, social groups such as indigenous people, descendants of slaves, women or landless agricultural workers. This raises sensitive issues within Latin American societies and, in many cases, intensifies internal conflicts focusing on internal, never solved social fragmentation.

Thus, the twentieth century was targeting unity, finding Latin Americanism and social cohesion, defining Latin American characteristics, while on the other hand, the twentieth century also brought fragmentation, disintegration, and internal challenges. The question is whether in the coming decades, globalisation and technological development, as well as the strengthening of the democratic 
political system and the civil sphere, will be able to influence the process of social harmony, will the next generation become closer to each other in this coordinate system or local responses, a return to identity seeking the roots, which is expected to exacerbate existing internal social conflicts.

\subsubsection{Conclusion}

As can be seen from the foregoing, the existence of Latin American civilisation, and most of all its peculiarities, are far from clear. We can answer the question whether there is a Latin American civilisation, depending on the interpretation of the concept of civilisation. If civilisation means "the widest cultural entity" or the common historical, religious, cultural background, roots, Latin America is difficult to interpret as an independent civilisation. At the same time, however, Latin Americans' "common" hundreds of years of history, or more precisely, their cohabitation (coexistence?), only give us a sense of belonging, a common identity. The question, then, is whether the interaction of three civilisations, as stated in the title, is acceptable as a separate civilisation: its interacting system, its coexistence? Is there a longing for unity, togetherness, a common future?

The presence of the descendants of the Iberian conquerors and their decisive role in the political, economic organisation and managing of the states in the region, their centuries-long leadership in devising (adopting) and implementing catching-up strategies, could make Latin America part or a branch of Western civilisation. However, we have to argue with this approach. On the one hand, because the majority of Latin Americans are of Mestizo origin, the centuries-old mixing, even if it has not created a new "cosmic race", the clear predominance of "mixed" (Mestizo, Mulattoes, Zambos) separates Latin America from the West. On the other hand, because the West does not consider Latin America to be part of it, it does not enter into community with it (the regular Ibero-American summits are seen as an element of the Spanish foreign policy toolkit rather than as an expression of civilisational unity), and although in Latin Americans' self-definition, in their quest for identity, the West and reaching the West in terms of development is constantly present, self-definition is, by contrast, articulated in relation to it, too.

At first glance, Latin America may seem a bit Western (or similar), since the vast majority of the population in the region declare themselves Catholic, and in all of these countries, the official language is European. One step closer, however, the picture is more mosaic-like: we see syncretism rather than "pure" Catholicism, while in European languages, if not everywhere, we find many indigenous languages and linguistic elements brought from Africa. The picture 
7.2. Latin America: An Interactive System of Civilisations

only becomes more complex when we consider the ethnic diversity that lies behind these fractures.

The above ideas are based on the idea that Latin America is treated as one, but another aspect of Latin American civilisation may be to disregard the "Latin American" category. In this case, the question is: where and what boundaries do we draw? Can the states of the southern cone (Cono Sur), namely Chile, Argentina and Uruguay, which are the "whiter" and most homogeneous countries in Latin America, be classified as Western civilisation? Even if the answer is yes, and if these countries (or the Catholic whites in the region) are elevated (raised to the West), we are stuck here: what do we have to do with the rest of the Latin American population - the Mestizo and Mulatto part - since they cannot be classified as any civilisation?

All this leads us to the dilemma that just the fact that the Latin American states cannot be categorised as the West and not as other civilisations make Latin America an autonomous civilisation? If so, its specificity is precisely the hybridity, variety and diversity not seen elsewhere, whose unity and common path is one of the region's primary, major challenges.

\subsubsection{Chronological table}

\begin{tabular}{c|l} 
Date & \multicolumn{1}{c}{ Event } \\
\hline $6000-3000$ BC & The emergence of agricultural activity in Mesoamerica and the Andes \\
\hline $150-900$ AD & Mayan classic period \\
\hline $1300-1500$ & The rise of the Aztec and Inca empires \\
\hline 1492 & $\begin{array}{l}\text { Spaniards recapture the Iberian Peninsula (reconquista) and } \\
\text { Christopher Columbus discover America }\end{array}$ \\
\hline 1494 & The Treaty of Tordesillas \\
\hline 1524 & Establishment of the Council of Indies in Spain \\
\hline 1535 & $\begin{array}{l}\text { Establishing the first viceroyalty in Spanish America under the name } \\
\text { of New Spain on the ruins of the Aztec Empire }\end{array}$ \\
\hline 1537 & Sublimus Deus, Pope Paul III declares that Indians are human \\
\hline 1655 & The English acquire Jamaica \\
\hline 1767 & Expulsion of Jesuits from Spanish America \\
\hline 1804 & Independence of Haiti \\
\hline $1810-1824$ & Wars of Independence in Latin America \\
\hline $1864-1870$ & $\begin{array}{l}\text { Triple Alliance (Brazil, Argentina and Uruguay) wars against } \\
\text { Paraguay }\end{array}$ \\
\hline 1888 & Abolition of slavery in Brazil \\
\hline 1898 & Spanish-American War \\
\hline 1903 & Independence of Panama \\
\hline 1910 & $\begin{array}{l}\text { The outbreak of the Mexican Revolution and the creation of the Pan- } \\
\text { American Union }\end{array}$ \\
\hline
\end{tabular}


Civilisations from East to West

\begin{tabular}{|c|c|}
\hline Date & Event \\
\hline 1932-1935 & Chaco war between Bolivia and Paraguay \\
\hline 1948 & $\begin{array}{l}\text { The Organisation of American States is established and the military } \\
\text { institution in Costa Rica is abolished }\end{array}$ \\
\hline 1952 & Beginning of the Bolivian Revolution \\
\hline 1959 & Victory of the Cuban Revolution \\
\hline 1964 & Military takeover in Brazil \\
\hline 1967 & $\begin{array}{l}\text { Miguel Ángel Asturias wins Nobel Prize for Literature, Gabriel } \\
\text { García Márquez announces One Hundred Years of Solitude }\end{array}$ \\
\hline 1973 & $\begin{array}{l}\text { Military coup ends Salvador Allende presidency in Chile, new presi- } \\
\text { dent is Augusto Pinochet }\end{array}$ \\
\hline 1979 & Sandinista takeover in Nicaragua \\
\hline 1982 & $\begin{array}{l}\text { Beginning of the debt crisis in Latin America, Mexico announces } \\
\text { insolvency }\end{array}$ \\
\hline 1991 & The Southern Common Market is established (MERCOSUR) \\
\hline 1992 & $\begin{array}{l}\text { Rigoberta Menchú, Guatemalan human rights activist receives a } \\
\text { Nobel Peace Prize }\end{array}$ \\
\hline $2001-2002$ & Political, economic and social crisis in Argentina \\
\hline 2003 & $\begin{array}{l}\text { The Hispanic population in the United States is greater than that of } \\
\text { African Americans }\end{array}$ \\
\hline 2006 & $\begin{array}{l}\text { Inauguration of democratically elected politician of Aymara descent } \\
\text { from Evo Morales in Bolivia }\end{array}$ \\
\hline 2010 & $\begin{array}{l}\text { The Community of Latin American and Caribbean States (CELAC) is } \\
\text { established }\end{array}$ \\
\hline 2015 & $\begin{array}{l}\text { Historical meeting between Raul Castro and Barack Obama at the } \\
\text { Pan American Summit }\end{array}$ \\
\hline
\end{tabular}

\subsubsection{Bibliography}

ANDERLE, ÁDÁM 1992: Latin-Amerika története [The History of Latin America]. Budapest: Pannonica

BRUCKMANN, MonicA 2010: Alternative Visions of the Indigenous People's Movement in Latin America: Reflections on Civilisation and Modernity. Social Change, 40(4) 601-608.

EAKIn, MARSChall C. 2007: The History of Latin America: Collision of Cultures. New York: Palgrave Macmillan.

GREEN, DunCAN 2006: Faces of Latin America. London: Latin America Bureau LARRAIN, JORGE 2000: Identity and Modernity in Latin America. Cambridge: Polity

Wiarda, Howard J. 2001: The Soul of Latin America: The Cultural and Political Tradition. New Haven, CT \& London: Yale University Press

WiLliamson, EDWIN 1992: The Penguin History of Latin America. Penguin

WiLliamson, RoBerT C. 2006: Latin America: Cultures in Conflict. New York: Palgrave Macmillan 


\section{List of Maps and Figures}

\subsection{M aps}

1. The geographical location and natural conditions of China 49

2. Assumed location of the first mythical dynasty 61

3. Chinese territories from the fifth century BCE to 221 BCE 65

4. China at the end of the third century BCE 67

5. Chinese states in the first half of the tenth century 70

6. China in the thirteenth and fourteenth centuries 72

7. The territory of China during the last dynasty 75

8. Japan's topography, major volcanos and cities 90

9. The Indian subcontinent 135

10. The Maurya Empire c. 250 BCE 144

11. The Gupta Empire and its neighbours c. $400 \mathrm{CE} \quad 145$

12. The greatest expansion of the Mughal Empire (late seventeenth, early eighteenth century) 146

13. British India in $1906 \quad 147$

14. Migration routes of the Patriarchs according to the Bible 190

15. Map of the twelve tribes of Israel 192

16. The Assyrian Empire following the annexation of Israel 194

17. The world's Muslim population in $2018 \quad 222$

18. The major ethnic and cultural groups in Islam in 2018223

19. Geographical characteristics of the Islamic world 224

20. The Arab League 226

21. The expansion of Islam 237

22. The Mamluk Sultanate at its greatest extension 246

23. The so-called Gunpowder Empires 249

24. The major branches and schools of law of Islam 259

25. Language families of Africa 299

26. Religions of Africa 313

27. Major pre-colonial states in Africa 315

28. Orthodox churches in Europe and the Middle East 330

29. Growth of the areas under Moscow's influence up to the sixteenth century 334

30. Territorial expansion of Russia between the seventeenth century to WWI 335

31. Carolingian Europe 377

32. Europe at the end of the eleventh century 384 
33. Europe in the fourteenth century 392

34. Religious congregations in early modern Europe 395

35. Nation states in Europe in the last third of the nineteenth century 399

36. US territorial growth between 1776 and $1853 \quad 425$

37. Location of major pre-Columbian cultures 450

38. Colonial Latin America 461

39. The countries of Latin American today 464 


\subsection{Figures}

1. The Inglehart-Welzel cultural map 32

2. Correlation between modernisation and Westernisation 35

3. Family altar demonstrating a mixture of religions and politics 47

4. Buddhist women of the Bai ethnic community at a festival 52

5. The sacredness of writing. Outdoor calligraphy in Beijing 53

6. Wheel of life. Rock carving reflecting Buddhism, Confucianism, and Taoism 55

7. Ancestral Temple. Tengchong, Yunnan province 58

8. The Terracotta Army near the city of Xi'an 66

9. The construction of the Great Wall began during the Han dynasty 68

10. Inscribed stone tablets at Yunju Temple, near Beijing 69

11. Folk play performed in Kunming, Yunnan province 71

12. The still active sulphur vents of the volcanic Mount Hakone 92

13. The row of gates of one of the biggest Shintō shrines, the Fushimi Inari Shrine 95

14. Garden designed according to the principles of Japanese Zen Buddhism 96

15. Ceramics from the Jōmon period 100

16. Terracotta statue (haniwa) showing the contemporary warrior costume 102

17. The Haruna Shrine, founded in $586 \quad 103$

18. A woman's dress from the Nara period 104

19. A woman's dress from the Heian period 105

20. Dolls depicting the emperor, the empress and three ladies-in-waiting in Heian period costume for Hinamatsuri (Doll's Day) 106

$\begin{array}{lr}21 . & \text { Samurai costume } \\ & 107\end{array}$

22. The Great Buddha of Kamakura 108

23. The Osaka castle and garden originally built in the sixteenth century 110

24. Castle built at the beginning of the Edo period in Himeji 111

25. Interior of a house from the Edo period 112

26. Skyscrapers in Tokyo 122

27. Advertisement in the Dōtonbori district (Osaka) 124

28. Traditional yet modern Japanese serving 125

29. Morning rite on the Ganges in Varanasi 138

30. Male figure sitting in yoga pose. Indus Valley seal, Mohenjo Daro (Pakistan) 26001900 BCE

31. Meditating Buddha. Relief panel at the eastern side of the Stupa I (Great Stupa). Sanchi (Madhya Pradesh), Gupta period, c. mid-fifth century 
32. Stupa I (Great Stupa) at Sanchi (Madhya Pradesh), third century BCE through first century CE

33. Bimbisara, the king of Rajagriha emerging from the royal palace to visit the Buddha. Relief at the eastern gateway of Stupa I (Great Stupa). Sanchi (Madhya Pradesh), c. second-third decades of the first century CE

34. Tree goddess at the eastern gateway of Stupa I (Great Stupa). Sanchi (Madhya Pradesh), c. second-third decades of the first century CE

35. Upper part of a pillar from Budhagupta's reign depicting the mythical sunbird Garuda. Eran (Madhya Pradesh), Gupta period, $484 \mathrm{CE}$

36. Vishnu lying on the Serpent of Infinity (detail). Dashavatara Temple, Deogarh (Uttar Pradesh), early sixth century

37. Linga with the head of Shiva. Udayagiri (Madhya Pradesh), Cave 4. Gupta period, early fifth century

38. Temples of Khajuraho. Chandela dynasty, eleventh century

39. Arunachalesvara Temple, Tiruvannamalai (Tamil Nadu)

40. Gwalior Fort, Madhya Pradesh. In its present form it was built in the fifteenth and sixteenth centuries

41. Torah scroll from the Munk-Munkácsy collection, MILEV (XIX-69) 199

42. Torah pointer, Marrakesh, Jewish Museum 200

43. Lazama Synagogue in Marrakesh 200

44. Babylonian Talmud. Prague: Landau, 1832

45. Prayer shawl (tallit) with silver embroidery, MILEV 205

46. Sephardi mezuzah from Macedonia 205

47. Man blowing a ram's horn (shofar). Festive prayer book (mahzor), South Germany, end of the thirteenth century 210

48. F. Kaskeline, Celebrating Sukkot in the synagogue, MILEV 212

49. Depiction of the menorah in a manuscript of Maimonides's Mishneh Torah, North-East France, 1296

50. Spinning top (dreidel) played during Hanukkah, MILEV 214

51. Table set for the Seder meal 215

52. In the barren countryside, date palm oases continue to be a major source of living to this day

53. The fortress of Monastir (Tunisia) originally built by the Abbasid governor in the late eighth century, later used and enlarged by the local dynasties 239

54. Gold dinar with an Arabic inscription, Museum of Mahdia (Tunisia) 240

55. The Bab al-Futuh (Gate of Conquests) built by the Fatimids in the eleventh century, in Cairo. In the background, a minaret of the Hakim Mosque 
56. The mosque built in the territory of the citadel of Cairo by the Bahri Mamluk Sultan al-Nasir Muhammad ibn Qalawun in the early fourteenth century 247

57. The profession of faith in calligraphic form on the wall of a Cairo mosque 251

58. Mihrab and minbar in a Cairo mosque 253

59. Mecca and Medina in a Muslim prayer book copied in the eighteenth century 255

60. The madrasa of Sarghatmish in Cairo built in 1356. It houses a mosque and a mausoleum as well 256

61. Ali's wise saying in a calligraphic arrangement on six tiles: "There is no higher nobility than Islam".

269

62. The Great Mosque of Qayrawan founded by Uqba ibn Nafi in 670, which gained its final form during the reign of the Aghlabid dynasty in the ninth century 279

63. The Mosque of Ibn Tulun in Cairo built in 879 and its minaret 280

64. The iwans of three madrasas built between the fifteenth and seventeenth centuries in the Registan, the main square of Samarkand in the Timurid period

65. Quran excerpts $(1: 7 ; 12: 53)$ in Kufic script from the eighth century, with a decorative sura dividing panel. Museum of Islamic Art, Istanbul

66. The tiles on the facade of the Abdullah Khan Madrasa covered with inscriptions, Bukhara, sixteenth century 282

67. Modern street art in Cairo making use of calligraphy 282

68. Mistrels (griot) from King Sambala's court (Medina, Mali) 304

69. First page of a nineteenth-century family chronicle from Northern Ghana 305

70. Book written in the script of the Bamum people of Cameroon, c. 1910306

71. Ethiopian manuscript including gospel extracts and prayers in Ge'ez language. Archangels Michael and Gabriel on the right

72. Local commanders of the Tijaniyyah Sufi Order in the town of Kiota, SW Niger 312

73. Dutch image of the city of Benin (today in Nigeria), 1668316

74. Three warriors, c sixteenth-century Yoruba bronze plaque from Benin 318

75. Yoruba bronze portrait from the city of Ife, today in the British Museum 319

76. Ashanti copper figurines from Ghana, for weighing gold, in the British Beaney House of Art and Knowledge (Canterbury) collection 320

77. Bete Giyorgis (Church of St. George) in Lalibela (Ethiopia) 321

78. Part of the Great-Zimbabwe Buildings 322

79. Great Mosque of Djenne, one of the greatest architectural gems of the Sudanese-Gothic style

80. Pyramid of the Niches, El Tajín (Veracruz, Mexico). This edifice which was probably built in the twelfth century is rich in symbolism 449

81. Olmec altar (La Venta, Tabasco, Mexico) 451 
82. Step pyramid in Tikal (Guatemala), the largest city of Mayan civilisation

83. Mayan Toltec step pyramid, Chichen Itza (Yucatan Peninsula, Mexico) 


\section{Glossary}

\section{Term \\ Definition}

Afrocentrism

Agama (Sanskrit)

age set

ahimsa (Sk. "non-

harm”)

Ahl al-Bayt

Ajami

aladura

allodial title

anomie

Aranyaka (Sk. "forest book")

arhat (Sk. "worthy", "respectable")

artha (Sk. "wealth", "property")

Aryan (Sk. "noble”)

Ashkenazi

atman (Sk.)

audiencia
Literary and scholarly movement among Afro-American intellectuals, supporting a return to supposed African cultural roots.

Religious texts of devotional Hindu schools. There are Shaiva, Vaishnava and Shakta Agamas, the latter are also called Tantras.

Institutionalised social category encompassing people of roughly the same age and having its specific social role.

The principle of non-violence and respect for every way of life in Indian religions.

"People of the House", meaning the Prophet Muhammad's family.

Writing that uses Arabic fonts to record various African languages.

"Praying" sects; a unique type of south Nigerian Christianity, blending African traditions and Christian doctrines.

Generally speaking, it is property free of feudal services that equals the land estate inherited from father to son, called votchina in Russia.

Weakening of the guiding role of social values and norms, that usually evolves in modern societies or as a result of major social changes.

Commentaries on the Vedas explaining the secret symbolism of the sacrifices.

The highest rank in Buddhist hierarchy.

One of the life goals in Hinduism.

Self-designation of ethnic groups belonging to the Indo-Iranian branch of the Indo-European language family.

Jewish people who originally settled in Germany or Northern France and their descendants.

The inner self or soul of the individual.

The principal apparatus and governmental unit of the Spanish-American colonial period that managed jurisdiction, administration and finances and supervised the church too. 
autarchic development A development model based on self-sufficiency. States going through such development usually turn away from world trade and have low foreign trade traffic.

autocephalic church Independent churches in Eastern or orthodox Christianity.

avatara (Sk. “descent”) Incarnation of a deity, primarily those of Vishnu. These are Matsya (Fish), Kurma (Tortoise), Varaha (Boar), Narasimha (Man-lion), Vamana (Dwarf), Parashurama (Rama with an axe), Rama, Krishna, Buddha (or Balarama) and Kalki.

axis mundi (Latin

"world axis")

The centre of the world in certain religions, a passage between Heaven and Earth. It is also related to the world tree idea

bakufu

The $\rightarrow$ shōgun's government.

Bantu

bar mitzvah

A group of the Niger-Congo language family that consists of 250 languages, spoken in the entire southern half of Africa.

A boy reaching the age of thirteen who is given the responsibilities and duties of Jewish religion (mitzvahs). The term also denotes the ceremony in which the boy first time performs a commandment he was not obliged to perform before (like reading the weekly portion of the Torah in the synagogue service).

beneficium Generally, it is the land tenure or benefice for feudal services that equals the pomesztye in Russia, to render the service to the state.

bhakti (Sk. "devotion") Ardent, unconditional love of a god, typical for medieval Hindu religiousness.

Bharat Mata (Sk. A national symbol evolving during the Indian independence movement, Mother India) personification of India as a mother goddess.

bodhisattva (Sk. Compassionate, merciful beings in $\rightarrow$ Mahayana Buddhism. The Buddha

"enlightenment being") himself was a bodhisattva in his earlier births as well as in his last birth before his enlightenment.

Brahman (Sk.) The absolute reality.

Brahmana (Sk.) 1. Members of the priestly class $(\rightarrow$ varna). Their primary task was to perform sacrifices, studying, explaining and passing on sacred texts. Later, they gained dominance over all kinds of intellectual occupations. 2. Commentaries on the $\rightarrow$ Vedas, which contain the rules and explanations of sacrificial rites.

Brahmi

Ancient Indian writing system identified on inscriptions from the third century BCE. Modern Indian alphabets evolved from this script.

bushi

$\rightarrow$ samurai 
Term

caesaropapism

caliph (Arabic

"successor")

caste

caudillo

\section{Definition}

Merger of the Church and the state with the leading role of the state. Caesaropapism is most commonly used with regard to the Greek church and Russia in the medieval and modern history. Historians share different opinions on the usage of caesaropapism as a concept.

Religious and secular ruler of the Muslim community after Muhammad's death, later called God's vicegerents and God's shadow on Earth.

A word of Portuguese origin to denote the occupation units of Indian society $(\rightarrow$ jati).

Military leader in Spanish America who typically strengthened its position during the independence wars that and afterwards was capable of controlling a given region with his army and retinue of clients, often affecting domestic politics in new-born Latin American states. In twentieth-century Spain and Latin America the word means strong political leader.

chakra (Sk. "wheel", Solar symbol; in Buddhism, it refers to the wheel of law (dharmachakra); "discus") in Hinduism, it is a symbol and weapon (discus) of Vishnu.

chakravartin (Sk.) Universal ruler, emperor.

christology dogma The Church's teaching about the interpretation of Christ's divine and human natures and their relationship.

Congo velvet

Velvet-like, embroidered fabric made of the raffia palm fibres that is a unique type of the Congo Basin art.

cultural pessimism

All the negative feedbacks on the present and future of a culture or civilisation. The phenomenon is part of a rather broader category of cultural criticism that particularly appeared in the western cultures and among intellectuals, mostly phrased pessimistic value judgement on the European civilisation in the twentieth century for example on the descendance of the culture and communities falling apart etc.

Cushitic

A subgroup in the Afro-Asian language group, spread in the North East region of Africa.

daimyō

Landholding $\rightarrow$ samurai magnate in the fourteenth-nineteenth centuries.

darshana (Sk.)

Ancient Indian philosophical system, school. The six orthodox darshanas are $\rightarrow$ Sankhya, $\rightarrow$ Yoga, Nyaya, Vaisheshika, Mimamsa, and Vedanta. 
Term

desacralisation

deus otiosus

deva (Sk.)

devanagari (Sk.

"divine city")

devaraja (Sk. "god-

king”)

Dhamma (Pali)

dharma (Sk.)

dhimmi (Arabic

"protected person")

diarchic system

diaspora

Diffidatio/diffidation

Digambara (Sk.

"sky-clad")

dravida (Sk.)

egungun

emir (Arabic)

endogamy

ethnic religion

fatwa (Arabic)

felony
Definition

On one hand these words are synonyms, on the other hand they have their individual meanings, too. They incorporate many layers of meanings, in the modern age, mostly the elimination of the sacral orientation, nature of social norms, values and institutions.

A creator God that, after having created the world, withdraws from governing the affairs of the created world.

Vedic god.

A syllabic alphabet in which Sanskrit, Hindi, Marathi etc. are written. It evolved from $\rightarrow$ Brahmi.

Cult of the deified monarch in Southeast Asia.

The Teachings of the Buddha.

Religion, religious duty, standard of conduct, law; one of the life goals in Hinduism.

Legal status of Christians, Jews, and Zoroastrians in the Islamic Empire.

A system based on two influences or powers, just like Russia before Peter I., Russian czar, where the shared rules of secular power and church power, not subject to each other, were applied.

Ethnicity living away from their motherland.

Right to renunciate allegiance, "revocation of allegiance".

A monastic order in Jainism that follows rigorous asceticism.

The southern style of Hindu temple architecture.

The most important spirit type for the Yoruba of South Nigeria: the spirits of the ancestors manifesting themselves to their offspring during masquerades.

Military commander ruling a territory independently accepting the authority of the caliph, primarily in religious matters.

Marriage only between members of the same group.

A religion practiced by a single ethnicity that does not seek to spread its beliefs among other groups.

A nonbinding legal decision in Islam, response to questions of individuals about criminal law, religious ceremonies or ordinary life.

Treason, breach of feudal homage. 
Term

fiqh (Arabic)

first emigration

(al-hijra al-ula)

foquismo

frontier

garbhagriha (Sk.

"womb chamber")

gerontocracy

gilded age

Great Society

griot

gullah
Definition

Jurisprudence elaborated by jurists (faqih, plural fuqaha) using their individual effort based on the detailed study of the sources of the divine law ( $\rightarrow$ sharia) concerning general principles and details.

An important episode of early Muslim history when (during the lifetime of the Prophet Muhammad) a group of the early Muslim community in Mecca emigrated $(\rightarrow$ hijra) to Ethiopia.

A theory, formed by Regis Debray French philosopher, based on the ideas of Ernesto Che Guevara, trying to give a solution for the guerrilla warfare against the existing order, motivated by the victory of the Cuban revolution, namely it says that armoured attacks should be started from small centres (foco), that would mobilise the entire society and convince them to stand on the guerrilla side due to gaining more support from the general dissatisfaction.

The western ("fuzzy") border of the United States that has been moved westward in the nineteenth century, thanks to the expansion of the settlers. Turner, who worked out the classical frontier thesis, says that it truly facilitated the establishment of civilisation characteristics that pertain to America.

The sanctuary of Hindu temples.

Rule by the elders: a type of social organisation in which the cohort of old men or a council of elders governs the community.

Mark Twain used this expression for the American society of the last third of the nineteenth century, characterised by rapid economic growth, the rise of monopolies, as well as corruption and holder groups influencing political life.

A set of political and welfare measurements in the United States, starting in the mid 1960's during the presidency of the democrat Johnson, mostly for the total elimination of poverty and the expansion of health care. The Great Society sought to complete social emancipation and was seen as an attempt to create an American version of the post-World War II welfare state.

French word, for the $\rightarrow$ endogamous caste that exists in many West African societies which is in charge of memorising, passing on, and performing historical traditions (often to musical accompaniment).

Dialect and culture, showing strong African influence on the coast and islands of South Carolina (USA). 
Term

hacienda

hadith (Arabic)

halal (Arabic)

han

haram (Arabic

"forbidden")

haveli

heterodoxy

high level equilibrium

trap

hijra (Arabic)

Hinayana (Sk. "Lesser Vehicle”)

hsiung nu (xiongnu)

\section{Definition}

Self-sufficient estate on Spanish and Portuguese colonies in the Americas, usually sustaining itself from agriculture and husbandry, it is home for the owner's family and the staff at the same time.

The tradition of the Prophet Muhammad, his oral communication transmitted by those who heard it. It has two parts, one is the isnad, that is the chain of narrators who have transmitted the report and the other one is the matn, the actual text.

The method of any compulsory act, as prescribed by the rules of Islam, e.g. the way of slaughtering animals

The greatest ethnic group, 92 percent of the population in China. Although it can be divided into many smaller language and customs subgroups, they are still the core of the Chinese civilisation and the people of China.

A major sin in Islam that must be judged by the court of the qadi.

Large traditional townhouse in India, sometimes a palace, built around a courtyard. In most cases, it is a type of building of architectural and cultural significance.

Different or foreign belief.

Thanks for the effective trade and production system, the supply and demand reached the equilibrium in the Chinese Empire, local shortages could be balanced by surpluses from other regions and labour was extremely cheap. All these factors together resulted that capital investment in technological development and indirectly in improving efficiency was no longer profitable and therefore no industrial and technological revolution was accomplished in China.

The Prophet Muhammad's emigration from Mecca to Medina in 622, which is also the beginning of the Muslim calendar, i.e. the first lunar year.

Buddhist schools, teaching that enlightenment is only available only to an exceptional few. The number of Hinayana schools once reached eighteen, but of these, only the $\rightarrow$ Theravada school has survived to this day.

Nomadic tribal confederation once living north of China, also called Asian Huns, who used to be at war against the state of China, so they have had a substantial role in building the Great Wall. Some Chinese consider that they are ancient relatives of Hungarians therefore the Chinese word for Hungary (Xiongyali) also indicates that. 
Term

hudud (Arabic)

huppah, chuppah

ijma (Arabic

"consensus")

ijtihad (Arabic

"individual effort"

ie

imam (Arabic)

inquisition

isolationism

Jain

jati (Sk. "birth”)

jatidharma (Sk.)

jihad (Arabic)

Jina ("Conqueror")

jiva (Sk.)

\section{Definition}

"Limits" defined by God, the crossing of which means deadly sins. The punishments for committing hudud crimes - e.g. murder, theft, adultery, defamation - are clearly described in the Quran.

Jewish canopy for weddings.

Agreement of jurists in a school of law concerning a certain ruling, in a given age or territory.

When Muslim religious scholars, thanks to divine grace, are absorbed in the study of the texts of divine revelation, trying to determine God's will $(\rightarrow$ Quran and $\rightarrow$ hadith).

$\rightarrow$ Bushi family pattern. Japanese patriarchal, hierarchic family where the surname and the property or land are inherited.

In Sunni Islam, one who leads the prayer, in Shi Islam, members of the Prophet Muhammad's family who are descendants of Ali's sons, appointed by God to lead the community.

Court of judgement to abolish heresy, starting its duty in 1478 in Spain, and appeared in the sixteenth century in Spanish-America, closely intersecting with the state apparatus.

A unique nature of American foreign policy that, in different historical situations, has been a recurrent theme in the nineteenth and twentieth centuries. Instead of applying an active world policy the U.S. prefers and expresses its restraint against international obligations and the outside world. There are variations and extents as it has never been applied clean and it describes the American foreign policy with serious doubts.

Follower of Jainism. Today there are about 4.5 million Jains in India, but their number exceeds 7 million including the diaspora.

Hereditary occupational groups in Indian society, characterised by intragroup marriage (endogamy) and a common ritual tradition.

Religious obligations and requirements of conduct for an individual's birth group $(\rightarrow$ jati) in the Indian society.

"Effort" for the sake of God and Islam. The "greater jihad" is a fight for strengthening faith while the "lesser jihad" is a fight against external enemies.

Vardhamana Mahavira, the founder of Jainism, who lived between 599527 or $540-468$ BCE. He considered himself the $24^{\text {th }} \rightarrow$ tirthankara (spiritual leader) in the ascetic sect founded by Parshvanatha 200 years earlier.

Soul. 
Term

kakadoxia

kalpa (Sk.)

kama (Sk. "lust")

kami

karkhana

karma (Sk. “action”)

Kaurava

kavya (Sk. "poetry”)

Kharosthi

Kofun

kosher

kowtow (koutou)

Kshatriya (Sk.)

Kumbh Mela

kuraka

laicisation
Definition

Misbelief

In Indian mythology, it is a cosmic cycle from the creation to the dissolution of the universe, corresponding to a day of the god Brahma. Its duration is equal to 4,320,000,000 earth years.

Love, pleasure; one of the Hindu goals of life.

Gods in the Japanese belief. There is nearly an uncountable number of gods, they reside in natural phenomena, but even human beings may evolve into a kami after death. Human life is dependent on them, kamis can aid and get angry but can be pleased via ceremonies, sacrifices and prayers. Every community, family has had their own patron deity who was often a proud ancestor.

Courtly arts and crafts workshops that manufactured their products to meet the needs of the Sultans in Delhi and the Mughal court.

Destiny determined by a person's actions in previous lives.

Descendants of Kuru, a royal family opposed to the Pandavas in the $\rightarrow$ Mahabharata.

Epic poetry written by a single author in ancient Indian literature.

Writing used in ancient Gandhara.

Tumulus, in Japanese "ancient grave". It is similar to kurgan that are all around North Asia. In third to six century Japan, graves and burial chambers of nobles were covered with earth mound, similar to the traditions in Korean kingdoms at the time.

Corresponding to the requirements of Jewish law.

Ancient rite for greeting the Chinese emperor. It implies getting down on both knees and the forehead must touch the floor 9 times.

The order of warriors in Indian society. Traditionally, kings came from this class.

Mass pilgrimage of Hindus to the Ganges River, which takes placed every four years on a rotating basis in Allahabad (Prayag), Haridwar, Nashik and Ujjain. As the largest peaceful religious gathering in the world, it was added to the UNESCO List of Intangible Cultural Heritage in 2017.

Indian noble that facilitated the internal order and collected tax from Indians for privileges, integrated into the Spanish American colonial system

$\rightarrow$ desacralisation 
Term

legalism

levellers

liberation theology

linga (Sk. "sign”)

lost-wax technique

(cire-perdue)

machismo

madhhab (Arabic)

magic realism
Definition

A key branch of Chinese philosophies in which law is an essential part, as the word legalism also proves, that is a social order based on rules and law. An important factor is morality, that is an approach that mergers social norms and legal norms. Law and ethics were not severable while judicial and administrative powers were united, so it is not surprising that individual vs. state disputes got settled pro state based on authoritarian customs.

"Equalisers". A movement during the English Civil War (1640-1649), denying the priority of nobles and claimed equal rights and extension of the right to vote.

A movement strengthening in the 1960's Latin America, that appoints the protection of the poor and oppressed as the main task for the Catholic Church, based on the definition of evangelical poverty, focusing on ending social injustice, while moving the emphasis from teaching to practice; its main representative was Gustavo Gutiérrez, Peruvian philosopher-theologian.

Male genitalia, phallus, fertility symbol; in Hinduism it is associated with Shiva.

A technique of metal sculpture in which a wax model of the final metal product is made and enclosed in clay, and its place is finally filled with molten metal. It can be found in the Indus Valley civilisation and in African (Yoruba) metalworking.

The word macho in Portuguese and Spanish means a man's role that fits the community or societal expectations, basically in terms of strength, courage and wisdom as values; the expression machismo was first used by Latin American feminists in the 1960-1970's, that is a strong critique against the Latin American patriarchal systems.

Legal and ritual school in Sunni Islam that unites the jurists' individual activities which does not require clear rules to be followed but leaves jurists to think independently. The four recognised schools, Hanafi, Maliki, Shafii and Hanbali were established by the tenth century with a purpose to provide the independence of jurisprudence against external intervention, mainly against the state.

Art movement that got better known through the prosperity of the LatinAmerican literature in the twentieth century. The point is using legends, folk tales and myths in the epic, so reality is mixed with magic and fiction. In Latin-American literature One hundred years of solitude from Gabriel García Márquez is considered to be the fundamental work in magic realism. 


\section{Term}

Mahabharata (Sk. "Great War of the Bharata Dynasty”)

mahajanapada (Sk. "great kingdom")

\section{Definition}

Indian epic that recounts the struggle of the two branches of Bharata clan, the Pandavas and the Kauravas, for the throne of Hastinapura, interwoven with side stories, legends, religious and moral teachings and philosophical material.

Buddhist sources from before the Maurya period tell about sixteen significant states (Mahajanapada) that existed from the sixth to fourth centuries BCE in North India.

Mahayana (Sk. "Great A branch of Buddhism that spread north of India. An important role is Vehicle") played by the $\rightarrow$ bodhisattvas who, as helpers and protectors of the Doctrine, represent the ideal of Mahayana Buddhism.

Mahdi (Arabic, "the guided one")

In Islam, guided to the right path by God who will come to Earth as the redeemer before the Day of Judgement. Shiis believe that the twelfth missing imam will return as the Mahdi. Many in history claimed to be the Mahdi, last time the leader of a revolt in Sudan at the end of the nineteenth century.

mandala (Sk. "circle”) A circular diagram with magical or symbolic meaning; a visualisation aid used in meditation in Indian religions.

mantra (Sk.) Charm, spell; a mystical syllable or series of syllables suitable for summoning a deity.

maritime nature Coastal nature

mask In its African sense: a metallic or wooden object that covers the face, replete with a covering for the full body, and representing a spirit during rituals and ceremonies.

matrika (Sk. "mother") Divine mother, mother goddess. Their number may differ, but it is often seven (saptamatrika, "Seven Mothers").

maya (Sk. "illusion", Supernatural power, witchcraft, magic, one of the nine energies of "magic")

Mayor of the Palace Vishnu; it also refers to the illusionary nature of the phenomenal world.

Office in the Frankish Empire in the early middle ages. Mayor of the Palace is the first man at the king's court, guardian of the royal lands and leader of the army. During the weakening of the Merovingians the office gradually took over the state control in the seventh-eighth centuries.

mezuzah A small case fixed to the doorpost of Jewish homes with a small parchment scroll having passages from the Torah written on it. 
Term

minimal state

Mishnah

\section{Definition}

State approach primarily related to liberal and libertarian views in western political views of the nineteenth and twentieth centuries, aiming to tighten the role of the state, mostly economically and politically. In this view, the State is not primarily responsible for "public good" but a guarantee of individual freedom.

The first major collection of Jewish religious law. The traditions and laws contained in it had been transmitted orally until they were collected and redacted in the second century CE. See also $\rightarrow$ Talmud.

Mita ("forced labour") Quechua word for the labour duties of adult men, reaching back to preColumbian times. In the colonial period it mostly covers the forced labour in Indian mines.

mitzvah Jewish religious commandment.

moksha (Sk. "release") Liberation in Hinduism when the soul leaves the chain of rebirths and unites with the transcendent reality ( $\rightarrow$ brahman). One of the four life goals in Hinduism.

Monophysitism

Christological doctrine in early Christian era. It had significant influence on the Egyptian and Syrian churches. The doctrine teaches that Christ has only one nature as the divine nature has absorbed human nature. The churches of Rome and Constantinople rejected Monophysite teaching.

mufti (Arabic)

Islamic jurist qualified to make decisions, and ready to give a religiously authentic response ( $\rightarrow$ fatwa) to the questions asked, based on his own efforts.

multilinear

$\rightarrow$ unilinear vs. multilinear view

murid (Arabic "one

1. A name for the disciples of the Sufi masters in Islam $(\rightarrow$ Sufi $)$ who wish who desires/seeks") to reach God on the mystical path. 2. Islamic mystical (Sufi) order in Senegal, mostly followed by the Wolof people.

nagara (Sk. "city”, The northern style of Hindu temple architecture.

"related to the city")

Nataraja (Sk. "King Shiva as a lord of dance.

of Dance")

négritude

Literary and cultural movement of French-speaking Black intellectuals, stressing solidarity and cultural unity among Black people. 
Term

Nestorians

New Deal

\section{Definition}

Christology teaching of Nestorius in the fifth century, stressing the independence and separation of the divine and human natures of Christ. Although the majority of the church disagreed with this teaching in the fifth century, dogmatic history today sees it as an inconvenient wording rather than a faulty teaching (heresy). The mission of Nestorian Christians developed on the Asian continent in the first millennium.

A set of measurements taken in the U.S. during the presidency of F.D. Roosevelt after the great economy crisis (1929-1933), attempting to support social groups in difficulties and stabilise their income via expanding the state's intervention. New Deal was an economy and social policy representing great involvement of the state, exceeding the practices of $\rightarrow$ laissez faire and $\rightarrow$ minimal state. It was striving to create jobs, state investments, and to stabilise the demand side via social benefits.

nirvana (Sk., nibbana in The attainment of enlightenment in Buddhism, extinction of $\rightarrow$ karma, Pali, "blow out") liberation from the constraints of existence.

Nitishastra (Sk.) Treatises on political ethics.

$\overline{o k i m i}$

Name of the ruler in ancient Japan ("High King") until the seventhcentury reforms based on the Chinese model.

Old Believers

Orthodox Christians that did not adopt the church reforms of Patriarch Nikon in 1650 and therefore got excluded from the official church.

orisha

Deities (or spirits) worshipped among the Yoruba of Nigeria and Benin and their Brazilian descendants.

Pandavas

Descendants of Pandu, one of the royal families competing for power in the $\rightarrow$ Mahabharata. The Pandava brothers are Yudhisthira, Bhima, Arjuna, Nakula and Sahadeva, their common wife is Draupadi.

patriarch

pauperising

1. Ancestor, in the Old Testament Abraham, Isaac and Jacob. 2. Catholic church leader.

Social phenomenon, pauperisation of individuals, groups or social classes.

pentarchy

Perception in the early Christian era and the middle-age that lived on to a certain extent in orthodox Christian practice after the Schism of 1054. It means that the Christian church is governed by five patriarchs, Rome, Alexandria, Antioch, Jerusalem and Constantinople, whose particular prestige is based on the ancient foundation of their church.

peon

Spanish-American day-labourer or farm worker.

Pesach

Jewish Easter. 
Term

pinyin

pir

populus Romanus

possession cults

pradakshina (Sk.

"to the right"

Pravoslav

preindustrial society

progressivism

puja

Puranas (Sk. "old")

Putonghua

qibla (Arabic)

qiyas (Arabic

"analogy")

Quran (Arabic

"recitation")

\section{Definition}

Chinese writing officially converted into Latin letters, developed in the 1950's and internationally accepted.

$\rightarrow$ sheikh

Roman people. All citizens with rights in ancient Rome.

Religious cults for the placating and peaceful removal of spirits that take possession of a human body (e.g. zar in the Arab world, voodoo in the Caribbean, etc.).

Clockwise movement or circumambulation; the auspicious direction of the ritual circumambulation in Indian religions. It also denotes the passageway for circumambulation surrounding a sacred object or temple.

Slav translation of the Greek word "orthodox" that means true believer.

Society before the industrialisation (manufacturing industry, industrial capitalism) where the majority works in agriculture and is characterised by high numbers of live births and deaths, also there was no permanent economic growth.

A group name for social reform movements developed at the end of the nineteenth and beginning of the twentieth century in the United States. Progressivism, in the context of old American ideals, i.e. capitalism based on wide participation, aimed to confine the infiltration of great capital and monopolies into domestic and local politics. It strived to reach integrity of the public life, ruling monopolies, women's suffrage, educational reforms and the extension of their accessibility and minimising the negative impacts of industrial modernisation in general.

The acts performed to honour a deity, e.g. the offering of flowers, food, water.

Encyclopaedic prose works, collections of Indian mythological and historical tradition.

The official state language in China based on the Beijing dialect.

The direction of the prayer in Islam, indicated by a niche (mihrab) that needs to be oriented towards the Kaaba, "God's house" in Mecca.

A method applied by Muslim jurists, deducing laws on matters not explicitly covered by religious texts.

The holy book of Islam that, according to Muslim belief, is literally God's words in Arabic which God sent to Earth via the Prophet Muhammad to strengthen and finalise the books sent with former prophets. 
Term

rajadharma (Sk.)

Rajput

Ramayana (Sk.)

rasa (Sk. "juice”, "taste")

Rastafari

Requerimiento

("requirement")

restitution period

restricted literacy

Ritsuryō

romanisation

Rosh ha-Shanah

Sahel (region)

salaf (Arabic "pious

predecessors")
Definition

Duty of the rulers in Hinduism.

From the Sanskrit word rajaputra, meaning "son of a king". Western Indian kshatrya clans who played major role in the resistance against Mongolians.

Ancient Hindu epic about the exile of prince Rama, abduction and rescue of his wife Sita and then their return and Rama's crowning to be king of Ayodhya. The author is considered to be Valmiki.

The essence or character, dominant emotions of an artwork. Their number is usually eight or ten: sringara (love, affection), vira (heroism), vibhatsa (disgust), raudra (fury), hasya (laughter), bhayanaka (terror), karuna (compassion), adbhuta (wonder), shanti (peace), vatsalya (parental love). The last two may be omitted.

A unique religious movement and community developed in Jamaica and promoting the resettlement in Africa.

A document worded by the Council of Castile in 1513 read as an ultimatum by the Spanish conquerors to the conquered Indians, with no interpreter, demanding to accept the Spanish authority. The document has confirmed the Spanish conquest on legal and religious bases and declared a "just war" against indigenous peoples in case of resistance.

This is how the decade after the American civil war (1861-1865) was called in the U.S. history but even more in the conquered southern states, when these southern were integrated into the federal state system with special regard to the management of freed slaves.

A specific type of the use of writing wherein writing is monopolised by specialists and utilised only for certain social and religious purposes.

Lawbook issued in 701 introducing a legal system and government based on the Chinese model.

Disperse of elements of the Roman civilisation and Latin language in conquered provinces. It firstly evolved in the imperial age in the firstfourth centuries in the long term, accompanied by the domestication of Latin language and school system and the spread of Roman urbanisation achievements

Jewish New Year.

Dry savanna zone just south of the Sahara.

Members of the first three generations of Muslims. Their words and acts reflect the Prophet's norms and help Muslims follow the religious path. 
Term

samsara (Sk.)

samskara (Sk.)

samurai (bushi)
Definition

The chain of rebirths, transmigration.

Rites of passage in Indian religions. Twelve (sixteen or forty according to some sources) such ceremonies are prescribed for the twice born.

Japanese warrior caste, evolved from local elite gunmen, mostly in the countryside since the ninth century. Originally, the warrior troops were organised on a family basis with a strong dependency system. The warriors soon picked up the term saburai, samurai originated in the word saburau ("serving someone") as well as the term bushi ("warrior knight"). Their society was based on a system of feudal dependency.

Sanatana Dharma (Sk. A term used for Hindu religion that emphasises its eternal spiritual aspect "eternal law") over the differences in the religious practices of castes and sects.

Sangam (Sk.)

Ancient Tamil literature.

sangha (Sk.)

The community of Buddhist monks.

Sankhya (Sk.)

A dualistic philosophical system in ancient India, based on the duality of purusha (consciousness) and prakriti (matter); one of the six orthodox $\rightarrow$ darshanas.

secularisation $\rightarrow$ desacralisation

Sephardi

Descendant of the Jews who lived in the Iberian Peninsula.

Shaiva (Sk. "relating to Follower of Shiva; a collective term for Hindu religious trends that focus the god Shiva) on Shiva.

Shakti (Sk. "energy", Female creative power; in personalised form it is identical with the "power") Goddess Devi.

Shakyamuni (Sk. "Sage One of the titles of the Buddha. It indicates that he was born into the of the Shakya clan”) Shakya clan near today's Nepalese border.

Shakyasimha (Sk. "Lion One of the titles of the Buddha.

of the Shakya clan")

Sharia (Arabic "path") The divine law in Islam, the pathway to be followed, designated by God to Muslims for all areas of life. The divine guidance and instructions are in texts ( $\rightarrow$ Quran and $\rightarrow$ hadith) explained and interpreted by jurisprudence $(\rightarrow$ fiqh $)$

sheikh (Arabic "old 1. The leader of a tribe. 2. Teacher in a traditional Islamic school. 3. Sufi man") 
Term

Shii

Shintō (Japanese)

shōgun (Japanese)

shramana (Sk.)

Shudra (Sk.)

Shvetambara (Sk.

"white-clad")

slavophilism

soma (Sk.)

stele

stridharma (Sk.)

stupa (Sk. "crest", "summit")

Sudanic Gothic

Sufi (Arabic)

\section{Definition}

The followers of the Shii Islam, which evolved from the party (Shia) of Caliph Ali, the Prophet's cousin, and brother in law. They have never accepted elected caliphs, only Ali's successors, called $\rightarrow$ imam. Depending on the number of imams they recognise, there are Twelver or Imami Shiis, Sevener or Ismaili Shiis and the Fivers or Zaydis.

"Gods' path" is an archaic, naturist mythology, ceremonies, sorcery, a mass of local cults originally without moral teachings and metaphysical message. The respect of the ancestors, the adoration of natural phenomena, and the belief in the immortality of the spirit, were characterised by millions of $\rightarrow$ kami.

The supreme feudal lord of $\rightarrow$ samurais Japan, with the authority from the emperor (militarily enforced), has built a nationwide enforcement and control system since 1192 with his vassals. His power was built on land ownership and the feudal hierarchy built upon it, where personal loyalty linked the feudal lord and the vassal.

An ascetic, a monk, follower of heterodox sects in the first millennium BCE.

The lowest class of the ancient Indian society ( $\rightarrow$ varna system). Servants belonged here who did not receive ritual initiation.

A Jainist sect.

Russian ideology developed in the 1840s, a stream of the European romantic nationalism. Followers stood by the unique Russian development that was different from Western European.

A narcotic fermented drink used in Vedic sacrifices.

Large, upright stone slab, stone or wooden pillar, erected as a monument.

Religious precepts for women in Hinduism.

Buddhist monument, reliquary. The first stupas were erected to accommodate the corporeal relics of the Buddha. Later, its symbolic nature became more prominent.

A unique style of West and Central African mud architecture in which the wooden scaffolding is part of the huge mud buildings and towers, facilitating the yearly re-plastering of the construction.

Follower of Islamic mysticism. 
Term

sunna (Arabic

"custom")

Sunni

sutra (Sk. "thread")

svadharma (Sk.)

swastika (Sk.

"of good fortune")

syncretism

synoikismos

tallit

Talmud

tefillin

tennō

tetragrammaton

theocracy

\section{Definition}

The entirety of the Prophet Muhammad's acts and words that God inspired, and that Muslims must follow in all areas of life.

Follower of the customs of the Prophet Muhammad and the so-called orthodox Islam, although the Shiis also say they follow the $\rightarrow$ sunna of the Prophet.

Textbook or manual consisting of aphoristic thoughts or rules.

The individual's own life tasks and religious duties in Hinduism.

A cross with bent legs. It is an ancient sun symbol referring to prosperity and good luck in Indic religions.

A religious phenomenon where religious traditions of different origins are merged and united, a common feature of common religion. In China, this is to pursuit reconciliation of different views. One of its typical manifestations is that Chinese (Eastern) people consider that there can be multiple truths simultaneously. All this makes Eastern cultures receptive in spiritual terms, as they are able to adapt other spiritual tendencies to their own image, not merely adhere to a particular philosophy or religion, but use the doctrines useful to them in a pragmatic way. In Latin America it means the 'interaction' of Spanish Catholicism with native American and African religious beliefs and traditions.

In the history of ancient Hellas, the "settlement" of villages and small settlements "gathering" into a single city-state, which is typical mainly in the first centuries of Greek history (eighth-sixth centuries BC). As a result of the synokismos, the inhabitants became citizens of the one polis, which might have led to the elaboration of political rules of coexistence (a "constitution")

Cloth for prayer in Jewish religion.

The most important source of Jewish religious law redacted in the fifth century CE. See also $\rightarrow$ Mishnah.

Phylacteries used in Jewish religious practice.

The title of Japanese chief of state since the seventh century derived from the Chinese ("heavenly emperor" or "lord of the heaven").

The Hebrew name for God consisting of four consonants which is prohibited to be pronounced according to Jewish law.

A form of government in which secular power is derived from a deity of the given culture, states of such form are called theocratic governments. 
Term

Theravada (Pali, "speech of the elders")

tianxia
Definition

The only surviving $\rightarrow$ Hinayana Buddhist school today, the dominant religion in Sri Lanka, Myanmar, Thailand, Laos, Cambodia and South Vietnam.

A significant component of the "under heaven" holistic concept, providing philosophical grounds and explanation for the $\rightarrow$ tributary system. In traditional Chinese thinking the meaning of "under heaven" is more than physical world, it truly is a cultural idea that implies morality and how the world works.

tirthankara (Sk. "path- Teachers of Jainism. According to tradition, Vardhamana Mahavira, conmaker", "ford-finder") sidered the founder of Jainism, was the $24^{\text {th }}$ tirthankara.

Torah "Law" or "teaching", the five books of Moses from the Bible.

tributary system

The core of the Chinese tributary system is the inequality however it is pervaded by the $\rightarrow$ tianxia and the endeavour to reach "great harmony" ta-tung (datong). The point of the system is that existing things (in this case: people, clans, lands) are not equal, China is in the centre surrounded by other lands in concentric circles. However, everything under heaven is part of a big, hierarchical system where antagonisms, by definition, do not exist as every country is part of a world lead by China.

trimurti (Sk. "triple Hindu triad of the supreme godhead in which Brahma is the creator, form", "triple image") Vishnu the maintainer and Shiva the destructive deity.

tsunami A tsunami created by seaquake (earthquake at the seabed) or underwater volcanic eruption (in Japanese "harbour wave").

uji

Clan or tribe in ancient Japan. Being a warrior aristocracy, they owned lands cultivated by common workers and taxpayers. Their leader was called "patriarch" and the members were his "family". The head was called "head of the clan" and members were "family members". The clan was supposed to be ceased in the seventh century when taking over the Chinese government system however it remained during the ancient times.

umma (Arabic)

The community of all the Muslims around the world, irrespective of where they live. It used to be a kind of "super tribe".

unilinear vs. multilinear Unilinear theory is an evolutionary social theory of the twentieth century. concept It represents that there is only one way to reach modernity and western modernisation gives the example. Whereas multilinear theory represents that there are many ways to reach modernity and individual civilisations provide different funds for that.

Upanishads (Sk.) A body of ancient Indian esoteric texts related to the Vedas that contain philosophical speculations. 
Term

$\operatorname{Urdu}(U r d u$, "camp") Urdu is an Indo-Aryan language with a mixed North Indian and ArabicPersian vocabulary. It is spoken in India and Pakistan and has a rich literary tradition.

Vaishnava

Vaishya (Sk.)

Vajrayana (Sk.

"diamond carriage",

"diamond path")

varna (Sk. “colour”)

varnashrama dharma

Vastu Shastra (Sk.)

Vedanta (Sk. "end of the A Hindu philosophical system based on the $\rightarrow$ Upanishads; one of the six Vedas")

Vedas (Sk.

"knowledge")

verism

WASP (White

Anglo-Saxon

Protestant)

yoga (Sk.)

Yom Kippur (Hebrew) Jewish holiday, "Day of Atonement".

A follower of Vishnu.

The third $\rightarrow$ varna of Indian society. The Vaishyas were commoners associated with agriculture, cattle rearing and trading.

A tantric version of $\rightarrow$ Mahayana Buddhism. It is an esoteric system where manifestations of gods impersonate the psychic stages of meditation.

Traditional units in the hierarchically ordered Indian society. There were four varnas, the $\rightarrow$ _Brahmana, $\rightarrow$ _Kshatriya, $\rightarrow$ _Vaishya and $\rightarrow$ _Shudra varna. The first three varnas comprised the so-called "twice-born", who underwent a ritual initiation ceremony while the members of the lowest class were obliged to serve the upper three varnas.

Obligations and ritual rules for social classes ( $\rightarrow$ varna $)$ and life stages (ashrama).

Manuals of architecture in the Indian tradition. orthodox schools of ancient Indian philosophy ( $\rightarrow$ darshana). Its most significant representative is Shankara who lived in the eighth century and professed monistic views.

The oldest and most sacred religious books of the Aryans. Their number is four: Rigveda, Yajurveda, Samaveda and Atharvaveda. The core of the Vedas consists of collections of hymns.

Emphasising truth and reality in art.

An Anglo-Saxon Protestant middle class whose characteristics played a great role in the historical evolution of the United States and contributed significantly to the development of American civilisational values.

Exercises and meditation techniques, with the aim of uniting with the divine spirit. 
yuga (Sk.)

An age of mankind. One day of the god Brahma ( $\rightarrow$ kalpa) is divided into four Yugas (Satya, Treta, Dvapara and Kali Yuga), which are of decreasing duration and are characterised by a gradual deterioration of morals. According to this view, humanity currently lives in the 432,000year-old Kali Yuga, of which five thousand years have passed.

zebu

A variety of cattle originating in South Asia (scientific name: Bos taurus indicus). Presumably it was domesticated in the Indus Valley Civilisation. It is characterised by a large hump over the shoulder. 


\section{Civilisations from East to West}

The present volume introduces the world's great civilisations from the beginning of their formation to the first half of the twentieth century. The purpose of the authors was to go beyond the events and write a book on the history of cultures and civilisations that also elucidates the background of contemporary events, starting from the understanding that even modern events and customs are rooted in history. The importance of this endeavour lies in that it comprises in one volume all the significant civilisations still existing in our days, while presenting regions and not modern countries. This is true even if, on the one hand, three civilisations are found today in three countries each (China, Japan and India), and on the other hand, the three monotheistic religions having developed in the Middle East (Judaism, Christianity and Islam) have fundamentally determined the civilisations in two regions (the Middle East and Europe). The bibliographies at the end of each chapter of the richly illustrated book provide more details for an in-depth study on each civilisation. 